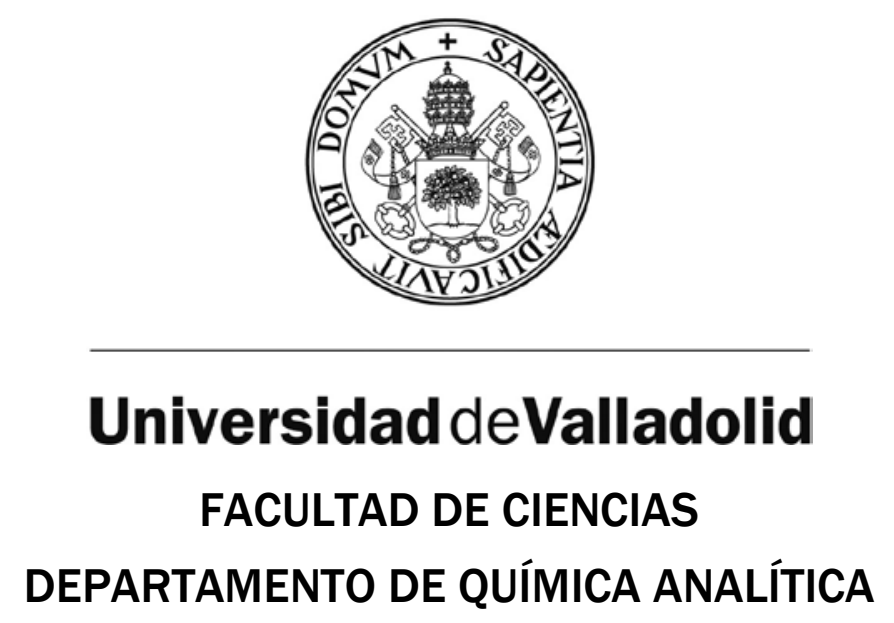

TESIS DOCTORAL

\title{
Hidrogeoquímica de aguas subterráneas de un sector de la Cuenca del Duero con altos niveles de arsénico
}

Presentada por $\mathbf{M}^{\mathbf{a}}$ Concepción Carretero Rivera para
optar al Grado de Doctora por la Universidad de Valladolid

Dirigida por:

María del Sol Vega Alegre

Rafael Pardo Almudí 



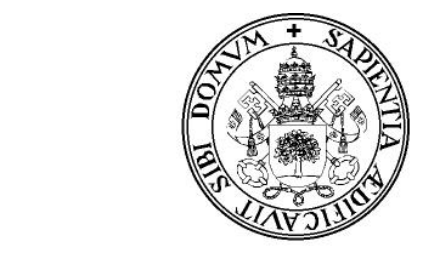

\section{Universidad deValladolid}

Impreso 2T

\section{AUTORIZACIÓN DEL DIRECTOR DE TESIS}

(Art. 2.1. c de la Normativa para la presentación y defensa de la Tesis Doctoral en la UVa)

D. MARÍA DEL SOL VEGA ALEGRE, con D.N.I. n¹0.190.648 S

profesora del departamento de QUÍMICA ANALÍTICA

Centro: FACULTAD DE CIENCIAS

Correo electrónico: solvega@qa.uva.es

como Directora de la Tesis Doctoral titulada HIDROGEOQUÍMICA DE AGUAS

SUBTERRÁNEAS DE UN SECTOR DE LA CUENCA DEL DUERO CON ALTOS NIVELES DE ARSÉNICO

presentada por Dña. MARÍA CONCEPCIÓN CARRETERO RIVERA

alumna del programa QUÍMICA ANALÍTICA APLICADA. CONTAMINACIÓN Y MEDIO

AMBIENTE

impartido por el departamento de QUÍMICA ANALÍTICA

autoriza la presentación de la misma, considerando que cumple todos los requisitos establecidos en la legislación vigente, y que el trabajo presentado reúne todas las características de interés, originalidad y rigor en sus aportaciones dentro del campo de la Química Medioambiental para ser defendido como Tesis Doctoral.

Valladolid, 16 de OCTUBRE de 2015

La Directora de la Tesis,

Fdo.: María del Sol Vega Alegre

SRA. PRESIDENTA DE LA COMISIÓN DE DOCTORADO 



\section{Universidad deValladolid}

Impreso 2T

\section{AUTORIZACIÓN DEL DIRECTOR DE TESIS}

(Art. 2.1. c de la Normativa para la presentación y defensa de la Tesis Doctoral en la UVa)

D. RAFAEL PARDO ALMUDÍ, con D.N.I. n¹2.220.129 E profesor del departamento de QUÍMICA ANALITICA

Centro: FACULTAD DE CIENCIAS

Correo electrónico: rpardo@qa.uva.es

como Director de la Tesis Doctoral titulada HIDROGEOQUÍMICA DE AGUAS SUBTERRÁNEAS DE UN SECTOR DE LA CUENCA DEL DUERO CON ALTOS NIVELES DE ARSÉNICO

presentada por Dña. MARÍA CONCEPCIÓN CARRETERO RIVERA

alumna del programa QUÍMICA ANALÍTICA APLICADA. CONTAMINACIÓN Y MEDIO AMBIENTE

impartido por el departamento de QUÍMICA ANALIITICA

autoriza la presentación de la misma, considerando que cumple todos los requisitos establecidos en la legislación vigente, y que el trabajo presentado reúne todas las características de interés, originalidad y rigor en sus aportaciones dentro del campo de la Química Medioambiental, para ser defendido como Tesis Doctoral.

Valladolid, 16 de OCTUBRE de 2015

El Director de la Tesis,

Fdo.: Rafael Pardo Almudí

SRA. PRESIDENTA DE LA COMISIÓN DE DOCTORADO 

"Empieza por hacer lo necesario luego haz lo posible y de pronto estarás logrando lo imposible"

(San Francisco de Asís) 



\section{Agradecimientos}

Me gustaría que estas líneas sirvieran para expresar mi más profundo y sincero agradecimiento a todas aquellas personas que con su apoyo prestado y el cariño demostrado me han ayudado en la realización de esta Tesis Doctoral, en especial a Marisol Vega Alegre y Rafael Pardo Almudí, directores de este trabajo.

Especial reconocimiento merece la colaboración, el interés mostrado por mi trabajo y las sugerencias recibidas por parte de D. Jose Manuel Fernández en los temas relativos a geología, D. Luis Fernández en los temas relativos a hidrogeología y Dr. José Luis García Cuesta en la elaboración de los mapas. José Manuel, ojalá estuvieses aún aquí para ver el resultado de estos años de trabajo.

A los Doctores Javier Medina, profesor del Dpto. de Física de la Materia Condensada y Jaime Delgado, profesor del Dpto. de Didáctica de las Ciencias Experimentales, por su asesoramiento en la caracterización de arcillas y roca total.

Quisiera hacer extensiva mi gratitud a todos los compañeros que he tenido la suerte de conocer en el Departamento de Química Analítica, por su apoyo y por los tantos momentos compartidos, que aún hoy seguimos recordando...

A los técnicos de laboratorio del Dpto. de Química Analítica, Francisco de la Rosa y Rosario Gómez, mi más sincero agradecimiento por su paciencia y dedicación.

Este trabajo no habría sido posible sin la ayuda financiera que, en forma de proyectos de investigación, ha aportado la Consejería de Educación de la Junta de Castilla y León, a través de los proyectos; VA045/02, VA077A05, VA291U14.

Por último, quiero dar las gracias de una forma muy especial a mi familia, amigos y a Jorge por la comprensión, paciencia y el ánimo recibidos.

A todos ellos, MUCHAS GRACIAS. 



\section{Resumen}

La contaminación de las aguas subterráneas por arsénico y otros elementos tóxicos es una de las mayores amenazas sanitarias y medioambientales a las que se enfrenta la humanidad. Las aguas subterráneas son el único recurso hídrico en muchas regiones del planeta y se destinan tanto al consumo humano como a la agricultura y ganadería, por lo que su calidad debe ser cuidadosamente controlada. Aunque estos contaminantes pueden tener un origen antropogénico, en la gran mayoría de los acuíferos su origen es geogénico, producto de las interacciones agua-roca que provocan la lixiviación de minerales cuando se dan las condiciones químicas y físicas adecuadas.

Desde hace más de una década se conoce la presencia de niveles anormalmente altos de arsénico y de otros elementos geogénicos tóxicos en aguas subterráneas de la margen sur de la Cuenca del Duero, cuenca sedimentaria semiárida. La necesidad de comprender el origen y mecanismos de dispersión del arsénico en los acuíferos afectados ha motivado esta Tesis Doctoral.

Para investigar la hidrogeoquímica de las aguas subterráneas se eligió un sector limitado de la comarca de Tierra de Pinares, entre los municipios segovianos de Mata de Cuéllar, Vallelado y San Cristóbal de Cuéllar, que puede ser considerado representativo de toda la comarca debido a su funcionamiento hidrogeológico. Se localizaron más de 80 puntos de muestreo incluyendo pozos, sondeos y manantiales y se muestrearon dos veces (2002 y 2003). Se analizaron más de 20 parámetros en las muestras de agua subterránea, incluyendo $\mathrm{pH}$, conductividad, temperatura, oxígeno disuelto, arsénico, vanadio, cationes y aniones mayoritarios, hierro y manganeso.

Se han identificado dos acuíferos superficiales interconectados hidráulicamente, el acuífero aluvial $\left(\mathrm{Ca}^{2+}-\mathrm{Mg}^{2+}-\mathrm{SO}_{4}{ }^{2-}-\mathrm{HCO}_{3}{ }^{-}\right)$y el acuífero carbonatado $\left(\mathrm{Ca}^{2+}-\mathrm{Mg}^{2+}-\mathrm{HCO}_{3}{ }^{-}\right)$; debajo hay un tercer acuífero detrítico profundo $\left(\mathrm{Na}^{+}-\mathrm{HCO}_{3}{ }^{-}\right)$con aguas alcalinas $(\mathrm{pH}>8,5)$ y con un ligero carácter termal.

La distribución de arsénico en las aguas subterráneas del área de studio es muy variable: En más del $80 \%$ de las muestras de agua subterránea pertenecientes a los acuíferos aluvial y detrítico profundo se han encontrado concentraciones de arsénico superiores al nivel máximo tolerado para aguas destinadas al consumo humano $(10 \mu \mathrm{g} / \mathrm{L})$, mientras que en el acuífero carbonatado las concentraciones de arsénico son inferiores a dicho valor. El $12 \%$ de las muestras analizadas superaron los $200 \mu \mathrm{g} / \mathrm{L}$ de arsénico (todas ellas del acuífero aluvial).

Las altas concentraciones de arsénico en los acuíferos aluvial y detrítico profundo parecen estar causadas por diferentes mecanismos de movilización: la intensa recirculación de aguas provocada por la sobreexplotación del acuífero aluvial, que además causa la salinización del agua. El incremento de la fuerza iónica y, especialmente, del anión sulfato, provoca la desorción de arseniato por intercambio iónico competitivo. En el acuífero detrítico profundo el mecanismo de movilización de arsénico parece ser la desorción competitiva de arseniato en aguas alcalinas causada por el ión hidróxido. 
El estudio de la distribución de arsénico en los materiales sedimentarios puede ayudar a comprender las fuentes y los mecanismos de movilización del arsénico. Para ello se tomaron 57 muestras, entre las altitudes 600 y los 850 m, en las que se analizaron 35 parámetros geoquímicos y mineralógicos. La concentración media de arsénico en los sedimentos analizados fue $14,7 \mathrm{mg} / \mathrm{kg}$, aunque los valores varían de forma significativa de un estrato a otro, siendo los valores más altos los encontrados en facies Tierra de Campos, Dueñas y algunas muestras de Villalba de Adaja.

La composición mineralógica de los materiales sedimentarios de la zona influye en la retención del arsénico, estando éste asociado a los filosilicatos, minerales abundantes en la zona y con elevada capacidad de intercambio iónico.

A pesar de que la concentración de arsénico en algunas muestras de sedimento es elevada (>50 mg/kg), los niveles de arsénico en las fracciones minerales más fácilmente solubilizables son bajos, por lo que el riesgo de movilización a las aguas es limitado. No obstante, la facies Cuestas tiene un porcentaje no despreciable de arsénico en la fracción fácilmente intercambiable, lo que implica un riesgo de liberación de arsénico por lixiviación. 


\begin{abstract}
Contamination of groundwater by arsenic and other toxic elements is one of the major health and environmental threats that humanity must face. Groundwater is the only water resource in many parts of the world and it is used for both human consumption and agriculture and livestock, so its quality should be carefully controlled. Although these pollutants may have an anthropogenic origin, in the vast majority of aquifers its origin is geogenic, as a result of water-rock interactions that cause the leaching of minerals when suitable conditions exist.
\end{abstract}

For over a decade ago it has been known the presence of abnormally high levels of arsenic and other toxic geogenic elements in groundwaters from the south bank of the sedimentary semiarid Duero basin (central Spain). The need to understanding the sources and mobilization pathways of arsenic in the affected aquifers has prompted this Doctoral Thesis.

A confined area of the Tierra de Pinares region covering the municipalities of Mata de Cuéllar, Vallelado and San Cristóbal de Cuéllar (Segovia province, Spain) was selected to investigate the groundwater hydrogeochemistry as it possesses representative hydrogeological features. More than 80 sampling points, including shallow dug wells, deep drilled wells and springs were located and sampled twice (2002 and 2003). More than 20 hydrochemical variables were determined in the groundwater samples, including $\mathrm{pH}$, conductivity, temperature, dissolved oxygen, arsenic, vanadium, major cations and anions, iron and manganese.

Two shallow aquifers, alluvial $\left(\mathrm{Ca}^{2+}-\mathrm{Mg}^{2+}-\mathrm{SO}_{4}{ }^{2-}-\mathrm{HCO}_{3}{ }^{-}\right)$and carbonated $\left(\mathrm{Ca}^{2+}-\mathrm{Mg}^{2+}-\mathrm{HCO}_{3}{ }^{-}\right)$, exist in the area hydraulically interconnected, and below there is a deep detritic aquifer $\left(\mathrm{Na}^{+}-\mathrm{HCO}_{3}{ }^{-}\right)$with alkalinized $(\mathrm{pH}>8.5)$ and slightly thermal groundwaters.

The distribution of As in groundwater from this area varies widely: In more than $80 \%$ of groundwater samples from the alluvial and deep detritic aquifers, the arsenic concentration exceeds the maximum tolerable value for drinking water $(10 \mu \mathrm{g} / \mathrm{L})$, while in the carbonated aquifer arsenic occurs at a concentration below that value. About $12 \%$ of the analyzed groundwater samples contained As levels higher than $200 \mu \mathrm{g} / \mathrm{L}$ (all of them in the alluvial aquifer).

The high arsenic levels found in the alluvial and detritic aquifers seem to be caused by different mobilization mechanisms: The intense water recirculation related to overexploitation of the alluvial aquifer causes groundwater salinization. The increase in ionic strength and especially in sulphate concentration causes desorption of arsenate due to competitive ionic exchange. In the deep detritic aquifer, the prevalent mobilization mechanism is likely the desorption of arsenate ions from sediment caused by competition of hydroxyl groups at alkaline $\mathrm{pH}$ values

High arsenic levels in groundwater have prompted the need to investigate the distribution of arsenic in sediments from the area to understand the mobilization pathways. 35 geochemical and mineralogical parameters were determined in 57 sediment samples collected at different depths (from 600 to $850 \mathrm{~m}$ altitude). Arsenic mean concentration was $14.7 \mathrm{mg} / \mathrm{kg}$, although arsenic concentration varied widely with the geological stratum and hence with the mineralogical composition of the sediments. 
The higher concentrations were detected in Cuestas facies, Dueñas facies and Villalba de Adaja facies.

The mineralogical composition of the sediments influences the retention of arsenic, which is mainly associated to phyllosilicates, a clay mineral abundant in the region and with high ionic exchange capacity.

Despite arsenic levels in some sediment samples are high (>50 mg/kg), the presence of easily mobilizable arsenic mineral fractions is in general very scarce, thus the risk of arsenic mobilization to the groundwaters is low. However, sediments from the Cuestas facies contained significant amounts of arsenic in the readily exchangeable fraction, thus implying a risk of arsenic leaching. 
ÍNDICE 



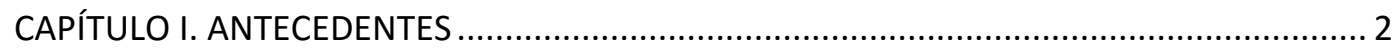

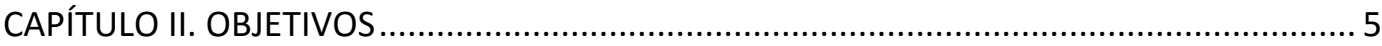

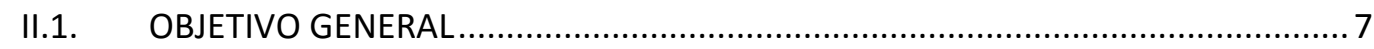

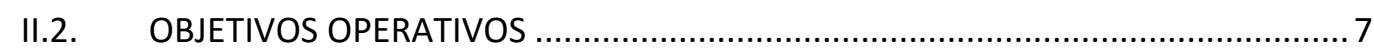

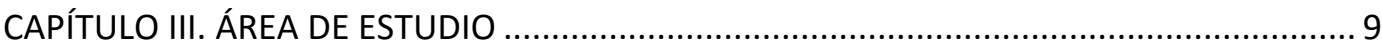

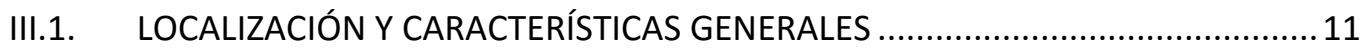

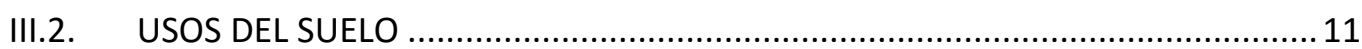

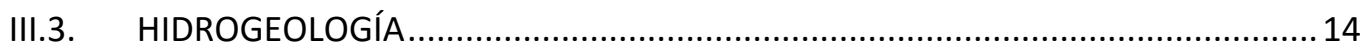

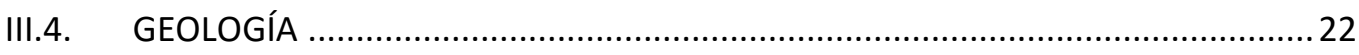

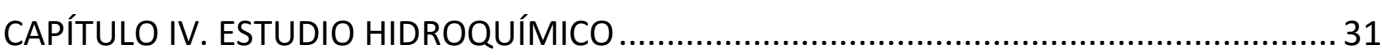

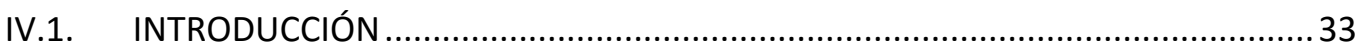

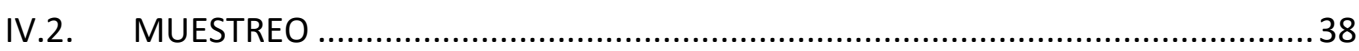

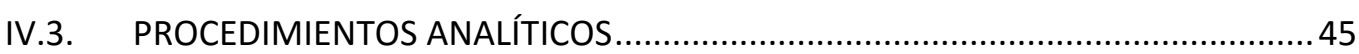

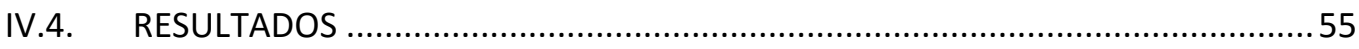

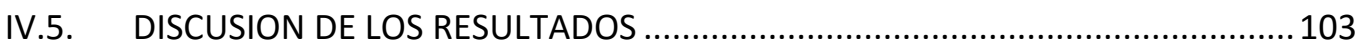

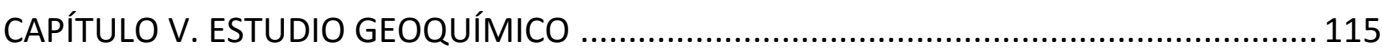

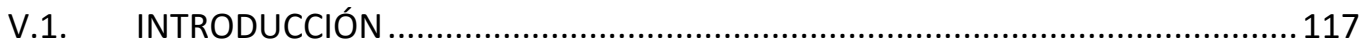

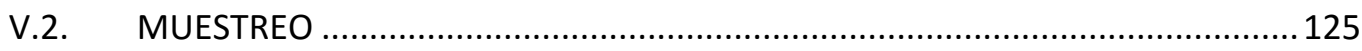

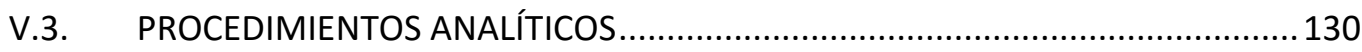

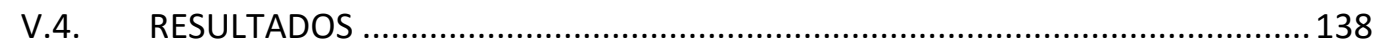

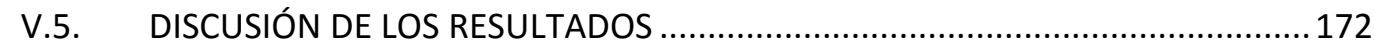

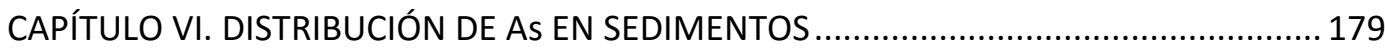

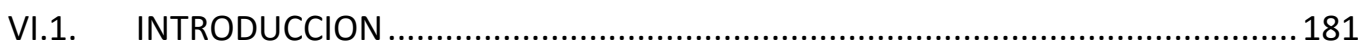

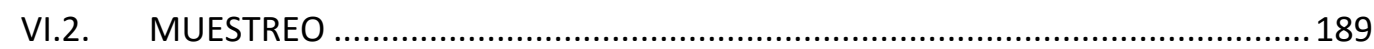

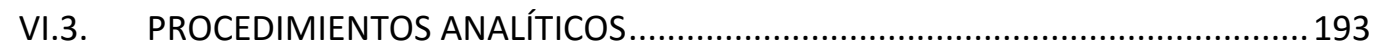

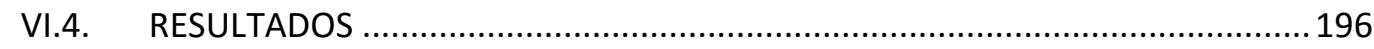

VI.5. DISCUSIÓN DE LOS RESULTADOS …….................................................... 210

CAPÍTULO VII. INFLUENCIA DE LAS PRÁCTICAS AGRÍCOLAS EN LA MOVILIZACIÓN Y

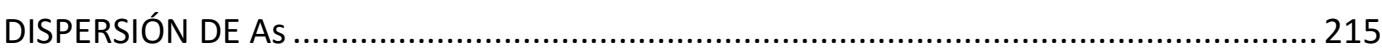

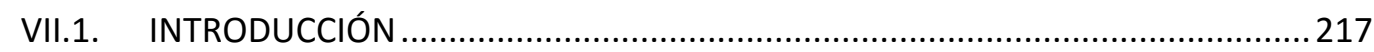

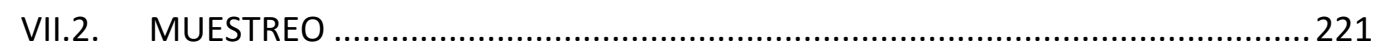

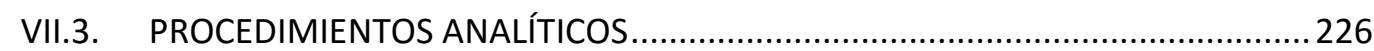

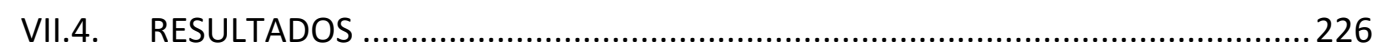

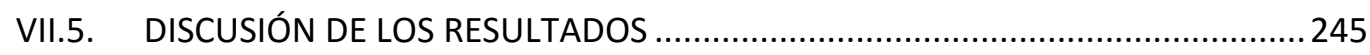

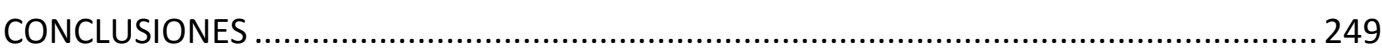

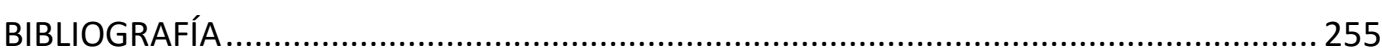

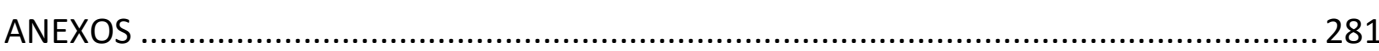

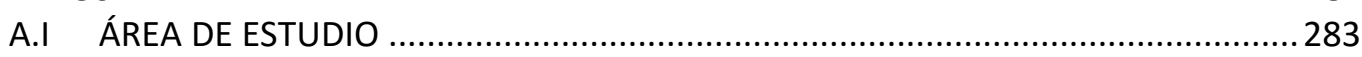

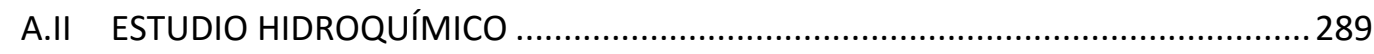

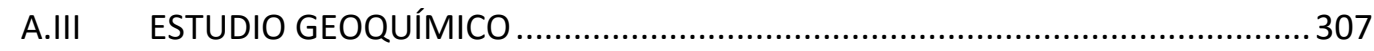

A.IV DISTRIBUCIÓN DE ARSÉNICO EN SEDIMENTOS.............................................. 317

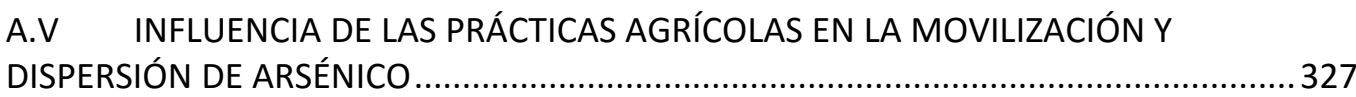




\section{INDICE DE TABLAS}

Tabla III.1.Usos del suelo de la zona de estudio...................................................................14

Tabla III.2. Datos climatológicos de la estación de Sanchonuño................................................22

Tabla IV.1. Técnicas recomendadas de conservación de muestras de agua para análisis físicoquímicos. P, plástico; $V$, vidrio (APHA, 1985) ............................................................................44

Tabla IV.2. Condiciones experimentales para los diferentes metales............................................48

Tabla IV.3. Condiciones experimentales para los diferentes metales..........................................49

Tabla IV.4. Parámetros analíticos determinados en las aguas. ......................................................55

Tabla IV.5. Parámetros estadísticos de las variables físico-químicas determinadas en el Muestreo

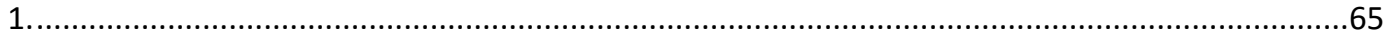

Tabla IV.6. Parámetros estadísticos de las variables físico-químicas determinadas en el Muestreo

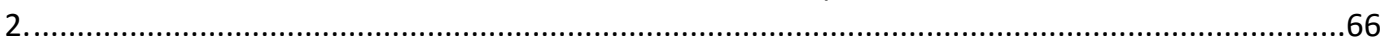

Tabla IV.7. Prueba no paramétrica de Wilcoxon. ..........................................................................71

Tabla IV.8.Diferencias entre las tres unidades hidrológicas en el muestreo M1. ..........................72

Tabla IV.9. Diferencias entre las tres unidades hidrológicas en el muestreo M2 .......................73

Tabla IV.10. Media, mediana, mínimo y máximo de los índices de saturación (IS) de una variedad de fases minerales en los acuíferos estudiados para los muestreos M1 y M2. (F. mineral: fase

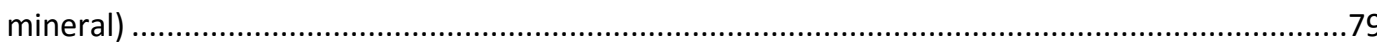

Tabla IV.11.. Correlaciones bivariadas entre los parámetros analizados en el Muestreo 1. Valores críticos para $n-1=57$ grados de libertad y $\alpha=0.05: r=0,256$ y $r s=0,257$.

Tabla IV.12.. Correlaciones bivariadas entre los parámetros analizados en el Muestreo 2. Valores

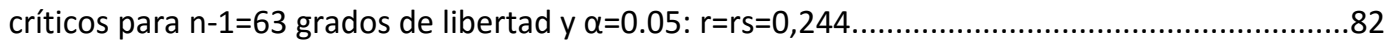

Tabla IV.13. Cargas de los componentes principales retenidos .................................................90

Tabla IV.14. Puntos de agua seleccionados para los muestreos mensuales. ..............................93

Tabla IV.15. Prueba ANOVA de los scores de los tres primeros PCs. ............................................98

Tabla V.1. Minerales de arsénico más frecuentes.....................................................................117

Tabla.V.2. Concentración de arsénico en algunos de los minerales más comunes (Baur y Onishi, 1969; Boyle y Jonasson, 1973, Pichler y col., 1999). ......................................................................118

Tabla V.3. Ejemplos de superficies específicas de arcillas ........................................................121

Tabla.V.4. Capacidades de cambio catiónico de algunas arcillas (en meq/100g) ......................121

Tabla V.5. Relaciones $\mathrm{m} / \mathrm{z}$ empleadas para la cuantificación de elementos traza por ICP-MS .....137

Tabla V.6. Parámetros analíticos determinados en los sedimentos............................................138

Tabla V.7. Composición mineralógica y concentración de arsénico de las muestras elegidas .....139

Tabla V.8. Composición elemental de los sedimentos analizados ..............................................140

Tabla V.9. Parámetros estadísticos de las variables físico-químicas determinadas ......................153

Tabla V.10. Cargas de los componentes principales retenidos ...............................................169

Tabla VI.1. Procedimientos de extracción simple más utilizados. Adaptado de Rauret, 1998......182

Tabla VI.2. Rangos y media de concentraciones, en valores absolutos y porcentuales, de las diferentes fracciones.................................................................................................................196 Tabla VI.3. Diferencia entre las concentraciones de arsénico medidas como suma de fracciones y concentración de arsénico total ..................................................................................................203 Tabla VI.4. Porcentajes de la desviación estándar relativa (DER) de los resultados obtenidos ....205 Tabla VII.1. Concentraciones de arsénico de las distintas muestras de suelos tomadas en las tres

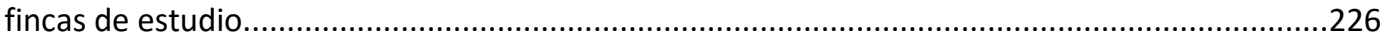
Tabla VII.2. Parámetros analíticos analizados en las cápsulas de succión y en los pluviómetros. 227 Tabla VII.3. Parámetros físico-químicos analizados en las muestras de suelos agrícolas. .............230 Tabla VII.4. Concentraciones medias de arsénico de los suelos agrícolas, NGR y niveles propuestos

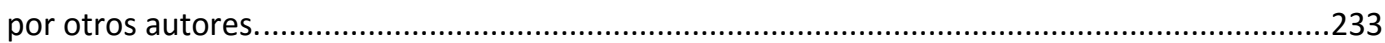
Tabla VII.5. Estadísticos de los resultados obtenidos en los análisis de los suelos agrícolas. .......234 


\section{TABLAS DE LOS ANEXOS}

Tabla A.I.1. Inventario puntos de agua.

Tabla A.II.1. Características hidrogeológicas y resultados analíticos del Muestreo M1.

Tabla A.II.2. Características hidrogeológicas y resultados analíticos del Muestreo M2.

Tabla A.II.3. Valor del índice de cambio de bases para los puntos de agua del muestreo M1 y M2.

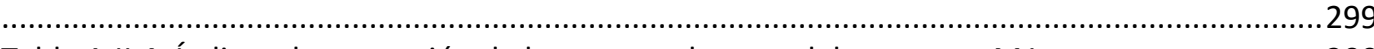

Tabla A.Il.4. Índices de saturación de los puntos de agua del muestreo M1..............................300

Tabla A. II.5. Índices de saturación de los puntos de agua del muestreo M2 ..............................301

Tabla A.II.6. Características físico-químicas de los puntos de agua del muestreo de los puntos de

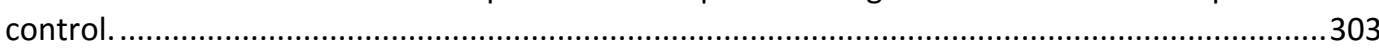

Tabla A.III.1. Identificación y resultados físico-químicos de las muestras de suelos. ...................309

Tabla A.III.2. Matriz de correlación de los parámetros investigados. En la diagonal superior se presentan las correlaciones de Spearman y en la diagonal inferior las de Pearson. ...................313

Tabla A.IV.1. Resúmen de diversosmétodos de extracción secuencial......................................319

Tabla A.IV.2. Resultados del fraccionamiento de arsénico en las 31 muestras seleccionadas.....322 Tabla A.IV.3. Matriz de correlación de los parámetros investigados en el capítulo VI. Distribución de arsénico en sedimentos. ...................................................................................................323 Tabla A.V.1. Resultados obtenidos de la cápsula de succión y del pluviómetro instalados en la finca F1.

Tabla A.V.2. Resultados obtenidos de la cápsula de succión y del pluviómetro instalados en la finca F2.

Tabla A.V.3. Resultados obtenidos de la cápsula de succión y del pluviómetro instalados en la finca F3.

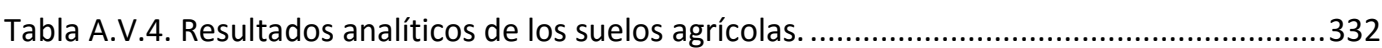

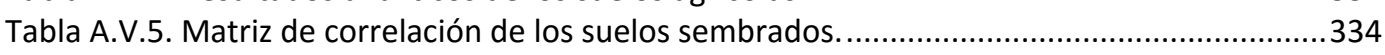

Tabla A.V.6. Matriz de correlación de los suelos en barbecho. .....................................................337 


\section{ÍNDICE DE FIGURAS}

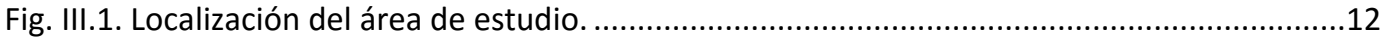

Fig. III.2. Ortofoto del área de estuido. ...............................................................................13

Fig. III.3. Inventario de los puntos de agua sobre el área de estudio...........................................19

Fig. III.4. Mapa hidrológico del área de estudio. .......................................................................20

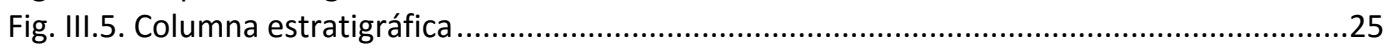

Fig. III.6. Mapa geológico del área investigada.........................................................................28

Fig. III.7. Perfiles geológicos del área investigada ..................................................................29

Fig. IV.1. Diagrama Eh-pH de especies acuosas de arsénico en el sistema ...................................33

Fig. IV.2. a) Especies de As(III) como función de pH. b) Especies de As(V) como función del pH....34

Fig. IV.3. Curvas de adsorción de As(III) y As(V), en función del pH. (Smedley y Kinniburgh, 2001).

Fig. IV.4. Inventario de los puntos de agua de ambos muestreos (M1 y M2) sobre el mapa geológico del área de estuido. Muestreo M1: Verde; Muestreo M2: naranja; ambos muestreos: morado.

Fig. IV.5. Inventario de los puntos de agua de ambos muestreos (M1 y M2) sobre el mapa hidrológico del área de estudio. Acuífero aluvial: rojo; acuífero carbonatado: verde; acuífero detrítico profundo: azul.

Fig. IV.6. Red de control de aguas subterráneas sobre mapa geológico del área de estudio. .........42

Fig. IV.7. Red de control de aguas subterráneas sobre el mapa hidrológico del área de estudio.

Acuífero aluvial: rojo; acuífero carbonatado: verde; acuífero detrítico profundo: azul.

Fig. IV.8. Esquema del tratamiento estadístico MA-PCA .....................................................52

Fig. IV.9. Estructura tridimensional del conjunto de datos. ....................................................53

Fig. IV.10. Esquema de los procedimientos de PARAFAC y TUCKER 3............................................54

Fig. IV.11. Concentración de As de los puntos del muestreo M1 sobre el mapa geológico. Verde: acuífero carbonatado; rojo: acuífero aluvial; azul: acuífero detrítico profundo.............................57 Fig. IV.12. Concentración de As de los puntos del muestreo M1 sobre el mapa hidrológico. Verde: acuífero carbonatado; rojo: acuífero aluvial; azul: acuífero detrítico profundo..............................58 Fig. IV.13. Concentración de As de los puntos del muestreo M2 sobre el mapa geológico. Verde: acuífero carbonatado; rojo: acuífero aluvial; azul: acuífero detrítico profundo..........................59 Fig. IV.14. Concentración de As de los puntos del muestreo M2 sobre el mapa hidrológico. Verde: acuífero carbonatado; rojo: acuífero aluvial; azul: acuífero detrítico profundo.............................60 Fig. IV.15. Concentraciones de los componentes mayoritarios de los puntos del acuífero aluvial y carbonatado del muestreo M1 sobre el mapa geológico. 661 Fig. IV.16. Concentraciones de los componentes mayoritarios de los puntos del acuífero aluvial y carbonatado del muestreo M2 sobre el mapa geológico. ......................................................62 Fig. IV.17. Concentraciones de los componentes mayoritarios de los puntos del acuífero detrítico profundo del muestreo M1 sobre el mapa hidrológico. ..................................................................63 Fig. IV.18. Concentraciones de los componentes mayoritarios de los puntos del acuífero detrítico profundo del muestreo M2 sobre el mapa hidrológico. .........................................................64 Fig. IV.19. Gráficos box-plot de los parámetros analizados. M1: Muestreo 1; M2: Muestreo 2; 12: Acuífero Aluvial; 13: Acuífero Carbonatado; 17: Acuífero Detrítico Profundo ................................68

Fig. IV.20. Diagrama de Piper para el Muestreo 1................................................................75

Fig. IV.21. Diagrama de Piper para el Muestreo 2 .................................................................76

Fig. IV.22. Diagrama de Piper de los puntos comunes de los muestreos M1 y M2.......................77

Fig. IV.23. Representación de los icb de los muestreos $\mathrm{M} 1$ y M2 ..............................................78

Fig. IV.24. a) Representación de C.E frente a As; b) Representación de bicarbonato frente a As; c)

Representación de sulfato frente a As ....................................................................................83

Fig. IV.25. a) Representación de P frente a As; b) Representación de Mo frente a As; c)

Representación de $\mathrm{V}$ frente a As. 
Fig. IV.26. Análisis clúster de los datos del muestreo M1 ..................................................87

Fig. IV.27. Análisis clúster de los datos del muestreo M2 .........................................................8 88

Fig. IV.28. Gráfico de autovalores de los muestreos M1 y M2 ...................................................89

Fig. IV.29. Representación de las cargas de los dos primeros PCs para los muestreos M1 y M2...91

Fig. IV.30. Representación de los scores de las muestras del muestreo M1. .............................92

Fig. IV.31. Representación de los scores de las muestras del muestreo M2 . .............................92

Fig. IV.32. Variación de la hidroquímica de los puntos de control en el periodo investigado........94

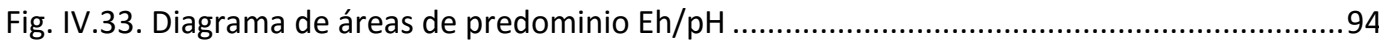

Fig. IV.34. Evolución temporal de Ca y As en los puntos de la red de control. ............................95

Fig. IV.35.Evolución temporal de Ca y As en el punto S90.......................................................95

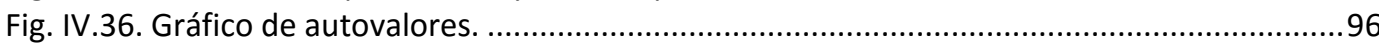

Fig. IV.37. Representación gráfica de las cargas de los dos primeros PCs. .................................97

Fig. IV.38. Representación de los scores de las muestras. ........................................................97

Fig. IV.39. Cargas de los factores de los tres modos. A (puntos de muestreo), B (parámetros

analizados) y C (mes del muestreo). ............................................................................. 100

Fig. IV.40. Representación de las cargas de los factores para el modelo Tucker3 [2 2 1]...........102

Fig. IV.41. Diagrama de Piper de las muestras del Muestreo M1.............................................105

Fig. IV.42. Diagrama de Piper de las muestras del Muestreo M2 ..........................................106

Fig. IV.43. Representación de $\mathrm{pH}$ frente a As de los puntos de agua del acuífero detrítico profundo

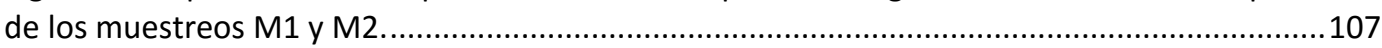

Fig. IV.44. Representación de P frente a As en los muestreos M1 y M2 .................................108

Fig. IV.45. Representación de V frente a As. ...................................................................... 108

Fig. IV.46. Representación de C.E frente a As. ................................................................... 108

Fig. IV.47. Representación de la C.E frente a As.....................................................................111

Fig. IV.48. Representación de K frente a As. ........................................................................ 111

Fig. IV.49. Representación de sulfato frente a As. ....................................................................112

Fig. IV.50. Esquema del origen y dispersión del As ....................................................................114

Fig. V.1. Cargas en los coloides de los sedimentos .............................................................120

Fig.V.2. Retención del fosfato por coadsorción con un ión metálico en una partícula de arcilla. 122

Fig. V.3. Esquema del sistema de perforación de recirculación inversa empleado ......................126

Fig. V.4. Inventario de los puntos de muestreo de sedimentos sobre el mapa geológico............127

Fig. V.5. Inventario de los puntos de muestreo de sedimentos sobre la columna estratigráfica.128

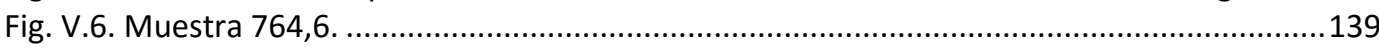

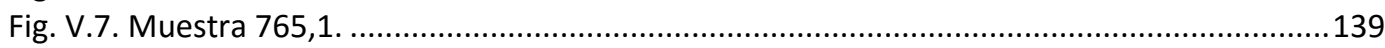

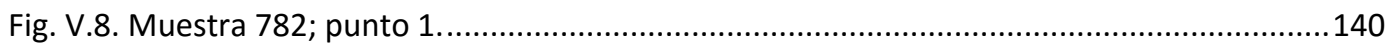

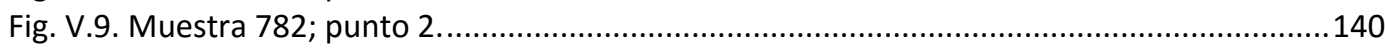

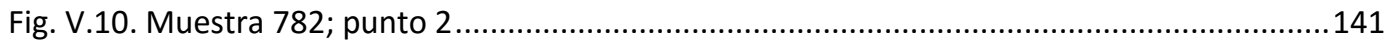

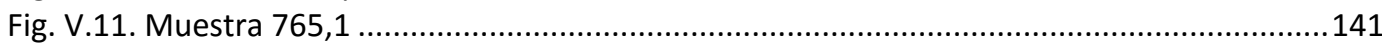

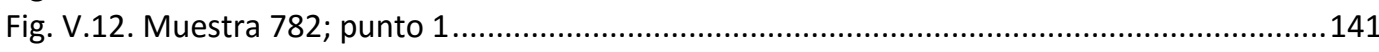

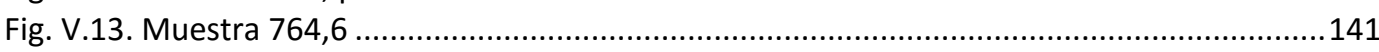

Fig. V.14. Perfiles de distribución verticales de los parámetros analizados.................................143

Fig. V.15. Representación de la composición mineralógica en las diferentes muestras, se ha señalado el contenido de arsénico debajo del diagrama circular .............................................148

Fig. V.16. Representación de los niveles de arsénico en las muestras superficiales.....................151

Fig. V.17. Representación de los niveles de fósforo extraíble y potasio total en las muestras superficiales

Fig. V.18. Diagramas de cajas y bigotes (box-plots) de todos los parámetros analizados. 1-CP: Calizas del Páramo; 2-TP: Transición al Páramo; 3-C: Cuestas; 4-Z: Zaratán; 5-TC: Tierra de Campos; 6-D: Dueñas; 7-VA: Villalba de Adaja; 8-TS: Toro Superior y 9-TI: Toro Inferior. Fig. V.19. Box-plot del As según sean las muestras superficiales o sub-superficiales..... 
Fig. V.20. Mosaico de color mostrando las correlaciones entre parámetros. Por debajo de la diagonal se muestran los coeficientes de correlación de Pearson y por encima los de Spearman.

Fig. V.21. Correlación entre resultados de componentes minerales y tamaño de partículas: (a) cuarzo y arenas; (b) filosilicatos y arcillas. Partículas gruesas: aquellas partículas entre 2-0,02 $\mathrm{mm}$. Partículas finas: aquellas partículas menores de $0,002 \mathrm{~mm}$.

Fig. V.22. Diagrama textural, en el que se indica la concentración de As de las muestras de sedimentos tomadas.

Fig. V.23. Porcentaje de los compuestos minerales filosilicatos, cuarzo y resto de minerales en un diagrama triangular, con indicación de la concentración de As..................................................165 Fig. V.24. Dendrogramas obtenidos por análisis clúster de las 57 muestras de sedimentos y de los 26 parámetros analizados, complementado con un mosaico de colores que indica los niveles relativos de los parámetros en las muestras.......................................................................167

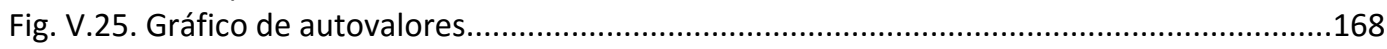

Fig. V.26. Representación gráfica de las cargas de los dos primeros componentes principales...170 Fig. V.27.Representación de los scores de las muestras indicando la concentración de As (en $\mathrm{mg} / \mathrm{kg})$.

Fig. V.28. Representación de los scores de las muestras indicando la cota (m.a.s.l)..................171

Fig. VI.1. Localización espacial sobre el mapa geológico de las muestras sometidas a fraccionamiento químico de arsénico.....

Fig. VI.2. Localización vertical sobre la columna estratigráfica de muestras elegidas para el fraccionamiento de arsénico

Fig. VI.3. Esquema de fraccionamiento de arsénico en sedimentos (Wenzel y col., 2001)...........194

Fig. VI.4. Contenido de arsénico en las distintas fracciones extraídas de 31 muestras de sedimentos. Muestras subterráneas: $610-724$; muestras superficiales: 727-864, excepto la muestra 736 que pertenece a las muestras subterráneas.

Fig. VI.5. Concentración porcentual de arsénico en las diferentes fracciones extraídas del suelo Muestras subterráneas: 610-724; muestras superficiales: 727-864 excepto la muestra 736 que pertenece a las muestras subterráneas.

Fig. VI.6. Mapa geológico mostrando la distribución horizontal del fraccionamiento de arsénico en sedimentos y la concentración en agua subterránea.....

Fig. VI.7. Mapa hidrológico mostrando la distribución horizontal del fraccionamiento de arsénico en sedimentos y la concentración en agua subterránea...............................................................200 Fig. VI.8. Distribución y fraccionamiento de arsénico en sedimentos en función de la profundidad

Fig. VI.9. Diferencias entre la suma de fracciones y el arsénico total analizado según norma EPA

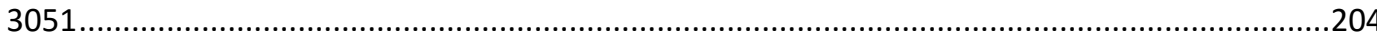
Fig. VI.10. Distribución del arsénico en las diferentes fracciones y representación de la desviación

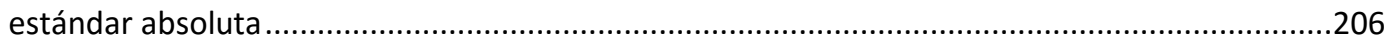
Fig. VI.11. Correlaciones bivariadas entre los distintos parámetros analizados en las muestras de suelos, representados con un mosaico de colores......................................................................208

Fig. VI.12. Correlación entre las fracciones de As y el contenido de filosilicatos ........................209

Fig. VI.13. Resultados experimentales/Fe total.......................................................................209

Fig. VI.14. Representación del \% filosilicatos frente a la suma de las fracciones 3,4 y5 ..............210

Fig. VII.1. Curvas de adsorción de As(III) y As(V), en función del pH. (Tomado de Smedley y

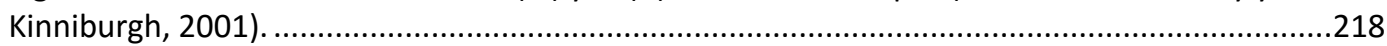

Fig. VII.2. Localización de las cápsulas de succión y de los pozos con los que son regadas ...........222

Fig. VII.3. Inventario de los puntos de suelos agrícolas del área investigada sobre la ortofoto...225 Fig. VII.4. Representación de las concentraciones de arsénico en las diferentes profundidades de suelo muestreadas. 
Fig. VII.5. Evolución temporal de las concentraciones de As y $\mathrm{Cl}^{-}$en la cápsula de succión (CS) y pluviómetro $(P)$ de la finca F1.

Fig. VII.6. Evolución temporal de las concentraciones de As y $\mathrm{Cl}^{`}$ en la cápsula de succión (CS) y pluviómetro $(P)$ de la finca $F 2$.

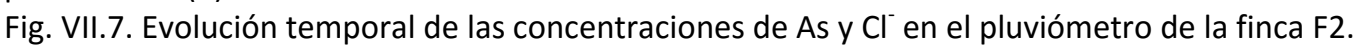

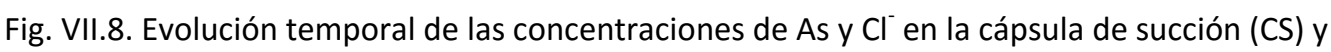
pluviómetro $(\mathrm{P})$ de la finca F3.

Fig. VII.9. Concentraciones de arsénico de los suelos agrícolas. Entre paréntesis: concentración de As $(\mu \mathrm{g} / \mathrm{L})$ de los pozos con los que son regados.

Fig. VII.10. Diagramas circulares de los componentes minerales de los suelos.

Fig. VII.11. Representación de los datos obtenidos en box-plot según pertenezcan a suelos sembrados o en barbecho

Fig. VII.12. Representación de las correlaciones de los parámetros estudiados mediante mapas de colores.

Fig. VII.13. Dendrogramas obtenidos por análisis clúster de las 24 muestras de suelos agrícolas y de los 24 parámetros analizados, complementado con un mosaico de colores que indica los niveles relativos de los parámetros en las muestras.

Fig. VII.14. Representación gráfica de las cargas de los dos primeros componentes principales. 243 Fig. VII.15. Representación de los dos primeros scores. El asterisco identifica a las muestras que se tomaron de campos en barbecho.

Fig. VII.16. Representación de los dos primeros scores. Identificando para cada muestra el contenido de arsénico en la muestra de suelo y entre paréntesis el contenido del agua de riego. 

CAPÍTULO I. ANTECEDENTES

(2) 

El arsénico (As) es un elemento muy común en la atmósfera, rocas y suelos, en la hidrosfera y biosfera. Es el vigésimo en abundancia dentro de la corteza terrestre, el catorceavo en agua de mar y el duodécimo en el cuerpo humano (Woolson y col., 1975).

Su aislamiento se produjo en el s.XIII por Alberto Magno. Desde entonces se ha utilizado en diversos campos tales como la producción industrial de metales, la combustión de carbón y petróleo, el uso de compuestos arsenicales en agricultura, o el uso de productos fungicidas en la industria maderera, originando una enorme dispersión de arsénico en aire, agua y suelos. Entre las fuentes naturales de arsénico cabe destacar la actividad volcánica y el lixiviado de arsénico de minerales y rocas. Debido a esta ubicuidad y alta dispersión en el medio ambiente, el arsénico se encuentra en la mayor parte de alimentos y bebidas (Seiler y col., 1994; Kabata-Pendias y Pendias, 1985).

En la actualidad, el arsénico está considerado como un elemento extremadamente tóxico para el organismo humano. En España desde 1985, la Ley de Aguas 29/85 y su reglamento, RD 849/86, señalan en el Anexo al Título III en la lista II que el arsénico es una sustancia contaminante.

La toxicidad del arsénico depende del estado de oxidación, de la estructura química y de la solubilidad en el medio biológico (Nriagu y col., 1994). De esta manera la escala de toxicidad del arsénico decrece en el siguiente orden:

Arsina $\left(\mathrm{H}_{3} \mathrm{As}\right)>\mathrm{As}(\mathrm{III})$ inorgánico (arsenito) $>\mathrm{As}(\mathrm{III})$ orgánico $>\mathrm{As}(\mathrm{V})$ inorgánico (arsenato) $>\mathrm{As}(\mathrm{V})$ orgánico $>$ compuestos arsenicales y arsénico elemental.

El agua constituye probablemente la principal vía de entrada de arsénico en la cadena alimenticia humana, lo que justifica la gran preocupación de las autoridades sanitarias por vigilar y controlar los niveles de calidad del agua exigida para consumo humano en numerosas normativas al respecto desde 1980 (USEPA, 1980; WHO, 1993, WHO, 1996). Según la Directiva 98/83/CE, que entró en vigor en el año 2003, el nivel máximo de As admisible es de $10 \mu \mathrm{g} / \mathrm{L}$.

Se han detectado problemas de contaminación por arsénico en más de 20 países, incluyendo la práctica totalidad del lejano oriente (Bangladesh, India, Tailandia, Vietnam, China...), pero también en Hungría, Estados Unidos, Argentina, Méjico, Chile, España... En Bangladesh, la contaminación de las aguas subterráneas por arsénico es de tal magnitud que está siendo considerado el peor envenenamiento masivo del siglo, con más de 50 millones de personas expuestas a este elemento tóxico.

En España, los datos epidemiológicos en relación con la ingesta de arsénico en el agua de bebida son prácticamente inexistentes. Los primeros estudios en relación con niveles de arsénico en aguas de abastecimiento de origen subterráneo se realizaron en Salamanca (Blanco y col., 1998) y en Madrid (Hernández y col., 2002), detectándose niveles de arsénico superiores a $50 \mu \mathrm{g} / \mathrm{L}$ (nivel máximo permitido antes del año 2003). En España se han detectado problemas de contaminación significativos en las Marismas del Pinar, Huelva (causado por cenizas de pirita procedentes de la planta de fosfórico de Fertiberia, que cerró en el año 2000), en la cuenca del Tajo y en la cuenca del Duero (Gómez y col., 2006). 
Las comarcas más afectadas de Castilla y León son Tierra de Pinares (Valladolid), El Carracillo y Las Cogotas (Segovia) y La Moraña (Ávila), donde se cree que la presencia de arsénico es debida a procesos de desorción relacionados con intercambio iónico y favorecidos por la recirculación del agua causada por el bombeo de los acuíferos (Moyano y col., 2003).

En Tierra de Pinares los altos contenidos de arsénico superiores a $50 \mu \mathrm{g} / \mathrm{L}$ se detectaron en el verano del año 2000, a raíz de la realización de análisis químicos en las aguas que abastecían a la población de Íscar (Valladolid).

Los análisis en otras localidades confirmaron la verdadera envergadura del problema, ya que los altos contenidos de arsénico en las aguas subterráneas se extendían por un amplio sector de la Cuenca del Duero que comprendía la zona de Tierra de Pinares (Valladolid), El Carracillo y Las Cogotas (Segovia) y La Moraña (Ávila) y afectaba los abastecimientos de más de 40 poblaciones.

Ante la alarma social y sanitaria que suponía las altas concentraciones de esta sustancia en aguas para consumo humano, la Junta de Castilla y León puso en marcha en 2002 un ambicioso plan de trasvase de agua desde el río Eresma a buena parte de los municipios afectados situados en las provincias de Valladolid y Segovia, con el que intentó solucionar el problema del arsénico en las comarcas afectadas. No obstante, considerando la importante utilización de las aguas subterráneas en agricultura y ganadería y la acusada interacción de los procesos que intervienen en el funcionamiento de las aguas subterráneas, se hacía necesario profundizar más sobre el posible origen del arsénico y en los mecanismos que intervienen en su dispersión en el medio hidrogeológico.

Ante la dificultad que suponía abordar un estudio en una comarca tan extensa en la que existen condicionantes hidrogeológicos complejos, se seleccionó un área piloto en la que estuviesen presentes aquellos factores más significativos a fin de evaluar su incidencia en el origen y dispersión del arsénico y, de esta manera, intentar generalizar las conclusiones al resto de la región.

La zona seleccionada se encuentra situada en la margen derecha del río Cega, al oeste de Cuellar, y comprende parte de los términos municipales de Vallelado, Mata de Cuellar, San Cristóbal y Torregutiérrez (Cuellar) pertenecientes a la provincia de Segovia.

Entre los estudios de evaluación indispensables para dilucidar el origen y mecanismos de dispersión del arsénico en el área investigada está la determinación de diversos parámetros físico-químicos, tanto en el agua como en sedimentos, a fin de establecer las correlaciones que puedan existir entre este contaminante y resto de variables características del acuífero, y de discernir el ciclo hidrogeoquímico del arsénico en el acuífero afectado. 
CAPÍTULO II. OBJETIVOS 


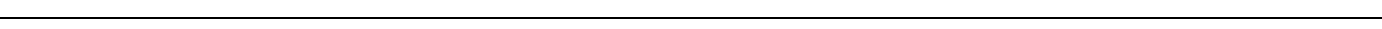




\section{II.1. OBJETIVO GENERAL}

Esta Tesis Doctoral pretende ahondar en el conocimiento de la relación entre el entorno geológico natural y la calidad de las aguas subterráneas, a través de la identificación de los procesos naturales y contaminantes que regulan la liberación y movilización de arsénico y otros elementos geogénicos potencialmente tóxicos.

Se propone investigar, en aguas y sedimentos, la distribución de arsénico y otros elementos traza geogénicos, así como de otros factores que influyen en los procesos de intercambio agua-sedimento tales como la composición mineral y química del acuífero. El estudio se centrará en un área de la cuenca del Duero afectada por elevados niveles de arsénico en las aguas subterráneas. Se ha elegido un área perteneciente a la comarca Tierra de Pinares, localizada en la margen derecha del río Cega y que comprende los municipios segovianos de Mata de Cuéllar, Vallelado y San Cristóbal de Cuéllar.

El objetivo general será extraer la mayor información posible sobre el ciclo hidrogeoquímico del arsénico, y determinar los principales factores geoambientales que regulan la presencia, movilidad y dispersión del arsénico en las aguas subterráneas de la zona de estudio. Esto permitirá elucidar las causas de las anomalías hidroquímicas observadas, con el objetivo último de que las conclusiones ayuden a las autoridades competentes a establecer patrones de utilización segura y racional de los recursos subterráneos, así como delimitar zonas vulnerables o sujetas a riesgo potencial debido a la presencia de este elemento tóxico.

\section{II.2. OBJETIVOS OPERATIVOS}

Para lograr el objetivo general, el estudio se articulará teniendo en cuenta los siguientes aspectos:

- Delimitar un área de estudio representativa del sector sur de la Cuenca del Duero, donde existe el problema ambiental de contaminación de las aguas subterráneas por arsénico.

- Obtención de la piezometría de la zona objeto de estudio para conocer el estado de los acuíferos y la dirección de los flujos de agua subterránea.

- Realizar un inventario de puntos de agua del área investigada y seleccionar los puntos a muestrear, la frecuencia de muestreo y las técnicas de muestreo adecuadas a cada tipo de muestra.

- Obtención de datos estacionales de la concentración de arsénico y otras variables hidroquímicas de interés para caracterizar las aguas subterráneas del área investigada.

- Establecer una pequeña red de control y llevar a cabo su seguimiento mensual para investigar variaciones estacionales de la hidroquímica del acuífero causadas por el régimen de precipitaciones y por los usos del agua y del suelo. 
- Obtener datos de la concentración de arsénico y otros parámetros químicos y mineralógicos en muestras de sedimentos del área estudiad, representativas de las diferentes unidades litoestratográficas identificadas en la región.

- Análisis de los resultados con técnicas hidroquímicas y geoquímicas clásicas para interpretar las características hidrogeológicas de la zona y el ciclo hidrológico del arsénico.

- Tratamiento multivariante de los datos mediante las adecuadas técnicas estadísticas para encontrar asociaciones entre las muestras y entre las variables investigadas, generando modelos descriptivos y, en su caso, predictivos del comportamiento del arsénico y otros elementos traza geogénicos en los acuíferos existentes en la zona objeto de estudio.

- Investigar la movilidad del arsénico en los sedimentos mediante procedimientos de extracción secuencial de las fases minerales de arsénico de estabilidad creciente, para evaluar el riesgo potencial de movilización del arsénico presente en los materiales sedimentarios del acuífero.

- Evaluar el efecto que ejercen las actividades agrícolas (uso del agua y del suelo) en el transporte de arsénico en el agua subterránea de la zona de estudio. 
CAPÍTULO III. ÁREA DE ESTUDIO 



\section{III.1. LOCALIZACIÓN Y CARACTERÍSTICAS GENERALES}

Se ha escogido un área bien delimitada y representativa de la Cuenca del Duero, en donde fueron detectados altos niveles de arsénico, con el objeto de extraer la mayor información acerca del ciclo hidrogeoquímico del arsénico en el medio. Esto facilitará extraer conclusiones acerca del origen y formas de propagación de este elemento tóxico en esta zona afectada.

El área elegida se halla situada en la margen derecha del río Cega, entre las localidades de Cuellar e Iscar, y comprende los municipios de Mata de Cuellar, Vallelado y San Cristóbal de Cuellar, todos ellos pertenecientes a la provincia de Segovia (Fig. III.1).

Esta área está delimitada al norte por el páramo y al sur por el cauce del río Cega, y presenta diferentes tipos de terreno aflorantes: Calizas del Páramo, facies de Transición al Páramo, facies Cuestas, arcillas, arenales... que previsiblemente afectarán la composición del agua subterránea.

Los principales recursos económicos de esta zona se centran en la actividad agraria y ganadera, con importantes regadíos de aguas subterráneas dedicados principalmente al cultivo de la zanahoria, patata y remolacha, así como abundantes granjas porcinas y avícolas.

En esta zona destaca la existencia de abundantes pozos excavados que extraen aguas de acuíferos superficiales que principalmente se destinan al riego de cultivos, junto a sondeos perforados que extraen aguas subterráneas profundas que se utilizan tanto al riego de cultivos como a las explotaciones ganaderas $y$, en menor medida, al abastecimiento de poblaciones. También es relativamente frecuente, principalmente a comienzos de la época de riego, el bombeo directo de las aguas del río Cega para uso agrícola, así como utilización esporádica de arroyos a los que se vierten efluentes de aguas residuales de las poblaciones.

\section{III.2. USOS DEL SUELO}

El área vertiente al acuífero aluvial, sin considerar la superficie de los páramos y los escarpes erosivos del río Cega, tiene una superficie total de $42,4 \mathrm{~km}^{2}$ de los que un $14,0 \%$ corresponde a terreno ocupado por pinar, un $14,8 \%$ a matorral o terreno baldío, un $69,6 \%$ tiene aprovechamiento agrícola y el 1,5\% restantes corresponde a zona urbana (Mata de Cuellar, Vallelado y San Cristóbal de Cuellar) (Tabla III.1). Los distintos usos del suelo se pueden observar en la ortofoto (Fig. III.2) realizada en el verano del año 2001 

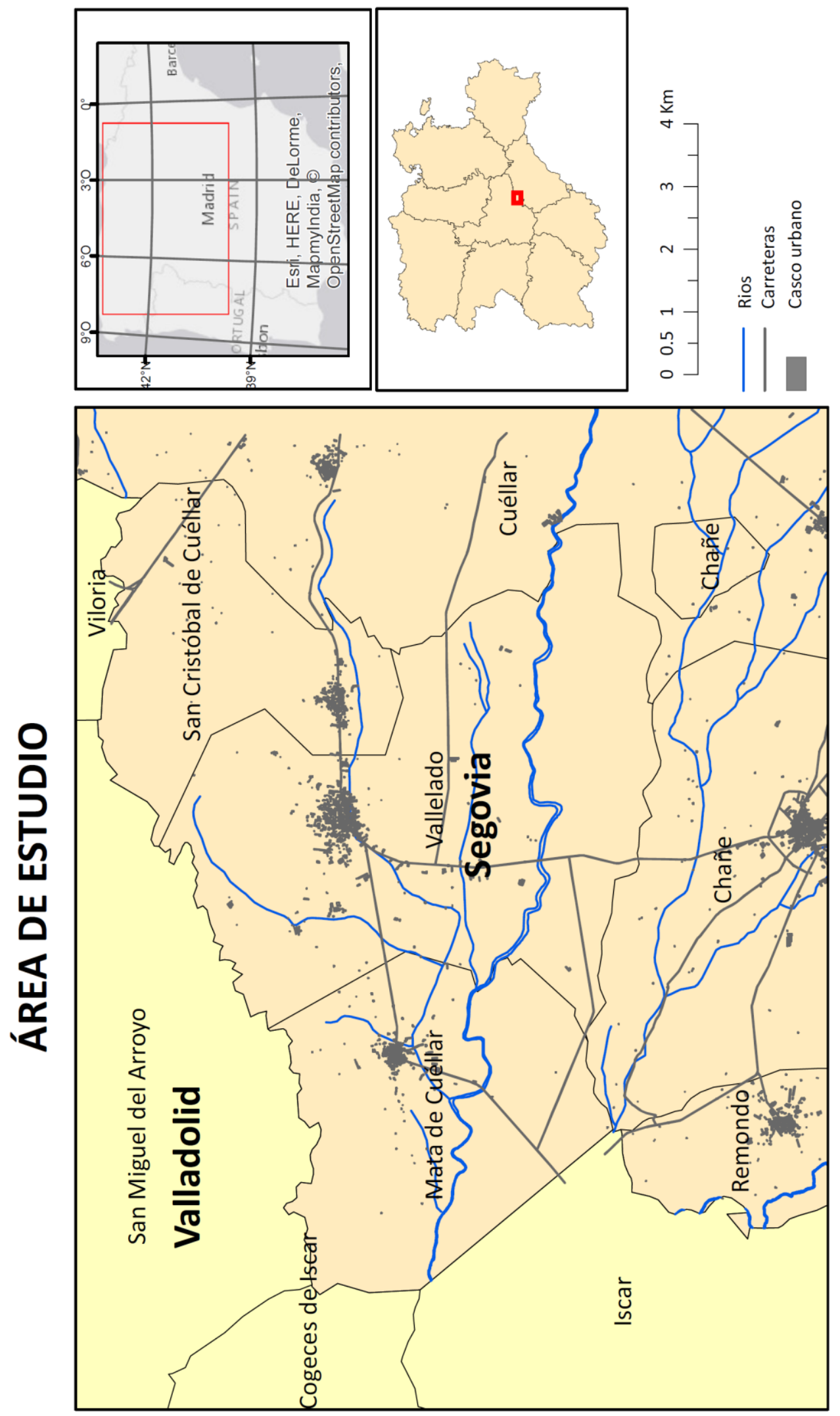

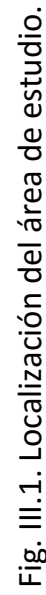




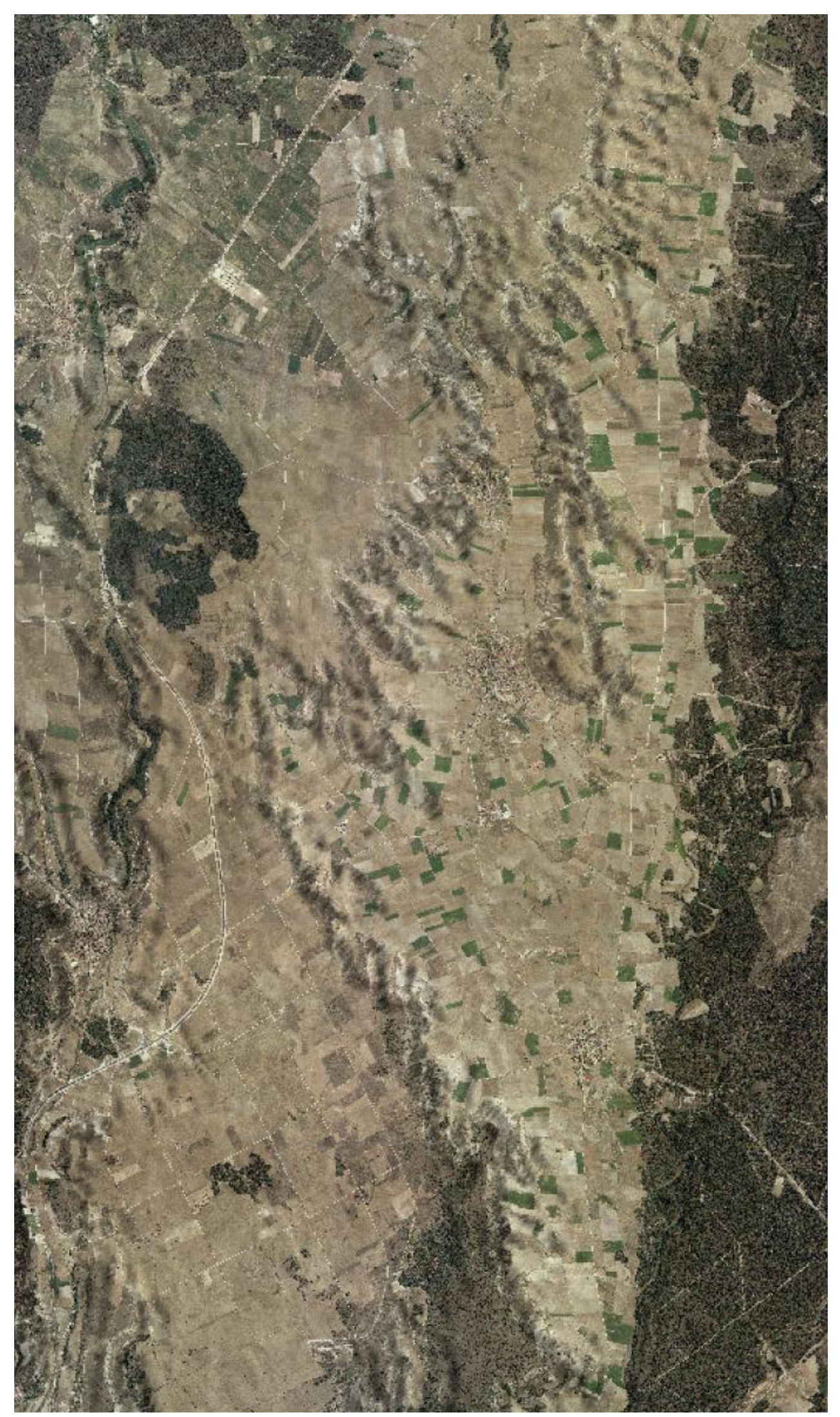

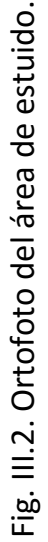


Tabla III.1.Usos del suelo de la zona de estudio.

\begin{tabular}{lcc} 
Uso del suelo & Superficie $\left(\mathbf{k m}^{\mathbf{2}}\right)$ & $\mathbf{\%}$ \\
\hline Pinar & 6,0 & 14,0 \\
Matorral/baldío & 6,3 & 14,8 \\
Agrícola & 29,5 & 69,6 \\
Urbano & 0,6 & 1,5 \\
\hline
\end{tabular}

Los pinares, por lo general, se extienden a lo largo del borde meridional y en el extremo noroeste, asociados generalmente a los depósitos de manto eólico. Los terrenos de matorral y baldíos, por el contrario, se disponen en las zonas de ladera en los que aflora la facies Cuestas.

Los terrenos agrícolas ocupan las zonas topográficamente más deprimidas que corresponden a los depósitos coluviales, depósitos aluviales y depósitos de superficie. Del total de la superficie dedicada a cultivos un $80,4 \%$ se destina a secano y el $19,6 \%$ restante a regadío.

\section{III.3. HIDROGEOLOGÍA}

\section{III.3.1. HIDROGEOLOGÍA REGIONAL}

En la Cuenca del Duero se han diferenciado diversas unidades hidrogeológicas formadas por uno o varios acuíferos agrupados de forma que permitan una administración racional y eficaz del agua (Moptma-Miner, 1994). El bloque levantado del zócalo. correspondiente a la alineación de Santa María la Real de Nieva-Zarzuela del PinarFuentidueña, delimita al sureste la Unidad Hidrogeológica de Segovia (02.18); mientras que, al noroeste, en el sector donde se han detectado valores elevados de arsénico en las aguas subterráneas, se encuentra la Unidad Hidrogeológica Región de los Arenales (02.17) y la Unidad Hidrogeológica Central del Duero (02.08).

Los acuíferos de estas unidades hidrogeológicas están constituidos por los niveles de arenas y gravas intercalados en una secuencia terciaria predominantemente limoarcillosa. La existencia de niveles permeables (arenas y gravas) intercalados dentro de un conjunto poco permeable (limos y arcillas) configura la existencia de un acuífero heterogéneo y anisótropo donde el agua subterránea circularía preferentemente a través de los niveles más permeables (acuíferos), mientras que en los materiales menos permeables (acuitardos) el flujo subterráneo sería mucho más lento.

Los páramos carbonatados existentes en el extremo nororiental de este sector y que constituyen el último episodio de la sedimentación neógena dan lugar a la Unidad Hidrogeológica "Páramo de Cuellar" (02.13) y constituyen un acuífero carbonatado de carácter libre superficial. 
Las plataformas aluviales o depósitos de superficie de edad Cuaternario que recubren los materiales terciarios y se extienden principalmente sobre la Unidad Hidrogeológica "Región de los Arenales", originan acuíferos superficiales de carácter libre, al igual que los depósitos aluviales asociados a la red de drenaje actual. Según el Moptma-Miner estos acuíferos superficiales se integran dentro de la Unidad Hidrogeológica "Aluviales del Duero y afluentes" (02.12).

En general las aguas subterráneas asociada a los acuíferos profundos son captadas mediante sondeos de más de $100 \mathrm{~m}$ de profundidad, perforados mediante maquinaria. En los acuíferos asociados a los páramos calcáreos, las captaciones se realizan mediante sondeos de varias decenas de metros de profundidad, aunque en las zonas de borde pueden existir pozos o galerías excavadas. Por último, en los acuíferos aluviales de carácter superficial el sistema de captación se realiza generalmente mediante pozos excavados.

El flujo de agua subterránea en los acuíferos profundos tiene lugar generalmente hacia el noroeste, en dirección al río Duero (IGME, 1980), mientras que en los acuíferos aluviales de carácter superficial, los flujos subterráneos generalmente convergen aguas abajo en dirección a los principales ríos que atraviesan la zona o se infiltran verticalmente a través del sustrato terciario recargando los acuíferos profundos.

La existencia de niveles piezométricos progresivamente más profundos conforme aumenta la profundidad de los sondeos pone de manifiesto la existencia de una notable componente vertical descendente en el flujo subterráneo, indicando que este sector situado al noroeste del zócalo levantado de la alineación de Santa María la Real de Nieva-Zarzuela del Pinar-Fuentidueña constituye una zona de recarga de los acuíferos profundos.

\section{III.3.2. HIDROGEOLOGÍA LOCAL}

\section{III.3.2.1 Descripción de las unidades acuíferas}

Atendiendo a las características hidrogeológicas de las formaciones geológicas se han diferenciado las siguientes unidades acuíferas en la zona:

\section{Acuífero aluvial}

Comprende los recubrimientos de edad Cuaternario constituidos principalmente por los depósitos de superficie existentes en la margen derecha del río Cega y los depósitos aluviales asociados a los arroyos de Valdelacasa, Horcajo y Torregutiérrez, abarcando una superficie total de $27,3 \mathrm{Km}^{2}$. La base de este acuífero está formada generalmente por las margas carbonosas de la facies Zaratán y por las margas y margocalizas de las facies Cuestas de edad Terciario.

Su espesor es variable y oscila generalmente entre 3 y $9 \mathrm{~m}$. Debido al carácter detrítico de estos depósitos (arenas, gravas y arcillas) constituyen un acuífero aluvial de carácter libre y superficial, con una permeabilidad media-alta debida a la porosidad intersticial existente entre sus partículas. Las zonas más permeables se asocian a la existencia de 
depósitos de canal constituidos por arenas y gravas, mientras que las menos permeables corresponden a las zonas de llanura de inundación y de conos de deyección, en las que existe una mayor proporción de partículas finas (arcillas y limos) en los sedimentos.

Especial interés hidrogeológico presentan los paleocanales existentes en los depósitos de superficie ya que son zonas que corresponden a surcos excavados en el sustrato terciario rellenados por arenas y gravas permeables. Se ha observado la existencia de estos surcos en los depósitos de superficie existentes en la zona de La Gila-Cuatro Caminos, al sur del páramo de El Llano. Por el contrario, existen áreas correspondientes a zonas de umbral del sustrato terciario en las que el aluvial es de naturaleza arcillosa y presenta escaso espesor, presentando poco interés como acuífero, como ocurre en el área de Cañamares-La Llosa, al sureste de Mata de Cuellar.

Durante la época de invierno, este acuífero se descarga de forma natural a través de manantiales situados a lo largo del escarpe erosivo de la margen derecha del río Cega, así como en determinados puntos situados más norte, asociados a la presencia de umbrales del sustrato terciario (La Dehesa y Entre Cotarras al oeste y noreste respectivamente de Mata de Cuellar) o presencia de conos de deyección menos permeables (Camino del Monje en la parte baja del arroyo de Valdelacasa).

\section{Acuífero carbonatado}

Está constituido por las calizas de edad Mioceno que coronan el páramo de Cuellar y que forman el borde septentrional, occidental y oriental de la zona estudiada. Su espesor aumenta progresivamente de Oeste a Este desde los 10-15 m a los 25-30 m. Su base está formada por las arcillas margosas de la parte superior de la Transición al Páramo, si bien los niveles más carbonatados de esta unidad también tienen interés en este acuífero.

Se trata de un acuífero de tipo carbonatado y libre cuya permeabilidad es debida a la presencia de fisuras en la roca, así como a huecos originados por fenómenos cársticos. La descarga del mismo se produce de forma natural a través de una serie de manantiales situados generalmente en la base del tramo carbonatado, coincidiendo con la presencia de fracturas o de una mayor carstificación de la roca.

\section{Acuífero detrítico profundo}

Está constituido por los niveles detríticos de carácter permeable intercalados en los sedimentos terciarios que se encuentran por debajo de la facies Cuestas. Su límite inferior lo constituye el zócalo mesozoico y/o paleozoico.

Se trata de un medio heterogéneo estratificado y anisótropo o acuífero multicapa en el que los niveles permeables (arenas y gravas) se encuentran intercalados en un conjunto limo-arcilloso que se comporta como acuitardo. El flujo subterráneo se dirige hacia el norte, presentando componente descendente, con niveles piezométricos progresivamente más profundos, conforme aumenta la profundidad de los niveles acuíferos. 


\section{III.3.2.2 Inventario de puntos de agua}

En total se han inventariado 128 puntos de agua de los que 76 corresponden a pozos, 26 a sondeos, 21 a manantiales y 5 a piezometros. En la tabla A.I.1 del Anexo se detalla la denominación, coordenadas y características de los mismos mientras que en la Fig. III.3 se muestra su ubicación en el área de estudio.

\section{Pozos}

Los pozos inventariados generalmente captan aguas subterráneas de los acuíferos de carácter superficial asociados a los aluviales de fondo de valle y glacis de los arroyos de Valdelacasa, Horcajo y Torregutiérrez, así como a los depósitos de superficie existentes en la margen derecha del río Cega.

Se trata de construcciones excavadas de forma artesanal con profundidades generalmente comprendidas entre 3 y $8 \mathrm{~m}$ y diámetros que oscilan entre 2 y $6 \mathrm{~m}$. En los pozos más antiguos el revestimiento se efectúa mediante sillería o mampostería mientras que en los más modernos se utilizan anillos de hormigón prefabricado.

Debido al descenso de la superficie freática, algunos pozos han tenido que ser reprofundizados mediante la excavación de su interior y la instalación de un revestimiento concéntrico de menor diámetro más profundo. En otros, en los que la excavación alcanza el sustrato terciario, se observa la realización de drenes horizontales en su fondo, al objeto de incrementar su productividad.

Los caudales de bombeo generalmente oscilan entre los 0,4 y los 5 L/s. El sistema de extracción generalmente se efectúa mediante bombas de aspiración que se sitúan en la superficie del terreno o se colocan en zanjas laterales en aquellos pozos en los que la superficie freática se encuentra a una profundidad excesiva. En los casos en los que la superficie regada se encuentra a cierta distancia de la captación o a una cierta altura respecto a la misma, se intercalan bombas de impulsión al objeto de reducir las pérdidas de carga.

En su mayor parte las aguas captadas mediante pozos se utilizan para regadío y, en menor medida para ganadería. Las superficies regadas generalmente oscilan entre las 0,4 y las $5 \mathrm{Ha}$ y el sistema de riego se realiza mediante aspersores bien de forma directa desde el mismo pozo o bien a partir de balsas en los casos de que la productividad sea baja o se tengan más de una captación para el riego.

\section{Sondeos}

Los sondeos existentes en la zona captan aguas de los acuíferos detríticos profundos existentes en las Unidades Hidrogeológicas Región de los Arenales (02.17) y Central del Duero (02.08), así como del acuífero carbonatado del Páramo de Cuellar (02.18) situado en la parte septentrional.

Se trata de perforaciones de pequeño diámetro (inferior a 0,8 $\mathrm{m}$ ) efectuadas mediante maquinaria de sondeo que perfora utilizando un útil de corte que se introduce en el terreno por percusión o por rotación. Las profundidades de estos sondeos oscilan entre los 100 y $500 \mathrm{~m}$ en el caso de los acuíferos detríticos profundos y entre los 40 y $50 \mathrm{~m}$ en el caso del acuífero carbonatado del páramo de Cuellar. 
Los caudales de bombeo oscilan entre los 4 y 15 L/s. El sistema de extracción más comúnmente empleado es mediante bomba eléctrica sumergible, bien accionada mediante grupo electrógeno o conectada a la red eléctrica. En los sondeos efectuados en el acuífero carbonatado, debido a su menor profundidad, también se utilizan bombas de eje vertical para la extracción del agua subterránea.

Las aguas captadas mediante sondeos se utilizan tanto para regadío como para ganadería y el abastecimiento de poblaciones. Las superficies regadas generalmente se encuentran comprendidas entre 3 y $8 \mathrm{Ha}$. Los sondeos que se destinan a ganadería corresponden a las granjas porcinas y avícolas existentes en los municipios de Vallelado y de Mata de Cuellar. Actualmente los únicos sondeos que se destinan al abastecimiento corresponden al ayuntamiento de San Cristóbal ( $\mathbf{5 0}$ y $\mathbf{S 8 1}$ ) que captan sus aguas del acuífero carbonatado del páramo de Cuellar. Otras perforaciones que captaban agua del acuífero detrítico profundo, y que se destinaban al abastecimiento de poblaciones son los puntos de Vallelado (S23 y S82) y Mata de Cuellar (S1), aunque no se han vuelto a utilizar desde que en 2002 entró en funcionamiento el trasvase de agua desde el río Eresma, realizado por la Junta de Castilla y León para solucionar el problema del arsénico.

Además de los sondeos que se utilizan para la captación de aguas subterráneas existen otras perforaciones realizadas ex profeso o correspondientes a sondeos de captación abandonados que se utilizan únicamente como piezómetros de observación de la posición y evolución de los niveles piezométricos de los acuíferos. Se han inventariado 5 de los que 4 se utilizan para el control de los acuíferos detríticos profundos (S8, S83, S89 y S91) y uno para el del acuífero carbonatado del Páramo de Cuellar (S84).

\section{Manantiales}

Los manantiales existentes en la zona corresponden a dos tipologías diferenciadas. Por un lado, se encuentran los que se asocian a las descargas del acuífero carbonatado del Páramo de Cuellar situados en los escarpes de (M11, M12, M19, M22, M24, M72 y M85) y por otro los que se asocian a las descargas de los acuíferos aluviales. Dentro de éstos se distinguen varios tipos: los situados en los escarpes erosivos del río Adaja (M44, M46, M47), los que se originan por desmontes en la red viaria (M95), o los que se asocian a la presencia de umbrales del sustrato mioceno(M121, M122) o simplemente a cambios en la permeabilidad del acuífero aluvial o a efectos orográficos.

Los caudales de estos manantiales son muy variables y oscilan generalmente entre los 0,1 y los 3 L/s. A lo largo del año pueden presentar una marcada fluctuación, de manera que en la época estival la descarga natural puede llegar a desaparecer totalmente, especialmente los que se asocian al acuífero aluvial. En algunos de los manantiales correspondientes a las descargas del páramo de Cuellar (M22 y M24) se han realizado obras de captación mediante galerías al objeto de incrementar los aportes de agua subterránea.

Mientras que las descargas del acuífero aluvial no presentan ninguna utilización, los manantiales asociados a las descargas del páramo de Cuellar se utilizan bien para bebida, uso esporádico en ganadería, riego o abastecimiento (M24 abastecimiento en San Cristóbal) 


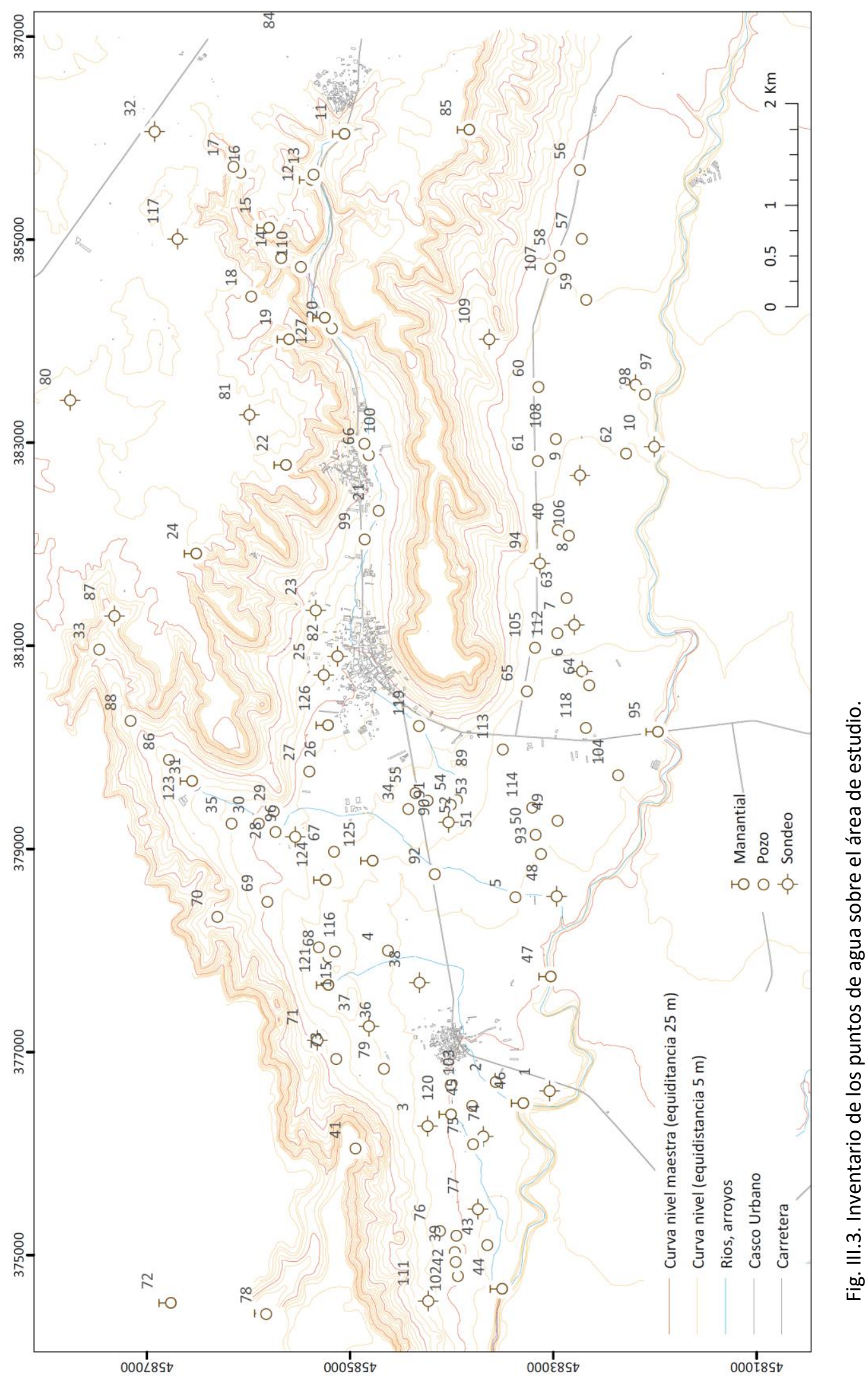




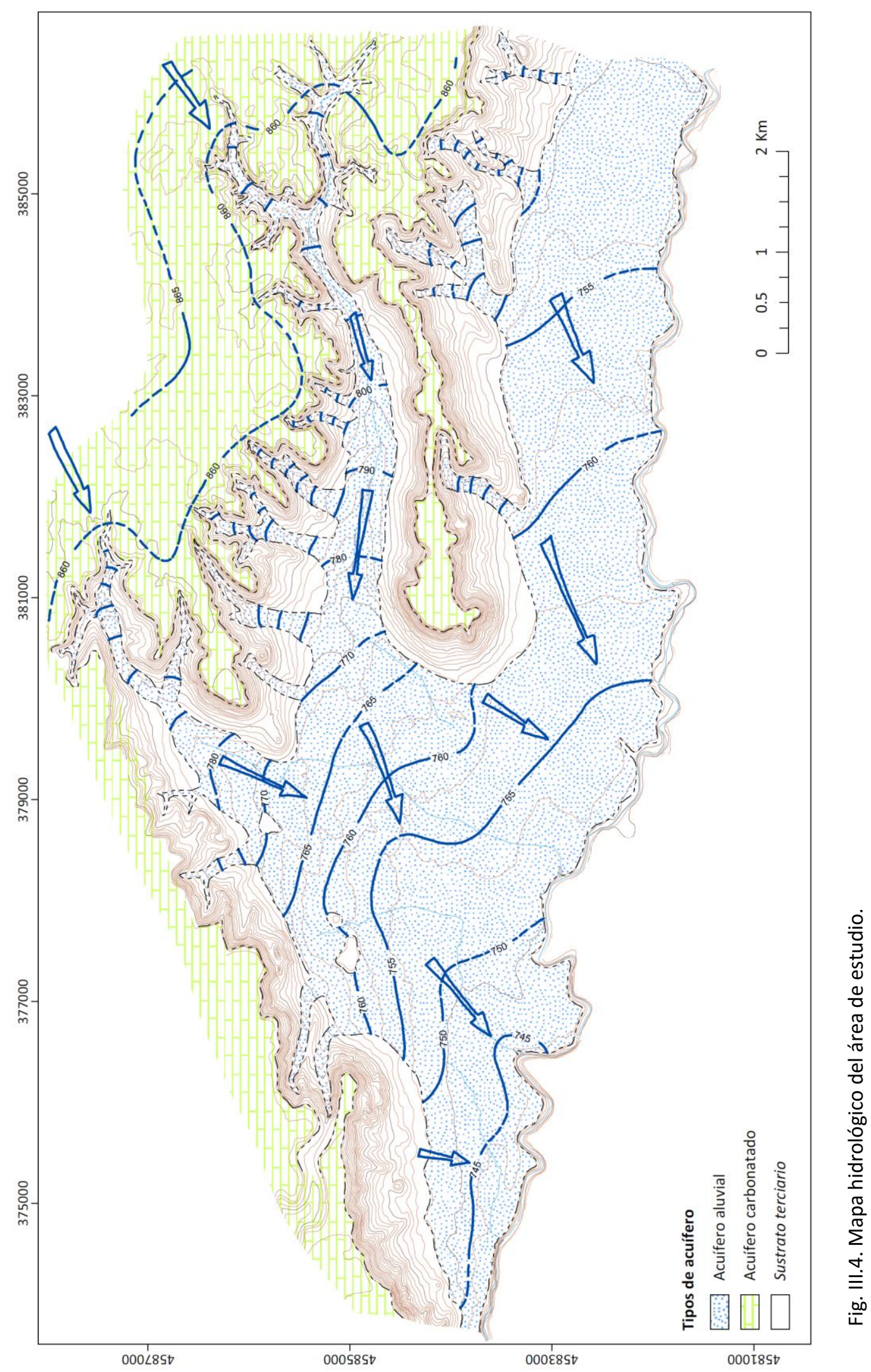




\section{III.3.2.3 Piezometría}

Se denomina nivel piezométrico o carga hidráulica a la altura que alcanza el nivel de agua en un tubo vertical denominado piezómetro cuyo extremo inferior se encuentra en un medio poroso saturado donde existe una cierta presión de agua. La carga hidráulica es la suma de dos componentes: la altura del punto de medida o carga de altura y la carga de presión. Las medidas piezométricas de los acuíferos se efectúan a partir de las alturas que alcanza el nivel de agua en pozos y sondeos, referidas a un cierto nivel de profundidad.

El nivel freático corresponde al nivel piezométrico con una carga de presión igual a la atmosférica y coincide con el nivel de saturación de agua del subsuelo. Sólo en el caso de que la carga hidráulica permanezca constante en la vertical, se produce una coincidencia entre el nivel freático y el piezométrico. Esto generalmente ocurre en acuíferos homogéneos y de escasa potencia como son los acuíferos aluviales. Sin embargo, en los grandes sistemas acuíferos con varios centenares de metros de espesor, esta situación hidrodinámica no se produce y se tiene un nivel freático que coincide con el nivel de saturación del subsuelo y distintos niveles piezométricos en función de la profundidad de la porción de acuífero que se considere.

La superficie piezométrica es el lugar geométrico de los puntos que señalan la altura piezométrica de cada una de las porciones de un acuífero referidas a una determinada profundidad, mientras que las isopiezas son líneas de igual altura piezométrica y son proporcionales a las equipotenciales. El flujo subterráneo en el subsuelo se produce de las zonas de mayor potencial o carga hidráulica a las de menor, siendo su traza perpendicular a las isopiezas.

En los acuíferos homogéneos de geometría tabular, los flujos subterráneos son predominantemente bidimensionales, sin apenas componente vertical. Por el contrario, en sistemas acuíferos heterogéneos, de gran espesor, los flujos subterráneos son de tipo tridimensional, con zonas de recarga en que se producen descensos y zonas de descarga en las que existen ascensos, siguiendo trayectorias más o menos complejas en función de las condiciones hidrodinámicas existentes en el medio hidrogeológico.

A partir de las medidas de nivel efectuadas en más de 60 pozos inventariados, 5 sondeos y de la situación de casi 20 manantiales, se ha construido el mapa de isopiezas correspondiente a los meses de mayo-junio de 2002 (Fig. III.4).

\section{III.3.2.4 Datos climatológicos}

Los datos climatológicos utilizados corresponden a la estación de Sanchonuño (E-208) situado en la provincia de Segovia. Para las precipitaciones totales mensuales se ha considerado el período: 1955-2003 y para las temperaturas medias mensuales el período: 1972-2003. 
Tabla III.2. Datos climatológicos de la estación de Sanchonuño.

\begin{tabular}{lcc} 
Mes & Temperatura (oC) & Precipitación $(\mathbf{m m})$ \\
\hline Ene & 3,7 & 44,5 \\
Feb & 5,5 & 39,2 \\
Mar & 8,3 & 42,6 \\
Abr & 10,3 & 48,0 \\
May & 14,4 & 57,1 \\
Jun & 19,0 & 36,5 \\
Jul & 22,3 & 18,8 \\
Ago & 21,8 & 15,3 \\
Sep & 17,8 & 35,9 \\
Oct & 12,3 & 47,4 \\
Nov & 7,1 & 51,4 \\
Dic & 4,4 & 49,4 \\
\hline
\end{tabular}

La temperatura media más baja tiene lugar en el mes de enero con 3,70 $\mathrm{C}$ mientras que la más alta se produce en el mes de julio con $22,3 \circ \mathrm{C}$. La precipitación media anual es de $486 \mathrm{~mm}$, con valores mensuales que oscilan entre $18,8 \mathrm{~mm}$ en el mes de julio y $51,4 \mathrm{~mm}$ en el mes de noviembre.

La temperatura media de la estación es de $12,2^{\circ} \mathrm{C}$. Por estaciones, la mayor precipitación se produce en primavera $(147,7 \mathrm{~mm})$, seguida de otoño $(134,7 \mathrm{~mm})$, invierno $(133,1 \mathrm{~mm})$ y por último verano $(70,6 \mathrm{~mm})$. El índice de humedad es de $20,8 \%$ mientras que el índice de aridez es de 52,1\%.

\section{III.4. GEOLOGÍA}

\section{III.4.1. GEOLOGÍA REGIONAL}

La Cuenca del Duero constituye una gran cubeta tectónica que se originó y rellenó durante la época terciaria. En general la sedimentación terciaria de la Cuenca del Duero muestra una distribución de facies de tipo centrípeto, con una orla de facies aluviales en las zonas de borde que hacia el centro de la cuenca dan paso a una sedimentación evaporítico-carbonatada propia de ambientes lacustres. Según Siemcalsa (1997) la facies aluviales son más importantes en los bordes suroriental, oriental y nororiental con aporte de material siliciclástico paleozoico y granítico (Macizo Hespérico), mientras que en los bordes nororientales, orientales y surorientales predomina la sedimentación clástica carbonatada y poligénica de origen mesozoico (Región Vasco-Cantábrica).

La característica geológica más importante del margen meridional de la Cuenca es la presencia de un conjunto de fosas y umbrales paralelos al Sistema Central, de dirección $\mathrm{SO}-\mathrm{NE}$, delimitados por fallas inversas y de desgarre originadas durante la orogenia alpina. Las fallas inversas de dirección SO-NE hacen cabalgar el basamento hercínico y la cobertera mesozoica sobre el terciario de la Cuenca del Duero, mientras que las de 
desgarre son fallas conjugadas de dirección SO-NE (dextras) y NNO-SSE (senestras) resultado de un acortamiento de dirección N155E (de Vicente y col., 1994).

Los afloramientos del basamento hercínico y de cobertera mesozoica de Santa María la Real de Nieva-Zarzuela del Pinar-Fuentidueña y la Sierra de Honrubia-Pradales al noreste constituyen un gran bloque levantado de dirección SO-NE que cabalga sobre el terciario de la Cuenca del Duero, originando la cubeta tectónica terciaria de Segovia limitada al noroeste por este umbral tectónico, al este por Somosierra y al sur por la sierra de Guadarrama.

La zona en la que se han detectado altos contenidos de arsénico en las aguas subterráneas se extiende al noroeste de este gran bloque levantado y parece corresponder a otra cubeta marginal de dirección SO-NE limitada por fracturas tectónicas de las que únicamente se tiene evidencia su borde meridional constituido por la falla inversa de la alineación Santa María la Real de Nieva-Fuentidueña. Los bordes noroccidental y oriental podrían estar constituidos respectivamente por la falla de AlbaVilloria y la alineación del río Duratón que limitaría otra cubeta marginal situada al norte de la Sierra de Pradales-Honrubia (Armenteros y col., 1986). Al igual que otras cubetas tectónicas existentes en el Duero, sus características geométricas y sedimentarias se encontrarían condicionadas por las deformaciones tectónicas en sus bordes.

Colmenero y col., 2001, a través del estudio de las columnas geológicas de sondeos profundos, han contribuido a mejorar el conocimiento estratigráfico de los sedimentos detríticos que rellenan la margen meridional de la Cuenca. Los resultados obtenidos indican que los aportes sedimentarios de los abanicos aluviales en este sector no proceden de las sierras de Guadarrama y Somosierra, sino que provienen del oeste y se deben fundamentalmente a la actividad sinsedimentaria de la falla Alba-Villoria durante el Neógeno.

Las características texturales que se observan en los materiales neógenos situados sobre los anteriores indican que corresponden a áreas dístales de dichos abanicos aluviales, es decir, a zonas más alejadas en la que los procesos de transporte presentan poca energía y dan paso a una sedimentación evaporítico-carbonatada típica de ambientes lacustres. En este sector, el tránsito desde el ambiente de sedimentación aluvial a lacustre se produce gradualmente y pone de manifiesto la expansión o progradación de las facies lacustres hacia el oeste, coincidiendo posiblemente con el cese de actividad tectónica de la falla de Alba-Villoria.

Durante el Cuaternario es cuando se produce la erosión de los materiales terciarios y la formación en gran parte de este sector de amplias plataformas aluviales ("superficies") que proceden de la erosión de los bordes montañosos meridionales (sierra de Guadarrama y bloque levantado de Santa María la Real de Nieva-Zarzuela del Pinar). Están constituidas por arenas arcósicas y gravas con algunas intercalaciones de arcilla y limo. Presentan un espesor generalmente inferior a $10 \mathrm{~m}$ aunque localmente pueden llegar a alcanzar los $20 \mathrm{~m}$. 


\section{III.4.2. GEOLOGÍA LOCAL}

A grandes rasgos, la geología de la zona seleccionada comprende materiales terciarios constituidos por arcillas, margas y calizas de edad Neógeno parcialmente recubiertos por depósitos cuaternarios de carácter fundamentalmente detrítico, asociados a distintos sistemas de sedimentación (aluvial, eólico, gravedad/laderas, etc.).

\section{III.4.2.1 Descripción de las unidades litoestratigráficas}

A continuación se detallan las diferentes unidades litoestratigráficas predominantes en la zona de estudio, las cuales se pueden visualizar en la Fig. III.5. Los límites asignados a cada estrato son aproximados.

\section{OLIGOCENO - AGENIENSE}

Facies Toro Inferior (TI):

Esta facies aparece entre las cotas 603 y $628 \mathrm{~m}$, y está compuesta por limos y arcillas con intercalaciones de areniscas y conglomerados de color beige-ocre.

\section{MIOCENO - AGENIENSE}

Facies Toro Superior (TS):

Esta facies se da entre las cotas 629 y 647 m, y está formada por limos, areniscas y arcillas de color rojizo, de espesor variable.

\section{MIOCENO - ORLEANIENSE}

Facies Villalba de Adaja (VA):

Esta facies se da entre las cotas 648 y $711 \mathrm{~m}$ y está formada por limos y arcillas arenosas compactas de color beige-ocre, con intercalaciones de arena.

Desde el punto de vista hidrogeológico, esta unidad se puede considerar moderadamente impermeable, con presencia de zonas más permeables (paleocanales arenosos o con gravillas) e impermeables (niveles más arcillosos) de distribución irregular. Pueden aparecer pequeños niveles acuíferos locales en relación con lentejones detríticos.

\section{MIOCENO MEDIO - ASTARACIENSE}

Facies Dueñas (D)

Esta facies se da entre las cotas 712 y 726 y está formada por margas de color grisverdosas con intercalaciones de margocalizas blanquecinas. 
Capítulo III. Área de estudio

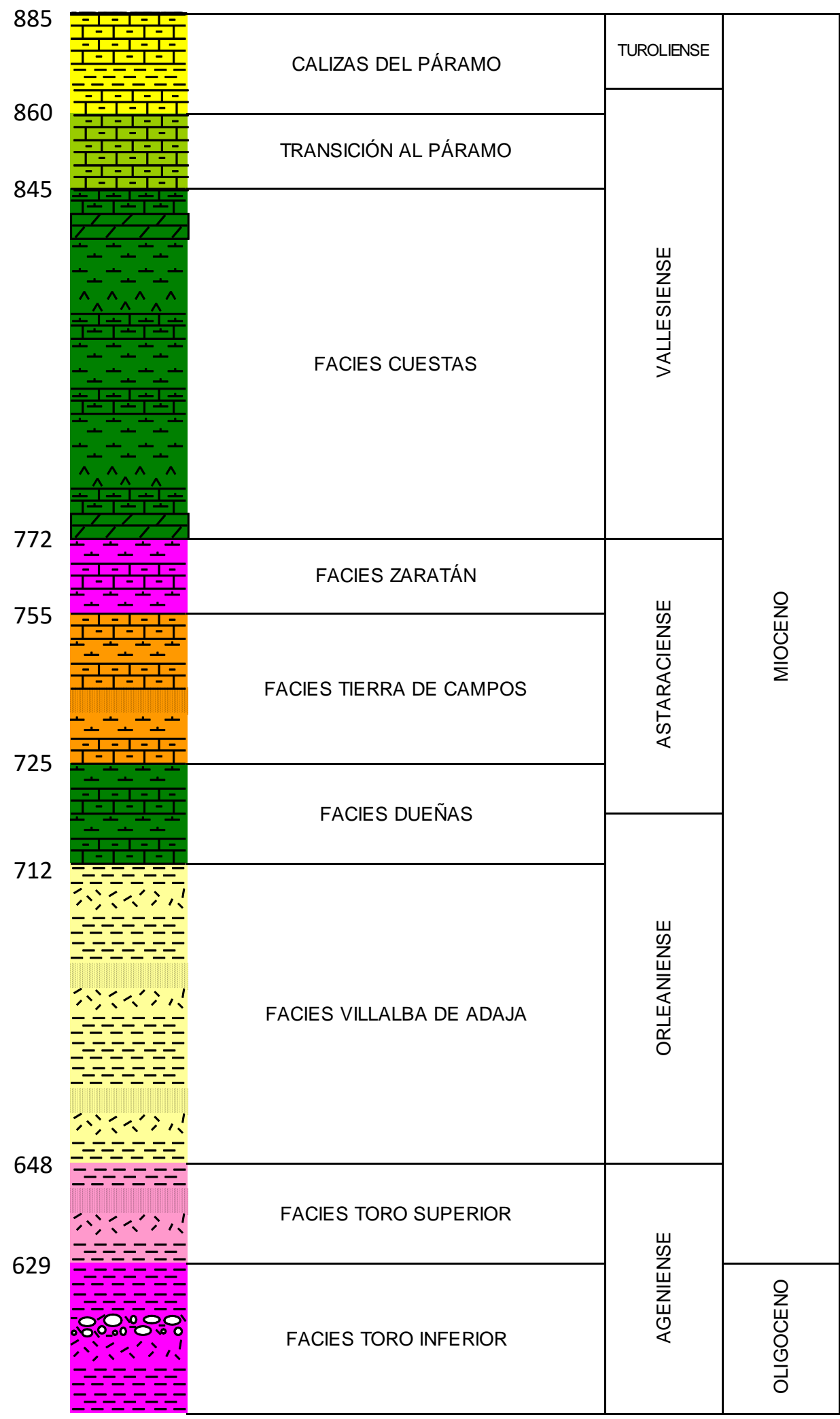

603

Fig. III.5. Columna estratigráfica 


\section{MIOCENO MEDIO - ASTARACIENSE}

Facies Tierra de Campos (TC):

Aflora en la mitad oeste del borde meridional, a lo largo de los escarpes de la incisión fluvial del río Cega, entre la cota 725 y 755 m. Está constituida por arcillas margosas verdes y rojas con intercalaciones de margocalizas blancas y niveles decimétricos de arenas limo-arcillosas verdosas.

Las secuencias sedimentarias corresponden a una sedimentación tipo abanico aluvial en las que se diferencian ciclos con un tramo basal constituido por arenas y limos de escaso espesor, a los que suceden arcillas que corresponden a las facies más distales de la sedimentación detrítica. La secuencia, a menudo, culminan en costras calcáreas que indican la aparición de lagos salinos efímeros.

Facies Zaratán (FZ):

Aflora en el tercio occidental del borde meridional a lo largo del escarpe erosivo del río Cega, así como en la ladera meridional de los páramos de Monterrey-El Cabezo y Peña Roada, entre las cotas 755 y $772 \mathrm{~m}$. Está constituida por margas y arcillas carbonosas de color marrón y negro, con restos de gasterópodos e intercalaciones de margocalizas blancas y arcillas verdes.

\section{MIOCENO SUPERIOR - VALLESIENSE}

Facies Cuestas (FC):

Aflora principalmente en el tramo intermedio de las laderas de los páramos, entre las cotas 772 y $845 \mathrm{~m}$. Está constituida por margas yesíferas de color gris claro y verdoso con alguna intercalación de calizas y dolomía de espesor decimétrico a métrico. El yeso generalmente es de tipo diagenético originando grandes cristales en punta de lanza aunque también pueden existir pequeños niveles con yeso mesocristalino. En su tramo inferior presenta alguna intercalación de arcilla roja de espesor decimétrico. En general, las secuencias sedimentarias que se observan corresponden a ciclos en lagos salinos efímeros con un tramo inferior de fango salino, al que siguen fangos con yesos diagenéticos abundantes y terminan en niveles de costras dolomíticas (IGME, 1982).

Transición al Páramo (TP):

Aflora en el tramo superior de las laderas de los páramos, entre las cotas 845 y $860 \mathrm{~m}$. Está constituido por una alternancia de margocalizas y margas blancas de espesor decimétrico a métrico en las que se observan fenómenos de pseudomorfósis de yeso en calcita. Hacia el techo aparecen niveles finos de arcilla oscura de tipo esmectítico que indican condiciones de encharcamiento (IGME, 1982).

\section{MIOCENO SUPERIOR-PLIOCENO (TUROLIENSE)}

\section{Calizas del Páramo (CP):}

Aflora en la parte superior de los páramos, entre las cotas 860 y $885 \mathrm{~m}$, representando la culminación de la sedimentación terciaria. Está constituida por calizas de carácter micrítico más o menos fosilíferas (biomicritas), con algún nivel fino intercalado de arcillas oscuras de carácter hojoso correspondientes a una sedimentación típicamente 
lacustre. En general se encuentran muy carstificadas y pueden dar lugar al desarrollo de suaves dolinas y a la formación de depósitos de terra rossa en algunas zonas, resultado de los procesos de disolución de las calizas.

\section{CUATERNARIO}

\section{Sistema aluvial:}

Fondo de charca (Ch): Se encuentran ocupando el fondo de unas depresiones alargadas situadas al oeste de la localidad de Mata de Cuéllar. Constituyen recubrimientos de escaso espesor formados por arcillas y limos de color gris-blanquecino con cierto contenido en sales solubles.

Depósito aluvial (Al): Ocupan los fondos de valle de los arroyos de Horcajo, Valdelacasa y Torregutiérrez, así como los afluentes tributarios de los mismos. Presentan un espesor variable comprendido entre los 2 y $6 \mathrm{~m}$ y están constituidos por arenas, arcillas y gravas.

Depósito de superficie (DS): Se sitúan en la margen derecha del río Cega ocupando la planicie existente entre este río y las estribaciones meridionales de los páramos. Presentan un espesor variable comprendido entre 3 y $9 \mathrm{~m}$ y están constituidos por arenas, gravas, arcillas y, ocasionalmente, niveles de turba.

Depósitos de terraza (DT): Se localizan en las márgenes del río Cega, dentro de la incisión fluvial, representando períodos de inundación del mismo. Están constituidos por arenas, gravas y limos.

\section{Sistema de gravedad/laderas y poligénico:}

Depósitos coluviales (Col): Se encuentran recubriendo buena parte de las laderas de las cuestas y están constituidos por arcillas, arenas y gravas, originados por procesos erosivos y gravitacionales en laderas.

Depósitos de glacis (DG): Ocupan la parte inferior de los valles aluviales más importantes (Horcajo y Valdelacasa) originando planicies suavemente convexas. Están constituidos por arcillas, arenas y gravas que pueden alcanzar espesores de 3 a $7 \mathrm{~m}$.

Conos de deyección $(C D)$ : Ocupan la parte inferior de las vaguadas y arroyos de menor entidad y jerarquía, estando formados por arenas, arcillas y gravas, con espesores que oscilan entre 2 a $5 \mathrm{~m}$.

Sistema eólico:

Manto eólico (Me): Se extiende tanto por el borde meridional de la zona recubriendo parte de los depósitos de superficie como por el extremo noroeste recubriendo las Calizas del Páramo. Están constituidos por arenas finas de naturaleza arcósica que forman depósitos bastante degradados correspondientes a procesos eólicos que en algunas zonas pueden alcanzar espesores superiores a los $2 \mathrm{~m}$.

En la Fig. III.6 se expresa la distribución espacial de las distintas unidades geológicas y en la Fig. III.7 se puede observar la disposición vertical de las mismas en dos perfiles geológicos. 


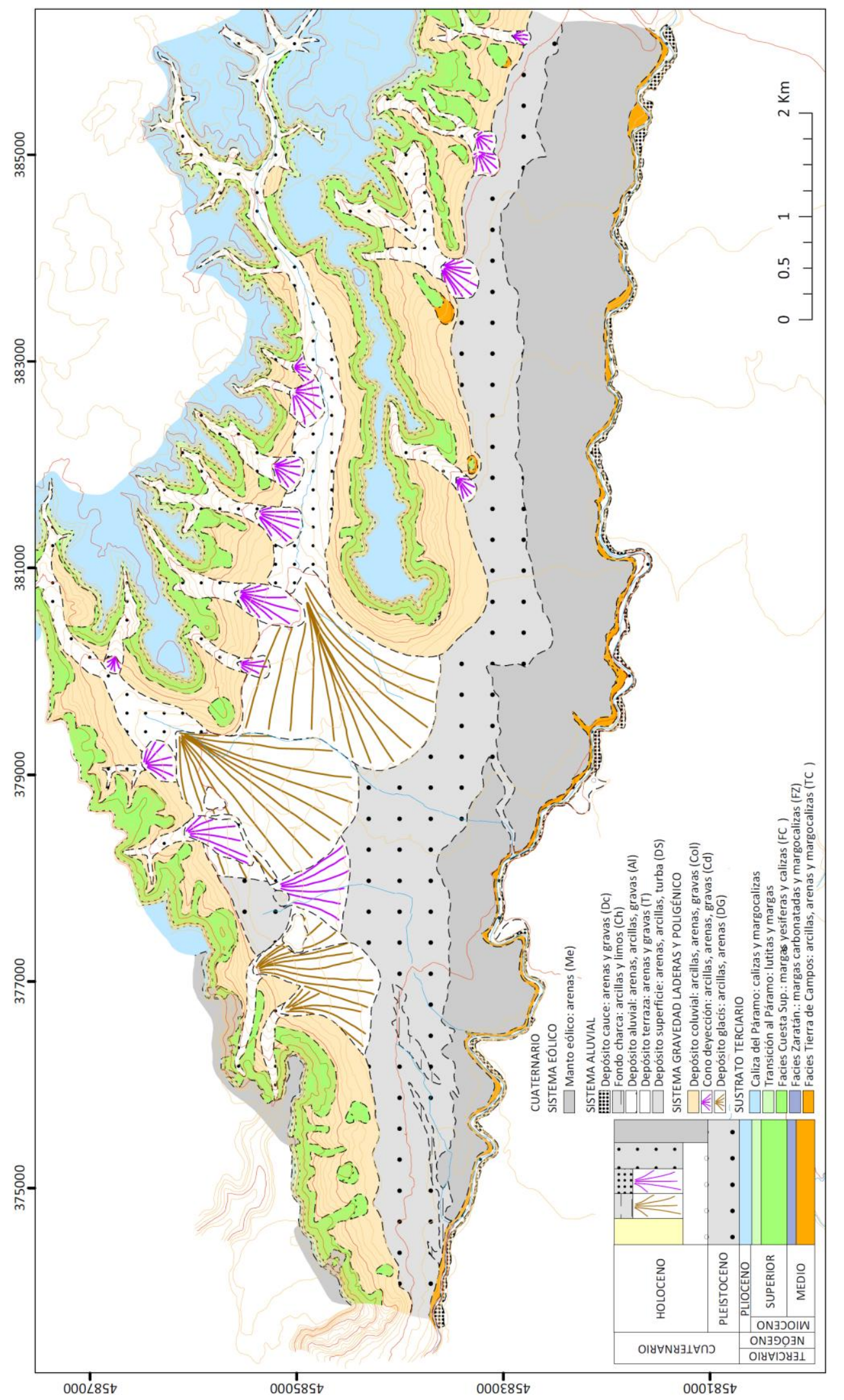

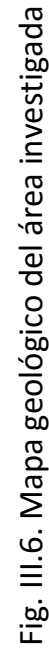




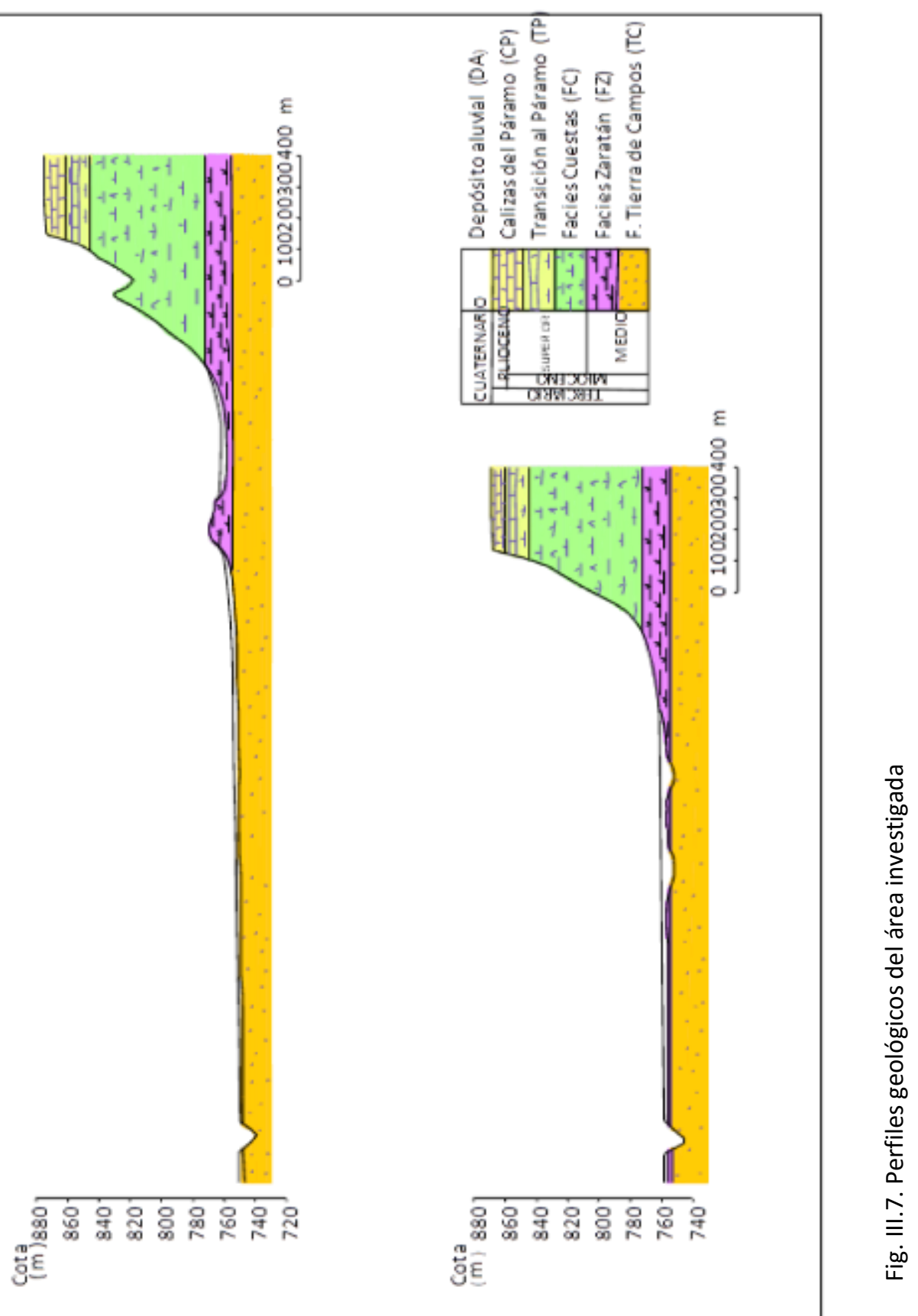




\section{III.4.2.2 Geomorfología}

De la geomorfología de este sector de la Cuenca que vamos a estudiar podemos decir que el relieve desarrollado es suave, con cotas que oscilan entre $885 \mathrm{~m}$ en el borde oriental correspondiente a la superficie del páramo de Cuéllar y los $725 \mathrm{~m}$ en el extremo occidental correspondiente al cauce del río Cega.

Morfológicamente se diferencian dos tipos de relieves: por un lado las plataformas o páramos en la que la superficie es prácticamente llana, con pequeñas irregularidades, que se desarrollan entre los 870-885 m; y por otro, los valles, entre los que destaca el del río Cega que constituye el borde meridional del sector estudiado que se desarrolla entre los 725 y $755 \mathrm{~m}$, encajándose unos 10-15 m bajo la planicie aluvial inferior asociada a los depósitos de superficie. Otros valles de interés son el de los arroyos de Horcajo/Torregutiérrez y de Valdelacasa que se desarrollan entre la superficie de los páramos y la superficie aluvial inferior en la margen derecha del río Cega.

En el estudio del modelado, son las formas fluviales las que alcanzan un mayor desarrollo en este sector. Dentro de ellas cabe destacar las planicies aluviales que ocupan el tercio meridional de la zona y dan lugar a los depósitos de superficie situados en la margen derecha del río Cega. Se trata de un amplio sistema de terraza en el que existen zonas de paleocauce, con mayor espesor de sedimentos y zonas de umbral, con un espesor más reducido.

Dentro de las formas fluviales se encuentran los depósitos aluviales que ocupan los cauces o fondos de valle de los arroyos, y los conos de deyección formados a la salida de los mismos. Los depósitos de glacis son formas similares pero más complejas que se encuentran en el tramo inferior de los arroyos más importantes en su conexión con la planicie aluvial inferior.

Las formas fluviales de tipo erosivo se localizan en el escarpe sobre el que se encaja el río Cega y en las laderas de los páramos, originando formas de incisión lineal (barrancos, cárcavas y retroceso de cabeceras).

Dentro de las formas de gravedad se encuentran los coluviales en las zonas de ladera o cuestas y los deslizamientos de ladera que han dado lugar a la formación de "cotarras" o cerros aislados al pie de las cuestas.

Las formas cársticas se circunscriben a los páramos calcáreos y originan dolinas y depresiones cársticas, a menudo relacionados con los procesos de encajamiento de la red fluvial. Por otro lado, las formas eólicas se localizan a lo largo del borde meridional, sobre los depósitos de superficie asociados a la planicie aluvial, originando mantos eólicos y sistemas de dunas degradados.

Por último, la superficie del páramo de Cuellar que se extiende por el borde septentrional y en las zonas de interfluvio de la red de drenaje encajante, constituye una forma poligénica creada a partir de una superficie estructural con algunos retoques erosivos, cársticos y eólicos. 
CAPÍTULO IV. ESTUDIO HIDROQUÍMICO

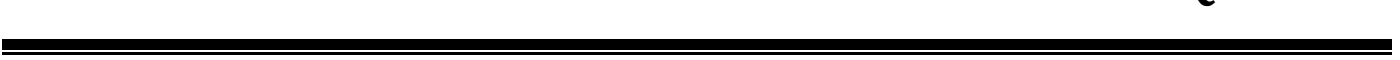





\section{IV.1. INTRODUCCIÓN}

El arsénico se halla en las aguas naturales como especie disuelta, la cual se presenta por lo común como oxoaniones con arsénico en dos estados de oxidación, arsénico trivalente, $\mathrm{As}(\mathrm{III})$, y arsénico pentavalente, $\mathrm{As}(\mathrm{V})$, y con menos frecuencia como $\mathrm{As}(0)$ y As(-III). As(V) aparece como $\mathrm{H}_{3} \mathrm{AsO}_{4}$ y sus correspondientes productos de disociación ácido-base $\left(\mathrm{H}_{2} \mathrm{AsO}_{4}{ }^{-}, \mathrm{HAsO}_{4}{ }^{2-}\right.$ y $\left.\mathrm{AsO}_{4}{ }^{3-}\right)$. Por su parte, $\mathrm{As}(\mathrm{III})$ aparece como $\mathrm{H}_{3} \mathrm{AsO}_{3}$ y sus productos de disociación $\left(\mathrm{H}_{2} \mathrm{AsO}_{3}{ }^{-}, \mathrm{HAsO}_{3}{ }^{2-}\right.$ y $\left.\mathrm{AsO}_{3}{ }^{3-}\right)$. Aunque tanto $\mathrm{As}(\mathrm{V})$ como $\mathrm{As}(\mathrm{III})$ son móviles en el medio acuático, es precisamente el As(III) el estado más lábil y biotóxico.

El estado de oxidación del arsénico, y por tanto su movilidad, están controlados fundamentalmente por las condiciones redox (potencial redox, Eh) y el pH (Fig. IV.1). De hecho, el arsénico es un elemento singular entre los metaloides pesados y elementos formadores de oxoaniones por su facilidad para movilizarse a los valores de $\mathrm{pH}$ típicos de las aguas subterráneas $(6,5-8,5)$. Como aproximación, y sin tener en cuenta otros factores como contenido en materia orgánica, en condiciones oxidantes el estado As(V) predomina sobre $\mathrm{As}(\mathrm{III})$, encontrándose fundamentalmente como $\mathrm{H}_{2} \mathrm{AsO}_{4}{ }^{-}$a valores de $\mathrm{pH}$ bajos (inferiores a 6,9), mientras que a pH más alto la especie dominante es $\mathrm{HAsO}_{4}{ }^{2-}$. En condiciones de acidez o basicidad extremas las especies predominantes serán $\mathrm{H}_{3} \mathrm{AsO}_{4}$ y $\mathrm{AsO}_{4}{ }^{3-}$, respectivamente (Fig. IV.2b). En condiciones reductoras a $\mathrm{pH}$ inferior a 9,2, predominará la especie neutra $\mathrm{H}_{3} \mathrm{AsO}_{3}$ (Fig. IV.2a) (Brookins, 1988; Yan y col., 2000).

No obstante, la presencia de determinados elementos puede alterar el estado de oxidación del arsénico y por tanto su movilidad. Por ejemplo, cuando se establecen condiciones reductoras y ácidas, la presencia de concentraciones altas de sulfuro provoca la precipitación de sulfuros de arsénico (oropimente, $\mathrm{As}_{2} \mathrm{~S}_{3}$, y rejalgar, $\mathrm{As}_{4} \mathrm{~S}_{4}$ ).

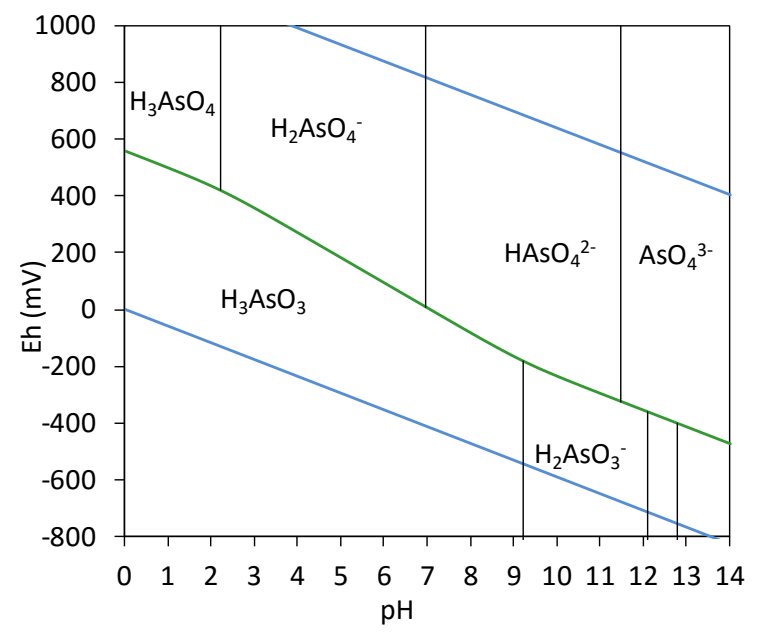

Fig. IV.1. Diagrama Eh-pH de especies acuosas de arsénico en el sistema As $-\mathrm{O}_{2}-\mathrm{H}_{2} \mathrm{O}$ a 25 으 y 1 bar de presión total. 

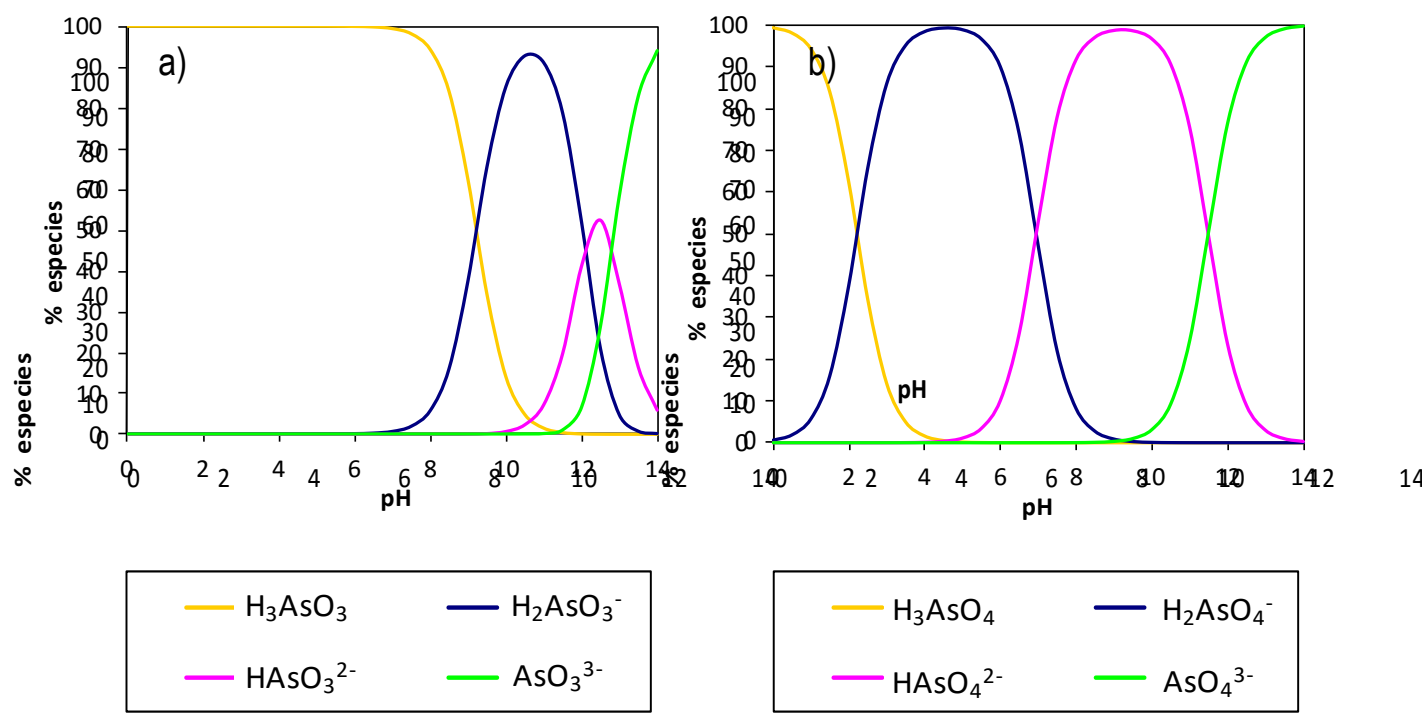

Fig. IV.2. a) Especies de As(III) como función de pH. b) Especies de As(V) como función del $\mathrm{pH}$

Los valores fondo de concentración de arsénico en aguas subterráneas son, en general, inferiores a $10 \mu \mathrm{g} / \mathrm{L}$ (Edmunds y col., 1989; Welch y col., 2000). Sin embargo, se encuentra un amplio rango de valores (entre $<0,5$ y $5.000 \mu \mathrm{g} / \mathrm{L}$ ) para distintas aguas en condiciones naturales (Smedley y Kinniburgh, 2002).

La contaminación de los acuíferos por arsénico puede deberse a procesos naturales o antropogénicos. Los procesos antropogénicos, tales como actividades mineras, industriales, agropecuarias o asentamientos urbanos provocan una contaminación de carácter más local. Por el contrario, los elevados niveles de arsénico de origen natural hallados en acuíferos afectan a grandes áreas.

Una de las peculiaridades más notables del problema del arsénico de origen natural en las aguas subterráneas es que no siempre hay una relación directa entre el alto contenido en arsénico en el agua y un alto contenido en arsénico en los materiales que constituyen el acuífero (BGS y DPHE, 2001; Smedley y Kinniburgh, 2002). De hecho, la contaminación por arsénico de los acuíferos se ha relacionado con ambientes geológicos muy diferentes: metasedimentos con filones mineralizados, formaciones volcánicas, formaciones volcano-sedimentarias, distritos mineros, sistemas hidrotermales, cuencas aluviales terciarias y cuaternarias... (BGS y DPHE, 2001; Boyle y col., 1998; Smedley y Kinniburgh, 2002).

La contaminación de acuíferos por arsénico no se restringe a determinadas condiciones, sino que se ha observado tanto en ambientes con condiciones reductoras como en condiciones oxidantes, o en acuíferos sobreexplotados, tanto en zonas áridas como en zonas húmedas, o tanto en acuíferos superficiales libres como en acuíferos profundos confinados. Esta variedad de situaciones es la consecuencia de un ambiente geoquímico y unas condiciones hidrogeológicas específicos. 
Algunos ejemplos encontrados en la bibliografía, donde la presencia de arsénico no está relacionada directamente con procesos geotermales o con actividades mineras y depósitos minerales, se muestran a continuación:

En zonas como la India (BGS y DPHE, 2001; Anawar y col., 2003), Mongolia (Smedley y col., 2001; Smedley y Kinniburgh, 2002), Taiwan (Smedley y Kinniburgh, 2002), China (Wang y Huang, 1994), Vietnam (Berg y col., 2001), Hungría y Rumanía (Varsányi y col., 1991; Gurzau y Gurzau, 2001), los altos niveles de arsénico en el flujo subterráneo se encuentran ligados a ambientes reductores, en algunos casos facilitado por la presencia de materia orgánica. Sin embargo, el tipo de acuífero, la geología, las condiciones hidrogeológicas, hidroquímicas y geoquímicas son particulares para cada zona.

Existen otras regiones con altas concentraciones de arsénico donde el ambiente es oxidante, y el arsénico se encuentra mayoritariamente como As(V). Así, en México (región de Lagunera) (del Razo y col., 1990), además de altas concentraciones de arsénico, también aparecen altas concentraciones de fluoruro. En Chile, región de Antofagasta (Sancha y Castro, 2001), las altas concentraciones de arsénico aparecen en aguas con salinidad alta y contenidos altos de boro, lo cual podría deberse a procesos evaporativos y/o a las entradas geotermales de El Tatio. En Argentina (Llanura Chacopampeana) (Sancha y Castro, 2001; Smedley y Kinniburgh, 2002), las reacciones de degradación de silicatos y carbonatos aumentan el $\mathrm{pH}$ de las aguas, encontrándose valores de $\mathrm{pH}$ entre 7-8,7 (Smedley y Kinniburgh, 2002). Las aguas presentan bajas concentraciones de $\mathrm{Fe}$, y $\mathrm{Mn}$, la salinidad es alta y la concentración de arsénico se correlaciona con los contenidos en $\mathrm{F}, \mathrm{V}, \mathrm{HCO}_{3}, \mathrm{~B}$, y Mo.

Está diversidad de condiciones ambientales en las cuales se encuentran altas concentraciones de arsénico hace que no sea posible plantear un único modelo geológico/hidrogeológico para explicar la contaminación por arsénico de los acuíferos.

Además, una característica común a todos los acuíferos contaminados por arsénico, tanto en España como en otras latitudes, es el elevado grado de variabilidad espacial en la concentración de arsénico en las aguas subterráneas, hasta el punto que es muy difícil predecir la concentración del elemento en un pozo concreto a partir de los resultados de los pozos circundantes (Smedley y Kinniburg, 2002; Carretero y col., 2004; Sahún y col., 2004). También se han detectado variaciones estacionales no muy bien explicadas hasta la fecha (Calvo-Revuelta y col., 2003; Vega y col., 2004).

Aunque los materiales de la geosfera no presenten grandes concentraciones de arsénico en la fase sólida, una pequeña cantidad relativa de arsénico liberado de esa fase sólida por procesos de desorción o disolución puede elevar la concentración de arsénico en el agua por encima de $10 \mu \mathrm{g} / \mathrm{L}$. Para que se existan aguas con contenidos altos en arsénico no basta con que tengan lugar mecanismos por los cuales éste se libere de la fase sólida, sino que además el arsénico liberado tiene que permanecer en el agua, es decir, no tiene que ser transportado ni transferido a otro medio, ni tampoco se han de producir procesos de dilución por mezcla.

Los fenómenos de transporte dependerán del régimen hidrogeológico y paleohidrogeológico del acuífero, así si el tiempo de residencia del agua en el acuífero es grande, la tasa de renovación será menor, y por tanto no habrá prácticamente pérdida 
de arsénico por flujo. Los fenómenos de transferencia de arsénico a otros medios dependen de los coeficientes de adsorción sobre los materiales disponibles en los acuíferos. Mientras que, los procesos de dilución obedecerán al régimen hidrogeológico del acuífero.

Otra consideración que hay que hacer es la diferente naturaleza de las aguas superficiales y las aguas subterráneas: las aguas superficiales constituyen sistemas abiertos donde los factores ambientales están continuamente variando; en contraste, las aguas subterráneas se pueden considerar, en la mayoría de los casos, sistemas semicerrados, donde las condiciones pueden variar, pero de forma discontinua en el tiempo, permitiendo que el sistema solución-fase sólida pueda reequilibrarse (Smedley y Kinniburgh, 2002). Ello implica que, en condiciones naturales y si no se producen grandes cambios en la evolución de un acuífero, este llegará a una etapa donde la interacción agua-fase sólida será mínima, y por tanto no habrá transferencias de arsénico. Este escenario contrasta con el de las aguas superficiales donde no tienen por qué alcanzarse situaciones próximas al equilibrio solución-fase sólida.

A continuación se describen varios mecanismos geoquímicos que provocan la liberación y movilización de arsénico en aguas subterráneas (BGS y DPHE, 2001, y Semedley y Kinniburgh, 2002):

- Oxidación de sulfuros:

Según los trabajos existentes, es un mecanismo importante solo localmente y en áreas mineras con abundancia de sulfuros, aunque también puede involucrar pirita autigénica en sucesiones sedimentarias. La oxidación de sulfuros tiene lugar cuando el medio se halla en condiciones oxidantes. El hierro disuelto tiende a precipitar como sulfato de hierro (jarosita) y óxidos y oxihidróxidos de hierro, con readsorción y coprecipitación de arsénico. Como señalan BGS y DPHE, 2001, la readsorción de arsénico en los óxidos, que puede llegar al $90 \%$ del arsénico codisuelto de la pirita, hace que el mecanismo de movilización de arsénico por oxidación de pirita no se considere como el más eficiente en cuanto a movilización de arsénico.

- Disolución de óxidos e oxihidróxidos de hierro y manganeso en condiciones ácidas:

Los óxidos y oxihidróxidos de hierro y manganeso se disuelven en condiciones fuertemente ácidas. El arsénico presente en ellos, tanto adsorbido como coprecipitado, será movilizado durante la disolución. A diferencia de la desorción, la disolución es eficaz en la movilización de arsénico no lábil, incorporado en la red estructural del mineral. Esto explica, al menos en parte, las concentraciones altas de arsénico en el drenaje ácido de minas.

- Desorción en condiciones oxidantes a pH alto:

La acusada naturaleza no lineal de la isoterma de adsorción para As(V) (Fig. IV.3) determina que la cantidad de arsénico adsorbido sea grande, incluso cuando las concentraciones de arsénico disuelto son bajas. Pero, en condiciones oxidantes, se produce la desorción de arsénico si se alcanzan valores de $\mathrm{pH}$ alto $(>8,5)$. Normalmente el incremento de $\mathrm{pH}$ se produce como consecuencia de los procesos de meteorización e 
intercambio iónico, combinado con los efectos de un incremento en salinidad en climas áridos y semiáridos.

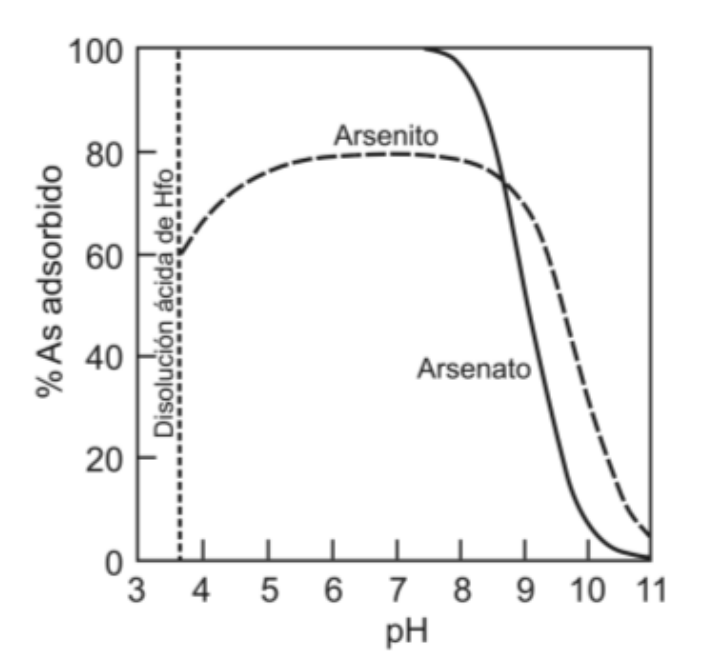

Fig. IV.3. Curvas de adsorción de As(III) y As(V), en función del pH. (Smedley y Kinniburgh, 2001).

El proceso de desorción en condiciones alcalinas es considerado como uno de los mecanismos más efectivos en cuanto a movilización de arsénico en condiciones oxidantes, dándose además una correlación positiva entre la concentración de arsénico en la fase acuosa y los valores de $\mathrm{pH}$.

Los procesos de desorción liberan además una amplia variedad de oxoaniones como vanadatos, fosfatos, wolframatos y molibdatos. El papel del anión bicarbonato en relación a los procesos de desorción de arsénico no está claro. A menudo se observan, en las aguas ricas en arsénico, concentraciones altas en carbono orgánico disuelto como ácidos fúlvicos y húmicos, aunque todavía no se ha podido establecer una relación causal entre el carbono orgánico disuelto y arsénico desorbido (Smedley y Kinniburgh, 2002).

La presencia de cationes como $\mathrm{Ca}^{2+}$ y $\mathrm{Mg}^{2+}$ puede facilitar la adsorción de especies de $\mathrm{As}(\mathrm{V})$ negativamente cargadas. Efectos similares pueden tener el $\mathrm{Al}^{3+}$ en aguas ácidas $\mathrm{Y}$ el $\mathrm{Fe}^{2+}$ en aguas reductoras.

Los procesos evaporativos en ambientes áridos permiten el mantenimiento de valores altos de $\mathrm{pH}$, así como concentraciones altas en $\mathrm{Cl}, \mathrm{F}$ y U. En general, este mecanismo no explicaría las concentraciones altas de arsénico observadas en ambientes reductores, ya que estos suelen tener un $\mathrm{pH}$ próximo al valor neutro.

- Desorción y disolución de óxidos y oxihidróxidos en condiciones reductoras:

Este constituye otro de los mecanismos más importantes en cuanto a movilización de arsénico. La causa más común es el enterramiento rápido de sedimentos, donde la cantidad de materia orgánica presente en el sedimento determinará la rapidez con que se alcanzarán las condiciones reductoras. Se requiere además que sea un sistema 
cerrado a la entrada de oxígeno o al menos la disponibilidad de este sea muy pequeña. En condiciones reductoras, parece que una de las primeras reacciones que se producen es el paso de arseniato adsorbido en condiciones oxidantes a arsenito que está adsorbido más débilmente en la superficie de los óxidos y oxihidróxidos de Fe y $\mathrm{Mn}$. Además, estos minerales se disuelven en condiciones reductoras, aunque la disolución reductiva por sí sola no explicaría todo el arsénico que se encuentra en las aguas subterráneas en condiciones reductoras. Por otra parte, en ambientes reductores las aguas tienen por lo general valores de $\mathrm{pH}$ próximos al valor neutro, por lo que en este caso el pH no parece ejercer un control importante sobre la desorción de arsénico.

- Desorción por reducción de superficie específica en la fase sólida:

Este es un mecanismo que tiene especial incidencia en los óxidos e hidróxidos de Fe, donde se produce una mayor adsorción de arsénico en las etapas iniciales de su formación, generalmente como oxihidróxidos formados por agregados de micropartículas de pequeño tamaño. Al evolucionar y transformarse en fases de mayor cristalinidad, las partículas y agregados aumentan su tamaño, reduciendo así su superficie específica y por tanto los lugares de intercambio donde se halla el arsénico adsorbido, con la consiguiente movilización de este a la fase acuosa. Debido al carácter no lineal más acusado de la isoterma de $A s(V)$, la desorción mediante este mecanismo es mucho más acusada para As(V) que para As(III).

- Desorción por reducción en la carga de superficie de la fase sólida:

Pueden ocurrir una serie de fenómenos que causen una reducción de la carga neta de superficie en los óxidos, con la consiguiente desorción de arsénico. Estos fenómenos incluyen cambios estructurales en los óxidos de Fe que tienen lugar al pasar de condiciones oxidantes a condiciones reductoras que pueden asociar cambios netos en la carga de superficie, en intensidad y densidad.

- Transformaciones microbianas de arsénico

La movilización de arsénico en ecosistemas naturales es predominantemente conducida por microorganismos mediante interacciones biogeoquímicas. Según Ahmann y col., 1997; Jones y col., 2000 los procesos microbianos que involucran la reducción del $\mathrm{As}(\mathrm{V})$ y su movilización son mucho más rápidos que las transformaciones químicas inorgánicas.

Para poder establecer el mecanismo de movilización predominante en el área objeto de estudio es necesario conocer la composición de las aguas subterráneas e investigar las correlaciones que se establecen entre los distintos parámetros físico-químicos. La aplicación de herramientas hidroquímicas clásicas (diagramas de Piper, índices de saturación...) y de métodos estadísticos multivariantes (análisis en componentes principales, análisis de conglomerados...) resulta muy adecuada para este propósito.

\section{IV.2. MUESTREO}

Se han inventariado 128 puntos de agua en la zona de estudio, entre los que podemos encontrar pozos, sondeos y manantiales, en los que se ha determinado el nivel freático (pozos) y el caudal (manantiales), y el uso del agua en los años 2002 y 2003. De todos 
esos puntos, se han muestreado 59 entre los meses de julio, agosto y septiembre de 2002 (Muestreo M1), coincidiendo con la época de riego y por tanto de menor nivel freático. En el mes de junio del año 2003 se muestrearon un total de 65 puntos (Muestreo M2), coincidiendo con el inicio de la época de riego, periodo en que el acuífero está más recargado. De los 65 puntos de agua muestreados, 40 coinciden con puntos tomados en el muestreo M1.

De todos los puntos de agua muestreados en 2002 (muestreo M1) se escogieron 9 puntos representativos de las principales unidades geológicas ubicadas en la zona objeto de estudio para establecer una red de control y observar las variaciones estacionales de todos los parámetros analizados. Esta red de control se muestreó mensualmente entre Noviembre de 2002 y Octubre de 2003, completando un año hidrológico.

En la Fig. IV.4 y en la Fig. IV.5 se muestra la localización de los puntos de agua muestreados sobre el mapa geológico e hidrológico, respectivamente, de la zona estudiada. En la Fig. IV.4 se identifican los puntos de agua dependiendo en que muestreo se tomaron, mientras que en la Fig. IV.5 se identifican los puntos de ambos muestreos según el acuífero al que pertenecen.

En la Fig. IV.6 y en la Fig. IV.7 se representan los 9 puntos de la red de control sobre el mapa geológico e hidrológico, respectivamente, de la zona estudiada.

Los pozos y sondeos se muestrearon después de haber sido bombeados durante al menos 10 minutos. El objetivo de esta purga es desalojar el agua estancada en el pozo con el fin de obtener muestras representativas del acuífero.

Tras bombear las captaciones durante al menos 10 minutos, se llenó de agua un recipiente de plástico de unos $20 \mathrm{~L}$ de capacidad. El agua de este recipiente se empleó para tomar las muestras analíticas y para medir in situ los parámetros $\mathrm{pH}$, conductividad, oxígeno disuelto y la temperatura con una sonda multiparamétrica YSI 556 MPS, previamente calibrada.

Las muestras analíticas se almacenaron y conservaron en contenedores de polietileno de alta densidad de $500 \mathrm{~mL}$ de capacidad, con tapón interior de seguridad y tapón exterior de rosca.

Los botes fueron acondicionados, una semana antes de ser usados, lavándolos abundantemente con agua desionizada, y rellenándolos con una disolución 0,25 M de ácido nítrico para eliminar las posibles trazas de metales o suciedad que pudieran tener. Una vez en el punto de muestreo, la disolución ácida fue desechada y los recipientes enjuagados abundantemente con el agua a muestrear. Las muestras fueron filtradas in situ a través de filtros de acetato de celulosa de $0,45 \mu \mathrm{m}$ de tamaño de poro y $47 \mathrm{~mm}$ de diámetro, colocados en un sistema de filtración Sartorius de policarbonato. Se hizo vacío con una bomba manual. Los recipientes de muestra, previamente enjuagados, se llenaron completamente con el agua filtrada procurando no dejar una cámara de aire entre el agua y el tapón de cierre. 


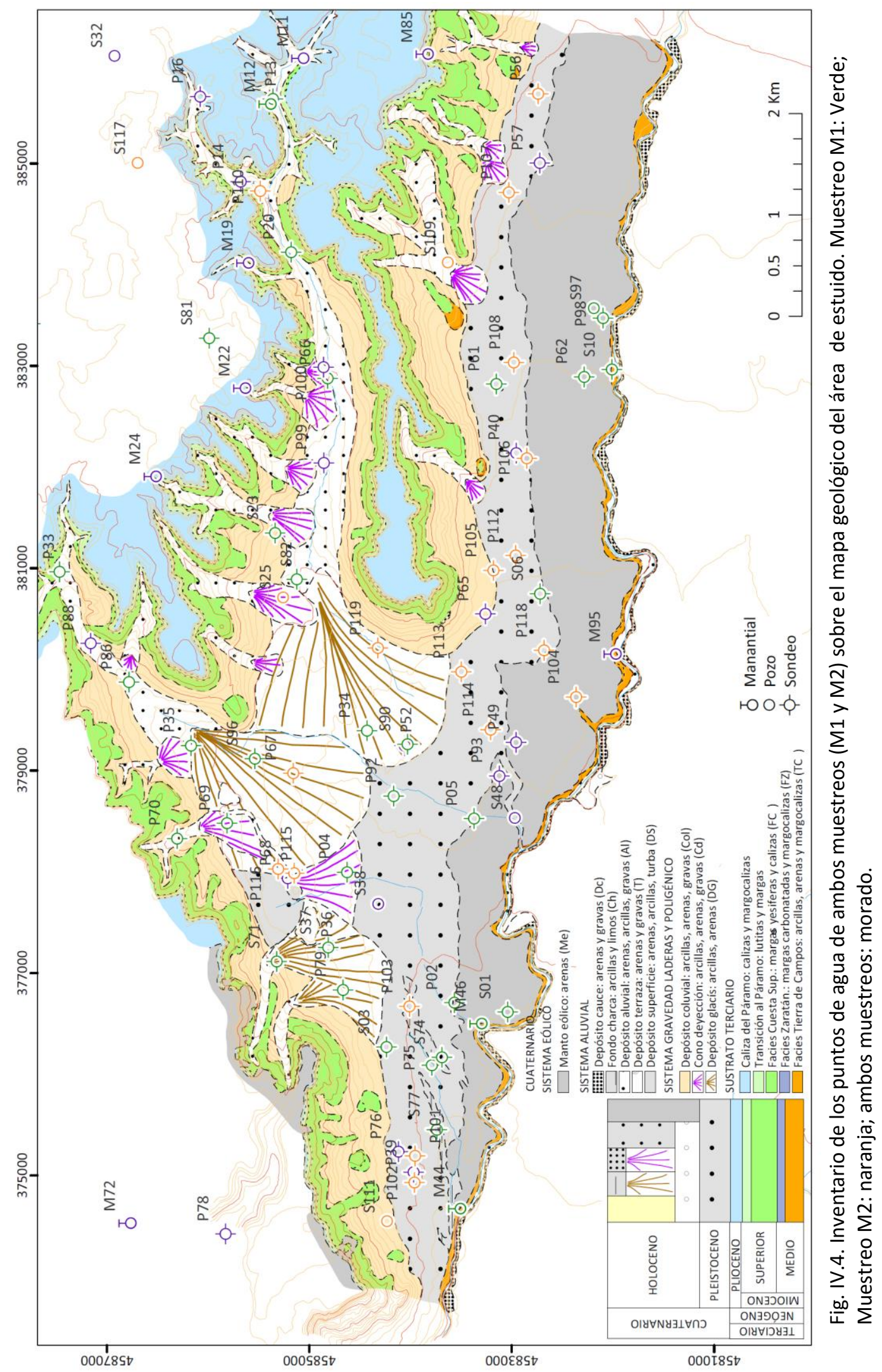




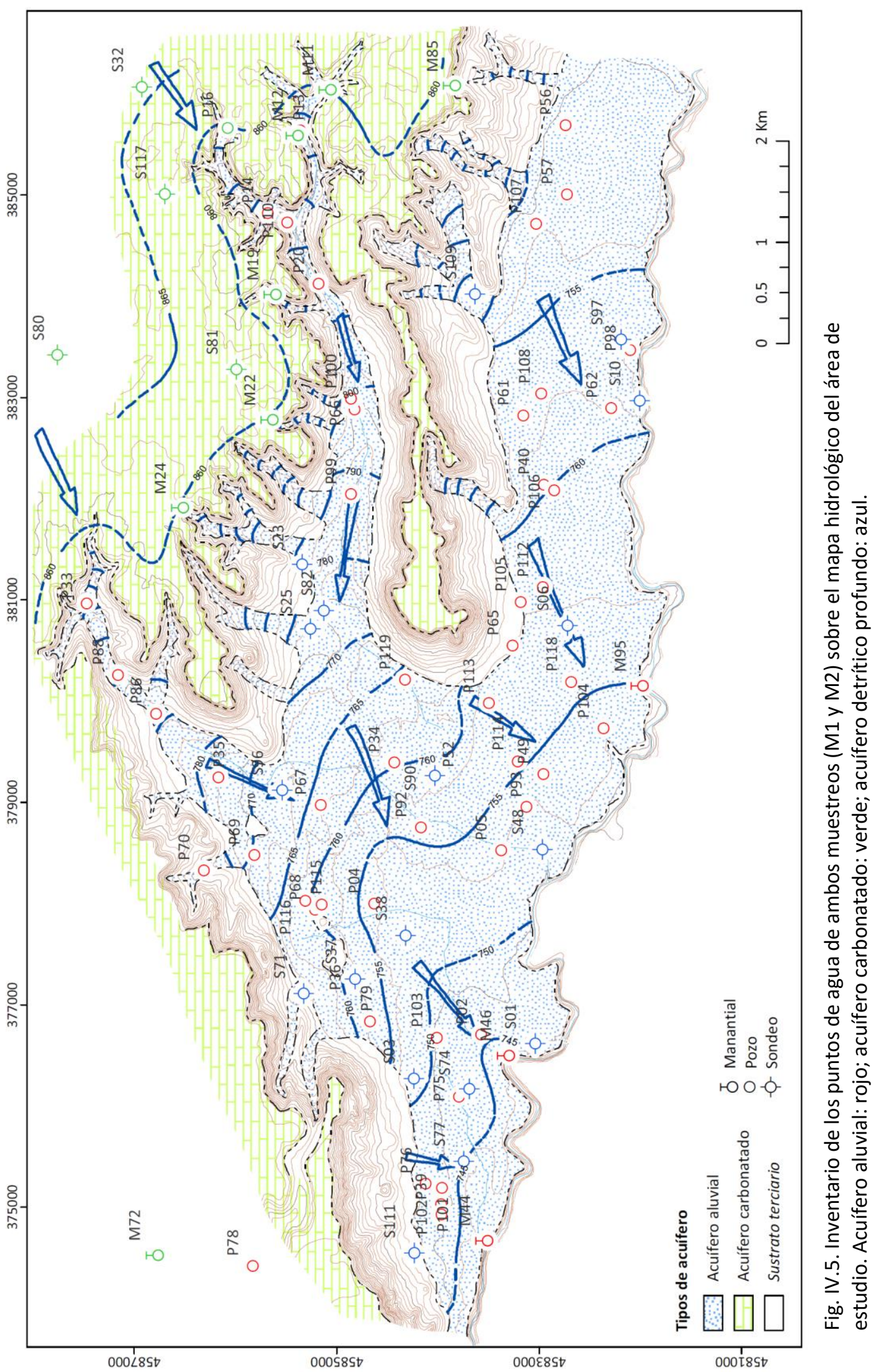




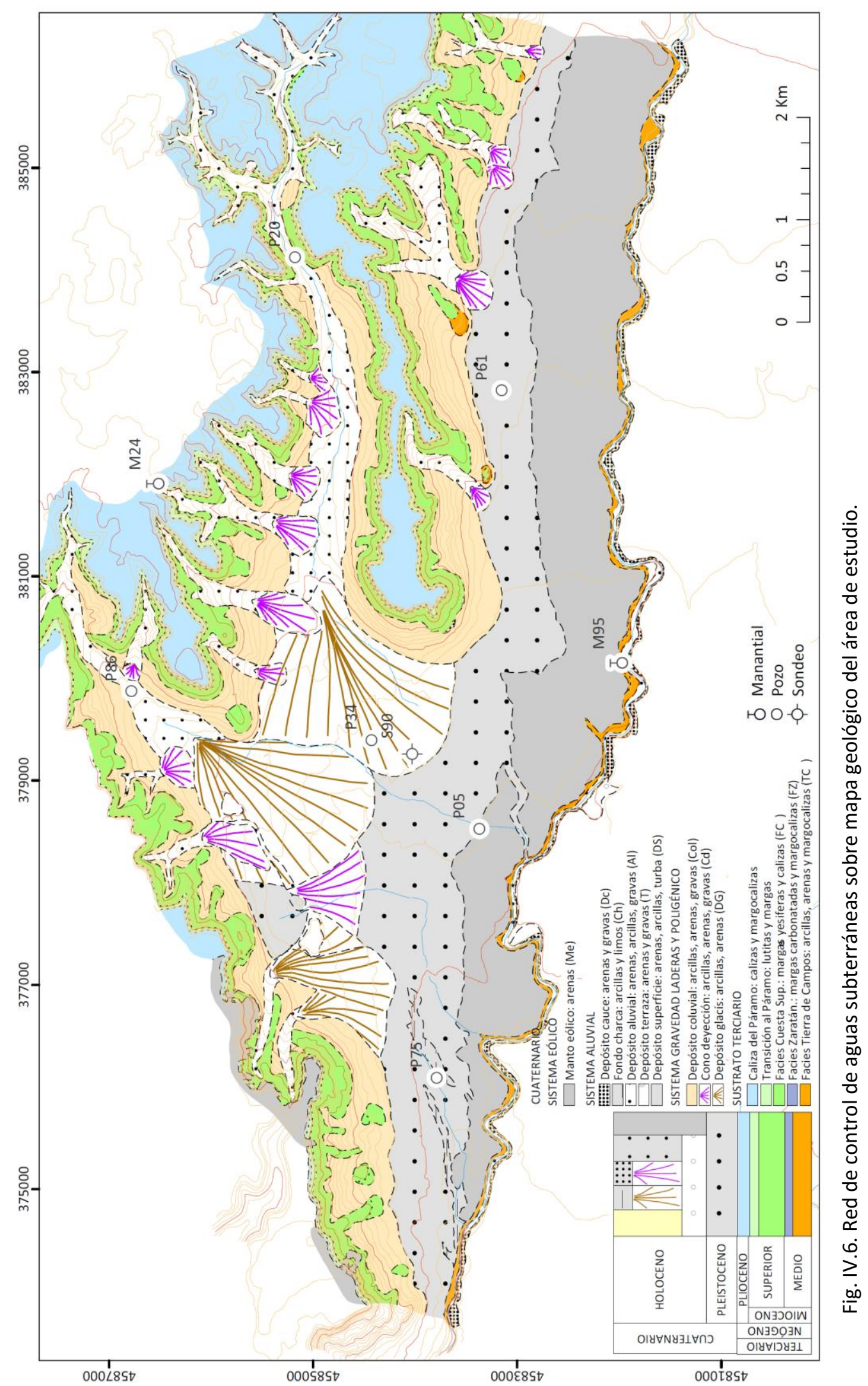




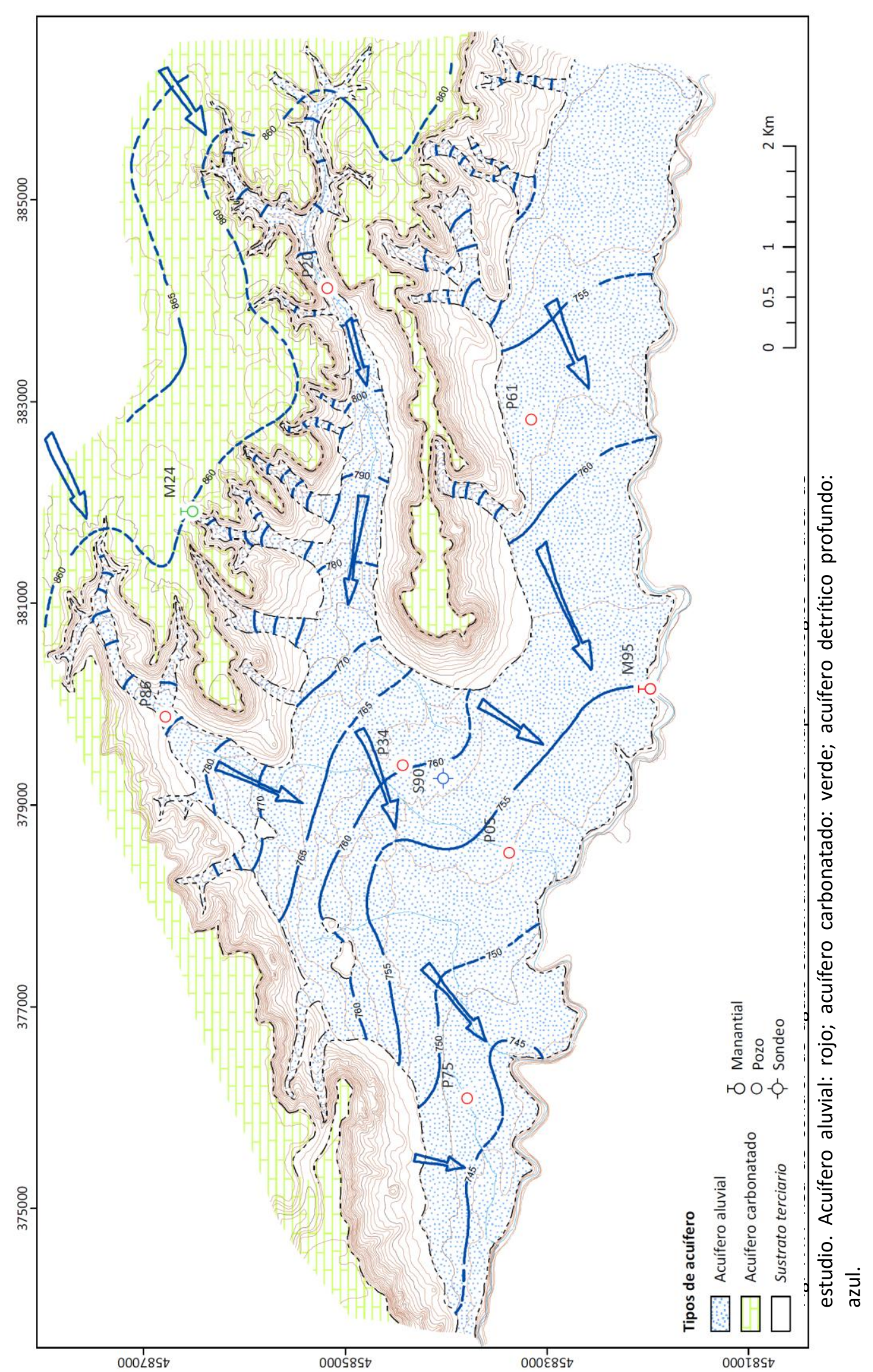


En cada punto de muestreo se tomaron dos muestras: a una de ellas no se le adicionó ningún reactivo ya que se utilizaría para determinar aniones, y la segunda se acidificó con $\mathrm{HNO}_{3} 1: 1$ a razón de $1 \mu \mathrm{L}$ por cada $1 \mathrm{~mL}$ de muestra, para conseguir un $\mathrm{pH}$ de $1-2$ y estabilizar los cationes metálicos.

Para asegurarnos de que los conservantes no causaban contaminación de la muestra se tomaron blancos de campo utilizando contenedores idénticos a los usados para el muestreo y sometiéndolos a las mismas manipulaciones que las muestras, salvo que se añadía agua desionizada en lugar de muestra.

Los recipientes se guardaron en bolsas de plástico con cierre de cremallera para prevenir contaminaciones cruzadas en caso de derrame accidental de una muestra durante el transporte. Las muestras se transportaron al laboratorio en neveras refrigeradas con hielo.

La identificación de las muestras se realizó mediante la siguiente codificación:

- Fecha y hora de recogida.

- Tipo de captación: Pozo (P), Manantial (M), Sondeo(S)

- Número de identificación: según la asignación que se les había dado en el inventario previo.

- Letras A (muestra filtrada sin conservante) o B (muestra filtrada acidificada)

Cada punto de agua muestreado se localizó geográficamente tomando sus coordenadas UTM mediante un sistema de geolocalización GARMIN GPS12XL, para facilitar su localización posterior y la digitalización de los mapas geológicos.

Se midió el nivel de agua de la captación para evaluar las fluctuaciones temporales de la piezometría y el sistema de flujo subterráneo y determinar su relación con la composición del agua, facilitando en muchas ocasiones la correcta interpretación de resultados. En la medida en la que las captaciones eran lo suficientemente accesibles, se utilizó una sonda de nivel con sistema acústico y cable graduado para realizar la lectura de la profundidad.

Una vez en el laboratorio, las muestras se almacenaron en una cámara frigorífica a +4 으 hasta el momento de ser analizadas.

La Tabla IV.1 resume las técnicas de conservación recomendadas para análisis físicoquímicos de muestras de agua.

Tabla IV.1. Técnicas recomendadas de conservación de muestras de agua para análisis físicoquímicos. P, plástico; V, vidrio (APHA, 1985)

\begin{tabular}{lcccc} 
Parámetro & Recipiente & Conservante & Tiempo máximo & Observaciones \\
\hline Arsénico & $\mathrm{P} \circ \mathrm{V}$ & $\mathrm{pH}<2$ & 1 mes & \\
Calcio & $\mathrm{P} \circ \mathrm{V}$ & $\mathrm{pH}<2$ & 1 mes & \\
Cloruros & $\mathrm{P} \circ \mathrm{V}$ & & 1 mes & \\
Conductividad & $\mathrm{P} \circ \mathrm{V}$ & Refrigerar & 24 horas & \\
Fluoruros & $\mathrm{P}$ & & 1 mes & No emplear PTFE \\
Metales totales & $\mathrm{P} \circ \mathrm{V}$ & $\mathrm{pH}<2$ & 1 mes & Excepto mercurio \\
Nitrato & $\mathrm{P} \circ \mathrm{V}$ & $\mathrm{pH}<2$ o & 24 horas & \\
Nitrito & $\mathrm{P} \circ \mathrm{V}$ & Refrigeración & & \\
& & Refrigeración & 24 horas &
\end{tabular}




\begin{tabular}{|c|c|c|c|c|}
\hline Parámetro & Recipiente & Conservante & Tiempo máximo & Observaciones \\
\hline $\mathrm{pH}$ & P o V & $\begin{array}{l}\text { Guardar a } \\
\text { menor } \\
\text { temperatura } \\
\text { que la inicial }\end{array}$ & 6 horas & $\begin{array}{l}\text { El pH debe determinarse en el } \\
\text { momento de la toma de muestra }\end{array}$ \\
\hline Fosforo disuelto & VB o V & $\begin{array}{l}\text { Refrigeración } \\
\text { tras filtrado } \\
\text { inmediato in } \\
\text { situ }\end{array}$ & 24 horas & $\begin{array}{l}\text { Se recomienda el uso de botellas } \\
\text { yodizadas }\end{array}$ \\
\hline Potasio & $\mathrm{P}$ & & 1 mes & \\
\hline Sodio & $\mathrm{P}$ & & $1 \mathrm{mes}$ & \\
\hline Sulfatos & $\mathrm{PoV}$ & Refrigeración & 1 semana & \\
\hline
\end{tabular}

\section{IV.3. PROCEDIMIENTOS ANALÍTICOS}

La metodología utilizada en la determinación de los parámetros físico-químicos de las muestras estudiadas se describe brevemente a continuación:

\section{IV.3.1. TEMPERATURA, pH, CONDUCTIVIDAD Y OXÍGENO DISUELTO}

Estos parámetros fueron determinados in-situ utilizando la multisonda YSI 556 MPS.

La calibración del pH se llevó a cabo con disoluciones tampón de $\mathrm{pH} 7$ y 9,26.

La calibración de la conductividad se llevo a cabo con una disolución de $\mathrm{KCl} 0,0100 \mathrm{~N}$, la cual posee una conductividad de $1413 \mu \mathrm{S} / \mathrm{cm}$ a $25^{\circ} \mathrm{C}$. Los valores medidos están ya referidos a $25 \circ \mathrm{C}$.

La calibración del oxígeno disuelto se realizó en una atmósfera de aire saturado de agua, y se consideró aquella lectura que no mostró un cambio significante durante aproximadamente 30 segundos.

Las medidas se realizaron con agitación constante, esperando unos minutos hasta alcanzar lecturas estables de los parámetros.

\section{IV.3.2. POTENCIAL REDOX}

Este parámetro se determinó in situ en algunas muestras del muestreo mensual de control, utilizando un electrodo de potencial redox CRISON 507 conectado a un milivoltímetro portátil CRISON. Las lecturas fueron corregidas para referir los potenciales medidos al electrodo normal de hidrógeno.

\section{IV.3.3. DETERMINACIÓN DE CARBONATO Y BICARBONATO}

La determinación de los aniones carbonato y bicarbonato se realizó mediante una volumetría ácido-base. 
Como reactivo valorante se empleó una disolución de ácido clorhídrico de concentración aproximadamente $0,1 \mathrm{M}$, que fue normalizada frente a una disolución 0,05 $\mathrm{M}$ de carbonato sódico tipo primario.

Para llevar a cabo la valoración se tomaron alícuotas de $25 \mathrm{~mL}$ de las muestras de agua a las que se les adicionaron 1 o 2 gotas del indicador fenoftaleína; en la mayoría de las muestras la fenolftaleína permaneció incolora, indicando la ausencia de carbonato en la muestra; en las raras ocasiones en que la muestra se tiño de rosa, se procedió a valorar con la disolución normalizada de $\mathrm{HCl}$ hasta viraje a incoloro. A continuación se añadieron 1 ó 2 gotas del indicador heliantina (naranja de metilo) para realizar la valoración del bicarbonato con la misma disolución valorante, hasta viraje de amarillo a rojo.

Todas las valoraciones se realizaron por triplicado.

\section{IV.3.4. DETERMINACIÓN DE ANIONES: CLORURO, NITRATO Y SULFATO}

La determinación de cloruro, nitrato y sulfato se realizó por cromatografía iónica $(\mathrm{Cl})$ empleando un cromatógrafo iónico de líquido WATERS 590 con columna de intercambio iónico WATERS IC-Pak Anion $4.6 \times 50 \mathrm{~mm}$ Column y detector conductimétrico WATERS 431. Como eluyente se empleó una disolución de borato-gluconato, con un flujo de 1,2 $\mathrm{mL} / \mathrm{min}$.

Antes de ser inyectadas, las muestras fueron filtradas a través de filtros de nylon de 0,20 $\mu \mathrm{m}$ de tamaño de poro. El volumen de inyección fue de $20 \mu \mathrm{L}$.

Los tiempos de retención para los aniones a determinar fueron: $\mathrm{Cl}^{-}: 3,4$ min; $\mathrm{NO}_{3}: 7,2$ min y $\mathrm{SO}_{4}{ }^{2-}: 13,8 \mathrm{~min}$. La determinación se llevó a cabo mediante el método de la línea de calibrado. El parámetro usado para cuantificación fue el área de pico. Las concentraciones de los patrones estaban comprendidas entre 4 y $80 \mathrm{mg} / \mathrm{L}$ para sulfato y nitrato y entre 2 y $40 \mathrm{mg} / \mathrm{L}$ para cloruro. El límite de detección para estos aniones es 0,1 $\mathrm{mg} / \mathrm{L}$. En algunas muestras fue necesario hacer diluciones.

\section{IV.3.5. DETERMINACIÓN DE NITRITO}

Se tomaron $50 \mathrm{~mL}$ de las disoluciones patrón, del blanco (agua desionizada) y de las muestras, se adicionaron $2 \mathrm{~mL}$ del reactivo de Zambelli recientemente preparado y se dejó reaccionar 10 minutos, después se añadieron $2 \mathrm{~mL}$ de amoníaco concentrado, se homogeneizó y se esperaron 5 minutos.

Una vez desarrollado el color amarillo, se midió la absorbancia de las disoluciones a 425 $\mathrm{nm}$ con un espectrofotómetro UV-Visible PHILIPS PU 8710 de rendija fija y haz simple.

La línea de calibrado se llevó a cabo entre 0,02-0,20 mg/L y se determinó la concentración de la muestra por interpolación directa en la línea de calibrado. El límite de detección es de $0,4 \mu \mathrm{g} / \mathrm{L}$. 


\section{IV.3.6. DETERMINACIÓN DE FLUORURO}

En un vaso de precipitados se mezclaron $25 \mathrm{~mL}$ de muestra o patrón con $25 \mathrm{~mL}$ de solución TISAB, se sumergieron los electrodos de referencia (de $\mathrm{AgCl} / \mathrm{Ag}, \mathrm{KCl}$ ) e indicador (electrodo selectivo de fluoruros IS-550-F- PHILIPS) en el vaso que contenía la mezcla y se midió el potencial con un milivoltímetro digital PHILIPS PW 9414, manteniendo la disolución agitada. Se anotó la lectura una vez que se alcanzó un valor constante. A todas las muestras y patrones les fue restado el blanco.

Se determinó la concentración de analito en las muestras por interpolación en la línea de calibrado $\mathrm{E}$ - log [F]. Las concentraciones de $\mathrm{F}$ utilizadas para la línea de calibrado fueron desde 0,1 a $10^{-6} \mathrm{mg} / \mathrm{L}$. El límite de detección es de 0,10 mg/L.

\section{IV.3.7. DETERMINACIÓN DE SÍLICE}

A $50 \mathrm{~mL}$ de muestra o patrón se añaden sucesivamente $1,0 \mathrm{~mL}$ de $\mathrm{HCl}(1: 1)$ y $2,0 \mathrm{~mL}$ de molibdato amónico, se mezcla y se deja reposar de 5 a 10 minutos. A continuación se añaden $2,0 \mathrm{~mL}$ de ácido oxálico, se homogeniza la disolución agitando vigorosamente y se espera entre 2 y $15 \mathrm{~min}$, después se adicionan $2,0 \mathrm{~mL}$ de una disolución filtrada del agente reductor, preparado disolviendo $500 \mathrm{mg}$ de ácido 1-amino-2-naftol-4-sulfónico, 1 $\mathrm{g}$ de $\mathrm{Na}_{2} \mathrm{SO}_{3}$ y $30 \mathrm{~g}$ de $\mathrm{NaHSO}_{3}$ en $200 \mathrm{~mL}$ de agua desionizada. Tras homogeneizar la disolución, se deja reposar 5 min y se mide el color azul con un Espectrofotómetro UVVisible PHILIPS PU 8710 de rendija fija y haz simple. A todas las muestras y patrones les fue restado el blanco.

Se preparó una línea de calibrado de 0,36 a 1,8 ppm y se determinó la concentración de la muestra por interpolación directa en la línea de calibrado. En caso de que las muestras presentaran concentraciones superiores a las del calibrado se procedió a su dilución. El límite de detección es de 0,02 mg/L.

\section{IV.3.8. DETERMINACIÓN DE FOSFATO}

Se toman $20 \mathrm{~mL}$ de las muestras o patrones en vasos de precipitados de $50 \mathrm{~mL}$, añadiendo a continuación $\mathrm{H}_{2} \mathrm{SO}_{4} 1,5 \mathrm{M}$ hasta conseguir un $\mathrm{pH}$ de 5 . Se transfiere la disolución acidificada a un matraz aforado de $50 \mathrm{~mL}$, se añaden unos $20 \mathrm{~mL}$ de agua desionizada, $8 \mathrm{~mL}$ del reactivo para desarrollar el color, y se enrasa con agua desionizada. Se esperan entre 15 y 60 min y se lee la absorbancia a una longitud de onda de $882 \mathrm{~nm}$ con un espectrofotómetro UV-Visible PHILIPS PU 8710 de rendija fija y haz simple. A todas las muestras y patrones les fue restada la lectura el blanco.

Se preparó una línea de calibrado de 0,01 a 0,4ppm y se determinó la concentración de la muestra por interpolación directa en la línea de calibrado. Cuando las muestras presentaron concentraciones superiores a las del calibrado se procedió a su dilución. El límite de detección es de $0,4 \mu \mathrm{g} / \mathrm{L}$.

El reactivo para desarrollar el color azul se preparó de la siguiente forma: $12,0 \mathrm{~g}$ de $\left(\mathrm{NH}_{4}\right)_{6} \mathrm{Mo}_{7} \mathrm{O}_{24} 4 \mathrm{H}_{2} \mathrm{O}$ se disuelven en $250 \mathrm{~mL}$ de agua desionizada; $0.2908 \mathrm{~g}$ de tartrato 
antimónico se disuelven en $100 \mathrm{~mL}$ de agua desionizada; $135 \mathrm{~mL}$ de $\mathrm{H}_{2} \mathrm{SO}_{4}$ concentrado se diluyen a $1 \mathrm{~L}$ con agua desionizada; se mezclan estas tres disoluciones y se llevan a $2 \mathrm{~L}$ con agua desionizada. Finalmente, se mezclan $250 \mathrm{~mL}$ de esta disolución con 1,32 g de ácido ascórbico.

\section{IV.3.9. DETERMINACIÓN DE Ca, Na, K y Mg}

La determinación de $\mathrm{Ca}, \mathrm{Na}, \mathrm{K}$, y Mg se llevó a cabo por espectroscopía atómica de llama con un espectrómetro de absorción/emisión GCB-933AA. Calcio y magnesio se determinaron por espectroscopía de absorción atómica (AAS) con una lámpara de cátodo hueco GBC bielemental de $\mathrm{Ca}-\mathrm{Mg}$, mientras que $\mathrm{Na}$ y $\mathrm{K}$ se determinaron por espectroscopía de emisión atómica (FES). En todas las determinaciones se empleó una llama de aire-acetileno.

Las líneas de calibrado se prepararon de 1,0-30 mg/L para el Ca; de 0,25-2,0 mg/L para el $\mathrm{Mg}$; de 0,10-3,0 mg/L para el $\mathrm{Na}$ y de 0,50-4,0 mg/L para el $\mathrm{K}$.

La cuantificación de los elementos en las muestras se llevó a cabo mediante el método de la línea de calibrado, diluyendo la muestra cuando fue necesario. A todas las muestras y patrones les fue restada la lectura del blanco. Los límites de detección son de $0,20 \mathrm{mg} / \mathrm{L}$ para Ca, Na y K y de 0,10 mg/L para el Mg.

Las condiciones experimentales fueron las siguientes:

Tabla IV.2. Condiciones experimentales para los diferentes metales.

\begin{tabular}{lcccc} 
Elementos & Técnica & Intensidad $(\mathbf{n A})$ & Longitud $(\mathbf{n m})$ & Rendija $(\mathbf{n m})$ \\
\hline Calcio & AAS & 5 & 427,7 & 0,5 \\
Magnesio & AAS & 5 & $285,2\left(\mathrm{D}_{2}\right)$ & 0,5 \\
Sodio & FES & - & 589,0 & 0,2 \\
Potasio & FES & - & 766,5 & 0,5 \\
\hline
\end{tabular}

\section{IV.3.10. DETERMINACIÓN DE As, Mn, Fe y Mo}

La determinación de As, Mn, Fe y Mo se llevó a cabo con un espectrofotómetro de absorción atómica con cámara de grafito (marca VARIAN GTA 100 Espectra AA-800), empleando gas $\operatorname{Ar}(99,995 \%$ de pureza) a una presión de 140-200 kPa. Como fuente de radiación se emplearon lámparas de cátodo hueco del elemento correspondiente.

La muestra es sometida a un tratamiento térmico en un horno de grafito que consta de cuatro etapas: secado, destrucción, atomización y limpieza de la cámara de grafito a temperatura elevada para eliminar restos de muestra. Cada uno de los metales precisa un programa ligeramente diferente y unas condiciones experimentales distintas. 
Tabla IV.3. Condiciones experimentales para los diferentes metales.

\begin{tabular}{lcccc} 
Elementos & Técnica & Intensidad (nA) & Longitud (nm) & Rendija (nm) \\
\hline Arsénico & GF-AAS & 10 & 197,2 & 1,0 \\
Manganeso & GF-AAS & 5 & 279,5 & 0,2 \\
Hierro & GF-AAS & 5 & 248,3 & 0,2 \\
Molibdeno & GF-AAS & 7 & 313,3 & 0,5 \\
\hline
\end{tabular}

Las líneas de calibrado se prepararon de 16-96 $\mu \mathrm{g} / \mathrm{L}$ para el As; de 1-6 $\mu \mathrm{g} / \mathrm{L}$ para el Mn; de $5-20 \mu \mathrm{g} / \mathrm{L}$ para el Fe $\mu \mathrm{g} / \mathrm{L}$ y de $4-20 \mu \mathrm{g} / \mathrm{L}$ para el Mo.

La cuantificación de los elementos se llevó a cabo mediante el método de la línea de calibrado, diluyendo la muestra cuando fue necesarioA todas las muestras y patrones les fue restado el blanco. Los límites de detección son de 0,10 $\mu \mathrm{g} / \mathrm{L}$ para el $\mathrm{Mn}$ y Mo; de $0,20 \mu \mathrm{g} / \mathrm{L}$ para el Fe y de 2,10 para el As.

\section{IV.3.11. DETERMINACIÓN DE VANADIO}

La determinación de vanadio se llevó a cabo por voltamperometría de redisolución catalítica adsortiva siguiendo el método descrito por Vega y Van den Berg, 1994 empleando un polarógrafo METROHM E-506 con Stand METROHM 663 VA y un equipo de redisolución METROHM E-608.

En la celda voltamperométrica se mezclaron $25 \mathrm{~mL}$ de agua desionizada, $1 \mathrm{~mL}$ de muestra, $18 \mu \mathrm{l}$ de $\mathrm{NH}_{3} 1 \mathrm{M}, 0,5 \mathrm{~mL}$ de PIPES $1 \mathrm{M}$ y $1 \mathrm{~mL}$ de una mezcla de catecol y bromato. Tras preconcentrar el complejo catecol-V sobre el electrodo de gota de mercurio, se registra el pico de redisolución del vanadio a $-0,9 \vee$ realizando un barrido catódico en modo de onda cuadrada. La cuantificación se realizó mediante el método de adiciones patrón. Se determinó un blanco de agua desionizada de forma idéntica, obteniéndose por diferencia la concentración de la muestra.

Condiciones experimentales:

\begin{tabular}{lc} 
Condiciones & Valores \\
\hline Potencial de deposición de & $-0,1 \mathrm{~V}$ \\
potencial & \\
Tiempo de deposición & $15 \mathrm{~s}$ \\
Tiempo de equilibrado & $10 \mathrm{~s}$ \\
Frecuencia de la onda & $50 \mathrm{~Hz}$ \\
Velocidad de barrido & $120 \mathrm{mV} / \mathrm{s}$ \\
Amplitud de la onda & $25 \mathrm{mV}$ \\
\hline
\end{tabular}




\section{IV.3.12. $\quad$ ANÁLISIS ESTADÍSTICO DE LOS RESULTADOS}

Para el desarrollo de los cálculos derivados del análisis univariante y multivariante se han utilizado los programas SPSS (IBM SPSS Statistics versión 20.0.0) para Windows y Matlab Version 6.0.0.88 Release 12.

Antes de aplicar las técnicas estadísticas multivariantes, los datos experimentales se estandarizaron para evitar el efecto de variables con diferentes rangos de concentración y/o órdenes de magnitud y permitir que todas las variables contribuyan por igual a la caracterización. En nuestro caso, los datos fueron normalizados por el procedimiento de autoescalado (media cero y varianza unidad).

El preprocesado de los datos en métodos de tres vías no es tan sencillo como en el caso de dos vías, ya que existen varias posibilidades de realizarlo. Para que todas las variables tuvieran las mismas posibilidades de contribuir al modelo propuesto y que se mantuviesen las diferencias entre los puntos muestreados y entre los meses en que se llevaron a cabo, se llevó a cabo el centrado y escalado en el segundo modo (variables).

Los métodos multivariantes empleados han sido el Análisis Clúster o de Conglomerados, y el Análisis en Componentes Principales (ACP) clásico y de $\mathrm{N}$ vías, cuyo fundamento resumimos brevemente a continuación (Pardo y Barrado, 1988; Vandeginste y Massart D.L. y col., 1998; Ramis y García, 2001).

\section{IV.3.12.1 Análisis Clúster}

El análisis de conglomerados jerárquico o análisis clúster es un método de reconocimiento no supervisado de pautas cuyo objetivo es precisamente clasificar objetos en clases, de manera que los objetos similares se encuentren en la misma clase. Los grupos no se conocen antes de realizar el análisis matemático y no se realiza ningún supuesto sobre la distribución de las variables, por lo que el método es robusto frente a la falta de normalidad (Sharaf y col., 1986).

Este análisis calcula las distancias entre todos los pares posibles de muestras y concentra una muestra dentro de otra, paso a paso, hasta reunir todas las muestras en un solo grupo (Willet, 1987).

De entre las diferentes alternativas, hemos seleccionado el método de agrupamiento de Ward, ya que conduce a agrupaciones más compactas y diferenciadas, y la distancia euclídea como medida de similitud o distancia entre los agrupamientos.

Estos métodos se emplean de forma rutinaria en multitud de áreas científicas (Singh y col., 2006; Wang y col., 2014). Su aplicación a datos medioambientales se detalla en Smolinski (2002) y, en el caso de los procedimientos de fraccionamiento químico, en Giacomino y col (2011). 


\section{IV.3.12.2 Análisis de Componentes Principales (ACP)}

El análisis en componentes principales, ACP (Hopke, 1983; Mengle, 1991 y Wenning, 1994), es un procedimiento matemático que permite extraer gran cantidad de información, a veces no aparente a primera vista, de una serie de datos relativos a diversas muestras u objetos. Es de utilidad cuando el volumen de datos de que se dispone dificulta el reconocimiento de pautas.

El ACP permite reducir la dimensionalidad en un conjunto de datos encontrando asociaciones, interpretadas como correlaciones entre las variables medidas y entre las muestras (Eriksson y col., 2001)

El procedimiento matemático conlleva la diagonalización de la matriz de covarianzas, la cual coincidirá con la matriz de correlación si las variables están estandarizadas, para transformar las variables originales en unas nuevas variables ortogonales, que no están correlacionadas entre sí, llamadas componentes principales (PC) y que son combinaciones lineales de las variables originales.

Como se parte de la hipótesis de que no todas las variables originales medidas contienen información relevante sobre los objetos y de que algunas de ellas están correlacionadas entre sí, su reducción no implica una pérdida significativa de información.

Los valores propios de los componentes principales representan el porcentaje de varianza que puede explicar el componente principal, mientras que las cargas de los factores (loadings) son coeficientes que expresan la contribución de las variables originales al componente principal. Los valores de las variables transformados se denominan puntuaciones o scores.

El número de componentes principales que vamos a mantener en el modelo son aquellos cuyo valor propio es mayor que la unidad, es decir, aquellos que contienen más información que una de las variables originales.

La interpretación del ACP se hace visualizando, por separado o conjuntamente, los gráficos de cargas y puntuaciones. En general, las variables originales que aparezcan agrupadas en el gráfico de cargas estarán muy relacionadas entre sí. Asimismo, aquellos objetos que aparezcan cercanos entre sí en el gráfico de puntuaciones se comportarán de forma similar y se parecerán entre ellos. Por el contrario, aquellas variables u objetos que aparezcan separadas en dichos gráficos se parecerán muy poco entre sí. Habitualmente, y con el fin de facilitar la interpretación, se representan solo los 2 ó 3 primeros componentes, lo cual suele bastar para explicar una cantidad significativamente importante de información.

El ACP se utiliza con profusión en aquellos campos científicos como el medioambiental, en que se conocen una gran cantidad de parámetros químicos correspondientes a una gran cantidad de muestras (Barbieri y col 1998; Salman y col., 1999; Helena y col., 2000; Simeonov y col., 2000; Singh, y col 2007; Salman y col., 2009; Cid y col 2011) o a estudios de fraccionamiento químico (Pardo y col., 2002, 2004, 2008, 2013; Abollino y col., 2011; Wang, 2014). 


\section{IV.3.12.3 Métodos estadísticos Multivariantes de $\mathbf{N}$ vías}

Los métodos de análisis multivariante de $\mathrm{N}$ vías tienen cada vez más interés en áreas relacionadas con la ciencia y la industria debido a la complejidad de los datos obtenidos, que se traduce en matrices de $\mathrm{N}$ dimensiones. El ACP clásico o de 2 vías (2-ACP) solo es aplicable a matrices de dos dimensiones, en las que las columnas representan las variables y las filas los objetos o casos. Cuando se introducen dimensiones adicionales (por ejemplo, se miden " $x$ " variables en muestras tomadas en " $y$ " puntos de muestreo durante " $\mathrm{z}$ " campañas de muestreo diferentes), el 2-ACP clásico puede aún ser utilizado si la matriz de datos $\underline{\mathbf{X}}$ de tres dimensiones se despliega de manera que se transforma en una matriz bidimensional $\underline{\underline{x}}^{\text {aug }}$ de dimensiones [(puntos $\mathrm{x}$ variables) $\mathrm{x}$ campañas]. Este procedimiento se denomina MA-PCA (Matrix Augmentation-Principal Component Analysis) y su modelo matemático es el siguiente:

$$
\mathrm{x}_{\mathrm{ij}}^{\text {aug }}=\sum_{\mathrm{f}=1}^{\mathrm{F}} \mathrm{u}_{\mathrm{if}}^{\text {aug }} \mathrm{b}_{\mathrm{fj}}+\mathrm{e}_{\mathrm{ij}}
$$

O, en forma matricial, $\mathbf{X}^{\text {aug }}=\mathbf{U}^{\text {aug }} \mathbf{B}$ (Fig. IV.8).

Los parámetros del modelo tienen el mismo significado que en el 2-ACP normal y se interpretan igual, pero la información correspondiente a puntos y campañas (es decir a las filas de la nueva matriz $\mathbf{X}^{\text {aug }}$ ) aparece mezclada, no permitiendo discernir la información de las dimensiones ubicación-tiempo, por lo que los efectos espacial y temporal sobre el problema estudiado no pueden ser correctamente evaluados.

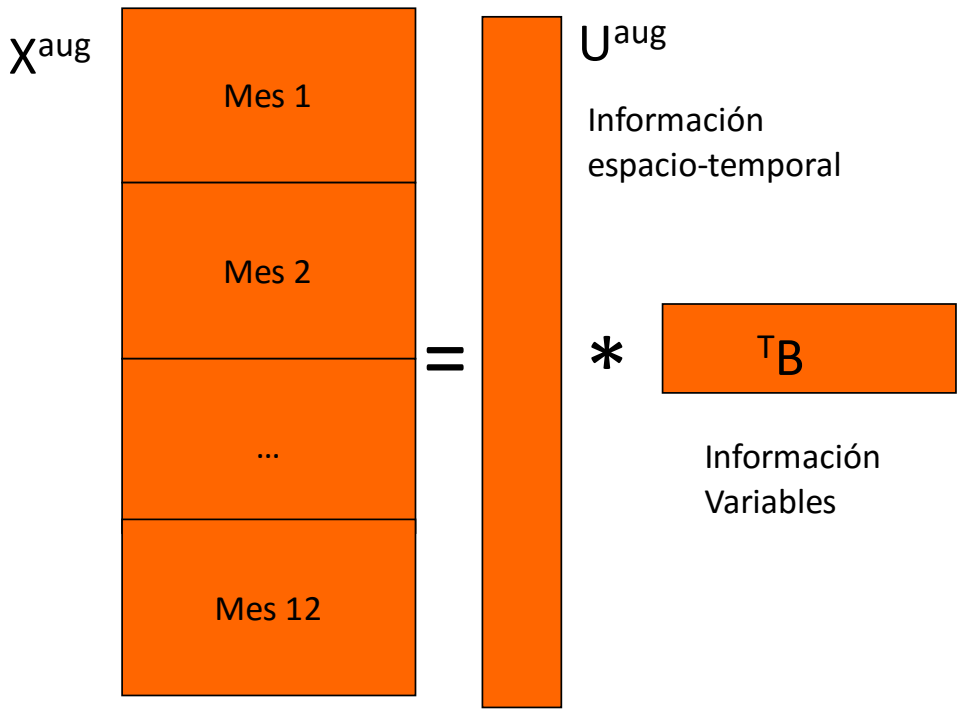

Fig. IV.8. Esquema del tratamiento estadístico MA-PCA

Sin embargo, la mejor forma de extraer la información contenida en una matriz de datos tridimensional es utilizar métodos intrínsecamente $\mathrm{N}$-way, denominados $\mathrm{n}$-ACP, que se aplican directamente a la matriz de datos original, en nuestro caso una matriz $\underline{\mathbf{X}}$ de tres dimensiones (puntos de muestreo $\mathrm{x}$ variables $\mathrm{x}$ meses). 
PARAFAC Y TUCKER3 son los métodos de descomposición de datos de tres o más vías más ampliamente usados por su robustez y su fácil interpretación.

Los datos obtenidos en el estudio de los muestreos de control pueden ser ordenados en una matriz de tres vías, $\underline{\mathbf{X}}$ (Fig. IV.9), en la cual el primer modo corresponde a los 9 puntos de muestreo, el segundo a los 16 parámetros físico-químicos analizados y el tercero a los 12 meses en los cuales se determinaron esos parámetros. Así, nuestra matriz de datos tendrá dimensiones $(9 \times 16 \times 12)$.

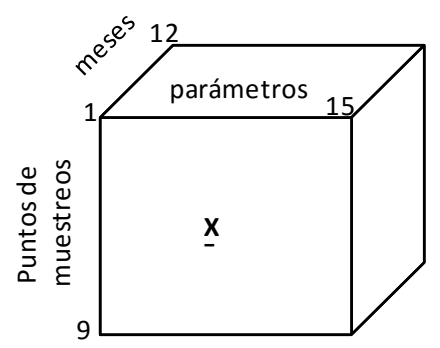

Fig. IV.9. Estructura tridimensional del conjunto de datos.

\section{El modelo PARAFAC}

Este modelo fue propuesto independientemente por Harshman, 1970 y por Carroll y Chang, 1970, quien llamó al modelo CANDECOMP (canonical decomposition). El modelo PARAFAC es una generalización del Análisis en Componentes Principales (ACP) a matrices de órdenes mayores, aunque algunas de las características de este método difieren de las del modelo de dos vías.

El modelo PARAFAC se basa en el siguiente algoritmo:

$$
x_{i j k}=\sum_{f=1}^{F} a_{i f} b_{j f} c_{k f}+e_{i j k}
$$

donde $a_{i f}, b_{j f}$ y $c_{k f}$ son los componentes de las matrices $\mathbf{A}$ (puntos de muestreo $\times$ F), B (variables $\times$ F) y C (meses $\times$ F) que contienen, respectivamente, información existente en $\underline{\mathbf{X}}$ relativa a ubicación, parámetros físico-químicos y mes de muestreo, donde $i, j$ y $k$ son las dimensiones de los modos y $F$ correspondería al número de factores elegidos en el modelo.

Una característica del modelo PARAFAC es que posee el mismo número de factores, $F$, en todas las matrices de cargas $\mathbf{A}(/ \times F), \mathbf{B}(J \times F)$ y $\mathbf{C}(K \times F)$.

Para determinar el número de factores óptimo del modelo se utilizó el criterio de "core consistency", el cual se basa en examinar, según el número de factores elegido "a priori", cuanto de adecuado es el modelo estructural. La "core consistency" es siempre menor o igual al 100\% e incluso puede ser negativa. Una "core consistency" cercana al $100 \%$ implica un modelo adecuado (Bro y col., 2003).

El modelo PARAFAC fue aplicado al conjunto de datos de muestreo para explorar la estructura intrínseca y descubrir la información que subyace en el conjunto de datos originales. 


\section{El modelo TUCKER3}

El modelo Tucker 3 debe su nombre a Ledyard R. Tucker quien lo propuso en 1996. Este modelo supone una fuerte herramienta para análisis de conjuntos de datos de tres o más vías. El hecho de que este modelo contiene al modelo Parafac como caso especial lo convierte en un modelo muy usado para la interpretación en muchas aplicaciones. El modelo Tucker3 con factores ortogonales es también conocido como análisis en componentes principales de 3 vías.

El modelo Tucker3 se basa en el siguiente algoritmo:

$$
\mathrm{x}_{\mathrm{ijk}}=\sum_{\mathrm{l}=1}^{\mathrm{L}} \sum_{\mathrm{m}=1}^{\mathrm{M}} \sum_{\mathrm{n}=1}^{\mathrm{N}} \mathrm{a}_{\mathrm{il}} \mathrm{b}_{\mathrm{jm}} \mathrm{c}_{\mathrm{kn}} \mathrm{g}_{\mathrm{lmn}}+\mathrm{e}_{\mathrm{ijk}}
$$

Donde, además de las matrices A, B y C también presentes en PARAFAC, contiene una matriz $\underline{\mathbf{G}}$ de interacciones, formada por los valores $\mathrm{g}_{\mathrm{Imn}}$.

De nuevo, $a_{i j}, b_{j m}$ y $c_{k n}$ son los elementos de las tres matrices de cargas, A, B y C, de dimensiones $\left(n_{\text {puntos }} \times L\right),\left(n_{\text {variables }} \times M\right),\left(n_{\text {meses }} \times N\right)$; donde $L, M$ y $N$ son los números de los factores extraídos en cada uno de los modos, los cuales se eligen de manera que sean lo más pequeños posible y que expliquen la máxima varianza.

El elemento $g_{I m n}$ denota los elementos $(I, m, n)$ del "core array" $\underline{\mathbf{G}}(\mathrm{LxMxN})$ y $\mathrm{e}_{\mathrm{ijk}}$ es el termino de error de los elementos del conjunto de datos. El cuadrado del valor de los elementos del "core array" $\left(\mathrm{g}^{2}{ }_{\mathrm{Imn}}\right)$ refleja la interacción entre los tres modos (A, B y C) y muestra la importancia de la combinación de factores que hemos supuesto ortogonales.

Mientras que PARAFAC asigna el mismo número de dimensiones $F$ a las tres matrices $\mathbf{A}$, B y C, el modelo Tucker3 permite asignar un número diferente de dimensiones ( $L, M$ y N) a cada vía, simplificando así la interpretación global del modelo a costa de aumentar la complejidad del mismo al precisar de una matriz de interacciones $\underline{\mathbf{G}}$.

El número de factores en cada modo se eligió en base al porcentaje de varianza que explica cada combinación de factores.

La siguiente Fig. IV.10 muestra un esquema de ambos procedimientos.

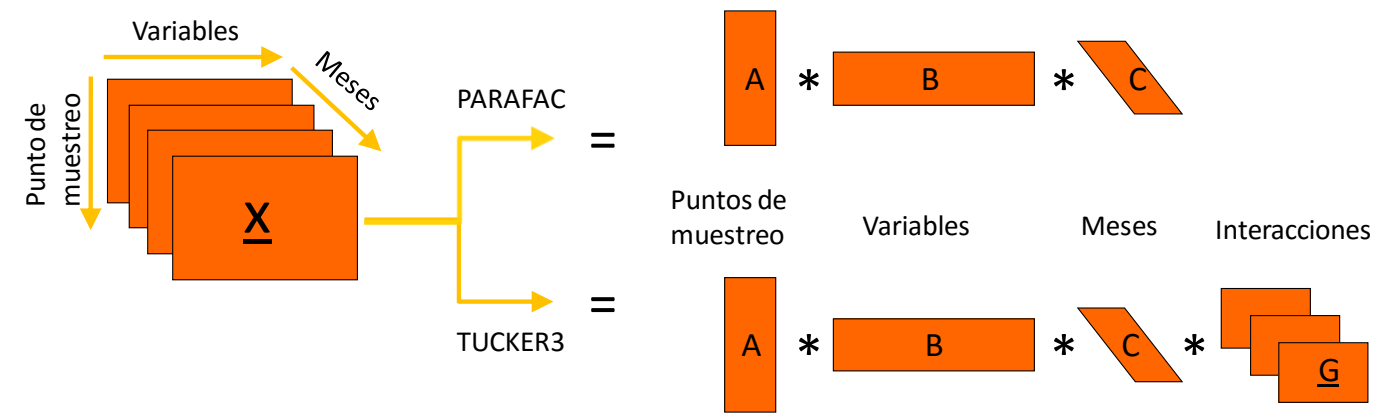

Fig. IV.10. Esquema de los procedimientos de PARAFAC y TUCKER 3 


\section{IV.3.13. CÁLCULOS HIDROQUÍMICOS}

Para el cálculo de los índices de saturación se ha utilizado el programa AQUACHEM 4.0 y Y PHREEQC.

\section{IV.3.14. DISEÑO DE MAPAS}

El programa ArcGIS 10.2.1 ha sido utilizado para la elaboración de los mapas.

\section{IV.4. RESULTADOS}

Todas las muestras de agua fueron caracterizadas analizando un total de 21 parámetros físico-químicos, que se resumen en la Tabla IV.4, junto con las unidades en las que se han expresado los resultados, empleando los métodos analíticos que se han descrito en el apartado anterior. Los resultados numéricos de los muestreos $M 1$ y $M 2$ se muestran en las Tabla A.II.1 y Tabla A.Il.2 del Anexo. Las variables nitrito, sílice y vanadio solo fueron determinadas en el muestreo M2.

Tabla IV.4. Parámetros analíticos determinados en las aguas.

\begin{tabular}{ll} 
Parámetro & Unidad \\
\hline Temperatura (T) & $\underline{\mathrm{o}}$ \\
Conductividad eléctrica (C.E) & $\mu \mathrm{S} / \mathrm{cm}$ \\
$\mathrm{pH}$ & Unidades de $\mathrm{pH}$ \\
Oxígeno disuelto (O.D) & $\mathrm{mg} / \mathrm{L}$ \\
Aniones inorgánicos: & \\
$\mathrm{Cl}^{-}, \mathrm{HCO}_{3}^{-}, \mathrm{SO}_{4}{ }^{2-}, \mathrm{NO}_{3}{ }^{-}, \mathrm{F}^{-}$y $\mathrm{NO}_{2}{ }^{-}$ & $\mathrm{mg} / \mathrm{L}$ \\
$\mathrm{SiO}_{3}{ }^{2-}$ expresado como $\mathrm{SiO}_{2}$ & $\mathrm{mg} / \mathrm{L}$ \\
$\mathrm{PO}_{4}{ }^{3-}$ expresado como $\mathrm{P}$ & $\mathrm{mg} / \mathrm{L}$ \\
$\mathrm{Cationes} \mathrm{mayoritarios:}_{\mathrm{Ca}, \mathrm{Mg}, \mathrm{Na}, \mathrm{K}}$ & $\mathrm{mg} / \mathrm{L}$ \\
$\mathrm{Elementos}$ traza & \\
$\mathrm{As}, \mathrm{Fe}, \mathrm{Mn}, \mathrm{Mo}$ y V & $\mu \mathrm{g} / \mathrm{L}$ \\
\hline
\end{tabular}

Para validar los resultados analíticos se comprobó la electroneutralidad de las muestras de agua comparando la concentración, en meq/L, de cargas positivas y de cargas negativas aportadas por los cationes y aniones mayoritarios analizados. Los cationes considerados fueron $\mathrm{Ca}^{2+}, \mathrm{Mg}^{2+}, \mathrm{K}^{+}$y Na${ }^{+}$, mientras que los aniones fueron $\mathrm{HCO}_{3}{ }^{-} \mathrm{Cl}^{-}$, $\mathrm{SO}_{4}{ }^{2-}$ y $\mathrm{NO}_{3}{ }^{-}$. Si el balance de cargas no es neutro significa, o bien que se ha ignorado un ion mayoritario, o que se ha producido algún error analítico (APHA, 1999; Apello y Postma, 2005). El criterio para validar los resultados fue una diferencia inferior al 5\% entre el balance de cargas positivas y negativas, calculado mediante la expresión:

$$
\% \text { diferencia }=\frac{\sum \text { cationes }-\sum \text { aniones }}{\sum \text { cationes }+\sum \text { aniones }} \times 100
$$


en la que las concentraciones se expresan en meq/L.

Aunque en un número muy pequeño de muestras la diferencia observada fue significativa, la diferencia media para el Muestreo M1 fue del $-4 \%$, y del $-0.3 \%$ para las muestras del Muestreo M2.

\section{IV.4.1. DISTRIBUCIÓN ESPACIAL DEL ARSÉNICO}

Se han representado las concentraciones de arsénico de los puntos de agua sobre el mapa geológico e hidrológico respectivamente de los puntos de agua del muestreo M1 (Fig. IV.11 y Fig. IV.12). Para el muestreo M2 se han realizado los mismos gráficos (Fig. IV.13 y Fig. IV.14).

En el muestreo M1, un el 80\% (47 de 59) de los puntos de agua superan el límite de 10 $\mu \mathrm{g} / \mathrm{L}$, establecido en el Real Decreto $140 / 2003$, como límite máximo para consumo humano. De estos, un $27 \%$ (16 de 59) se encuentran entre $10-50 \mu \mathrm{g} / \mathrm{L}$, el límite anteriormente establecido para considerar un agua contaminada para consumo humano, un $22 \%$ (13 de 59) se encuentran entre 50-100 $\mu \mathrm{g} / \mathrm{L}$, otro $22 \%$ (13 de 59) se encuentran en un rango de $100-200 \mu \mathrm{g} / \mathrm{L}$, y un $8 \%$ (5 de 59) superan los $200 \mu \mathrm{g} / \mathrm{L}$.

En el muestreo M2 los porcentajes encontrados son similares a los del muestreo M1, así, un $83 \%$ (54 de 65) de los puntos de agua superan los $10 \mu \mathrm{g} / \mathrm{L}$. De estos, un $28 \%$ (18 de 65) se encuentran entre $10-50 \mu \mathrm{g} / \mathrm{L}$, un $23 \%$ (15 de 65 ) entre $50-100 \mu \mathrm{g} / \mathrm{L}$, otro $23 \%$ (15 de 65 ) se hallan en un rango de $100-200 \mu \mathrm{g} / \mathrm{L}$, y un 6\% (6 de 65) superan los $200 \mu \mathrm{g} / \mathrm{L}$.

En los mapas se observa como los puntos de agua del acuífero carbonatado son los que menores concentraciones de arsénico poseen, no llegando a superar los $10 \mu \mathrm{g} / \mathrm{L}$ y por tanto susceptibles de poder ser utilizados para el abastecimiento de poblaciones.

En el acuífero aluvial y detrítico profundo se han encontrado altos niveles de este contaminante, así las medias de concentración de arsénico de estos acuíferos aluvial y detrítico profundo respectivamente, son de $91 \mu \mathrm{g} / \mathrm{L}$ y $85 \mu \mathrm{g} / \mathrm{L}$ en el muestreo M1 y 101 $\mu \mathrm{g} / \mathrm{L}$ y $78 \mu \mathrm{g} / \mathrm{L}$ para el muestreo M2. Los valores máximos en ambos muestreos se han encontrado en el pozo P2, de uso agrícola, siendo los valores $385 \mu \mathrm{g} / \mathrm{L}$ en el muestreo M1 y $357 \mu \mathrm{g} / \mathrm{L}$ en el muestreo M2.

La representación en diagramas circulares de los iones mayoritarios $(\mathrm{Ca}, \mathrm{Mg}, \mathrm{Na}, \mathrm{K}$, $\mathrm{HCO}_{3}{ }^{-}, \mathrm{SO}_{4}{ }^{2-}, \mathrm{NO}_{3}{ }^{-} \mathrm{y} \mathrm{Cl}^{-}$) de los puntos de agua de los acuíferos aluvial y carbonatado para ambos muestreos sobre el mapa geológico (Fig. IV.15 y Fig. IV.16), nos permite saber que iones son mayoritarios en cada punto, las variaciones que se producen de unos puntos a otros o si existe alguna anomalía en algún punto concreto. En los acuíferos aluvial y carbonatado los cationes mayoritarios son calcio y magnesio, y mientras que el bicarbonato es el anión mayoritario en el acuífero carbonatado, el sulfato lo es para el acuífero aluvial. Cantidades apreciables de nitratos se pueden observar en puntos al suroeste de la zona de estudio en el muestreo $\mathrm{M} 2$, en la zona este de la zona de estudio en el muestreo M1 y en el acuífero carbonatado en ambos muestreos M1 y M2. 

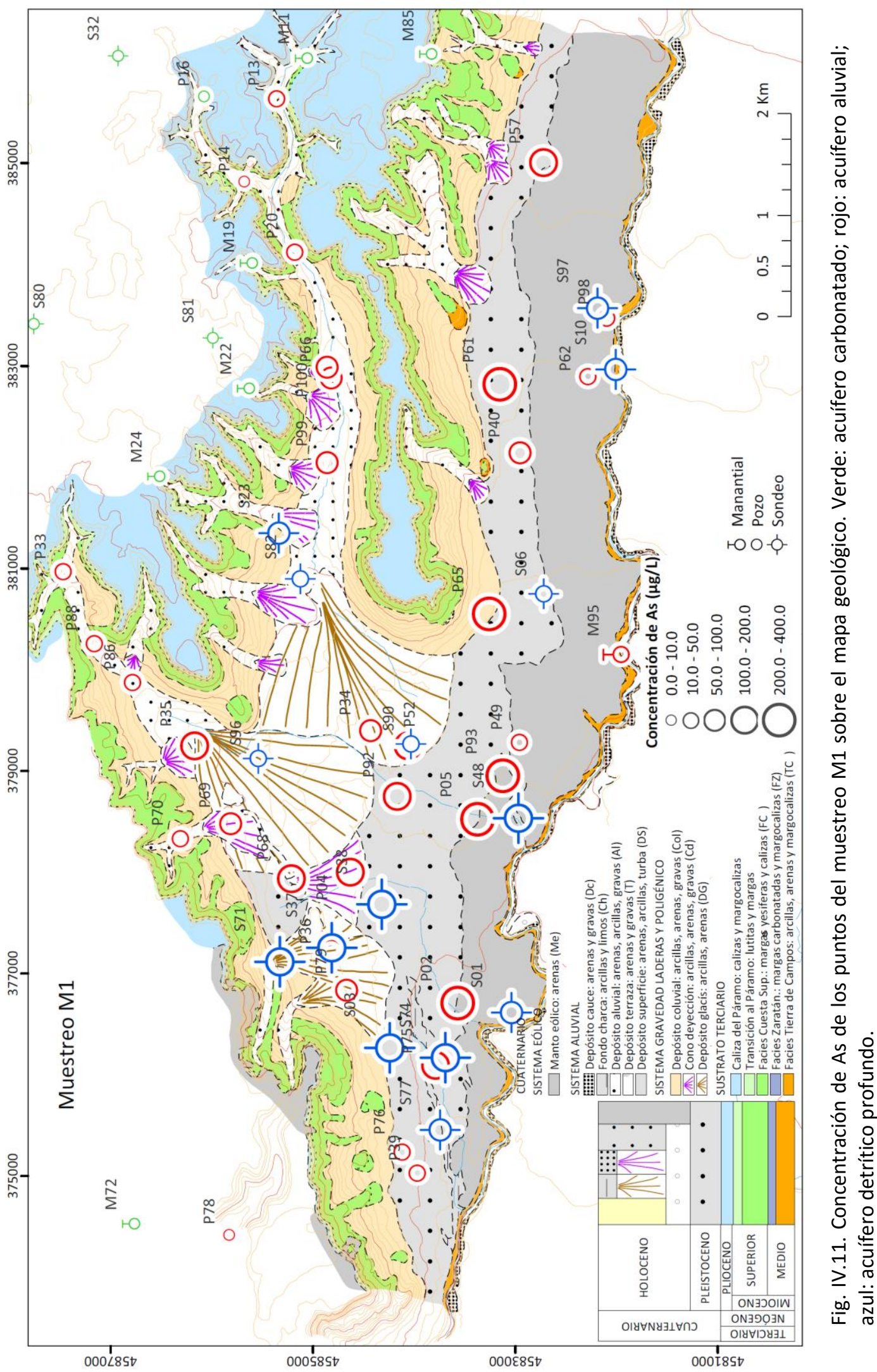


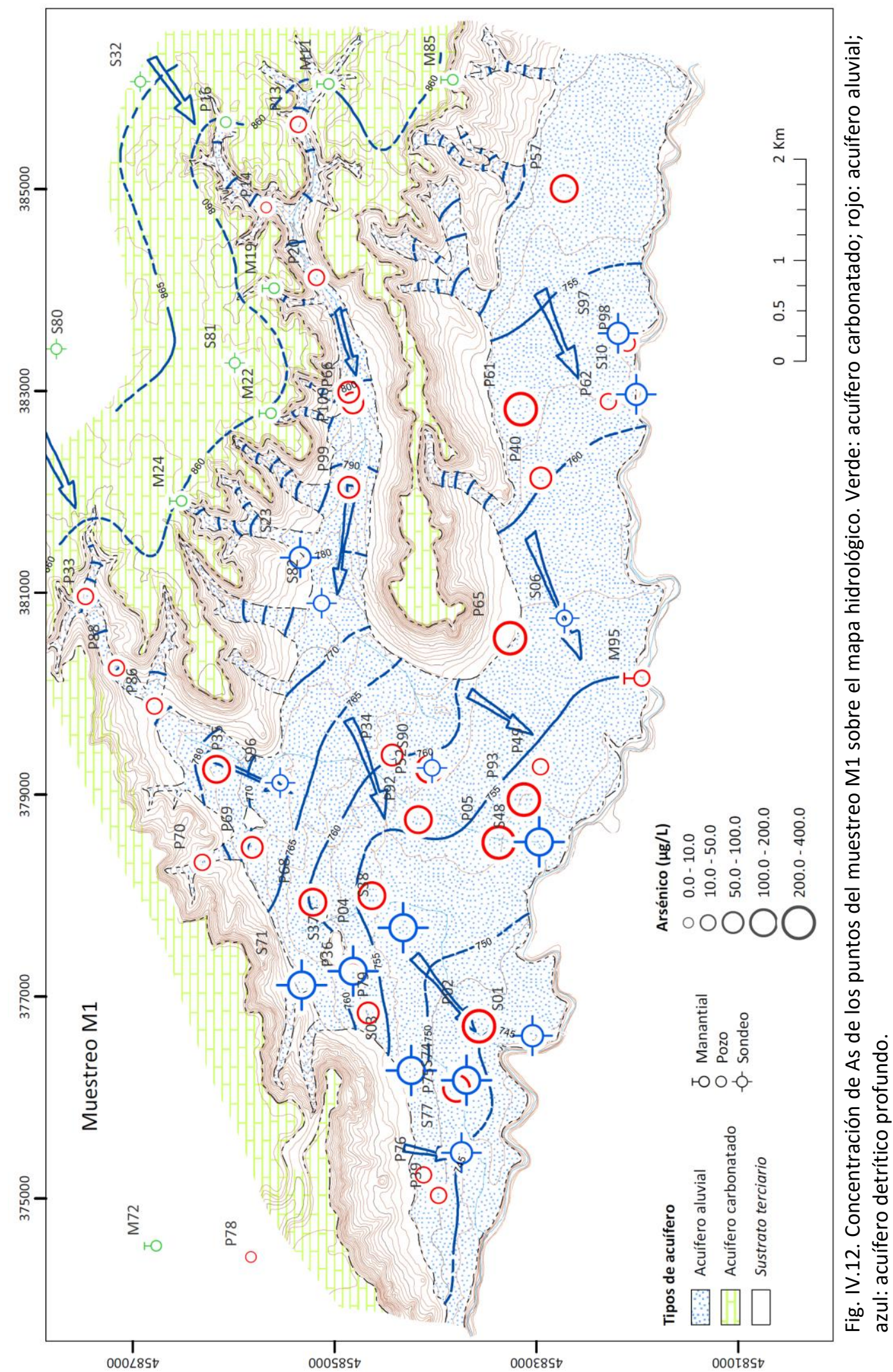



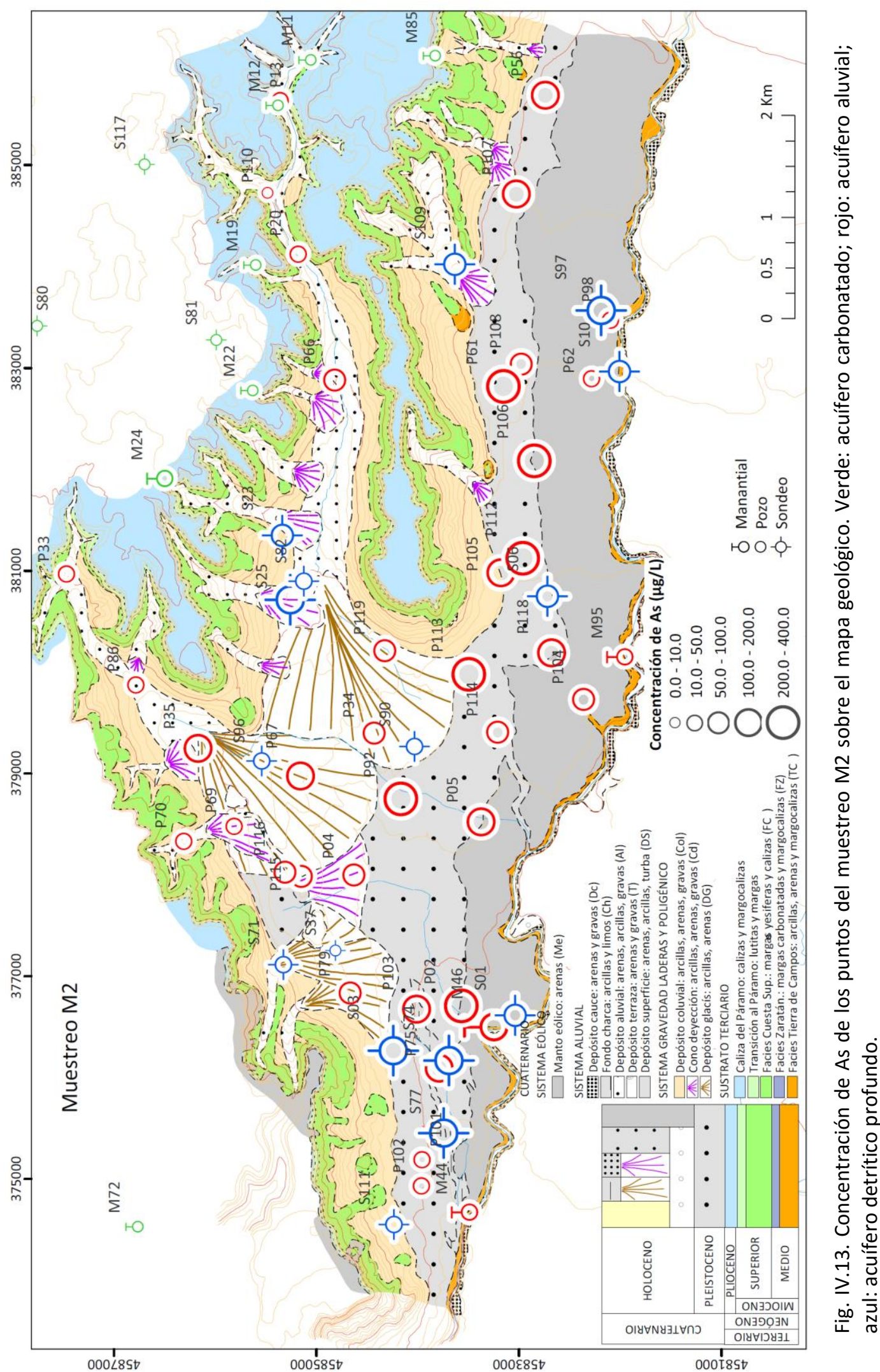


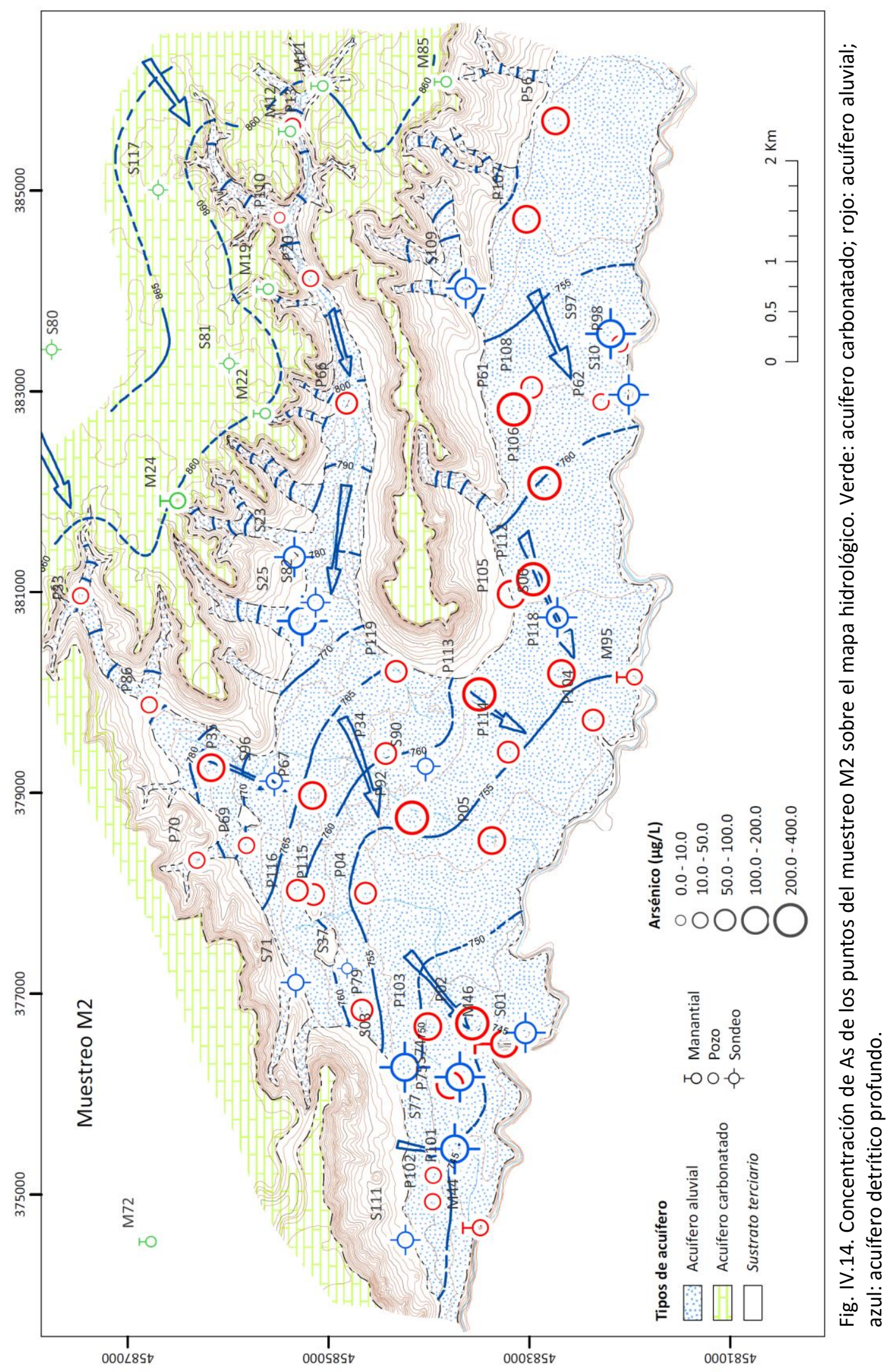




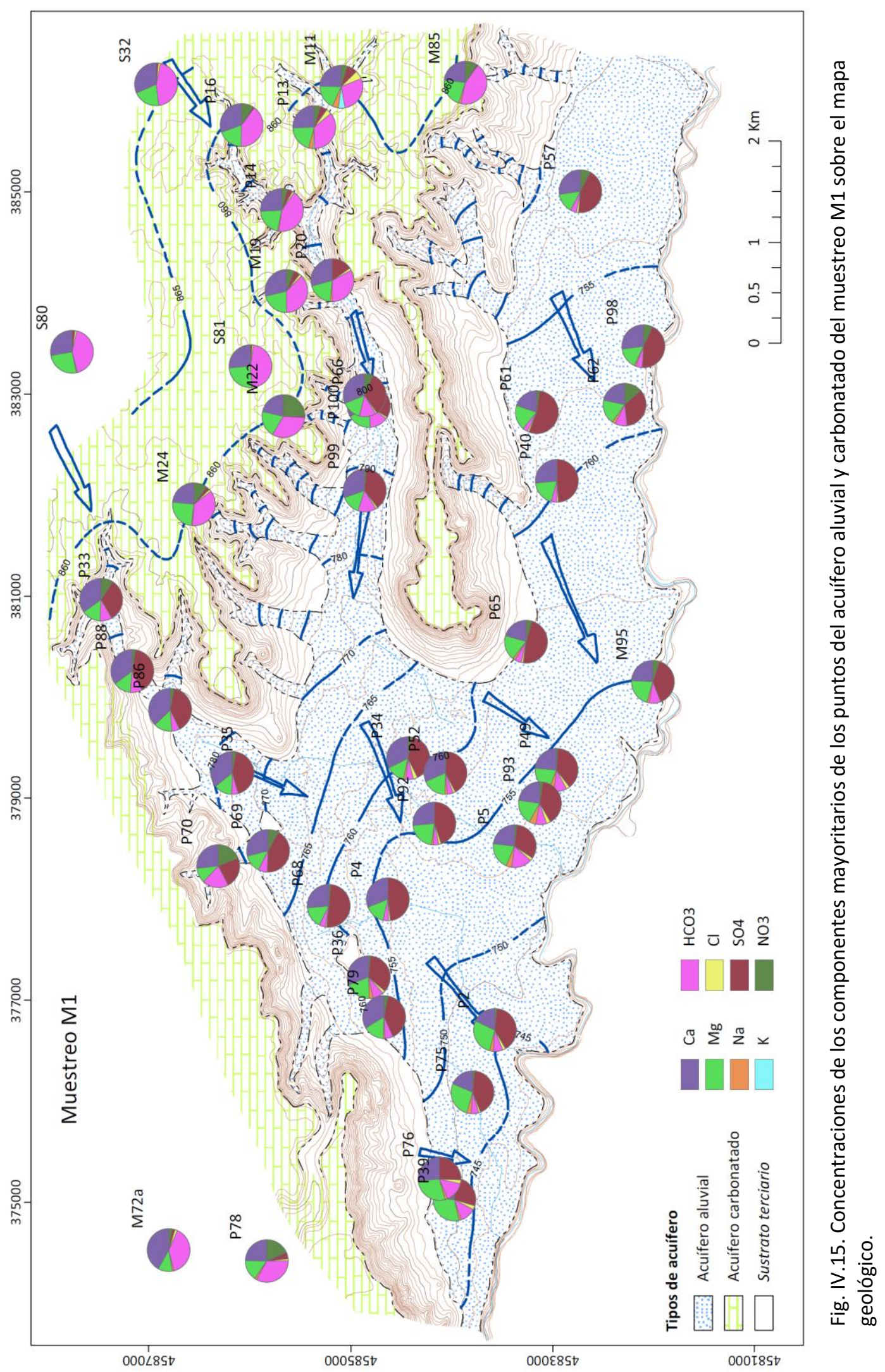




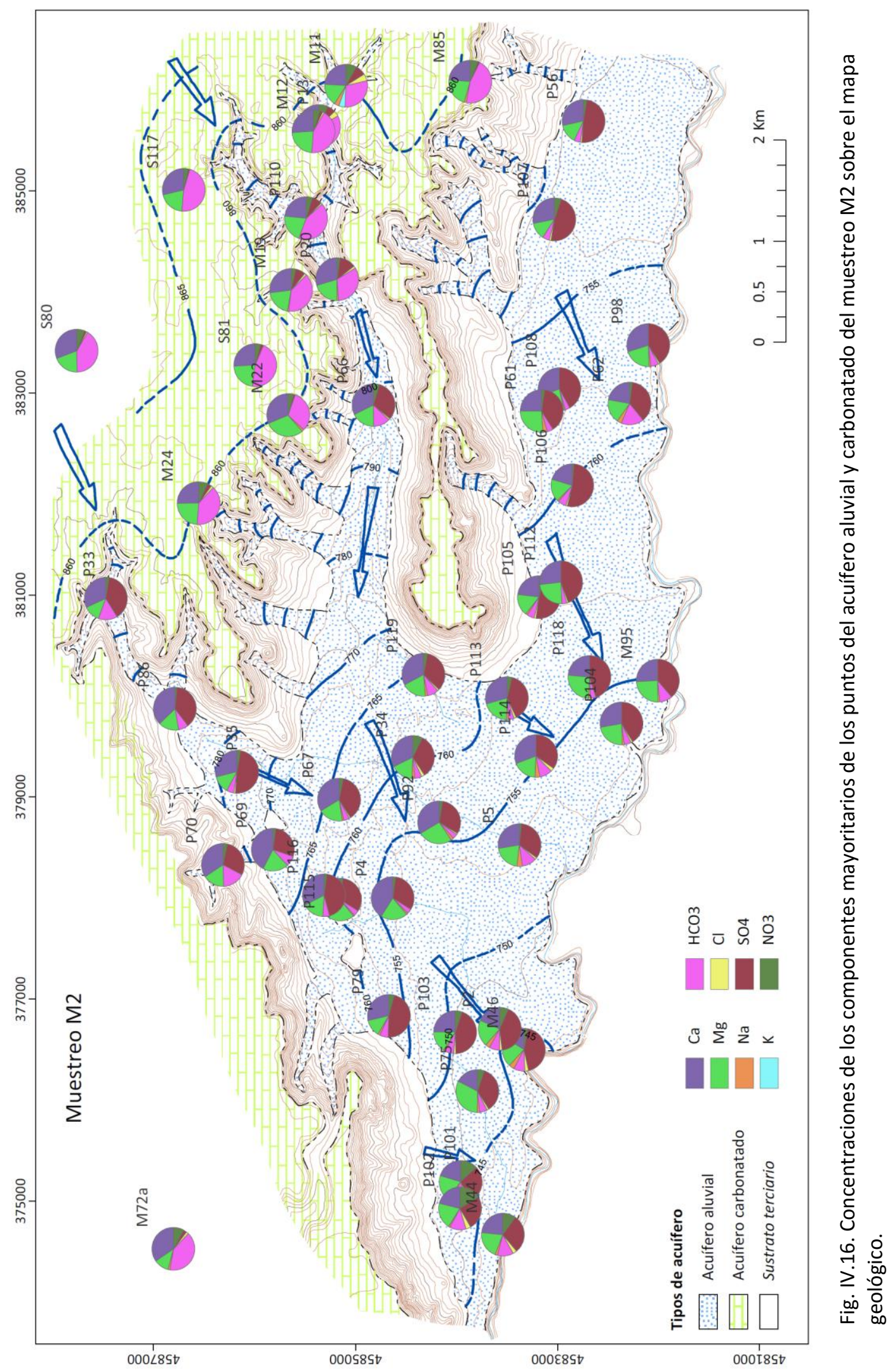




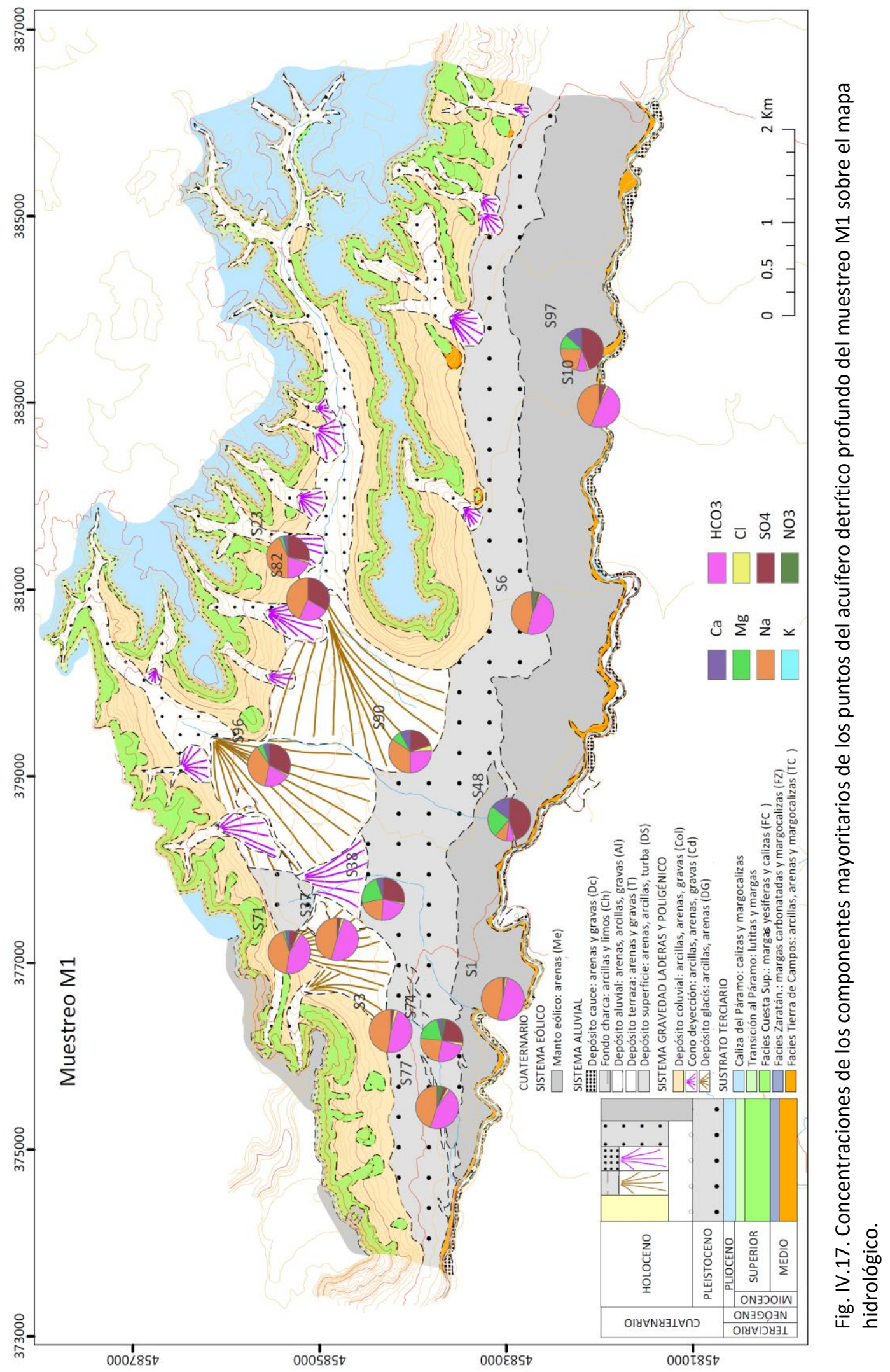




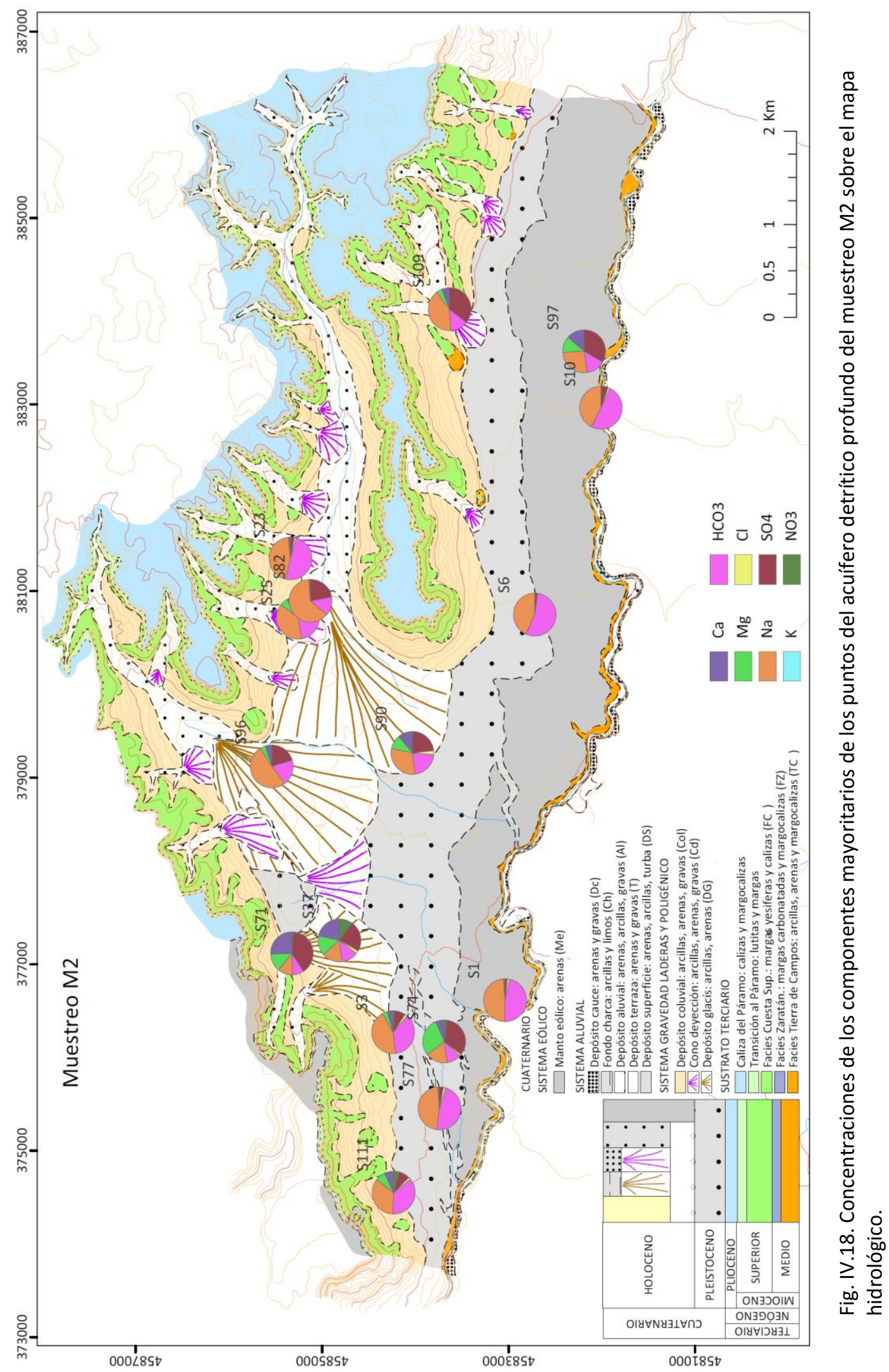


Los diagramas circulares del acuífero detrítico profundo se han representado en las Fig. IV.17 y Fig. IV.18, sobre el mapa hidrológico. La mayoría de las muestras presentan aguas bicarbonatadas sódicas, sin embargo existen varios puntos con cantidades significativas de sulfatos, calcio y magnesio.

\section{IV.4.2. ESTADÍSTICA DESCRIPTIVA}

Antes de abordar análisis estadísticos más complejos, se han obtenido, para cada uno de los parámetros físico-químicos medidos en ambos muestreos, algunos estadísticos que proporcionan información sobre la tendencia central, la dispersión y la forma de las distribuciones de las variables investigadas. Dichos estadísticos se resumen en la Tabla IV.5 y en la Tabla IV.6.

Como medidas de tendencia central se han incluido la media y la mediana; como parámetros de dispersión se muestran la desviación estándar y los valores mínimo y máximo que presenta la variable; los coeficientes de curtosis y asimetría dan idea de la forma de la distribución de los datos. El valor $\mathrm{p}$ obtenido en la prueba de normalidad de Kolmogorov-Smirnov nos ha permitido establecer si las variables analizadas siguen o no una distribución normal. En negrita se han señalado las variables que siguen una distribución normal.

Para todos los cálculos estadísticos realizados se ha asignado valor cero a todos aquellos valores por debajo del límite de detección.

Tabla IV.5. Parámetros estadísticos de las variables físico-químicas determinadas en el Muestreo 1.

\begin{tabular}{lrrrrrrrr}
\multicolumn{7}{c}{ MUESTREO 1 } \\
\hline Parámetro & Media & Mediana & Desv estándar & Curtosis & Asimetría & Mínimo & Máximo & Valor p \\
\hline $\mathrm{T}$ & 17,2 & 16,2 & 3,84 & 3,93 & 1,61 & 12,6 & 32,90 & $\mathbf{0 , 1 7 4}$ \\
$\mathrm{C} . \mathrm{E}$ & 1366 & 1214 & 907,74 & $-0,75$ & 0,69 & 306 & 3443 & $\mathbf{0 , 1 1 2}$ \\
$\mathrm{O} . \mathrm{D}$ & 7,35 & 7,90 & 2,99 & 0,58 & 0,18 & 0,80 & 17,10 & $\mathbf{0 , 2 9 7}$ \\
$\mathrm{pH}$ & 7,74 & 7,48 & 0,76 & 0,23 & 0,96 & 6,27 & 9,47 & 0,010 \\
$\mathrm{Cl}^{-}$ & 23,6 & 14,2 & 22,11 & 2,46 & 1,61 & 3,4 & 99,2 & 0,033 \\
$\mathrm{HCO}_{3}{ }^{-}$ & 290,7 & 284,2 & 85,81 & 3,48 & 1,29 & 140,1 & 633,4 & $\mathbf{0 , 3 7 0}$ \\
$\mathrm{SO}_{4}{ }^{2-}$ & 692,3 & 468,2 & 715,70 & $-0,70$ & 0,78 & 6,5 & 2218 & 0,023 \\
$\mathrm{~F}^{-}$ & 1,1 & 0,9 & 0,75 & 11,34 & 2,98 & 0,3 & 4,6 & $\mathbf{0 , 0 5 7}$ \\
$\mathrm{NO}_{3}{ }^{-}$ & 79,3 & 53,1 & 89,91 & 1,88 & 1,53 & 0,0 & 386,6 & 0,012 \\
$\mathrm{P}$ & 0,1 & 0,0 & 0,16 & 19,30 & 4,22 & 0,0 & 0,9 & 0,000 \\
$\mathrm{Ca}^{-13}$ & 198,8 & 132,0 & 175,01 & $-0,81$ & 0,64 & 0,9 & 566,0 & $\mathbf{0 , 1 0 1}$ \\
$\mathrm{Mg}$ & 85,0 & 63,0 & 75,64 & 0,58 & 1,03 & 0,0 & 303,0 & $\mathbf{0 , 1 6 0}$ \\
$\mathrm{Na}$ & 47,1 & 16,1 & 55,73 & 0,60 & 1,28 & 2,0 & 213,0 & 0,000 \\
$\mathrm{~K}$ & 3,9 & 2,1 & 6,63 & 28,47 & 4,86 & 0,0 & 46,0 & 0,000 \\
$\mathrm{As}$ & 74,9 & 51,5 & 75,14 & 4,43 & 1,81 & 2,0 & 384,7 & $\mathbf{0 , 0 7 8}$ \\
$\mathrm{Fe}$ & 47,9 & 10,3 & 92,12 & 6,87 & 2,72 & 0,0 & 404,1 & 0,000 \\
$\mathrm{Mn}$ & 12,1 & 0,3 & 29,99 & 8,93 & 3,04 & 0,0 & 145,6 & 0,000 \\
$\mathrm{Mo}$ & 3,0 & 1,5 & 5,42 & 26,96 & 4,59 & 0,0 & 37,0 & 0,000 \\
\hline
\end{tabular}


Tabla IV.6. Parámetros estadísticos de las variables físico-químicas determinadas en el Muestreo 2.

\begin{tabular}{lrrrrrrrr}
\multicolumn{7}{c}{ MUESTREO 2 } \\
\hline Parámetro & Media & Mediana & Desv estándar & Curtosis & Asimetría & Mínimo & Máximo & Valor p \\
\hline $\mathrm{T}$ & 16,42 & 15,10 & 3,54 & $-0,70$ & 0,71 & 11,90 & 24,20 & $\mathbf{0 , 0 9 6}$ \\
$\mathrm{C} . \mathrm{E}$ & 1314 & 1186 & 874,81 & $-1,12$ & 0,46 & 227 & 3125 & $\mathbf{0 , 2 0 6}$ \\
$\mathrm{O} . \mathrm{D}$ & 6,47 & 6,30 & 3,66 & 1,97 & 1,00 & 0,90 & 20,00 & $\mathbf{0 , 7 2 2}$ \\
$\mathrm{pH}$ & 7,78 & 7,57 & 0,73 & 0,44 & 1,13 & 6,72 & 9,75 & 0,035 \\
$\mathrm{Cl}^{-}$ & 25,1 & 20,3 & 21,59 & 0,89 & 1,09 & 2,0 & 94,7 & 0,036 \\
$\mathrm{HCO}_{3}{ }^{-}$ & 319,5 & 304,5 & 97,88 & 6,10 & 2,09 & 195,4 & 732,2 & $\mathbf{0 , 0 9 9}$ \\
$\mathrm{SO}_{4}{ }^{2-}$ & 885,8 & 632,9 & 831,74 & $-1,13$ & 0,52 & 6,6 & 2862,9 & $\mathbf{0 , 0 6 2}$ \\
$\mathrm{SiO}_{2}$ & 39,9 & 38,9 & 20,68 & $-1,19$ & 0,14 & 9,0 & 84,1 & $\mathbf{0 , 3 6 5}$ \\
$\mathrm{F}^{-}$ & 1,1 & 0,9 & 0,88 & 23,55 & 4,42 & 0,3 & 6,4 & 0,000 \\
$\mathrm{NO}_{3}{ }^{-}$ & 99,2 & 57,4 & 112,44 & 1,49 & 1,42 & 0,0 & 488,6 & 0,004 \\
$\mathrm{NO}_{2}{ }^{-}$ & 0,3 & 0,0 & 1,26 & 47,52 & 6,71 & 0,0 & 9,5 & 0,000 \\
$\mathrm{P}$ & 0,1 & 0,0 & 0,35 & 25,89 & 4,99 & 0,0 & 2,2 & 0,000 \\
$\mathrm{Ca}^{-1}$ & 277,6 & 208,0 & 257,67 & 0,27 & 0,96 & 1,0 & 1020,0 & $\mathbf{0 , 0 8 6}$ \\
$\mathrm{Mg}$ & 120,5 & 91,3 & 114,25 & 0,87 & 1,16 & 0,0 & 476,0 & $\mathbf{0 , 1 2 6}$ \\
$\mathrm{Na}$ & 59,7 & 27,5 & 78,34 & 6,67 & 2,31 & 1,9 & 423,0 & 0,002 \\
$\mathrm{~K}$ & 5,3 & 2,7 & 7,55 & 11,57 & 3,01 & 0,0 & 44,9 & 0,000 \\
$\mathrm{As}$ & 81,0 & 57,6 & 75,19 & 1,60 & 1,27 & 2,5 & 357,0 & $\mathbf{0 , 0 6 1}$ \\
$\mathrm{Fe}$ & 167,9 & 29,2 & 470,57 & 31,99 & 5,24 & 0,0 & 3310,0 & 0,000 \\
$\mathrm{Mn}$ & 22,2 & 2,7 & 51,03 & 8,04 & 2,92 & 0,0 & 234,0 & 0,000 \\
$\mathrm{Mo}$ & 4,5 & 2,2 & 5,52 & 4,16 & 2,06 & 0,0 & 25,2 & 0,007 \\
$\mathrm{~V}$ & 27,5 & 24,8 & 23,42 & 1,59 & 1,31 & 0,2 & 98,3 & $\mathbf{0 , 1 2 2}$ \\
\hline & & & & & & &
\end{tabular}

La enorme dispersión que muestran algunas variables se evidencia por los altos valores de la desviación estándar, y la gran diferencia entre los valores máximo y mínimo de la variable. Dicha dispersión demuestra la gran variabilidad encontrada para la mayoría de las variables físico-químicas en el área objeto de estudio. Los coeficientes de curtosis y de asimetría dan idea de la forma de la distribución de la variable en las aguas analizadas. Así, la mayoría de las distribuciones son asimétricas con largas colas hacia los valores más altos, destacando por su asimetría las variables fosfato, nitrito, fluoruro, potasio, hierro, manganeso y molibdeno.

Un valor $p$ del test de normalidad de Kolmogorov-Smirnov superior a 0,05 (para un nivel de confianza del 95\%) nos indica que las variables siguen una distribución normal. Cuanto más pequeño sea el valor $p$, tanto más alejada de la normalidad se encontrará la distribución. Atendiendo a este estadístico, observamos en la Tabla IV.5 y en la Tabla IV.6 que los parámetros $\mathrm{pH}, \mathrm{Cl}^{-} ; \mathrm{NO}_{3}{ }^{-} ; \mathrm{NO}_{2}{ }^{-} ; \mathrm{PO}_{4}{ }^{3-}, \mathrm{Na}^{+}, \mathrm{K}^{+}, \mathrm{Fe}, \mathrm{Mn}$ y Mo no siguen una distribución normal. El resultado del test de normalidad no varía entre los muestreos, con la excepción de sulfato y fluoruro.

El hecho de que buena parte de las variables analizadas no sigan una distribución normal condicionará las técnicas estadísticas a emplear para analizar los datos experimentales, con vistas a extraer conclusiones sobre relaciones entre las variables investigadas y sobre su distribución espacio-temporal. 
Para una mejor visualización de los niveles, dispersión y forma de la distribución de los parámetros analizados, se han representado los resultados analíticos en los gráficos de cajas y bigotes (box-and-whisker plot) que se muestran en la Fig. IV.19, en los que se han agrupado los resultados por muestreo y por unidad hidrológica, para mostrar más claramente las similitudes y diferencias entre las dos campañas de muestreo y/o entre las tres unidades del acuífero existentes en el área del estudio.

Se observa que la temperatura del acuífero profundo se mantiene prácticamente constante en ambos muestreos y que supera en unos $5^{\circ} \mathrm{C}$ a los otros dos acuíferos. En los acuíferos superficiales (aluvial y carbonatado), la mayoría de puntos de muestreo se corresponden con pozos de riego poco profundos y por tanto más influenciados por las variaciones estacionales de la temperatura del aire.

$\mathrm{El} \mathrm{pH}$ en los acuíferos aluvial y carbonatado no supera un valor de 8 y presenta poca dispersión en sus valores, mientras que el acuífero detrítico profundo presenta valores mucho más dispersos y cercanos a 9.

La conductividad en el acuífero aluvial muestra una gran dispersión, con los valores medios cercanos a $2000 \mu \mathrm{S} / \mathrm{cm}$, mientas que los acuíferos carbonatado y detrítico profundo presentan menor dispersión y valores inferiores a $1000 \mu \mathrm{S} / \mathrm{cm}$, a excepción de algún punto anómalo. La mayor salinidad del acuífero aluvial queda evidenciada por la concentración significativamente mayor de cloruro, sulfato, sílice, nitrato, calcio y magnesio en esas aguas.

La concentración de oxígeno disuelto es ligeramente inferior en el acuífero detrítico profundo. Hay que tener en cuenta que en los otros acuíferos los puntos de agua son superficiales (pozos y manantiales) y están en contacto directo con la atmósfera, lo que justifica un mayor contenido de O.D.

La concentración de nitrito y de fosfato es muy baja en las tres unidades hidrogeológicas. No obstante, en el acuífero aluvial se observan algunos valores anormalmente elevados de ambos parámetros, probablemente asociados a episodios de contaminación puntual de origen antropogénico, dado que la zona está sometida a intensa actividad agrícola y ganadera, el uso de fertilizantes inorgánicos (N-P-K) y orgánicos (purines) puede provocar niveles altos puntuales de estos contaminantes.

La concentración de bicarbonato está en torno a los $300 \mathrm{mg} / \mathrm{L}$ en los tres acuíferos, siendo el acuífero carbonatado el que presenta mayores valores.

El sodio presenta niveles muy superiores en el acuífero detrítico profundo. Por su parte, el potasio presenta valores en general bajos, aunque ligeramente superiores en el acuífero aluvial. Esta variable muestra diversos valores anormalmente elevados que, como en el caso del fósforo, podrían ser justificados por el uso de fertilizantes N-P-K.

El cuanto al arsénico, los niveles y dispersión de valores en los acuíferos detrítico profundo y aluvial son similares, y muy superiores a las concentraciones halladas en las muestras de agua del acuífero carbonatado. 
Temperatura

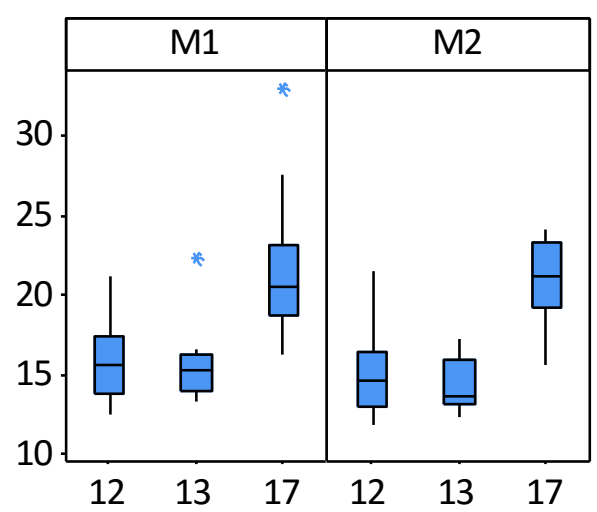

C.E

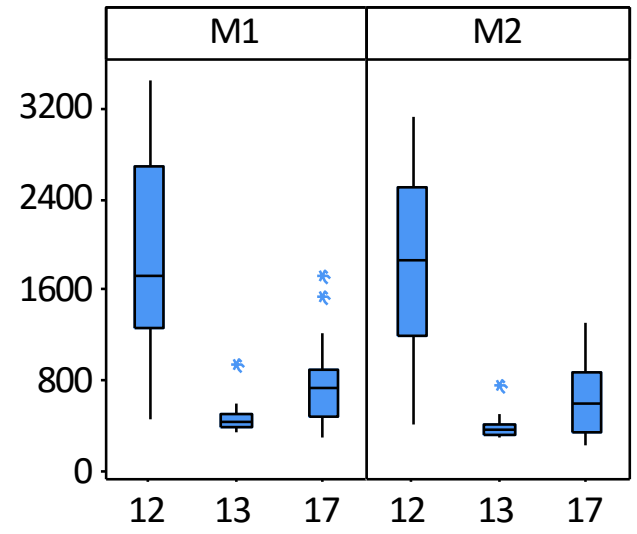

Sulfato

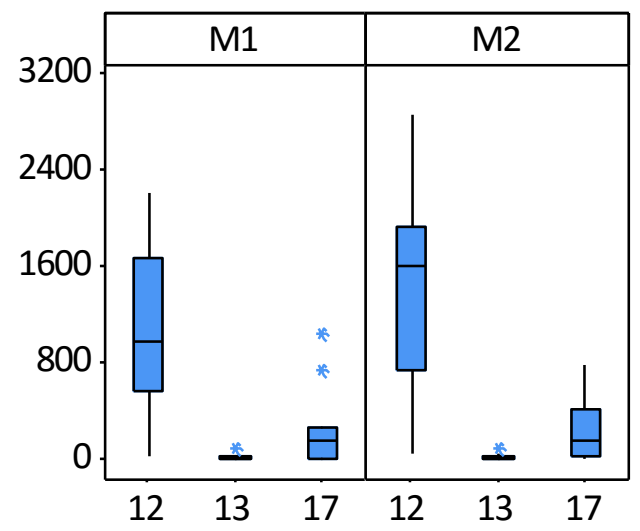

$\mathrm{pH}$

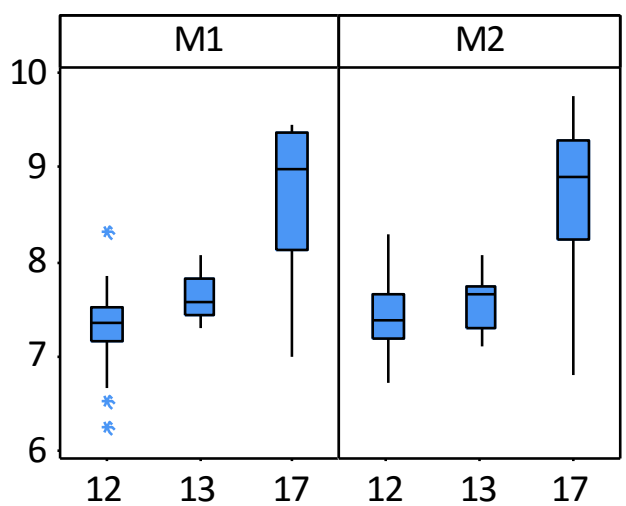

O.D

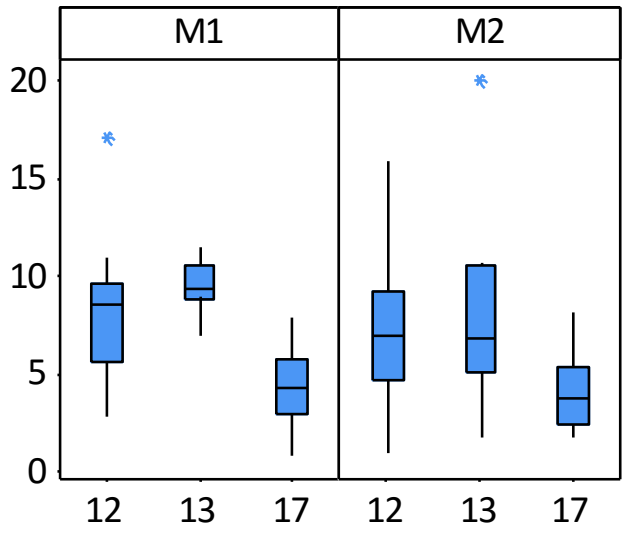

Bicarbonato

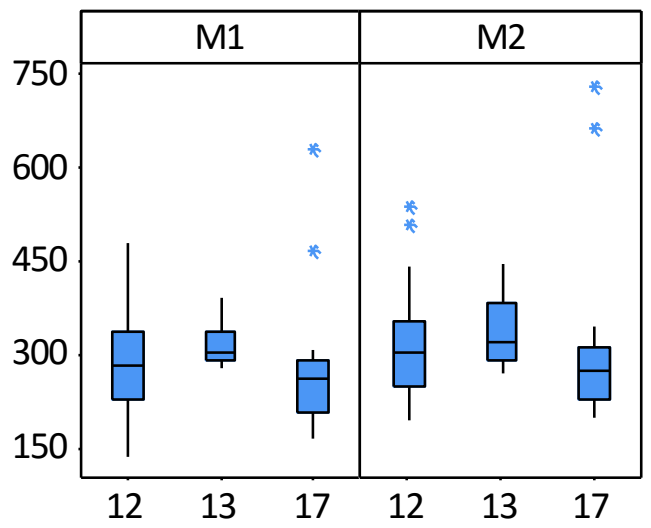

Fig. IV.19. Gráficos box-plot de los parámetros analizados. M1: Muestreo 1; M2: Muestreo 2; 12: Acuífero Aluvial; 13: Acuífero Carbonatado; 17: Acuífero Detrítico Profundo 
Cloruro

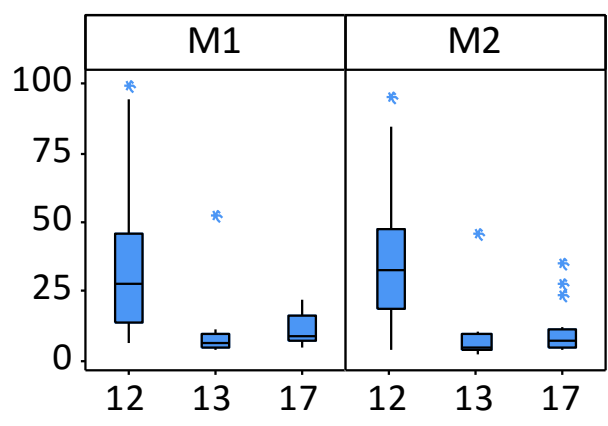

Nitrato

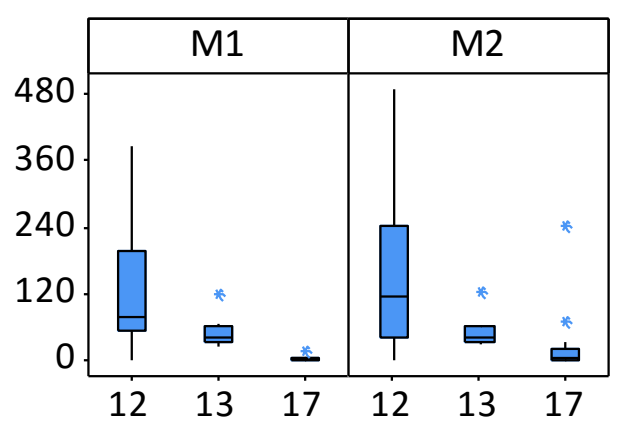

Silice

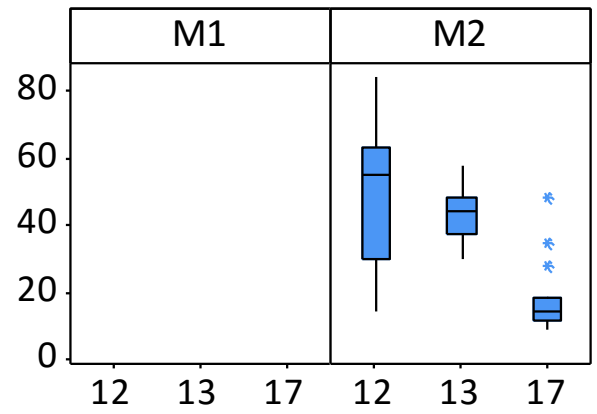

Calcio

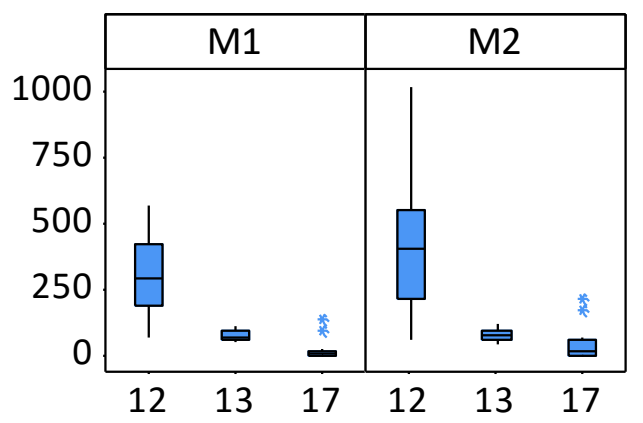

Fluoruro

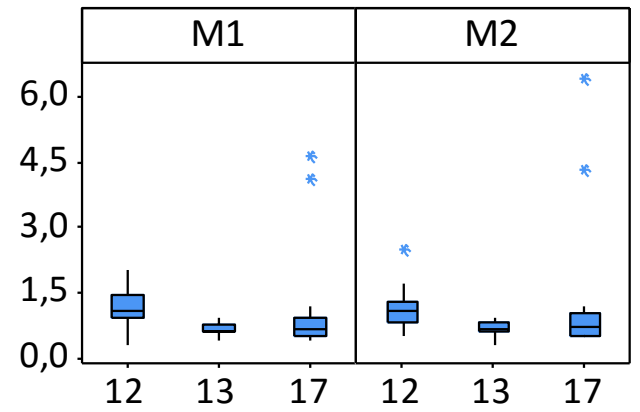

Nitrito

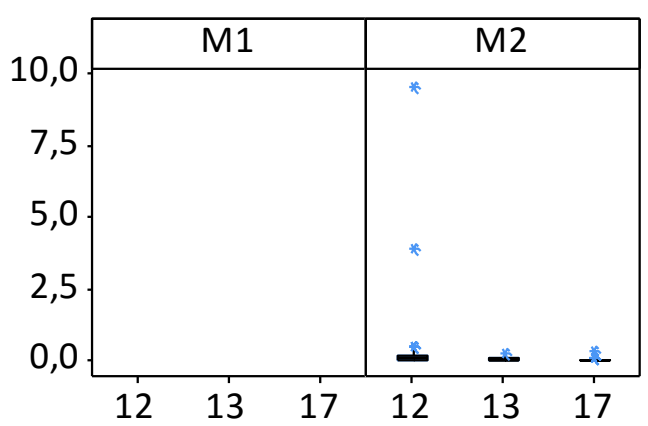

Fosfato

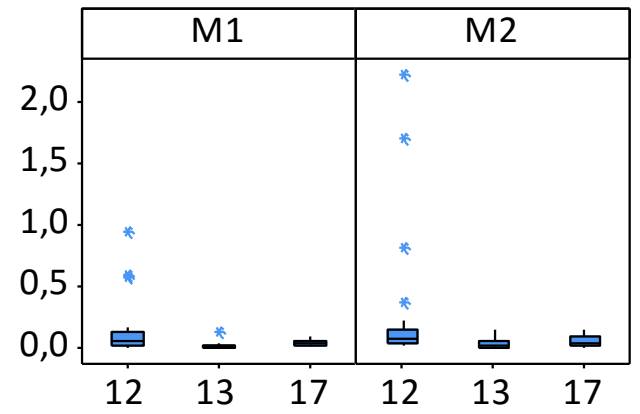

Magnesio

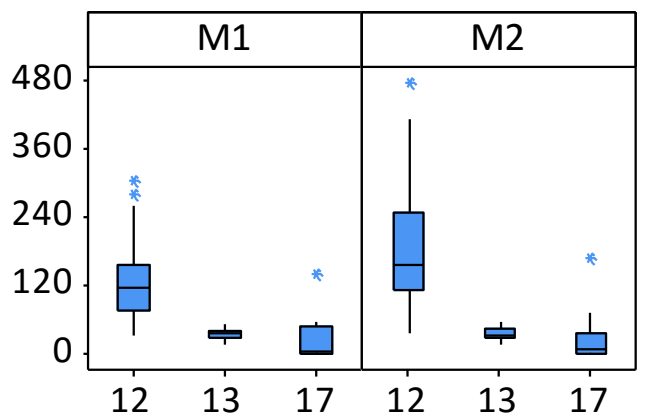

Fig. IV.19. Continuación 

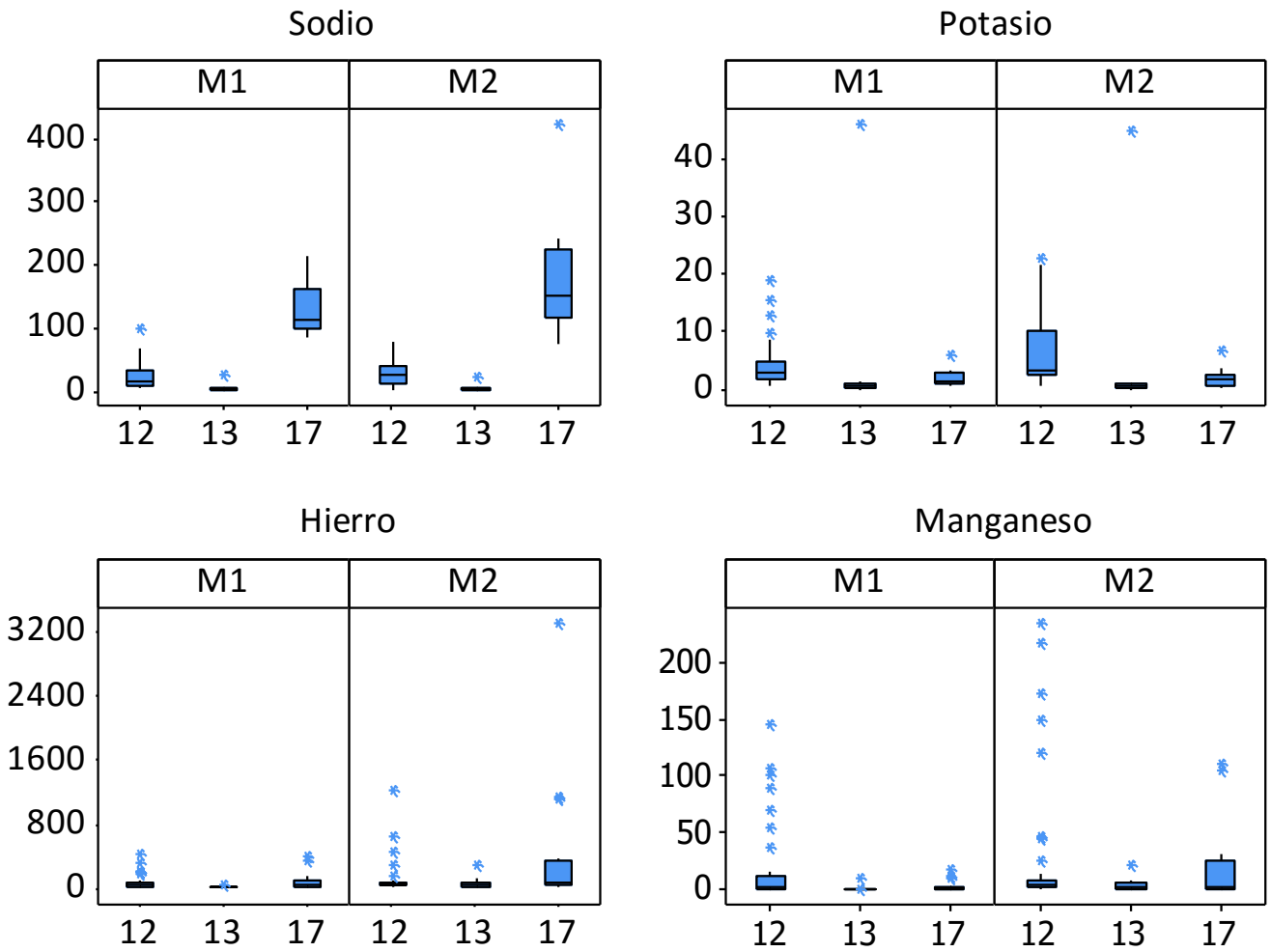

Arsénico

Molibdeno
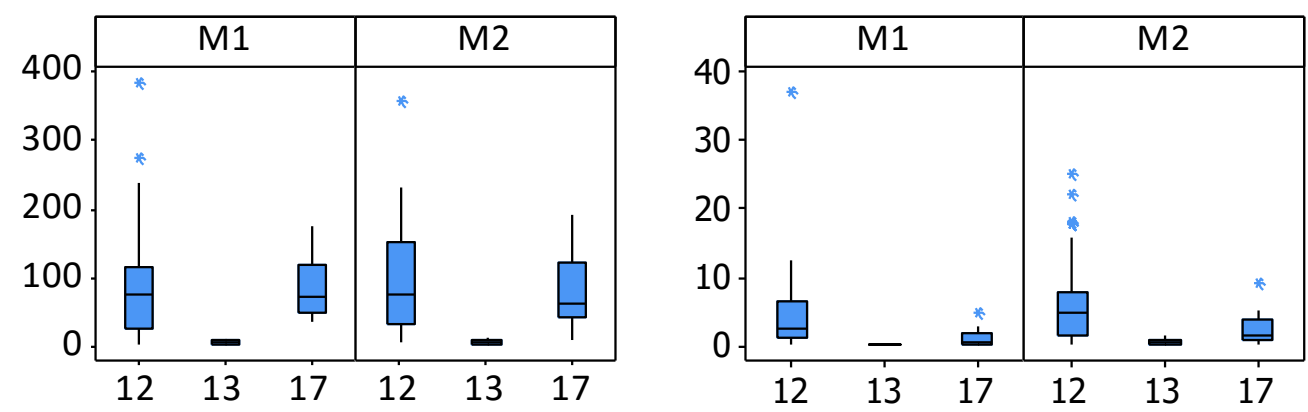

Vanadio

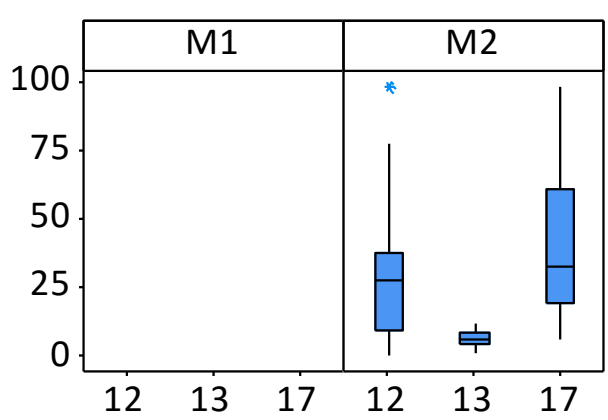

Fig. IV.19. Continuación 
A grandes rasgos, se puede observar que la forma de las distribuciones de las variables analizadas y los rangos de valores que presentan son similares en ambos muestreos. No obstante, debe comprobarse si la variación es significativa. Para ello se ha procedido a comparar los puntos comunes a ambos muestreos para cada uno de los parámetros analizados, mediante una prueba de significación de medidas emparejadas. Se ha realizado la prueba de significación no paramétrica de Wilcoxon, para todos los parámetros excepto para el O.D, dado que las diferencias entre ambos muestreos no siguen una distribución normal. Para el O.D se ha realizado la prueba t-student ya que las diferencias entre ambos muestreos son normales (prueba de Shapiro-Wilk, valor $p>0,05)$. La Tabla IV.7 recoge los valores $p$ obtenidos, que demuestran que existen diferencias significativas entre los dos muestreos para la mayoría de variables $(p<0,05$, resaltados en rojo). No es por tanto recomendable mezclar los resultados de ambos muestreos para tener una única matriz de datos, por lo que analizaremos los resultados de los dos muestreos por separado.

Tabla IV.7. Prueba no paramétrica de Wilcoxon.

\begin{tabular}{lr} 
Parámetro & Valor $\mathbf{p}$ \\
\hline $\mathrm{T}$ & 0,012 \\
$\mathrm{C} . \mathrm{E}$ & 0,000 \\
$\mathrm{O} . \mathrm{D}$ & 0,012 \\
$\mathrm{pH}$ & 0,961 \\
$\mathrm{Cl}$ & 0,030 \\
$\mathrm{NO}_{3}{ }^{-}$ & 0,006 \\
$\mathrm{SO}_{4}{ }^{2-}$ & 0,073 \\
$\mathrm{P}^{-}$ & 0,045 \\
$\mathrm{HCO}_{3}$ & 0,000 \\
$\mathrm{~F}^{-}$ & 0,754 \\
$\mathrm{Ca}^{2+}$ & 0,006 \\
$\mathrm{~K}^{+}$ & 0,308 \\
$\mathrm{Mg}^{2+}$ & 0,011 \\
$\mathrm{Na}^{+}$ & 0,002 \\
$\mathrm{As}$ & 0,946 \\
$\mathrm{Fe}$ & 0,011 \\
$\mathrm{Mn}$ & 0,016 \\
$\mathrm{Mo}$ & 0,100 \\
\hline
\end{tabular}

Para comprobar si son significativas las diferencias composicionales observadas entre las muestras de agua procedentes de los tres acuíferos existentes en la zona de estudio, se han utilizado dos técnicas estadísticas diferentes. Así, si la variable sigue una distribución normal y hay homogeneidad de varianzas entre los tres acuíferos, realizaremos una prueba ANOVA, mientras que si las varianzas son inhomogéneas se aplicará una prueba robusta de medias. Por el contrario, si la variable no sigue una distribución normal, la prueba a aplicar será el test no paramétrico de Kruskal-Wallis. 
La Tabla IV.8 y Tabla IV.9 resume los valores $\mathrm{p}$ obtenidos para la prueba de homogeneidad de varianzas, el ANOVA, la prueba robusta de medias y el test de KruskalWallis. También se muestran los valores $p$ obtenidos en los test de significación aplicados para identificar el nivel del factor, es decir, el acuífero, responsable de las diferencias. En todos los casos, un valor $p$ inferior a 0,05 demuestra que la diferencia introducida por el factor/nivel es significativa (SPSS, tutorial).

Tabla IV.8.Diferencias entre las tres unidades hidrológicas en el muestreo M1.

\begin{tabular}{|c|c|c|c|c|c|c|c|c|}
\hline \multirow[b]{2}{*}{ Parámetro } & \multicolumn{2}{|c|}{$\begin{array}{l}\text { HOMOGENEIDAD } \\
\text { DE VARIANZAS }\end{array}$} & \multicolumn{2}{|l|}{$\begin{array}{l}\text { ¿FACTOR ACUÍFERO } \\
\text { SIGNIFICATIVO? }\end{array}$} & \multicolumn{4}{|c|}{ DIFERENCIAS ENTRE ACUÍFEROS } \\
\hline & $\begin{array}{c}\text { Distribución } \\
\text { normal }\end{array}$ & valor $p$ & prueba & valor $\mathbf{p}$ & Dif. & Prueba & valor $\mathbf{p}$ & Dif \\
\hline T & SI & 0,162 & ANOVA & 0,000 & SI & Scheffé & $\begin{array}{l}0,998 \\
0,000 \\
0,000\end{array}$ & $\begin{array}{l}12=13 \\
12 \neq 17 \\
13 \neq 17\end{array}$ \\
\hline C.E & SI & 0,000 & $\begin{array}{l}\text { Robusta de } \\
\text { medias }\end{array}$ & 0,000 & SI & $\begin{array}{l}\text { T3 de } \\
\text { Dunnett }\end{array}$ & $\begin{array}{l}0,000 \\
0,000 \\
0,046\end{array}$ & $\begin{array}{l}12 \neq 13 \\
12 \neq 17 \\
13 \neq 17\end{array}$ \\
\hline O.D & SI & 0,044 & $\begin{array}{l}\text { Robusta de } \\
\text { medias }\end{array}$ & 0,000 & SI & $\begin{array}{l}\text { T3 de } \\
\text { Dunnett }\end{array}$ & $\begin{array}{l}0,064 \\
0,000 \\
0,000\end{array}$ & $\begin{array}{l}12=13 \\
12 \neq 17 \\
13 \neq 17\end{array}$ \\
\hline $\mathrm{pH}$ & NO & 0,001 & Kruskal-Wallis & 0,000 & SI & $\begin{array}{l}\text { Mann- } \\
\text { Whitney }\end{array}$ & $\begin{array}{l}0,009 \\
0,000 \\
0,002\end{array}$ & $\begin{array}{l}12 \neq 13 \\
12 \neq 17 \\
13 \neq 17\end{array}$ \\
\hline $\mathrm{Cl}^{-}$ & NO & 0,001 & Kruskal-Wallis & 0,000 & SI & $\begin{array}{l}\text { Mann- } \\
\text { Whitney }\end{array}$ & $\begin{array}{l}0,000 \\
0,000 \\
0,103\end{array}$ & $\begin{array}{l}12 \neq 13 \\
12 \neq 17 \\
13=17\end{array}$ \\
\hline $\mathrm{NO}_{3}^{-}$ & NO & 0,000 & Kruskal-Wallis & 0,000 & SI & $\begin{array}{l}\text { Mann- } \\
\text { Whitney }\end{array}$ & $\begin{array}{l}0,019 \\
0,000 \\
0,000\end{array}$ & $\begin{array}{l}12 \neq 13 \\
12 \neq 17 \\
13 \neq 17\end{array}$ \\
\hline $\mathrm{SO}_{4}{ }^{2-}$ & NO & 0,000 & Kruskal-Wallis & 0,000 & SI & $\begin{array}{l}\text { Mann- } \\
\text { Whitney }\end{array}$ & $\begin{array}{l}0,000 \\
0,000 \\
0,008\end{array}$ & $\begin{array}{l}12 \neq 13 \\
12 \neq 17 \\
13 \neq 17\end{array}$ \\
\hline$P$ & NO & 0,028 & Kruskal-Wallis & 0,002 & SI & $\begin{array}{l}\text { Mann- } \\
\text { Whitney }\end{array}$ & $\begin{array}{l}0,001 \\
0,067 \\
0,076\end{array}$ & $\begin{array}{l}12 \neq 13 \\
12=17 \\
13=17\end{array}$ \\
\hline $\mathrm{HCO}_{3}$ & sì & 0,134 & Anova & 0,555 & NO & . & & \\
\hline $\mathrm{F}^{-}$ & SI & 0,002 & $\begin{array}{l}\text { Robusta de } \\
\text { medias }\end{array}$ & 0,275 & NO & & & \\
\hline $\mathrm{Ca}$ & SI & 0,000 & $\begin{array}{l}\text { Robusta de } \\
\text { medias }\end{array}$ & 0,000 & SI & $\begin{array}{l}\text { T3 de } \\
\text { Dunnett }\end{array}$ & $\begin{array}{l}0,000 \\
0,000 \\
0,001\end{array}$ & $\begin{array}{l}12 \neq 13 \\
12 \neq 17 \\
13 \neq 17\end{array}$ \\
\hline K & NO & 0,005 & Kruskal-Wallis & 0,000 & SI & $\begin{array}{l}\text { Mann- } \\
\text { Whitney }\end{array}$ & $\begin{array}{l}0,000 \\
0,005 \\
0,013\end{array}$ & $\begin{array}{l}12 \neq 13 \\
12 \neq 17 \\
13 \neq 17\end{array}$ \\
\hline $\mathrm{Mg}$ & SI & 0,001 & $\begin{array}{l}\text { Robusta de } \\
\text { medias }\end{array}$ & 0,000 & SI & $\begin{array}{c}\text { T3 de } \\
\text { Dunnett }\end{array}$ & $\begin{array}{l}0,000 \\
0,000 \\
0,573\end{array}$ & $\begin{array}{l}12 \neq 13 \\
12 \neq 17 \\
13=17\end{array}$ \\
\hline $\mathrm{Na}$ & NO & 0,000 & Kruskal-Wallis & 0,000 & SI & $\begin{array}{l}\text { Mann- } \\
\text { Whitney }\end{array}$ & $\begin{array}{l}0,000 \\
0,000 \\
0,000\end{array}$ & $\begin{array}{l}12 \neq 13 \\
12 \neq 17 \\
13 \neq 17\end{array}$ \\
\hline
\end{tabular}


Capítulo IV. Estudio Hidroquímico

\begin{tabular}{|c|c|c|c|c|c|c|c|c|}
\hline \multirow[b]{2}{*}{ Parámetro } & \multicolumn{2}{|c|}{$\begin{array}{l}\text { HOMOGENEIDAD } \\
\text { DE VARIANZAS }\end{array}$} & \multicolumn{2}{|l|}{$\begin{array}{l}\text { ¿FACTOR ACUÍFERO } \\
\text { SIGNIFICATIVO? }\end{array}$} & \multicolumn{4}{|c|}{ DIFERENCIAS ENTRE ACUÍFEROS } \\
\hline & $\begin{array}{c}\text { Distribución } \\
\text { normal }\end{array}$ & valor $p$ & prueba & valor $p$ & Dif. & Prueba & valor $p$ & Dif \\
\hline As & $\mathrm{SI}$ & 0,002 & $\begin{array}{l}\text { Robusta de } \\
\text { medias }\end{array}$ & 0,000 & SI & $\begin{array}{l}\text { T3 de } \\
\text { Dunnett }\end{array}$ & $\begin{array}{l}0,000 \\
0,982 \\
0,000\end{array}$ & $\begin{array}{l}12 \neq 13 \\
12=17 \\
13 \neq 17\end{array}$ \\
\hline $\mathrm{Fe}$ & NO & 0,017 & Kruskal-Wallis & 0,003 & SI & $\begin{array}{l}\text { Mann- } \\
\text { Whitney }\end{array}$ & $\begin{array}{l}0,001 \\
0,837 \\
0,012\end{array}$ & $\begin{array}{l}12 \neq 13 \\
12=17 \\
13 \neq 17\end{array}$ \\
\hline $\mathrm{Mn}$ & NO & 0,000 & Kruskal-Wallis & 0,000 & SI & $\begin{array}{l}\text { Mann- } \\
\text { Whitney }\end{array}$ & $\begin{array}{l}0,000 \\
0,006 \\
0,165\end{array}$ & $\begin{array}{l}12 \neq 13 \\
12 \neq 17 \\
13=17\end{array}$ \\
\hline Mo & NO & 0,012 & Kruskal-Wallis & 0,000 & SI & $\begin{array}{l}\text { Mann- } \\
\text { Whitney }\end{array}$ & $\begin{array}{l}0,000 \\
0,007 \\
0,002\end{array}$ & $\begin{array}{l}12 \neq 13 \\
12 \neq 17 \\
13 \neq 17\end{array}$ \\
\hline
\end{tabular}

Tabla IV.9. Diferencias entre las tres unidades hidrológicas en el muestreo M2.

\begin{tabular}{|c|c|c|c|c|c|c|c|c|}
\hline \multirow[b]{2}{*}{ Parámetro } & \multicolumn{2}{|c|}{$\begin{array}{l}\text { HOMOGENEIDAD } \\
\text { DE VARIANZAS }\end{array}$} & \multicolumn{2}{|c|}{ DIFERENCIAS ENTRE ACUIFEROS } & \multicolumn{4}{|c|}{ FORMA DE LAS DIFERNCIAS } \\
\hline & $\begin{array}{c}\text { ción } \\
\text { normal }\end{array}$ & valor $\mathbf{p}$ & prueba & valor $p$ & Dif. & Prueba & valor $p$ & Dif \\
\hline \multirow{3}{*}{$\mathrm{T}$} & \multirow{3}{*}{ SI } & \multirow{3}{*}{0,331} & \multirow{3}{*}{ Anova } & \multirow{3}{*}{0,000} & \multirow{3}{*}{ SI } & \multirow{3}{*}{ Scheffé } & 0,631 & $12=13$ \\
\hline & & & & & & & 0,000 & $12 \neq 17$ \\
\hline & & & & & & & 0,000 & $13 \neq 17$ \\
\hline \multirow{3}{*}{ C.E } & \multirow{3}{*}{ SI } & \multirow{3}{*}{0,000} & \multirow{3}{*}{$\begin{array}{l}\text { Robusta de } \\
\text { medias }\end{array}$} & \multirow{3}{*}{0,000} & \multirow{3}{*}{ SI } & \multirow{3}{*}{$\begin{array}{c}\text { T3 de } \\
\text { Dunnett }\end{array}$} & 0,000 & $12 \neq 13$ \\
\hline & & & & & & & 0,000 & $12 \neq 17$ \\
\hline & & & & & & & 0,060 & $13=17$ \\
\hline \multirow{3}{*}{ O.D } & \multirow{3}{*}{ SI } & \multirow{3}{*}{0,080} & \multirow{3}{*}{ Anova } & \multirow{3}{*}{0,003} & \multirow{3}{*}{ SI } & \multirow{3}{*}{ Scheffé } & 0,688 & $12=13$ \\
\hline & & & & & & & 0,023 & $12 \neq 17$ \\
\hline & & & & & & & 0,022 & $13 \neq 17$ \\
\hline \multirow{3}{*}{$\mathrm{pH}$} & \multirow{3}{*}{ NO } & \multirow{3}{*}{0,734} & \multirow{3}{*}{ Kruskal-Wallis } & \multirow{3}{*}{0,000} & & & 0,054 & $12=13$ \\
\hline & & & & & SI & Mann- & 0,000 & $12 \neq 17$ \\
\hline & & & & & & vinitney & 0,001 & $13 \neq 17$ \\
\hline & & & & & & & 0,000 & $12 \neq 13$ \\
\hline $\mathrm{Cl}^{-}$ & NO & 0,006 & Kruskal-Wallis & 0,000 & SI & Mann- & 0,000 & $12 \neq 17$ \\
\hline & & & & & & & 0,206 & $13=17$ \\
\hline & & & & & & & 0,026 & $12 \neq 13$ \\
\hline $\mathrm{NO}_{3}^{-}$ & NO & 0,000 & Kruskal-Wallis & 0,000 & SI & $\begin{array}{l}\text { Mlann- } \\
\text { Whitney }\end{array}$ & 0,000 & $12 \neq 17$ \\
\hline & & & & & & & 0,001 & $13 \neq 17$ \\
\hline & & & & & & & 0,012 & $12 \neq 13$ \\
\hline $\mathrm{NO}_{2}^{-}$ & NO & 0,138 & Kruskal-Wallis & 0,000 & SI & Whitney & 0,000 & $12 \neq 17$ \\
\hline & & & & & & & 0,915 & $13=17$ \\
\hline & & & & & & & 0,000 & $12 \neq 13$ \\
\hline $\mathrm{SO}_{4}^{2-}$ & SI & 0,000 & medias & 0,000 & SI & $\begin{array}{l}\text { Is de } \\
\text { Dunnett }\end{array}$ & 0,000 & $12 \neq 17$ \\
\hline & & & & & & & 0,012 & $13 \neq 17$ \\
\hline & & & & & & & 0,003 & $12 \neq 13$ \\
\hline$P$ & NO & 0,052 & Kruskal-Wallis & 0,001 & SI & Mlann- & 0,007 & $12 \neq 17$ \\
\hline & & & & & & & 0,245 & $13=17$ \\
\hline
\end{tabular}




\begin{tabular}{|c|c|c|c|c|c|c|c|c|}
\hline \multirow[b]{2}{*}{ Parámetro } & \multicolumn{4}{|c|}{$\begin{array}{l}\text { HOMOGENEIDAD } \\
\text { DE VARIANZAS }\end{array}$} & \multicolumn{4}{|c|}{ FORMA DE LAS DIFERNCIAS } \\
\hline & $\begin{array}{c}\text { Distribu } \\
\text { ción } \\
\text { normal }\end{array}$ & valor $p$ & prueba & valor $p$ & Dif. & Prueba & valor $p$ & Dif \\
\hline $\mathrm{HCO}_{3}^{-}$ & $\mathrm{SI}$ & 0,090 & Anova & 0,772 & NO & & & \\
\hline$F^{-}$ & NO & 0,001 & Kruskal-Wallis & 0,007 & SI & $\begin{array}{l}\text { Mann- } \\
\text { Whitney }\end{array}$ & $\begin{array}{l}0,003 \\
0,052 \\
0,409\end{array}$ & $\begin{array}{l}12 \neq 13 \\
12=17 \\
13=17\end{array}$ \\
\hline $\mathrm{SiO}_{2}$ & $\mathrm{SI}$ & 0,000 & $\begin{array}{l}\text { Robusta de } \\
\text { medias }\end{array}$ & 0,000 & SI & $\begin{array}{c}\text { T3 de } \\
\text { Dunnett }\end{array}$ & $\begin{array}{l}0,661 \\
0,000 \\
0,000\end{array}$ & $\begin{array}{l}12=13 \\
12 \neq 17 \\
13 \neq 17\end{array}$ \\
\hline $\mathrm{Ca}$ & SI & 0,000 & $\begin{array}{l}\text { Robusta de } \\
\text { medias }\end{array}$ & 0,000 & SI & $\begin{array}{c}\text { T3 de } \\
\text { Dunnett }\end{array}$ & $\begin{array}{l}0,000 \\
0,000 \\
0,143\end{array}$ & $\begin{array}{l}12 \neq 13 \\
12 \neq 17 \\
13=17\end{array}$ \\
\hline K & NO & 0,006 & Kruskal-Wallis & 0,000 & SI & $\begin{array}{l}\text { Mann- } \\
\text { Whitney }\end{array}$ & $\begin{array}{l}0,000 \\
0,000 \\
0,035\end{array}$ & $\begin{array}{l}12 \neq 13 \\
12 \neq 17 \\
13 \neq 17\end{array}$ \\
\hline Mg & $\mathrm{SI}$ & 0,000 & $\begin{array}{l}\text { Robusta de } \\
\text { medias }\end{array}$ & 0,000 & SI & $\begin{array}{c}\text { T3 de } \\
\text { Dunnett }\end{array}$ & $\begin{array}{l}0,000 \\
0,000 \\
0,833\end{array}$ & $\begin{array}{l}12 \neq 13 \\
12 \neq 17 \\
13=17\end{array}$ \\
\hline $\mathrm{Na}$ & NO & 0,000 & Kruskal-Wallis & 0,000 & SI & $\begin{array}{l}\text { Mann- } \\
\text { Whitney }\end{array}$ & $\begin{array}{l}0,000 \\
0,000 \\
0,000\end{array}$ & $\begin{array}{l}12 \neq 13 \\
12 \neq 17 \\
13 \neq 17\end{array}$ \\
\hline As & $\mathrm{SI}$ & 0,000 & $\begin{array}{l}\text { Robusta de } \\
\text { medias }\end{array}$ & 0,000 & SI & $\begin{array}{c}\text { T3 de } \\
\text { Dunnett }\end{array}$ & $\begin{array}{l}0,000 \\
0,501 \\
0,000\end{array}$ & $\begin{array}{l}12 \neq 13 \\
12=17 \\
13 \neq 17\end{array}$ \\
\hline $\mathrm{Fe}$ & NO & 0,000 & Kruskal-Wallis & 0,098 & nO & & & \\
\hline $\mathrm{Mn}$ & NO & 0,026 & Kruskal-Wallis & 0,214 & nO & & & \\
\hline Mo & NO & 0,001 & Kruskal-Wallis & 0,000 & SI & $\begin{array}{l}\text { Mann- } \\
\text { Whitney }\end{array}$ & $\begin{array}{l}0,000 \\
0,007 \\
0,006\end{array}$ & $\begin{array}{l}12 \neq 13 \\
12 \neq 17 \\
13 \neq 17\end{array}$ \\
\hline V & $\mathrm{SI}$ & 0,006 & $\begin{array}{l}\text { Robusta de } \\
\text { medias }\end{array}$ & 0,001 & SI & $\begin{array}{c}\text { T3 de } \\
\text { Dunnett }\end{array}$ & $\begin{array}{l}0,000 \\
0.395 \\
0,001\end{array}$ & $\begin{array}{l}12 \neq 13 \\
12=17 \\
13 \neq 17\end{array}$ \\
\hline
\end{tabular}

En general, los tres acuíferos presentan unas características significativamente diferentes para diversos parámetros analizados ( $\mathrm{C} . \mathrm{E}, \mathrm{NO}_{3}{ }^{-}, \mathrm{SO}_{4}{ }^{2-}, \mathrm{K}, \mathrm{Na}$ y $\mathrm{Mo}$ ). Para los muestreos $\mathrm{M} 1$ y $\mathrm{M} 2$ el único parámetro que se mantiene constante entre los tres acuíferos existentes es el bicarbonato. En el muestreo M2 tampoco hay diferencias composicionales entre acuíferos para los metales Fe y $\mathrm{Mn}$.

El acuífero aluvial se distancia en el cloruro, calcio y magnesio de los otros dos acuíferos, los cuales presentan similares concentraciones en dichos parámetros.

Arsénico y vanadio presentan diferencias significativas en el acuífero carbonatado con respecto a los otros dos acuíferos, que entre sí no muestran diferencias en estos dos parámetros. El Fe muestra un comportamiento análogo al de As y V en el muestro M1. 


\section{IV.4.3. CARACTERIZACIÓN HIDROQUÍMICA}

\section{IV.4.3.1 Determinación de las facies hidroquímicas}

Para las aguas de flujos locales o de corto tiempo de residencia, como puede ser el caso de manantiales que drenen acuíferos aislados, se cumple que la litología de la zona proporciona al agua una huella hidrogeoquímica precisa que, sin embargo, difícilmente se conserva en aguas de flujos de mayor recorrido en las que es previsible la interacción con diversas litologías que pueden provocar, además de aportes iónicos diferenciales, modificaciones hidrogeoquímicas que afecten a la estabilidad de ciertas especies en disolución (Garay, 2000).

La caracterización hidroquímica básica de las aguas de la zona de estudio, para las dos campañas de muestreos realizadas, M1 y M2, se refleja en los diagramas de Piper (Fig. IV.20 y Fig. IV.21). Para una mayor claridad en su representación gráfica se han utilizado diferentes símbolos según las unidades hidrogeológicas a las que pertenecen las muestras de agua analizadas.

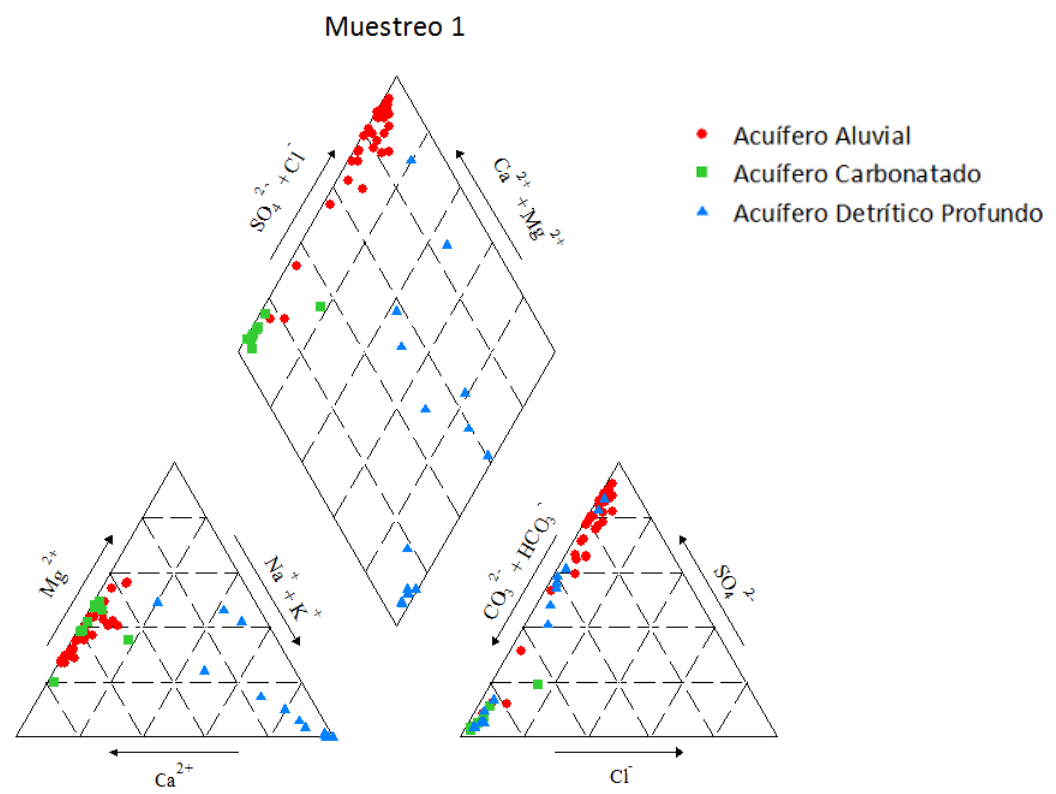

Fig. IV.20. Diagrama de Piper para el Muestreo 1. 


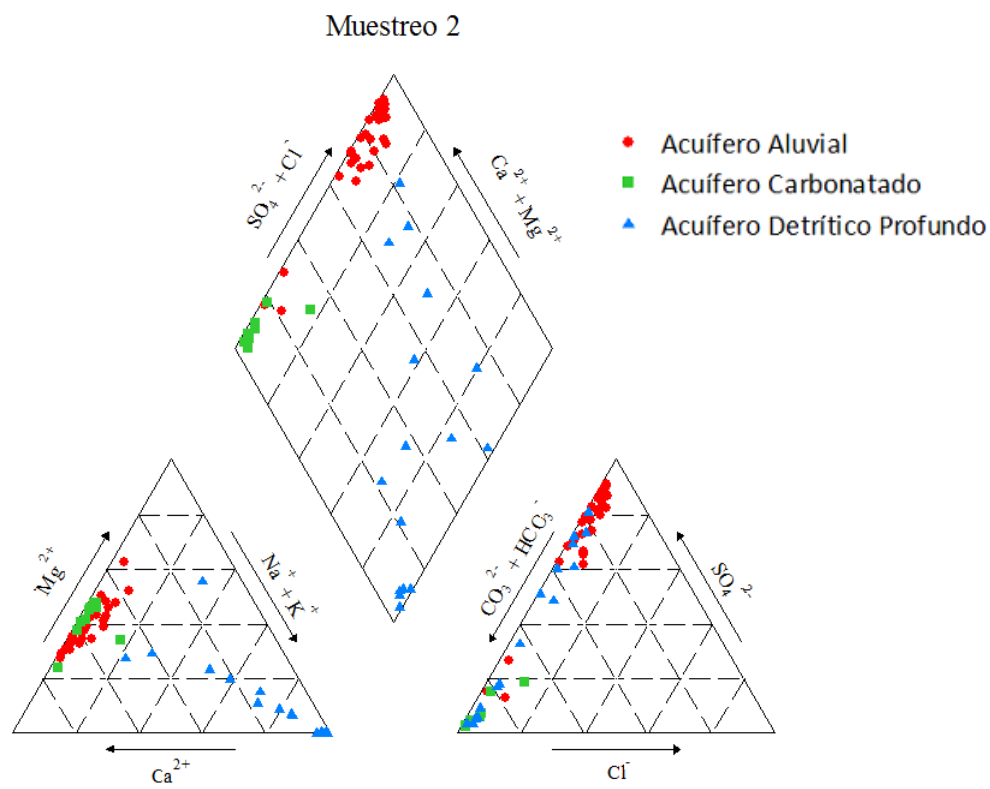

Fig. IV.21. Diagrama de Piper para el Muestreo 2.

En los diagramas de los aniones se observa, en general, un escaso contenido relativo de $\mathrm{Cl}^{-}$respecto a $\mathrm{HCO}_{3}{ }^{-}$y $\mathrm{SO}_{4}{ }^{2-}$.

El diagrama de Piper nos permite distinguir tres tipos de facies hidroquímicas predominantes que se corresponden con los acuíferos estudiados. Así, las muestras tomadas en el acuífero aluvial son principalmente de naturaleza sulfatadas cálcicomagnésicas ( $\mathrm{Ca}-\mathrm{Mg}-\mathrm{SO}_{4}{ }^{2-}$ ); las del acuífero carbonatado son bicarbonatadas cálcicomagnésicas ( $\mathrm{Ca}-\mathrm{Mg}-\mathrm{HCO}_{3}^{-}$) y las del acuífero detrítico profundo, bicarbonatadas sódicas $\left(\mathrm{Na}-\mathrm{HCO}_{3}{ }^{-}\right)$.

Un análisis más detallado de los diagramas de Piper nos permite establecer que:

La facies hidroquímica del acuífero carbonatado muestra una composición muy homogénea, lo cual se pone de manifiesto en la proximidad de sus puntos, a excepción de la muestra M11, que presenta un porcentaje de aniones, cloruro y sulfato, y de cationes sodio y potasio, sensiblemente mayor que el resto de muestras.

Las muestras del acuífero aluvial presentan una moderada variabilidad espacial en su composición química. En un pequeño número de muestras de este acuífero (P13, P14, P20, P110), el contenido de bicarbonato iguala o supera al del anión mayoritario, sulfato. Esos puntos se encuentran muy próximos a la facies Cuestas que delimita el acuífero aluvial del carbonatado, donde existe una conexión hidraúlica entre ambos.

Las muestras procedentes del acuífero detrítico profundo se corresponden con diversos tipos de aguas y parecen evolucionar de bicarbonatadas sódicas a sulfatadas cálcicomagnésicas, con un incremento paralelo de la mineralización de las aguas. 
Dado que el muestreo M1 se realizó entre agosto y septiembre, finalizando la época de riego, y por tanto con menor nivel freático debido a la intensa explotación de los acuíferos y al estiaje), y el muestreo M2 tuvo lugar en el inicio de la época de riego (junio), en el que el acuífero está recargado tras las lluvias del invierno y primavera, la representación de los puntos comunes de los dos muestreos en un diagrama de Piper pondría de manifiesto la variación estacional durante el período de recarga (Fig. IV.22). Se observa que los componentes mayoritarios para los acuíferos aluvial y carbonatado varían ligeramente entre los dos muestreos. Sin embargo, para el acuífero detrítico profundo se observan notables variaciones composicionales para algunas muestras, aunque no siguen la misma tendencia en todas ellas. Así, para las muestras S23, S96 y S97 se observa una disminución en el porcentaje de sulfato manteniéndose los cationes prácticamente en las mismas proporciones, mientras que para las muestras S37, S71, S74 y S90 se observa un aumento tanto del anión sulfato como de los cationes calcio y magnesio.

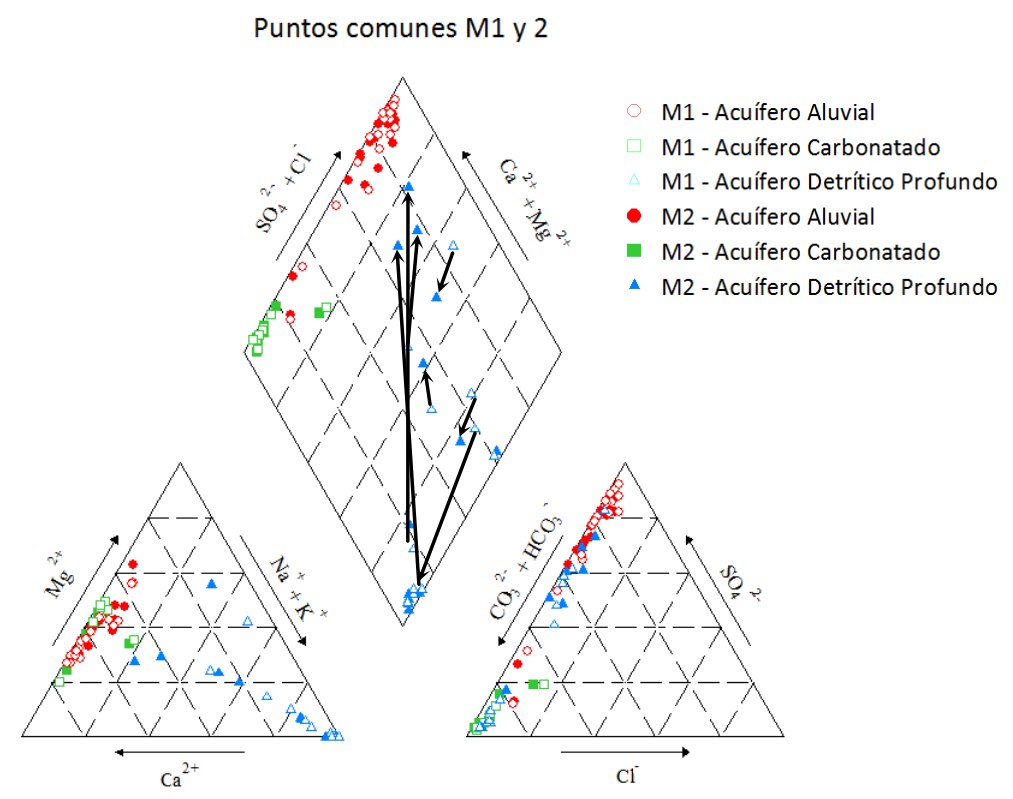

Fig. IV.22. Diagrama de Piper de los puntos comunes de los muestreos M1 y M2.

Para saber si se ha producido un ablandamiento o endurecimiento de las aguas del muestreo M1 (final de la época de riego) al muestreo M2 (inicio de la época de riego), se ha calculado el índice de cambio de bases, para los puntos comunes del muestreo M1 y M2, según la expresión (Schoeller, 1962):

$$
\mathrm{icb}=\frac{\mathrm{rCl}^{-}-\mathrm{r}\left(\mathrm{Na}^{+}+\mathrm{K}^{+}\right)}{\mathrm{r} \mathrm{Cl}^{-}}
$$

Donde $r$ indica las concentraciones iónicas en meq/L. 
Los resultados aparecen tabulados en la Tabla A.Il.3 del Anexo. Un aumento en el valor del icb indica un endurecimiento del agua, mientras que su disminución pone de manifiesto un ablandamiento.

En la Fig. IV.23 se puede apreciar que las mayores variaciones se producen en el acuífero detrítico profundo y que los icb del muestreo 2, icb2, son en general inferiores a los calculados para el muestreo 1 , icb1, por lo que se ha producido un ablandamiento de las aguas, es decir un aumento del contenido de $\mathrm{Na}^{+}$y $\mathrm{K}^{+}$al inicio del verano, cuando el acuífero está recargado tras las lluvias del invierno y primavera.

\section{0}

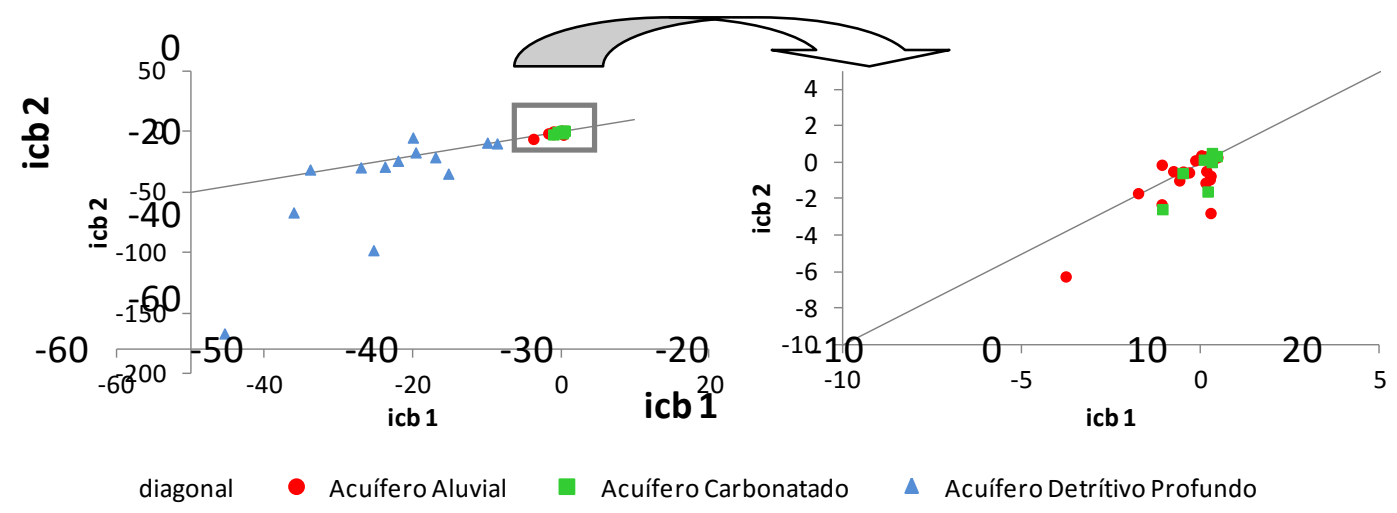

Fig. IV.23. Representación de los icb de los muestreos M1 y M2

\section{IV.4.3.2 Determinación de los índices de saturación}

El estado de saturación de un agua respecto a los distintos minerales que pueden existir en el acuífero o en su zona de influencia puede tener gran importancia. Mediante la determinación de los índices de saturación mineral pueden conocerse fenómenos modificadores, como los de precipitación en el caso de sobresaturación o los de disolución en el caso de no saturación. En el primer caso, tenderá a disminuir la concentración de determinados componentes químicos disueltos en el agua, mientras que en el segundo se producirá un incremento en las concentraciones de estos componentes.

Los resultados de los índices de saturación (IS) de los siguientes minerales; Calcita, $\mathrm{CaCO}_{3}$; Aragonito, CaCO3; Dolomita, $\mathrm{CaMg}\left(\mathrm{CO}_{3}\right)_{2}$; Siderita, $\mathrm{FeCO}_{3} ; \mathrm{Hematite}, \mathrm{Fe}_{2} \mathrm{O}_{3}$; Goethita, $\alpha-\mathrm{FeO}(\mathrm{OH})$; Anhidrita, $\mathrm{CaSO}_{4}$; Yeso, $\mathrm{CaSO}_{4} \cdot 2 \mathrm{H}_{2} \mathrm{O}$; Halita, $\mathrm{NaCl}$; Fluorita, $\mathrm{CaF}_{2}$; Pirita, $\mathrm{FeS}_{2}$, en ambos muestreos, se recogen en las tablas Tabla A.II.4 y Tabla A. II.5 del Anexo. La Tabla IV.10 muestra los valores promedio obtenidos por muestreo y por unidad hidrológica.

Una muestra puede considerarse en equilibrio si el índice de saturación está comprendido entre $-0,1$ y $+0,1$ (Langmuir, 1971). Valores inferiores o superiores a esta cifra indicarían aguas sub-saturadas o sobresaturadas, respectivamente, en relación a un determinado mineral. 
Tabla IV.10. Media, mediana, mínimo y máximo de los índices de saturación (IS) de una variedad de fases minerales en los acuíferos estudiados para los muestreos M1 y M2. (F. mineral: fase mineral)

\begin{tabular}{|c|c|c|c|c|c|c|c|c|c|c|c|c|}
\hline \multirow[b]{3}{*}{ F. mineral } & \multicolumn{12}{|c|}{ MUESTREO M1 } \\
\hline & \multicolumn{4}{|c|}{12} & \multicolumn{4}{|c|}{13} & \multicolumn{4}{|c|}{17} \\
\hline & Media & Mediana & Mín & Máx & Media & Mediana & Mín & Máx & Media & Mediana & Mín & Máx \\
\hline Calcita & 0,28 & 0,36 & $-0,79$ & 1,36 & 0,32 & 0,28 & 0,14 & 0,66 & $-17,04$ & 0,28 & -258 & 0,99 \\
\hline Aragonito & 0,13 & 0,21 & $-0,94$ & 1,22 & 0,17 & 0,12 & $-0,01$ & 0,51 & $-17,18$ & 0,13 & $-258,1$ & 0,84 \\
\hline Dolomita & 0,38 & 0,47 & $-1,81$ & 2,98 & 0,50 & 0,31 & $-0,07$ & 1,30 & $-300,8$ & $-0,52$ & -1000 & 2,83 \\
\hline Siderita & 1,03 & 1,08 & $-0,98$ & 2,39 & $-110,7$ & 0,59 & -1000 & 1,11 & $-85,20$ & $-2,38$ & -1000 & 2,06 \\
\hline Hematite & 20,37 & 20,52 & 13,29 & 24,10 & $-93,34$ & 19,99 & -1000 & 21,04 & $-46,48$ & 21,36 & -1000 & 24,39 \\
\hline Anhydrita & $-0,81$ & $-0,65$ & $-2,43$ & $-0,30 i$ & $-2,81$ & $-2,82$ & $-3,15$ & $-2,24$ & $-3,01$ & $-2,96$ & $-4,67$ & $-0,92$ \\
\hline Yeso & $-0,56$ & $-0,40$ & $-2,18$ & $-0,06$ & $-2,56$ & $-2,57$ & $-2,91$ & $-2,00$ & $-2,78$ & $-2,73$ & $-4,42$ & $-0,67$ \\
\hline Halita & $-8,05$ & $-8,05$ & $-9,22$ & $-6,69$ & $-9,34$ & $-9,33$ & $-9,72$ & $-8,97$ & $-7,49$ & $-7,52$ & $-7,95$ & $-7,10$ \\
\hline Fluorita & $-0,66$ & $-0,55$ & $-1,75$ & 0,02 & $-1,32$ & $-1,31$ & $-1,59$ & $-1,07$ & $-2,26$ & $-2,18$ & $-3,22$ & $-1,14$ \\
\hline Pirita & $-93,93$ & $-93,87$ & $-113,9$ & $-77,82$ & $-202,6$ & $-102,25$ & -1000 & $-96,54$ & $-181,0$ & $-130,35$ & -1000 & $-88,47$ \\
\hline
\end{tabular}

\begin{tabular}{|c|c|c|c|c|c|c|c|c|c|c|c|c|}
\hline \multirow[b]{3}{*}{ F. mineral } & \multicolumn{12}{|c|}{ MUESTREO M2 } \\
\hline & \multicolumn{4}{|c|}{12} & \multicolumn{4}{|c|}{13} & \multicolumn{4}{|c|}{17} \\
\hline & Media & Mediana & Mín & Máx i & Media & Mediana & Mín & Máx i & Media & Mediana & Mín & Máx \\
\hline Calcita & $-6,42$ & 0,45 & $-260,7$ & 1,32 & $-28,12$ & 0,32 & $-255,4$ & 0,59 & $-51,75$ & 0,40 & $-261,9$ & 1,45 \\
\hline Aragonito & $-6,58$ & 0,30 & $-260,9$ & 1,18 & $-28,27$ & 0,17 & $-255,6$ & 0,44 & $-51,90$ & 0,25 & $-262,1$ & 1,30 \\
\hline Dolomita & $-13,01$ & 0,68 & $-521,5$ & $2,65 !$ & $-56,39$ & 0,41 & $-511,0$ & 1,13 & $-103,7$ & 0,67 & $-525,1$ & 3,67 \\
\hline Siderita & $-5,60$ & 1,27 & $-262,2$ & 2,44 & $-27,49$ & 1,08 & $-256,7$ & $2,36 !$ & $-53,03$ & $-1,64$ & $-263,9$ & 2,09 \\
\hline Hematite & 21,18 & 21,31 & 17,91 & 24,95 & 21,85 & 22,33 & 18,09 & 24,39 & 22,21 & 21,74 & 16,89 & 25,90 \\
\hline Goethita & 9,61 & 9,67 & 7,98 & 11,47 & 9,95 & 10,18 & 8,07 & 11,22 & 10,11 & 9,88 & 7,44 & 11,97 \\
\hline Anhydrita & $-0,72$ & $-0,46$ & $-3,52$ & $-0,14$ & $-2,71$ & $-2,80$ & $-3,16$ & $-2,02 !$ & $-2,75$ & $-2,68$ & $-5,57$ & $-0,81$ \\
\hline Yeso & $-0,47$ & $-0,21$ & $-3,29$ & 0,10 & $-2,46$ & $-2,55$ & $-2,92$ & $-1,77$ & $-2,52$ & $-2,43$ & $-5,34$ & $-0,58$ \\
\hline Halita & $-7,93$ & $-7,75$ & $-9,56$ & $-6,95$ & $-9,20$ & $-9,28$ & $-9,75$ & $-7,91$ & $-7,58$ & $-7,57$ & $-9,74$ & $-6,95$ \\
\hline Fluorita & $-0,70$ & $-0,52$ & $-3,01$ & $0,44 i$ & $-1,33$ & $-1,28$ & $-2,02$ & $-0,88$ & $-1,86$ & $-1,46$ & $-4,21$ & $-0,90$ \\
\hline Pirita & $-95,28$ & $-94,48$ & $-132,3$ & $-81,5 i$ & $-104,2$ & $-101,76$ & $-123,1$ & $-92,4 i$ & $-120,6$ & $-125,09$ & $-144,0$ & $-85,9$ \\
\hline
\end{tabular}

De los valores de los índices de saturación obtenidos se deduce que, de los compuestos formados por sulfatos, la anhidrita y el yeso no llegan a la saturación en ninguno de los acuíferos estudiados, siendo la condición de sub-saturación más acusada para los acuíferos detrítico profundo y carbonatado que para el aluvial.

Otros compuestos que tampoco llegan a la saturación en ninguno de los tres acuíferos son la fluorita, halita y pirita. La fluorita se encuentra en estado de equilibrio en algunas muestras concretas.

Goethita y hematite, minerales compuestos por óxidos de hierro, en cambio, presentan altos índices de sobresaturación en todos los acuíferos.

Las aguas de los tres acuíferos se encuentran saturadas de los minerales formados por carbonatos, aragonito, calcita, dolomita y siderita, si bien hay que destacar que existen muestras puntuales, en los tres acuíferos, que se encuentran en equilibrio o incluso alguna de ellas presenta sub-saturación. 


\section{IV.4.4. CORRELACIÓN ENTRE LOS PARÁMETROS INVESTIGADOS}

El estudio de las correlaciones existentes entre los valores experimentales de los parámetros analizados puede revelar datos adicionales acerca de los orígenes y comportamiento de los parámetros estudiados en la zona, entre ellos el arsénico. Así, si se produjeran correlaciones estadísticamente significativas y positivas entre el arsénico y otros parámetros se podría pensar en un origen común para los mismos, contribuyendo así a dilucidar el origen del arsénico.

En la Tabla IV.11 y Tabla IV.12 se recogen los coeficientes de correlación bivariada entre los parámetros analizados en ambos muestreos: los valores tabulados por debajo de la diagonal se corresponden con los coeficientes de correlación de Pearson ( $r$ ). Dado que muchos de los parámetros analizados no siguen una distribución normal, en la parte de la tabla por encima de la diagonal se han representado los coeficientes de correlación de Spearman $\left(r_{s}\right)$, más adecuados para distribuciones no simétricas.

Para una mejor visualización de las correlaciones positivas y/o negativas se han coloreado las celdas en tonos fríos (azules y verdes) para representar las correlaciones negativas y en tonos cálidos (amarillos y rojos) las positivas, siendo la correlación tanto más fuerte cuanto más intenso es el color. Los valores críticos de los estadísticos $r$ y $r_{s}$ se muestran en la tabla.

Se observan fuertes correlaciones positivas entre el siguiente grupo de parámetros: conductividad, aniones mayoritarios (sulfato, nitrato y cloruro), cationes mayoritarios (calcio, magnesio y potasio) y los elementos molibdeno y arsénico.

Algunos de los parámetros adicionales que se midieron en el muestreo 2, como nitrito y sílice, muestran también ciertas correlaciones significativas. Así, el nitrito, con una distribución no normal, se correlaciona positivamente con el grupo de parámetros descrito anteriormente, excepto con arsénico y molibdeno (valores de $r_{s}$ superiores al valor crítico). La sílice, que sigue una distribución normal, presenta una correlación negativa con sodio (valor $r$ superior al valor crítico, en valor absoluto) y positiva con calcio, lo que parece indicar la preponderancia de los procesos de disolución incongruente de feldespatos cálcicos (anortita) respecto a los de feldespatos sódicos (albita).

La conductividad está fuertemente correlacionada con los cationes y aniones mayoritarios, por lo que utilizaremos este parámetro para representarlo frente al arsénico y ver si las tres unidades del acuífero muestran esta correlación. En la Fig. IV.24a se observa cómo, en el acuífero aluvial, la concentración de arsénico aumenta con la conductividad hasta su valor máximo de unos $3000 \mu \mathrm{S} / \mathrm{cm}$, alcanzándose niveles de arsénico aún mayores sin que se registre mayor conductividad. En el acuífero carbonatado también se observa esa correlación entre ambos parámetros. Por el contrario, en el acuífero detrítico profundo no se observa tal correlación. 


\begin{tabular}{|c|c|c|c|c|c|c|c|c|c|c|c|c|c|c|c|c|c|c|c|}
\hline \multirow{19}{*}{ 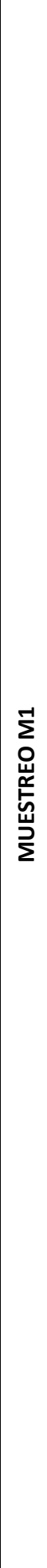 } & $\vdash$ & $\begin{array}{l}\text { ô } \\
\text { o. }\end{array}$ & $\begin{array}{l}\text { ठ̊ } \\
\text { o. }\end{array}$ & $\begin{array}{c}f \\
\text { w } \\
\text { ô. }\end{array}$ & $\begin{array}{l}\text { ָू. } \\
\text { o. }\end{array}$ & $\begin{array}{l}\text { Dे } \\
\text { o. } \\
\text { i. }\end{array}$ & $\begin{array}{l}\overrightarrow{0} \\
\stackrel{0}{0}\end{array}$ & $\begin{array}{l}\infty \\
0_{0}^{\infty} \\
0\end{array}$ & 莕 & 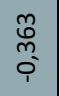 & 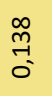 & 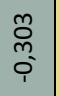 & $\begin{array}{l}\stackrel{0}{\circ} \\
\text { o. }\end{array}$ & ్ָ & $\begin{array}{l}\infty \\
\text { o̊ } \\
\vdots\end{array}$ & 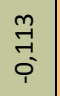 & $\begin{array}{l}\text { भे } \\
\text { fे }\end{array}$ & 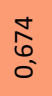 & $\underset{-i}{\stackrel{-}{0}}$ \\
\hline & $\frac{\pi}{2}$ & 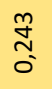 & 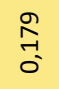 & $\begin{array}{l}\text { Ñ } \\
\text { i }\end{array}$ & $\begin{array}{l}\text { 总 } \\
\text { o. }\end{array}$ & $\begin{array}{c}\underset{\hat{N}}{\tilde{N}} \\
0\end{array}$ & $\begin{array}{l}\infty \\
o_{0}^{\infty} \\
0\end{array}$ & $\begin{array}{l}\text { ò } \\
\text { o. } \\
0\end{array}$ & 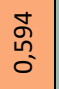 & $\begin{array}{l}\stackrel{n}{N} \\
\stackrel{N}{i}\end{array}$ & 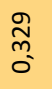 & $\begin{array}{l}\tilde{N}_{0} \\
\text { ô } \\
\text { in }\end{array}$ & $\begin{array}{l}\stackrel{0}{\sim} \\
\underset{0}{0}\end{array}$ & 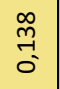 & $\begin{array}{c}\stackrel{\text { q }}{ \pm} \\
\stackrel{1}{1}\end{array}$ & $\begin{array}{l}\text { oे } \\
\text { o. }\end{array}$ & 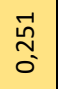 & $\underset{i}{\stackrel{\text { o }}{ }}$ & \\
\hline & I & 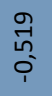 & 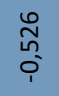 & $\begin{array}{l}\stackrel{8}{0} \\
\stackrel{\circ}{i}\end{array}$ & $\begin{array}{l}\text { 엉 } \\
\text { o. }\end{array}$ & \begin{tabular}{l} 
我 \\
\multirow{i}{*}{}
\end{tabular} & $\begin{array}{l}\tilde{y} \\
\text { ó }\end{array}$ & $\begin{array}{l}\vec{J} \\
0 \\
i\end{array}$ & $\begin{array}{l}\tilde{m} \\
\stackrel{0}{1}\end{array}$ & $\begin{array}{l}\stackrel{n}{\hat{n}} \\
\hat{0}\end{array}$ & $\begin{array}{l}\hat{N} \\
\text { O. }\end{array}$ & 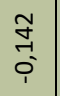 & $\begin{array}{l}\overrightarrow{\breve{b}} \\
\stackrel{1}{0} \\
\end{array}$ & $\begin{array}{l}\stackrel{n}{m} \\
\stackrel{m}{0} \\
\rho^{\prime}\end{array}$ & $\begin{array}{l}\text { 㟔 } \\
\text { O. }\end{array}$ & $\begin{array}{l}\text { oे } \\
\text { m. } \\
\text { o. }\end{array}$ & $\underset{-}{\text { o }}$ & $\begin{array}{l}\text { ָे } \\
\text { ¿. }\end{array}$ & $\begin{array}{l}\text { 员 } \\
\text { مी }\end{array}$ \\
\hline & 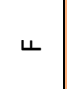 & 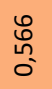 & 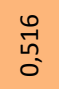 & 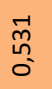 & $\begin{array}{l}\underset{\mathcal{Z}}{\Delta} \\
\text { s }\end{array}$ & $\begin{array}{l}\stackrel{\infty}{0} \\
\stackrel{0}{0}\end{array}$ & 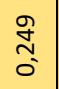 & \begin{tabular}{l}
$\stackrel{u}{m}$ \\
\multirow{0}{0}{}
\end{tabular} & 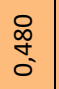 & $\begin{array}{l}\text { ơ } \\
\text { hn } \\
0\end{array}$ & 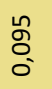 & $\begin{array}{l}\underset{\widetilde{N}}{\tilde{O}} \\
0\end{array}$ & $\begin{array}{l}\text { D̃. } \\
\text { o. }\end{array}$ & 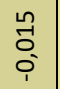 & $\begin{array}{l}\mathscr{0} \\
\stackrel{0}{0} \\
0\end{array}$ & $\underset{-i}{\stackrel{-}{\text { d }}}$ & $\begin{array}{l}\text { o } \\
\text { ö } \\
0\end{array}$ & 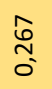 & \begin{tabular}{l}
$\infty$ \\
\multirow{2}{*}{} \\
0 \\
0
\end{tabular} \\
\hline & 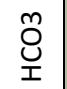 & $\begin{array}{l}\text { ñ } \\
\text { in }\end{array}$ & $\begin{array}{c}\text { fy } \\
\text { ô. } \\
\text { o. }\end{array}$ & $\begin{array}{l}\vec{\infty} \\
\stackrel{0}{1}\end{array}$ & $\begin{array}{l}\text { స్ } \\
\text { î }\end{array}$ & 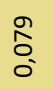 & $\begin{array}{l}\text { ò } \\
\text { o. }\end{array}$ & $\begin{array}{l}\tilde{N} \\
\tilde{m} \\
\varphi^{2}\end{array}$ & $\begin{array}{l}\text { ¿̊ } \\
\text { ì }\end{array}$ & 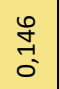 & $\begin{array}{l}\text { 管 } \\
\text { - }\end{array}$ & $\begin{array}{l}0 \\
0 \\
0 \\
0\end{array}$ & 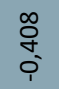 & 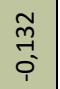 & 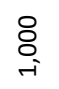 & 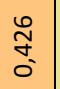 & $\begin{array}{l}\text { Oे } \\
\stackrel{9}{0}\end{array}$ & 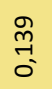 & ఫે \\
\hline & $\sum^{\complement}$ & 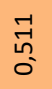 & $\begin{array}{l}\text { 总 } \\
\text { on }\end{array}$ & \begin{tabular}{l}
$\tilde{\tilde{m}}$ \\
\multirow{\sigma}{0}{}
\end{tabular} & $\begin{array}{l}\text { जे } \\
\text { ㅇ. }\end{array}$ & $\begin{array}{l}\tilde{N} \\
\text { \& }\end{array}$ & $\begin{array}{l}\text { Oू } \\
\text { ô. }\end{array}$ & \begin{tabular}{l}
$f$ \\
\multirow{+}{0}{} \\
0
\end{tabular} & $\begin{array}{l}\hat{a} \\
\text { aे }\end{array}$ & $\begin{array}{l}\hat{0} \\
\stackrel{1}{0}\end{array}$ & $\begin{array}{l}\text { ô } \\
\text { fo } \\
0\end{array}$ & $\begin{array}{l}\text { â } \\
\text { â }\end{array}$ & $\begin{array}{l}\vec{N} \\
\text { 促 }\end{array}$ & 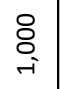 & 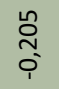 & $\begin{array}{l}0 \\
0 \\
\rightarrow-1 \\
i\end{array}$ & 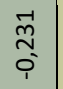 & $\begin{array}{l}\text { o. } \\
\text { : } \\
i\end{array}$ & $\begin{array}{l}\stackrel{0}{0} \\
\text { i. }\end{array}$ \\
\hline & ¿ & 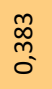 & \begin{tabular}{l}
$\tilde{N}$ \\
\multirow{0}{0}{}
\end{tabular} & $\begin{array}{l}\underset{\tilde{N}}{\tilde{D}} \\
\text { o }\end{array}$ & $\begin{array}{l}\text { o̊ } \\
\text { on } \\
\text { - }\end{array}$ & $\begin{array}{l}\text { ָे } \\
\text { ô }\end{array}$ & 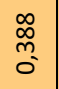 & $\begin{array}{l}\vec{y} \\
0\end{array}$ & $\begin{array}{l}\text { 学 } \\
\text { - }\end{array}$ & $\begin{array}{l}m \\
0 \\
0 \\
i\end{array}$ & $\begin{array}{l}\text { शे } \\
\text { ने }\end{array}$ & 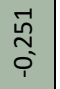 & 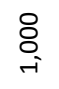 & $\begin{array}{l}\stackrel{0}{0} \\
0 \\
0\end{array}$ & 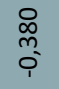 & $\begin{array}{l}0 \\
0 \\
0 \\
0 \\
1\end{array}$ & 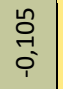 & 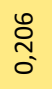 & $\begin{array}{l}\text { fे } \\
\text { o }\end{array}$ \\
\hline & $\stackrel{\circ}{\circ}$ & \begin{tabular}{l}
\multirow{\Delta}{*}{} \\
$:$
\end{tabular} & $\begin{array}{l}5 \\
\hat{0} \\
0 \\
0\end{array}$ & 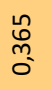 & 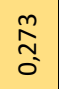 & $\begin{array}{l}\underset{J}{J} \\
\text { 咅 }\end{array}$ & $\begin{array}{l}\tilde{\tilde{n}} \\
\text { o. }\end{array}$ & $\begin{array}{l}\text { fo } \\
\stackrel{4}{0}\end{array}$ & $\begin{array}{l}\stackrel{g}{N} \\
\text { i }\end{array}$ & $\begin{array}{l}\overrightarrow{0} \\
\text { 䓵 }\end{array}$ & 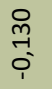 & $\underset{i}{\stackrel{i}{0}}$ & 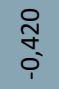 & 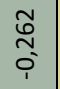 & $\begin{array}{l}\text { oे } \\
\text { ì }\end{array}$ & $\begin{array}{l}\text { 京 } \\
\text { i. }\end{array}$ & 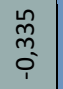 & 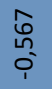 & 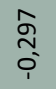 \\
\hline & ¿ & $\begin{array}{l}\tilde{o} \\
\stackrel{0}{0}\end{array}$ & $\begin{array}{l}\stackrel{0}{7} \\
\text { fo }\end{array}$ & 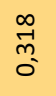 & $\begin{array}{l}\text { 马े } \\
\text { fे }\end{array}$ & $\begin{array}{l}\text { 总 } \\
\text { on }\end{array}$ & $\begin{array}{l}\text { on } \\
\text { in } \\
\text { s. }\end{array}$ & 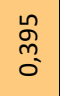 & $\begin{array}{l}\text { O⿱艹 } \\
\text { 茴 }\end{array}$ & $\begin{array}{l}\text { مू } \\
\text { on } \\
0\end{array}$ & $\begin{array}{l}\stackrel{8}{0} \\
-i\end{array}$ & 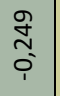 & $\begin{array}{l}\hat{n} \\
\text { o. } \\
\text { in }\end{array}$ & \begin{tabular}{l}
$\stackrel{0}{0}$ \\
\multirow{0}{0}{}
\end{tabular} & 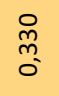 & $\begin{array}{l}\tilde{o} \\
0 \\
i\end{array}$ & 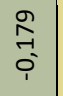 & $\begin{array}{l}\text { 学 } \\
0 \\
0\end{array}$ & $\begin{array}{l}0 \\
0 \\
0 \\
0\end{array}$ \\
\hline & 姿 & 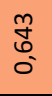 & $\begin{array}{l}\text { d } \\
\text { o. } \\
0^{2}\end{array}$ & $\begin{array}{l}\text { ¿े } \\
\infty \\
0\end{array}$ & $\begin{array}{l}\text { 合 } \\
\text { o }\end{array}$ & $\begin{array}{l}\stackrel{\infty}{N} \\
\text { - }\end{array}$ & \begin{tabular}{l}
$\tilde{f}$ \\
\multirow{0}{*}{}
\end{tabular} & $\begin{array}{l}\tilde{y} \\
\tilde{c} \\
0\end{array}$ & 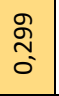 & $\underset{-i}{\stackrel{8}{a}}$ & $\begin{array}{l}\text { } \\
\stackrel{m}{m} \\
o\end{array}$ & $\begin{array}{l}m \\
\stackrel{1}{1} \\
0 \\
i\end{array}$ & 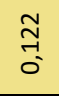 & $\begin{array}{l}\stackrel{1}{1} \\
\stackrel{1}{0}\end{array}$ & $\begin{array}{l}\tilde{z} \\
\text { Oे }\end{array}$ & $\begin{array}{l}\stackrel{\infty}{\beth} \\
0\end{array}$ & $\begin{array}{l}\tilde{n} \\
\tilde{o} \\
i\end{array}$ & $\begin{array}{l}\underset{I}{I} \\
0\end{array}$ & $\begin{array}{l}\hat{o} \\
0 \\
0\end{array}$ \\
\hline & $\stackrel{n}{2}$ & $\begin{array}{l}\vec{t} \\
0 \\
0\end{array}$ & $\begin{array}{l}\text { ָे } \\
0 \\
0\end{array}$ & 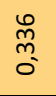 & 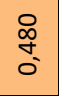 & $\begin{array}{l}8 \\
0 \\
0\end{array}$ & $\begin{array}{l}\text { Fे } \\
\text { 范 }\end{array}$ & $\begin{array}{l}\text { 怘 } \\
\text { م. }\end{array}$ & $\underset{-}{\stackrel{8}{-}}$ & 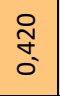 & $\begin{array}{l}\text { م् } \\
\stackrel{-}{0}\end{array}$ & 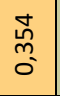 & $\begin{array}{l}\text { ठे } \\
\text { o. }\end{array}$ & $\begin{array}{l}\text { 苟 } \\
\text { ci }\end{array}$ & : & $\begin{array}{c}0 \\
\stackrel{\infty}{0} \\
0\end{array}$ & $\begin{array}{l}0 \\
\stackrel{0}{0} \\
\vdots \\
i\end{array}$ & 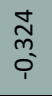 & 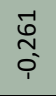 \\
\hline & $\stackrel{\circ}{\Sigma}$ & $\begin{array}{c}\text { to } \\
\infty \\
0 \\
0\end{array}$ & 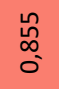 & $\begin{array}{l}\stackrel{0}{0} \\
0 \\
0\end{array}$ & 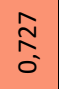 & $\begin{array}{l}\text { 心్ } \\
\stackrel{0}{0}\end{array}$ & $\begin{array}{l}\text { స్ } \\
\text { o. }\end{array}$ & 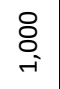 & $\begin{array}{l}\text { f } \\
\text { O }\end{array}$ & $\begin{array}{l}\stackrel{\leftrightarrow}{\infty} \\
0 \\
0\end{array}$ & $\begin{array}{l}\text { হે } \\
\text { Oे }\end{array}$ & $\begin{array}{l}00 \\
\stackrel{0}{0} \\
i=0\end{array}$ & $\begin{array}{l}\text { ô } \\
\text { ò }\end{array}$ & $\begin{array}{l}\stackrel{0}{\%} \\
\text { fे }\end{array}$ & $\begin{array}{l}\vec{H} \\
0 \\
0\end{array}$ & 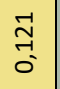 & $\underset{\substack{\mathbb{Z} \\
\text { i }}}{ }$ & $\begin{array}{l}\text { ò } \\
\vdots \\
i\end{array}$ & $\begin{array}{l}\text { స̃ } \\
\text { i. }\end{array}$ \\
\hline & 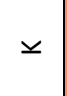 & $\begin{array}{l}\stackrel{D}{0} \\
\stackrel{0}{0}\end{array}$ & $\begin{array}{l}\vec{n} \\
\hat{0}\end{array}$ & $\begin{array}{l}\hat{\sigma} \\
\hat{n} \\
\text { م. }\end{array}$ & $\begin{array}{l}\stackrel{\infty}{N} \\
\stackrel{0}{0}\end{array}$ & $\begin{array}{l}0 \\
0 \\
0 \\
0 \\
0\end{array}$ & 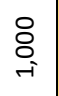 & $\begin{array}{l}\stackrel{n}{m} \\
\tilde{m} \\
0\end{array}$ & 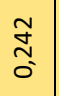 & $\begin{array}{l}\stackrel{0}{\tilde{n}} \\
\tilde{0}\end{array}$ & 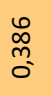 & $\begin{array}{l}0 \\
\text { On } \\
0 \\
0\end{array}$ & $\begin{array}{l}\ddot{0} \\
0 \\
0 \\
0\end{array}$ & 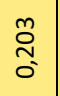 & $\begin{array}{l}\stackrel{0}{n} \\
\stackrel{0}{0}\end{array}$ & 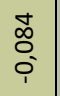 & $\begin{array}{l}\infty \\
\stackrel{\infty}{0} \\
\stackrel{0}{0}\end{array}$ & $\begin{array}{l}\hat{o} \\
\text { ò }\end{array}$ & 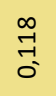 \\
\hline & $\bar{U}$ & $\begin{array}{l}\hat{\alpha} \\
\text { o } \\
0\end{array}$ & 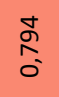 & 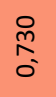 & $\begin{array}{l}\stackrel{0}{0} \\
0 \\
0 \\
0\end{array}$ & $\begin{array}{l}\stackrel{8}{0} \\
\text { i }\end{array}$ & $\begin{array}{l}\text { స్ } \\
\text { న్ }\end{array}$ & $\begin{array}{l}\hat{f} \\
\dot{0} \\
0\end{array}$ & $\begin{array}{l}\overrightarrow{1} \\
\stackrel{1}{0}\end{array}$ & $\begin{array}{l}\text { 文 } \\
\text { un. }\end{array}$ & $\begin{array}{l}\frac{\tilde{m}}{\text { f. }} \\
0\end{array}$ & $\begin{array}{l}\stackrel{0}{a} \\
\stackrel{1}{0}\end{array}$ & $\begin{array}{l}\text { శ్ } \\
\text { ô } \\
\text { - }\end{array}$ & $\begin{array}{l}\stackrel{0}{0} \\
\stackrel{0}{0}\end{array}$ & $\begin{array}{l}\vec{m} \\
\stackrel{-}{0}\end{array}$ & $\begin{array}{l}0 \\
\stackrel{1}{0} \\
0\end{array}$ & $\begin{array}{l}-\overrightarrow{0} \\
\text { m. } \\
0 .\end{array}$ & 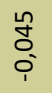 & \\
\hline & $\sum^{\infty 0}$ & $\begin{array}{c}\tilde{\infty} \\
\infty \\
0 \\
0\end{array}$ & $\begin{array}{c}\tilde{N} \\
\infty \\
\infty \\
0\end{array}$ & $\begin{array}{l}\text { ঃ } \\
\text { o. }\end{array}$ & 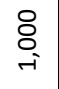 & $\begin{array}{l}\stackrel{0}{:} \\
0 \\
0\end{array}$ & $\begin{array}{l}\text { ô } \\
\text { ô } \\
\text { - }\end{array}$ & $\begin{array}{l}\text { } \\
\text { O } \\
0\end{array}$ & $\begin{array}{l}\tilde{\infty} \\
\stackrel{\infty}{0} \\
0\end{array}$ & $\begin{array}{l}\stackrel{n}{0} \\
0 \\
0\end{array}$ & $\begin{array}{l}\text { న్ } \\
\text { o. }\end{array}$ & $\begin{array}{l}\hat{\tilde{m}} \\
\text { o. }\end{array}$ & $\begin{array}{c}\tilde{N} \\
\stackrel{-}{0}\end{array}$ & $\begin{array}{l}\infty \\
\stackrel{m}{0} \\
0\end{array}$ & $\begin{array}{l}\underset{\mathbb{Z}}{\mathbb{Z}} \\
i\end{array}$ & \begin{tabular}{l}
$\stackrel{0}{0}$ \\
\hdashline \\
0
\end{tabular} & 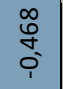 & $\begin{array}{l}\vec{d} \\
\stackrel{0}{0}\end{array}$ & \\
\hline & త & $\begin{array}{l}0 \\
0 \\
\infty \\
0\end{array}$ & $\begin{array}{l}0 \\
\text { o } \\
0 \\
0\end{array}$ & 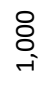 & $\begin{array}{l}\text { 今. } \\
\text { o. } \\
0\end{array}$ & $\begin{array}{l}\hat{\tilde{b}} \\
0 \\
0\end{array}$ & $\begin{array}{c}\frac{9}{d} \\
-1\end{array}$ & $\stackrel{\substack{d \\
0}}{0}$ & $\begin{array}{l}\text { O̊. } \\
\text { o. }\end{array}$ & $\begin{array}{l}\stackrel{n}{n} \\
\hat{m} \\
0\end{array}$ & 兑 & 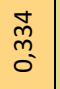 & $\begin{array}{l}\overrightarrow{0} \\
0 \\
0\end{array}$ & 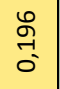 & $\begin{array}{l}\stackrel{\sim}{N} \\
\stackrel{i}{i}\end{array}$ & $\begin{array}{l}\stackrel{d}{J} \\
\text { d }\end{array}$ & $\begin{array}{l}\overrightarrow{0} \\
0 \\
0 \\
i\end{array}$ & $\begin{array}{l}\text { ने } \\
\text { c- }\end{array}$ & \\
\hline & ర్ & $\begin{array}{l}\sqrt{1} \\
\text { مू }\end{array}$ & $\underset{-}{\stackrel{8}{0}}$ & $\begin{array}{l}\text { के } \\
\infty \\
0 \\
0\end{array}$ & $\begin{array}{l}\text { ô } \\
\text { ô. }\end{array}$ & $\begin{array}{l}\vec{\rho} \\
\stackrel{0}{0}\end{array}$ & 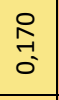 & $\begin{array}{l}\text { N్ } \\
\text { مू }\end{array}$ & $\begin{array}{l}\hat{o} \\
\text { o. }\end{array}$ & $\begin{array}{l}\infty \\
\stackrel{0}{0} \\
0\end{array}$ & $\begin{array}{l}\text { Dे } \\
\text { Oे }\end{array}$ & $\begin{array}{l}\hat{\infty} \\
\stackrel{-}{0}\end{array}$ & 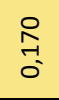 & $\begin{array}{l}\text { న్ } \\
\text { Oे }\end{array}$ & $\begin{array}{l}\text { ô } \\
\text { } \\
\text { Q }\end{array}$ & 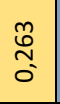 & $\begin{array}{l}\text { g } \\
\text { i } \\
\text { i }\end{array}$ & 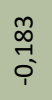 & 文 \\
\hline & نّ & $\begin{array}{l}\text { ০ } \\
\text { - }\end{array}$ & $\begin{array}{l}\text { 命 } \\
\text { g. }\end{array}$ & $\begin{array}{l}\mathbb{0} \\
\infty \\
0 \\
0\end{array}$ & $\begin{array}{l}\text { ָ̃ } \\
\text { o. }\end{array}$ & $\begin{array}{l}\hat{\sigma} \\
\hat{o}\end{array}$ & $\begin{array}{l}\hat{n} \\
\tilde{n} \\
0\end{array}$ & $\begin{array}{l}\text { ஸ̊ } \\
\text { ڤn }\end{array}$ & $\begin{array}{l}\hat{2} \\
\hat{o} \\
0\end{array}$ & $\begin{array}{l}\hat{\tilde{o}} \\
\stackrel{0}{0}\end{array}$ & 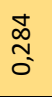 & $\begin{array}{l}\hat{\infty} \\
\stackrel{1}{0}\end{array}$ & $\underset{\substack{\tilde{q} \\
0}}{ }$ & $\begin{array}{l}\hat{n} \\
0 \\
0\end{array}$ & 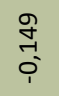 & $\begin{array}{l}\overrightarrow{\tilde{N}} \\
\tilde{O}_{0}\end{array}$ & 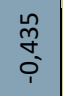 & $\begin{array}{l}\tilde{0} \\
\text { - } \\
\text { in }\end{array}$ & 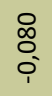 \\
\hline & & ن & రి & త & $\sum^{\infty 0}$ & $\bar{\tau}$ & 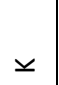 & $\stackrel{\circ}{\Sigma}$ & $\stackrel{m}{2}$ & 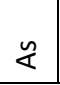 & 잉 & $\stackrel{\circ}{\circ}$ & ๗ँ & $\sum$ & $\begin{array}{l}\tilde{O} \\
\text { ư }\end{array}$ & 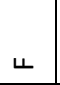 & I & $\frac{\pi}{2}$ & \\
\hline
\end{tabular}




\begin{tabular}{|c|c|c|c|c|c|c|c|c|c|c|c|c|c|c|c|c|c|c|c|c|c|c|}
\hline & - & $\begin{array}{l}\hat{n} \\
0 \\
0\end{array}$ & $\begin{array}{c}2 \\
7 \\
7 \\
1 \\
1\end{array}$ & $\mid \begin{array}{l}\infty \\
\infty \\
\infty \\
0 \\
i \\
\end{array}$ & 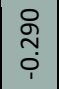 & 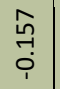 & 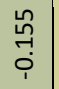 & $\begin{array}{l}\text { on } \\
0 \\
0 \\
i\end{array}$ & $\begin{array}{l}\stackrel{0}{0} \\
m \\
i\end{array}$ & $\begin{array}{l}\text { ָ̊ } \\
\text { On }\end{array}$ & $\begin{array}{l}\tilde{N} \\
0 \\
0\end{array}$ & 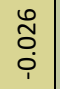 & $\begin{array}{l}\hat{m} \\
\stackrel{1}{i} \\
i\end{array}$ & $\begin{array}{l}8 \\
0 \\
0 \\
i\end{array}$ & $\begin{array}{c}8 \\
\stackrel{9}{7} \\
0 \\
1\end{array}$ & $\begin{array}{l}0 \\
\stackrel{0}{0} \\
0\end{array}$ & 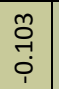 & 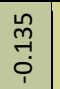 & $\begin{array}{l}\overrightarrow{\hat{y}} \\
\dot{i}\end{array}$ & $\begin{array}{l}\stackrel{n}{2} \\
\stackrel{0}{0}\end{array}$ & 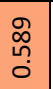 & ৪্ \\
\hline & $\frac{\pi}{2}$ & $\begin{array}{l}\stackrel{0}{n} \\
\stackrel{0}{0}\end{array}$ & 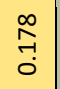 & 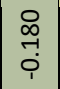 & $\begin{array}{l}\overrightarrow{0} \\
0 \\
0 \\
0\end{array}$ & 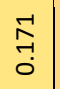 & 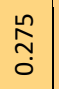 & $\begin{array}{l}\underset{N}{\tilde{N}} \\
0\end{array}$ & $\begin{array}{l}\stackrel{\omega}{N} \\
\stackrel{0}{i}\end{array}$ & $\begin{array}{l}\text { से } \\
\text { ஸे }\end{array}$ & \begin{tabular}{l}
$\infty$ \\
\multirow{l}{0}{} \\
0
\end{tabular} & $\begin{array}{l}\stackrel{N}{1} \\
0\end{array}$ & $\begin{array}{l}\hat{n} \\
0 \\
i \\
i\end{array}$ & $\begin{array}{c}0 \\
0 \\
01 \\
i \\
i\end{array}$ & $\begin{array}{c}\tilde{0} \\
\text { ְñ } \\
i\end{array}$ & 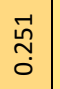 & $\begin{array}{l}0 \\
\stackrel{0}{0} \\
0\end{array}$ & $\begin{array}{l}\infty \\
0 \\
0 \\
i\end{array}$ & $\begin{array}{l}\tilde{N} \\
\stackrel{n}{0} \\
0\end{array}$ & 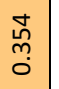 & & $\vec{~}$ \\
\hline & I & 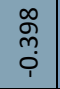 & $\begin{array}{l}0 \\
o \\
o \\
i \\
1\end{array}$ & $\begin{array}{l}\qquad n \\
\infty \\
0 \\
0 \\
1\end{array}$ & 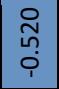 & 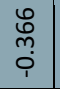 & 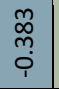 & $\begin{array}{l}\underset{N}{N} \\
\stackrel{1}{1}\end{array}$ & $\begin{array}{l}0 \\
\stackrel{\infty}{0} \\
\stackrel{1}{1}\end{array}$ & $\begin{array}{l}0 \\
0 \\
0 \\
i \\
i\end{array}$ & $\begin{array}{l}0 \\
\text { H̊ } \\
0\end{array}$ & $\begin{array}{l}\vec{J} \\
\stackrel{N}{1} \\
\stackrel{1}{1}\end{array}$ & 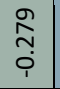 & $\begin{array}{c}\infty \\
m \\
m \\
i\end{array}$ & $\begin{array}{l}8 \\
\stackrel{1}{0} \\
0\end{array}$ & 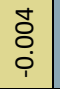 & $\begin{array}{c}m \\
m \\
o \\
i\end{array}$ & $\begin{array}{l}\tilde{N} \\
0 \\
0 \\
0\end{array}$ & 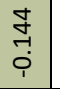 & 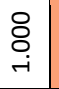 & $\begin{array}{l}0 \\
\stackrel{0}{0} \\
0\end{array}$ & ז̊ \\
\hline & ч & 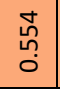 & 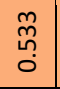 & $\begin{array}{l}\hat{0} \\
0 \\
0 \\
0\end{array}$ & 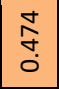 & $\underset{\substack{0 \\
0}}{0}$ & $\begin{array}{l}m \\
\vec{f} \\
0\end{array}$ & $\begin{array}{l}\overrightarrow{7} \\
0 \\
0\end{array}$ & $\begin{array}{l}\hat{m} \\
0\end{array}$ & 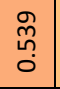 & 苂 & $\begin{array}{c}0 \\
7 \\
0 \\
0\end{array}$ & \begin{tabular}{l}
\multirow{\Delta}{0}{} \\
0 \\
$i$
\end{tabular} & $\begin{array}{l}0 \\
0 \\
\vdots \\
0\end{array}$ & $\begin{array}{l}0 \\
0 \\
0 \\
0\end{array}$ & $\begin{array}{l}0 \\
0 \\
i \\
1\end{array}$ & $\begin{array}{l}\overrightarrow{0} \\
\overrightarrow{1} \\
i\end{array}$ & $\begin{array}{l}\overrightarrow{1} \\
7 \\
0\end{array}$ & $\begin{array}{l}\stackrel{\text { }}{ } \\
\text { }\end{array}$ & \begin{tabular}{c} 
J \\
\multirow{2}{*}{} \\
0
\end{tabular} & 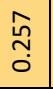 & ઼ָ \\
\hline & 䓵 & $\begin{array}{l}\hat{o} \\
0 \\
0\end{array}$ & $\begin{array}{l}\overrightarrow{0} \\
\stackrel{0}{0} \\
0\end{array}$ & 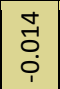 & $\begin{array}{l}\infty \\
\stackrel{\infty}{0} \\
\stackrel{0}{0}\end{array}$ & $\stackrel{\substack{N \\
0}}{0}$ & $\begin{array}{l}\mathbb{0} \\
\stackrel{\leftrightarrow}{0} \\
0\end{array}$ & $\begin{array}{l}\hat{\tilde{o}} \\
\stackrel{0}{0}\end{array}$ & 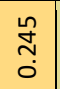 & $\begin{array}{l}\infty \\
\stackrel{\infty}{0} \\
0\end{array}$ & 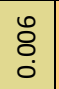 & $\underset{\substack{\tilde{N} \\
0}}{0}$ & $\begin{array}{l}0 \\
\stackrel{\leftrightarrow}{0} \\
0\end{array}$ & $\begin{array}{l}0 \\
\stackrel{0}{0} \\
\stackrel{0}{0}\end{array}$ & $\begin{array}{l}\text { g. } \\
\stackrel{7}{1}\end{array}$ & 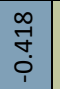 & $\begin{array}{l}0 \\
\stackrel{0}{7} \\
i \\
i\end{array}$ & 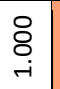 & $\begin{array}{l}\tilde{n} \\
\stackrel{0}{0} \\
0\end{array}$ & $\begin{array}{l}\infty \\
\infty \\
0 \\
0\end{array}$ & 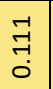 & 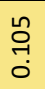 \\
\hline & $\sum_{\Sigma}^{c}$ & 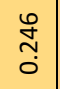 & $\begin{array}{l}\overrightarrow{\tilde{m}} \\
\stackrel{0}{0}\end{array}$ & 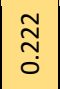 & $\begin{array}{l}\stackrel{\text { L }}{0} \\
\text {. }\end{array}$ & $\begin{array}{l}\stackrel{8}{9} \\
\stackrel{1}{0}\end{array}$ & $\begin{array}{l}\text { ț } \\
\text { m. } \\
0\end{array}$ & 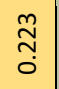 & $\begin{array}{l}n \\
\stackrel{0}{0} \\
0 \\
1\end{array}$ & $\begin{array}{l}\stackrel{g}{+} \\
\stackrel{1}{0}\end{array}$ & $\begin{array}{c}9 \\
\overrightarrow{7} \\
0 \\
1\end{array}$ & \begin{tabular}{l}
$\infty$ \\
\multirow{n}{*}{} \\
0
\end{tabular} & \begin{tabular}{l}
$m$ \\
\multirow{l}{\sharp}{} \\
0
\end{tabular} & $\begin{array}{c}0 \\
0 \\
\stackrel{0}{1} \\
1\end{array}$ & 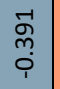 & $\begin{array}{l}0 \\
0 \\
0 \\
0 \\
0\end{array}$ & 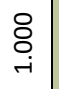 & 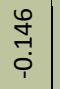 & $\begin{array}{l}\hat{0} \\
\vdots \\
0 \\
1\end{array}$ & 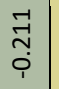 & 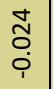 & 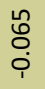 \\
\hline & 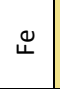 & $\begin{array}{l}\stackrel{0}{0} \\
0 \\
0\end{array}$ & 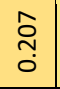 & $\begin{array}{l}\infty \\
\stackrel{1}{-1} \\
0\end{array}$ & $\begin{array}{l}\text { O̊ } \\
\text { Oे } \\
0\end{array}$ & \begin{tabular}{l}
$\vec{J}$ \\
\multirow{1}{*}{} \\
$\stackrel{0}{0}$
\end{tabular} & $\begin{array}{l}\text { ò } \\
\text { o. }\end{array}$ & $\begin{array}{l}\stackrel{M}{\hat{N}} \\
\stackrel{0}{0}\end{array}$ & $\begin{array}{l}m \\
m \\
m \\
i\end{array}$ & $\begin{array}{l}\infty \\
\stackrel{0}{0} \\
0\end{array}$ & $\begin{array}{l}\text { ष̊ } \\
\text { i. }\end{array}$ & 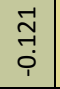 & $\begin{array}{l}\infty \\
\stackrel{\infty}{0} \\
0\end{array}$ & 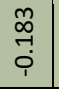 & 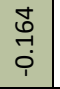 & 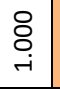 & \begin{tabular}{l}
$\mathscr{g}$ \\
\multirow{f}{0}{} \\
0
\end{tabular} & 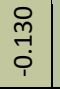 & $\begin{array}{c}\overrightarrow{1} \\
\overrightarrow{7} \\
0\end{array}$ & 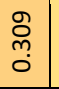 & ָ̃ ָָ & $\begin{array}{l}\hat{1} \\
\text { ने } \\
0\end{array}$ \\
\hline & $\stackrel{\text { ò }}{ }$ & 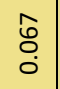 & $\begin{array}{l}\text { ָे } \\
\text { ¿ }\end{array}$ & $\begin{array}{l}\text { ¿े } \\
\text { ¿ }\end{array}$ & $\begin{array}{l}\stackrel{0}{\sim} \\
\stackrel{0}{0}\end{array}$ & 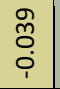 & 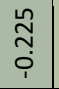 & \begin{tabular}{l}
$\infty$ \\
\multirow{1}{1}{} \\
$\stackrel{1}{1}$
\end{tabular} & $\begin{array}{l}\stackrel{0}{n} \\
\\
0\end{array}$ & $\begin{array}{l}n \\
0 \\
0 \\
0 \\
1\end{array}$ & $\begin{array}{l}\stackrel{0}{N} \\
\stackrel{0}{i}\end{array}$ & $\begin{array}{c}\mathbb{1} \\
0 \\
0 \\
i \\
1\end{array}$ & $\begin{array}{c}\tilde{n} \\
7 \\
i \\
i\end{array}$ & $\begin{array}{l}0 \\
o \\
0 \\
0\end{array}$ & 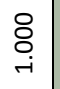 & 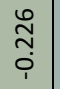 & 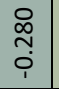 & 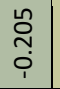 & \begin{tabular}{c}
$m$ \\
\multirow{7}{7}{} \\
$\vdots$ \\
$i$
\end{tabular} & $\begin{array}{l}\infty \\
0 \\
-1 \\
0 \\
1\end{array}$ & 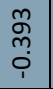 & $\begin{array}{l}\text { Iี } \\
\text { ¿. }\end{array}$ \\
\hline & 於 & 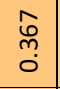 & $\begin{array}{l}\overrightarrow{\tilde{m}} \\
\stackrel{0}{0}\end{array}$ & $\begin{array}{l}0 \\
0 \\
0 \\
0\end{array}$ & $\begin{array}{l}\stackrel{\text { }}{f} \\
0 \\
0\end{array}$ & $\begin{array}{l}\hat{0} \\
\text { on } \\
0\end{array}$ & $\begin{array}{l}0 \\
\stackrel{0}{0} \\
0\end{array}$ & $\begin{array}{l}\tilde{\tilde{z}} \\
\dot{i} \\
\end{array}$ & $\begin{array}{l}\hat{n} \tilde{h} \\
\text { on }\end{array}$ & $\begin{array}{l}\tilde{O} \\
\stackrel{0}{0}\end{array}$ & $\begin{array}{l}\text { ọ̊ } \\
\text { in }\end{array}$ & $\stackrel{\infty}{\infty}$ & $\begin{array}{l}0 \\
\stackrel{1}{0} \\
0\end{array}$ & 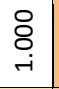 & $\begin{array}{l}\text { 胥 } \\
0 \\
0\end{array}$ & 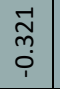 & 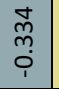 & $\begin{array}{l}\tilde{O} \\
0 \\
0\end{array}$ & \begin{tabular}{l}
\multirow{8}{*}{} \\
0 \\
0
\end{tabular} & 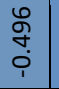 & 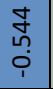 & 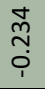 \\
\hline & $\frac{1}{2}$ & $\begin{array}{l}\text { fo } \\
0\end{array}$ & $\begin{array}{l}\vec{r} \\
m \\
0\end{array}$ & $\begin{array}{c}\text { ô } \\
\text { on }\end{array}$ & $\begin{array}{l}\text { ơ } \\
\text { o }\end{array}$ & $\begin{array}{l}\vec{f} \\
\text { 莒 }\end{array}$ & $\begin{array}{l}\overrightarrow{0} \\
0 \\
0\end{array}$ & $\begin{array}{l}\text { 足 } \\
\stackrel{1}{0}\end{array}$ & $\begin{array}{l}\stackrel{\leftrightarrow}{0} \\
\stackrel{a}{0}\end{array}$ & ôे & $\begin{array}{l}\tilde{Z} \\
0 \\
0\end{array}$ & $\begin{array}{l}\stackrel{\Im}{y} \\
\text { o }\end{array}$ & 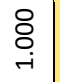 & \begin{tabular}{l}
\multirow{1}{7}{} \\
0
\end{tabular} & $\begin{array}{l}0 \\
0 \\
0 \\
i\end{array}$ & $\begin{array}{l}\hat{\delta} \\
0 \\
i\end{array}$ & $\begin{array}{l}\mathscr{0} \\
\stackrel{0}{0} \\
\dot{0}\end{array}$ & $\begin{array}{l}\text { ఫे } \\
0 \\
0\end{array}$ & $\begin{array}{l}\overrightarrow{\tilde{n}} \\
\dot{i} \\
\dot{i}\end{array}$ & 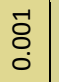 & $\begin{array}{l}\text { ôn } \\
\text { o. } \\
i\end{array}$ & 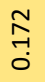 \\
\hline $\begin{array}{l}\sum_{0}^{N} \\
\text { U్ }\end{array}$ & a & $\begin{array}{l}\text { 莒 } \\
\text { on }\end{array}$ & \begin{tabular}{l}
$\stackrel{0}{f}$ \\
\multirow{f}{0}{}
\end{tabular} & $\begin{array}{c}\mathcal{N} \\
\stackrel{m}{0}\end{array}$ & $\begin{array}{l}\text { Pु } \\
\text { for }\end{array}$ & $\begin{array}{l}\overrightarrow{0} \\
0 \\
0\end{array}$ & \begin{tabular}{l}
\multirow{f}{f}{} \\
0
\end{tabular} & $\begin{array}{l}\overrightarrow{0} \\
\prod_{0}^{0}\end{array}$ & $\begin{array}{l}\stackrel{n}{N} \\
\stackrel{0}{0}\end{array}$ & $\begin{array}{l}0 \\
\stackrel{0}{h} \\
0\end{array}$ & 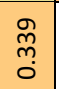 & 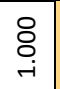 & 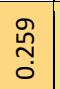 & $\begin{array}{l}\tilde{O} \\
\stackrel{0}{0} \\
0\end{array}$ & 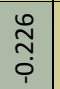 & $\begin{array}{l}0 \\
0 \\
0 \\
0 \\
i\end{array}$ & $\begin{array}{l}\tilde{\tilde{o}} \\
\dot{0} \\
\dot{i}\end{array}$ & 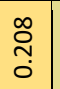 & 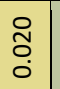 & 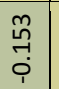 & $\begin{array}{l}\dot{y} \\
\text { o. } \\
\dot{0}\end{array}$ & 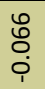 \\
\hline $\begin{array}{l}\stackrel{5}{\breve{~}} \\
\stackrel{\Sigma}{\Sigma}\end{array}$ & $>$ & 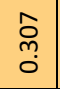 & $\begin{array}{l}\infty \\
\vec{m} \\
0\end{array}$ & $\begin{array}{l}0 \\
\stackrel{m}{1} \\
0\end{array}$ & $\begin{array}{l}\hat{n} \\
\text { ă } \\
0\end{array}$ & 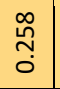 & 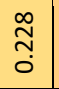 & $\begin{array}{c}\stackrel{m}{m} \\
0 \\
0\end{array}$ & $\begin{array}{l}0 \\
\text { ने } \\
0\end{array}$ & 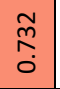 & $\underset{\text { ¿ }}{\stackrel{\text { }}{2}}$ & $\begin{array}{l}\stackrel{0}{\oplus} \\
\stackrel{\leftrightarrow}{0}\end{array}$ & $\begin{array}{l}\hat{f} \\
\dot{0}\end{array}$ & $\begin{array}{l}\stackrel{ \pm}{7} \\
\stackrel{0}{0}\end{array}$ & 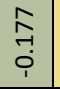 & $\begin{array}{l}\text { 巳q } \\
0 \\
0\end{array}$ & \begin{tabular}{l}
$\tilde{\sigma}$ \\
\multirow{2}{1}{} \\
$i$
\end{tabular} & $\begin{array}{l}g \\
0 \\
0 \\
0\end{array}$ & $\begin{array}{l}\tilde{N} \\
\stackrel{2}{0}\end{array}$ & 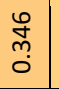 & ્ָ̃ & 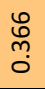 \\
\hline & 足 & $\begin{array}{l}0 \\
\stackrel{0}{0} \\
0\end{array}$ & $\begin{array}{l}0 \\
\hat{1} \\
0\end{array}$ & $\begin{array}{l}\stackrel{\sim}{\Im} \\
0\end{array}$ & 合 & $\begin{array}{l}\overrightarrow{0} \\
\stackrel{\leftrightarrow}{0} \\
0\end{array}$ & $\begin{array}{l}m \\
\vec{f} \\
0\end{array}$ & 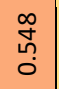 & $\begin{array}{l}\vec{N} \\
\stackrel{0}{0}\end{array}$ & 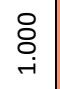 & $\begin{array}{l}\text { O̊. } \\
0\end{array}$ & $\begin{array}{l}\stackrel{n}{0} \\
\stackrel{0}{0}\end{array}$ & $\begin{array}{l}m \\
0 \\
0 \\
0\end{array}$ & $\begin{array}{l}\tilde{\Xi} \\
0 \\
0\end{array}$ & 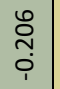 & $\begin{array}{l}\widetilde{\tilde{~}} \\
\text { i. }\end{array}$ & $\begin{array}{l}\infty \\
0 \\
0 \\
0\end{array}$ & $\begin{array}{l}\tilde{n} \\
\stackrel{\mathscr{O}}{0} \\
0\end{array}$ & $\begin{array}{l}m \\
\stackrel{m}{0} \\
0\end{array}$ & $\begin{array}{l}n \\
\tilde{n} \\
0 \\
i\end{array}$ & $\begin{array}{l}0 \\
\stackrel{7}{1} \\
0\end{array}$ & $\begin{array}{l}\text { o } \\
\stackrel{0}{0} \\
0\end{array}$ \\
\hline & $\stackrel{\infty}{\infty}^{\infty}$ & $\begin{array}{l}\text { o. } \\
\text { hִ } \\
0\end{array}$ & 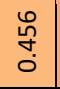 & $\begin{array}{l}\text { مे } \\
\text { مٌ }\end{array}$ & 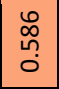 & $\begin{array}{l}\vec{R} \\
\stackrel{0}{0}\end{array}$ & $\begin{array}{l}\mathscr{N} \\
\stackrel{0}{0}\end{array}$ & 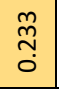 & 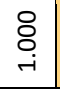 & $\begin{array}{l}\stackrel{\llcorner}{\infty} \\
\stackrel{0}{0}\end{array}$ & 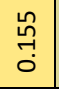 & $\begin{array}{l}\infty \\
0 \\
\vdots \\
i\end{array}$ & ठ̊̆ & 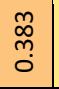 & $\begin{array}{l}0 \\
\stackrel{\leftrightarrow}{0} \\
0\end{array}$ & 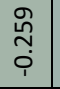 & 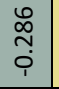 & $\begin{array}{l}0 \\
0 \\
0 \\
0\end{array}$ & $\begin{array}{l}\tilde{0} \\
0 \\
0 \\
0\end{array}$ & 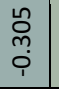 & 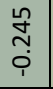 & $\begin{array}{l}\text { ָ̃̃ } \\
\text { în }\end{array}$ \\
\hline & $\stackrel{\circ}{\Sigma}$ & $\begin{array}{l}0 \\
0 \\
0 \\
0\end{array}$ & $\begin{array}{c}9 \\
1 \\
0 \\
0\end{array}$ & $\begin{array}{l}m \\
0 \\
0 \\
0\end{array}$ & $\begin{array}{l}0 \\
: \\
0 \\
0\end{array}$ & $\begin{array}{l}\tilde{N} \\
\\
0\end{array}$ & $\begin{array}{l}8 \\
\stackrel{2}{0} \\
0\end{array}$ & $\begin{array}{l}\text { ৪ } \\
-i\end{array}$ & 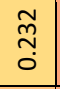 & $\begin{array}{l}\text { o } \\
\text { } \\
0\end{array}$ & $\begin{array}{l}\hat{0} \\
\tilde{m} \\
0\end{array}$ & 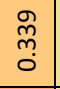 & 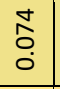 & $\begin{array}{l}n \\
0 \\
0 \\
0\end{array}$ & $\begin{array}{l}0 \\
\stackrel{0}{0} \\
0 \\
1\end{array}$ & $\begin{array}{l}0 \\
\stackrel{0}{0} \\
0 \\
i\end{array}$ & $\begin{array}{l}\overrightarrow{7} \\
0 \\
0\end{array}$ & $\begin{array}{l}0 \\
0 \\
0 \\
0\end{array}$ & $\begin{array}{l}\hat{n} \\
0 \\
0 \\
0\end{array}$ & \begin{tabular}{c}
$\infty$ \\
$\infty$ \\
\hdashline \\
0 \\
1
\end{tabular} & $\begin{array}{l}m \\
\stackrel{0}{0} \\
0\end{array}$ & 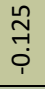 \\
\hline & 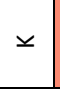 & $\begin{array}{l}\overrightarrow{0} \\
0 \\
0\end{array}$ & 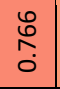 & $\begin{array}{l}\mathscr{l} \\
0 \\
0 \\
0\end{array}$ & 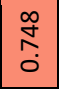 & $\begin{array}{l}\frac{m}{\mathcal{1}} \\
0 \\
0\end{array}$ & 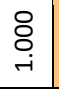 & $\begin{array}{l}m \\
\vec{J} \\
0\end{array}$ & $\begin{array}{l}\text { ơ } \\
\text { ơ }\end{array}$ & $\begin{array}{l}\text { 员 } \\
\text { مٌ }\end{array}$ & $\begin{array}{l}\hat{n} \\
0\end{array}$ & $\begin{array}{l}m \\
\hat{n} \\
0\end{array}$ & $\begin{array}{l}\widetilde{0} \\
\stackrel{?}{0}\end{array}$ & 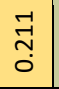 & $\begin{array}{l}0 \\
\stackrel{0}{1} \\
\stackrel{1}{1}\end{array}$ & 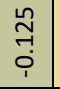 & $\begin{array}{l}\hat{n} \\
\text { o } \\
0\end{array}$ & $\begin{array}{l}\stackrel{0}{0} \\
0 \\
0\end{array}$ & $\begin{array}{l}\tilde{o} \\
\grave{i} \\
i\end{array}$ & 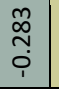 & $\begin{array}{l}\overrightarrow{0} \\
0 \\
i \\
i\end{array}$ & 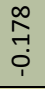 \\
\hline & $\bar{\mho}$ & $\begin{array}{c}n \\
0 \\
0 \\
0 \\
0\end{array}$ & \begin{tabular}{l}
\multirow{J}{0}{} \\
$\stackrel{0}{0}$ \\
\end{tabular} & $\begin{array}{l}m \\
\infty \\
0 \\
0 \\
0\end{array}$ & $\begin{array}{l}\stackrel{0}{0} \\
\stackrel{0}{0} \\
0\end{array}$ & 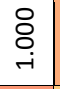 & $\begin{array}{l}0 \\
0 \\
\vdots \\
0 \\
0\end{array}$ & $\begin{array}{l}m \\
\overrightarrow{7} \\
0\end{array}$ & 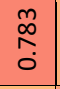 & $\begin{array}{l}\text { mે } \\
\text { م્ }\end{array}$ & 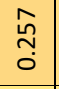 & $\stackrel{\substack{\sim \\
0}}{0}$ & 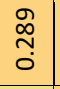 & 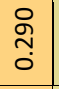 & $\begin{array}{l}0 \\
0 \\
0 \\
i\end{array}$ & 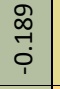 & $\begin{array}{l}\overrightarrow{\tilde{D}} \\
\dot{0}\end{array}$ & \begin{tabular}{l}
\multirow{I}{*}{} \\
0
\end{tabular} & $\begin{array}{l}0 \\
0 \\
0 \\
0\end{array} \mid$ & 总 & 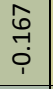 & $\begin{array}{l}\hat{\Omega} \\
0 \\
0 \\
i\end{array}$ \\
\hline & $\sum^{\infty}$ & $\left|\begin{array}{c}1 \\
\infty \\
0 \\
0\end{array}\right|$ & $\begin{array}{l}\stackrel{+}{0} \\
\infty \\
0\end{array}$ & $\begin{array}{l}\hat{\tilde{\sigma}} \\
0 \\
0\end{array}$ & $\underset{i}{\stackrel{\leftrightarrow}{0}}$ & $\begin{array}{l}\infty \\
0 \\
0 \\
0\end{array}$ & $\begin{array}{c}\stackrel{\text { fે }}{\mathrm{m}} \\
0\end{array}$ & $\begin{array}{l}\text { ô } \\
\text { ڤn } \\
0\end{array}$ & $\begin{array}{l}\text { 导 } \\
0\end{array}$ & $\begin{array}{l}\stackrel{0}{0} \\
\text { ஸn } \\
0\end{array}$ & กี & $\stackrel{\substack{n \\
0}}{0}$ & $\begin{array}{l}\overrightarrow{0} \\
0 \\
0\end{array}$ & $\begin{array}{l}\vec{D} \\
\stackrel{2}{0}\end{array}$ & $\begin{array}{l}0 \\
\tilde{D} \\
0\end{array}$ & 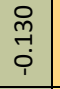 & 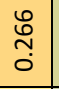 & $\begin{array}{l}0 \\
0 \\
0 \\
i\end{array}$ & $\begin{array}{l}\tilde{O} \\
0 \\
0\end{array}$ & 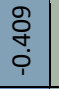 & 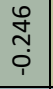 & $\begin{array}{c}\text { J } \\
\text { - } \\
\end{array}$ \\
\hline & త & $\begin{array}{l}\hat{f} \\
\infty \\
0 \\
0\end{array}$ & $\begin{array}{c}0 \\
0 \\
\infty \\
0 \\
0\end{array}$ & 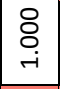 & $\begin{array}{c}\tilde{0} \\
\infty \\
0 \\
0\end{array}$ & \begin{tabular}{l} 
o. \\
$\stackrel{\infty}{0}$ \\
\hdashline
\end{tabular} & 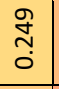 & $\begin{array}{l}\text { fy } \\
\text { O }\end{array}$ & $\begin{array}{l}\text { ⿰彳 } \\
\text { fे }\end{array}$ & $\begin{array}{c}\hat{m} \\
\stackrel{y}{0}\end{array}$ & $\stackrel{m}{7}$ & $\begin{array}{l}0 \\
\stackrel{1}{0}\end{array}$ & $\begin{array}{l}\text { ָ̊ } \\
\text { Oे }\end{array}$ & $\begin{array}{c}\text { o. } \\
\text { ñ. } \\
0\end{array}$ & $\begin{array}{l}\infty \\
\stackrel{1}{0} \\
0\end{array}$ & 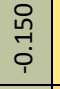 & \begin{tabular}{l}
0 \\
\multirow{2}{1}{} \\
0
\end{tabular} & $\begin{array}{l}\hat{m} \\
\vec{p} \\
\hat{1}\end{array}$ & $\begin{array}{c}m \\
\stackrel{m}{a} \\
0\end{array}$ & 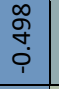 & $\begin{array}{c}m \\
m \\
m \\
i \\
i\end{array}$ & $\begin{array}{l}\text { ָे } \\
\text { ָे }\end{array}$ \\
\hline & $\dot{\tilde{r}}_{+}^{+}$ & 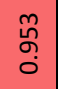 & 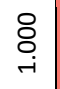 & $\begin{array}{l}0 \\
0 \\
\infty \\
0\end{array}$ & $\begin{array}{c}\infty \\
\infty \\
\infty \\
0\end{array}$ & 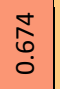 & $\begin{array}{l}\stackrel{n}{0} \\
0 \\
0\end{array}$ & 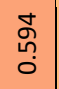 & 旁 & $\begin{array}{l}\overrightarrow{6} \\
0 \\
0\end{array}$ & 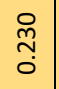 & 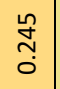 & $\begin{array}{l}\text { ô. } \\
\text { O. }\end{array}$ & $\begin{array}{c}0 \\
m \\
0 \\
0\end{array}$ & 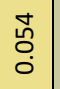 & $\begin{array}{c}m \\
7 \\
\vdots \\
1\end{array}$ & $\begin{array}{l}\stackrel{\infty}{\sim} \\
0 \\
0\end{array}$ & $\begin{array}{c}\vec{J} \\
\overrightarrow{7} \\
\dot{1}\end{array}$ & $\begin{array}{l}\overrightarrow{1} \\
\overrightarrow{9} \\
0\end{array}$ & 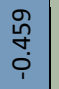 & 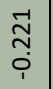 & $\begin{array}{l}\text { ind } \\
\text { ind }\end{array}$ \\
\hline & بن & $\underset{+}{\stackrel{\leftrightarrow}{-}}$ & $\begin{array}{l}\infty \\
\stackrel{\infty}{0} \\
0 \\
0\end{array}$ & $\begin{array}{l}\infty \\
0 \\
\infty \\
0 \\
0\end{array}$ & $\begin{array}{c}N \\
\infty \\
0 \\
0\end{array}$ & $\begin{array}{l}\begin{array}{c}0 \\
\infty \\
0 \\
0\end{array}\end{array}$ & $\begin{array}{l}0 \\
0 \\
⿱ 亠 乂 \\
0\end{array}$ & $\begin{array}{l}0 \\
\hat{n} \\
0\end{array}$ & $\begin{array}{l}\infty \\
\infty \\
0 \\
0\end{array}$ & $\begin{array}{l}\infty \\
0 \\
0 \\
0\end{array}$ & $\begin{array}{l}\stackrel{0}{N} \\
0 \\
0\end{array}$ & 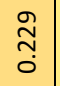 & $\begin{array}{l}\hat{m} \\
\stackrel{\theta}{0}\end{array}$ & 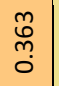 & $\begin{array}{l}\stackrel{n}{2} \\
0 \\
0\end{array}$ & 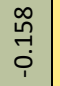 & 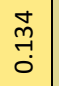 & $\begin{array}{l}0 \\
0 \\
0 \\
i\end{array}$ & $\begin{array}{l}\stackrel{\infty}{0} \\
\stackrel{?}{0} \\
0\end{array}$ & 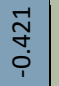 & 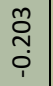 & 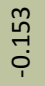 \\
\hline & & 状 & 告 & త & $\sum^{\infty}$ & $\bar{U}$ & 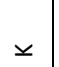 & $\sum^{\circ}$ & $\stackrel{0}{n}^{\infty}$ & $\frac{\pi}{4}$ & $>$ & Ot & $\stackrel{\tilde{O}}{2}$ & in & 0 & $\ddot{L}$ & $\sum^{\complement}$ & 조 & & $\frac{I}{\alpha}$ & $\frac{\pi}{2}$ & \\
\hline
\end{tabular}


Teniendo en cuenta, además, la composición predominante de las aguas en las tres unidades del acuífero, se podría concluir que los procesos de interacción aguasedimento son diferentes en el acuífero detrítico profundo, cuyas aguas son bicarbonatadas sódicas, a diferencia de las facies de los acuíferos aluvial y carbonatado, con predominancia de metales alcalinotérreos y sulfatos. Para comprobar este punto se han representado, frente a la concentración de arsénico, los aniones más abundantes, bicarbonato (Fig. IV.24b) y sulfato (Fig. IV.24c). Dado que los resultados obtenidos en las representaciones de los distintos parámetros frente al arsénico son similares para ambos muestreos, se ha optado por mostrar únicamente los gráficos para el muestreo M2.
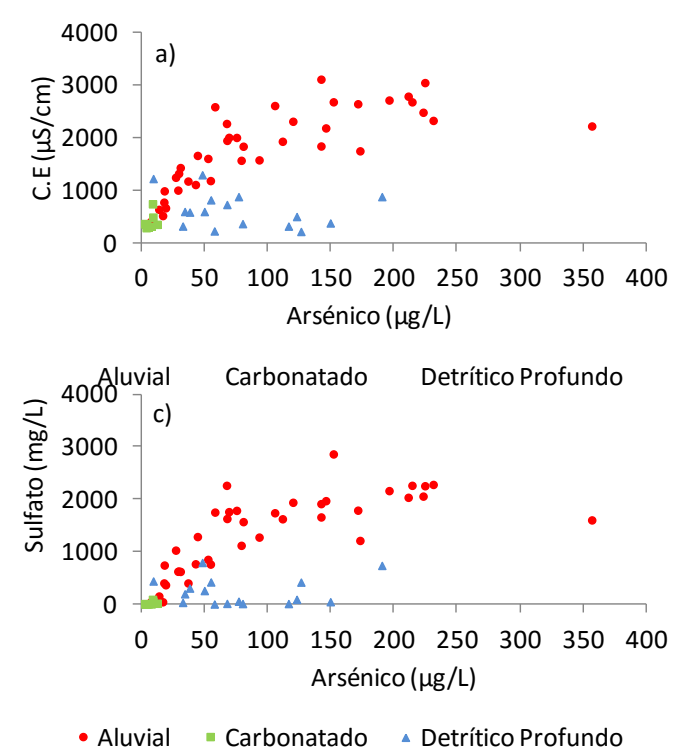

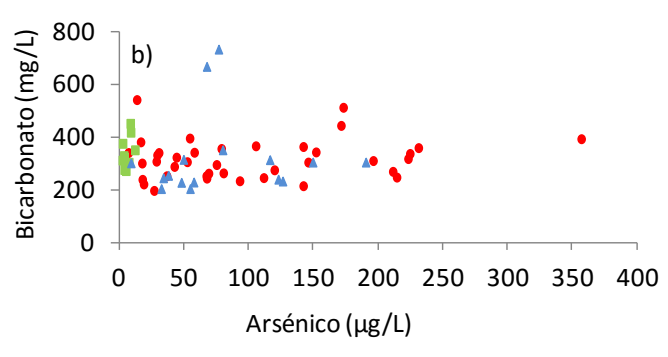

Aluvial Carbonatado Detrítico Profundo

Fig. IV.24. a) Representación de C.E frente a As; b) Representación de bicarbonato frente a As; c) Representación de sulfato frente a As

Se observa, en cada unidad hidrológica, una relación entre el arsénico y el sulfato similar a las observadas con la conductividad. Sin embargo, no se observa correlación del arsénico con el bicarbonato.

Muchos estudios relacionan el vanadio, molibdeno y fosfato con elevados niveles de arsénico en aguas subterráneas (Smedley y col., 2002; Nicolli y col., 1989; Nicolli y Merino, 2000; Blarasin y col., 2000; Farnfield y col., 2012). En este estudio también se ha encontrado esta correlación positiva significativa.

La Fig. IV.25 muestra, por unidad hidrológica, la relación entre cada una de estas variables con el nivel de arsénico en agua, se observa que el vanadio es que presenta mayor correlación con el arsénico, en los tres acuíferos. En el gráfico del fosfato se han eliminado tres puntos con elevados contenidos, para poder observar la tendencia que siguen los puntos. 

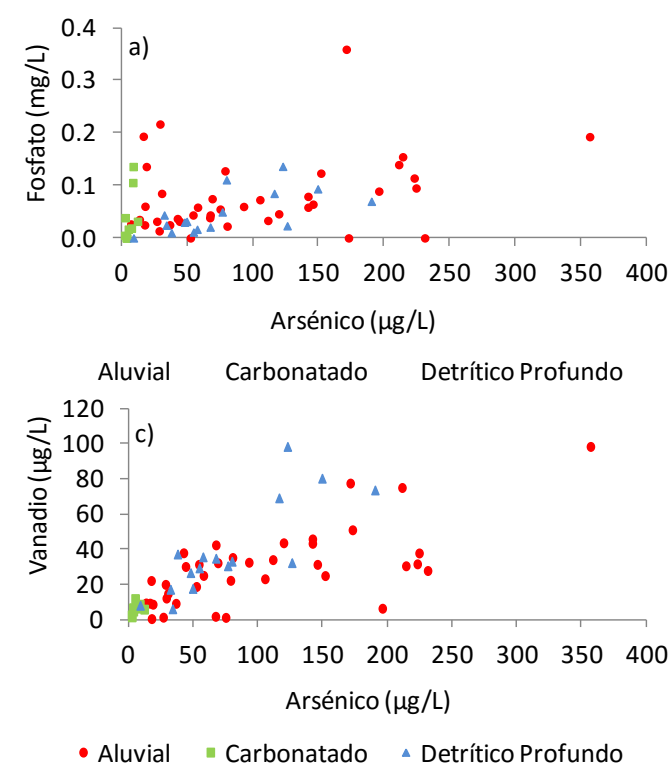

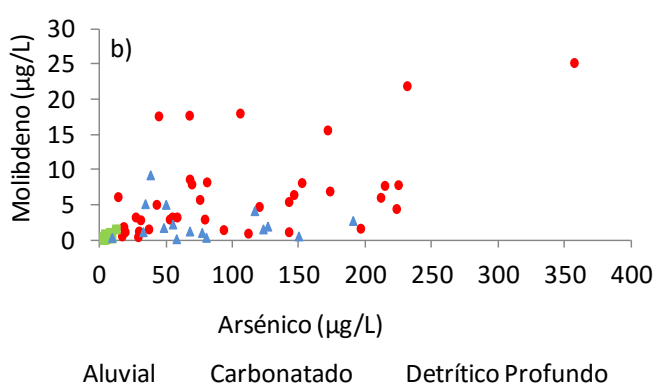

Aluvial

Fig. IV.25. a) Representación de P frente a As; b) Representación de Mo frente a As; c) Representación de $\mathrm{V}$ frente a As.

Las variables $\mathrm{pH}$, sodio y temperatura están fuertemente correlacionadas entre sí, y negativamente con el grupo de iones relacionados con la conductividad eléctrica. Esto parece indicar un origen diferenciado de las aguas alcalino-sódicas (acuífero profundo, con aguas a mayor temperatura), del resto de aguas, más salinas y con temperaturas más bajas por estar los puntos de muestreo (pozos y manantiales) más influenciados por la temperatura del aire.

Otras correlaciones positivas significativas de interés son las existentes entre hierro y manganeso, pudiendo indicar que estos dos elementos aparecen en el agua por procesos químicos similares (disolución de óxidos e hidróxidos), o la existente entre potasio y fosfato, que podrían tener un origen antropogénico causado por el uso de fertilizantes químicos en agricultura.

\section{IV.4.5. ANÁLISIS MULTIVARIANTE}

Para resaltar las diferencias y similitudes composicionales entre las muestras analizadas se aplicaron técnicas estadísticas multivariantes de clasificación (análisis clúster jerarquizado no supervisado, HCA), y de visualización (análisis en componentes principales, ACP)

A fin de disminuir la información irrelevante de la matriz de datos que aumenta la varianza residual, se decidió eliminar en ambos muestreos la variable Temperatura, ya que el valor de esta, en los acuíferos superficiales, depende de las condiciones meteorológicas y la variable de oxígeno disuelto, ya que no presenta correlaciones prácticamente con ninguno de los parámetros analizados o estas son muy débiles. 


\section{IV.4.5.1 Análisis clúster jerarquizado}

El análisis de conglomerados o análisis clúster agrupa las muestras de agua basándose en sus similitudes composicionales. Los dendrogramas resultantes para las muestras y para los parámetros de los muestreos M1 y M2 se presentan en las Fig. IV.26 y Fig. IV.27, respectivamente. Han sido complementados con un mosaico de colores para una mejor interpretación. Así, los colores azules oscuros muestran valores mínimos de concentración, que irán variando hacia colores rojos al aumentar la concentración del parámetro.

En la Fig. IV.26, correspondiente al muestreo M1, se aprecian cuatro grupos de variables (CV1, CV2, CV3 y CV4) y cinco agrupaciones de muestras (CM1, CM2, CM3, CM4 y CM5).

Las agrupaciones de variables que se observan son: conductividad, sulfato, cloruro, nitrato, calcio y magnesio en el grupo $\mathrm{CV} 1$; en el grupo $\mathrm{CV} 2$ se asocian $\mathrm{pH}$, sodio, bicarbonato y fluoruro; el conglomerado $\mathrm{CV} 3$, se encuentra formado por hierro y manganeso y, por último, en el arsénico, molibdeno, fosfato y fluoruro se agrupan en CV4.

La primera agrupación de muestras, CM1, no presenta apenas concentraciones destacables en ningún parámetro analizado salvo niveles moderados de bicarbonato y de $\mathrm{pH}$. Son destacables los bajos niveles de arsénico en este grupo de muestras. Estas muestras pertenecen mayoritariamente al acuífero carbonatado.

Las muestras pertenecientes al grupo $\mathrm{CM} 2$ poseen altos valores de $\mathrm{pH}$ y sodio y alguna muestra de este grupo posee relevantes niveles de bicarbonato, fluoruro (CV2). La concentración de arsénico en estas muestras varía dependiendo del subgrupo en el que se encuentren, y cabe destacar concentraciones moderadas para algunos subgrupos.

En el grupo $\mathrm{CM} 3$ encontramos muestras con niveles moderados de los parámetros pertenecientes al grupo CV1, relacionadas con la salinidad. Un subgrupo de estas muestras son las que mayores contenidos presentan de hierro y manganeso (CV3) y el otro subgrupo de muestras presentan elevados niveles de algunos parámetros del grupo CV4, en el que está incluido el arsénico.

Concentraciones moderadas de los grupos de variables CV1 y CV2 se hallan en el grupo de muestras etiquetadas como CM4. En este grupo no se observan concentraciones elevadas de ningún parámetro.

Los mayores valores de salinidad (CV1) se encuentran en el grupo de muestras CM5. Este grupo se caracteriza además por poseer moderadas concentraciones de arsénico, molibdeno y fluoruro.

En la Fig. IV.27 se muestran los resultados del análisis de conglomerados para el muestreo M2. Al igual que en el muestreo M1, se observan cuatro agrupamientos de variables, CV1, CV2, CV3 y CV4 y cinco conglomerados de muestras, CM1, CM2, CM3, CM4 y CM5.

En el agrupamiento de variables CV1 encontramos de nuevo parámetros relacionados con la salinidad (conductividad, sulfato, cloruro, nitrato, calcio, magnesio y sílice). El arsénico se encuentra asociado al vanadio, fosfato, potasio, molibdeno y nitrito en el 
grupo CV2; el vanadio y el nitrito se han determinado solamente en el muestreo M2. Hierro y manganeso aparecen también juntos en el grupo CV3. Y en el grupo CV4 tenemos los parámetros bicarbonato, fluoruro, $\mathrm{pH}$ y sodio, esta misma asociación de parámetros la encontramos también en el muestreo M1.

El grupo de muestras CM1 solamente presenta niveles moderadamente reseñables de bicarbonato y sílice; sin embargo, la concentración de arsénico en estas muestras es baja. Las muestras de este grupo pertenecen al acuífero carbonatado. Esta agrupación de muestras presenta características similares a la agrupación CM1 del muestreo M1

Los niveles más elevados del grupo de variables CV3 (hierro y manganeso) se dan en el grupo de muestras CM2. La concentración de las variables CV1 (aquellas relacionadas con la salinidad) diferencian dos subgrupos dentro de este grupo, con niveles moderados y bajos de estas variables, respectivamente. Las concentraciones de arsénico en este grupo no son destacables, a excepción de un par de muestras.

Las muestras del grupo $\mathrm{CM} 3$ exhiben relativa heterogeneidad entre ellas aunque se observan, en general, valores moderados del grupo de variables CV1 (relacionadas con la salinidad). Una de las muestras de este grupo posee un alto contenido en potasio, posiblemente debido a contaminación antropogénica relacionada con el uso de fertilizantes inorgánicos.

Las muestras del acuífero detrítico profundo, de naturaleza predominantemente bicarbonatada-sódica se agrupan fundamentalmente en el clúster CM4 que, como se puede observar, poseen un alto contenido en $\mathrm{pH}$ y sodio y escasos contenidos en los grupos de variables CV1 (relacionadas con la salinidad). A pesar de que los contenidos de bicarbonato y fluoruro son bajos en este grupo, dos muestras presentan valores elevados de estos parámetros. Cabe destacar también que algunas muestras presentan elevados contenidos en arsénico y vanadio.

El grupo de muestras CM5 es el que presenta mayores contenidos para las variables asociadas a los grupos CV1 y CV2, que se corresponden con variables asociadas a la conductividad (iones mayoritarios) y metales como arsénico, vanadio o molibdeno.

\section{IV.4.5.2 Análisis en componentes principales (ACP)}

El análisis en componentes principales (ACP) permite extraer información relacionada con la existencia de diferentes clases de objetos y variables en un espacio de dimensiones más reducido, facilitando así la visualización de las correlaciones entre muestras y/o variables.

A la vista de los resultados obtenidos en el clúster del muestreo $M 2$, se ha decidido no incluir en este análisis las variables sílice y nitrito. 

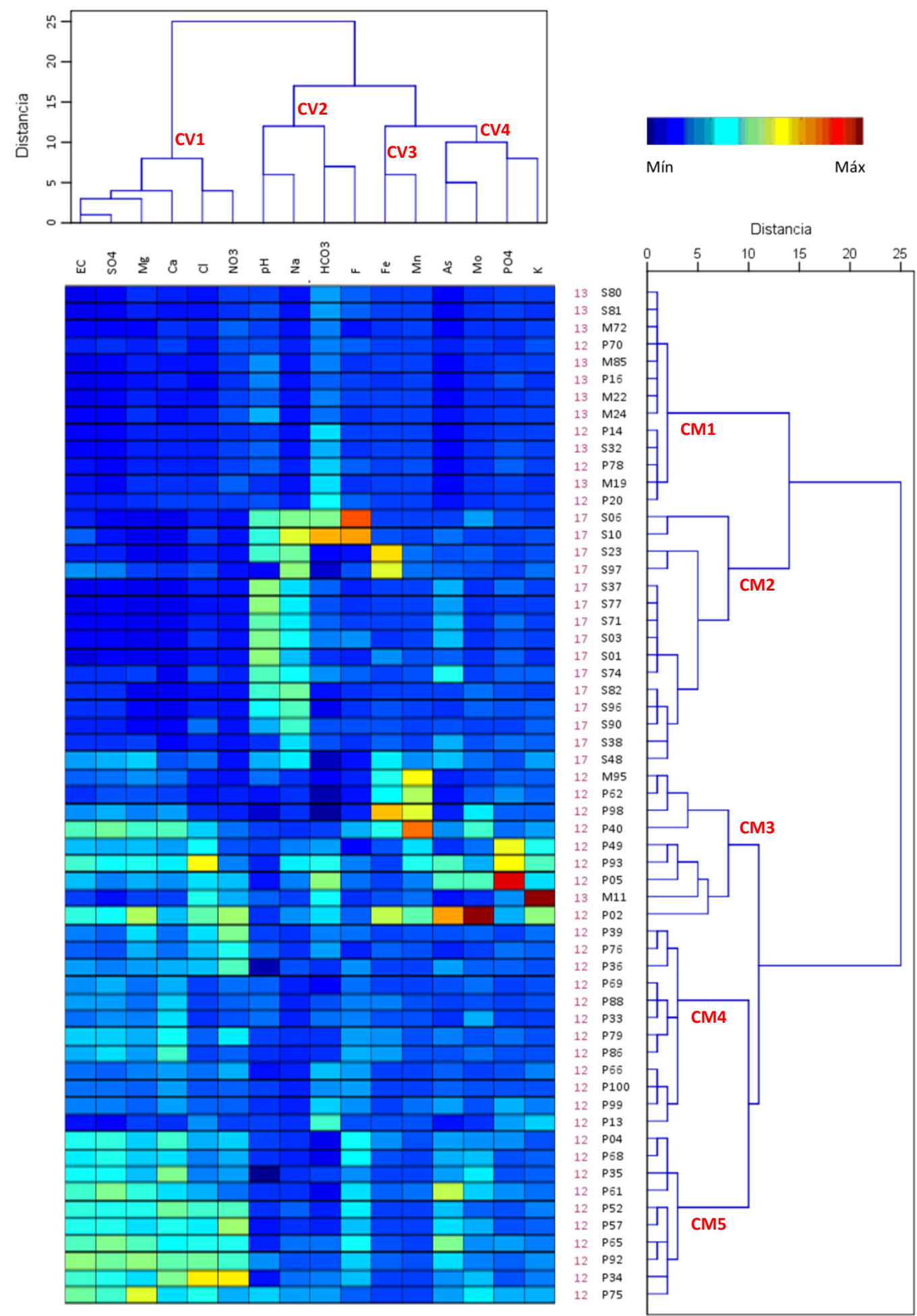

Fig. IV.26. Análisis clúster de los datos del muestreo M1 

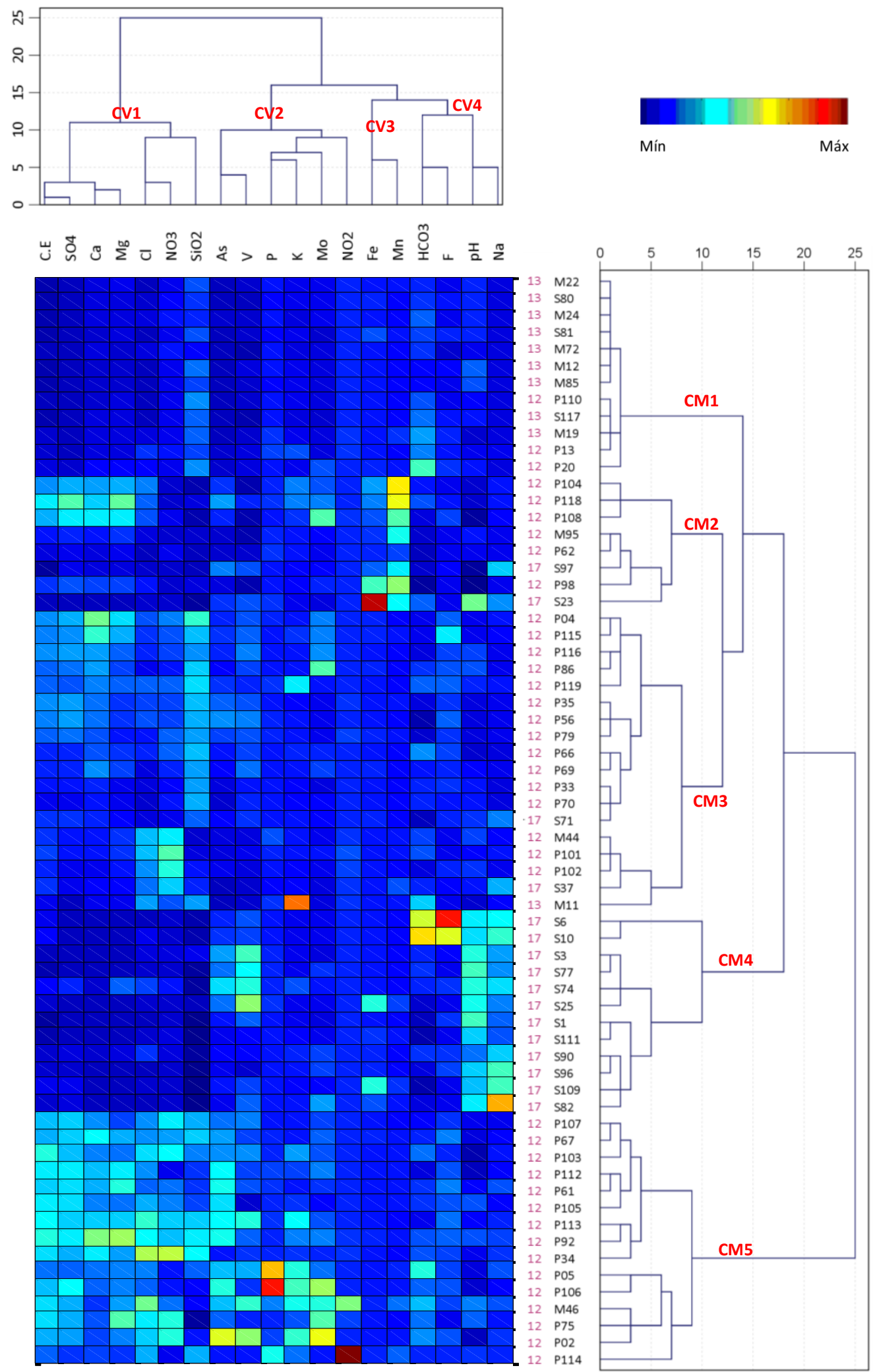

Fig. IV.27. Análisis clúster de los datos del muestreo M2 
Un paso previo a la visualización de los datos que nos proporcionará el ACP es la reducción de la dimensionalidad de la tabla original. Para ello se parte de la hipótesis de que no todas las variables contienen información relevante sobre los objetos, y que algunas variables están correlacionadas entre sí, por lo que existirá información redundante $y$, por tanto, la reducción en su número no implica una pérdida significativa de información.Teniendo en cuenta esta hipótesis, vamos a mantener únicamente aquellos componentes cuyo autovalor o valor propio sea mayor que la unidad, es decir, aquellos que explican más porcentaje de varianza que una variable original.

Al aplicar el ACP a las matrices de datos de los dos muestreos, formadas por las 16 variables elegidas y 59 muestras de aguas en el caso del muestreo M1, y 21 variables y 66 muestras de aguas en el muestreo $M 2$, se obtienen los valores propios mostrados en la Fig. IV.28 para los muestreos M1 y M2, respectivamente, donde se aprecia que hay 4 componentes principales (PCs) que poseen un autovalor mayor que la unidad para el muestreo 1 y 5 para el muestreo M2.

Como se demostró previamente (Tabla IV.11 y Tabla IV.12), algunas variables están débilmente correlacionadas con el resto, por lo que se decidió no incluirlas en el ACP para, de esa forma, reducir aún más el número de variables (PCs) latentes. Así, se excluyeron las variables temperatura, oxígeno disuelto, nitrito y sílice.

La Tabla IV.13 muestra las cargas de los nuevos factores para ambos muestreos, esto es, los coeficientes que muestran la participación de las variables originales en los PCs. Adicionalmente, se muestran sus correspondientes autovalores, la varianza explicada por cada PC y la varianza acumulada.

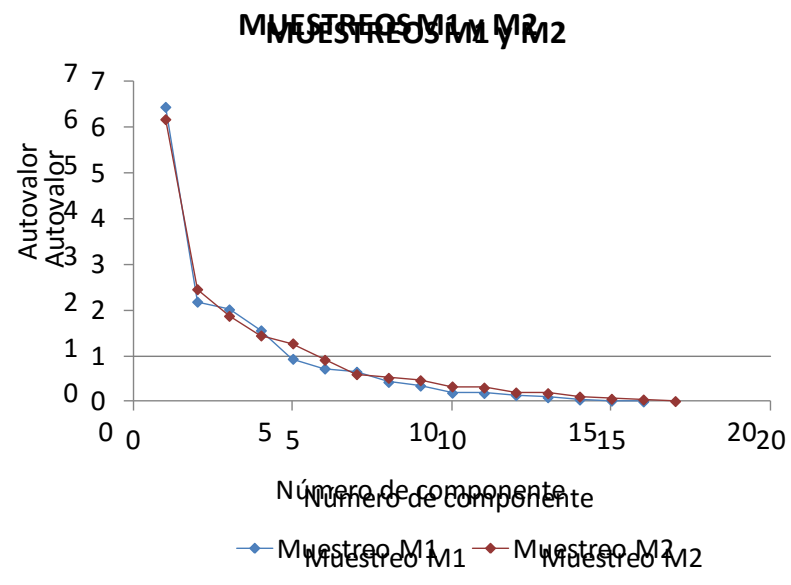

Fig. IV.28. Gráfico de autovalores de los muestreos M1 y M2.

Se observa que, para el muestreo M1, los cuatro primeros PCs explican el 76,4\% de la varianza contenida en el conjunto de datos, y para el muestreo M2 los 5 primeros PCs explican el $77,9 \%$ de la varianza consiguiendo una importante reducción de la dimensionalidad de los datos. Cada nuevo componente principal se puede interpretar en función de la combinación de las variables originales más correlacionadas con él. De 
esta manera se han marcado en negrita las correlaciones más significativas dentro de cada componente.

Tabla IV.13. Cargas de los componentes principales retenidos

\begin{tabular}{|c|c|c|c|c|c|c|c|c|c|}
\hline & & MUEST & 三 M1 & & & & ESTREO & & \\
\hline & PC1 & PC2 & PC3 & PC4 & PC1 & PC2 & PC3 & PC4 & PC5 \\
\hline C.E & 0,951 & 0,034 & $-0,023$ & 0,214 & 0,955 & $-0,021$ & 0,047 & $-0,104$ & 0,137 \\
\hline $\mathrm{pH}$ & $-0,552$ & 0,403 & 0,353 & 0,346 & $-0,491$ & 0,635 & 0,240 & $-0,301$ & $-0,006$ \\
\hline $\mathrm{Cl}$ & 0,849 & 0,282 & $-0,055$ & $-0,144$ & 0,832 & 0,040 & $-0,152$ & $-0,114$ & $-0,102$ \\
\hline $\mathrm{HCO}_{3}{ }^{-}$ & $-0,092$ & 0,776 & $-0,097$ & $-0,356$ & 0,028 & 0,508 & $-0,459$ & 0,459 & 0,353 \\
\hline $\mathrm{SO}_{4}{ }^{2-}$ & 0,922 & $-0,115$ & $-0,032$ & 0,274 & 0,930 & $-0,098$ & 0,196 & $-0,056$ & 0,148 \\
\hline $\mathrm{F}^{-}$ & 0,208 & 0,553 & $-0,137$ & 0,488 & 0,109 & 0,541 & $-0,319$ & 0,109 & 0,690 \\
\hline $\mathrm{NO}_{3}^{-}$ & 0,763 & 0,081 & $-0,361$ & 0,019 & 0,609 & $-0,084$ & $-0,393$ & $-0,417$ & $-0,136$ \\
\hline P & 0,370 & 0,362 & 0,231 & $-0,552$ & 0,338 & 0,256 & $-0,015$ & 0,622 & $-0,400$ \\
\hline $\mathrm{Ca}$ & 0,869 & $-0,181$ & $-0,311$ & 0,142 & 0,837 & $-0,239$ & 0,049 & $-0,130$ & 0,259 \\
\hline $\mathrm{Mg}$ & 0,941 & $-0,043$ & $-0,021$ & 0,049 & 0,894 & $-0,132$ & 0,149 & $-0,052$ & 0,203 \\
\hline $\mathrm{Na}$ & $-0,240$ & 0,509 & 0,596 & 0,388 & $-0,267$ & 0,669 & 0,298 & $-0,138$ & 0,122 \\
\hline K & 0,383 & 0,260 & 0,229 & $-0,598$ & 0,546 & 0,204 & $-0,089$ & 0,468 & $-0,362$ \\
\hline As & 0,662 & 0,338 & 0,336 & 0,206 & 0,711 & 0,477 & 0,232 & $-0,093$ & $-0,124$ \\
\hline $\mathrm{Fe}$ & 0,170 & $-0,473$ & 0,726 & 0,093 & $-0,221$ & 0,037 & 0,745 & 0,076 & 0,078 \\
\hline $\mathrm{Mn}$ & 0,336 & $-0,428$ & 0,581 & $-0,214$ & 0,115 & $-0,319$ & 0,695 & 0,373 & 0,296 \\
\hline Mo & 0,690 & 0,055 & 0,443 & $-0,021$ & 0,665 & 0,237 & 0,177 & 0,179 & $-0,102$ \\
\hline $\mathrm{V}$ & -- & -- & -- & -- & 0,313 & 0,686 & 0,208 & $-0,321$ & $-0,264$ \\
\hline Autovalor & 6,45 & 2,19 & 2,02 & 1,56 & 6,18 & 2,46 & 1,88 & 1,45 & 1,27 \\
\hline$\%$ var. explicada & 40,3 & 13,7 & 12,6 & 9,8 & 36,4 & 14,5 & 11,0 & 8,5 & 7,5 \\
\hline$\%$ var. acumulada & 40,3 & 54,0 & 66,6 & 76,4 & 36,4 & 50,9 & 61,9 & 70,4 & 77,9 \\
\hline
\end{tabular}

Los dos primeros componentes explican conjuntamente más de la mitad $(54,0 \%$ y $50,9 \%$ para el muestro $\mathrm{M} 1$ y $\mathrm{M} 2$, respectivamente) de la información de las variables originales. Las cargas de los factores representan las proyecciones de las variables originales en el subespacio de los componentes principales y pueden ser interpretados como coeficientes de correlación entre los componentes principales (PC) y las variables. La representación de las cargas de estos dos primeros componentes (Fig. IV.29) nos permitirá visualizar si hay agrupaciones importantes entre las variables. Se han señalado, mediante elipses, las principales agrupaciones de variables obtenidas. Puede observarse que los agrupamientos coinciden con los obtenidos por análisis clúster (Fig. IV.26 y Fig. IV.27).

A la vista de la Tabla IV.13 y de la Fig. IV.29 se observa que los agrupamientos de las variables en los PCs son muy similares en ambos muestreos.

Así, las variables C.E, cloruro, sulfato, nitrato, calcio, magnesio, arsénico y molibdeno quedan agrupadas en el PC1 con signo positivo. Dado que este factor está asociado a los cationes y aniones mayoritarios, se podría relacionar con la salinidad debida a sustancias procedentes tanto de procesos naturales (disolución de minerales) como antrópicos (disolución de fertilizantes agrícolas), con una alta solubilidad. Este PC1 explica un 40,3\% de la de la varianza total de la matriz de datos en el muestreo M1 y un $36,4 \%$ en el muestreo M2. 


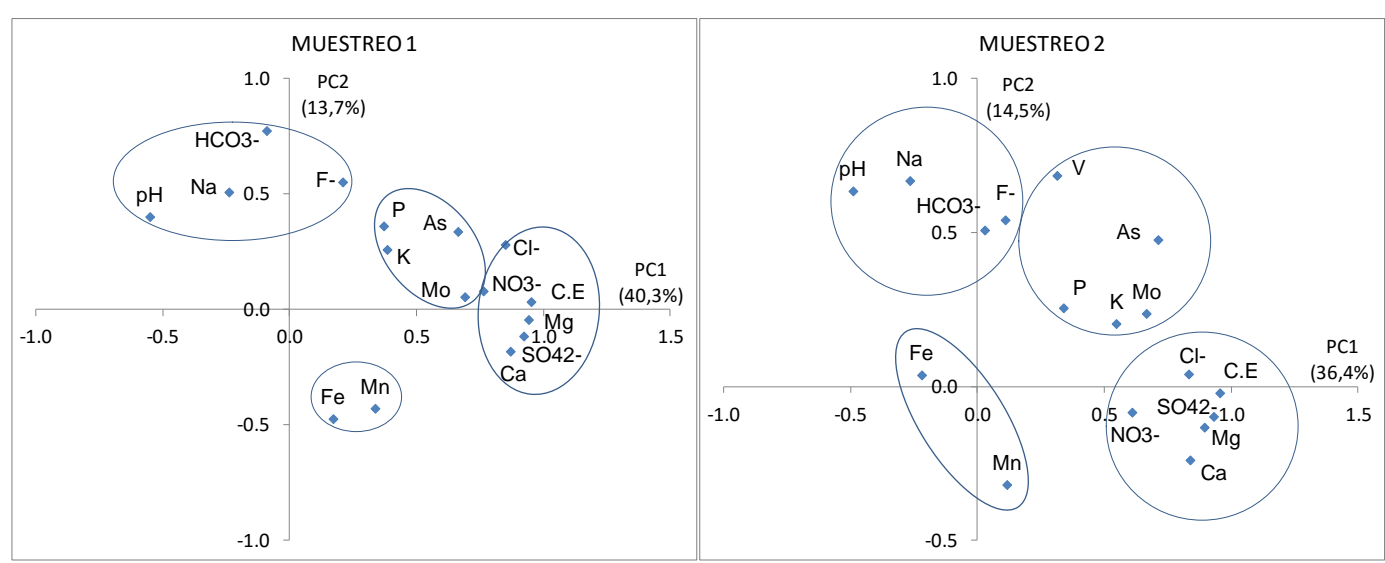

Fig. IV.29. Representación de las cargas de los dos primeros PCs para los muestreos M1 y M2.

El pH presenta cargas de similar magnitud pero distinto signo en los dos primeros PCs. Así, mientras en PC1 aparece con carga negativa, indicando correlación negativa con las otras variables agrupadas en este PC, en el PC2 aparece con carga positiva, asociado con bicarbonato, sodio y fluoruro y, en el muestreo $\mathrm{M} 2$, también con vanadio.

Este segundo factor explica un significativo 13,7 y $14,5 \%$ de la varianza total de la matriz de datos para los muestreos M1 y M2, respectivamente. El PC2 del muestreo M1 y M2 se podría asociar con la facies predominante en el acuífero detrítico profundo, $\mathrm{Na}-\mathrm{HCO}_{3}$.

Los cationes hierro y manganeso quedan agrupados en ambos muestreos en el PC3, con un $12,6 \%$ y $11,0 \%$ de varianza explicada.

El anión fosfato aparece asociado al potasio en el PC4, ambos con signo negativo en el muestreo M1 y con signo positivo en el muestreo M2.

Se han representado en las Fig. IV.30 y Fig. IV.31 los valores o puntuaciones (scores) de las muestras correspondientes a los muestreos $\mathrm{M} 1$ y $\mathrm{M} 2$ respectivamente, en el nuevo sub-espacio definido por PC1 y PC2 para facilitar la identificación de grupos de muestras con similar comportamiento. En ambas gráficas se muestran las concentraciones de arsénico que se han hallado en las muestras.

Se observa en ambos muestreos una separación de las muestras a lo largo del eje PC1, de acuerdo con el acuífero del que proceden, mientras que el eje PC2 discrimina entre muestras con altos contenidos en $\mathrm{pH}$, sodio y bicarbonato, si poseen elevados valores positivos del PC2, y muestras con altos contenidos en hierro y manganeso, si poseen valores negativos del PC2.

Al igual que en el análisis clúster, se pueden diferenciar cinco agrupaciones de muestras. 


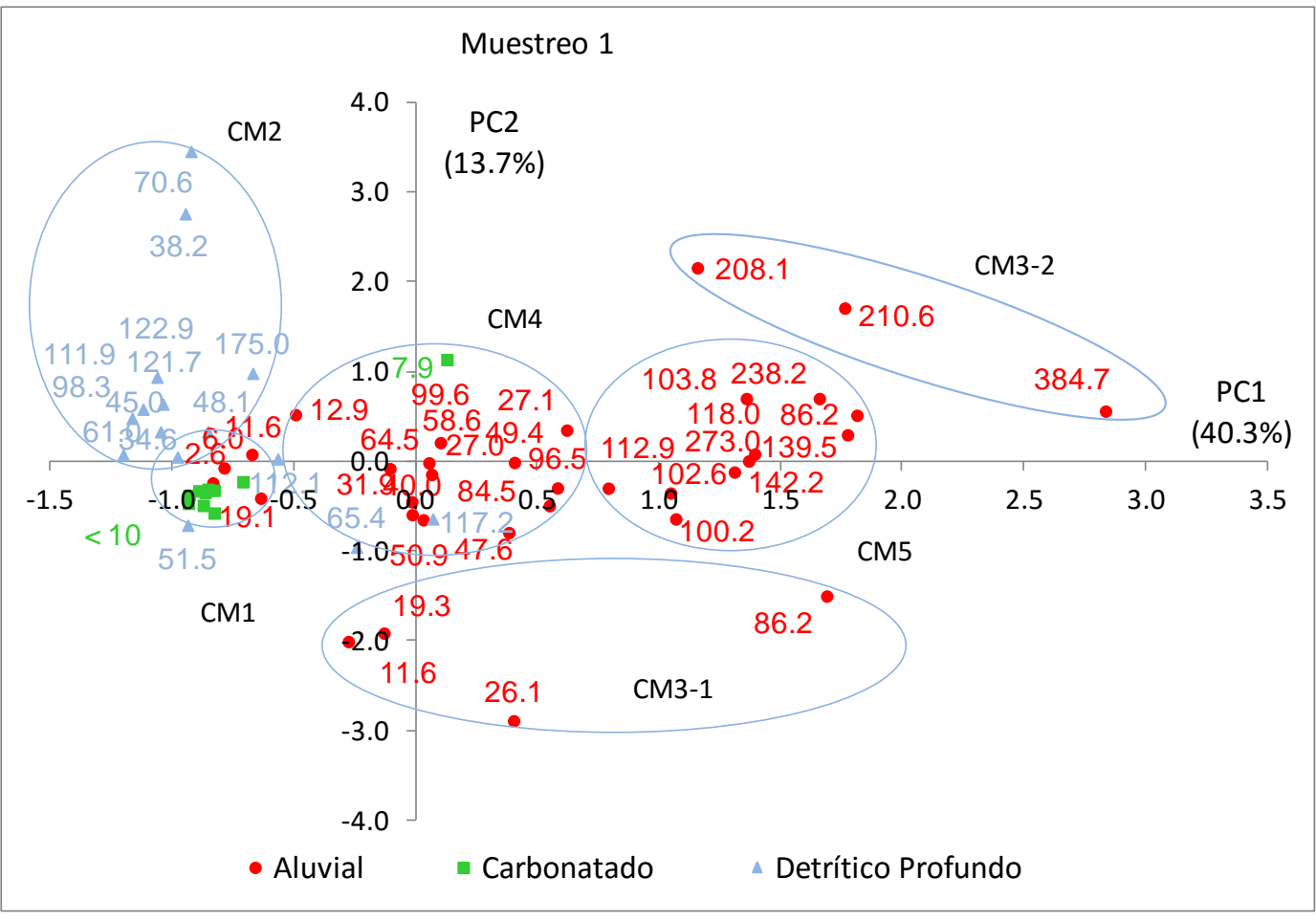

Fig. IV.30. Representación de los scores de las muestras del muestreo M1.

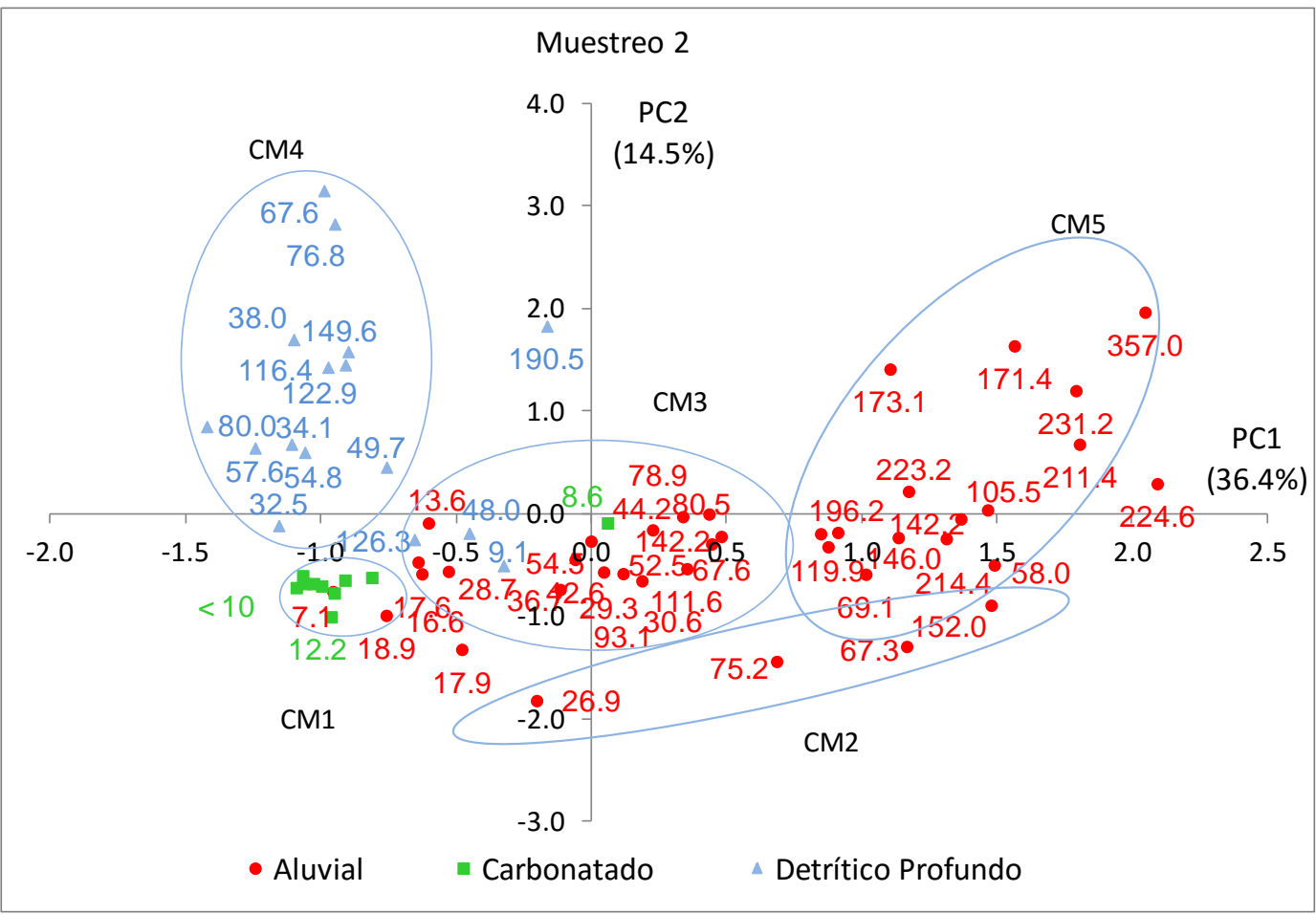

Fig. IV.31. Representación de los scores de las muestras del muestreo M2. 


\section{IV.4.6. VARIACIÓN ESTACIONAL DE LA HIDROQUÍMICA DEL ACUÍFERO}

De entre todos los puntos de agua muestreados durante la campaña de muestreo M1, se seleccionaron 9 puntos, representativos de las principales unidades geológicas ubicadas en la zona objeto de estudio, para realizar un seguimiento mensual durante un año hidrológico completo, que se llevó a cabo desde noviembre de 2002 a octubre 2003, con el fin de evaluar la variación de las concentraciones de arsénico y otros parámetros físico-químicos de interés. Los resultados numéricos se muestran en la Tabla A.Il.6 del Anexo.

Tabla IV.14. Puntos de agua seleccionados para los muestreos mensuales.

\begin{tabular}{cccc} 
Etiqueta & $\begin{array}{c}\text { Unidad } \\
\text { hidrogeológica }\end{array}$ & $\begin{array}{c}\text { Unidades } \\
\text { geológicas }\end{array}$ & Uso \\
\hline M95 & 12 & ME/SA-FVA & Ninguno \\
P5 & 12 & ME/SA-FVA & Ganadero \\
P20 & 12 & CA-FCS & Agrícola \\
P34 & 12 & CD/SA-FVA & Agrí́cola \\
P61 & 12 & SA-FVA & Agrícola \\
P75 & 12 & SA-FVA & Agrí́cola \\
P86 & 12 & CA-FCS & Agrícola \\
M24 & 13 & CP-TP & Agrí́cola \\
S90 & 17 & CD/SA-FVA-MP & Ganadero \\
\hline
\end{tabular}

Los parámetros analizados fueron los mismos determinados en los muestreos M1 y M2. El fosfato sólo se analizó en las muestras recogidas los últimos 6 meses, nitrito y sílice se analizó sólo en los últimos 5 meses y el potencial redox solamente en julio, septiembre y octubre.

En el diagrama de Piper, Fig. IV.32, se muestra la evolución de las facies hidroquímicas de los puntos de control en el año de estudio. Se observa que las facies hidroquímicas de algunos puntos ( $\mathrm{M} 24, \mathrm{M} 95, \mathrm{P} 34, \mathrm{P} 61$, P86 y $\mathrm{P} 75$ ) permanecen prácticamente constantes a lo largo del año mientras que en los puntos P5, P20 y S90, los componentes mayoritarios muestran una variación máxima del $20 \%$ en el periodo estudiado.

La representación gráfica de los valores experimentales de potencial redox y $\mathrm{pH}$ en un diagrama de áreas de predominio Eh/pH (diagrama de Pourbaix) permite predecir cuál es la especie de arsénico predominante en las aguas subterráneas muestreadas (Fig. IV.33). Se observa que la especie predominante en todos los puntos y meses de muestreo es la forma oxidada y monoprotonada $\mathrm{HAsO}_{4}{ }^{2-}$. Esta especie puede sufrir procesos de adsorción sobre diferentes óxidos metálicos, arcillas, etc. (Reynolds y col., 1999). Esto hace suponer que la concentración de arsénico en el agua de las muestras está regulada por procesos de adsorción-desorción, responsables de la solubilización o retención del arsénico (Masscheleyn y col., 1991). 


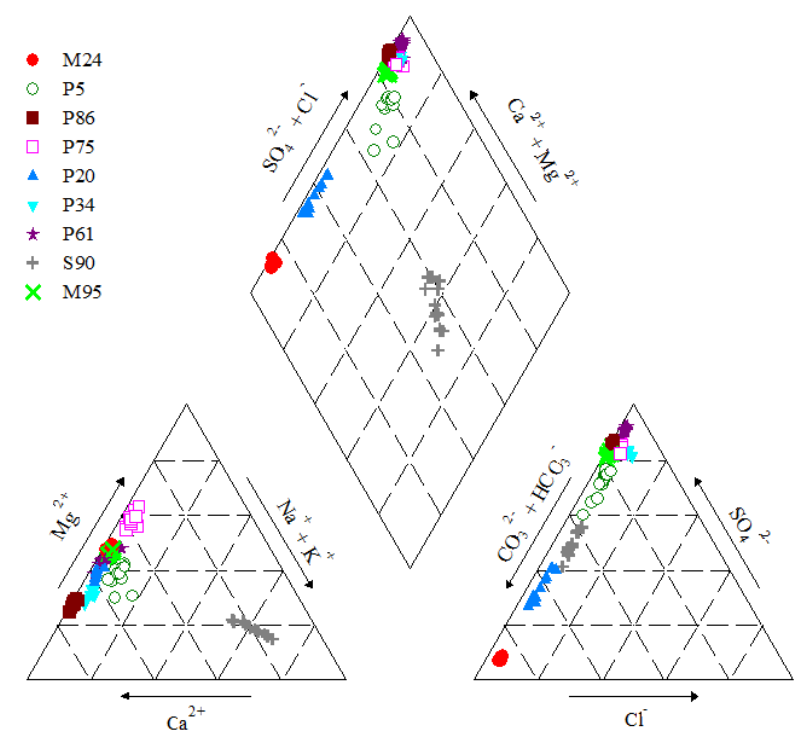

Fig. IV.32. Variación de la hidroquímica de los puntos de control en el periodo investigado.

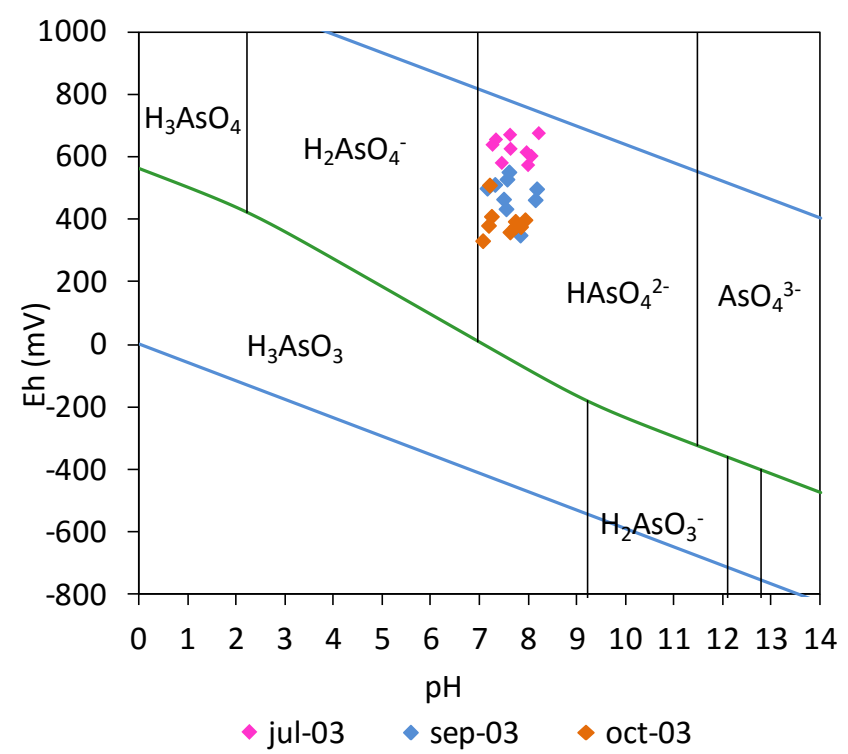

Fig. IV.33. Diagrama de áreas de predominio $\mathrm{Eh} / \mathrm{pH}$

En la Fig. IV.34 y Fig. IV.35 se muestra la variación temporal observada para el arsénico y el calcio en cada uno de los 9 puntos del estudio y la variación del potasio y del sodio para la muestra 590 , perteneciente al acuífero detrítico profundo. 

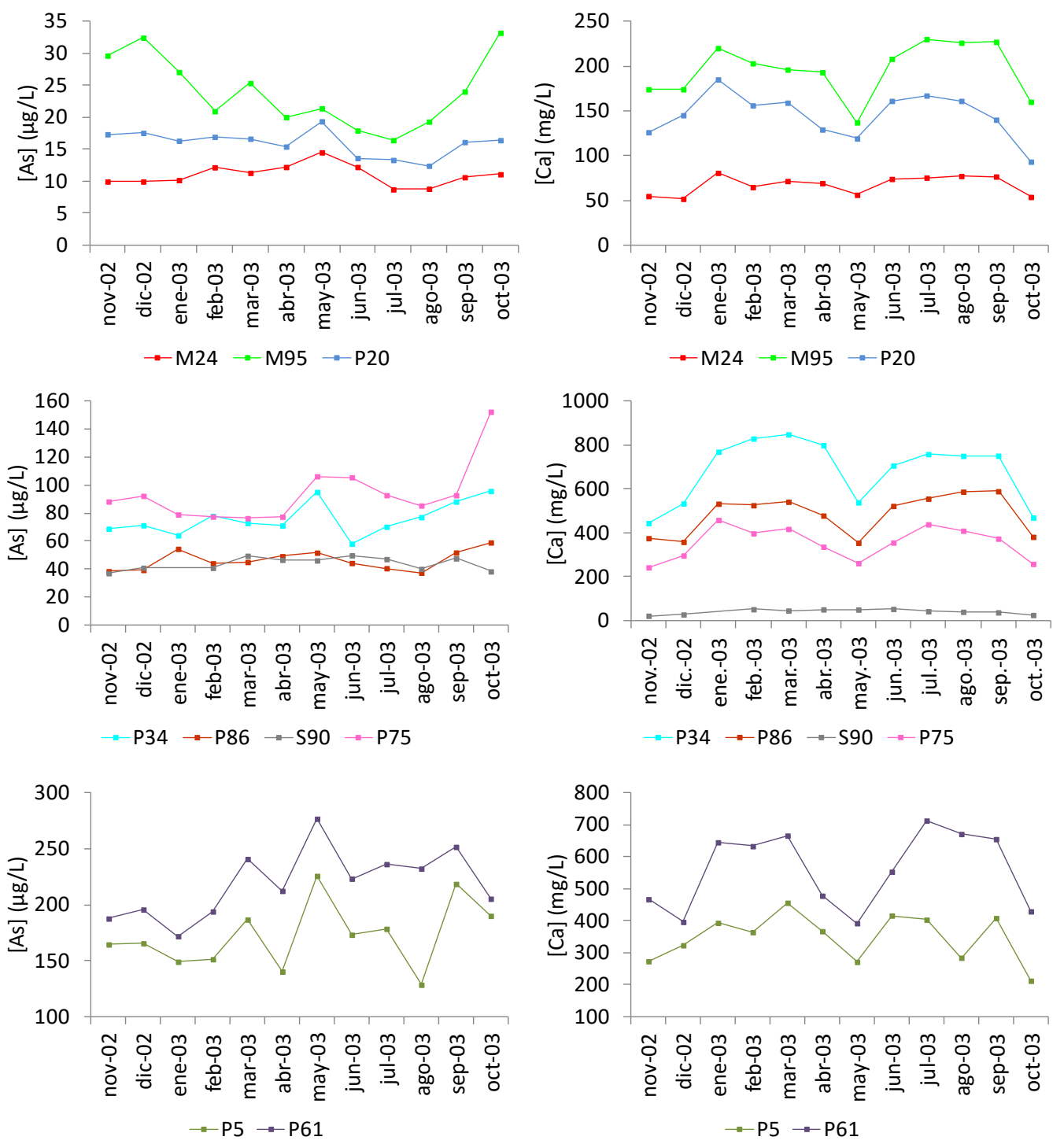

Fig. IV.34. Evolución temporal de Ca y As en los puntos de la red de control.

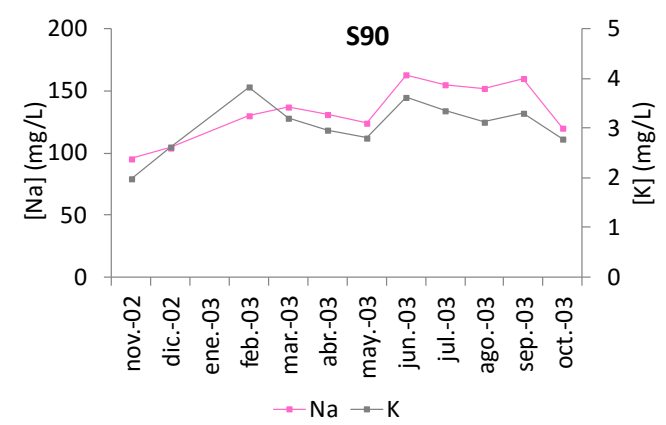

Fig. IV.35.Evolución temporal de Ca y As en el punto S90. 
En general, no se observan variaciones estacionales muy marcadas en los niveles de arsénico de los distintos puntos de agua, aunque se puede apreciar un ligero aumento en el mes de mayo. En el caso de los cationes mayoritarios como calcio, sodio y potasio, se observa una ligera disminución de los niveles en mayo, octubre y noviembre.

Los puntos de muestreo con concentraciones de arsénico inferiores a $20 \mu \mathrm{g} / \mathrm{L}$ (M24, ubicado en el acuífero carbonatado, y P20, en el acuífero aluvial pero con características muy similares al carbonatado) prácticamente no presentan variación en los niveles de este elemento, aunque se puede apreciar un ligero aumento en el mes de mayo, repunte también observado en los puntos P5, P34, P61 y P75. La variación es poco relevante también en los puntos P86 y $\mathrm{S90}$.

Los pozos con mayor contenido de arsénico (>150 $\mu \mathrm{g} / \mathrm{L}$ ), P5 y P61, presentan una mayor variabilidad temporal, que parece indicar que estos pozos más contaminados presentan una respuesta más sensible a la explotación agrícola del acuífero.

\section{IV.4.6.1 Métodos de tres vías}

La aplicación del análisis en componentes principales de tres vías a los datos de los muestreos mensuales permitirá identificar si las variaciones estacionales y espaciales son significativas, y cuál de ellas es más importante en la zona de estudio. Dichos datos conforman una matriz tridimensional $\underline{\mathbf{X}}$ de dimensiones (puntos de control, parámetros, muestreos), es decir, $(9,15,12)$.

En primer lugar se aplicó el ACP de dos vías clásico a la matriz bidimensional $\underline{\mathbf{x}^{\text {aug }}}$ obtenida al desplegar la matriz $\underline{\mathbf{X}}$, colocando cada muestreo debajo del anterior, lo que origina una matriz de $9 \times 12=108$ filas y 15 columnas. La Fig. IV.36 muestra los valores propios obtenidos al aplicar el ACP a la matriz desplegada $\mathbf{X}^{\text {aug }}$, donde se aprecia que hay 5 componentes principales (PCs) que poseen un autovalor mayor que la unidad. Estos cinco primeros PCs explican conjuntamente el $83,6 \%$ de la varianza.

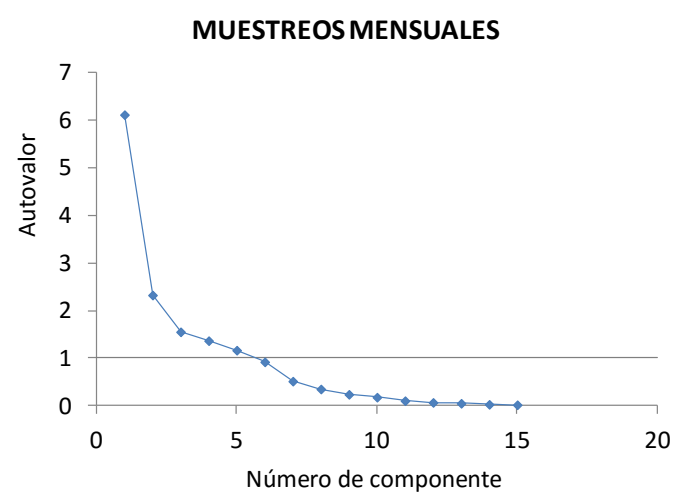

Fig. IV.36. Gráfico de autovalores. 
La Fig. IV.37 muestra la representación gráfica de las cargas de las variables originales en los dos primeros PCs. Se observa un primer grupo de variables, caracterizado por valores positivos elevados de PC1 y valores moderados o casi nulos de PC2, que incluye a los cationes y aniones mayoritarios, responsables de la salinidad, y a los elementos Mo, As y F. Un segundo grupo formado exclusivamente por Fe y $\mathrm{Mn}$ se caracteriza por una importante contribución positiva a PC2. Las variables bicarbonato, Na y K aparecen agrupadas en el eje negativo de $\mathrm{PC} 2$, con proyecciones positivas pero moderadas en PC1. Opuesto a este grupo está el pH, que aparece aislado.

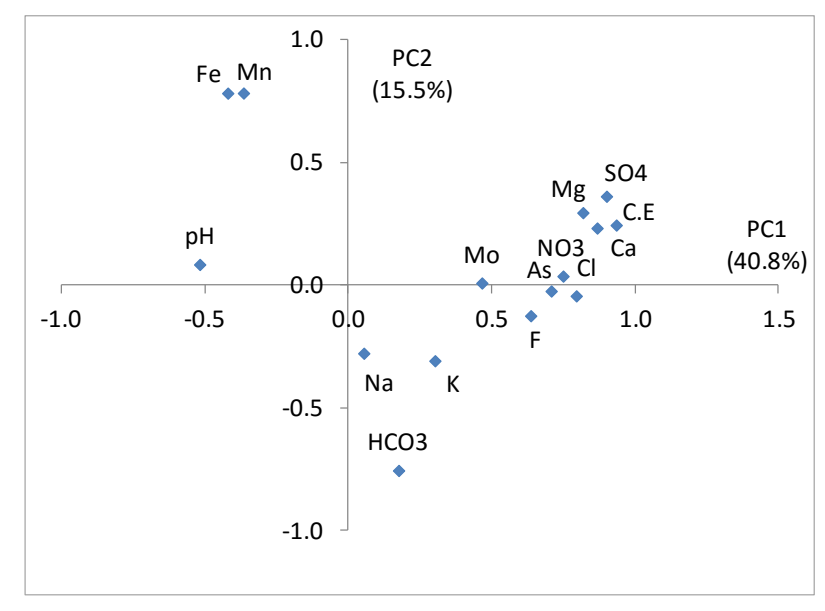

Fig. IV.37. Representación gráfica de las cargas de los dos primeros PCs.

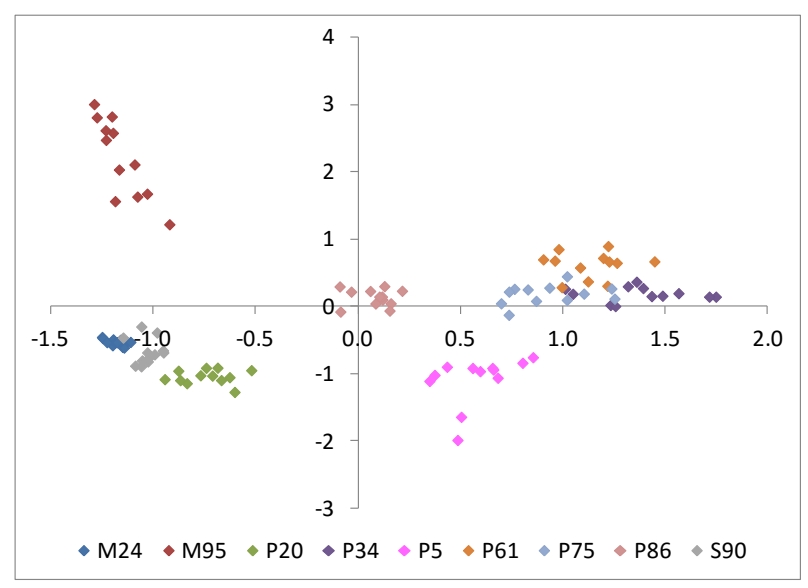

Fig. IV.38. Representación de los scores de las muestras. 
En la Fig. IV.38 se han representado los scores de las muestras en el espacio bidimensional definido por los dos primeros PCs, diferenciando los 9 puntos de agua analizados. En este gráfico se obtiene una combinación de la información espacial y temporal de los puntos de muestreo, observándose que la principal agrupación se debe a las características hidrogeoquímicas de los puntos muestreados. Así, la muestra M95 presenta los mayores niveles de Fe y Mn, mientras que los pozos P61, P75, P5 y P34 presentan los mayores niveles de salinización, combinados con niveles elevados de arsénico. El procedimiento no permite apreciar en qué sentido se produce la variabilidad estacional, ya que los puntos aparecen mezclados.

Los puntos de agua que mayor variabilidad temporal presentan son M95, P5 y P34, que muestran una mayor dispersión en la Fig. IV.38.

Un ANOVA de las puntuaciones o scores de las muestras sobre los tres PCs que explican más varianza ha permitido evaluar si las fuentes de variación espacial y temporal de los parámetros analizados en estas muestras son significativas, y cuál contribuye más a la variabilidad de la hidroquímica de la zona de estudio.

Tabla IV.15. Prueba ANOVA de los scores de los tres primeros PCs.

\begin{tabular}{|c|c|c|c|c|}
\hline Fuente de variacion & $\begin{array}{l}\text { Suma de los } \\
\text { cuadrados }\end{array}$ & Grados de libertad & $\begin{array}{c}\text { Varianza de los } \\
\text { cuadrados }\end{array}$ & $\mathbf{F}$ \\
\hline \multicolumn{5}{|l|}{$P C 1$} \\
\hline Mes de muestreo & 0,51 & 11 & 0,05 & 2,76 \\
\hline Punto de muestreo & 104,99 & 8 & 13,12 & 771,24 \\
\hline Residual & 1,50 & 88 & 0,02 & \\
\hline Total & 107,00 & 107 & & \\
\hline \multicolumn{5}{|l|}{$P C 2$} \\
\hline Mes de muestreo & 1,19 & 11 & 0,11 & 1,72 \\
\hline Punto de muestreo & 100,26 & 8 & 12,53 & 198,61 \\
\hline Residual & 5,55 & 88 & 0,06 & \\
\hline Total & 107,00 & 107 & & \\
\hline \multicolumn{5}{|l|}{ PC3 } \\
\hline Mes de muestreo & 3,38 & 11 & 0,31 & 1,68 \\
\hline Punto de muestreo & 87,53 & 8 & 10,94 & 59,85 \\
\hline Residual & 16,09 & 88 & 0,18 & \\
\hline Total & 107,00 & 107 & & \\
\hline \multicolumn{5}{|c|}{ El valor de F se calcula como la varianza del efecto/varianza del residual } \\
\hline \multicolumn{5}{|c|}{ Fcrit es 1,90 para 11 y 88 grados de libertad y 2,05 para 8 y 88 grados de libertad } \\
\hline
\end{tabular}

Se observa que tanto el punto como el mes de muestreo son factores significativos para las proyecciones de las muestras sobre el PC1, pero la varianza debida al punto de muestreo es muy superior, por lo que se concluye que la variabilidad espacial en la composición de iones mayoritarios relacionados con la salinidad y en elementos como As o $\mathrm{F}$ de las aguas subterráneas de la cuenca enmascara a la menor variabilidad temporal. Por el contrario, para PC2 y PC3, relacionados con el contenido de bicarbonato y sódico; y de Fe y $\mathrm{Mn}$, respectivamente, la fuente de variación debida a la 
estacionalidad no es significativa ( $\mathrm{F}<\mathrm{Fcrit}$ ), por lo que las diferencias de concentración halladas en esos parámetros tienen únicamente una componente espacial.

Por tanto, resulta más conveniente hacer estudios con el mayor número de puntos posibles, para poder caracterizar adecuadamente la zona.

El anterior análisis de dos vías, aunque sencillo de implementar, no permite separar la información espacial y temporal de los puntos de control, que aparece mezclada en $\mathbf{X}^{\text {aug }}$. Por dicho motivo, se llevó a cabo un análisis de los datos mediante los modelos ACP de 3-vías (Tucker3 y Parafac), sobre la matriz tridimensional $\underline{\mathbf{X}}$ original. Dicho análisis permitirá visualizar el efecto estacional sobre la composición físico-química de las aguas subterráneas, un efecto que, aunque menos acusado que la variación espacial, no puede ser ignorado.

En primer lugar, se aplicó el modelo PARAFAC, que se caracteriza por asignar un número idéntico de factores o componentes a cada modo o dimensión. El valor óptimo para dicho número, que marca la complejidad del modelo, se selecciona en función del parámetro de consistencia del core, que debe tener un valor próximo al 100\% (Bro, 1997). En nuestro caso, el mejor valor $(99,9218 \%)$ se obtuvo para un modelo de dos factores, que explica el $55,24 \%$ del total de la varianza $(40,13 \%$ y $15,11 \%$ para los factores 1 y 2 , respectivamente).

La Fig. IV.39 muestra las cargas de los factores de los modos A (puntos de muestreo), B (parámetros analizados) y C (mes de muestreo) del modelo seleccionado. La interpretación del modelo Parafac se basa, de forma similar al ACP de dos vías, en la existencia o ausencia de correlaciones entre las cargas de los tres modos, comparando simultáneamente, dentro de cada factor, las magnitudes y signos de las cargas de cada modo del modelo Parafac.

El factor 1 presenta valores positivos para el modo $\mathrm{C} 1$; así, este factor tendrá más importancia para dos clases de los puntos muestreados, el primero está formado por los puntos de agua con cargas positivas del modo A1 (puntos de agua P86, P34, P61, P5 y P75) y las variables que tienen cargas positivas en el modo $\mathrm{B} 1\left(\mathrm{CE}, \mathrm{Cl}^{-}, \mathrm{NO}_{3}{ }^{-}, \mathrm{SO}_{4}{ }^{2-}, \mathrm{F}, \mathrm{Ca}\right.$, $\mathrm{Mg}, \mathrm{K}, \mathrm{As}$ y Mo), así como los puntos de aguas con cargas negativas del modo A1 (M24, $\mathrm{M} 95, \mathrm{P} 20$ y S90) y las variables con carga negativa del modo $\mathrm{B} 1\left(\mathrm{pH}, \mathrm{HCO}_{3}{ }^{-}, \mathrm{Na}, \mathrm{Mn}\right.$ y Fe). Para la muestra P86 esta interacción es pequeña, por lo que el factor 1 no interpreta en modo alguno la hidroquímica de este punto.

El factor 1 diferencia por tanto las muestras según su composición hidrogeoquímica, si presentan altos contenidos en CE y agentes contaminantes o por el contrario poseen mayores valores de $\mathrm{pH}$ y una composición bicarbonatada. Las cargas en el modo $\mathrm{C} 1$, que explican la variación temporal, aumentan desde noviembre de 2002 a marzo de 2003, periodo de invierno, en el cual la lluvias lixivian o disuelven fertilizantes o componentes del suelo, tanto geogénicos como antropogénicos, aumentando su concentración en los acuíferos. A partir de mayo y hasta septiembre de 2003 se vuelve a observar un aumento de los valores del C1 que se podrían ser achacables a la concentración mineral causada por la explotación del acuífero. Su disminución a partir de septiembre puede deberse igualmente a un periodo más seco en el que además no se utiliza el riego. 

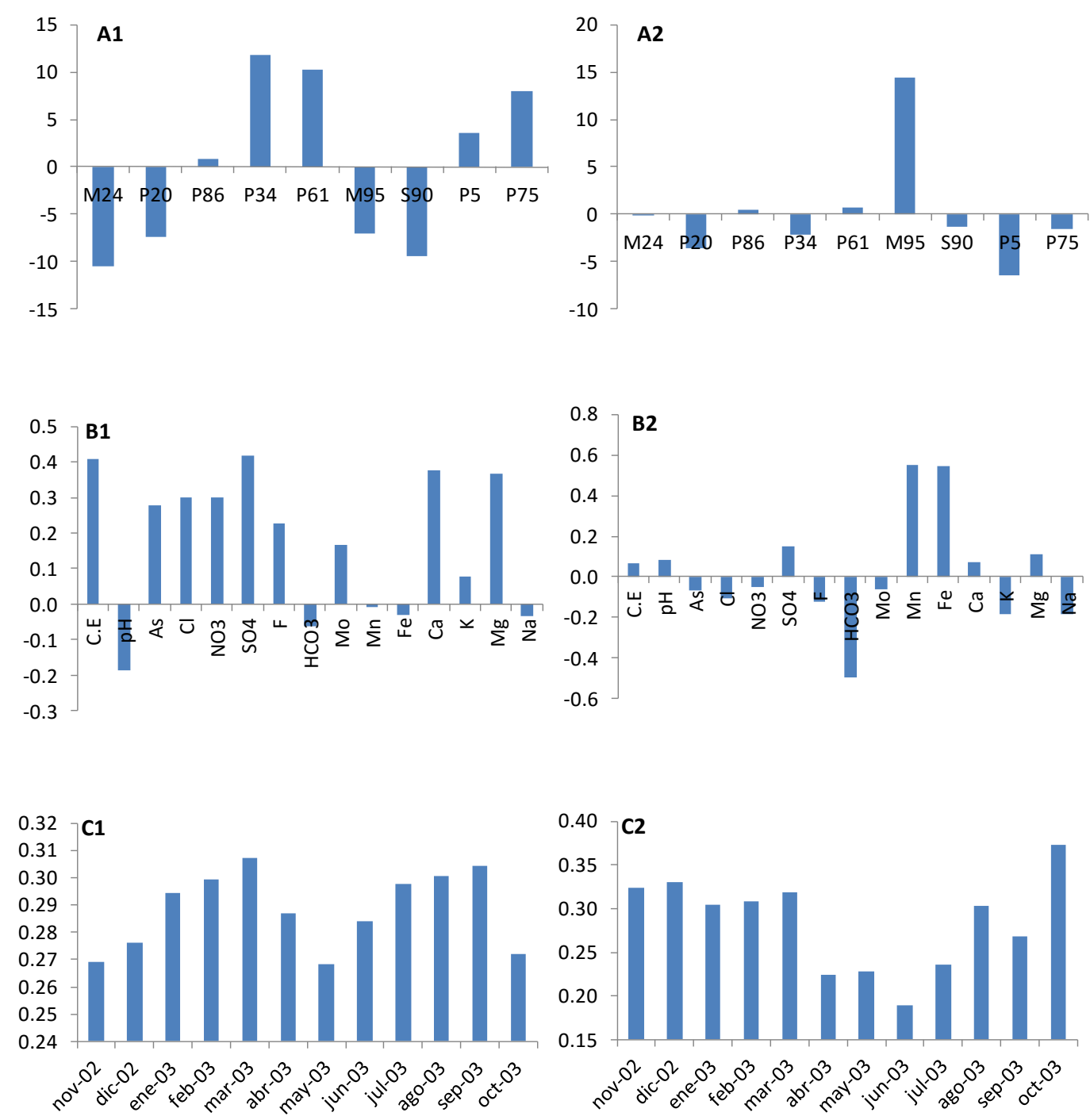

Fig. IV.39. Cargas de los factores de los tres modos. A (puntos de muestreo), B (parámetros analizados) y $\mathrm{C}$ (mes del muestreo).

Para el factor 2, el modo C2 presenta valores siempre positivos, por lo que tendremos también dos clases de puntos de muestreo que harán a este factor significativo. Uno estará formado por los puntos con cargas negativas en el modo A2 (M24, P20, P34, S90, $\mathrm{P} 5$ y $\mathrm{P} 75)$, correlacionadas con variables con cargas negativas en el modo $\mathrm{B2}\left(\mathrm{Cl}^{-}, \mathrm{NO}_{3}{ }^{-}\right.$, $\mathrm{HCO}_{3}{ }^{-}, \mathrm{F}^{-}, \mathrm{K}, \mathrm{Na}, \mathrm{As}$ y $\mathrm{Mo}$ ). El otro corresponde a los puntos con cargas positivas en el modo $\mathrm{A} 2$ (P86, P34, P61, M95 y P75) y las variables con carga positiva en el modo B2 ( $\mathrm{CE}, \mathrm{pH}, \mathrm{SO}_{4}{ }^{2-}, \mathrm{Ca}, \mathrm{Mg}, \mathrm{Fe}, \mathrm{Mn}$,). La contribución de las muestras $\mathrm{M} 24, \mathrm{P} 86, \mathrm{P} 61$ y S90 es pequeña. Debe destacarse que la muestra M95 posee altos contenidos en hierro y manganeso (como ya se detectó en el ACP de 2 vías), así como que los puntos P75 y P20 poseen altos niveles de bicarbonatos. Los valores del modo C2 se mantienen 
prácticamente constantes y elevados entre noviembre de 2002 y marzo de 2003, lo que podría explicarse por la lenta lixiviación de potasio procedente de los fertilizantes que se añaden a las tierras en primavera y verano. Los valores elevados que este factor vuelve a tomar en verano pueden ser debidos a la irrigación con aguas salinas profundas. En todo caso, la contribución de este segundo factor es bastante inferior a la del primero, el cual explica una cantidad cuatro veces mayor de información o varianza.

A continuación se aplicó el modelo Tucker3, que permite asignar diferente número de componentes a cada uno de los modos o dimensiones de la matriz $\mathbf{X}$. Para ello, se estudiaron todos los posibles modelos en busca de aquel que explicara la mayor cantidad de información posible con el menor número de factores en cada modo y que, además, fuera matemáticamente coherente. Se eligió el modelo [2 21 1], que explica un $54,83 \%$ de la varianza, similar al obtenido con el modelo Parafac, pero con una sola dimensión en el modo $C$, lo que permite una mayor simplicidad del modelo. La coherencia matemática queda asegurada por el carácter superdiagonal de la matriz de interacciones (o core) $\underline{\mathbf{G}}$.

La Fig. IV.40 muestra las cargas de los modos A, B y C para el modelo Tucker3 [2 2 1]. Su interpretación debe tener en cuenta la magnitud y signo de los elementos de la matriz $\underline{\mathbf{G}}$ a través de la regla de la conservación de los signos en la multiplicación.

$$
G=\left[\begin{array}{cc}
-25,354 & 0 \\
0 & 15,3997
\end{array}\right]
$$

Existen dos interacciones significativas que corresponden a los valores no nulos de la

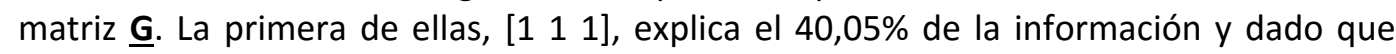
todas las cargas del modo C1 son positivas (Fig. IV.40C1) y el valor $\mathrm{g}_{111}$ es negativo, la interacción relaciona los puntos de muestreo con cargas negativas en A1 (P86, P34, P61, $\mathrm{P} 5$ y $\mathrm{P75}$ ) y las variables que tienen cargas positivas en el modo $\mathrm{B} 1\left(\mathrm{CE}, \mathrm{Cl}^{-}, \mathrm{NO}_{3}{ }^{-}, \mathrm{SO}_{4}{ }^{2-}, \mathrm{F}^{-}\right.$, $\mathrm{HCO}_{3}{ }^{-}, \mathrm{Ca}, \mathrm{Mg}, \mathrm{Na}, \mathrm{K}, \mathrm{As}$ y $\mathrm{Mo}$ ), así como los puntos de aguas con cargas positivas del modo A1 (M24, M95, P20 y S90) y las variables con carga negativa del modo B1 ( $\mathrm{pH}, \mathrm{Mn}$ y Fe). Esta interacción es idéntica a la presentada por el factor 1 de Parafac y coincide con el patrón encontrado para las cargas del PC1 en el ACP de dos vías de la matriz desplegada. De nuevo, esta interacción es pequeña para la muestra P86.

Por su parte, la interacción [2 2 1] explica un 14,78\% de varianza. Como todas las cargas del modo $\mathrm{C} 1$ y $\mathrm{g}_{221}$ son positivas, la interacción relaciona a los puntos con cargas positivas en $\mathrm{A} 2(\mathrm{M} 24, \mathrm{P} 20, \mathrm{~S} 90$ y $\mathrm{P} 5)$ y a las variables con cargas positivas en $\mathrm{B} 2\left(\mathrm{Cl}^{-}, \mathrm{F}^{-}\right.$, $\mathrm{HCO}_{3}{ }^{-}, \mathrm{K}, \mathrm{Na}$, As y Mo). También relacionará puntos con cargas negativas en A2 (P86, $\mathrm{P} 34, \mathrm{P} 61, \mathrm{M} 95$ y $\mathrm{P} 75)$ y variables con carga negativa en $\mathrm{B} 2$ ( $\mathrm{CE}, \mathrm{pH}, \mathrm{NO}_{3}{ }^{-}, \mathrm{SO}_{4}{ }^{2-}, \mathrm{Ca}, \mathrm{Mg}, \mathrm{Fe}$ y $\mathrm{Mn}$ ). Esta interacción es muy similar, en puntos y variables, al factor 2 del modelo Parafac y al del ACP de dos vías de la matriz desplegada. 

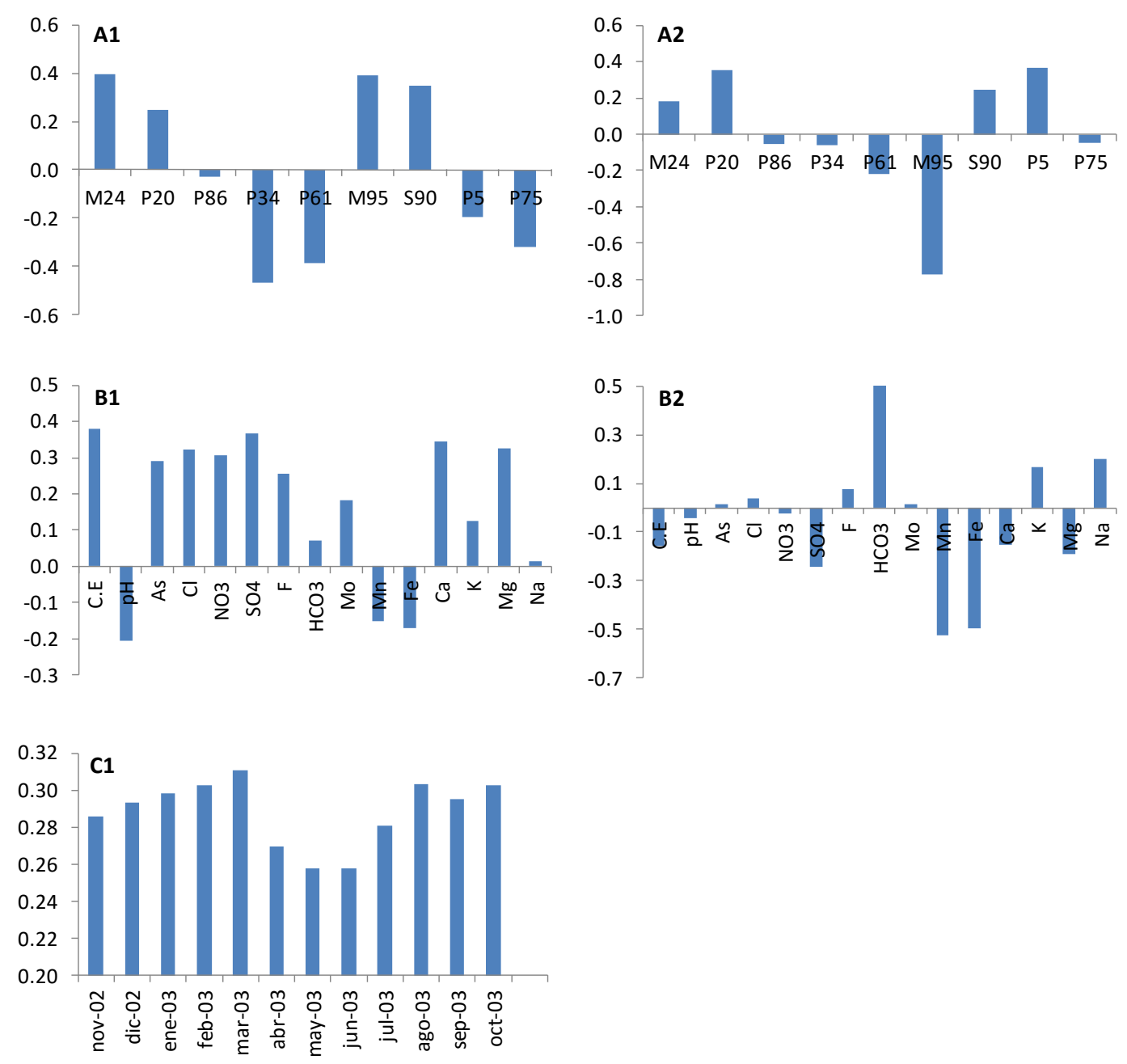

Fig. IV.40. Representación de las cargas de los factores para el modelo Tucker3 [2 2 1].

La principal diferencia del modelo Tucker3 respecto del Parafac es la existencia de un único componente para el modo $\mathrm{C}$ que lleva la información temporal del conjunto de datos. En este caso, los valores de $\mathrm{C} 1$ evolucionan a lo largo del año con valores mayores en invierno y menores en verano, de una manera que combina las dos variaciones que muestra el modelo Parafac. Por tanto, ambos algoritmos, Tucker3 y Parafac, dirigen a modelos similares que explican alrededor del $60 \%$ de la varianza de los datos originales, un porcentaje similar al encontrado por otros autores al aplicar herramientas de $\mathrm{N}$ vías a datos medioambientales (Leardi y col., 2000; Singh y col., 2006; Cid y col., 2011).

Los dos modelos conducen a agrupaciones de puntos y variables prácticamente idénticas, lo que demuestra la fuerza de dichas agrupaciones, siendo la principal diferencia el número de componentes de la información temporal. Mientras que el modelo Tucker3 tiene un único componente temporal $\mathrm{C}_{1}$, que es más difícil de explicar 
desde el punto de vista hidrogeoquímico que los dos comportamientos C1 y C2 del modelo Parafac.

Dado que, numéricamente, las cargas C1 del modeloTucker3 se pueden obtener mediante una combinación lineal de las cargas C1 y C2 del modelo Parafac (con un $r^{2}=$ 0,9997), es preferible el modelo Parafac, a priori más complicado, por su más fácil asignación hidroquímica.

\section{IV.5. DISCUSION DE LOS RESULTADOS}

La composición de los diferentes acuíferos estudiados refleja tanto las características hidroquímicas derivadas del contacto del agua con los materiales del subsuelo como la contaminación antropogénica. Además, debemos tener en cuenta la intensa explotación a la que están sometidos los acuíferos de esta región que favorece la recirculación y la mezcla de las aguas de las distintas unidades del acuífero.

Los tres acuíferos presentes en la zona de muestreo comparten algunas unidades estratigráficas; de entre ellas, las facies Cuestas y Villalba de Adaja son las que tienen un mayor espesor y por tanto exponen mayor superficie de contacto con las aguas subterráneas, por lo que cabría esperar una mayor influencia de estos sedimentos en la composición del agua subterránea. Las particularidades de los distintos acuíferos vienen marcadas por los aniones y cationes mayoritarios que definen la facies hidroquímica predominante en cada unidad hidrológica, y por los elementos traza investigados, cuya relación con la facies hidroquímica se pretende establecer. La presencia en algunas muestras de elevadas concentraciones de los iones $\mathrm{NO}_{3}{ }_{3}^{-} ; \mathrm{NO}_{2}^{-} ; \mathrm{PO}_{4}{ }^{3} ;$ y $\mathrm{K}^{+}$puede atribuirse a una contaminación antropogénica causada por el uso de fertilizantes inorgánicos y orgánicos (purines), muy empleados en agricultura. La heterogeneidad en la distribución de estos parámetros podría deberse a la diferente variedad de fertilizantes y de pautas de utilización.

Según se vio en el apartado de Resultados, los tres acuíferos estudiados presentan características particulares que hacen que se diferencien entre sí, por lo que vamos a abordar este apartado desde el punto de vista de los diferentes acuíferos.

Teniendo en cuenta las características geológicas de la zona estudiada, las actividades agropecuarias que se llevan a cabo y los núcleos urbanos existentes en la zona, los procesos que influyen previsiblemente en las características hidroquímicas de las aguas de la zona de estudio son:

- Disolución/precipitación de carbonatos.

- Disolución de yeso y margas yesíferas: Aporta a las aguas: $\mathrm{SO}_{4}{ }^{2-}$ y $\mathrm{Ca}^{2+}$.

- Acuífero profundo: Es el responsable de las aguas bicarbonatadas sódicas. La tendencia a la sodificación de las aguas captadas por algunos sondeos profundos parece estar relacionada con una menor influencia de los niveles más superficiales (aguas sulfatadas cálcico-magnésicas) 
- Factores locales que pueden modificar puntualmente las características hidroquímicas de las aguas como, por ejemplo, los vertidos de las aguas residuales, las cuales pueden aportar compuestos nitrogenados o fosfato, y el empleo de fertilizantes en agricultura intensiva, que aporta potasio, fosfato y compuestos nitrogenados.

Al representar en un diagrama de Piper (Fig. IV.41 y Fig. IV.42) las muestras de agua analizadas en función del nivel de concentración de arsénico, se ha evidenciado una cierta relación entre el contenido de arsénico y el tipo de facies hidroquímica de las aguas investigadas.

Las muestras provenientes del acuífero detrítico profundo aparecen en la representación gráfica de las puntuaciones de las muestras en el espacio definido por los dos primeros PC's (Fig. IV.30 y Fig. IV.31), en el cuadrante con PC1 negativo y PC2 positivo, tanto para el muestreo M1 como para el muestreo M2. Por lo tanto, las variables estudiadas que describen a este acuífero son el pH, sodio y bicarbonato, lo cual está en concordancia con las características hidroquímicas obtenidas en el diagrama de Piper (Fig. IV.20 y Fig. IV.21) para la aguas de este acuífero (bicarbonatadas sódicas).

En la Fig. IV.17 y Fig. IV.18 se han representado los diagramas circulares con los componentes mayoritarios de las aguas para las muestras del acuífero detrítico profundo, para las muestras analizadas en los muestreos $\mathrm{M} 1$ y $\mathrm{M} 2$, respectivamente, donde se puede ver la evolución de su composición en el sentido del flujo subterráneo.

El acuífero detrítico profundo presenta unas condiciones piezométricas derivadas de niveles confinados profundos y flujos descendentes, cuya recarga parece haber tenido lugar al sur de la zona de estudio, con unas características hidroquímicas diferenciadas correspondientes a aguas bicarbonatadas sódicas y $\mathrm{pH}$ alcalinos que parecen indicar la existencia de procesos de hidrólisis de feldespato sódico en el medio hidrogeológico.

La disolución incongruente de feldespatos se rige por la siguiente reacción:

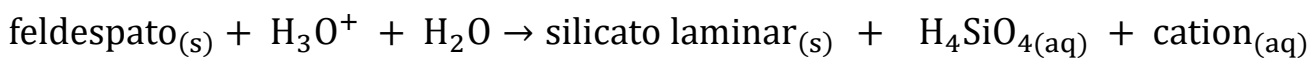

dando lugar a productos insolubles de naturaleza química muy distinta del compuesto inicial. El ácido silícico, cuyas constantes de acidez a $25^{\circ} \mathrm{C}$ son $\mathrm{pK}_{\mathrm{a} 1}=9,7$ y $\mathrm{pk}_{\mathrm{a} 2}=13,2$, se encontrará en su forma totalmente protonada $\mathrm{y}$, dada su relativamente elevada solubilidad (150 $\mathrm{mg} \mathrm{L}^{-1}$ ), se irá transfiriendo a la fase acuosa. Este tipo de proceso conlleva una transformación de silicatos, un aumento del $\mathrm{pH}$, puesto que la reacción consume protones, y una lixiviación de iones solubles alcalinos y/o alcalinotérreos (Domènech, 2000).

Otros procesos relacionados con estas variables que no se pueden descartar son la disolución de carbonatos y procesos de intercambio iónico, que implican la sustitución de $\mathrm{Na}^{+}$por $\mathrm{Ca}^{2+}$ en arcillas. 


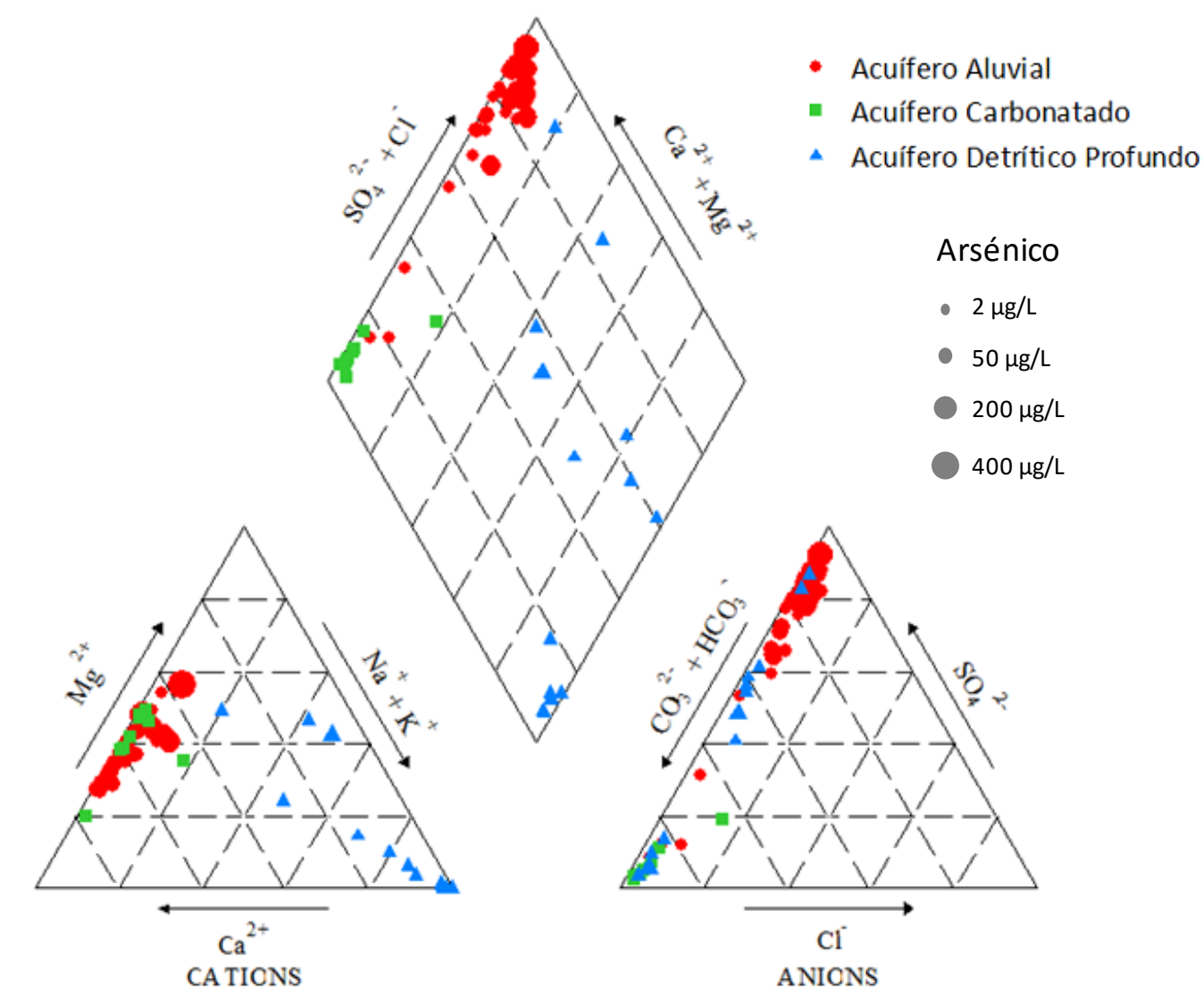

Fig. IV.41. Diagrama de Piper de las muestras del Muestreo M1.

Atendiendo a la distribución de las muestras en la representación de las puntuaciones de los dos primeros PCs para el muestreo M1 (Fig. IV.30), los puntos de agua S6 y S10 presentan los valores del PC2 más positivos, lo cual podemos interpretar como puntos de agua con unas características propias del acuífero detrítico profundo (aguas bicarbonatadas sódicas y $\mathrm{pH}$ elevado). Mientras que los puntos de agua con los valores más negativos del PC2, S23, S48 y S97, representan a muestras con altos niveles de Fe, como se aprecia también en el clúster de observaciones y variables(Fig. IV.26).

Los puntos $\mathrm{S48}$ y $\mathrm{S} 97$ poseen características similares a algunos pozos que captan agua del acuífero aluvial: elevada presencia de sulfato y mayor concentración de magnesio que de calcio, que podría ser causada por la disolución/precipitación de carbonatos. Así, mientras la disolución de calcita aporta bicarbonatos y calcio, la dolomita aporta además magnesio. En aguas con calcio y magnesio, la precipitación de la calcita disminuiría las concentraciones de bicarbonato y calcio provocando un incremento en la concentración de magnesio. 


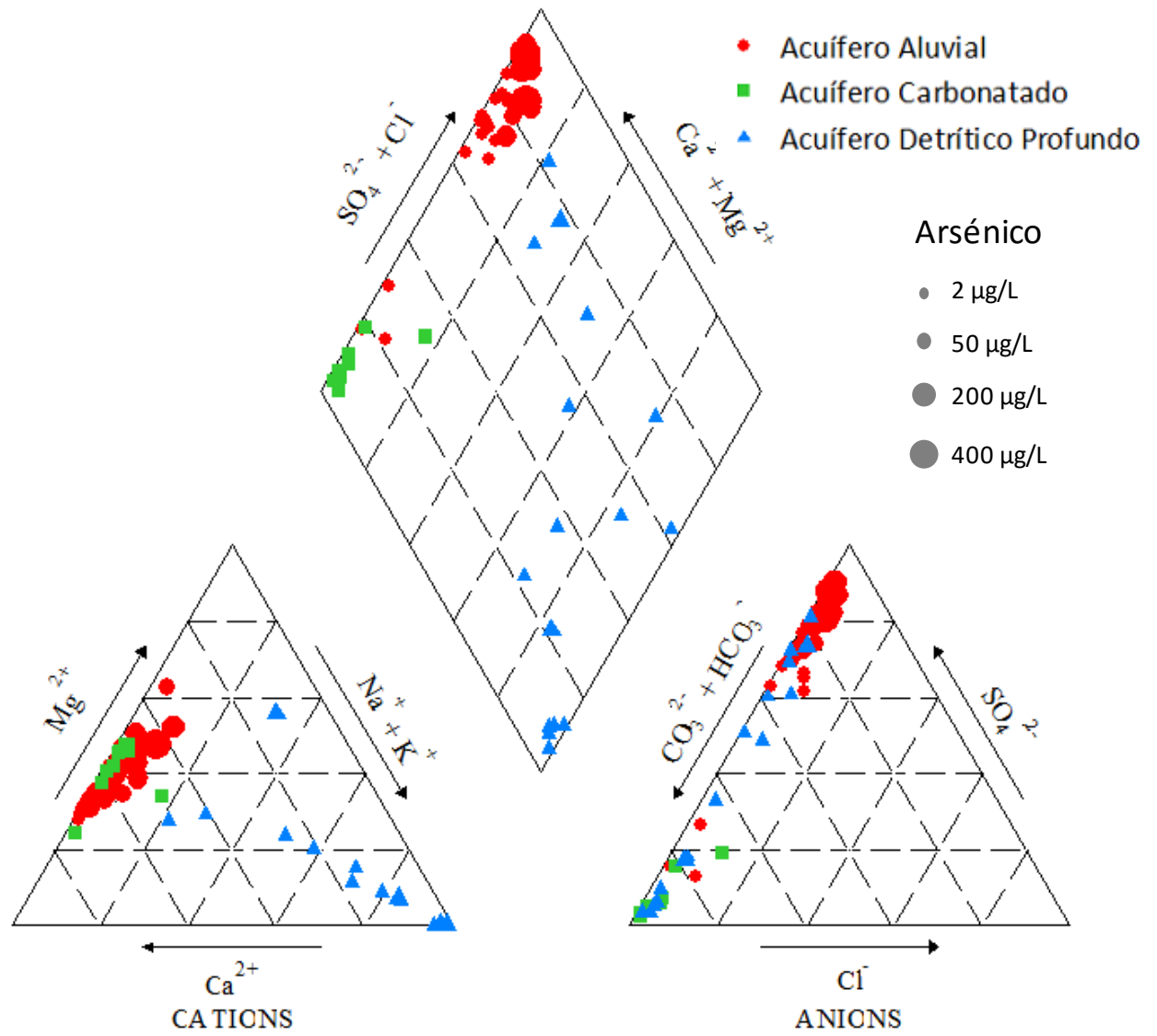

Fig. IV.42. Diagrama de Piper de las muestras del Muestreo M2.

Para el muestreo M2 (Fig. IV.27), se observa que los sondeos con los mayores valores de $\mathrm{pH}$ y sodio son, como en el muestreo M1, los sondeos S6 y S10. En este muestreo se observa como el PC2 (Fig. IV.29) discrimina distintos grupos de muestras en el acuífero detrítico profundo. Las muestras que aparecen con puntuaciones negativas del PC2 son S37, S71, S97 y S111 y todas ellas presentan moderados contenidos de manganeso.

En las Fig. IV.41 y Fig. IV.42 se observa que la concentración de arsénico es, en ambos muestreos, mayor en los puntos de agua que evolucionan hacia aguas sulfatadascálcico-magnésicas que en aquellos que poseen unas características bicarbonatadassódicas. Este hecho parece indicar que la presencia de arsénico está correlacionada con niveles muy elevados de sulfatos en el agua.

Cabe destacar las correlaciones encontradas en este acuífero entre el arsénico y algunos de los parámetros estudiados, así, la relación directamente proporcional entre el arsénico y el pH para la mayoría de los puntos de agua se muestra en la Fig. IV.43, excepto para los puntos de agua, S3, S25, S74, S77 y S97, que, todos ellos, poseen concentraciones de arsénico superiores a la media del acuífero. 

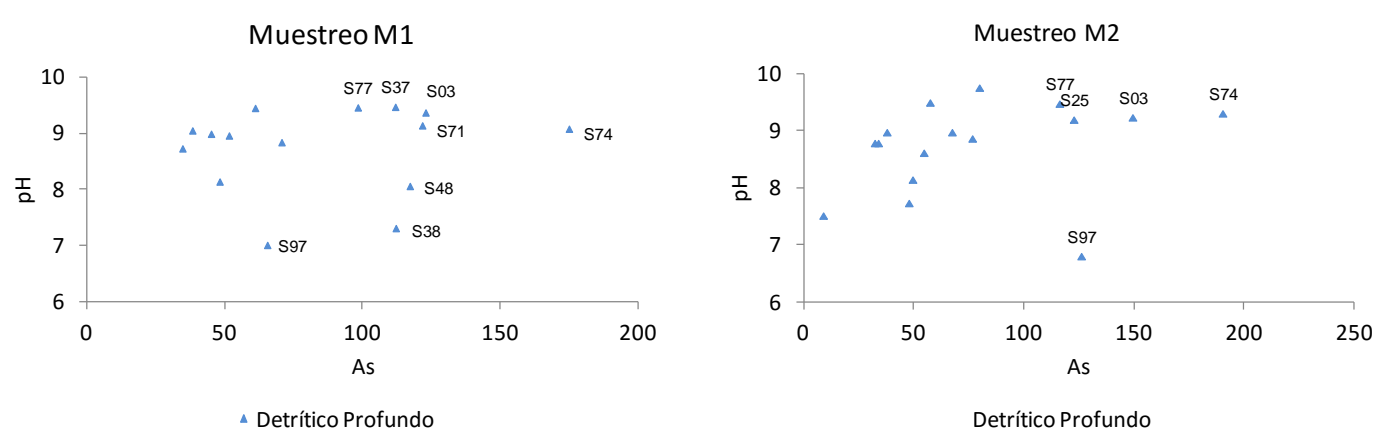

Fig. IV.43. Representación de pH frente a As de los puntos de agua del acuífero detrítico profundo de los muestreos M1 y M2.

La existencia débil pero significativa correlación entre el pH y el arsénico, tanto en el muestreo M1 como en el M2, parece apuntar a la presencia de procesos de desorción de arsénico en condiciones alcalinas (Robertson, 1989; Smedley y col., 2002; Smedley y Kinniburgh, 2002).

Tanto en el muestreo M1 como en el M2 se han identificado muestras cuya concentración de arsénico es más elevada de la que cabría esperar según la relación encontrada entre el $\mathrm{pH}$ y el arsénico (Fig. IV.43). Para el muestreo M1 existen más puntos con concentraciones elevadas de arsénico que para el muestreo $M 2$, este hecho podría deberse a los periodos en los cuales se han tomado las muestras ya que el muestreo M2 representa los puntos de agua al inicio del periodo de riego, mientras que el muestreo M1 se realizó a finales de la época de riego, por lo que las características de las aguas podrían haberse alterado debido tanto al diferente nivel freático como a la sobreexplotación del acuífero durante el muestreo M1.

Excepto para los puntos S3, S37 y S77 del muestreo M1 y para el punto S77 del muestreo M2, cuyas características hidroquímicas son propias del acuífero detrítico profundo, el resto de puntos de agua tienden hacia aguas sulfatadas-cálcico-magnésicas, por lo que se pueden estar produciendo otros procesos que hagan que aumenten los niveles de arsénico.

En las muestras con mayores niveles de arsénico (por encima de $50 \mu \mathrm{g} / \mathrm{L}$ ) se observa una correlación positiva significativa con el fosfato (Fig. IV.44). Y entre el vanadio y el arsénico también se ha encontrado una buena correlación (Fig. IV.45). Como se indicó anteriormente, es posible que en estos puntos de agua existan otros procesos además de la desorción de arsénico a pH alcalino, y estos mecanismos son los que provocarían también la dersorción de los fosfatos y vanadatos. 


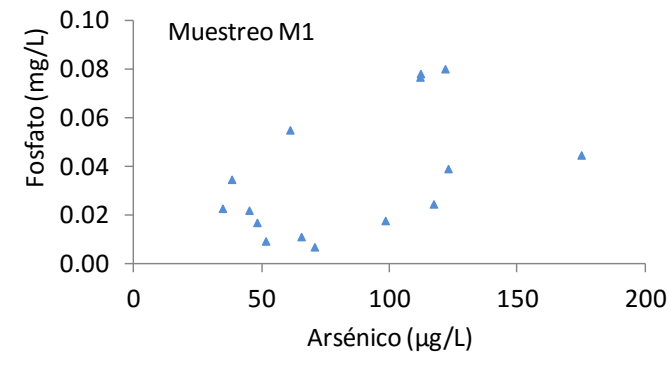

$\triangle$ Detrítico Profundo

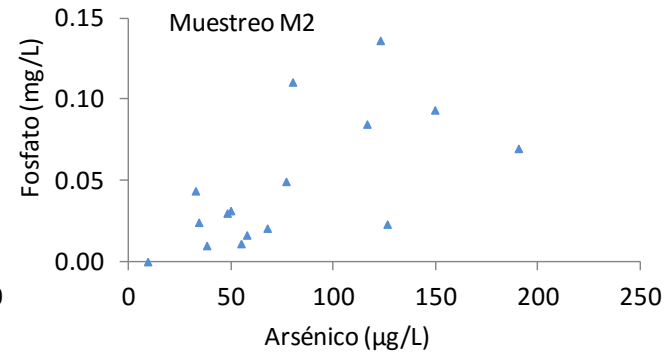

Detrítico Profundo

Fig. IV.44. Representación de P frente a As en los muestreos M1 y M2.

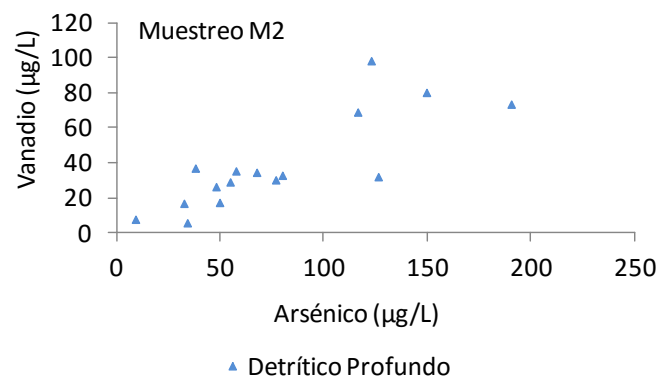

Fig. IV.45. Representación de V frente a As.

Si bien es cierto que las muestras de agua que poseen mayores contenidos de arsénico tienden en general hacia aguas sulfatadas-cálcico-magnésicas, las conductividades que presentan no son muy elevadas. En el muestreo M1 se observa una correlación entre el arsénico y la conductividad eléctrica para las muestras S10, S48 y S97, cuya conductividad eléctrica es superior a $1000 \mu \mathrm{S} / \mathrm{cm}$, y cuya correlación se aproxima a la del acuífero aluvial, este hecho podría deberse a la percolación de aguas del acuífero aluvial a través del espacio anular del sondeo.
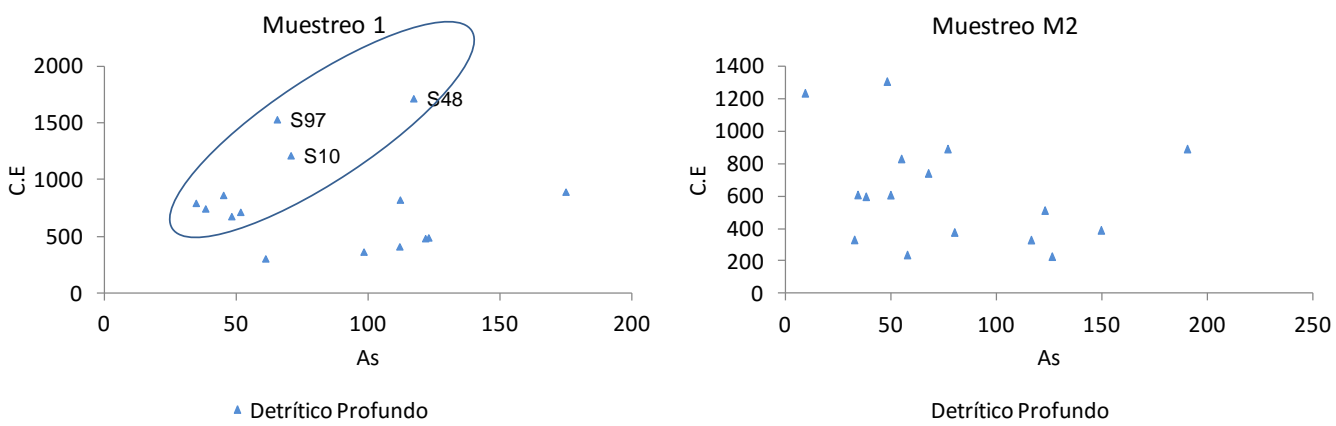

Fig. IV.46. Representación de C.E frente a As. 
La poca variación encontrada en las aguas subterránea del acuífero carbonatado, (Fig. IV.30 y Fig. IV.31) indica unas características muy definidas para este acuífero. Los valores de PC1 y PC2 para estas muestras son negativos, por lo que podemos decir que apenas presentan concentraciones relevantes de los grupos de variables CV1, CV2, CV3 y CV4, a excepción de niveles moderados de bicarbonato, como se puede apreciar también en la Fig. IV.26 y Fig. IV.27. En la representación de los diagramas circulares (Fig. IV.15 y Fig. IV.16) sobre el mapa geológico se puede ver que la composición de las aguas de este acuífero apenas muestra variación espacial. Atendiendo al diagrama de Piper, las aguas de esta unidad hidrológica son predominantemente bicarbonatadas-cálcicomagnésicas, teniendo en cuenta que están ubicadas en las calizas del Páramo de Cuéllar, las reacciones principales en este acuífero implicarán disolución/precipitación de carbonatos.

Las concentraciones de arsénico halladas en este acuífero son, por lo general, menores de $10 \mu \mathrm{g} / \mathrm{L}$ y no muestran correlación con ninguno de los parámetros estudiados, a excepción de magnesio $(r(M 1)=0,639 ; r(M 2)=0,519)$ y molibdeno $(r(M 1)=--$; $r(M 2)=0,4726)$. La escasa liberación de arsénico al acuífero carbonatado podría estar relacionada con la disolución de calcita y/o dolomitas o de cristalizaciones de arseniato cálcico que pudieran existir en la facies Calizas del Páramo.

La composición de las muestras del acuífero aluvial presenta una variabilidad gradual desde la zona de descarga del acuífero carbonatado (aguas bicarbonatadas-cálcicomagnésicas) y hacia el sentido del flujo (sulfatadas cálcico-magnésicas), lo cual se ve reflejado en los diagramas circulares representados sobre el mapa geológico (Fig. IV.15 y Fig. IV.16). Esto mismo se ve reflejado en las Fig. IV.30 y Fig. IV.31 donde observamos una gran dispersión de las muestras, tanto en el PC1 como en el PC2, debido a cambios de las características hidrogeoquímicas que experimentan las aguas a medida que avanzan en el sentido del flujo subterráneo.

En general, las aguas del acuífero aluvial son sulfatadas-cálcico-magnésicas, como se puede apreciar en los diagramas de Piper (Fig. IV.20 y Fig. IV.21), además en los diagramas circulares de los componentes mayoritarios representados sobre el mapa geológico (Fig. IV.15 y Fig. IV.16), se puede apreciar la evolución de las aguas en el sentido del flujo.

De esta manera, tanto en el muestreo M1 como en el M2, podemos apreciar como los puntos de agua que se encuentran en las cabeceras de los valles, próximos al acuífero carbonatado ( $\mathrm{P} 14, \mathrm{P} 20, \mathrm{P} 70$ y $\mathrm{P} 78$ en el muestreo $\mathrm{M} 1$ y $\mathrm{M} 72, \mathrm{M} 95, \mathrm{P} 13, \mathrm{P} 20, \mathrm{P} 70$ y $\mathrm{P} 93$ en el muestreo $\mathrm{M} 2$ ) poseen características hidroquímicas semejantes a éste, debido a la conexión hidráulica de ambos acuíferos en la cabecera de los arroyos. Este hecho se ve reflejado también en los clúster de observaciones (Fig. IV.26 y Fig. IV.27), dado que estos puntos de agua aparecen junto con las muestras del acuífero carbonatado. Los niveles de arsénico en estos puntos, al igual que en el acuífero carbonatado, son bajos. Por lo que teniendo en cuenta que las características geológicas e hidroquímicas son similares, es de esperar que actúen los mismos mecanismos de liberación de arsénico.

Los valores de PC1 en estas muestras son casi nulos o negativos (Fig. IV.30 y Fig. IV.31), indicando una baja salinización del agua. Una vez que las aguas avanzan en el sentido 
del flujo subterráneo desde las cabeceras de los valles, se observa que van adquiriendo un carácter más salino (principalmente sulfato, cloruro, nitrato, calcio y magnesio) debido a infiltración de aguas sulfatadas procedentes de la Facies Cuestas (margas yesíferas) y a la existencia de cultivos y regadíos en las vegas y planicies existentes en la margen derecha del río Cega.

Las descargas en invierno se producen a través de manantiales, mientras que en verano las aguas subterráneas son aprovechadas para el riego de cultivos. La acción antrópica resulta determinante para la calidad química de este acuífero debido a la intensa explotación en la época estival, el abono con purines y fertilizantes N-P-K y los importantes excedentes de riego que se producen.

Esto mismo se observa en los ACP de ambos muestreos, donde las muestras de agua van incrementando su valor del PC1 (salinización) desde los puntos de agua próximos al acuífero carbonatado.

Las muestras con elevada salinización pueden tener un origen natural y proceder directamente del material original, disolución de yesos, con el correspondiente aporte de sulfatos y calcio, pero también puede producirse por actuaciones antrópicas poco apropiadas en el campo de la agricultura, como la adición de fertilizantes en exceso con el consiguiente aporte de nitratos y la sobreexplotación de los acuíferos, producida por la recirculación en las aguas de riego, que conllevan a procesos de concentración evaporativa.

El grupo de muestras con valores altos de PC1, es decir, elevada salinización, pero valores de PC2 prácticamente nulos, se corresponderá con puntos de agua sometidos a una gran explotación durante la época de riego o a zonas con materiales muy solubles como yesos.

En el muestreo M2 se puede identificar un grupo de muestras (M46, P02; P05, P106 y P113) con valores elevados positivos del PC1 que indican alta salinización y valores positivos del PC2, que en este caso representan puntos de agua con altos niveles de variables pertenecientes al grupo CV2 (arsénico, vanadio, fosfato, potasio y molibdeno), que se asocian a la contaminación de los acuíferos.

Los parámetros relacionados con altos valores de $\mathrm{PC} 2$, tanto en el muestreo M1 como en el $\mathrm{M} 2$, parecen depender directamente de las prácticas agrícolas que se llevan a cabo en la zona de estudio, debido al empleo de elevadas cantidades de abonos y fertilizantes, especialmente los más solubles, provocando acumulaciones de altas concentraciones de sales que, por lixiviación, terminan en los acuíferos

También existe un grupo de muestras, con valores negativos del PC2, relacionadas con elevados niveles de hierro y manganeso, grupo CV3 (para ambos muestreos). La presencia en estas muestras de Fe y, en menor medida, de Mn, puede estar causada por procesos de disolución de óxidos de Fe y $\mathrm{Mn}$ existentes en las arcillas carbonosas de la Facies Zaratán cuando se modifican las condiciones de oxidación-reducción por un descenso del $\mathrm{pH}$ y/o la existencia de un ambiente reductor.

La relación entre el contenido en salinidad y el arsénico se pone claramente de manifiesto con las correlaciones encontradas entre el arsénico y conductividad eléctrica, 
sulfatos, cloruros, nitratos, calcio y magnesio Tabla IV.11 y Tabla IV.12. En la Fig. IV.47 se muestra la representación de la conductividad eléctrica con respecto al arsénico, en la cual se observan niveles de arsénico progresivamente más altos conforme aumenta la conductividad eléctrica. Este aumento denota la concentración salina que sufren las aguas de este acuífero por la elevada recirculación debida a los bombeos y excedentes de riego. Esta correlación se da únicamente en el acuífero aluvial, y es previsiblemente causado por la elevada recirculación de las aguas de riego.
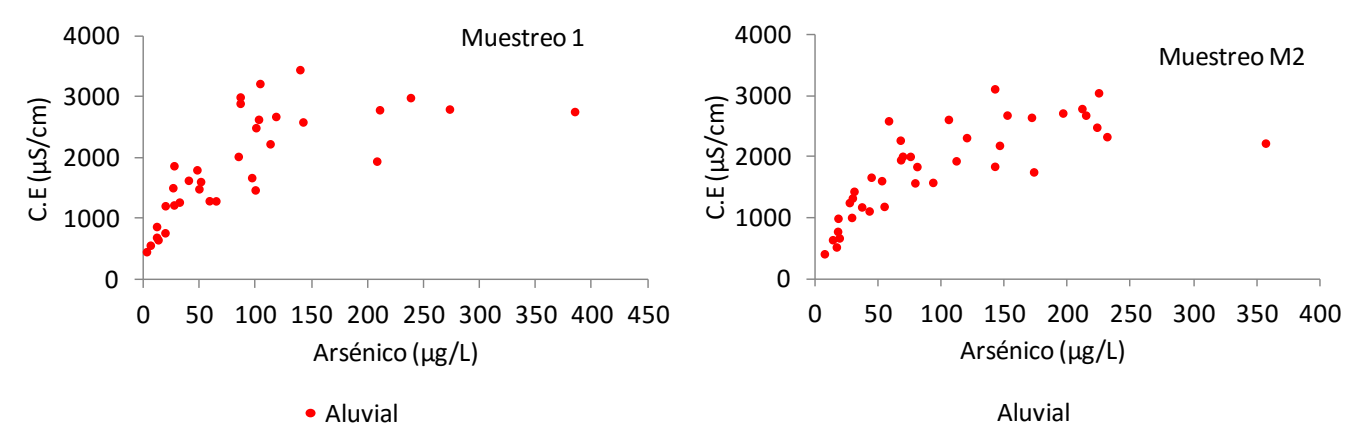

Fig. IV.47. Representación de la C.E frente a As.

La correlación con el potasio es sólo apreciable en el acuífero aluvial y podría ser debida a la concentración salina que ocurre a lo largo de este acuífero por recirculación de las aguas de riego contaminadas con fertilizantes (como en el caso de la conductividad ya mencionado). Algún sondeo del acuífero detrítico profundo podría presentar un mayor contenido de $\mathrm{K}$ por percolación de aguas del acuífero aluvial a través del espacio anular de captaciones profundas o por infiltración.
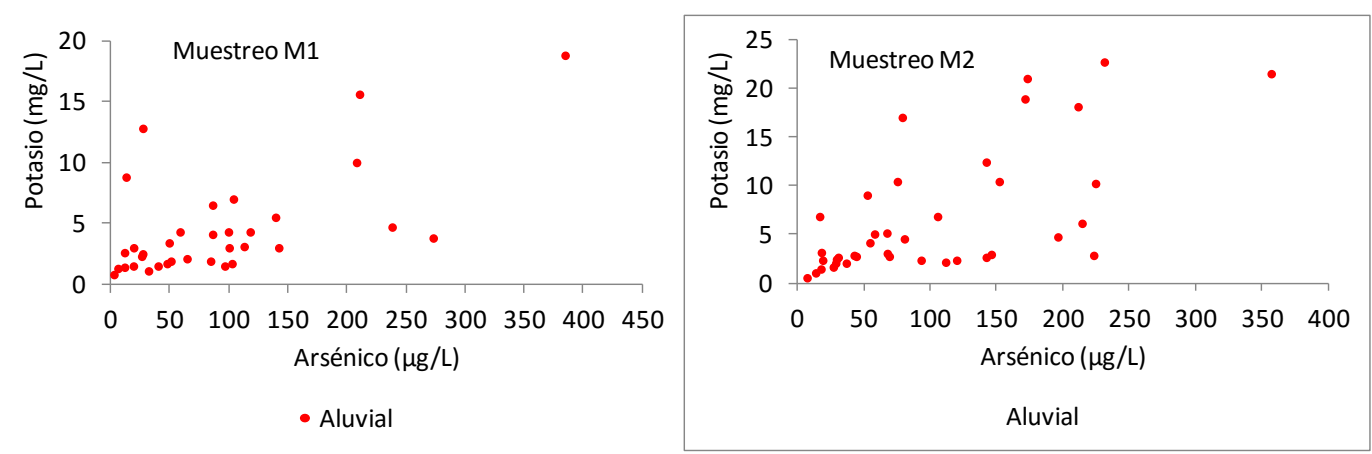

Fig. IV.48. Representación de K frente a As.

La máxima concentración de sulfatos encontrada en el muestreo M1 fue de $2218 \mathrm{mg} / \mathrm{L}$ en el pozo P65, y de $2863 \mathrm{mg} / \mathrm{L}$ en el pozo P118 en el muestreo M2. La representación del arsénico frente a los sulfatos muestra en el acuífero aluvial un incremento exponencial que apunta a la existencia además procesos de desorción de arsénico cuando el $\mathrm{SO}_{4}{ }^{2-}$ se encuentra en concentraciones superiores a $1500 \mathrm{mg} / \mathrm{L}$. 

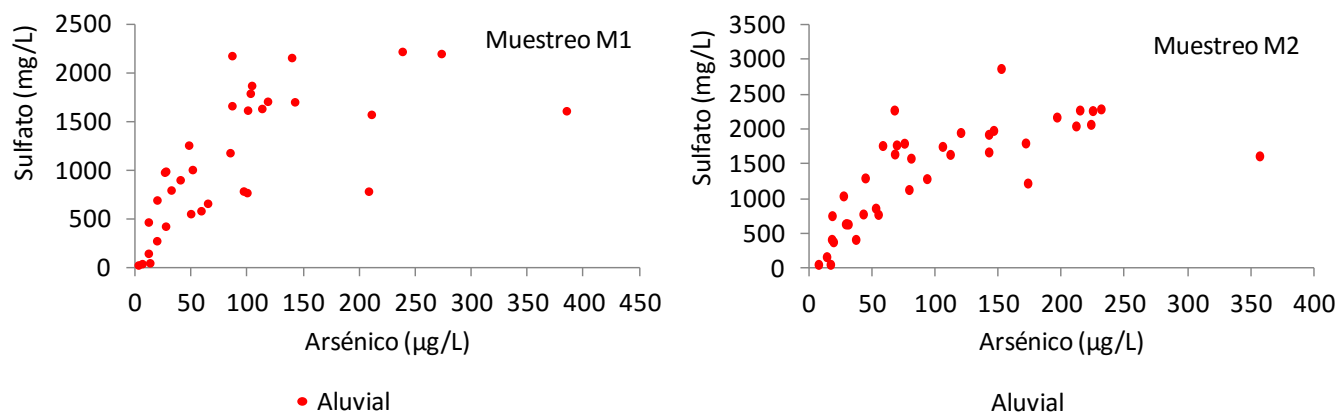

Fig. IV.49. Representación de sulfato frente a As.

Al igual que en los otros dos acuíferos, y en otros estudios reportados, el arsénico se correlaciona con el molibdeno y el vanadio. El molibdeno muestra una mejor correlación en el muestreo $M 1$ que en el $M 2$. $(r(M 1)=0,54 ; r(M 2)=0,27)$. El vanadio solo se determinó para el segundo muestreo y se observa una buena correlación $(r(M 2)=0,50)$.

A la vista de los resultados obtenidos, parece plausible la hipótesis de que el origen del arsénico en el acuífero aluvial se relaciona con la recirculación existente debida a los intensos bombeos y al efecto de concentración salina a partir de los excedentes de riego con aguas subterráneas, junto a la previsible desorción competitiva de arseniato que se observa para concentraciones de sulfatos superiores a $1500 \mathrm{mg} / \mathrm{L}$.

La influencia del empleo de purines como fertilizantes, práctica habitual en la zona, no parece en este caso que incremente la desorción del arsénico, ya que las correlaciones observadas entre arsénico y especies nitrogenadas son débiles.

La falta de correlación, en los tres acuíferos, entre los contenidos de arsénico y de hierro total parece indicar que el As disuelto no procede de la disolución/alteración de óxidos y sulfuros de hierro, sino que podría deberse a procesos de adsorción/desorción en los sedimentos. Este mismo proceso es el que se considera que controla la movilización del arsénico en La Pampa (Argentina) (Smedley y col., 2002).

La concentración de hierro hallada en la mayoría de los puntos muestreados es baja. Esto puede ser debido a que en las condiciones de pH/Eh de los pozos, la mayor parte del hierro se encontraría precipitado en forma de óxidos, como se ha demostrado con el cálculo de los índices de saturación, siendo muy baja la proporción de hierro en la disolución. Como con el hierro, no hay relación entre arsénico y el manganeso disuelto, por lo que el arsénico tampoco parece provenir de la disolución/alteración de minerales de manganeso.

No se observa relación clara entre el bicarbonato y el arsénico en ninguno de los acuíferos. Para este anión no existiría proceso de concentración salina debido a que se encuentra saturado o próximo a saturación y cuando alcanza su producto de solubilidad precipitarían carbonatos cálcico-magnésicos. 
Los resultados obtenidos mensualmente en las muestras de agua de la red de control han permitido extraer algunas conclusiones acerca de la variabilidad temporal de la hidroquímica de las aguas subterráneas investigadas. Como hemos visto hasta ahora, las aguas subterráneas, durante su movimiento a través del acuífero, experimentan variaciones en su composición química a medida que atraviesan materiales de diferente litología, debido a la existencia de fenómenos como la disolución mineral, precipitación, cambio de bases, reducción de sulfatos, etc.

Asimismo, existe también una variación temporal de los componentes químicos, relacionada con el régimen de recarga en el acuífero (infiltración de agua de lluvia, retornos de riego, pérdidas de canales, etc.) y con la presencia de focos contaminantes (agrícolas, industriales, urbanas, etc.).

De esta manera, cabría esperar oscilaciones estacionales en el nivel piezométrico del acuífero debidas a la recarga natural a partir del agua de lluvia en otoño-invierno y la inducida por los sistemas de riego a partir de los propios acuíferos en primavera-verano, lo que provocaría una dilución del sistema, y por tanto una disminución de los componentes químicos en los meses de invierno y un aumento en los meses de verano debido a las evaporaciones producidas.

En cuanto a los principales focos contaminantes, recordamos que las principales actividades de la zona son agrícolas y ganaderas, con importantes regadíos de aguas subterráneas dedicados principalmente al cultivo de la zanahoria, patata y remolacha, así como abundantes granjas porcinas y avícolas. Estas actividades llevan asociadas en períodos muy concretos el uso de fertilizante, abonos... los cuales contienen componentes químicos que, además de aumentar las concentraciones naturales del suelo, pueden alterar el equilibrio de las especies de la zona.

Los núcleos urbanos existentes en la zona de estudio también inciden sobre las aguas subterráneas a través de los vertidos industriales y urbanos.

La Fig. IV.34 muestra la variabilidad del arsénico en los diferentes puntos de control. No se ha observado un cambio radical en las concentraciones de este elemento debido al cambio de estaciones, es decir, que la recarga de los acuíferos con agua exenta de arsénico (proveniente de la lluvia) hacía esperar una disminución en la concentración de arsénico. Sin embargo, este efecto solamente ha sido observado en el manantial M95. Por el contrario, en algunos puntos de agua como el P5 y el P61, que poseen elevados contenidos en arsénico, se observa un incremento de concentración cuando el nivel de agua en los pozos aumenta, disminuyendo en épocas de verano. Esta falta de recarga de los acuíferos también se ha observado en estudios realizados en otras zonas con graves problemas de contaminación por arsénico (Smedley y col., 2001; Calvo Revuelta y col., 2003).

Los estudios realizados en Bangladesh por Shafi M. Tareq no muestran una variación en la concentración de arsénico de las aguas subterráneas debido a los cambios de estación, observándose únicamente una variación aleatoria del 10-16\% (Shafi M. Tareq y col., 2003).

En abril de 2003 se produjeron abundantes precipitaciones, por lo que el suelo quedo saturado de agua provocando una mayor interacción agua-roca con el consiguiente 
incremento de la lixiviación de minerales de arsénico que se refleja en un aumento de concentración apreciable en el mes de mayo. Estas precipitaciones provocaron simultáneamente la dilución de los acuíferos, lo cual se refleja en la disminución de los niveles de calcio en los acuíferos superficiales (aluvial y carbonatado), y en los niveles de potasio y sodio en la muestra del acuífero detrítico profundo (S90), Fig. IV.35.

La concentración de nitratos permanece prácticamente constante en todos los puntos muestreado a lo largo del año hidrológico, aunque en el P20 se observa una disminución a partir del mes de marzo y en el P61 hay un aumento hasta junio y luego una disminución. La correlación entre nitrato y nitrito es elevada $(r(M 2)=0,465)$, indicando una posible interconversión redox de estas especies.

La variabilidad espacial y estacional han sido puestas de manifiesto y modeladas mediante la aplicación de análisis en componentes principales de tres vías, siendo el algoritmo PARAFAC el que ha conducido a un modelo más sencillo y de más fácil interpretación.

En la Fig. IV.50 se han esquematizado las fuentes y vías principales de dispersión del arsénico en el área investigada que se proponen, a la vista de los resultados experimentales.

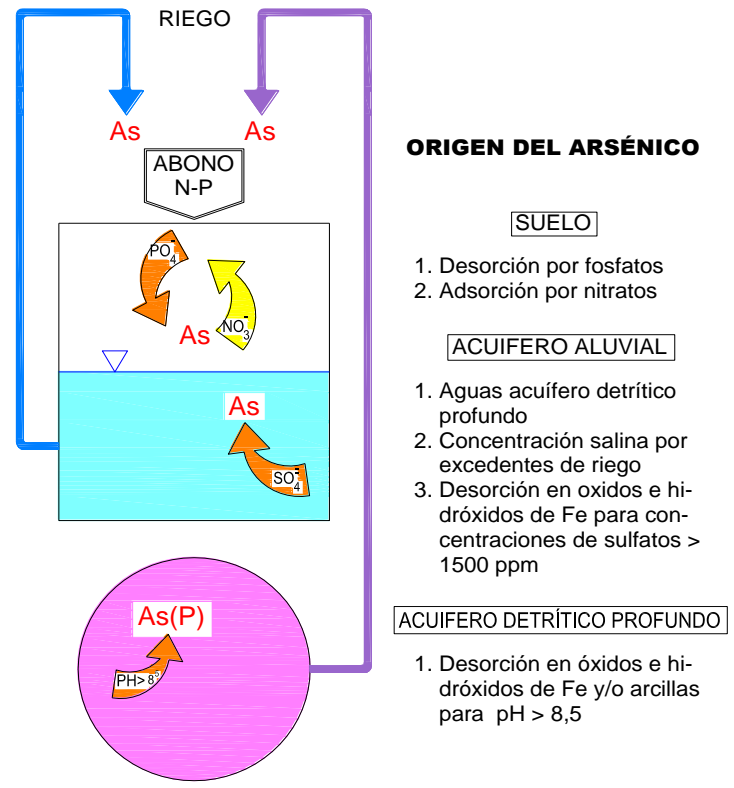

Fig. IV.50. Esquema del origen y dispersión del As 
CAPÍTULO V. ESTUDIO GEOQUÍMICO

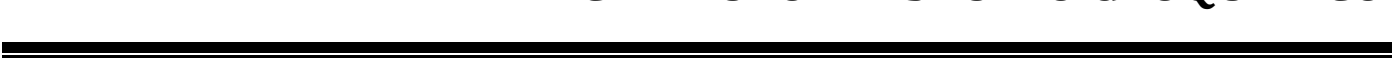





\section{V.1. INTRODUCCIÓN}

El arsénico aparece como un constituyente principal en más de 200 minerales (As nativo, arseniuros, sulfuros, óxidos, arseniatos y arsenitos), aunque apenas una docena son relativamente frecuentes (Tabla V.1).

Tabla V.1. Minerales de arsénico más frecuentes.

\begin{tabular}{|c|c|c|}
\hline Mineral & Composición & Presente en \\
\hline Arsénico nativo & As & Venas hidrotermales \\
\hline Niccolita & NiAs & Filones y noritas \\
\hline Rejalgar & AsS & $\begin{array}{l}\text { Filones, muchas veces asociado con oropimente, } \\
\text { arcillas y carbonatos en "hot springs" }\end{array}$ \\
\hline Oropimente & $\mathrm{As}_{2} \mathrm{~S}_{3}$ & $\begin{array}{l}\text { Venas hidrotermales, "hot springs". También como } \\
\text { producto de sublimación de emanaciones volcánicas }\end{array}$ \\
\hline Cobaltita & CoAsS & Depósitos de alta temperatura, rocas metamórficas \\
\hline Arsenopirita & FeAsS & $\begin{array}{l}\text { Es el mineral de As más abundante. Muy frecuente } \\
\text { en filones }\end{array}$ \\
\hline Tennantita & $(\mathrm{Cu}, \mathrm{Fe})_{12} \mathrm{As}_{4} \mathrm{~S}_{13}$ & Venas hidrotermales \\
\hline Enargita & $\mathrm{Cu}_{3} \mathrm{AsS}_{4}$ & Venas hidrotermales \\
\hline Arsenolita & $\mathrm{As}_{2} \mathrm{O}_{3}$ & $\begin{array}{l}\text { Mineral secundario formado por oxidación de } \\
\text { arsenopirita, arsénico nativo y otros minerales de } \\
\text { arsénico }\end{array}$ \\
\hline Claudetita & $\mathrm{As}_{2} \mathrm{O}_{3}$ & $\begin{array}{l}\text { Mineral secundario formado por oxidación de } \\
\text { realgar, arsenopirita, y otros minerales de arsénico }\end{array}$ \\
\hline Escorodita & $\mathrm{FeAsO}_{4} \cdot 2 \mathrm{H}_{2} \mathrm{O}$ & Mineral secundario \\
\hline Annabergita & $(\mathrm{Ni}, \mathrm{Co})_{3}\left(\mathrm{AsO}_{4}\right)_{2} \cdot 8 \mathrm{H}_{2} \mathrm{O}$ & Mineral secundario \\
\hline Hoernesita & $\mathrm{Mg}_{3}\left(\mathrm{AsO}_{4}\right)_{2} \cdot 8 \mathrm{H}_{2} \mathrm{O}$ & Mineral secundario, en escorias \\
\hline Hematolita & $(\mathrm{Mn}, \mathrm{Mg})_{4} \mathrm{Al}\left(\mathrm{AsO}_{4}\right)(\mathrm{OH})_{8}$ & Mineral en fisuras de rocas metamórficas \\
\hline Conicalcita & $\mathrm{CaCu}\left(\mathrm{AsO}_{4}\right)(\mathrm{OH})$ & Mineral secundario \\
\hline Farmacosiderita & $\mathrm{Fe}_{3}\left(\mathrm{AsO}_{4}\right)_{2}(\mathrm{OH})_{3} \cdot 5 \mathrm{H}_{2} \mathrm{O}$ & $\begin{array}{l}\text { Producto de oxidación de arsenopirita y otros } \\
\text { minerales de arsénico }\end{array}$ \\
\hline
\end{tabular}

También se encuentra formando parte, aunque no como componente mayoritario, de un gran número de minerales, tanto primarios como secundarios (Tabla.V.2).

En la Tabla.V.2 se puede observar que las mayores concentraciones de arsénico aparecen en sulfuros como pirita, calcopirita, galena y marcasita, aunque también se encuentran concentraciones apreciables en óxidos y oxihidróxidos.

Los fosfatos son otro grupo de minerales que pueden tener contenidos relativamente altos de arsénico. Además, el arsénico puede sustituir a Si(IV), $\mathrm{Al}(\mathrm{III}), \mathrm{Fe}$ (III) and Ti(IV) en muchas estructuras minerales, apareciendo en estos casos en concentraciones bajas. Por ejemplo, la mayoría de los silicatos contienen hasta $1 \mathrm{mg} / \mathrm{kg}$ de arsénico (Baur y Onishi, 1969).

Los carbonatos (calcita, dolomita y siderita) normalmente tienen menos de $10 \mathrm{mg} / \mathrm{kg}$ (Boyle y Jonasson, 1973). 
Tabla.V.2. Concentración de arsénico en algunos de los minerales más comunes (Baur y Onishi, 1969; Boyle y Jonasson, 1973, Pichler y col., 1999).

\begin{tabular}{|c|c|}
\hline Mineral & As (mg/kg) \\
\hline \multicolumn{2}{|l|}{ Sulfuros: } \\
\hline Pirita & $100-77.000$ \\
\hline Pirrotina & $5-100$ \\
\hline Galena & $5-10.000$ \\
\hline Esfalerita & $5-17.000$ \\
\hline Calcopirita & $10-5000$ \\
\hline \multicolumn{2}{|l|}{ Óxidos: } \\
\hline Hematite & Hasta 160 \\
\hline Óxidos de Fe & Hasta 2000 \\
\hline Oxihidróxido de Fe(III) & Hasta 76.000 \\
\hline Magnetita & $2,7-41$ \\
\hline \multicolumn{2}{|l|}{ Silicatos: } \\
\hline Cuarzo & $0,4-1,3$ \\
\hline Feldespato & $<0,1-2,1$ \\
\hline Biotita & 1,4 \\
\hline Anfíbol & $1,1-2,3$ \\
\hline Olivino & $0,08-0,17$ \\
\hline Piroxeno & $0,05-0,8$ \\
\hline \multicolumn{2}{|l|}{ Carbonatos: } \\
\hline Calcita & $1-8$ \\
\hline Dolomita & $<3$ \\
\hline Siderita & $<3$ \\
\hline \multicolumn{2}{|l|}{ Sulfatos: } \\
\hline Yeso/Anhidrita & $<1-6$ \\
\hline Barita & $<1-12$ \\
\hline Jarosita & $34-1000$ \\
\hline \multicolumn{2}{|l|}{ Fosfatos: } \\
\hline Apatito & $<1-1000$ \\
\hline
\end{tabular}

Las concentraciones de arsénico en las rocas ígneas son bajas, por lo general, con un valor medio de $1,5 \mathrm{mg} / \mathrm{kg}$ (Ure y Berrow, 1982) con pocas diferencias entre los distintos tipos litológicos. A pesar de ello, determinadas rocas de naturaleza muy reactiva como cenizas volcánicas de grano fino, pueden liberar cantidades relativamente altas a las aguas (Nicolli y col., 1989; Smedley y col., 2002).

Las rocas metamórficas también muestran contenidos bajos de arsénico, que no suelen superar $5 \mathrm{mg} / \mathrm{kg}$, excepto las metapelitas, que tienen un contenido medio de $18 \mathrm{mg} / \mathrm{kg}$ (Boyle y Jonasson, 1973).

Las rocas sedimentarias presentan una mayor variabilidad en cuanto al contenido de arsénico, con promedios y rangos algo superiores a los de las rocas ígneas o metamórficas, sobre todo las lutitas, con valores medios de $28,40 \mathrm{mg} / \mathrm{kg}$ (Gromet, 1984). En general, la pelitas de origen marino tienen los contenidos más altos de arsénico, que pueden ser excepcionalmente altos en ambientes medioceánicos, con promedios de 174 mg/kg (Smedley y Kinniburgh, 2002). 
Las rocas carbonatadas muestran contenidos bajos de arsénico, con valores medios inferiores a $5 \mathrm{mg} / \mathrm{kg}$ (Baur y Onishi, 1969), lo que es concordante con los bajos contenidos de arsénico de sus minerales constituyentes.

Los materiales sedimentarios más ricos en arsénico son los carbones, donde se han llegado a encontrar valores de hasta $35.000 \mathrm{mg} / \mathrm{kg}$ (Belkin y col., 2000). Otras formaciones sedimentarias como los "ironstones" (James, 1996) y fosforitas también son ricas en arsénico.

Localmente, en zonas con mineralizaciones o aguas bajo ellas, se pueden encontrar sedimentos enriquecidos en arsénico en un factor de hasta 89,4 respecto a los valores de referencia en sedimentos fluviales actuales y hasta en un factor de 468,8 en sedimentos lacustres holocenos (Oyarzun y col., 2004).

Aunque los niveles fondo de arsénico promedio son del orden de $5-6 \mathrm{mg} / \mathrm{kg}$ de media, el valor de referencia sugerido para sedimentos no contaminados es de $10 \mathrm{mg} / \mathrm{kg}$ (Adriano, 1986; Bowen, 1979; Smedley y Kinniburgh, 2002; Taggar, 2003). Sin embargo, la distribución de arsénico en los diferentes tipos de rocas está principalmente influenciada por la naturaleza de las rocas madre, por lo que este valor fondo puede ser ampliamente superado en aquellas rocas o sedimentos que se encuentran en áreas mineralizadas o formados a partir de materiales ricos en pirita $u$ otros sulfuros.

También podemos encontrar concentraciones elevadas de arsénico en sedimentos debido a actividades antrópicas como: vertidos industriales, combustión de carburantes, fertilizantes, pesticidas, escombreras y balsas mineras (Manning y col., 1998).

Uno de los mecanismos por los que el arsénico puede ser retenido son las reacciones de adsorción que tienen lugar en la superficie de las partículas coloidales del suelo. Estas partículas pueden ser superficies de óxidos o hidróxidos de aluminio, hierro y manganeso, arcillas, carbonato cálcico o materia orgánica.

La carga de los coloides depende de factores tales como su cristalinidad y composición química, $\mathrm{pH}$ del medio, impurezas presentes en los coloides, etc, que afectan al punto isoeléctrico de la carga de las partículas sólidas. La Fig. V.1 muestra el efecto del pH en la carga de diferentes minerales con elevada capacidad de adsorción, de donde se deduce la complejidad de los procesos de adsorción/desorción del arsénico en los sedimentos.

Los óxidos de hierro se encuentran, en general, recubriendo minerales primarios y secundarios o integrados en agregados de arcilla, estando presentes en mayor o menor cantidad en la práctica totalidad de sedimentos. Estos óxidos alteran la carga eléctrica, modifican las propiedades de la superficie de las partículas e incrementan la capacidad amortiguadora del suelo.

En muchos estudios se ha determinado que la actividad del arsénico en la interfase sedimento/disolución está controlada fundamentalmente por las reacciones de retención sobre las superficies de los óxidos y oxihidróxidos de hierro, aluminio y manganeso (Livesey y Huang, 1981; Inskeep y col., 2002; Fitz y Wenzel, 2002; de Brouwere y col., 2004; Fritzsche y col., 2006; Krysiak y Karczewska, 2007), ya que el arsénico (V) tiene una gran afinidad por las superficies de los óxidos de hierro (Waychaunas y col., 1993; Cheng y col., 2008). Estudios sobre la adsorción de arsénico 
sobre diferentes oxihidróxidos muestran su dependencia con el pH; así, la adsorción del arsénico sobre los oxihidróxidos disminuye cuando aumenta el pH debido a la afinidad del hierro por los grupos hidróxido (Manning y col., 1997, Matis y col., 1997; Xu y col., 1988; Giménez y col., 2006). La adsorción de arsénico en óxidos depende, además, del tiempo de interacción arsénico-óxido, siendo más difícil liberar el arsénico cuanto mayor haya sido éste (Gräfe y Sparks, 2006).

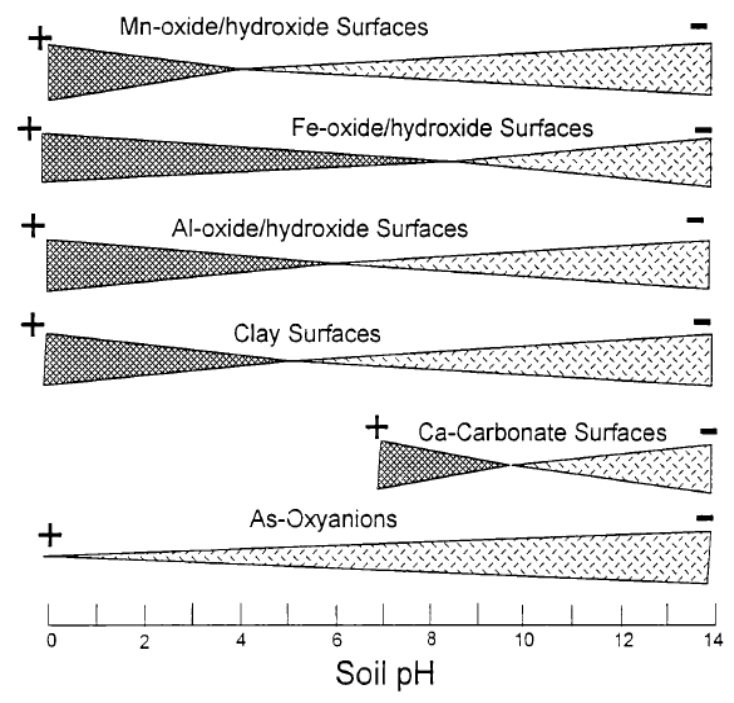

Fig. V.1. Cargas en los coloides de los sedimentos

Las arcillas están formadas por aluminosilicatos hidratados, frecuentemente con cantidades apreciables de hierro, magnesio, calcio, sodio y potasio. Son siempre de grano muy fino, dando lugar a menudo soluciones coloidales. La mayoría de las arcillas suelen ser producto de la meteorización y de la sedimentación, aunque también pueden formarse por actividad hidrotermal.

Los diferentes tipos de arcillas dependen sobre todo de la composición química del material de origen; del medio físico-químico en que se ha producido la transformación y del medio donde se ha producido la deposición y la diagénesis. Así, mientras que la estructura de la caolinita no permite que se acomoden más cationes que los de aluminio y silicio, la montmorillonita, la illita y la clorita siempre admiten otros elementos, especialmente hierro y magnesio. La elevada área superficial se traduce en una gran superficie activa, con enlaces no saturados que favorecen las interacciones con diversas sustancias. La Tabla V.3 muestra las superficies específicas de algunas arcillas. 
Tabla V.3. Ejemplos de superficies específicas de arcillas

\begin{tabular}{ll} 
Tipo de Arcilla & Superficie específica \\
\hline Caolinita de elevada cristalinidad & $15 \mathrm{~m}^{2} / \mathrm{g}$ \\
Caolinita de baja cristalinidad & $50 \mathrm{~m}^{2} / \mathrm{g}$ \\
Halloisita & $60 \mathrm{~m}^{2} / \mathrm{g}$ \\
Illita & $50 \mathrm{~m}^{2} / \mathrm{g}$ \\
Montmorillonita & $80-300 \mathrm{~m}^{2} / \mathrm{g}$ \\
Sepiolita & $100-240 \mathrm{~m}^{2} / \mathrm{g}$ \\
Paligorskita & $100-200 \mathrm{~m}^{2} / \mathrm{g}$ \\
\hline
\end{tabular}

Por otra parte, la existencia de carga en las láminas que conforman las arcillas benefician la entrada en el espacio interlaminar de cationes débilmente ligados y con estado variable de hidratación, que pueden ser intercambiados fácilmente mediante la puesta en contacto de la arcilla con una solución saturada en otros cationes (intercambio catiónico). De esta manera, las arcillas son capaces de cambiar fácilmente los iones fijados en la superficie exterior de sus cristales, en los espacios interlaminares o en otros espacios interiores de las estructuras, por otros existentes en las soluciones acuosas envolventes.

La capacidad de cambio catiónico es equivalente a la medida del total de cargas negativas del mineral, las cuales pueden ser generadas de tres formas diferentes:

- Sustituciones isomórficas dentro de la estructura.

- Enlaces insaturados en los bordes y superficies externas.

- Disociación de los grupos hidroxilos accesibles.

El primer tipo es conocido como carga permanente y supone un $80 \%$ de la carga neta de la partícula; además, es independiente de las condiciones de $\mathrm{pH}$ y actividad iónica del medio. En los dos últimos mecanismos, la carga varía en función del pH y de la actividad iónica y representan el $20 \%$ de la carga total de la lámina. A continuación se muestran algunos ejemplos de capacidad de intercambio catiónico (en meq/100 g):

Tabla.V.4. Capacidades de cambio catiónico de algunas arcillas (en meq/100g)

\begin{tabular}{ll} 
Tipos de arcillas & C.I.C \\
\hline Caolinita & $3-5$ \\
Halloisita & $10-40$ \\
Illita & $10-50$ \\
Clorita & $10-50$ \\
Sepiolita-paligorskita & $20-35$ \\
Esmectita & $70-130$ \\
Montmorillonita & $80-200$ \\
Vermiculita & $100-200$ \\
\hline
\end{tabular}

A pesar de que la retención de arsénico en las arcillas es menos eficaz que sobre los óxidos (Gräfe y Sparks, 2006), este proceso también contribuye de forma notable a la adsorción del arsénico en los sedimentos (Manning and Goldberg, 1997b). De hecho, se ha observado que los sedimentos con poco contenido en óxidos de hierro y aluminio y en arcillas no fijan el arsénico de forma eficiente y este es lixiviado (Quazi y col., 2011). 
Esto se debe a que los óxidos de hierro y aluminio y las arcillas son los compontes de los sedimentos con mayores puntos de adsorción de As(V) (Mahmairaja y col., 2005; Smith y col., 1998).

La estructura de los minerales de arcilla o el tiempo de interacción entre las arcillas y el arsénico son condiciones que influyen en la adsorción de arsénico en los minerales arcillosos. Algunos estudios han demostrado que la adsorción de arsénico por los minerales de la arcilla aumenta con el tiempo (Lin y Puls, 2000). Otros estudios han sugerido que las sustituciones isomórficas de hierro por aluminio en las arcillas pueden contribuir a la adsorción de arsénico (Zhang y Selim, 2008).

El carácter aniónico del arsénico sugiere que el mecanismo de retención de este metaloide en las arcillas podría ser similar al mecanismo de retención del fósforo en sedimentos mediado por calcio, mediante la presencia de cationes puente (Fixen y Grove, 1990). A continuación se muestra el mecanismo de retención del fósforo, en sedimentos calcáreos de $\mathrm{pH}$ elevado, donde la presencia del ion $\mathrm{Ca}^{2+}$ es abundante y se produce la coadsorción de este catión y del fosfato sobre las partículas de arcilla, de tal manera que el catión metálico actúa de puente entre la arcilla y el fosfato (Fig.V.2). Con el paso del tiempo los iones fosfato pueden combinarse con estos iones y formar fosfatos insolubles. Sin embargo, a medida que el $\mathrm{pH}$ se hace menos alcalino la solubilidad del fosfato de calcio aumenta (Domenech, 2000).

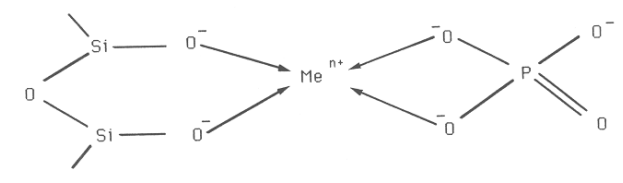

Fig.V.2. Retención del fosfato por coadsorción con un ión metálico en una partícula de arcilla.

Existen diversos estudios sobre la adsorción del arsénico en diferentes tipos de filosilicatos. Así, se ha demostrado la montmorillonita puede adsorber más As(V) y As(III) que la caolinita, debido a la mayor carga superficial de aquella (Frost y Griffin, 1977). Otros autores han hallado que la halosita y la clorita tienen mayor capacidad para adsorber $\mathrm{As}(\mathrm{V})$ que el resto de los minerales de la arcilla, y también que la caolinita, la illita y la montmorillonita presentan una adsorción moderada de As(V) (Lin y Puls, 2000).

Todo ello pone de manifiesto que, aunque la mayor parte de la carga de las arcillas es capaz de intercambiar cationes, éstas son también capaces de retener aniones mediante distintos mecanismos.

Los minerales carbonatados juegan un papel importante en la retención de arsénico en sedimentos alcalinos, sobre todo en los sedimentos calcáreos. Se han observado adsorciones máximas de arsénico en calcita con pH alrededor de 10 (Golberg y Glaubig, 1988). Por el contrario, otros estudios han mostrado que los contenidos de cal no se correlacionaban con la adsorción de arsénico (Polemio y col., 1982), por lo que se cree 
que la quimisorción o el intercambio de ligandos pudieran ser mecanismos responsables de la adsorción de arsénico en las superficies carbonatadas (Brannon y Patrick, 1987; Goldberg y Glaubig, 1988). El punto isoeléctrico de las superficies carbonatadas varía entre 7 y 10 , por lo que estas superficies podrían tener cargas positivas en sedimentos con pH inferiores a 9 y así jugarían un papel importante en la adsorción de arsénico en sedimentos alcalinos.

En los sedimentos, la materia orgánica o humus engloba fundamentalmente una serie de compuestos orgánicos de naturaleza química heterogénea en referencia a su grado de polimerización y peso molecular (Stevenson, 1982). El grado de polimerización de los compuestos del humus y su peso molecular influyen sobre su solubilidad: los más pequeños y con mayor proporción de grupos funcionales serán más solubles (ácidos orgánicos, fúlvicos y húmicos), mientras que los más polimerizados y con poca proporción de grupos funcionales (huminas) serán más estables a lo largo del tiempo e insolubles en agua.

Los efectos que va a tener la materia orgánica sobre los elementos traza de un suelo dependen de su composición cualitativa. Así, la fracción orgánica de alto peso molecular retendrá los elementos traza de forma efectiva, mientras que la más soluble y ligera solubilizará metales por quelación o aniones por desplazamiento. Dependiendo de la fracción dominante serán observables unos efectos u otros. Por todo ello, el papel de la materia orgánica sobre el arsénico del suelo está todavía en discusión. En algunos estudios la adición de materia orgánica ha conseguido disminuir la movilidad del arsénico (Gadepalle y col., 2007), pero en otros se ha observado una liberación de arsénico después de la aplicación de compost o una alta correlación entre carbono soluble y arsénico soluble en sedimentos (Mench y col., 2003; Clemente y col., 2008). Estudios recientes han mostrado que los ácidos fúlvicos y húmicos en disolución son capaces de disminuir la capacidad de la goetita de retener arseniato por competición electrostática (Weng y col., 2009).

La materia orgánica disuelta parece competir con arseniato y arsenito por los lugares de retención en los sedimentos (Bernal y col., 2009), aunque otros autores han demostrado que algunos ácidos húmicos forman complejos arcillo-húmicos que tienen capacidad para retener arsénico (Saada y col., 2003). Por tanto, la relación entre el arsénico del suelo y la materia orgánica va a ser compleja, dependiente, entre otros factores, de la proporción de carbono orgánico soluble, de las fracciones más estables e insolubles del humus y de la cantidad de hierro, aluminio y manganeso de dicha materia orgánica (Gräfe y Sparks, 2006).

En definitiva, la movilidad y el transporte del arsénico en el medio ambiente están fuertemente influenciados por las asociaciones que este elemento presenta con las fases sólidas de los sedimentos. Por ello, es importante conocer qué factores son capaces de alterar las formas en las que se encuentra presente el arsénico en la litosfera. Así, algunos de los factores más importantes que condicionan la movilidad del arsénico en los sedimentos, y de los cuales vamos a hablar a continuación, son el pH, la concentración aniones y cationes y la fuerza iónica. 
El pH es considerado uno de los factores primordiales a la hora de estudiar los procesos de adsorción de metales en los sediementos. Además, juega un papel importante en la retención por complejación con la materia orgánica e influye en el comportamiento del propio metal y de los grupos funcionales de las superficies activas de rocas, sedimentos y suelos.

Muchos autores han descrito que un aumento de $\mathrm{pH}$, en oposición con lo que pasa con otros elementos traza metálicos, moviliza el arsénico del suelo. Por regla general, un aumento de $\mathrm{pH}$ del suelo ocasiona una liberación de los aniones de las posiciones de cambio, posiblemente debido al efecto competitivo de los iones hidróxido, por lo que el arsénico se libera al medio (Fitz y Wenzel, 2002). Sin embargo, existen experimentos que han mostrado que, a altos valores de $\mathrm{pH}$ y en presencia de sulfatos y carbonatos, estos pueden jugar un papel importante en la retención del arsénico (García y col., 2009; Zhang y Selim, 2008). O que en sedimentos básicos con buena aireación la solubilidad del arsénico puede estar limitada por su precipitación como arseniatos de calcio o hierro o coprecipitación con jarosita, yeso o calcita (De Brouwere y col., 2004; Zhang y Selim, 2008; Cheng y col., 2009; Xie y Naidu, 2006; Burriel y col., 1999). Quizá por ello, algunos sedimentos muestran su máximo de retención de $\mathrm{As}(\mathrm{V})$ a pH cercano a 10,5 (Goldberg y Glaubig, 1988).

Los fosfatos no solo compiten con el arsénico en las posiciones de intercambio aniónico, sino que lo hacen también en reacciones de complejación o retención en óxidos. El fosfato y el arseniato se retienen de forma más efectiva que otros aniones del suelo como cloruros y nitratos, que son rápidamente movilizados y lixiviados. Esto podría deberse a que los cloruros y nitratos se adsorben de forma inespecífica sobre la superficie de los coloides, mientras que fosfatos y arseniatos lo hacen de forma específica. Se ha demostrado que la capacidad de retención del arsénico disminuye en presencia de iones fosfato (Roy y col., 1986), mientras que otros aniones no afectan de forma tan significativa (Livesey y Huang, 1981). En otros estudios se comprobó que los carbonatos podían competir ligeramente con el arseniato por los lugares de retención en ausencia de fosfato, pero cuando el fósforo estaba presente los efectos de los iones carbonato eran insignificantes (Stachowicz y col., 2008).

Los cationes también pueden alterar la retención/movilización de arsénico en los sedimentos. Se ha demostrado que la presencia de $\mathrm{Ca}^{2+}$ y Na${ }^{+}$provoca un incremento de la retención de arsénico (Smith y col., 2002) y que $\mathrm{Ca}^{2+}$ y $\mathrm{Mg}^{2+}$ pueden promover de forma similar la adsorción de fosfato y arseniato en los sedimentos (Stachowicz y col., 2008).

Las aguas subterráneas contienen distintos aniones y cationes y sus concentraciones varían bastante, tanto en el espacio como en el tiempo, por lo que realizar estudios en el laboratorio que representen los procesos medioambientales característicos de cada sedimento es laborioso y poco operativo. Por ello, muchos investigadores han preferido estudiar el efecto de la fuerza iónica en lugar de detallar el efecto de cada ión. Así, se ha comprobado que un aumento de la fuerza iónica de la solución en contacto con el suelo es capaz de disminuir la cantidad de arsénico retenido al provocar una competencia entre aniones por los lugares de retención (Gräfe y Sparks, 2006). De los resultados obtenidos en el estudio realizado por Pantsar-Kallio sobre la extracción de arsénico en 
muestras de sedimento con extractantes de diferente fuerza iónica $\left(1 \mathrm{M} \mathrm{NaNO}_{3}, \mathrm{I}=1 ; 1 \mathrm{M}\right.$ $\mathrm{K}_{2} \mathrm{SO}_{4}, \mathrm{l}=3$ ), todos ellos ajustados a pH 8, se obtiene que la concentración extraída con el sulfato es ligeramente superior a la extraída con el nitrato, por lo que lo que se confirma que al aumentar la fuerza iónica se produce un aumento del arsénico liberado (PantsarKallio, 1997). Cuando se compara el arsénico extraído con extractantes de la misma fuerza iónica y mismo $\mathrm{pH}$ de la disolución $(\mathrm{pH}=8)$ pero aniones distintos $\left(1 \mathrm{M} \mathrm{NaNO}_{3}, \mathrm{I}=1\right.$; $1 \mathrm{M} \mathrm{NaHCO}, \mathrm{I}=1$ ) se obtiene que el ión bicarbonato extrae mayor cantidad de arsénico que el nitrato.

También se estudió el efecto del pH utilizando para ello una solución $1 \mathrm{M} \mathrm{NaHCO}_{3}$ a pH=8 y otra de $1 \mathrm{M} \mathrm{Na}_{2} \mathrm{CO}_{3}$ a $\mathrm{pH}=11$, observándose una extracción de arsénico mucho mayor a $\mathrm{pH} 11$ por lo que se concluye que, para estos aniones, el efecto más significativo es el $\mathrm{pH}$.

El tiempo de interacción del arsénico con el sedimento es otro factor importante a tener en cuenta en aquellos sedimentos contaminados inicialmente por arsénico fácilmente extraíble. Nada más producirse la interacción arsénico-sedimento su disponibilidad será mayor que después de un periodo de equilibrado, ya que con el tiempo el arsénico inicialmente adsorbido en la superficie de la arcilla puede retenerse cada vez más fuertemente en la estructura del mineral, lo que pone de manifiesto que el paso del tiempo favorece la retención del arsénico en las fracciones menos disponibles en el sedimento (Lombi y col., 1999).

El tamaño de partícula de los sedimentos (textura) influye también en la retención del arsénico. Así, la disponibilidad del arsénico es, en general, mayor en los sedimentos de textura arenosa que en los arcillosos (Adriano, 2001).

Otro factor importante en cuanto al riesgo y movilidad del arsénico en los sedimentos es el régimen de precipitaciones, que obviamente tiene incidencia directa sobre la cantidad de arsénico que se lixivia del sedimento en forma de escorrentía superficial y subterránea.

En este estudio se ha optado por analizar muestras de sedimentos del área investigada para conocer su composición geoquímica y mineralógica, con el fin de dilucidar los equilibrios que sufre el arsénico en la interfase sedimento-disolución, responsables de los mecanismos de fijación y lixiviación que sufre este elemento en el medio natural.

\section{V.2. MUESTREO}

Se han tomado un total de 57 muestras de sedimento en zonas no sometidas a explotación agrícola o industrial. Las muestras fueron recogidas en diferentes años: 10 de ellas en octubre de 2002, 42 en febrero, marzo y agosto de 2004 y 5 más en noviembre de 2005. La elección de los puntos de muestreo se ha realizado en función de la unidad litoestratigráfica de pertenencia y la abundancia de ésta en la zona de estudio. Así, se han tomado 24 muestras en cotas aflorantes correspondientes a las diferentes unidades geológicas presentes en el sector del acuífero investigado y el resto de muestras (33) son sub-superficiales, no aflorantes, procedentes de un sondeo de $150 \mathrm{~m}$ 
de profundidad realizado en agosto de 2004 en una finca particular del término municipal de Mata de Cuellar (Segovia).

Las herramientas de muestreo utilizadas para la toma de muestra de los sedimentos aflorantes fueron una pequeña azada protegida con plástico para acceder al suelo situado a una profundidad de $10-15 \mathrm{~cm}$ y una barrena manual de pequeño tamaño para extraer la muestra cuando la profundidad era mayor $(15-50 \mathrm{~cm})$. Las muestras del sondeo (cotas no aflorantes) se consiguieron a partir de los ripios de perforación obtenidos con el sistema de perforación de recirculación inversa empleado para realizar el sondeo arriba mencionado (Fig. V.3). El sistema inyecta aire comprimido que circula a través de la zona anular de las varillas y, cuando llega al extremo inferior, sale fuera del varillaje, refrigera la trialeta perforadora $y$, por efecto Venturi, succiona el material perforado que sale por el tubo interior hasta la superficie. El material extraído se separó en función de la profundidad a la que correspondía, obteniéndose una muestra por cada metro de perforación. De las aproximadamente 150 muestras se seleccionaron 33 para ser analizadas, de forma que cada unidad litoestratigráfica estuviera representada por un número de muestras proporcional a su espesor.

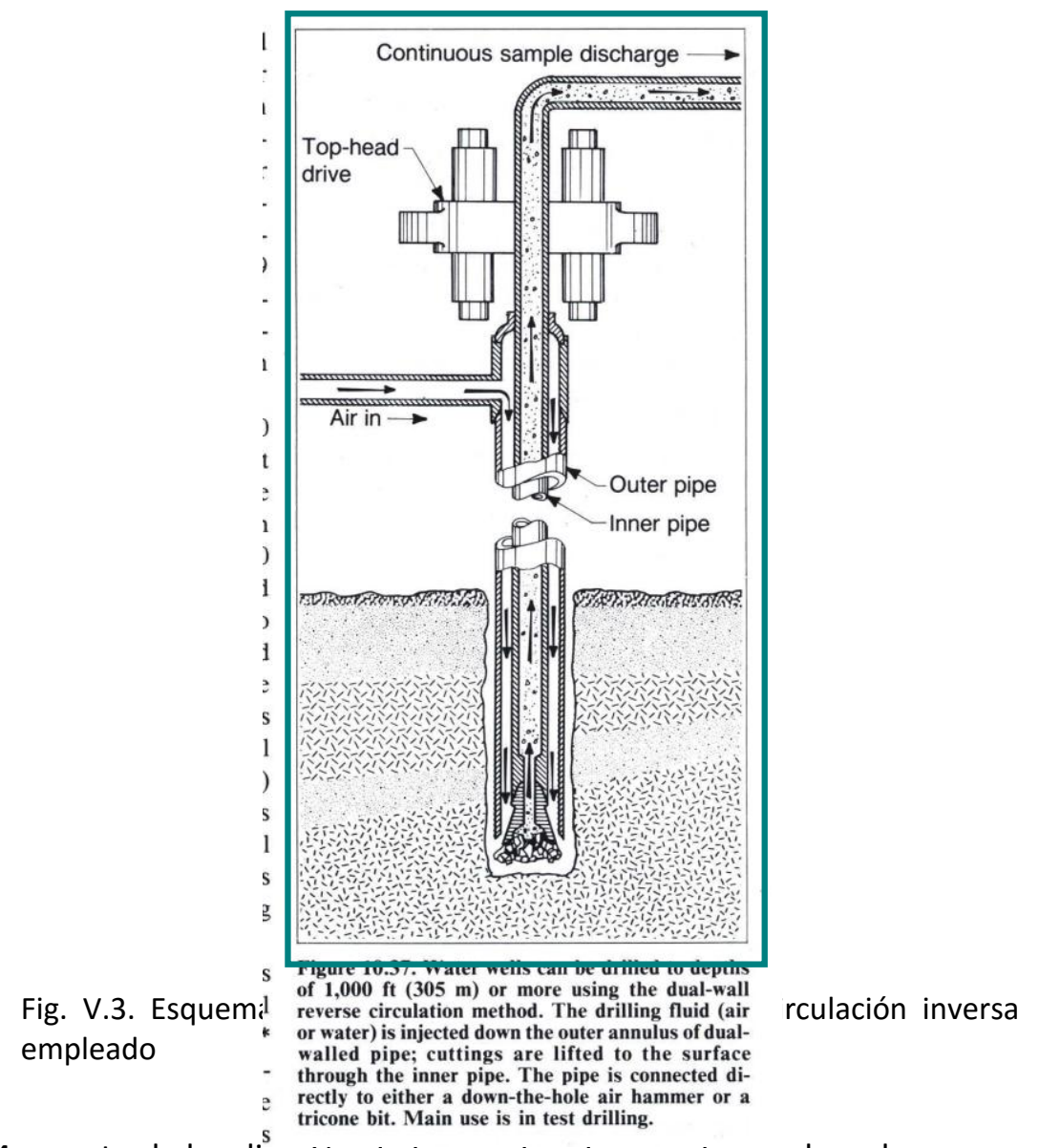

La Fig. V.4 muestra la localizacion de los puntos de muestreo sobre el mapa geológico de la zona; la Fig. V.5 representa dichas muestras sobre la columna estratigráfica. 


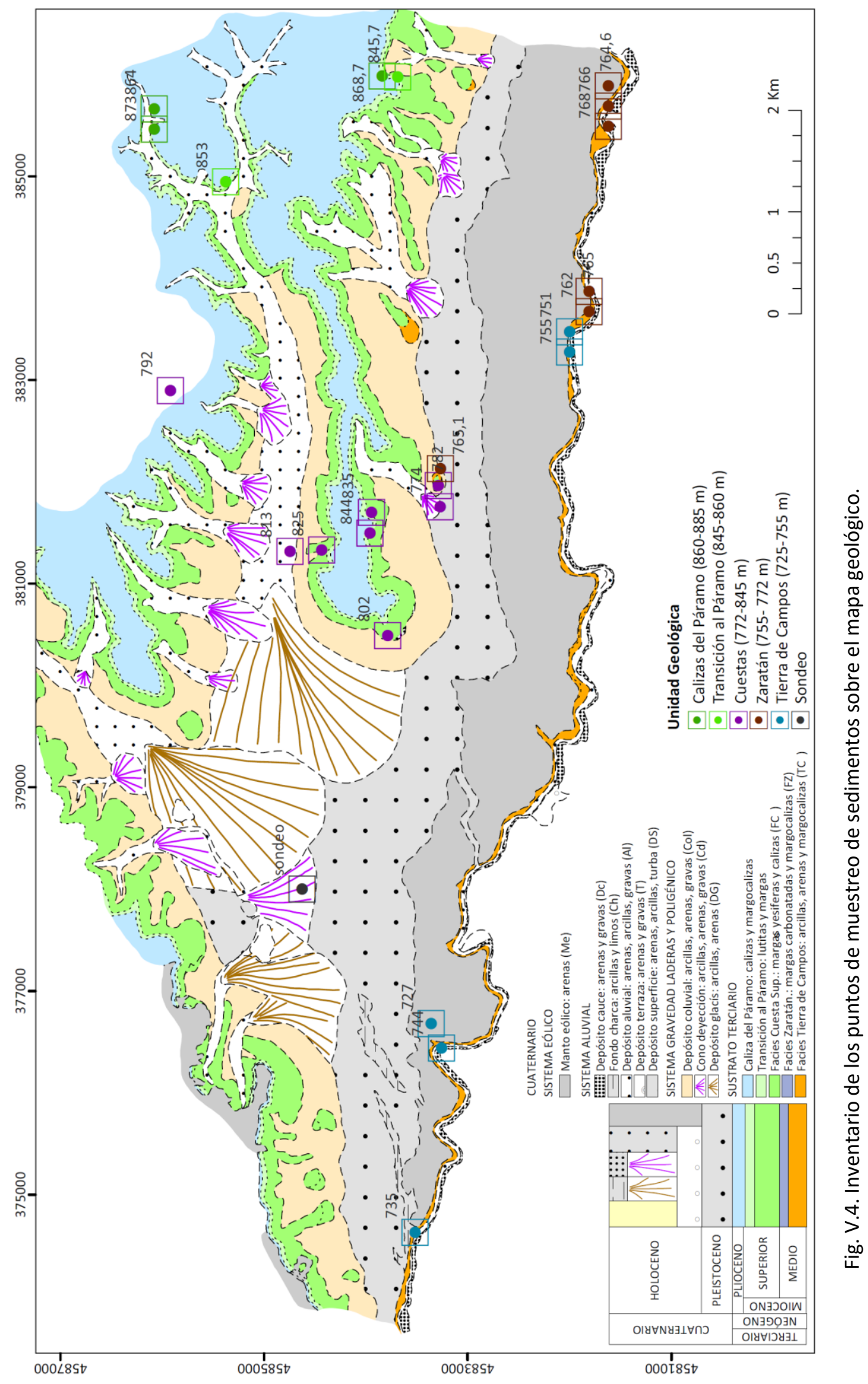




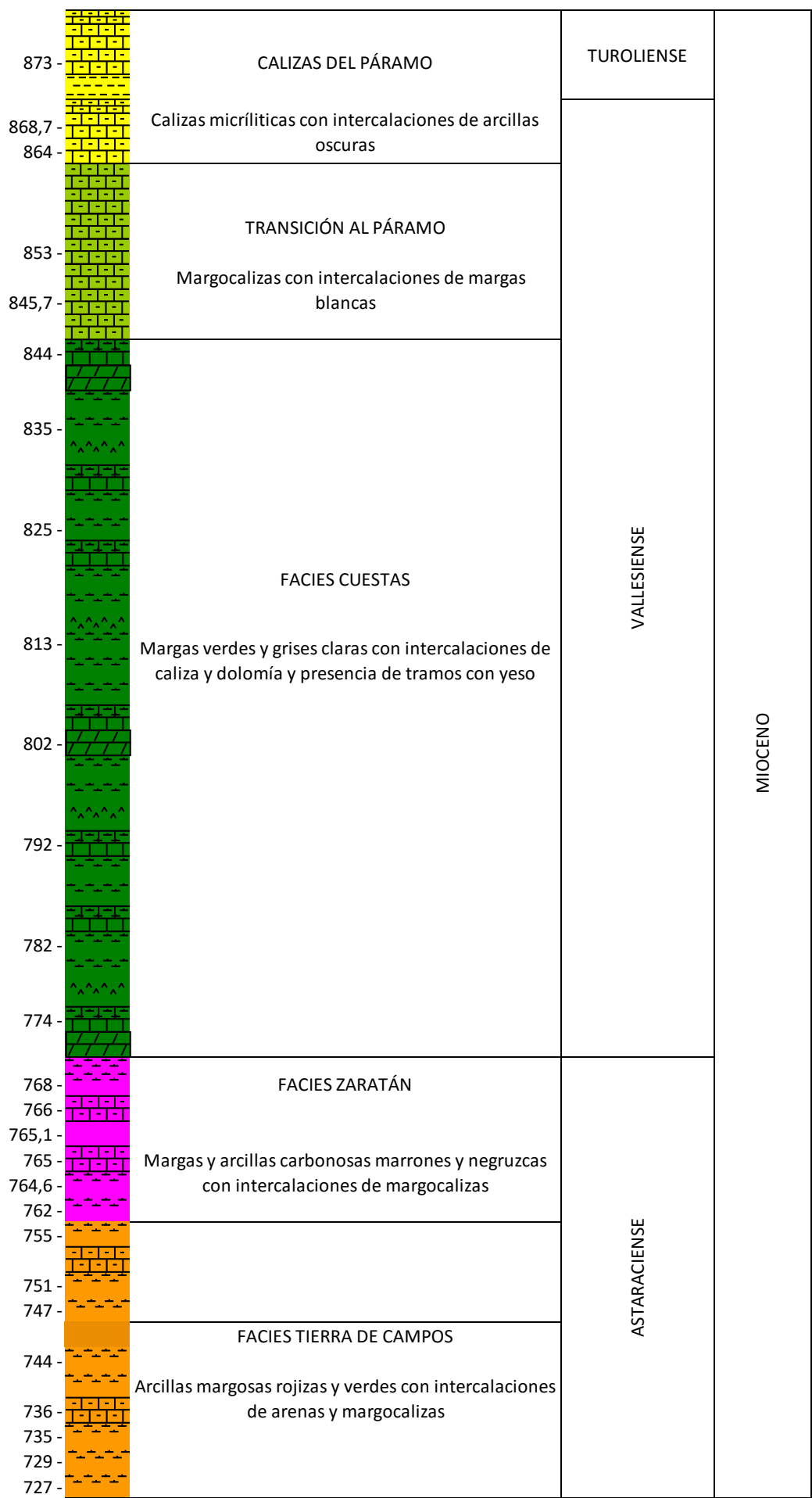

Fig. V.5. Inventario de los puntos de muestreo de sedimentos sobre la columna estratigráfica 


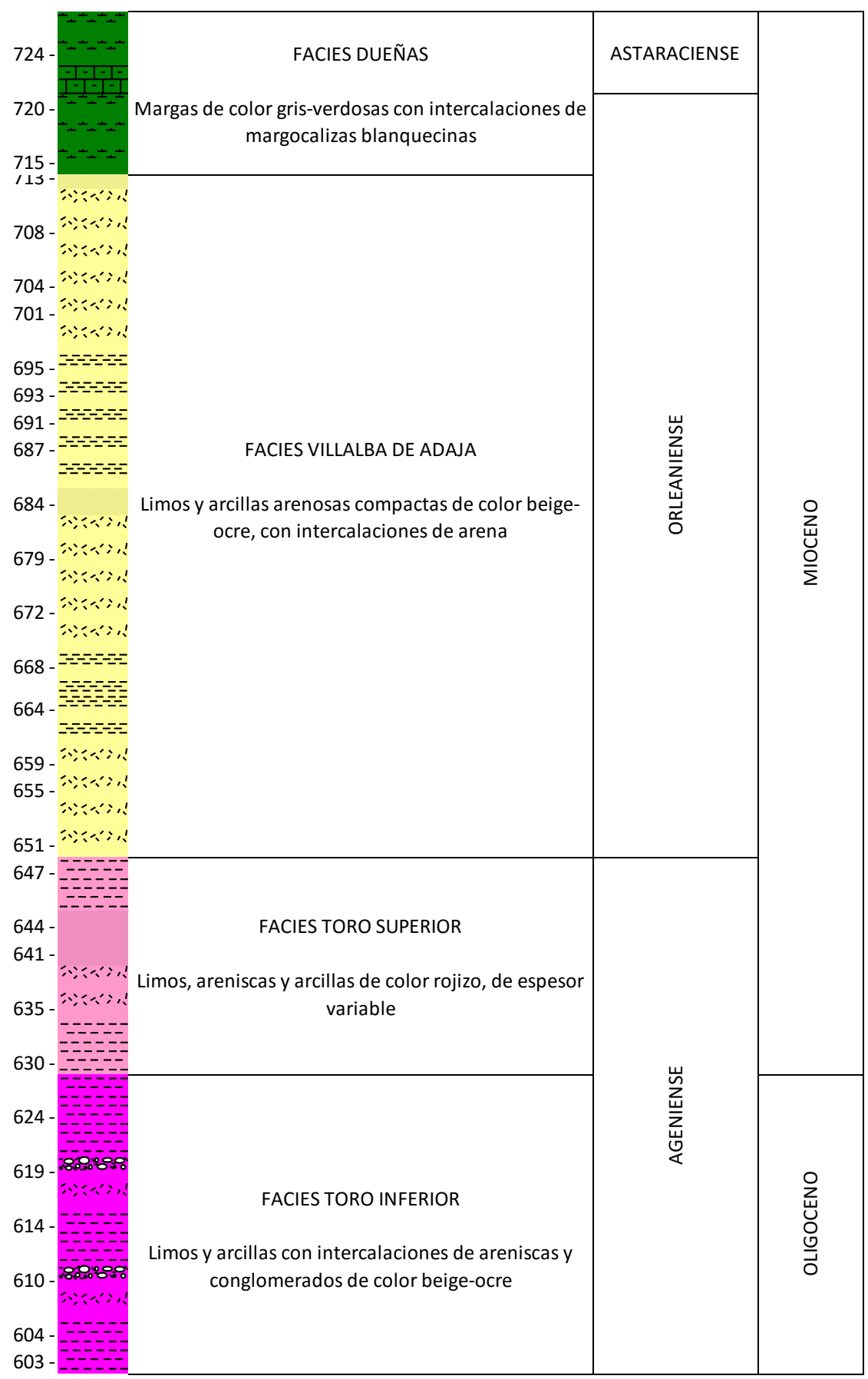

Fig. V.5. Continuación. 
De todo el material sólido obtenido en cada punto de muestreo, o en función de la profundidad en el caso del sondeo, se tomó una submuestra representativa que se guardó en una bolsa de plástico con cierre hermético tipo cremallera y que se etiquetó con una codificación que incluía la fecha de muestreo, la cota o altitud sobre el nivel del mar $(m)$ y el tipo de punto de muestreo (aflorante o procedente del muestreo). Los puntos de muestreo se geolocalizaron tomando las coordenadas UTM mediante un sistema GPS12XL GARMIN.

Una vez en el laboratorio, las muestras de sedimento se extendieron sobre papel de filtro en un área ventilada y se dejaron secar durante 48 horas para equilibrar su humedad con la del ambiente. Se eliminaron entonces todos aquellos materiales no minerales (hojas, ramitas...) y se redujo el tamaño de los agregados con ayuda de un rodillo de madera y de un martillo protegido con una bolsa de plástico con el fin de no contaminar las muestras con metales. A continuación se tamizó el sedimento a través de una malla de $2 \mathrm{~mm}^{2}$ de paso de luz.

La fracción tamizada se recogió y guardó dentro de bolsas herméticamente cerradas y perfectamente identificadas. Esta fracción de sedimento es la que se ha utilizado para los análisis.

\section{V.3. PROCEDIMIENTOS ANALÍTICOS}

\section{V.3.1. DETERMINACIÓN DEL PH}

Se pesan $5 \mathrm{~g}$ de suelo en un vaso de precipitados y se añaden $25 \mathrm{~mL}$ de agua desionizada. Se agita durante 30 minutos. Se mide el pH directamente en la suspensión obtenida utilizando un pH-metro CRISON micro pH 2001 (MAPA, 1994).

\section{V.3.2. DETERMINACIÓN DE LA CONDUCTIVIDAD}

Se mide en el líquido sobrenadante obtenido para la medida del $\mathrm{pH}$, con un Conductivimetro CRISON microCM 2200, tras dejarlo reposar 24 horas.

\section{V.3.3. DETERMINACIÓN DE LA CAPACIDAD DE CAMBIO CATIÓNICO}

El suelo se satura de sodio mediante tres lavados sucesivos con acetato sódico a pH 8,2. Se elimina el exceso de sodio por lavado con etanol y el sodio adsorbido se desplaza finalmente con acetato amónico, en cuya solución se determina el sodio por espectrometría de emisión atómica.

Se pesan entre 4 y $6 \mathrm{~g}$ de muestra, según textura tanta más muestra cuanto menor sea el contenido en limos y arcillas). Se coloca en un tubo de centrífuga y se añade $33 \mathrm{~mL}$ de acetato sódico $1 \mathrm{M}$. Se agita el tubo durante 5 minutos en el agitador mecánico. Se centrifuga hasta que el líquido sobrenadante esté claro. Se decanta el líquido sobrenadante y se desecha. Se repite el tratamiento otras dos veces resuspendiendo el 
sedimento antes de cada agitación. A continuación se suspende la muestra en $33 \mathrm{~mL}$ de etanol y se agita el tubo durante 5 min, se centrifuga y decanta el líquido claro que sobrenade. Se repite el tratamiento hasta que la conductividad eléctrica del último líquido que sobrenade sea inferior a $40 \mu \mathrm{S} / \mathrm{cm}$. A continuación se trata la muestra con tres porciones de $33 \mathrm{~mL}$ de acetato amónico $1 \mathrm{M}(\mathrm{pH} 7)$, decantando cada porción de líquido sobrenadante en un matraz aforado de $100 \mathrm{~mL}$, seguidamente se completa el volumen del matraz con la disolución de acetato amónico. La concentración de sodio en el extracto contenido en el matraz se determina por espectrometría de emisión atómica de llama. La capacidad de cambio catiónico, CIC, expresada en miliequivalentes de sodio por cada $100 \mathrm{~g}$ de suelo, se calcula como:

$$
\mathrm{CIC}=\frac{\mathrm{C}_{\text {ext }} \cdot \mathrm{V}}{\mathrm{m}_{\text {sedim }}} \cdot \frac{0,1}{\mathrm{M}_{\mathrm{at}, \mathrm{Na}}}
$$

donde $\mathrm{C}_{\text {ext }}$ es la concentración de sodio en el extracto de acetato amónico, en $\mathrm{mg} / \mathrm{L}, \mathrm{V}$ es el volumen del extracto $\left(100 \mathrm{~mL}\right.$ ), $\mathrm{m}_{\text {sed }}$ es la masa de muestra analizada, en $\mathrm{g}, \mathrm{y} \mathrm{M}_{\mathrm{at}}$, $\mathrm{Na}$ es la masa atómica del sodio, en $\mathrm{g} / \mathrm{mol}$.

\section{V.3.4. DETERMINACIÓN DE MATERIA ORGÁNICA}

Se empleó el método de Walkley-Black (MAPA 1994) que consiste en la oxidación de la materia orgánica fácilmente oxidable a $\mathrm{CO}_{2}$ por digestión por vía húmeda con un oxidante fuerte en exceso $\left(\mathrm{K}_{2} \mathrm{Cr}_{2} \mathrm{O}_{7}\right)$ en medio sulfúrico. El exceso de oxidante no consumido se valoró con una disolución patrón de Fe (II), utilizando como indicador difenilaminosulfonato sódico (DAS).

Se preparó la disolución valorante de $\mathrm{Fe}(\mathrm{II})$ 0,05 M a partir de sal de Mohr (sulfato ferroso amónico hexahidratado) y se normalizó frente a una disolución patrón de $\mathrm{K}_{2} \mathrm{Cr}_{2} \mathrm{O}_{7} 0,01 \mathrm{M}$. Una vez normalizada la disolución valorante de $\mathrm{Fe}(\mathrm{II})$, se procedió a valorar el carbono orgánico de las muestras por retroceso. Para ello, se pesó, con precisión de $\pm 0,1 \mathrm{mg}, 1 \mathrm{~g}$ de muestra de sedimento y se transfirió a un matraz aforado de $100,0 \mathrm{~mL}$. Se añadieron $20 \mathrm{~mL}$ del $\mathrm{H}_{2} \mathrm{SO}_{4}$ concentrado medidos con probeta y 10,0 $\mathrm{mL}$, tomados con pipeta, de la disolución digestora de $\mathrm{K}_{2} \mathrm{Cr}_{2} \mathrm{O}_{7} \mathrm{O}, 1 \mathrm{M}$. Se agitó cuidadosamente la mezcla y se dejó reposar durante 30 minutos. Transcurrido ese tiempo, se homogeneizó y enrasó la mezcla con agua destilada.

Por último, se tomaron con pipeta alícuotas de $10,00 \mathrm{~mL}$ de la disolución sobrenadante y se valoraron con la disolución valorada de Fe(II) $0,05 \mathrm{M}$, usando unas gotas de DAS como indicador del punto final. La valoración se realizó por triplicado.

El porcentaje de materia orgánica se calculó como:

$$
\begin{gathered}
\% \mathrm{C}_{\text {oxidable }}=\frac{\mathrm{mmol} \mathrm{C}_{\text {oxidable }}}{1000} \times \mathrm{M}_{\mathrm{at}, \mathrm{C}} \times \frac{100}{\mathrm{~m}_{\text {sed }}(\mathrm{g})} \\
\% \mathrm{C}_{\text {oxidable }}=\left(6 \cdot \mathrm{V}_{\mathrm{dig}} \cdot \mathrm{M}_{\mathrm{dig}}-\mathrm{V}_{\mathrm{Fe}(\mathrm{II})} \cdot \mathrm{M}_{\mathrm{Fe}(\mathrm{II})} \cdot \frac{100,0}{10,00}\right) \cdot \frac{12.011}{40 \cdot \mathrm{m}_{\text {sed }}}
\end{gathered}
$$


donde $\mathrm{V}_{\text {dig }}$ y $\mathrm{M}_{\text {dig }}$ representan el volumen $(10 \mathrm{~mL}$ ) y la concentración molar exacta de la disolución digestora, $\mathrm{V}_{\mathrm{Fe}(\mathrm{II})}$ y $\mathrm{M}_{\mathrm{Fe}(\mathrm{II})}$ son el volumen medio y la concentración molar de la disolución valorante de $\mathrm{Fe}$ (II) consumida en la valoración del exceso de dicromato, y $\mathrm{m}_{\text {sed }}$ es la masa de sedimento sometida a digestión.

Tradicionalmente se ha admitido que la materia orgánica oxidable del suelo contiene por término medio un $58 \%$ de $C$, y que esa materia orgánica oxidable solo supone un $77 \%$ de la materia orgánica total del suelo. Por tanto, a partir del $\% \mathrm{C}_{\text {oxidable }}$ se puede hacer una estimación del contenido total de materia orgánica:

$$
\% \text { M. O. }=\% \mathrm{C}_{\text {oxidable }} \cdot \frac{100}{77} \cdot \frac{100}{58}
$$

\section{V.3.5. DETERMINACIÓN DE CARBONATOS}

Se empleó el método del Calcímetro de Bernard, que consiste en comparar los volúmenes de $\mathrm{CO}_{2}$ desprendidos por masas conocidas del sedimento analizado y de un patrón de carbonato sódico, en las mismas condiciones de temperatura y presión.

Se pesan $0,2 \mathrm{~g}$ de carbonato sódico puro, previamente secado en la estufa a $110^{\circ} \mathrm{C}$, en un matraz erlenmeyer de $200 \mathrm{~mL}$, se introduce un tubo de vidrio con $\mathrm{HCl} 1 \mathrm{M}$, con cuidado de no derramarlo. Se ajusta el matraz erlenmeyer al dispositivo de medida. Se enrasa el tubo de nivel con la bureta y a continuación se agita el matraz erlenmeyer para que el tubo vuelque y vacíe el ácido, el cual empezará a reaccionar con el carbonato. Se desplaza el tubo de nivel lo necesario para enrasar con el nivel de agua en la bureta hasta que se estabilice, y se anota la lectura de volumen. Repetir el mismo procedimiento con $1 \mathrm{~g}$ de suelo. El contenido en carbonatos solubles en frío se determina mediante la siguiente ecuación:

$$
\% \mathrm{CaCO}_{3}=\frac{\mathrm{m}_{\mathrm{Na}_{2} \mathrm{CO}_{3}} \times \mathrm{V}_{\text {sed }}}{\mathrm{m}_{\text {sed }} \times \mathrm{V}_{\mathrm{Na}_{2} \mathrm{CO}_{3}}} \times 100
$$

En esta expresión, $m_{\mathrm{Na}_{2} \mathrm{CO}_{3}} \mathrm{y} m_{\text {sed }}$ simbolizan las masas tomadas de patrón y sedimento, respectivamente, y $\mathrm{V}_{\mathrm{Na}_{2} \mathrm{CO}_{3}}$ y $V_{\text {sed }}$ representan los volúmenes de $\mathrm{CO}_{2}$ desprendidos del patrón y de la muestra, en idénticas condiciones de presión y temperatura.

\section{V.3.6. DETERMINACIÓN DE FÓSFORO SOLUBLE EN BICARBONATO SÓDICO}

El fósforo se extrae con $\mathrm{NaHCO}_{3} 0,5 \mathrm{M}$ a un pH aproximadamente constante de 8,5 (MAPA, 1994). La concentración del complejo de color azul formado por la reducción con ácido ascórbico del fosfomolibdato obtenido cuando el molibdato amónico reacciona con el fósforo en medio ácido en presencia del ión antimonilo, se mide espectrofotométricamente a $882 \mathrm{~nm}$.

Se pesan $5 \mathrm{~g}$ de muestra y se llevan a un erlenmeyer de $250 \mathrm{~mL}$ al que se añaden $100 \mathrm{~mL}$ de solución extractora $\left(\mathrm{NaHCO}_{3} 0,5 \mathrm{M}\right)$. Esta suspensión se agita durante media hora en 
un agitador mecánico, filtrándose posteriormente a través de un papel de filtro Whatman 40 o similar.

De los extractos obtenidos se toman alícuotas de volumen $V_{\text {ext }}$ que se llevan a vasos de precipitados de $100 \mathrm{~mL}$, se diluye con agua y se añade $\mathrm{H}_{2} \mathrm{SO}_{4}(1,5 \mathrm{M})$ hasta conseguir un $\mathrm{pH}$ de 5 . Se transfiere la disolución a un matraz de $50 \mathrm{~mL}$, se añaden $8 \mathrm{~mL}$ del reactivo derivatizante descrito en el capítulo IV para formar el complejo azul, y se enrasa con agua desionizada. Tras dejar las disoluciones en reposo entre 15 y $60 \mathrm{~min}$, se lee la absorbancia a una longitud de onda de $882 \mathrm{~nm}$, con un epectrofotómetro UV-Visible PHILIPS PU 8710 de rendija fija y haz. Se preparan de igual forma patrones con un contenido de fósforo elemental comprendido entre 0,01 y 0,4 mg/L. La concentración de fósforo extraíble, $\mathrm{C}_{\mathrm{p}}$, se expresa en $\mathrm{mg} \mathrm{P} / \mathrm{kg}$ sedimento y se calcula como:

$$
\mathrm{C}_{\mathrm{P}}=\frac{\mathrm{C}_{\text {ext,dil }} \times 5000}{\mathrm{~V}_{\text {ext }} \times \mathrm{m}_{\text {sed }}}
$$

$C_{\text {ext,dil }}$ es la concentración de fósforo en el matraz de $50 \mathrm{~mL}$ y $\mathrm{m}_{\text {sed }}$ es el peso de muestra analizado.

\section{V.3.7. DETERMINACIÓN DE CATIONES EXTRAÍBLES ( $\mathrm{Na}, \mathrm{Ca}, \mathrm{K}, \mathrm{Mg}$ )}

Estos cationes se extraen del suelo con acetato amónico $1 \mathrm{M}$ a pH 7 (MAPA, 1994), determinando sodio y potasio en el extracto por fotometría de llama y calcio y magnesio mediante espectrofotometría de absorción atómica.

Se pesan $5 \mathrm{~g}$ de suelo y se llevan a un matraz erlenmeyer de $250 \mathrm{~mL}$ donde se añaden $100 \mathrm{~mL}$ de acetato amónico $1 \mathrm{M}$ de $\mathrm{pH}$ 7. Se agita durante 30 minutos en un agitador mecánico, tras lo cual se filtra a través de un filtro de acetato de celulosa de $0,45 \mu \mathrm{m}$ de tamaño de poro, recogiendo el filtrado en frascos de plástico.

Los cationes se determinaron por espectrometría de absorción ( $\mathrm{Ca}, \mathrm{Mg}$ ) o emisión ( $\mathrm{Na}$, $\mathrm{K}$ ) atómica, diluyendo las muestras convenientemente con acetato amónico.

Extractos y patrones se midieron con un espectrofotómetro de absorción/emisión atómica GCB-933AA empleando una llama de aire-acetileno. Las lámparas que se utilizaron son de cátodo hueco bielemental de Ca-Mg, marca GBC.

Las condiciones experimentales en las que se llevaron a cabo las medidas fueron ya descritas en el capítulo IV, apartado IV.3.9.

Los resultados se han expresado en g del catión analizado por kg de suelo de muestra seca al aire.

\section{V.3.8. DETERMINACIÓN DE ÓXIDOS DE HIERRO Y MANGANESO}

Para extraer la fracción de Fe y Mn soluble en hidroxilamina se trató $0,1 \mathrm{~g}$ de sedimento con $25 \mathrm{~mL}$ de $\mathrm{NH}_{2} \mathrm{OH}-\mathrm{HCl} 0,25 \mathrm{M}$, agitando la suspensión durante $16 \mathrm{~h}$ a temperatura ambiente, a una velocidad de aproximadamente $700 \mathrm{U} / \mathrm{min}$. Posteriormente se centrifugó durante 10 minutos y se filtró a través de filtros de acetato de celulosa de 
$0,45 \mu \mathrm{m}$ de tamaño de poro, recogiendo el extracto filtrado en frascos de plástico. Tras diluir convenientemente el extracto, los cationes $\mathrm{Fe}$ y $\mathrm{Mn}$ se determinaron por espectrometría de absorción atómica empleando una llama de aire-acetileno.

Las condiciones experimentales en que se llevaron a cabo las medidas de los analitos fueron:

\begin{tabular}{lccc} 
Catión & $\begin{array}{c}\text { Línea principal } \\
(\mathbf{n m})\end{array}$ & $\begin{array}{c}\text { Intensidad de lámpara } \\
(\mathbf{m A})\end{array}$ & $\begin{array}{c}\text { Anchura de rendija } \\
(\mathbf{n m})\end{array}$ \\
\hline $\mathrm{Fe}$ & 248,3 & 5 & 0,2 \\
$\mathrm{Mn}$ & 279,5 & 5 & 0,2
\end{tabular}

Los datos finales se han expresado en mg de catión analizado por kg de muestra seca al aire.

\section{V.3.9. DETERMINACIÓN DE LA TEXTURA}

Consiste en un proceso de segregación de partículas individuales agrupadas en fracciones. La materia orgánica forma complejos organominerales que mantienen los granos unidos formando agregados. Un tratamiento previo con peróxido de hidrógeno permite la destrucción de la materia orgánica para individualizar las partículas con un mínimo efecto sobre la fracción mineral.

El procedimiento es el siguiente (MAPA 1994):

\section{Destrucción de la materia orgánica:}

Se pesan $20 \mathrm{~g}$ de suelo y se llevan a un vaso de precipitados de $1000 \mathrm{~mL}$. Se añaden 20 $\mathrm{mL}$ de agua oxigenada al $30 \%(\mathrm{~m} / \mathrm{v})$ con una probeta y unos $150 \mathrm{~mL}$ de agua destilada. Se mezcla removiendo el vaso asegurándonos del exceso de agua oxigenada por la efervescencia observada.

Se calienta la suspensión en un baño de arena (SELECTA) a temperatura inferior a 80ㄷ para evitar que hierva, lo que provocaría la rotura de los carbonatos. En el caso de que se forme espuma de manera excesiva se rompe con unas gotas de etanol. Se tapa el vaso con un vidrio de reloj y se agita de vez en cuando para que las partículas no se adhieran a la superficie del vaso y no adquiera consistencia pastosa. Tras dos horas de mineralización, se lleva a ebullición durante 10 minutos con el fin de eliminar el exceso de agua oxigenada. Para asegurarse de que se ha eliminado todo el exceso se adicionan unas gotas de permanganato potásico; si no se decolora se calienta durante otros 10 minutos más.

\section{Dispersión:}

Una vez fría la suspensión se añaden $10 \mathrm{~mL}$ de hexametafosfato sódico 0,2 M y se agita durante media hora. Con esto se consigue individualizar las partículas de arcilla integradas en flóculos. Los agentes dispersantes a base de sodio permiten conseguir este efecto al sustituir el sodio por los cationes polivalentes sobre los que tiene un 
efecto complejante el anión hexametafosfato con lo que su efecto no se dejara sentir en la suspensión.

\section{Sedimentación:}

La mezcla resultante de la dispersión se pasa cuantitativamente a una probeta de 1000 $\mathrm{mL}$ a través de un tamiz de $0,2 \mathrm{~mm}$ previamente tarado. La probeta se enrasa hasta $1000 \mathrm{~mL}$ y el producto acumulado en el tamiz se toma como arena gruesa. La suspensión de la probeta se homogeniza y se toman las alícuotas correspondientes con la pipeta de Robinson que se basa en el principio de los vasos comunicantes y permite extraer la fracción de la suspensión. Teniendo en cuenta la ley de Stokes a temperatura de $20^{\circ} \mathrm{C}$ y una profundidad de pipeteado de $10 \mathrm{~cm}$ se sacan tres alícuotas de $20 \mathrm{~mL}$ cada una con las que podemos conocer la granulometría de la muestra. Para la primera alícuota el tiempo de sedimentación corresponde a $46 \mathrm{~s}$ y contendrá las fracciones de limo fino, limo grueso y arcilla. La segunda alícuota contiene las fracciones de limo fino y arcilla y su tiempo de sedimentación es de $4 \min 48 \mathrm{~s}$. Finalmente, la tercera alícuota tiene un tiempo de sedimentación de $8 \mathrm{~h}$ y se corresponderá con la fracción de arcilla.

La pipeta se introduce en la probeta, limpia y seca, a la profundidad indicada. Una vez cumplido el tiempo de extracción se abre lentamente la llave de la pipeta hasta que la suspensión la supere ligeramente. Se cierra la llave y el contenido es llevado a un vaso de precipitados previamente tarado. Se elimina el exceso que queda por encima de la llave, se enjuaga con agua destilada, quedando así preparada para la siguiente extracción. Las alícuotas recogidas en los vasos junto con la fracción de arena gruesa recogida en el tamiz se llevan a sequedad. El peso se corregirá teniendo en cuenta que se tomaron alícuotas de $20 \mathrm{~mL}$ de un volumen total de un litro.

Por un sencillo sistema de ecuaciones podemos determinar el porcentaje de cada tipo: 1a alícuota: Limo Fino + Limo Grueso + Arcilla; 2a alícuota: Limo Fino + Arcilla; 3a alícuota: Arcilla. Cada una de las fracciones individuales se determina por diferencia. La fracción de arena fina se obtiene restando a los $20 \mathrm{~g}$ iniciales de suelo los gramos de cada una de las otras fracciones.

\section{V.3.10.DIFRACCIÓN DE RAYOS X (XRD)}

Para obtener la composición mineralógica de las muestras de sedimento se empleó un equipo de difracción de Rayos X Philips PW1710 equipado con un ánodo de cobre, una rendija de divergencia automática y un monocromador de grafito.

Las muestras, pulverizadas en un mortero de ágata, se midieron en las siguientes condiciones experimentales: intervalo de barrido, 2-60o $(2 \theta)$; radiación $\mathrm{K}_{\alpha}(\mathrm{Cu}), 1,54 \AA$; voltaje, $40 \mathrm{kV}$; intensidad, $30 \mathrm{~mA}$; velocidad de barrido, 3\%/min. Los difractogramas obtenidos se compararon con las bases de datos existentes para conocer así la composición mineralógica de las muestras. 


\section{V.3.11. CARACTERIZACIÓN DE ARCILLAS POR DIFRACCIÓN DE RAYOS X (XRD)}

La identificación de los minerales de arcilla por difracción de Rayos $X$ se consigue observando las reflexiones basales en el diagrama de difracción del agregado orientado, que se obtiene por separación y adecuado tratamiento de la fracción de arcillas de la muestra de sedimento (Nemecz, 1981).

Para preparar el agregado orientado se extrae, con ayuda de un sifón, la fracción arcillosa sedimentada a $30 \mathrm{~cm}$ de profundidad en la probeta donde se llevó a cabo la determinación de la textura, tras $8 \mathrm{~h}$ de reposo. Se le agrega cloruro magnésico $1 \mathrm{M}$ y se deja reposar la mezcla para conseguir la floculación de las arcillas. Posteriormente se decanta el líquido sobrenadante, se centrifuga, y la fase sólida así obtenida se coloca en una cápsula de porcelana que se calienta en una estufa a $100^{\circ} \mathrm{C}$ hasta sequedad.

La arcilla así obtenida se muele en un mortero de ágata. Se pesan 0,4 g de arcilla pulverizada en un tubo de centrífuga con tapa al que se le agregan $10 \mathrm{~mL}$ de agua destilada y se somete durante $15 \mathrm{~min}$ a un baño de ultrasonidos. Pasado ese tiempo se añaden $10 \mathrm{~mL}$ de $\mathrm{MgCl}_{2} 1 \mathrm{M}$ y se mantiene $5 \mathrm{~min}$ en el baño de ultrasonidos. Posteriormente se agita 5 min y se centrífuga, decantando el líquido sobrenadante. Este proceso se repite tres veces, tras lo cual se procede a un lavado con agua destilada para eliminar el exceso de cloruro, hasta que el líquido sobrenadante obtenido tras la centrifugación no muestre reactividad con nitrato de plata.

A continuación se agregan $8 \mathrm{~mL}$ de agua destilada, se sumerge $15 \mathrm{~min}$ en el baño ultrasonidos y se agita durante $5 \mathrm{~min}$. La muestra, una suspensión homogénea de aguaarcilla, se coloca finalmente en un portamuestras de vidrio, se deja secar en un desecador $y$, una vez seco, se mide por XRD empleando las siguientes condiciones experimentales: intervalo de barrido, 2-40 $(2 \theta)$; radiación $\mathrm{K}_{\alpha}(\mathrm{Cu}), 1,54 \AA ̊$; voltaje, $40 \mathrm{kV}$; intensidad, $30 \mathrm{~mA}$; velocidad de barrido, $1 \% / \mathrm{min}$; rendijas de divergencia y recepción, $1^{\circ}$ y $0,1^{\circ}$, respectivamente. Los difractogramas obtenidos se compararon con las bases de datos existentes para conocer así la composición mineralógica de las muestras.

Las arcillas presentan reflexiones características que permiten su identificación. Sin embargo, en ocasiones, diferentes tipos de arcillas pueden tener señal en la misma zona del difractograma, de forma que es necesario realizar un tratamiento que será diferente en función del tipo de arcillas identificadas en el difractograma inicial. Se aplican dos tipos de tratamientos: (a) en el tratamiento con etilenglicol, el portamuestras con las arcillas se introduce en una placa Petri con atmósfera saturada de etilenglicol, y se deja en una estufa durante $24 \mathrm{~h}$ a una temperatura de 60 o C; (b) el tratamiento térmico consiste en calentar la muestra de arcillas en un horno de mufla a 450ㄷ durante $5 \mathrm{~h}$. Tras aplicar estos tratamientos, las muestras se caracterizaron de nuevo por XRD, observando la variación experimentada por la reflexión 001. Las reflexiones observadas por XRD, tanto en los agregados orientados originales como en los sometidos a tratamiento con etilenglicol y al tratamiento térmico, se interpretaron de acuerdo con las librerías disponibles para dilucidar la composición mineralógica de las arcillas presentes en las muestras. 


\section{V.3.12.DETERMINACIÓN DEL CONTENIDO TOTAL DE LOS METALES Mg, $\mathrm{Na}, \mathrm{K}$, $\mathrm{Cr}, \mathrm{Cu}, \mathrm{Fe}, \mathrm{Mn}, \mathrm{Pb}, \mathrm{V}, \mathrm{Zn}$ y As}

Los metales (pseudo)totales se extrajeron sometiendo las muestras de sedimento a una digestión ácida asistida por microondas, siguiendo el método EPA 3051 (USEPA, 1994). En vasos de PTFE del digestor se pesaron, con precisión de $\pm 0,1 \mathrm{mg}, 0,5 \mathrm{~g}$ de sedimento previamente tamizado y pulverizado y se añadieron $10 \mathrm{~mL}$ de $\mathrm{HNO}$ del $65 \%$. Una vez encamisados los vasos de reacción, se cerraron herméticamente y se colocaron en el rotor de un digestor de microondas ETHOS PLUS MILESTONE.

El vaso de control, en el que se introdujo una de las muestras, lleva una sonda de temperatura que permitió el control de la potencia de microondas para mantener la temperatura de digestión en los valores deseados. El programa de digestión se inicia irradiando la cavidad del horno con microondas de forma que la temperatura aumenta a velocidad constante hasta alcanzar 180 으, lo que se consigue en $5,5 \mathrm{~min}$. A continuación se mantiene la temperatura constante a ese valor durante 4,5 min. Una vez transcurrido ese periodo, se detiene la irradiación y se deja que las muestras se enfríen a una temperatura inferior a $40^{\circ} \mathrm{C}$, lo que se consigue al cabo de aproximadamente $1 \mathrm{~h}$. A continuación se abrieron los reactores en la campana extractora y se trasvasó cuantitativamente el contenido de los mismos a matraces aforados de $50 \mathrm{~mL}$, enrasando finalmente con agua desionizada. Finalmente, las disoluciones obtenidas se filtraron mediante filtros de jeringa de nylon de $0,45 \mu \mathrm{m}$ de tamaño de poro y se guardaron refrigeradas en botes de policarbonato hasta el momento de su análisis.

Se determinaron los contenidos (pseudo)totales de metales en los extractos filtrados, por ICP-OES e ICP-MS, utilizando los equipos ubicados en el Laboratorio de Técnicas Instrumentales de la Universidad de Valladolid, LTI-UVa.

Los elementos $\mathrm{Cr}, \mathrm{Cu}, \mathrm{Fe}, \mathrm{Mn}, \mathrm{Pb}, \mathrm{V}$ y $\mathrm{Zn}$ se determinaron por ICP-MS, empleando un instrumento Agilent 7500 c equipado con un detector de masas cuadrupolo y celda de colisión. El equipo fue calibrado con patrones preparados por dilución del multipatrón comercial. El flujo del gas portador fue de $1,05 \mathrm{~L} \mathrm{Ar} / \mathrm{min}$ y de $0,15 \mathrm{~L} \mathrm{Ar} / \mathrm{min}$ para el gas auxiliar. La bomba del nebulizador tenía una velocidad de 0,15 rps y en la celda de colisión el flujo de gas fue $3,5 \mathrm{~mL} \mathrm{He} / \mathrm{min}$. En la Tabla V.5 se muestran los valores de las relaciones $\mathrm{m} / \mathrm{z}$ de las especies determinadas mediante este método.

Tabla V.5. Relaciones $\mathrm{m} / \mathrm{z}$ empleadas para la cuantificación de elementos traza por ICP-MS

\begin{tabular}{cc} 
Elemento & $\mathbf{m} / \mathbf{z}$ \\
\hline $\mathrm{V}$ & 51 \\
$\mathrm{Cr}$ & 53 \\
$\mathrm{Mn}$ & 55 \\
$\mathrm{Fe}$ & 56 \\
$\mathrm{Cu}$ & 63 \\
$\mathrm{~Pb}$ & 208 \\
$\mathrm{Zn}$ & 66 \\
\hline
\end{tabular}


El arsénico fue determinado con un espectrofotómetro de absorción atómica con cámara de grafito VARIAN GTA 100 Espectra AA-800, empleando gas $\operatorname{Ar}$ (99,995 \% de pureza) a una presión de 140-200 kPpa y lámpara de cátodo hueco del elemento. La longitud de onda seleccionada fue 197,2 nm.

La determinación de $\mathrm{Na}, \mathrm{K}$, y $\mathrm{Mg}$ se llevó a cabo por espectroscopía atómica de llama, en las mismas condiciones experimentales ya descritas para los metales extraíbles con acetato amónico (apartado V.3.9).

\section{V.3.13. MÉTODOS ESTADÍSTICOS}

Los resultados experimentales se han analizado empleando herramientas estadísticas univariantes y multivariantes.

El análisis estadístico multivariante de los resultados fue llevado a cabo mediante métodos de visualización lineal (análisis en componentes principales, ACP) y métodos de reconocimiento de pautas no supervisado (método clúster jerárquico aglomerativo), que ya han sido explicado en el capítulo IV (Estudio Hidroquímico).

\section{V.3.14.DISEÑO DE MAPAS}

El programa ArcGIS 10.2.1 ha sido utilizado para la elaboración de los mapas.

\section{V.4. RESULTADOS}

Las 57 muestras de sedimentos analizadas fueron caracterizadas analizando un total de 44 parámetros físicos, químicos y mineralógicos, que se han descrito en las páginas anteriores y se resumen en la Tabla V.6, junto con las unidades en las que se han expresado los resultados. Los resultados numéricos se muestran en el Tabla A.III.1 del Anexo.

Tabla V.6. Parámetros analíticos determinados en los sedimentos.

\begin{tabular}{|l|l|}
\hline Parámetro analítico & Unidades \\
\hline $\mathrm{pH}$ (en extracto acuoso) & Unidades de $\mathrm{pH}$ \\
\hline Conductividad (en extracto acuoso) & $\mu \mathrm{S} / \mathrm{cm}$ \\
\hline Materia orgánica & $\%$ \\
\hline Carbonatos & $\% \mathrm{CaCO}_{3}$ \\
\hline Capacidad de intercambio catiónico & $\mathrm{meq} \mathrm{Na} / 100 \mathrm{~g}$ \\
\hline Textura (arena, limo, arcilla) & $\%$ \\
\hline Na, K, Ca y Mg intercambiables (solubles en acetato amónico $1 \mathrm{M}$ ) & $\mathrm{g} / \mathrm{kg}$ \\
\hline $\mathrm{P}$ intercambiable (soluble en bicarbonato sódico) & $\mathrm{mg} / \mathrm{kg}$ \\
\hline Fe y Mn reducibles (solubles en clorhidrato de hidroxilamina) & $\mathrm{mg} / \mathrm{kg}$ \\
\hline
\end{tabular}




\begin{tabular}{|c|c|}
\hline Parámetro analítico & Unidades \\
\hline $\begin{array}{l}\text { Metales pseudototales (solubles en ácido nítrico): } \\
\text { Mayoritarios: Fe, K, Mg, Na } \\
\text { Traza: As, } \mathrm{Cr}, \mathrm{Cu}, \mathrm{Mn}, \mathrm{Pb}, \mathrm{V}, \mathrm{Zn}\end{array}$ & $\begin{array}{l}\mathrm{g} / \mathrm{kg} \\
\mathrm{mg} / \mathrm{kg}\end{array}$ \\
\hline $\begin{array}{l}\text { Fases minerales: } \\
\text { Cuarzo, feldespato, filosilicatos, calcita, dolomita, yeso }\end{array}$ & $\%$ \\
\hline $\begin{array}{l}\text { Arcillas: } \\
\text { Illita, clorita, esmectita, caolinita, sepiolita, paligorkita, vermiculita }\end{array}$ & $\%$ \\
\hline
\end{tabular}

Para intentar detectar a qué minerales se encuentra asociado el arsénico en los sedimentos, se realizó un análisis mineralógico mediante las técnicas de EDX-SEM (microscopía electrónica de barrido acoplada con espectroscopía de energía dispersiva) y XRF (fluorescencia de Rayos X) sobre tres muestras pertenecientes a distintas unidades mineralógicas de la zona de estudio. Se eligieron las muestras tomadas a $764 \mathrm{~m}, 765,1 \mathrm{~m}$ y $782 \mathrm{~m}$, que poseen niveles de arsénico superiores a los valores fondo y simultáneamente contienen los minerales mayoritarios en el área de estudio. Los resultados se muestran en la Tabla V.7.

Tabla V.7. Composición mineralógica y concentración de arsénico de las muestras elegidas

\begin{tabular}{lccccccc}
\hline \multirow{2}{*}{ Muestra } & Cuarzo & Filosilicatos & Feldespato & Calcita & Dolomita & Yeso & [As] \\
\cline { 2 - 8 } & \multicolumn{7}{c}{$\begin{array}{c}c \\
(\%)\end{array}$} \\
\hline 764,6 & 2,6 & 22,3 & 0,0 & 75,1 & 0,0 & 0,0 & $\begin{array}{c}\text { mgAs/ } \\
\text { kg suelo }\end{array}$ \\
765,1 & 0,1 & 0,8 & 0,0 & 20,9 & 64,5 & 13,7 & 15,0 \\
782 & 2,0 & 71,1 & 0,0 & 0,0 & 13,9 & 13,0 & 35,5 \\
\hline
\end{tabular}

Aunque no se ha podido identificar el arsénico en los sedimentos debido a que su concentración es inferior a los límites de detección de estas técnicas, estos análisis nos han servido para verificar los resultados obtenidos por XRD.

A continuación se muestran los resultados obtenidos. El análisis elemental se ha realizado en el punto marcado con una cruz verde.

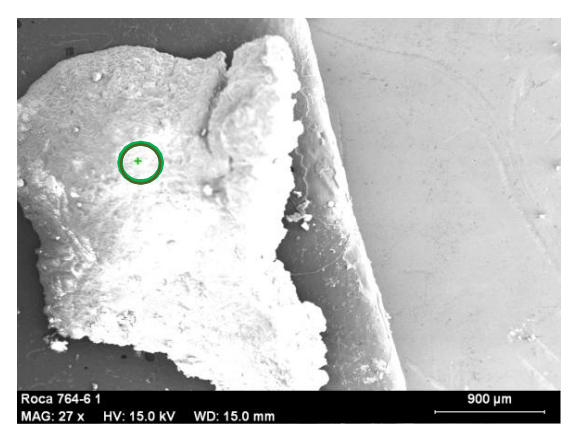

Fig. V.6. Muestra 764,6.

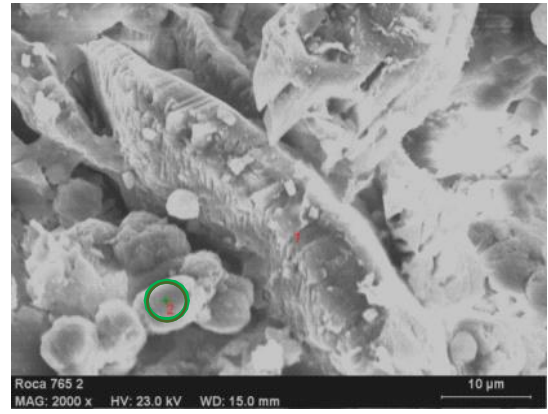

Fig. V.7. Muestra 765,1. 


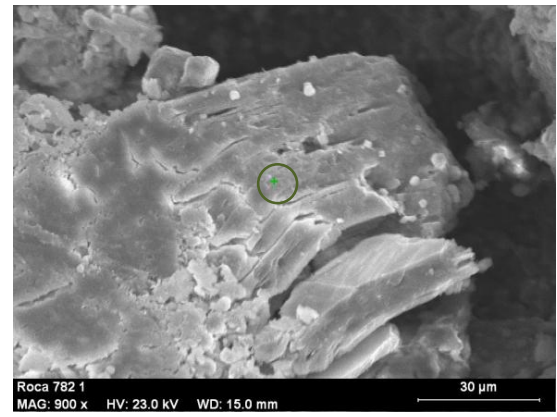

Fig. V.8. Muestra 782; punto 1.

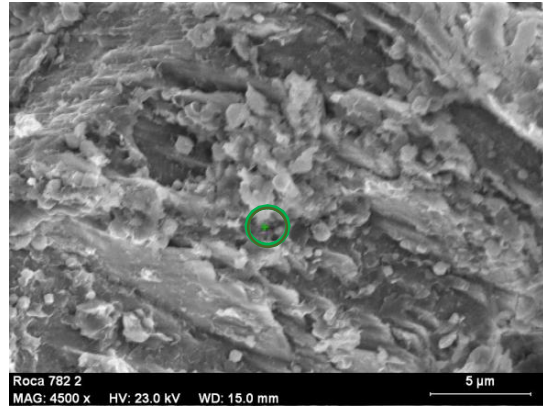

Fig. V.9. Muestra 782; punto 2.

Las composiciones elementales reflejadas en la ¡Error! La autoreferencia al marcador no es válida. son coherentes con los minerales mayoritarios determinados por XRD.

Tabla V.8. Composición elemental de los sedimentos analizados

\begin{tabular}{lcccc}
\hline \multirow{2}{*}{ Elemento (\%) } & \multicolumn{4}{c}{ Cota (m.a.s.I.) } \\
\cline { 2 - 5 } $\mathrm{Al}$ & 764.6 & 765,1 & $782(1)$ & $782(2)$ \\
$\mathrm{C}$ & 1,8 & & & 8,3 \\
$\mathrm{Ca}$ & & 8,7 & & \\
$\mathrm{Fe}$ & 39,9 & 20,2 & 18,7 & 9,5 \\
$\mathrm{~K}$ & 3,7 & & & 3,7 \\
$\mathrm{Mg}$ & 2,2 & & & 1,9 \\
$\mathrm{O}$ & 2,7 & 14,6 & & 10,8 \\
$\mathrm{~S}$ & 47,6 & 56,5 & 66,6 & 63,9 \\
$\mathrm{Si}$ & & & 14,8 & \\
\hline
\end{tabular}

Así, por ejemplo, la muestra tomada en la cota 765,1 m, constituida mayoritariamente por calcita $(20,9 \%)$ y dolomita $(64,5 \%)$, contiene calcio, magnesio, oxígeno y carbono como elementos mayoritarios.

En la muestra tomada en la cota $782 \mathrm{~m}$, compuesta por filosilicatos (71\%), dolomita (14 $\%)$ y yeso (13\%), se realizaron dos análisis EDX-SEM en dos puntos diferentes; el punto 1 se corresponde con yeso ya que contienen calcio, azufre y oxígeno como elementos mayoritarios, mientras que el análisis realizado en el punto 2 que contiene como elementos mayoritarios calcio, silicio, hierro, magnesio, aluminio, potasio y oxígeno, se corresponde con la composición de los filosilicatos. 

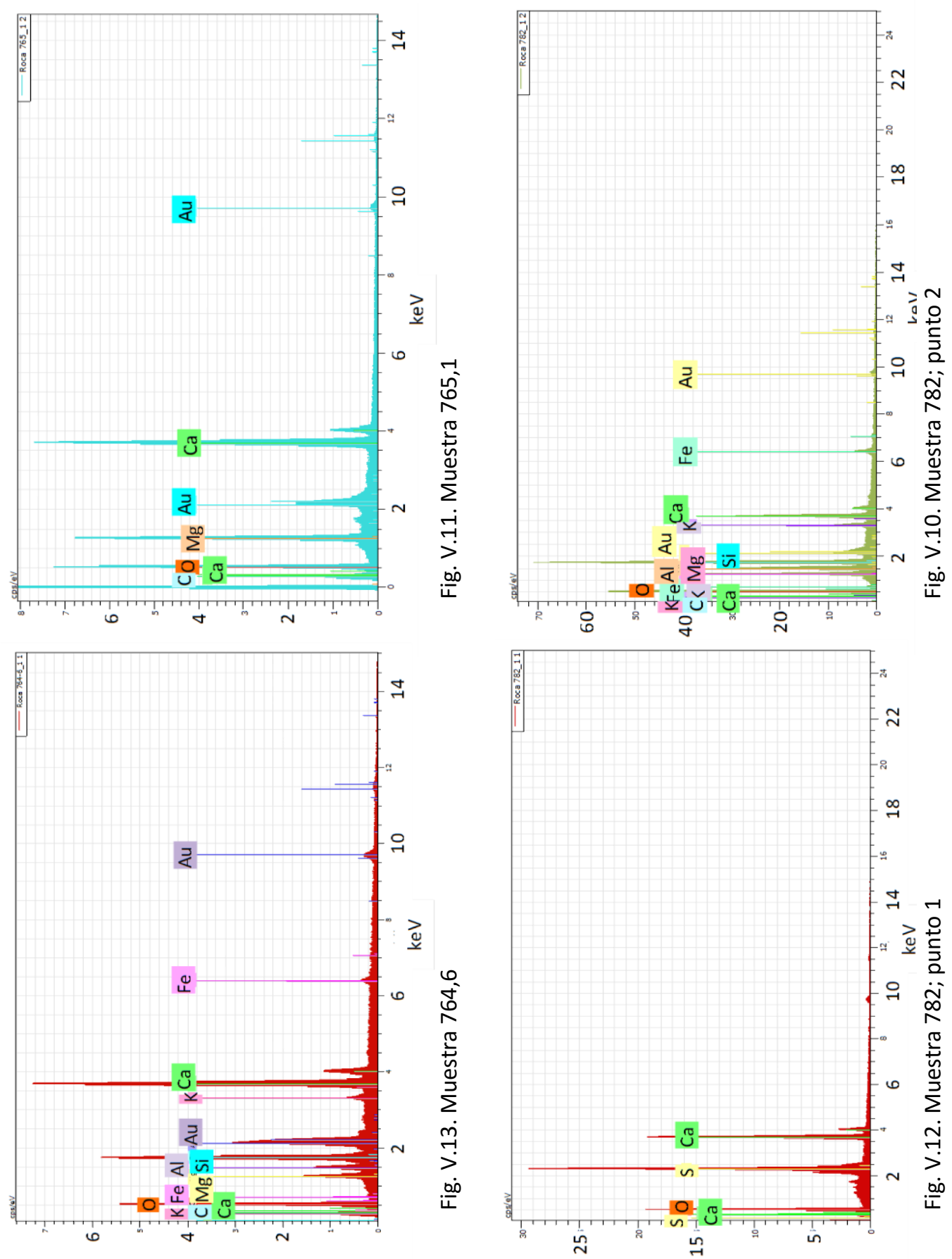


\section{V.4.1. DISTRIBUCIÓN VERTICAL DE LOS PARÁMETROS ANALIZADOS}

La representación gráfica de cada uno de los parámetros analizados frente a la cota o altitud a la que se ha tomado la muestra ha permitido obtener unos perfiles de distribución vertical que facilitan la visualización, no solo de la variación de cada magnitud con la altitud, sino también de comportamientos análogos entre variables. Dichos perfiles aparecen recopilados en la Fig. V.14.

Se observa que los sedimentos de nuestra zona de estudio son alcalinos; el pH en los estratos calizos superiores es básico (entre 9 y 9,5), disminuye en la facies Cuestas (pH próximo a 8) y a partir de ahí aumenta gradualmente con la profundidad hasta valores máximos en torno a 10.

La conductividad desde las cotas más altas hasta la facies Tierra de Campos muestra valores muy heterogéneos, llegando en algún caso a alcanzar casi los $4 \mathrm{mS} / \mathrm{cm}$. A partir de la facies Tierra de Campos este parámetro se estabiliza y presenta valores muy homogéneos (en torno a $500 \mu \mathrm{S} / \mathrm{cm}$ ).

En cuanto a la materia orgánica, se observan los valores más altos en la facies Zaratán. Otros autores han señalado la existencia de altos niveles de materia orgánica en esta unidad geológica (Sánchez de la Torre y col., 1979; Delgado y col., 2007; Gómez y col., 2006).

Los carbonatos, al igual que el $\mathrm{P}$ extraíble, aparecen en las cotas superiores hasta la facies Tierra de Campos, llegando los carbonatos en algunos casos a superar el $50 \%$ de la composición del suelo. A partir de la facies Tierra de Campos los niveles estos parámetros son prácticamente inexistentes.

La C.I.C presenta los valores más bajos en facies Zaratán y los más altos en Facies Tierra de Campos y Dueñas; el resto de facies presentan valores similares entre dichos extremos.

En cuanto a los niveles totales de metales mayoritarios, el contenido de magnesio decrece con la profundidad, encontrándose los mayores niveles en las facies superiores, desde Calizas del Páramo hasta Zaratán. Los niveles de sodio más bajos se encuentran en facies Cuestas; el resto de facies presentan una distribución similar de este elemento. Los niveles de potasio, manganeso y hierro muestran una distribución muy similar a la de la C.I.C.

Con respecto a los metales mayoritarios fácilmente solubilizables (extraíbles), hay tres muestras pertenecientes a las facies Cuestas y Zaratán que presentan concentraciones de calcio extraíble muy superiores, lo cual se debe a la presencia de yesos en esos sedimentos. Las mayores cantidades de magnesio y potasio extraíbles se obtienen en las facies Tierra de Campos y Dueñas y en algunas muestras de facies Transición al Páramo y Cuestas. En las facies Toro Superior e Inferior prácticamente no se extrae magnesio. El sodio extraíble aumenta con la profundidad, a excepción de la facies Transición al Páramo, donde se dan valores elevados. 


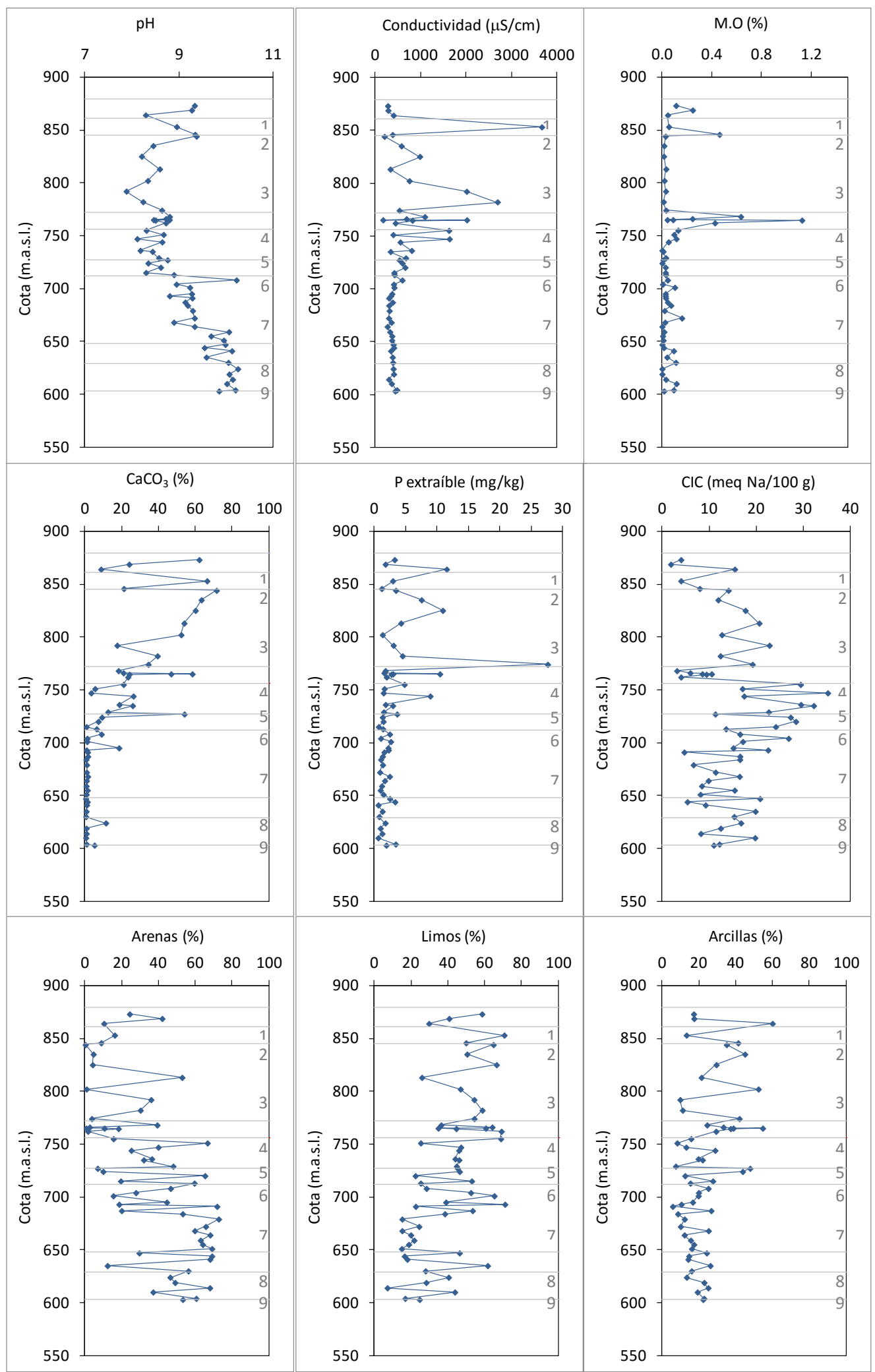

Fig. V.14. Perfiles de distribución verticales de los parámetros analizados.

1.-F. Calizas del Páramo; 2.-F. Transición al Páramo; 3.-F. Cuestas; 4.-F. Zaratán; 5.-F. Tierra de Campos; 6.- F. Dueñas; 7.-F. Villalba de Adaja; 8.- F. Toro Superior; 9.- F. Toro Inferior. 


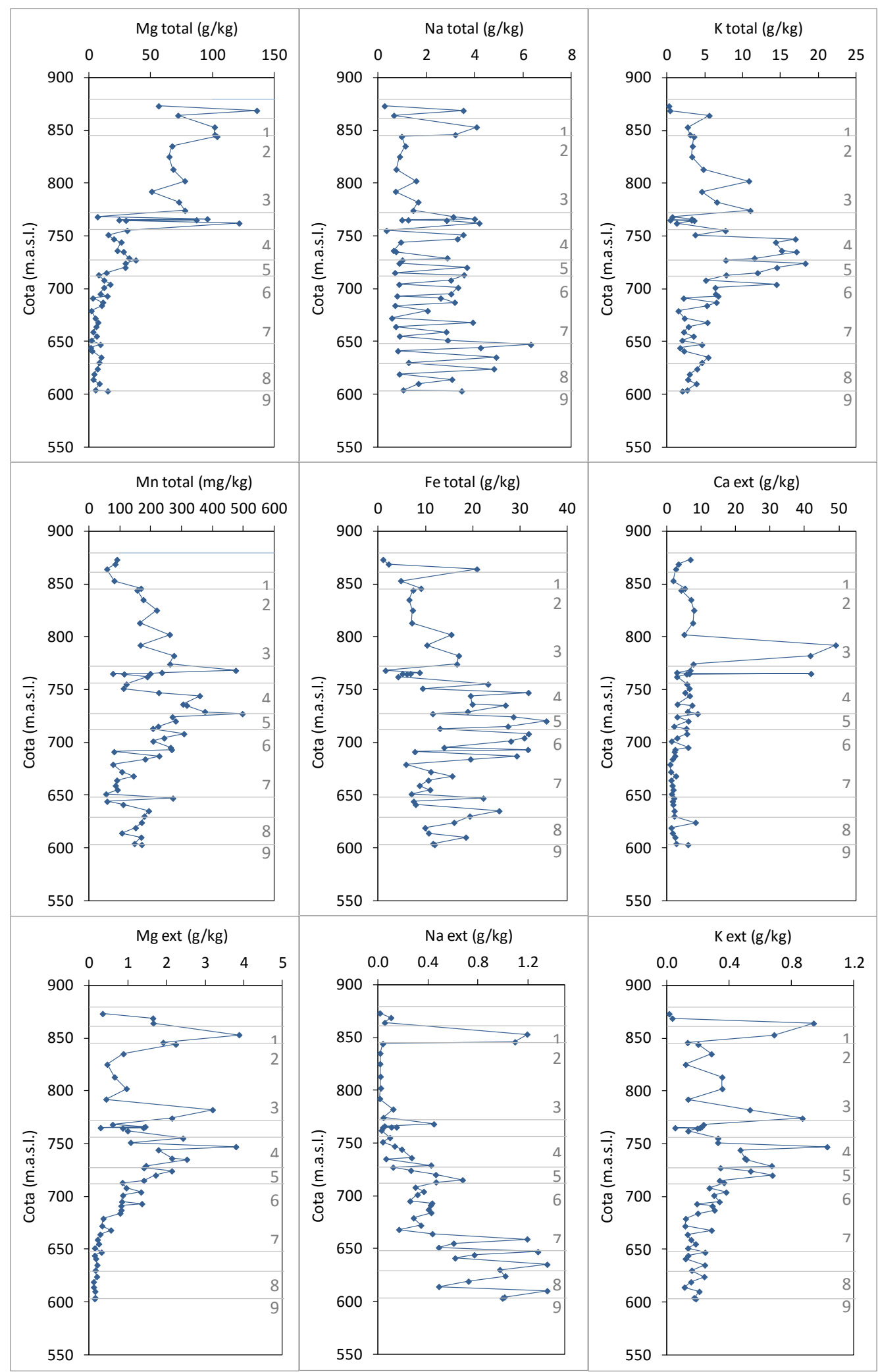

Fig. V.14. Continuación. 
Capítulo V. Estudio Geoquímico

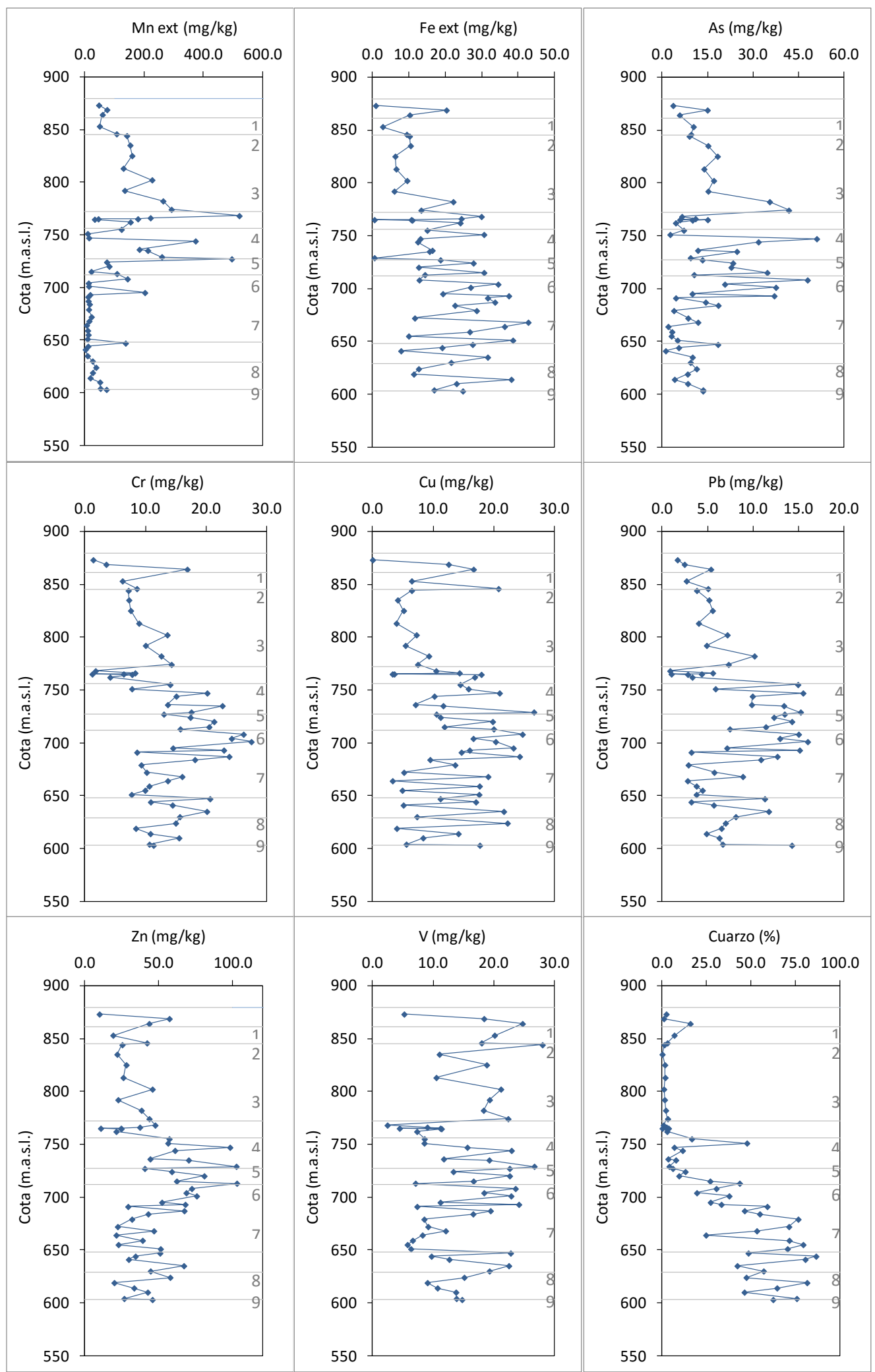

Fig. V.14. Continuación. 


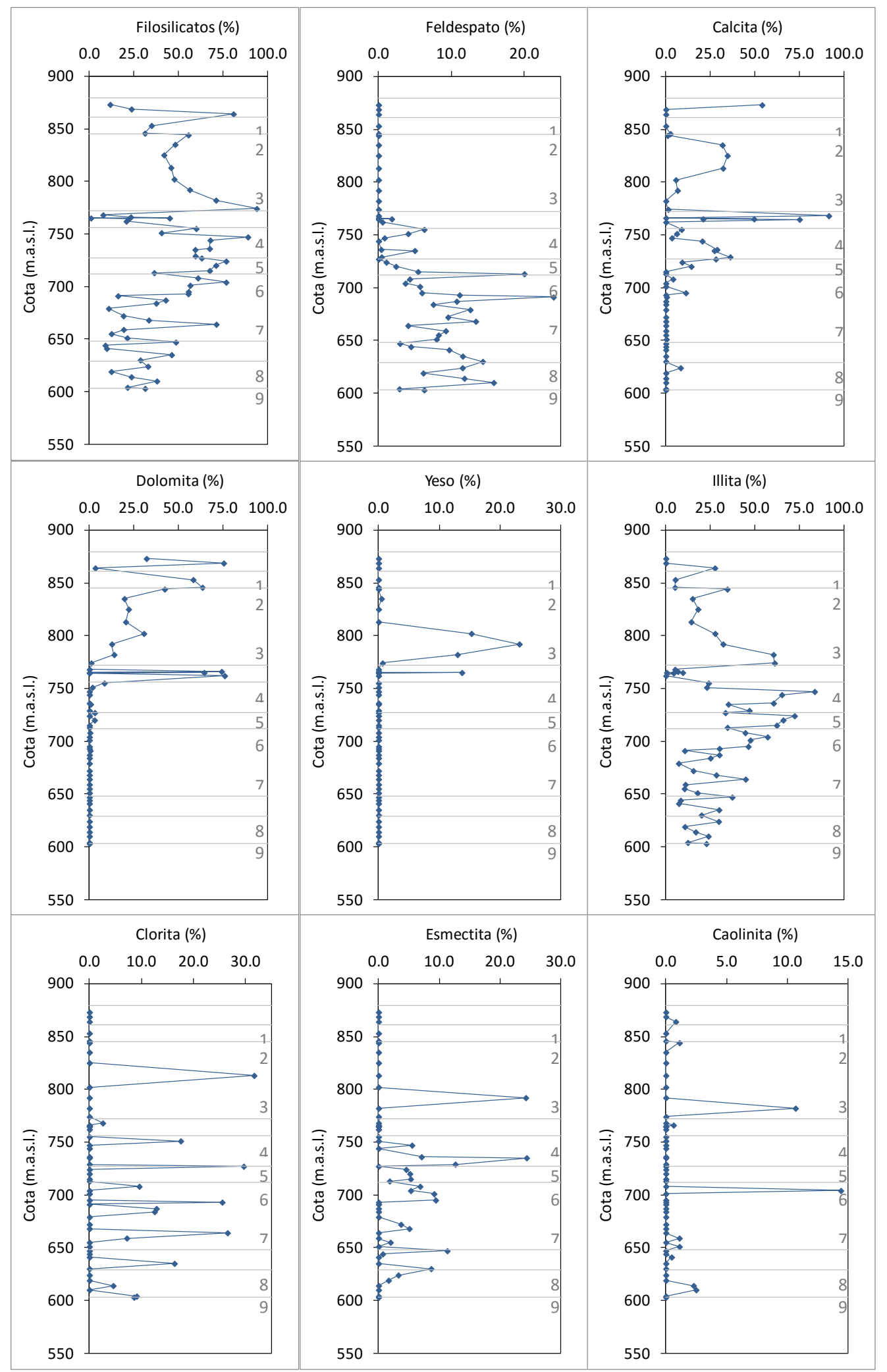

Fig. V.14. Continuación. 


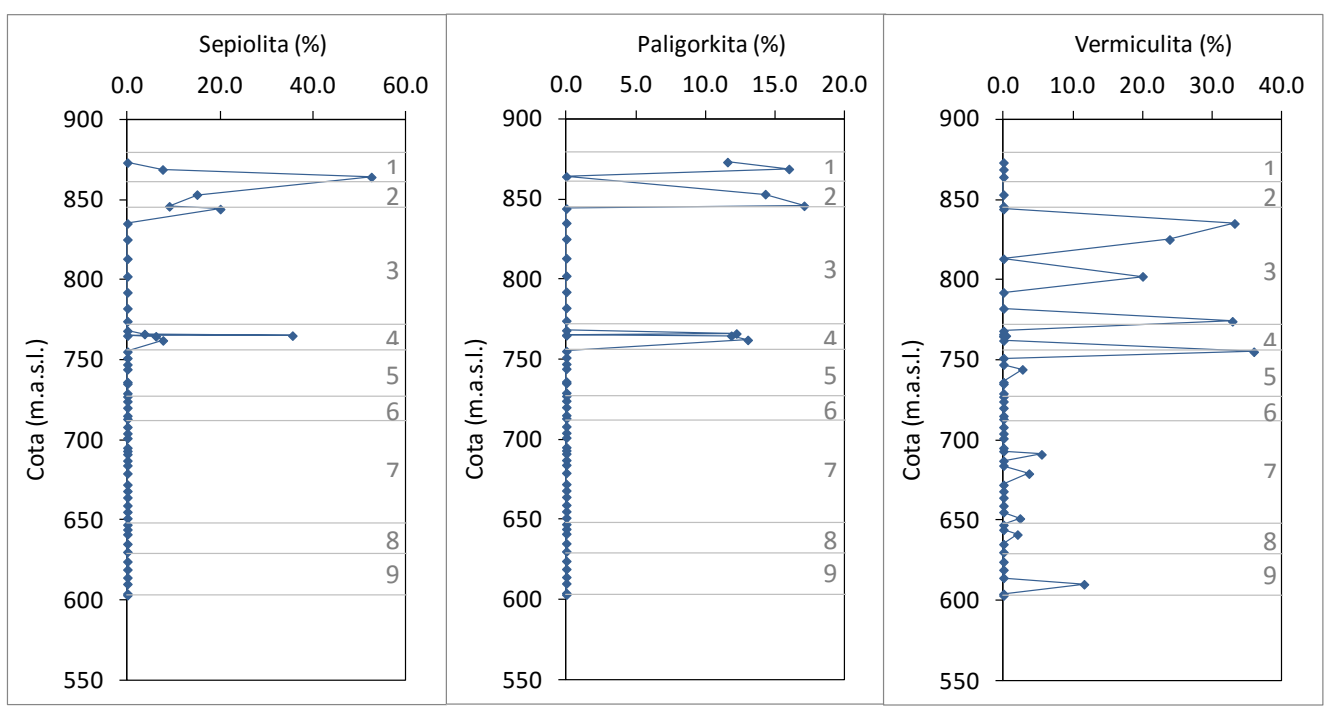

Fig. V.14. Continuación.

Los elementos traza arsénico, cromo, plomo y zinc presentan un perfil de distribución muy similar entre ellos y con la C.I.C. El vanadio también presenta los valores más bajos en la facies Zaratán; sin embargo, presenta valores elevados en más estratos que el resto de los metales: Calizas del Páramo, Transición al Páramo, Cuestas y Toro Superior. El cobre se diferencia del resto de los metales en que presenta concentraciones elevadas en la facies Zaratán, lo cual es lógico dada la elevada afinidad de este elemento por la materia orgánica (Fernández y col., 2015); en las facies Toro Superior e Inferior presenta una gran variabilidad.

En referencia a las unidades mineralógicas analizadas, se observa que el cuarzo y el feldespato están presentes mayoritariamente en cotas profundas, mientras que la calcita y la dolomita están mayoritariamente en las cotas superiores. El yeso se encuentra solamente en alguna muestra de facies Cuestas y Zaratán. Por su parte, los filosilicatos presentan sus menores porcentajes en facies Zaratán y los mayores en facies Tierra de Campos y Cuestas, al igual que C.I.C, $\mathrm{K}$ total, Mn total, Fe total y la mayoría de los metales traza. En cuanto a los diferentes tipos de filosilicatos determinados, la illita posee un perfil de distribución muy similar al de los filosilicatos, mientras que el resto de filosilicatos analizados solo se han hallado puntualmente en algunas muestras. La sepiolita y la paligorkita se encuentran en muestras pertenecientes a facies Zaratán, Calizas del Páramo y Transición al Páramo.

Para ver las distintas proporciones de minerales en las muestras tomadas, se han representado diagramas circulares sobre la columna estratigráfica (Fig. V.15) 


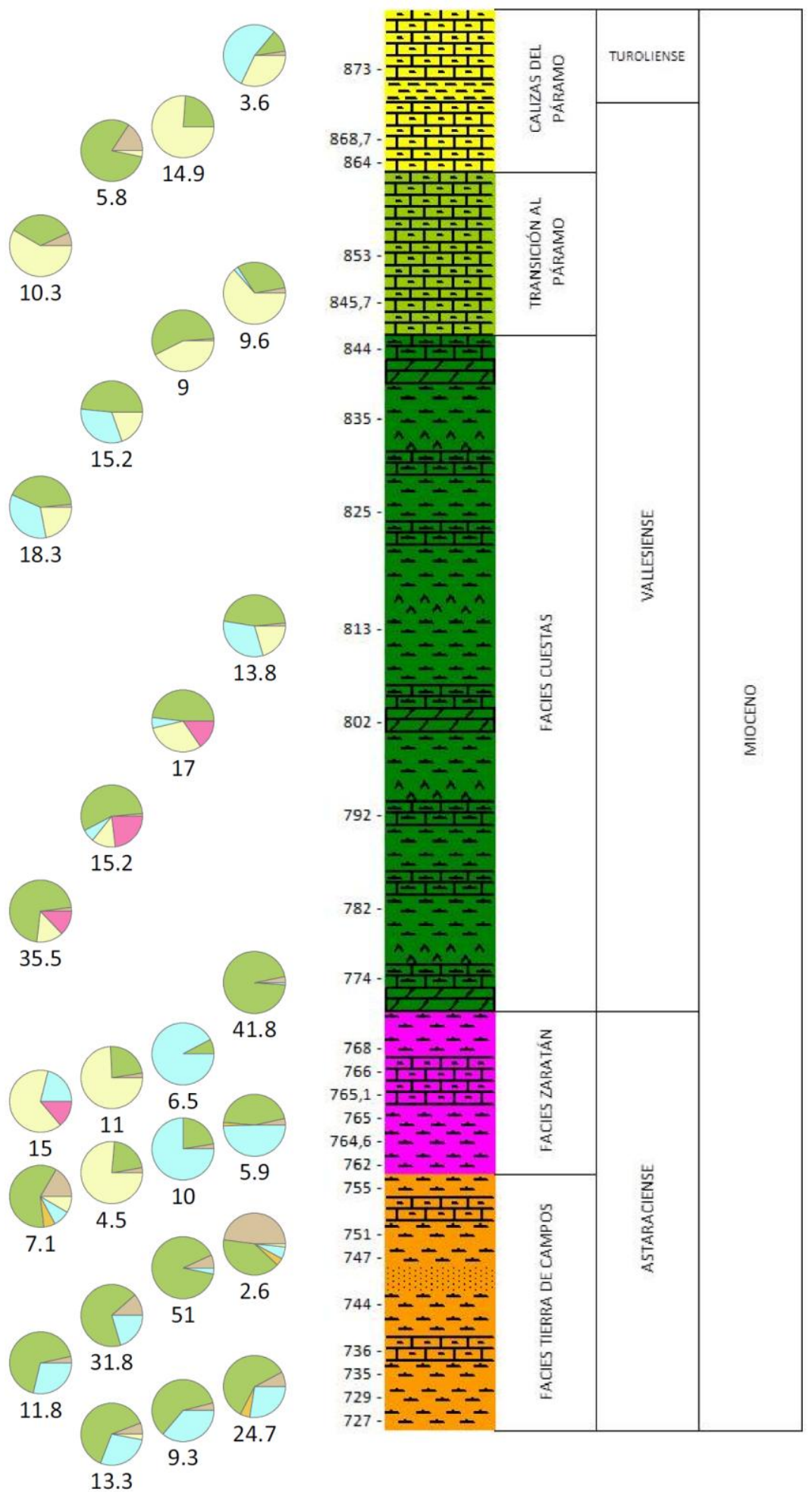

Fig. V.15. Representación de la composición mineralógica en las diferentes muestras, se ha señalado el contenido de arsénico debajo del diagrama circular 


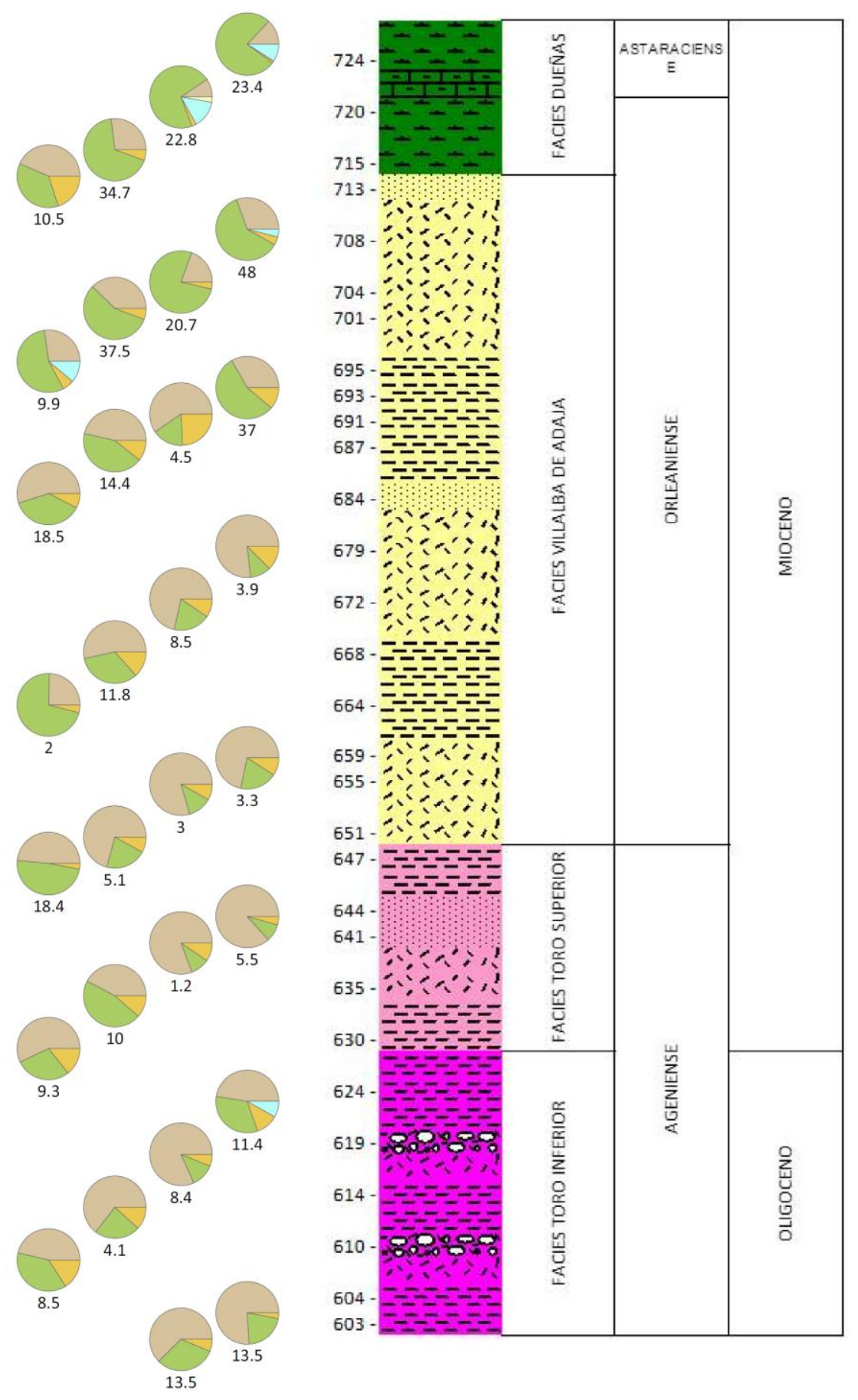

Minerales (\%)
$\square$ Cuarzo
$\square$ Calcita
$\square$ Filosilicatos
$\square$ Feldespato
$\square$ Dolomita
$\square$ Yeso

Fig. V.15. Continuación 
Los perfiles de distribución de manganeso total y manganeso reducible poseen cierta similitud. En las cotas superiores, correspondientes mayoritariamente a sedimentos superficiales, las concentraciones de ambas variables son prácticamente iguales, indicando que la práctica totalidad del $\mathrm{Mn}$ presente está en forma de $\mathrm{Mn}(\mathrm{IV})$, extraíble en condiciones reductoras, el cual estará formando fundamentalmente óxidos u oxohidróxidos de $\mathrm{Mn}(\mathrm{IV})$. Por el contrario, en las cotas inferiores, correspondientes a sedimentos no aflorantes, las concentraciones de $\mathrm{Mn}$ reducible son significativamente menores que el $\mathrm{Mn}$ total, por lo que puede deducirse que este elemento está presente mayoritariamente en forma reducida, $\mathrm{Mn}$ (II). Esta diferencia observada entre sedimentos superficiales y profundos puede ser debida a las diferentes condiciones redox presentes en ambos ambientes (Hindersmann, 2014; Remucal, 2014).

Antes de comparar las distribuciones de hierro total y hierro reducible hay que mencionar primeramente que las cantidades de hierro extraído en condiciones reductoras son prácticamente despreciables si las comparamos con la cantidad de hierro total, lo que parece indicar la ausencia de óxidos de Fe(III). Esta hipótesis está soportada por el hecho de que tampoco se identificaron óxidos de hierro en las muestras por XRD. Además, este elemento es más abundante en cotas inferiores a $750 \mathrm{~m}$, donde abundan las arcillas, lo que parece apuntar a estos minerales como la principal fuente de hierro en esta zona.

\section{V.4.1. DISTRIBUCION HORIZONTAL DE LOS PARÁMETROS ANALIZADOS}

Si bien es cierto que el número de datos puede ser insuficiente para que las conclusiones sean muy representativas, estos gráficos nos ayudarán a tener una idea aproximada de cómo se distribuyen espacialmente los parámetros físico-químicos investigados en la superficie de la zona de estudio. Así, la distribución horizontal del arsénico se ha representado en la Fig. V.16.

Para intentar ahondar sobre el origen de algunos niveles de $\mathrm{P}$ extraíble y $\mathrm{K}$ total anormalmente elevados, se han representado ambos parámetros total sobre la ortofoto de la zona de estudio (Fig. V.17), en la cual se observa que, en general, las muestras que presentan altos contenidos de potasio total también tienen altos contenidos en fósforo extraíble, y que además las zonas donde se muestrearon están próximas a campos de cultivo, por lo que estos niveles elevados pueden provenir de contaminación antropogénica.

\section{V.4.2. ESTADÍSTICA DESCRIPTIVA}

Un análisis estadístico nos permitirá confirmar los resultados cualitativos examinados hasta el momento. Este análisis comprende el cálculo de algunos estadísticos que proporcionan información sobre la tendencia central, la dispersión y la forma de las distribuciones de las variables investigadas, los cuales se presentan en la Tabla V.9. Para todos los cálculos estadísticos realizados se ha asignado valor cero a todos aquellos valores por debajo del límite de detección. 


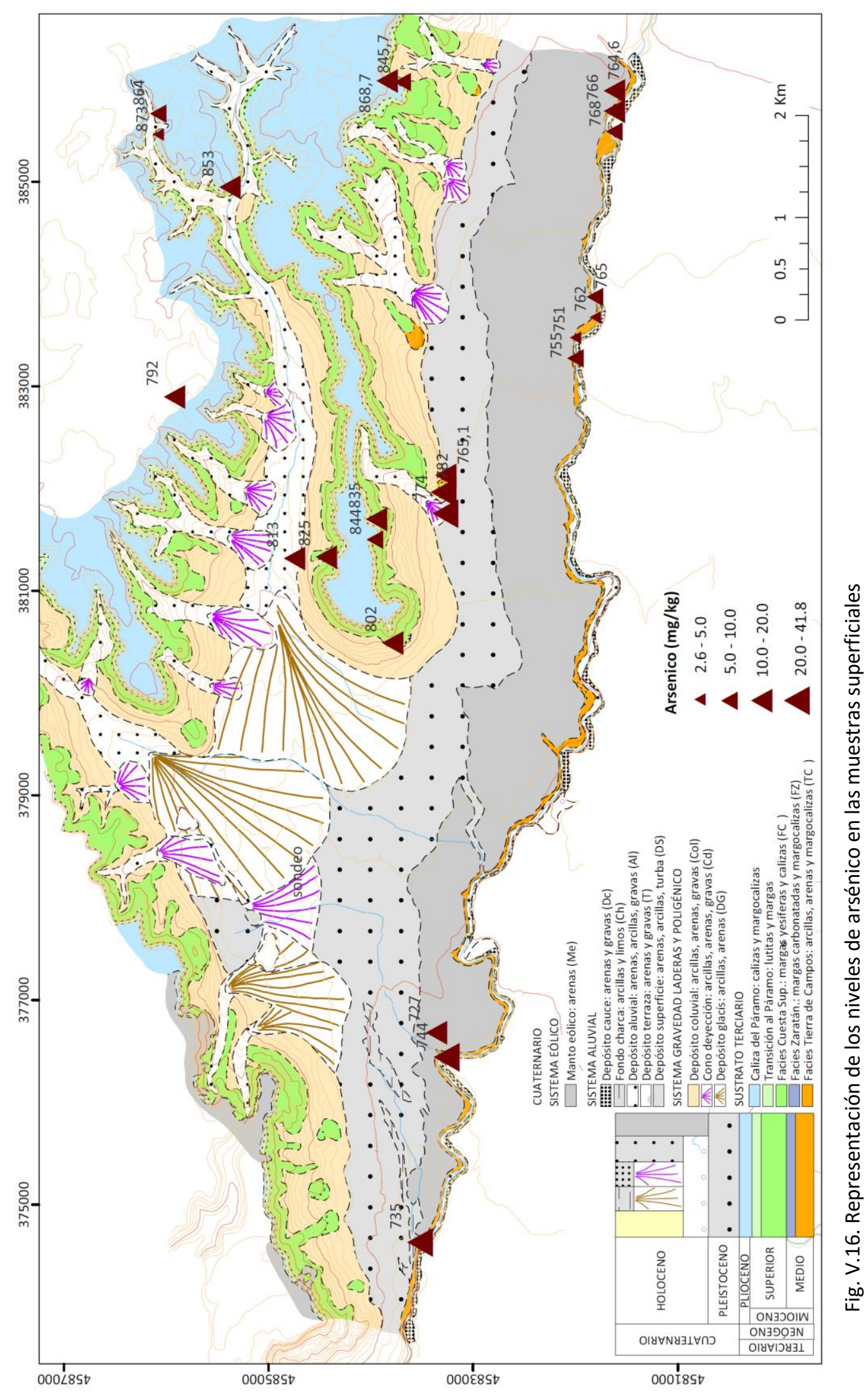




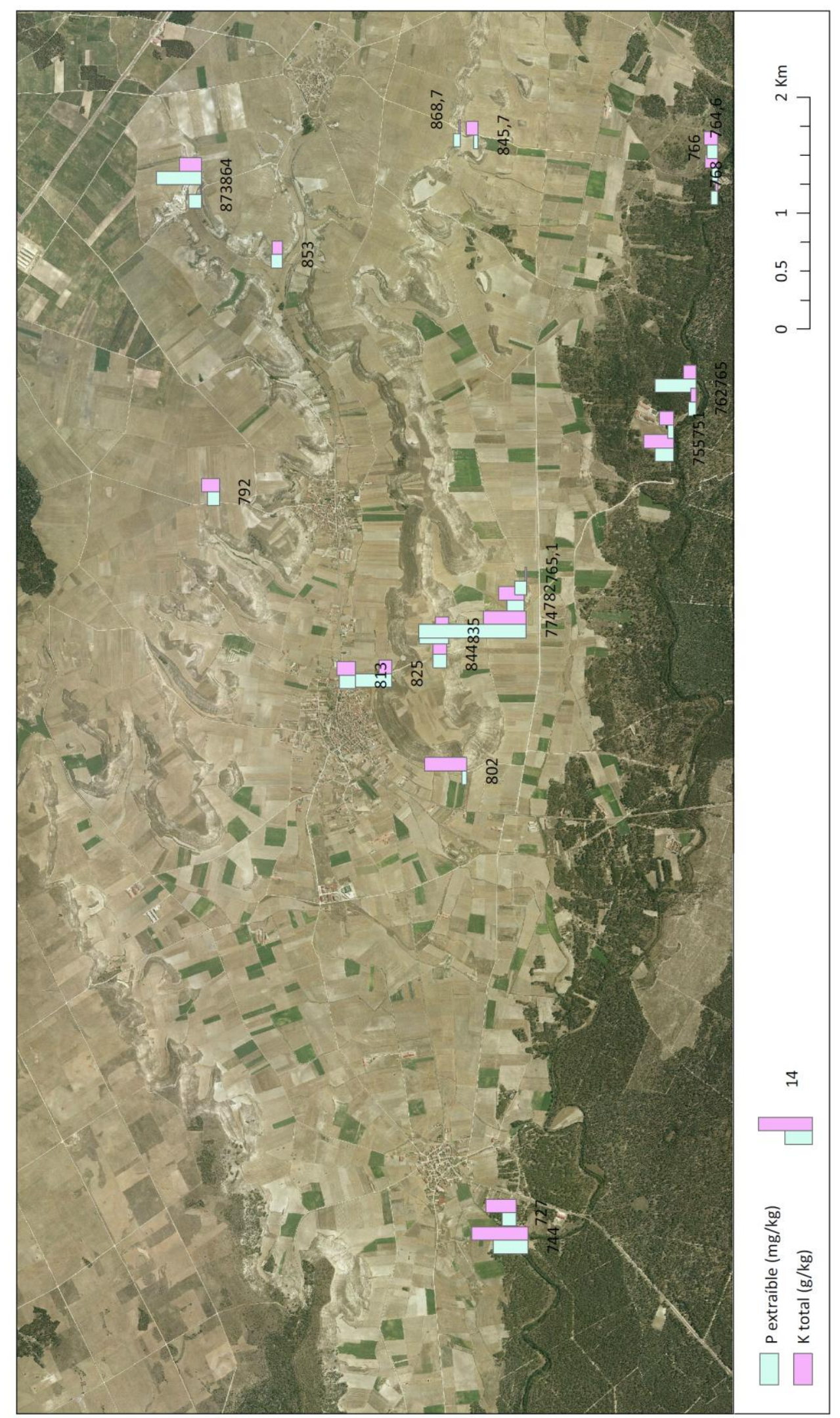

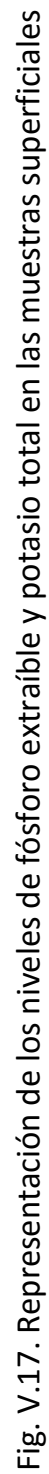


Como medidas de tendencia central se han incluido la media y la mediana; como parámetros de dispersión se muestran la desviación estándar y los valores mínimo y máximo que presenta la variable; los coeficientes de curtosis y asimetría dan idea de la forma de la distribución de los datos. El valor $\mathrm{p}$ a posteriori obtenido en la prueba de normalidad de Kolmogorov-Smirnov nos ha permitido establecer si las variables analizadas siguen o no una distribución normal. En negrita se han señalado las variables que no siguen una distribución normal.

La enorme dispersión que muestran algunas variables se evidencia por los altos valores revelados por la desviación estándar, y la gran diferencia entre los valores máximo y mínimo de las variables. Los coeficientes de curtosis y de asimetría dan idea de la forma de la distribución de la variable. Así, la mayoría de las distribuciones son asimétricas con largas colas hacia los valores más altos, destacando de entre las más asimétricas las distribuciones de la conductividad, materia orgánica, fósforo y calcio extraíble. Las distribuciones que tienden a ser más simétricas son las correspondientes a las variables $\mathrm{pH}$, arenas, limos, hierro extraíble, cromo, cobre, plomo, vanadio y filosilicatos.

El valor $\mathrm{p}$ a posteriori del test de normalidad de Kolmogorov-Smirnov nos ha permitido identificar las variables que siguen una distribución aproximadamente normal. Son aquellas cuyo valor $p$ es superior a 0,05 (para un nivel de confianza del 95\%). Cuanto más pequeño sea el valor $p$, tanto más alejada de la normalidad se encontrará la distribución. Atendiendo a este estadístico, observamos en la Tabla V.9, que 21 de los 39 parámetros analizados (54\%) no siguen una distribución normal, entre ellos el arsénico, algunas de las unidades mineralógicas, parámetros físico-químicos... Ello parece indicar que nuestra zona de estudio presenta cierta heterogeneidad en cuanto a las unidades geológicas, propiedades físico-químicas que presentan, presencia de metales traza...

Se destaca que algunos parámetros, como los diferentes tipos de filosilicatos, presentan valores nulos en las variables estadísticas mediana y mínimo, indicando que esas variables solo han sido cuantificadas en un reducido número de muestras, por lo que no se tendrán en cuenta en alguno de los análisis posteriores.

Tabla V.9. Parámetros estadísticos de las variables físico-químicas determinadas

\begin{tabular}{lcccccccc} 
& Media & Mediana & Desv. estándar & Curtosis & Asimetría & Mínimo & Máximo & p-value \\
\hline pH & 9,07 & 8,94 & 0,66 & $-1,04$ & 0,31 & 7,88 & 10,25 & 0,436 \\
C.E & 641,72 & 405,00 & 636,15 & 10,24 & 3,05 & 170,00 & 3665,00 & $\mathbf{0 , 0 0 0}$ \\
M.O. & 0,09 & 0,03 & 0,18 & 19,39 & 4,08 & 0,00 & 1,13 & $\mathbf{0 , 0 0 0}$ \\
Carbonato & 17,95 & 8,72 & 21,55 & 0,10 & 1,18 & 0,45 & 71,56 & $\mathbf{0 , 0 1 4}$ \\
P & 3,13 & 1,76 & 4,13 & 22,28 & 4,25 & 0,61 & 27,63 & $\mathbf{0 , 0 0 0}$ \\
C.I.C & 15,04 & 15,12 & 7,87 & $-0,18$ & 0,54 & 1,83 & 35,20 & 0,787 \\
Arenas & 35,80 & 36,38 & 23,82 & $-1,42$ & 0,02 & 0,25 & 72,72 & 0,440 \\
Limos & 40,78 & 43,95 & 17,52 & $-1,10$ & 0,00 & 7,06 & 71,03 & 0,462 \\
Arcilla & 23,43 & 19,82 & 12,80 & 0,55 & 1,06 & 5,71 & 59,98 & 0,297 \\
Mg tot & 33,29 & 15,36 & 35,70 & 0,46 & 1,24 & 1,17 & 136,05 & $\mathbf{0 , 0 1 1}$ \\
Na tot & 2,15 & 1,65 & 1,46 & $-0,53$ & 0,60 & 0,26 & 6,31 & $\mathbf{0 , 0 3 4}$ \\
K tot & 5,76 & 3,95 & 4,67 & 0,67 & 1,26 & 0,24 & 18,27 & $\mathbf{0 , 0 4 9}$ \\
Mn tot & 190,84 & 175,18 & 98,66 & 1,18 & 0,97 & 54,15 & 497,37 & 0,828 \\
Fe tot & 14,86 & 11,56 & 9,09 & $-0,69$ & 0,61 & 1,00 & 35,55 & 0,134 \\
Ca extr & 6,08 & 2,95 & 9,38 & 13,92 & 3,77 & 0,85 & 49,04 & $\mathbf{0 , 0 0 0}$ \\
Mg extr & 1,06 & 0,86 & 0,92 & 1,38 & 1,24 & 0,11 & 3,87 & 0,147 \\
Na extr & 0,42 & 0,31 & 0,40 & $-0,06$ & 1,00 & 0,01 & 1,36 & 0,082
\end{tabular}




\begin{tabular}{|c|c|c|c|c|c|c|c|c|}
\hline & Media & Mediana & Desv. estándar & Curtosis & Asimetría & Mínimo & Máximo & p-value \\
\hline K extr & 0,30 & 0,24 & 0,22 & 2,50 & 1,59 & 0,01 & 1,03 & 0,058 \\
\hline Mn extr & 103,53 & 52,28 & 117,52 & 3,56 & 1,80 & 1,69 & 521,57 & 0,028 \\
\hline Fe extr & 19,02 & 16,91 & 10,81 & $-0,82$ & 0,29 & 0,48 & 42,80 & 0,359 \\
\hline As & 14,69 & 10,99 & 11,79 & 1,67 & 1,48 & 1,15 & 51,02 & 0,019 \\
\hline $\mathrm{Cr}$ & 13,03 & 13,01 & 6,32 & $-0,42$ & 0,28 & 1,19 & 27,45 & 0,689 \\
\hline $\mathrm{Cu}$ & 12,57 & 11,85 & 6,73 & $-1,04$ & 0,17 & 0,00 & 26,62 & 0,522 \\
\hline $\mathrm{Pb}$ & 7,68 & 6,52 & 4,43 & $-1,08$ & 0,45 & 0,87 & 16,01 & 0,217 \\
\hline $\mathrm{Zn}$ & 45,27 & 43,42 & 21,86 & 0,37 & 0,77 & 9,76 & 102,71 & 0,735 \\
\hline V & 14,76 & 13,83 & 6,52 & $-1,10$ & 0,13 & 2,43 & 28,02 & 0,601 \\
\hline Cuarzo & 29,83 & 19,51 & 28,61 & $-1,19$ & 0,54 & 0,06 & 86,70 & 0,042 \\
\hline Filosilicatos & 42,31 & 41,90 & 23,19 & $-0,85$ & 0,21 & 0,79 & 94,04 & 0,545 \\
\hline Feldespato & 4,96 & 3,66 & 5,68 & 1,32 & 1,24 & 0,00 & 24,00 & 0,030 \\
\hline Calcita & 10,74 & 0,00 & 19,49 & 6,14 & 2,40 & 0,00 & 91,60 & 0,000 \\
\hline Dolomita & 10,99 & 0,00 & 22,03 & 3,07 & 2,08 & 0,00 & 76,03 & 0,000 \\
\hline Yeso & 1,16 & 0,00 & 4,33 & 14,84 & 3,88 & 0,00 & 23,18 & 0,000 \\
\hline Illita & 27,67 & 24,00 & 21,04 & $-0,23$ & 0,75 & 0,00 & 83,61 & 0,579 \\
\hline Clorita & 3,75 & 0,00 & 8,07 & 4,46 & 2,30 & 0,00 & 31,63 & 0,000 \\
\hline Esmectita & 2,76 & 0,00 & 5,29 & 8,31 & 2,72 & 0,00 & 24,38 & 0,000 \\
\hline Caolinita & 0,61 & 0,00 & 2,38 & 25,79 & 5,02 & 0,00 & 14,41 & 0,000 \\
\hline Sepiolita & 2,76 & 0,00 & 8,94 & 20,04 & 4,30 & 0,00 & 52,61 & 0,000 \\
\hline Paligorkita & 1,69 & 0,00 & 4,60 & 4,53 & 2,47 & 0,00 & 17,09 & 0,000 \\
\hline Vermiculita & 3,06 & 0,00 & 8,57 & 8,17 & 3,03 & 0,00 & 36,00 & 0,000 \\
\hline
\end{tabular}

Para una mejor visualización de la distribución de los parámetros analizados se han construido los gráficos box-plot que se muestran en la Fig. V.18. Para identificar si los niveles de cada parámetro varían a lo largo de la columna estratigráfica, se han representado estos gráficos en función de la unidad geológica en la que se han tomado las muestras de sedimento.

La representación de los resultados de los parámetros, agrupados por unidad geológica, en gráficos de cajas y bigotes (box-and-whisker plots), nos permite visualizar rápidamente el nivel de concentración, la dispersión de la variable, la forma de la distribución y las similitudes o diferencias entre estratos.

Pueden usarse en este caso como complemento a los perfiles de distribución vertical pues permiten visualizar si las diferencias entre la composición de los estratos para un parámetro determinado son significativas o no.

En la mayoría de los parámetros se observan diferencias apreciables entre los distintos estratos. De la dispersión de los valores dentro de cada estrato se puede decir que, en general, los parámetros dentro de cada unidad estratigráfica poseen distribuciones normales o al menos simétricas, siendo la facies Caliza del Páramo la que presenta una distribución más asimétrica en prácticamente todos los parámetros. La facies Cuestas presenta una media más cercana a los valores inferiores en los parámetros calcio, potasio, hierro, arsénico y filosilicatos. Todos estos parámetros están relacionados con la composición de los filosilicatos o con posibles elementos que estén atrapados en su estructura. 

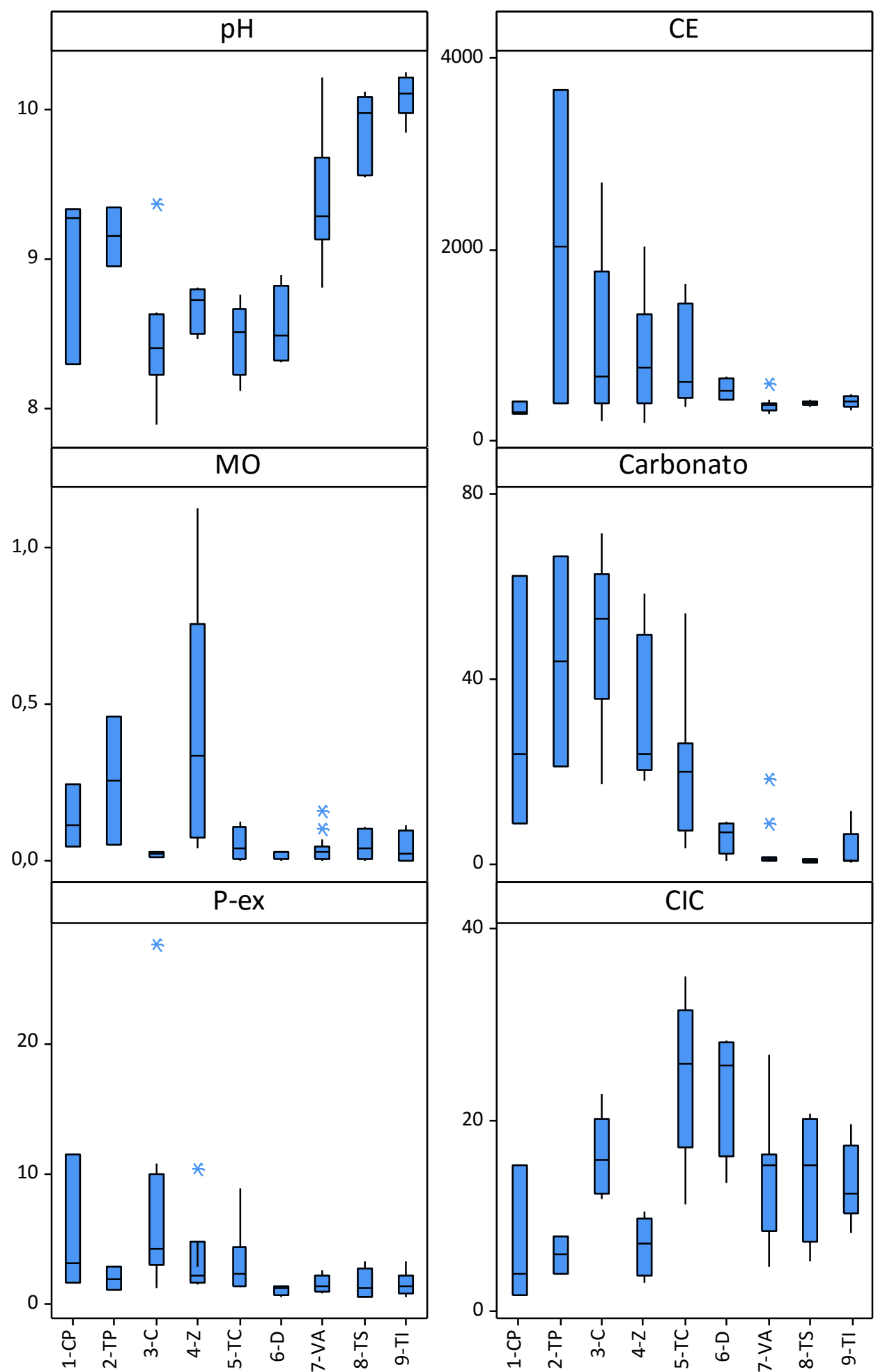

Fig. V.18. Diagramas de cajas y bigotes (box-plots) de todos los parámetros analizados. 1-CP: Calizas del Páramo; 2-TP: Transición al Páramo; 3-C: Cuestas; 4-Z: Zaratán; 5-TC: Tierra de Campos; 6-D: Dueñas; 7-VA: Villalba de Adaja; 8-TS: Toro Superior y 9-TI: Toro Inferior. 


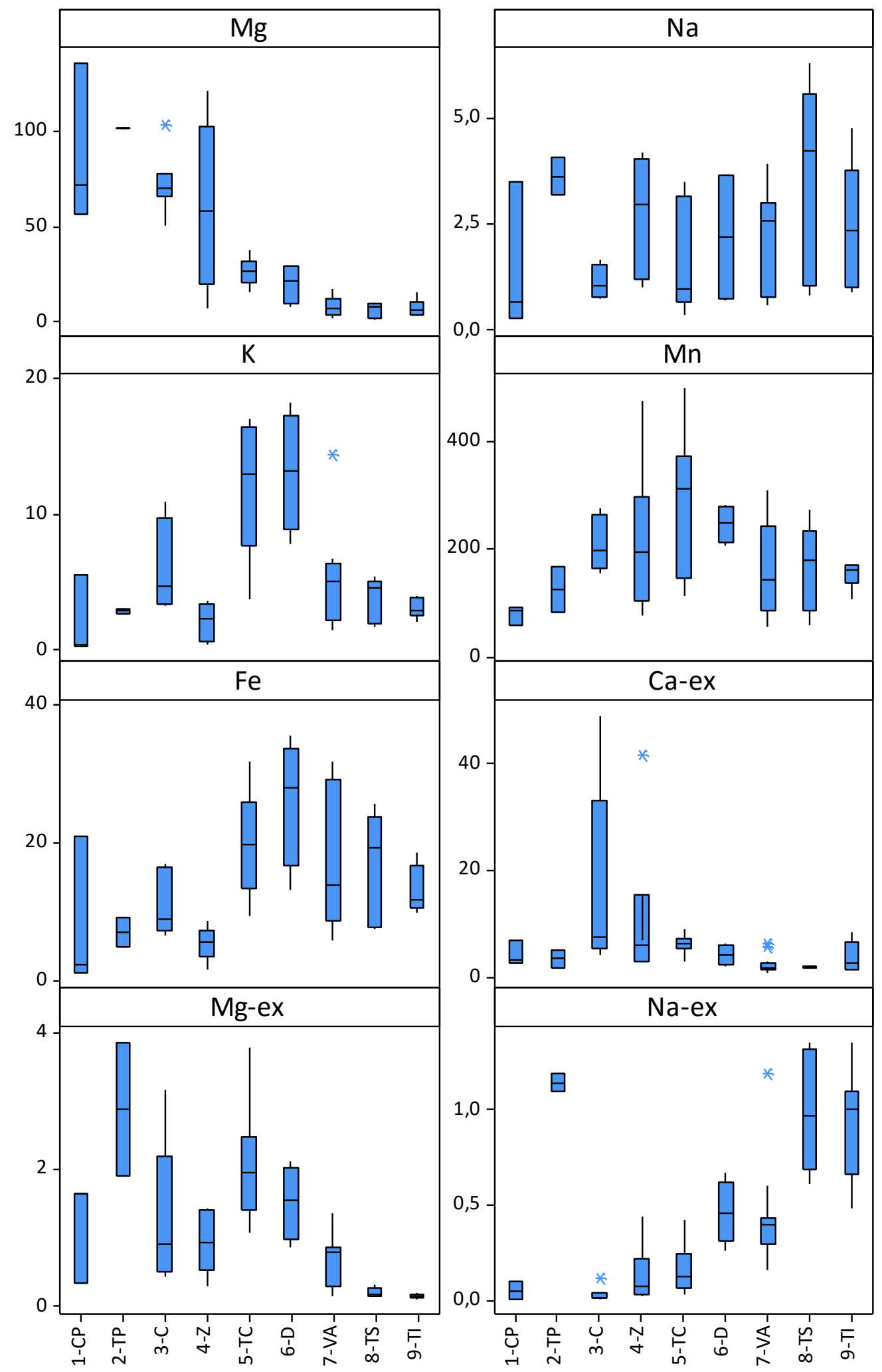

Fig. V.18. Continuación 

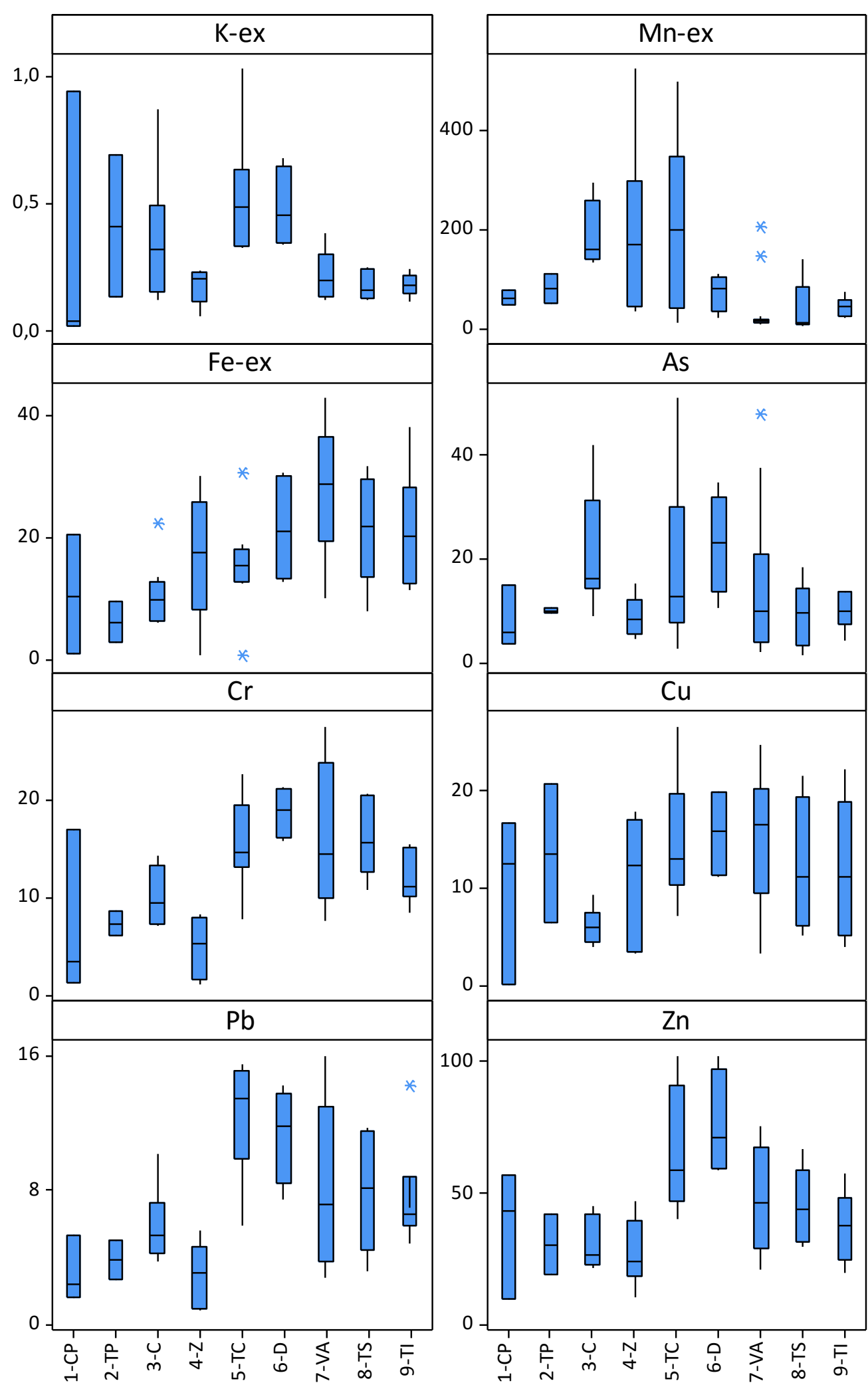

Fig. V.18. Continuación. 


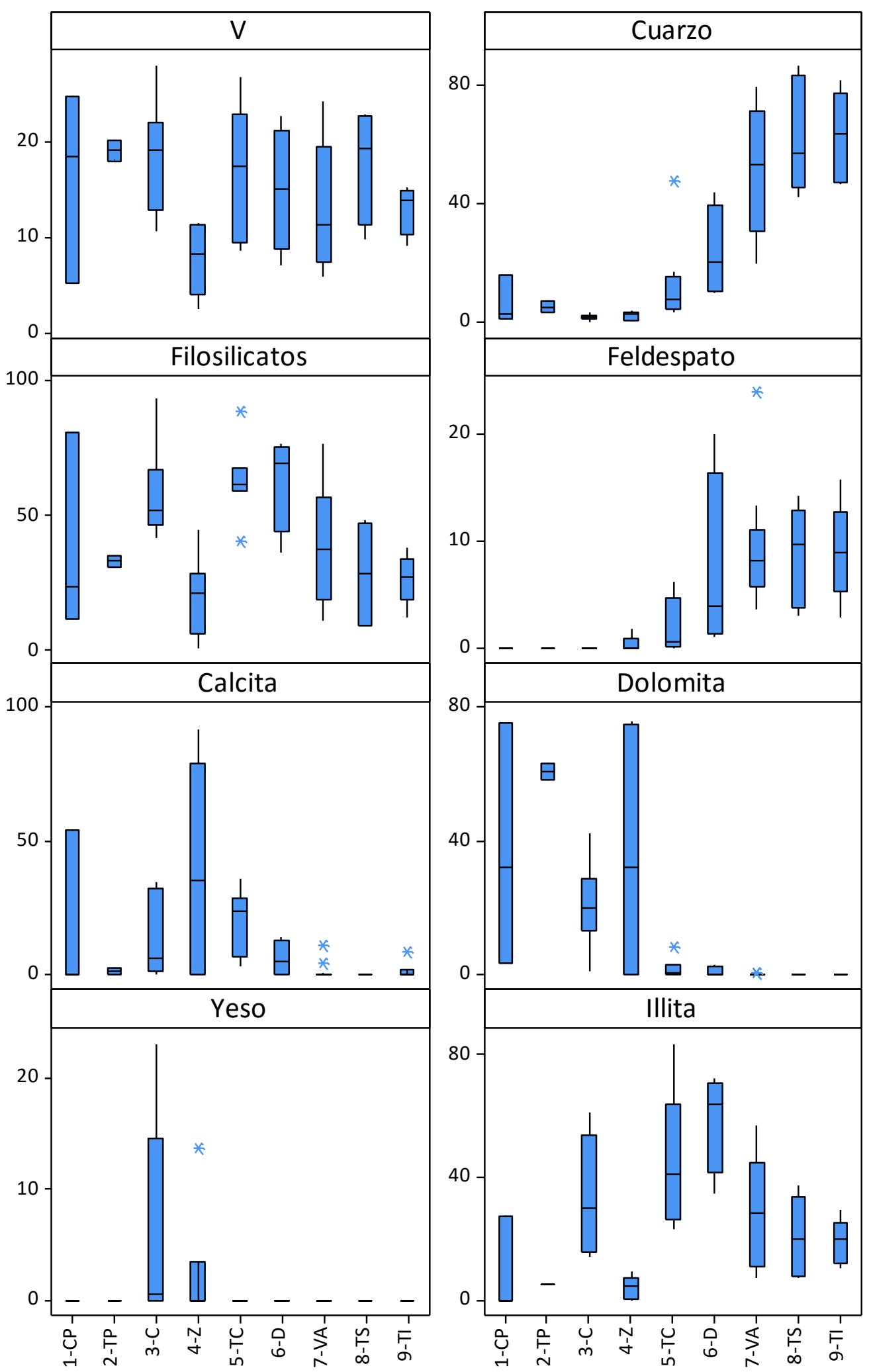

Fig. V.18. Continuación. 


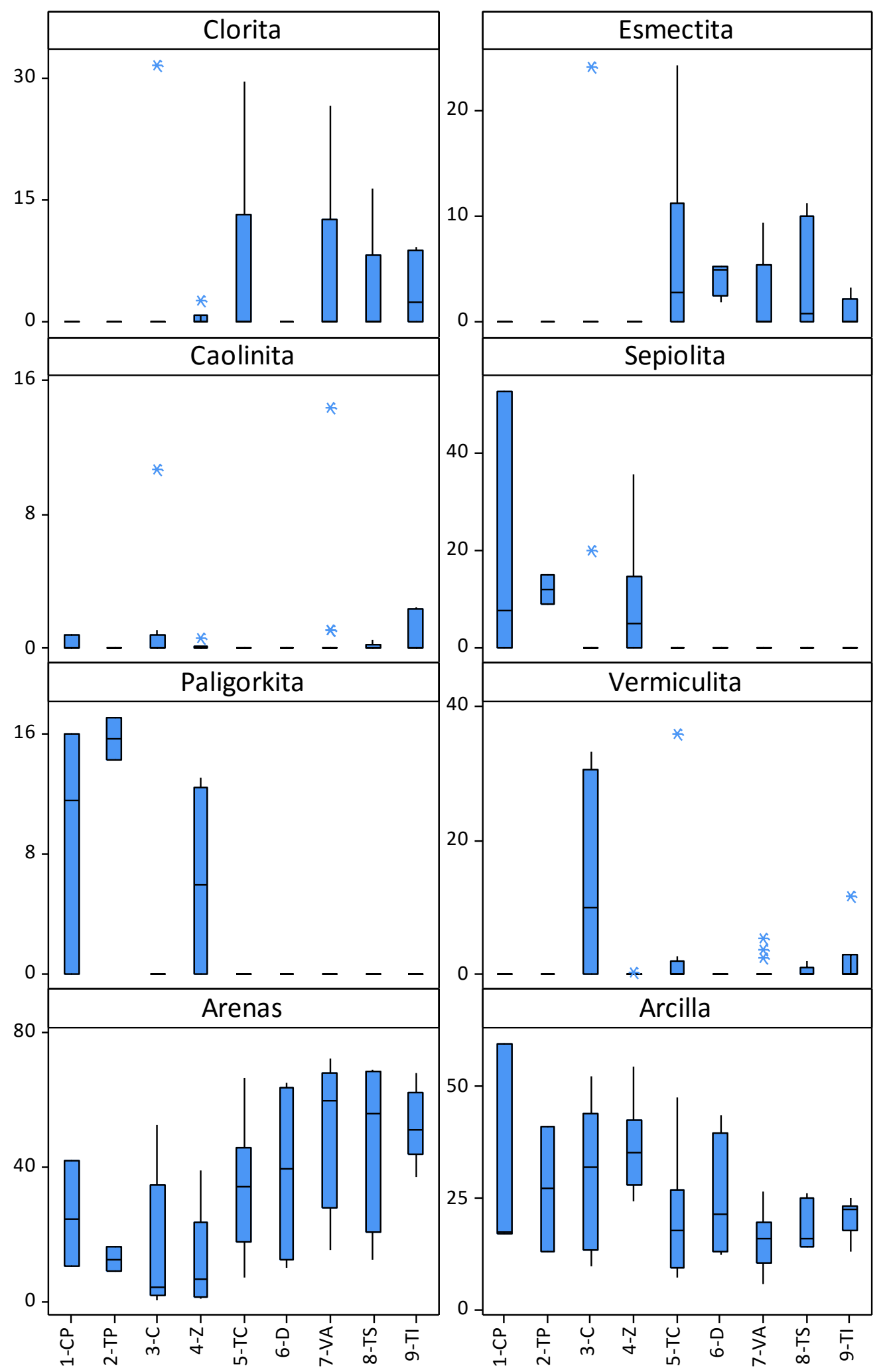

Fig. V.18. Continuación. 


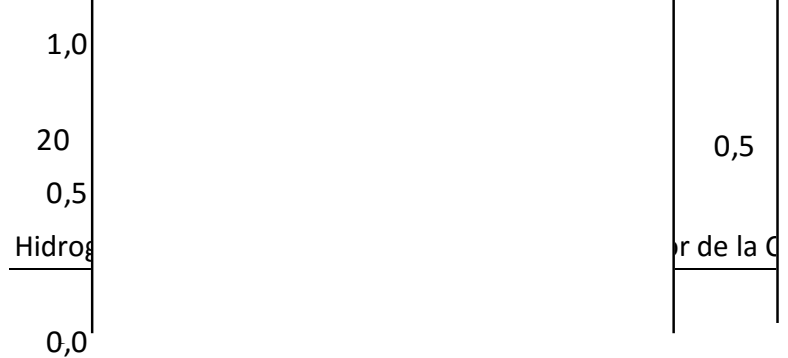

Fig. V.18. Continuación

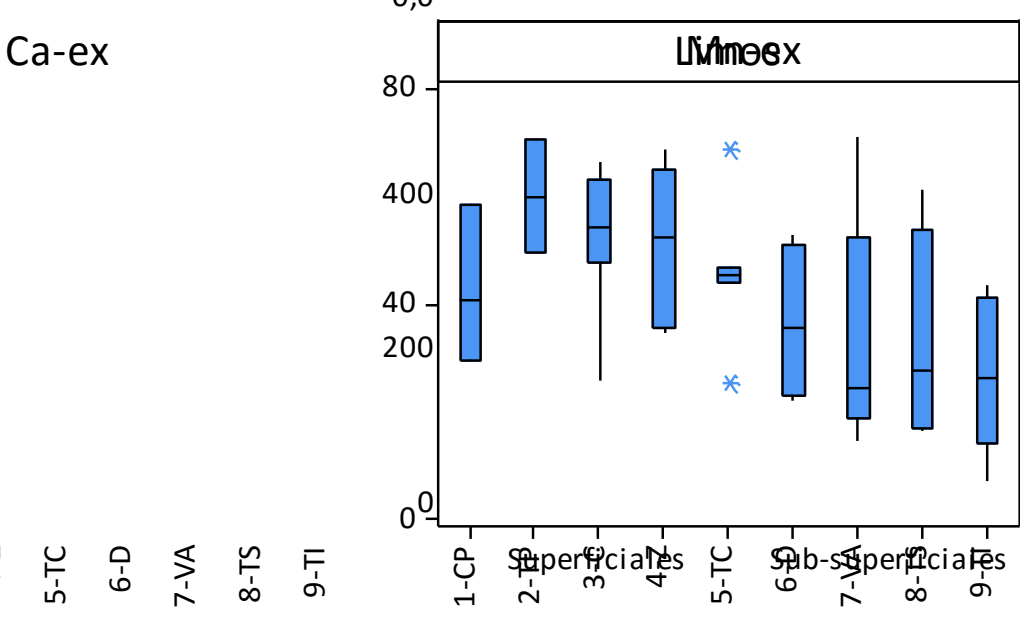

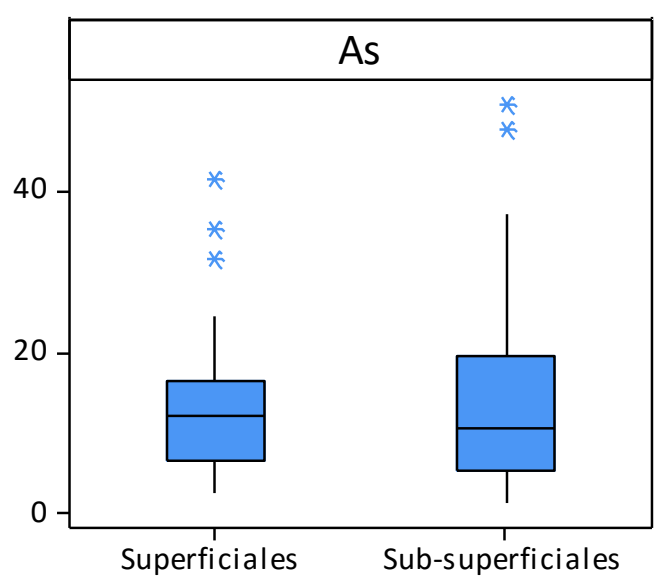

Fig. V.19. Box-plot del As según sean las muestras superficiales o sub-superficiales

En la facies Zaratán son los carbonatos los que parecen presentar una distribución no normal. En Tierra de Campos, son los parámetros como el sodio y el arsénico los que presentan valores de la media más cercanos a los valores inferiores. En la facies Villalba de Adaja, la C.I.C, el sodio y el magnesio extraíble presentan distribuciones no normales.

La Fig. V.19 muestra los box-plots correspondientes al arsénico diferenciando entre muestras tomadas superficialmente $o$ en la sub-superficie. A pesar de que no se aprecian diferencias significativas atendiendo a esta clasificación, la dispersión de valores es mayor en las muestras procedentes del sondeo. Los valores más elevados se han hallado en las muestras 708 (47,96 mg As/kg suelo) y 747 (51,02 mg As/kg suelo), pertenecientes a las unidades geológicas Facies Villalba y Facies Tierra de Campos, respectivamente.

En el estudio llevado a cabo por Gómez y col., 2006 encontraron también una gran asimetría en la distribución de arsénico de los sedimentos tomados en la Cuenca del Duero, hallándose un valor máximo de $337 \mathrm{mg} / \mathrm{kg}$ en la facies Zaratán y un nivel fondo de $28,5 \mathrm{mg} / \mathrm{kg}$.

\section{V.4.3. CORRELACIÓN ENTRE LOS PARÁMETROS INVESTIGADOS}

El estudio de las correlaciones bivariadas existentes entre los parámetros analizados puede revelar datos adicionales acerca de los orígenes y comportamiento del arsénico ligado a los sedimentos de la zona.

Así, si se produjeran correlaciones estadísticamente significativas y positivas entre el arsénico y otros parámetros se podría pensar en un origen común para los mismos y ello ayudaría a dilucidar el origen del arsénico.

En la Tabla A.III.2 del Anexo se recogen los coeficientes de correlación bivariada entre los parámetros analizados: los valores tabulados por debajo de la diagonal se 
corresponden con los coeficientes de correlación de Pearson ( $r$ ). Dado que muchos de los parámetros analizados no siguen una distribución normal, en la parte de la tabla por encima de la diagonal se han representado los coeficientes de correlación de Spearman $\left(r_{s}\right)$, más adecuados para distribuciones no simétricas. Los valores críticos de los coeficientes de correlación, para un nivel de significación $\alpha=0,05$ y n-2=57-2=55 grados de libertad son, para ambos, $r_{\text {crit }}(55 ; 0,05)=0,261$. Coeficientes de correlación superiores, en valor absoluto, a estos valores críticos, indican correlaciones significativas al $95 \%$ confianza, y se corresponderán con valores $\mathrm{p}$ a posteriori $<0,05$, siendo la correlación tanto más significativa cuanto mayor es $r$ y menor es $p$. En la tabla se han resaltado en rojo aquellas correlaciones significativas positivas $y$ en azul las correlaciones significativas negativas.

Al tratarse de una tabla tan grande, es más fácil visualizar las correlaciones significativas en un mosaico de color como el que se muestra en la Fig. V.20. Las correlaciones negativas son tanto más fuertes cuanto más intenso es el color azul, mientras que las correlaciones significativas positivas se representan con tonos que se intensifican hacia el rojo. La leyenda muestra la escala de color en relación con el nivel de significación.

Se observan fuertes correlaciones positivas entre la conductividad y los iones mayoritarios como calcio extraíble, magnesio, carbonatos y yeso, el cual es muy soluble en agua y aportará valores de conductividad elevados. La correlación de la conductividad con el cuarzo y el feldespato es negativa, ya que estos minerales son poco solubles y por tanto aportan pocos iones.

La correlación positiva de los carbonatos con el magnesio vendrá marcada por la presencia del mineral dolomita en las cotas aflorantes, como puede apreciarse en la Fig. V.15. Sin embargo, la correlación negativa con varios metales ( $\mathrm{Cr}, \mathrm{Cu}, \mathrm{Pb}, \mathrm{Zn}$ y Fe total) parece indicar que no existen metales retenidos en las estructuras de los carbonatos.

Lo que se observa, en general, es que aquellos parámetros que presentan correlación positiva con los filosilicatos no poseen correlación con cuarzo y feldespato o su correlación en negativa. Este hecho puede ser debido a las características tan contrapuestas que poseen ambas fracciones: mientras que los filosilicatos tienden a retener metales en su estructura, el cuarzo apenas posee esta propiedad (Forstner y col., 1982; Zollmer y col., 1993; Jha y col., 1993; Tam ycol., 2000; Gao y col., 2012).

De los metales pesados analizados, el único que parece distanciarse del comportamiento general es el cobre.

En cuanto a las correlaciones del arsénico, cabe destacar su correlación significativa positiva con los filosilicatos, la capacidad de intercambio catiónico, $\mathrm{K}$ total, Fe total, Mn total, $\mathrm{P}$ extraíble, $\mathrm{K}$ extraíble, Mg extraíble y todos los metales traza analizados, excepto el Cu. En otros estudios también se han encontrado fuertes correlaciones entre el arsénico y metales como cromo, níquel, zinc, cadmio y plomo, y concluyen que el arsénico hallado en los sedimentos proviene de las mismas fuentes que los metales traza con los que aparece correlacionado (Luo, 2008). 


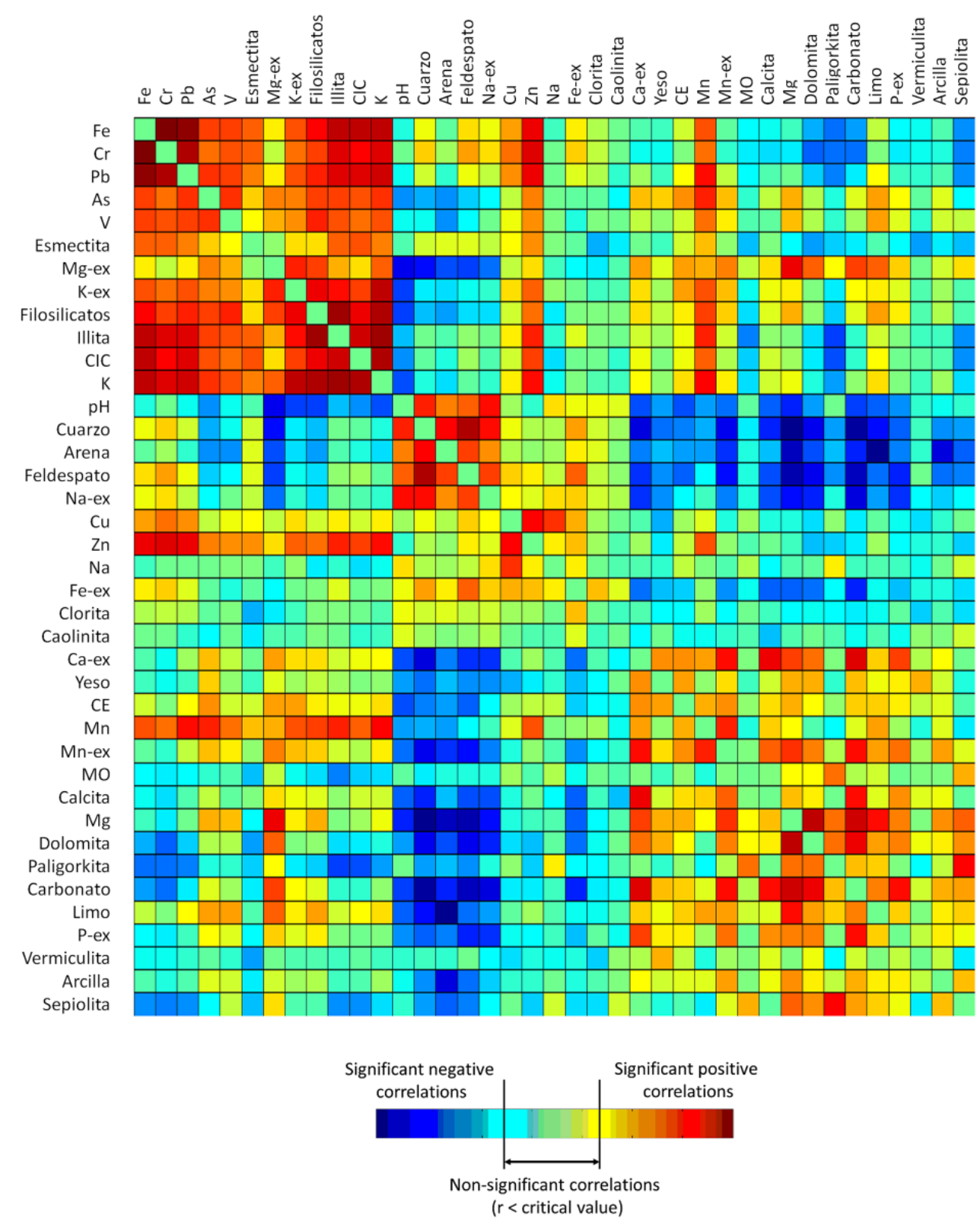

Fig. V.20. Mosaico de color mostrando las correlaciones entre parámetros. Por debajo de la diagonal se muestran los coeficientes de correlación de Pearson y por encima los de Spearman.

La concentración de arsénico está negativamente correlacionada con el $\mathrm{pH}$, al igual que ocurre en el estudio de Luo (Luo y col., 2008), lo que implica que, al aumentar el pH, la movilidad de arsénico aumenta debido a la liberación de arsénico bajo condiciones alcalinas $(\mathrm{pH}>8)$. 
El pH es uno de los principales factores que determinan la disponibilidad del arsénico en sedimentos contaminados por este elemento (Akins y Lewis, 1976; Bech y col., 1997; Adriano, 2001; Fayiga y col., 2007; Lockwood y col., 2014). Los efectos del pH entre 4 y 8 fueron examinados por Akins y Lewis (Akins y Lewis, 1976), quienes observaron que en los sedimentos de $\mathrm{pH}$ bajos $(\mathrm{pH}=4)$, Fe-As es la forma más abundante seguida de Al-As, mientras que a elevados $\mathrm{pH}(\mathrm{pH}=6-8) \mathrm{Ca}-\mathrm{As}$ es la forma predominante. Algo similar ocurre con el fósforo en sedimentos, las uniones Fe-P y Al-P predominan en sedimentos ácidos mientras que el Ca-P predomina en sedimentos alcalinos y calcáreos (Domenech, 2000).

La falta de correlación entre la materia orgánica y la concentración de arsénico, junto con la escasa concentración de materia orgánica en las muestras analizadas, sugieren que la materia orgánica no juega un papel importante en la movilidad del arsénico en el área objeto de estudio. En otros trabajos similares de zonas próximas (suelos de una antigua mina del norte del Madrid y en suelos con actividades mineras en Salamanca) tampoco se hallaron correlaciones significativas entre la materia orgánica o $\mathrm{pH}$ con el arsénico (García-Sánchez y col., 2003; Moreno-Jiménez y col., 2010).

Los contenidos de cuarzo y de partículas gruesas $(2-0,02 \mathrm{~mm})$ están significativamente correlacionados. Esta correlación se puede visualizar en la Fig. V.21-a, en la que se han diferenciado las muestras tomadas superficialmente de aquellas tomadas por debajo del nivel del suelo. Se puede observar cómo la mayoría de las muestras con mayores contenidos en partículas gruesas están más correlacionadas con el contenido de cuarzo.

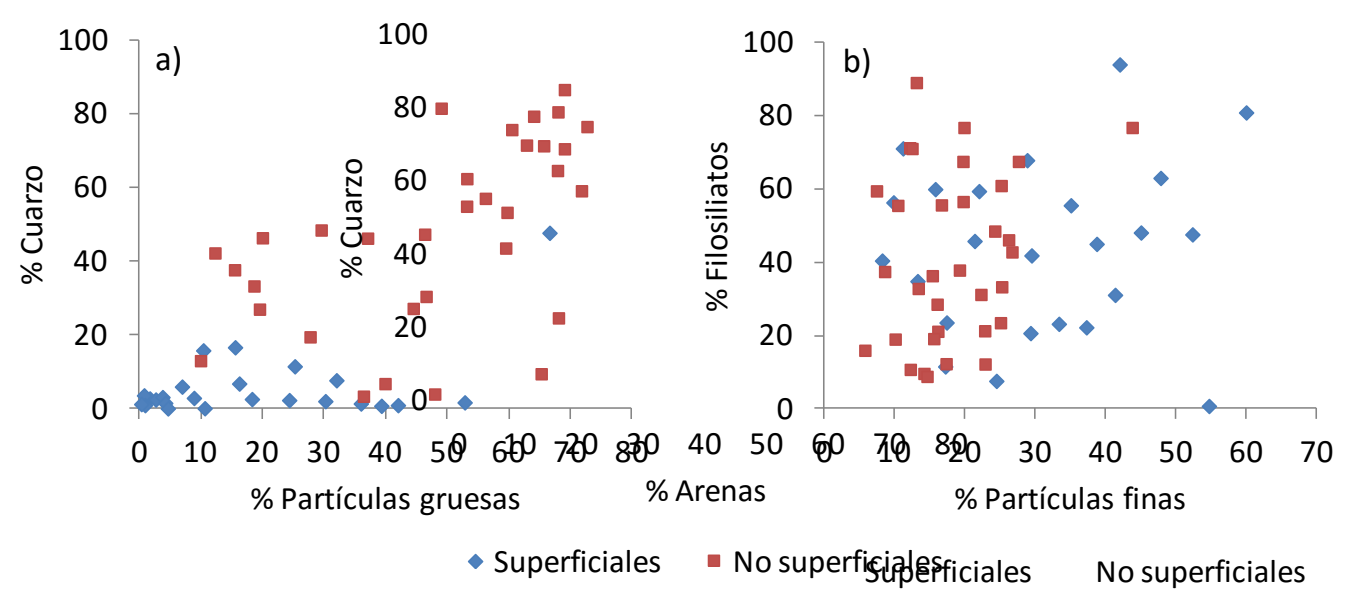

Fig. V.21. Correlación entre resultados de componentes minerales y tamaño de partículas: (a) cuarzo y arenas; (b) filosilicatos y arcillas. Partículas gruesas: aquellas partículas entre 2$0,02 \mathrm{~mm}$. Partículas finas: aquellas partículas menores de 0,002 $\mathrm{mm}$.

Por el contrario, la correlación entre el contenido de arcillas y el de filosilicatos no es significativa $(p>0,05)$. Esta ausencia de correlación significativa es común a las muestras superficiales y a las no superficiales, como se muestra en la Fig. V.21-b. Como el contenido de arcillas, limos y arenas se ha determinado mediante un método 
granulométrico basado en la separación de fracciones provocada por una diferente velocidad de sedimentación asociada al diferente tamaño de partícula, en la fracción más fina llamada arcillas están incluidos, además de filosilicatos, partículas de pequeño tamaño de otros minerales como cuarzos y otras formas de sílice $\left(\mathrm{SiO}_{2}\right)$, óxidos e hidróxidos de hierro y aluminio o carbonato cálcico, lo cual justificaría esa de falta de correlación.

Para visualizar mejor esta hipótesis se ha procedido a construir dos diagramas triangulares, que se muestran en la Fig. V.22 y Fig. V.23: en el primero se han representado los porcentajes de las fracciones arcillas, arenas y limos obtenidas en el análisis granulométrico, mientras que en el segundo se han sustituido estos porcentajes por los de filosilicatos, cuarzo, y resto de fracciones minerales (hasta completar el $100 \%)$, medidos por XRD. En ambos diagramas se han indicado los contenidos de arsénico en las muestras. Se puede observar que el contenido de arsénico no parece tener mucha relación con la composición granulométrica de los sedimentos; por el contrario, en el segundo diagrama se observa que las muestras con mayor concentración de arsénico se corresponden con aquellas con mayores porcentajes de filosilicatos. De aquí se deduce que el arsénico está aparentemente asociado a la fracción mineral filosilicatos. Por lo tanto, no se tendrán en cuenta los resultados de granulometría en el subsecuente análisis de los datos.

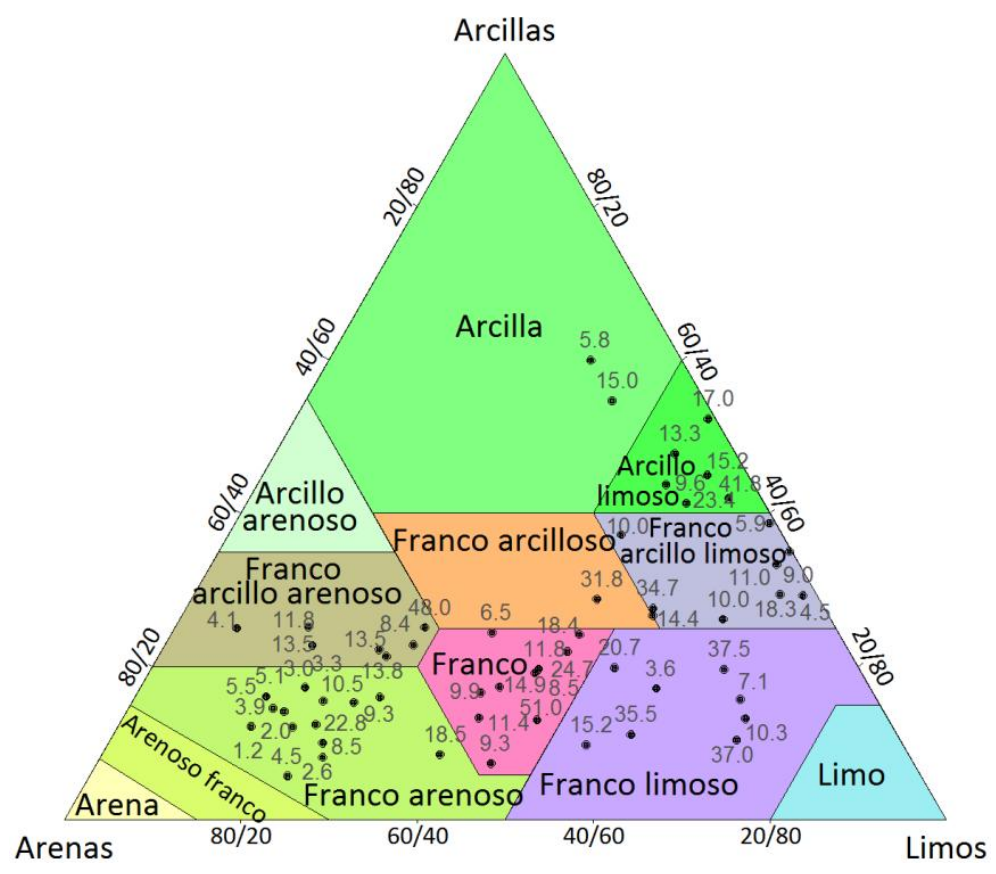

Fig. V.22. Diagrama textural, en el que se indica la concentración de As de las muestras de sedimentos tomadas. 


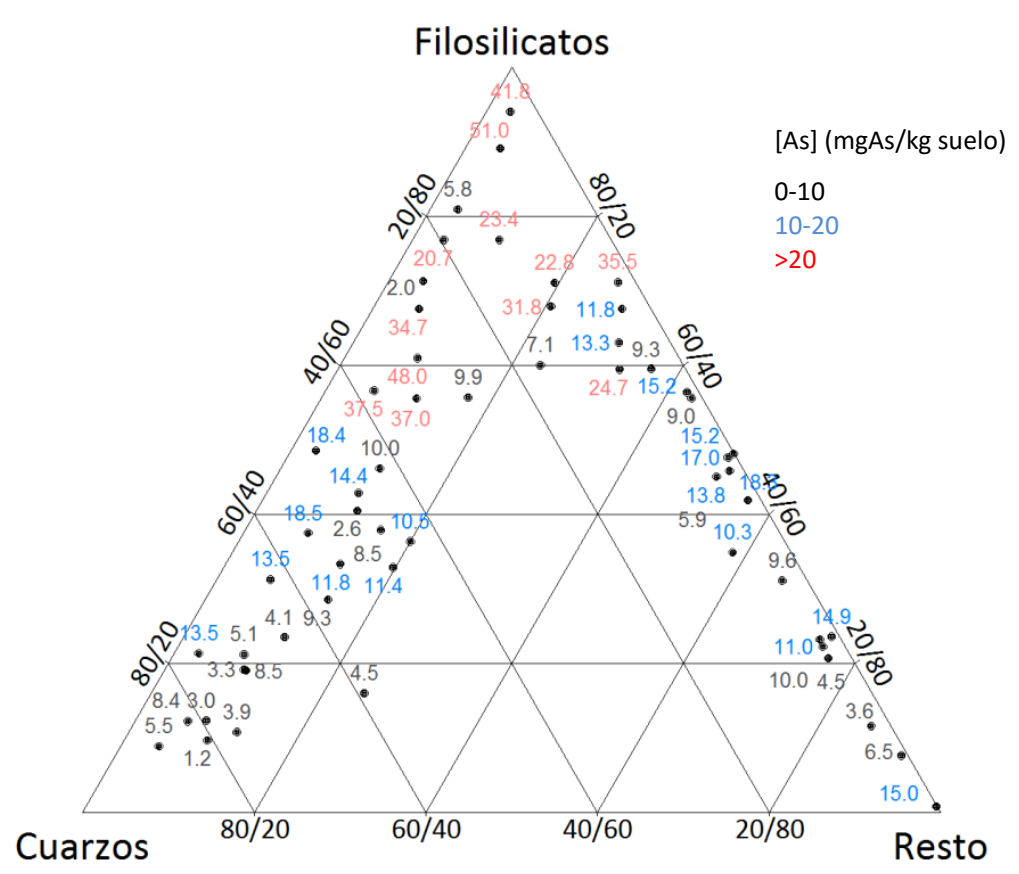

Fig. V.23. Porcentaje de los compuestos minerales filosilicatos, cuarzo y resto de minerales en un diagrama triangular, con indicación de la concentración de As.

\section{V.4.4. ANÁLISIS MULTIVARIANTE}

Para resaltar las diferencias y similitudes composicionales entre las muestras analizadas se aplicaron técnicas estadísticas multivariantes, como análisis clúster jerarquizado aglomerativo y análisis en componente principales (ACP).

A fin de disminuir la información irrelevante de la matriz de datos, que aumenta la varianza residual, se decidió eliminar aquellas variables que no se correlacionan con el resto o que se distribuyen de forma aproximadamente homogénea en los sedimentos analizados. A la vista de los resultados del análisis de correlaciones y de los perfiles de distribución vertical, se decidió no incluir en el análisis multivariante las siguientes variables: la granulometría, los diferentes tipos de filosilicatos, la materia orgánica y los metales extraíbles hierro y manganeso.

Como ya se dijo anteriormente, el arsénico parece estar más correlacionado con las fracciones mineralógicas que con la granulometría por lo que ésta no se va a considerar. De los diferentes tipos de filosilicatos determinados (illita, clorita, esmectita, caolinita, sepiolita, paligorkita y vermiculita), la illita es mayoritaria, y está presente en todas las muestras y correlacionada con el contenido de filosilicatos; el resto de filosilicatos fueron identificados en muy pocas muestras, por lo que las relaciones encontradas con 
estos parámetros no aportarán información relevante. La concentración de materia orgánica es solo apreciable en las muestras de la facies Zaratán y solo muestra correlaciones significativas con paligorkita y sepiolita, eliminadas, por lo que esta variable tampoco se tendrá en cuenta. Para reducir la dimensionalidad de la matriz de datos se ha eliminado el $\mathrm{Mn}$ extraíble ya que este parámetro está fuertemente correlacionado con el $\mathrm{Mn}$ total, por lo que no aportará mucha más información al estudio. Por último, no se observan correlaciones significativas con el resto de parámetros para el Fe extraíble, por lo que se va a prescindir de esta variable.

\section{V.4.4.1 ANÁLISIS CLUSTER}

El análisis clúster facilita el agrupamiento de las muestras de sedimentos basándose en los resultados de las variables analizadas. Los dendrogramas resultantes para las muestras y para los parámetros se presentan en la Fig. V.24. Han sido complementados con un mosaico de colores para una mejor interpretación. Así, los colores azules oscuros muestran los mínimos de concentración, los cuales irán variando hacia colores rojos que indican mayores concentraciones de los parámetros.

En la Fig. V.24 se observan tres grupos de variables (CV1, CV2 y CV3) y tres agrupaciones de muestras (CM1, CM2 y CM3).

La primera agrupación de muestras, $\mathrm{CM} 1$, presenta elevadas concentraciones de las variables pertenecientes al grupo $\mathrm{CV} 2(\mathrm{pH}$, sodio, feldespato y cuarzo) y se puede interpretar por tanto como un grupo de sedimentos arenosos. Este grupo se caracteriza también por contener bajas concentraciones de metales traza, a excepción de algunas muestras de las facies Toro Superior e Inferior que presentan algunos metales tales como $\mathrm{Fe}, \mathrm{Cr}, \mathrm{Pb}, \mathrm{Cu}$ y $\mathrm{Zn}$.

En la segunda agrupación de muestras, CM2, encontramos sedimentos con altos contenidos en filosilicatos y metales pesados, variables que se agrupan en el grupo CV1. Hay dos subgrupos diferenciados dentro de CM2: en el primero se observan niveles moderados de las variables asociadas a arenas (cuarzo y $\mathrm{Na}$ ) y engloba mayoritariamente muestras procedentes de la facies Villalba de Adaja. El otro subgrupo de $\mathrm{CM} 2$ se caracteriza por la poca presencia de arenas, mayores proporciones de metales y de arcillas y moderas cantidades de carbonatos.

El grupo CV3 engloba parámetros relacionados con los minerales calcita, dolomita y yeso. El grupo de muestras $\mathrm{CM} 3$ contiene los mayores niveles de estas variables. Este grupo presenta concentraciones moderadas de $\mathrm{As}, \mathrm{V}$ y $\mathrm{Mn}$, mientras que las concentraciones de $\mathrm{Cr}$, $\mathrm{Pb}$ y Fe son despreciables. 

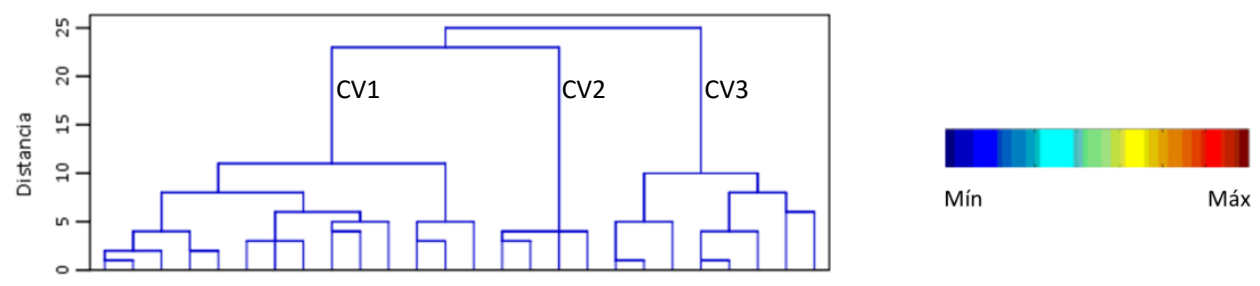

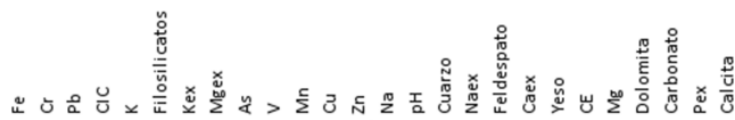
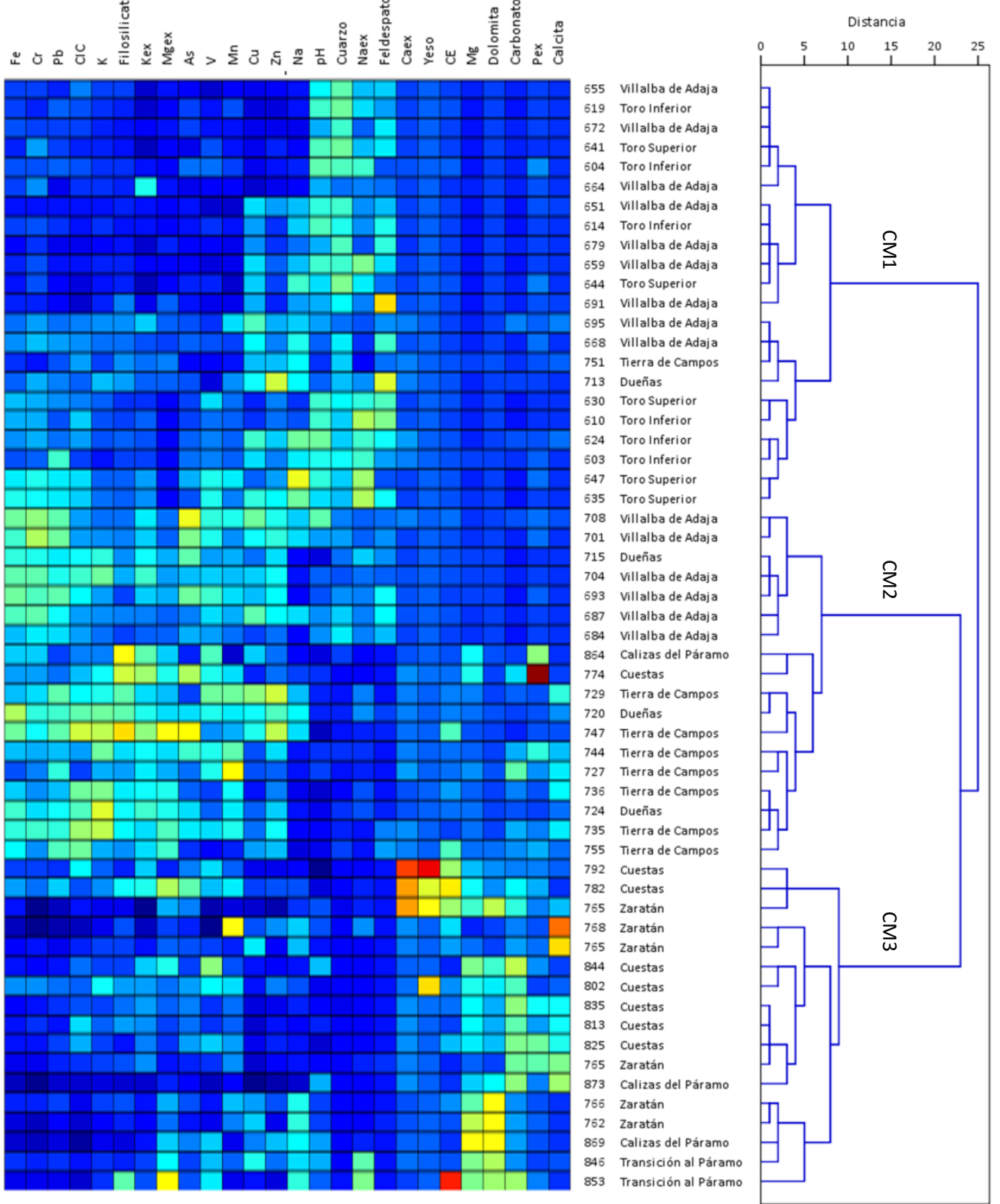

Fig. V.24. Dendrogramas obtenidos por análisis clúster de las 57 muestras de sedimentos y de los 26 parámetros analizados, complementado con un mosaico de colores que indica los niveles relativos de los parámetros en las muestras. 


\section{V.4.4.2 ANÁLISIS EN COMPONENTES PRINCIPALES (ACP)}

El ACP nos va a permitir extraer información relacionada con la existencia de diferentes clases de objetos y variables en un espacio de dimensiones más reducido. Un paso previo a la visualización de los datos que nos proporcionará el ACP es la reducción de la dimensionalidad de la tabla original. Para ello vamos a mantener únicamente aquellos componentes cuyo autovalor sea mayor que la unidad, es decir, aquellos que explican más varianza que una variable original.

Al aplicar el ACP a la matriz de datos formada por las 26 variables elegidas y las 57 muestras de sedimentos, se obtienen los valores propios mostrados en la Fig. V.25, donde se aprecia que hay 6 componentes principales (PCs) que poseen un autovalor mayor que la unidad.

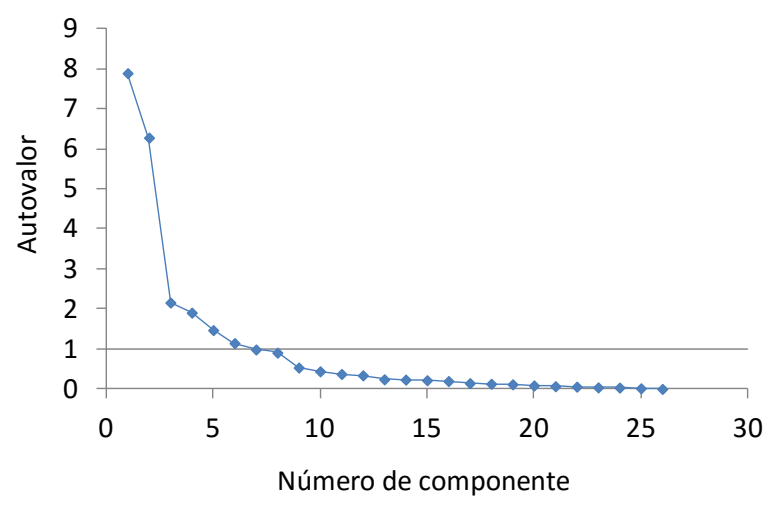

Fig. V.25. Gráfico de autovalores.

La Tabla V.10 muestra las cargas de los nuevos factores, esto es, los coeficientes que muestran la participación de las variables originales en los PCs. Adicionalmente, se muestran sus correspondientes autovalores, la varianza explicada por cada PC y la varianza acumulada. Se observa que los seis primeros PCs explican el $80,1 \%$ de la varianza contenida en el conjunto de datos, consiguiendo una importante reducción de la dimensionalidad de los datos con solo una ligera pérdida de información. Cada nuevo componente principal se puede interpretar en función de la combinación de las variables originales más correlacionadas con él. De esta manera, se han marcado en negrita las correlaciones más significativas dentro de cada componente.

El primer componente (PC1) explica el $30,3 \%$ de la varianza total de la matriz de datos y tiene una importante contribución positiva de los parámetros filosilicatos, C.I.C, metales totales mayoritarios (potasio, manganeso, hierro), metales extraíbles mayoritarios (magnesio y potasio) y metales traza (arsénico, cromo, plomo, zinc y vanadio). Por tanto, este primer componente se puede interpretar como una variable relacionada con la presencia de arcillas con alta capacidad para retener metales. 
Tabla V.10. Cargas de los componentes principales retenidos

\begin{tabular}{|c|c|c|c|c|c|c|}
\hline & PC1 & PC2 & PC3 & PC4 & PC5 & PC6 \\
\hline $\mathrm{pH}$ & $-0,465$ & $-0,673$ & 0,171 & $-0,003$ & $-0,193$ & 0,303 \\
\hline C.E & 0,129 & 0,544 & 0,344 & 0,455 & 0,126 & $-0,252$ \\
\hline Carbonato & $-0,097$ & 0,837 & $-0,045$ & $-0,203$ & $-0,064$ & 0,177 \\
\hline P-ex & 0,190 & 0,425 & $-0,261$ & $-0,213$ & $-0,446$ & 0,073 \\
\hline C.I.C & 0,825 & $-0,105$ & $-0,243$ & 0,167 & $-0,006$ & $-0,111$ \\
\hline Mg & $-0,067$ & 0,799 & 0,435 & $-0,168$ & $-0,236$ & 0,081 \\
\hline $\mathrm{Na}$ & $-0,047$ & $-0,315$ & 0,732 & $-0,224$ & 0,297 & 0,009 \\
\hline K & 0,883 & 0,029 & $-0,178$ & $-0,022$ & 0,031 & $-0,174$ \\
\hline $\mathrm{Mn}$ & 0,605 & 0,136 & $-0,132$ & $-0,227$ & 0,421 & 0,387 \\
\hline $\mathrm{Fe}$ & 0,867 & $-0,358$ & 0,017 & 0,147 & $-0,054$ & 0,052 \\
\hline Ca-ex & 0,031 & 0,553 & 0,044 & 0,687 & 0,270 & 0,133 \\
\hline Mg-ex & 0,587 & 0,515 & 0,317 & $-0,039$ & $-0,123$ & $-0,365$ \\
\hline Na-ex & $-0,167$ & $-0,607$ & 0,321 & 0,097 & $-0,098$ & 0,159 \\
\hline K-ex & 0,749 & 0,194 & 0,063 & $-0,129$ & $-0,150$ & $-0,389$ \\
\hline As & 0,756 & 0,114 & 0,078 & 0,130 & $-0,100$ & 0,200 \\
\hline $\mathrm{Cr}$ & 0,786 & $-0,509$ & 0,009 & 0,105 & $-0,087$ & 0,150 \\
\hline $\mathrm{Pb}$ & 0,845 & $-0,312$ & 0,029 & 0,057 & 0,064 & 0,161 \\
\hline v & 0,654 & 0,065 & 0,236 & $-0,035$ & $-0,301$ & 0,493 \\
\hline $\mathrm{Cu}$ & 0,388 & $-0,467$ & 0,500 & $-0,221$ & 0,326 & $-0,092$ \\
\hline $\mathrm{Zn}$ & 0,750 & $-0,373$ & 0,221 & $-0,149$ & 0,268 & $-0,069$ \\
\hline Cuarzo & $-0,368$ & $-0,823$ & $-0,072$ & 0,221 & $-0,175$ & $-0,080$ \\
\hline Filosilicatos & 0,876 & 0,190 & $-0,113$ & $-0,020$ & $-0,217$ & $-0,003$ \\
\hline Feldespato & $-0,182$ & $-0,755$ & $-0,028$ & 0,187 & $-0,020$ & $-0,185$ \\
\hline Calcita & $-0,085$ & 0,416 & $-0,421$ & $-0,383$ & 0,596 & 0,079 \\
\hline Dolomita & $-0,322$ & 0,603 & 0,580 & $-0,125$ & $-0,103$ & 0,051 \\
\hline Yeso & $-0,005$ & 0,475 & 0,064 & 0,764 & 0,183 & 0,171 \\
\hline Autovalor & 7,89 & 6,28 & 2,16 & 1,91 & 1,47 & 1,14 \\
\hline$\%$ var, explicada & 30,3 & 24,2 & 8,3 & 7,3 & 5,6 & 4,4 \\
\hline$\%$ var, acumulada & 30,3 & 54,5 & 62,8 & 70,1 & 75,7 & 80,1 \\
\hline
\end{tabular}

El componente PC2, que explica el $24,2 \%$ de la varianza total, está positivamente asociado a C.E; carbonatos, magnesio y dolomita, variables que abundan en sedimentos con minerales de $\mathrm{Ca}$ y $\mathrm{Mg}$, y tiene contribución negativa de los parámetros $\mathrm{pH}, \mathrm{Na}$ extraíble, cuarzo y feldespato, variables relacionadas con la abundancia de arenas.

El resto de los componentes, PC3-PC6, explican individualmente menos del $10 \%$ de la varianza y poseen como mucho un par de variables con una contribución importante. Así, el PC3 tiene una contribución positiva de sodio y cobre. El PC4 posee importantes contribuciones positivas de calcio extraíble y yeso. EI PC5 de fósforo extraíble con contribución negativa y calcita con contribuciones positivas. Y el PC6 no posee ninguna variable especialmente reseñable.

Los dos primeros componentes explican conjuntamente más de la mitad de la información de las 26 variables originales (54,5\%). Las cargas de los factores representan las proyecciones de las variables originales en el subespacio de los componentes principales y pueden ser interpretados como coeficientes de correlación entre los componentes principales (PC) y las variables. La representación de las cargas de estos dos primeros componentes (Fig. V.26) nos permitirá visualizar si hay agrupaciones 
importantes entre las variables. Se han señalado mediante elipses las principales agrupaciones de variables observadas. Puede observarse que los agrupamientos coinciden con los obtenidos por análisis clúster.

En la Fig. V.27 y Fig. V.28 se han representado los scores de las muestras en el nuevo sub-espacio definido por PC1 y PC2, para ayudar a reconocer grupos de muestras con similar comportamiento. Se han incluido en el gráfico los valores de las concentraciones de arsénico y la cota en cada muestra para ayudar a interpretar los resultados (en el apartado siguiente). Al igual que en el dendrograma de las muestras, se observan tres agrupaciones.

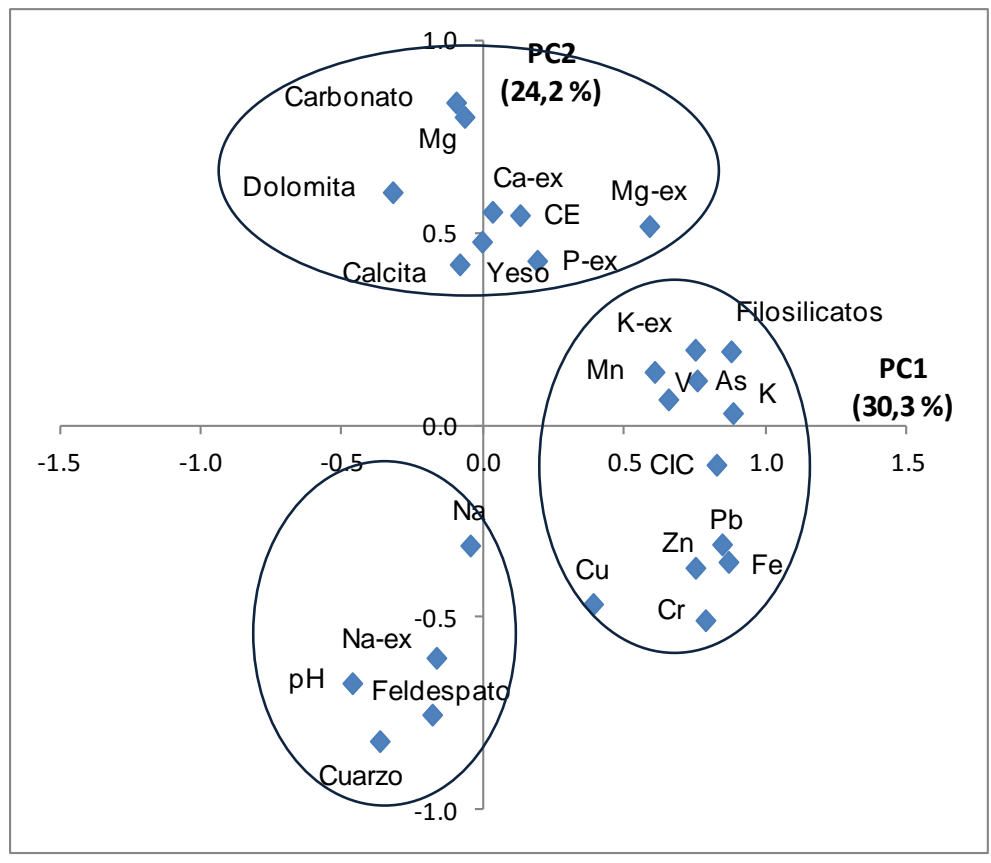

Fig. V.26. Representación gráfica de las cargas de los dos primeros componentes principales. 


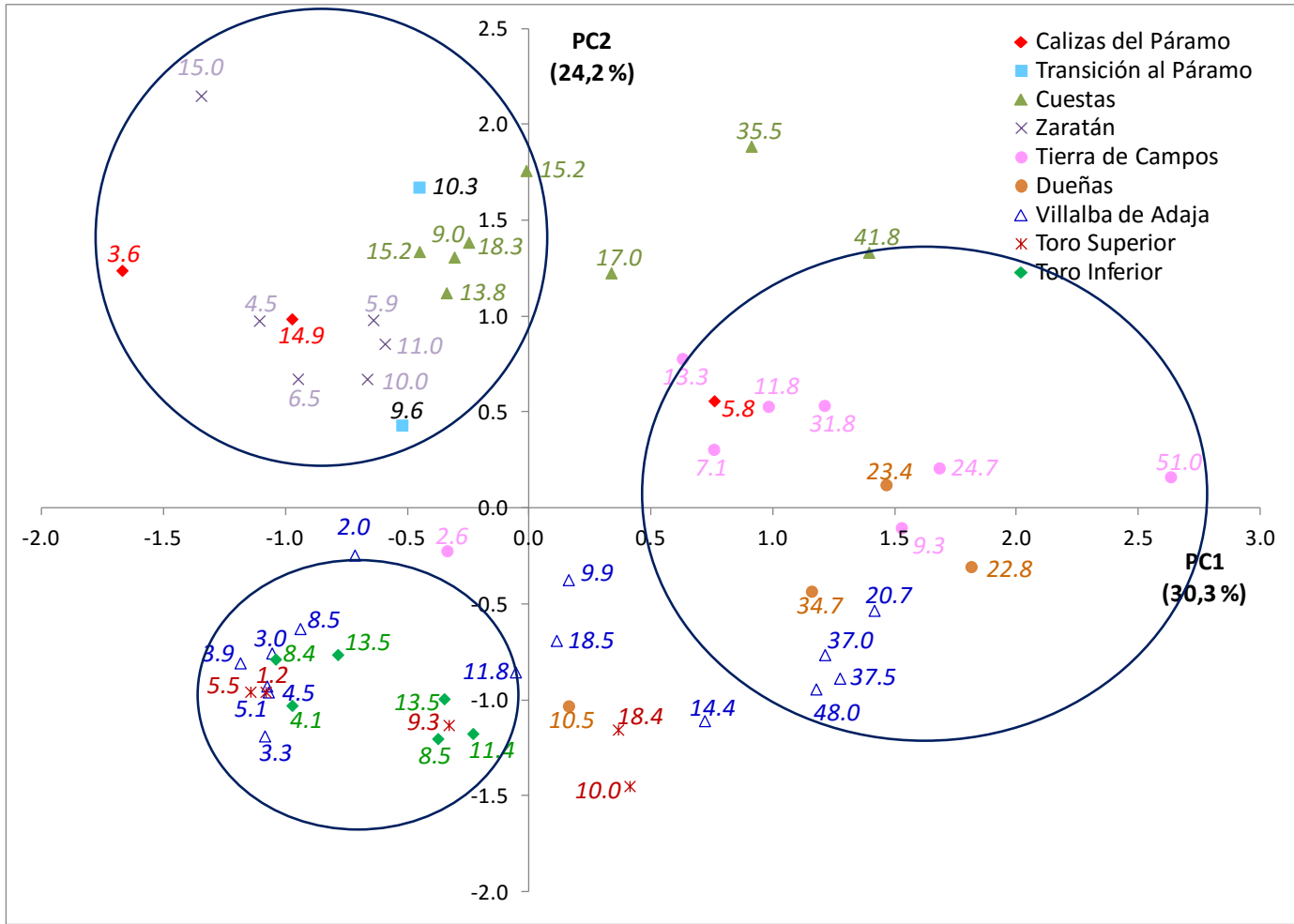

Fig. V.27.Representación de los scores de las muestras indicando la concentración de As (en $\mathrm{mg} / \mathrm{kg})$.

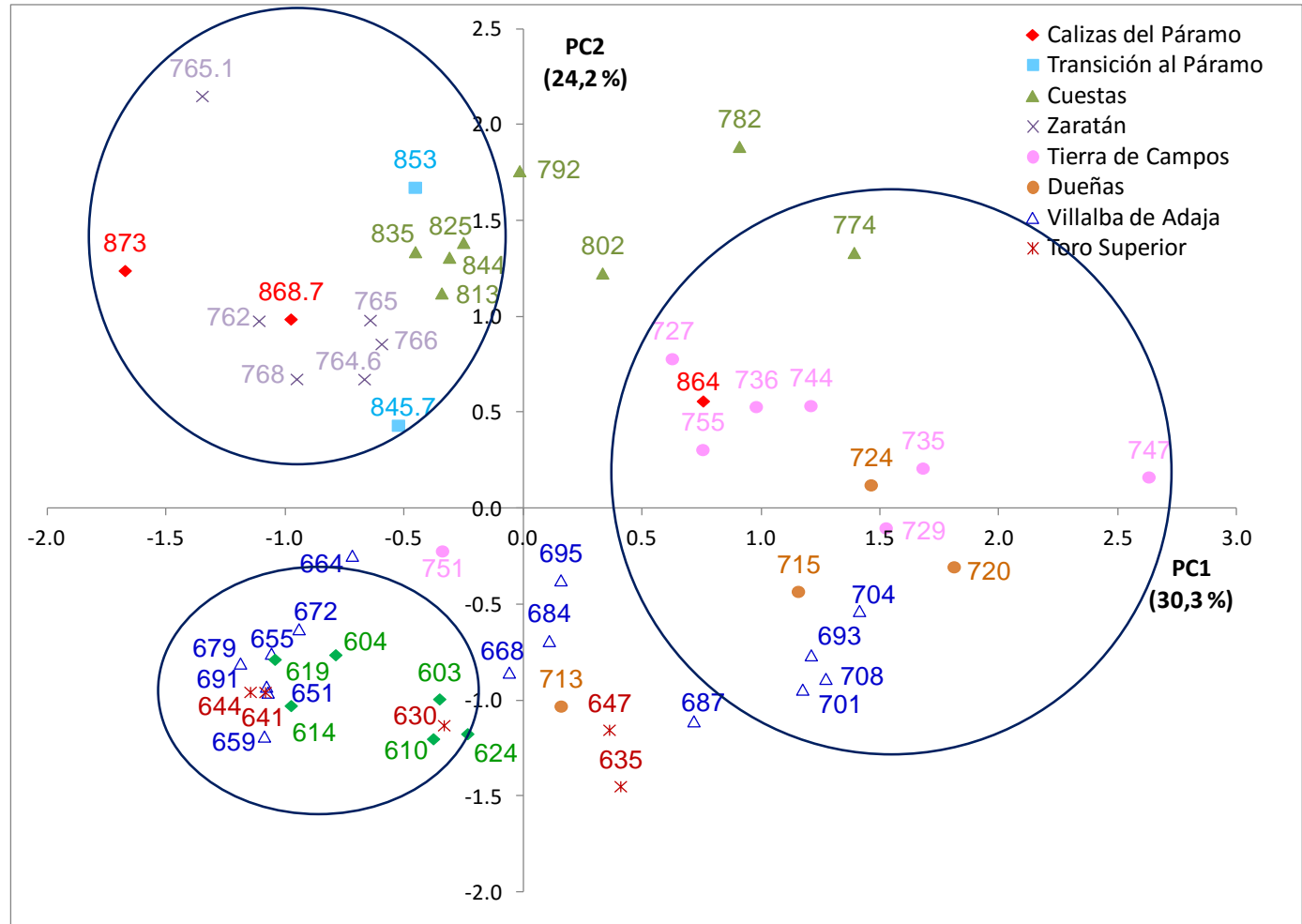

Fig. V.28. Representación de los scores de las muestras indicando la cota (m.a.s.l). 


\section{V.5. DISCUSIÓN DE LOS RESULTADOS}

De los resultados del ACP (Tabla V.10) se desprende que los dos primeros factores explican más de la mitad de la información $(55,1 \%)$.

En la representación de los dos primeros componentes de las cargas de las variables PC1 y PC2 (Fig. V.26), se pueden observar tres agrupaciones de los parámetros considerados Esta misma agrupación se puede ver también en el dendrograma de variables (Fig. V.24).

Una primera agrupación, localizada en el cuadrante positivo de los componentes, con una importante contribución del PC1 y una escasa contribución del PC2, concentra a los filosilicatos, C.I.C, K, Fe, Mn y elementos traza. Como se observa en la matriz de correlación (Fig. V.20), estas variables están fuertemente correlacionadas entre sí $(p<0,05)$, lo que parece indicar un mismo origen para estos elementos. La asociación de estos elementos en el ACP y la fuerte correlación entre ellos parece indicar que el arsénico está asociado a formaciones arcillosas (filosilicatos) con elevada capacidad de cambio catiónico. Como ya se ha comentado en el apartado de resultados y en la introducción, los filosilicatos, debido a su tamaño de partícula, presentan un área superficial muy grande, lo que unido a la estructura cristalina de estos minerales favorece los procesos de adsorción de elementos traza a su estructura.

Varios autores han encontrado una correlación positiva entre las arcillas y el contenido de arsénico en los sedimentos estudiados, debido a la fuerte asociación que existe con las partículas finas de los minerales arcillosos (Dunn and Irvine, 1993; Bhumbla and Keefer, 1994; Ghosh y col., 2006; Mohapatra, 2007; Roh Yul, 2011; Garcia-Lorenzo y col., 2015).

Algunos autores como Gómez y col. (Gómez y col., 2006), cuyo estudio se centra también en la Cuenca del Duero, han identificado trazas de arsénico en filosilicatos detríticos (heredados) de composición moscovítica-illitica en algunas muestras del intervalo del Mioceno medio. En nuestro estudio, no se detectó el arsénico en las muestras analizadas por SEM, debido probablemente a que los límites de detección eran superiores a las concentraciones de arsénico existentes en las muestras.

En la representación gráfica de las puntuaciones de las muestras en el espacio definido por los dos primeros PCs es de esperar que aparezcan en este cuadrante sedimentos con alto contenido en filosilicatos, arsénico y otros elementos traza. Si en la Fig. V.27 nos fijamos en dicho cuadrante, observamos que aparecen sedimentos tanto de las formaciones superficiales como las subterráneas, pertenecientes a las facies Cuestas, Tierra de Campos, Dueñas y en algunas muestras de Villalba de Adaja. En dicha figura se han indicado las concentraciones de arsénico halladas en las muestras, y se comprueba que los sedimentos agrupados en el primer cuadrante poseen, en general, las mayores concentraciones de arsénico.

Observando los gráficos box-plot y los perfiles de distribución vertical de las facies mencionadas, se puede apreciar como los parámetros de este primer grupo poseen unos niveles superiores al resto. 
Los resultados del análisis cluster aglomerativo jerarquizado mostrados en la Fig. V.24 coinciden con los del ACP. Así, el dendrograma de variables muestra estas mismas variables agrupadas estrechamente (CV1). Las muestras con puntuaciones positivas en PC1 y PC2 aparecen también agrupadas en el clúster CM2. En el mosaico de colores se aprecian los colores más cálidos, que representan mayores niveles de concentración, para las variables del grupo CV1 en las muestras CM2. Todos los análisis realizados han llevado a las mismas agrupaciones, en las que parece que los metales, incluido el arsénico, se encuentran asociados a los filosilicatos.

Las muestras tomadas en la facies Villalba de Adaja presentan una gran variabilidad en el componente PC1. Así, existen muestras con valores del PC1 negativos, con valores de PC1 cercanos a cero tanto positivos como negativos y con valores de PC1 positivos, que coinciden con el clúster $\mathrm{CM} 2$ que acabamos de discutir. En los perfiles de distribución verticales se puede ver como al ir aumentando la profundidad en dicho estrato geológico, la tendencia general es que el porcentaje de arenas aumenta mientras el de los filosilicatos disminuye, aunque hay muestras que no siguen este patrón, quizá debido a la propia unidad geológica, que está formada por limos y arcillas arenosas compactas con intercalaciones de arenas. La variabilidad encontrada en este estrato está relacionada con estas intercalaciones de diferentes minerales.

Cabe destacar que los niveles de filosilicatos en las muestras de este primer grupo, pertenecientes a las facies Cuestas, Tierra de Campos, Dueñas y algunas muestras de Villalba de Adaja, tienen una media de $58 \%$. Sin embargo, en el resto unidades geológicas estudiadas presentan niveles inferiores de filosilicatos. Así, las facies Transición al Páramo y Calizas del Páramo por lo general no superan el $35 \%$ de la composición del suelo. La facies Zaratán, a pesar de estar entre dos unidades con elevados niveles de filosilicatos, presenta solamente un contenido medio de filosilicatos del $20 \%$. En las cotas sub-superficiales no se supera, en general, el $40 \%$, lo cual puede reforzar la hipótesis de que el arsénico se encuentra adsorbido en los filosilicatos de los sedimentos.

En una segunda agrupación, con componente PC1 próximo a cero y componente PC2 negativo, se encuentran las unidades mineralógicas calcita, dolomita y yeso junto con sus cationes y aniones que se han analizado y, adicionalmente, la conductividad eléctrica y el fósforo intercambiable.

En la matriz de correlación (Fig. V.20) se puede observar que, además de las correlaciones esperadas entre carbonatos, calcio y magnesio $(p<0,05)$, la conductividad, el yeso y el calcio extraíble también presentan correlaciones significativas $(p<0,05)$. Los carbonatos también presentan una fuerte correlación con la conductividad y el fósforo extraíble $(p<0,05)$.

Los resultados del análisis clúster aglomerativo jerarquizado mostrados en la Fig. V.24 coinciden con los del ACP. El dendrograma de variables muestra estas mismas variables agrupadas estrechamente (CV3). Las muestras con puntuaciones PC1 próximos a cero y PC2 negativos aparecen también agrupadas en el clúster CM3. En el mosaico de colores se aprecian los colores más cálidos, que representan mayores niveles de concentración, para las variables del grupo $\mathrm{CV} 3$ en las muestras CM3. Si nos fijamos en la 
representación de los scores de las muestras, en este cuadrante aparecen las facies Caliza del Páramo, Transición al Páramo, Cuesta y Zaratán, que comprenden las cotas desde los 875,9 hasta los $756 \mathrm{~m}$.

En los perfiles de distribución vertical se puede confirmar como la calcita y la dolomita son prácticamente inexistentes en los sedimentos tomados en facies inferiores, estando su presencia muy marcada en los sedimentos pertenecientes sobre todo a las facies Calizas del Páramo, Transición al Páramo y Zaratán.

Las concentraciones de arsénico halladas en este grupo son moderadas, cercanas al nivel fondo establecido (10 mg/kg), llegando alcanzar los $18 \mathrm{mg} / \mathrm{kg}$. Bajos niveles de arsénico fueron encontrados también en la Cuenca del Duero por Gómez y col., (Gómez y col., 2006) en las facies Cuestas y Páramos.

A pesar de que en los sedimentos analizados en las facies con alto contenido en calcita no se han hallado elevadas cantidades de arsénico, existen varios estudios donde se ha puesto de manifiesto la unión de este contaminante a la calcita (Sadid, 1997; Goldberg y Glaubig, 1988; Magalhàes y col., 2002; Benedetto y col 2006; Winkel y col; 2012; Yokoyama y col., 2012; ILL, 2005). El arsénico puede encontrarse adsorbido sobre la calcita o estar coprecipitado junto a ella (Alexandratos y col., 2007). Estudios de extracción secuencial muestran que la fracción de arsénico no adsorbido específicamente domina frente al arseniato incorporado en la estructura del carbonato, indicando así una alta biodisponibilidad de este contaminante en sedimentos ricos en carbonatos con escasos porcentajes de óxidos de hierro y aluminio (Yolcubal and Akyol, 2008). La adsorción de arseniato sobre la calcita depende del $\mathrm{pH}$, aumentando desde $\mathrm{pH}$ 6 a 10, alcanzando máximos a pH entre 10 y 12, y decreciendo a partir de $\mathrm{pH} 12$ (Goldberg and Glaubig, 1988). Romero y col. (Romero y col., 2004) sugieren que la retención de arsénico en acuíferos ricos en materiales carbonatados podría ser debido a la adsorción sobre la calcita. Por otro lado, la desorción del arsénico de la calcita es rápida y se completa en varias horas, indicando que el arseniato no se incorpora rápidamente a la estructura de la calcita. Además, la adsorción se incrementa al disminuir la alcalinidad, indicando una competición entre los puntos de adsorción entre el arseniato y los carbonatos o bicarbonatos. El pH también afecta a la adsorción, probablemente como respuesta a cambios en la especiación del arseniato o por la protonación/desprotonación del ion arseniato adsorbido. Y por último, la adsorción también está influenciada por la fuerza iónica, posiblemente a los efectos electroestáticos (Sø y col., 2008).

Por lo tanto, la calcita proporcionaría un medio para inmovilizar el arsénico en ambientes naturales con $\mathrm{pH}$ alcalinos, donde los óxidos de hierro y manganeso pierden su eficacia de adsorción frente a este elemento. Sin embargo, en la zona de estudio hay que recordar que el arsénico, según hemos visto, parece estar asociado a los filosilicatos, y si observamos la (Fig. V.15), que muestra la composición mineral porcentual de cada muestra, vemos que los filosilicatos representan el segundo componente mineral más abundante, por lo que en estas facies parecen coexistir varios mecanismos de incorporación de arsénico a los componentes minerales presentes en el sedimento. 
El yeso se encuentra en elevadas concentraciones en algunas muestras de la facies Cuestas (772 m a $844 \mathrm{~m}$ ), la cual está formada por margas verdes y grises claras con intercalaciones de caliza y dolomita y presencia de tramos con yeso. La presencia de este mineral fue observada a simple vista durante la toma de muestra. Es este mineral el que explica los altos niveles de conductividad en este grupo, ya que es un mineral muy soluble. En principio este mineral apenas retiene arsénico (Boyle y Jonasson, 1973).

En cuanto al fósforo intercambiable, en los perfiles de distribución verticales se observan muy bajos niveles en las muestras correspondientes a sedimentos profundos $(<730 \mathrm{~m})$, y sensiblemente superiores en sedimentos superficiales, especialmente en la muestra tomada a $774 \mathrm{~m}$. En estas cotas el calcio es muy abundante y la fijación del fosfato en sedimentos alcalinos con elevados niveles de compuestos cálcicos (calcita, yeso...) se produce debido a la precipitación de fosfato de calcio, por lo que podría interpretarse que se han disuelto fosfatos de calcio. Aunque la solubilidad del fosfato cálcico al pH de la disolución del bicarbonato sódico es baja $\left(9,810^{-5} \mathrm{M}\right)$, la elevada concentración de extractante favorece la disolución de los fosfatos alcalinotérreos, de acuerdo con la reacción:

$\mathrm{Ca}_{3}\left(\mathrm{PO}_{4}\right)_{2}+3 \mathrm{HCO}_{3}^{-}+\mathrm{H}_{2} \mathrm{O} \leftrightarrow 3 \mathrm{CaCO}_{3}+2 \mathrm{HPO}_{4}{ }^{2-}+\mathrm{H}_{3} \mathrm{O}^{+}$

Dado que en los sedimentos profundos no hay presencia significativa de carbonatos, sino que predominan las arcillas y arenas, parece probable que el escaso fósforo extraído en las cotas inferiores se encuentre adsorbido sobre las partículas del sedimento, especialmente arcillas. La presencia en las partículas de arcilla de cationes como $\mathrm{Al}^{3+}, \mathrm{Fe}^{3+} \circ \mathrm{Mn}^{2+}$ provoca la coadsorción del fosfato, de tal manera que el catión metálico actúa de puente entre el silicato y el fosfato. Con el paso del tiempo los iones fosfato pueden combinarse con estos cationes formando fosfatos insolubles, más estables.

Los altos niveles de fósforo encontrados pueden ser debidos también a contaminación antropogénica, ya que las muestras de estos sedimentos se encuentran próximos a campos de cultivo (Fig. V.17), los cuales reciben aportes extra de fosfatos cuando se abonan.

El tercer grupo de parámetros, con PC1 positivo y PC2 negativo, se encuentra formado por cuarzo, feldespato, $\mathrm{pH}$ y sodio.

En la representación de las cargas de los scores de las muestras deberíamos encontrar en este cuadrante los sedimentos con mayores contenidos en arenas. Así, en dicha representación vemos que las muestras de las facies Toro Superior, Toro Inferior y parte de la muestras tomadas en Villalba de Abaja, cuyas cotas corresponden a las capas analizadas más profundas, pertenecen a este grupo.

En los perfiles de distribución vertical se observa que el cuarzo y el feldespato apenas están presentes en los sedimentos tomados en superficie; en Tierra de Campos hay alguna muestra con porcentajes significativos de cuarzo, pero es a partir de la facies Dueñas (cotas por debajo de los $720 \mathrm{~m}$, no aflorantes), donde estos minerales empiezan a tener una contribución importante en la composición del sedimento, lo cual está en concordancia con los resultados mostrados en el ACP. 
Según los resultados obtenidos en el ACP, este grupo de sedimentos presentaría escaso contenido de metales pesados por presentar un valor negativo del PC1. En el mosaico de color (Fig. V.24), se confirma que las muestras agrupadas en el CV2, que se corresponden con el CM1, presentan colores fríos que indican escasos contenidos en los metales traza.

Teniendo en cuenta que los sedimentos con altos contenidos en arena prácticamente no retienen iones debido a que presentan poca actividad ya que su superficie específica es baja y su estructura cristalina formada por silicatos cristalizados apenas poseen grupos funcionales en su superficie donde puedan unirse los metales (Koyama,1975; Shen, 1983; McBride, 1994), era de esperar que las concentraciones de metales, incluidas las de arsénico, en este grupo fueran las más bajas.

Según se observa en la representación de los scores, existen algunas muestras de las facies comentadas para este grupo que presentan valores del componente PC1 menos negativos, y en las cuales se observa que las concentraciones de arsénico son algo superiores. En la Fig. V.15, donde se representan los porcentajes de los distintos minerales que componen el sedimento, se puede observar que para estas facies las muestras con mayores contenidos de arsénico van asociadas, en general, a mayores niveles de filosilicatos. Por otro lado, en otro estudio llevado a cabo en la Cuenca del Duero se hallaron niveles generalmente bajos de arsénico en los sedimentos pertenecientes al Eoceno superior - Oligoceno, compuestos principalmente por conglomerados, arenas y limos, materiales comparables a los que forman las facies de este grupo (Gómez y col., 2006).

Sodio extraíble y $\mathrm{pH}$ exhiben un perfil casi paralelo, con valores que aumentan con la profundidad. Este hecho cobra sentido si tenemos en cuenta que los sedimentos más profundos están en contacto con el acuífero detrítico profundo, que presenta elevados niveles de sodio, bicarbonato y $\mathrm{pH}$. Al ser secado el sedimento, el bicarbonato sódico cristaliza sobre las partículas de sedimento, formando una fase fácilmente solubilizable o extraíble. Y puesto que el sodio y el pH han sido determinados a partir de una fracción extraíble del sedimento, es de esperar que ambos parámetros estén relacionados. El hecho de que no exista una correlación significativa también con el carbonato es debido a que el carbonato determinado era el total, que provendrá tanto de esta fuente como de los materiales de los que está formado el sedimento.

Otro hecho observable en la representación gráfica de los scores de las muestras es que el componente PC2 discrimina entre los sedimentos tomados superficialmente y los tomados en cotas subterráneas. Así, las muestras de sedimentos tomadas en cotas no superficiales (facies Toro Superior, Toro Inferior, Villalba de Adaja y Dueñas) poseen valores negativos del factor PC2, lo que nos indica que los sedimentos de estas unidades geológicas son principalmente arenosas, es decir, formadas por cuarzos y feldespatos. Por el contrario, las muestras superficiales (facies Tierra de Campos, Zaratán, Cuestas, Transición al Páramo y Calizas del Páramo) poseen valores positivos del factor PC2 y por tanto tendrán importantes contribuciones de minerales como calcita, dolomita y yeso. Esto mismo se observa también en los perfiles de distribución vertical y en los resultados del análisis clúster. 
Aunque los niveles fondo de As en sedimentos globales son del orden de $5-6 \mathrm{mg} / \mathrm{kg}$ de media, el valor de referencia sugerido para sedimentos no contaminados es de $10 \mathrm{mg} / \mathrm{kg}$ (Adriano, 1986; Bowen, 1979; Smedley y Kinniburgh, 2002)

En la zona de estudio el As presenta un valor medio de 14,69 mg As/ kg suelo, mientras que el valor de la mediana se corresponde con 10,99 mg As/ kg suelo, la diferencia entre estas dos medidas se debe a la gran variabilidad que presenta el As, la cual es debida principalmente a la diversidad de unidades litoestratigraficas que presentan diferentes composiciones. Así, se encuentra una población de muestras con niveles anormalmente elevados de este contaminante en las facies mencionadas, cuyo valor del componente PC1 es elevado.

En el estudio realizado por Gómez y col., 2006 en la zona central de la depresión del Duero, la cual contiene facies que también han sido estudiadas en este proyecto, se encontró, en términos globales, que la mayor abundancia de arsénico, incluyendo los valores más altos observados en ese estudio ( $337 \mathrm{mg} \mathrm{As} / \mathrm{kg}$ suelo) se hallaron en la facies Zaratán, caracterizada por poseer elevados niveles de materia orgánica (Gómez y col., 2006). Teniendo en cuenta que en nuestra zona de estudio se tomaron muestras en la facies Zaratán, las cuales contienen mayor contenido en M.O (de hecho son las únicas muestras en las que se ha cuantificado materia orgánica) y que las concentraciones de arsénico halladas en estas muestras no eran muy elevadas (promedio de 8,8 mg As/ $\mathrm{kg}$ suelo), se decidió tomar nuevas muestras de dicha facies para comprobar los resultados obtenidos. Así, se tomaron las muestras a cotas 757 y $762 \mathrm{~m}$ y se obtuvieron 4,29 y 4,46 $\mathrm{mg} \mathrm{As/kg} \mathrm{suelo,} \mathrm{respectivamente.} \mathrm{Hay} \mathrm{que} \mathrm{señalar,} \mathrm{no} \mathrm{obstante,} \mathrm{que} \mathrm{la} \mathrm{facies} \mathrm{Zaratán} \mathrm{no}$ representa más que unos pocos metros de profundidad en la zona de estudio.

El escaso porcentaje de la materia orgánica encontrada en las demás unidades geológicas estudiadas $(<0,01 \%)$ probablemente debido al débil desarrollo del suelo que apenas posee vegetación, parece indicar que la materia orgánica no ejerce mucha influencia en la retención y liberación del arsénico. En otros estudios (Cai, 2002) tampoco se ha encontrado una correlación notable con la materia orgánica.

Aunque en la bibliografía se encuentra que otro de los mecanismos de liberación de arsénico es la disolución de óxidos de hierro y manganeso, con la consecuente disolución del arsénico adsorbido en ellos (Jacobs y col., 1970; Ma y col., 2015), en nuestro caso no parece ser un fenómeno predominante ya que no se encontraron evidencias significativas de óxidos de hierro en los estudios realizados por XRD, y tampoco las cantidades extraídas de esos dos metales parecen indicar la presencia de altos contenidos de sus correspondientes óxidos.

En el estudio ya citado realizado en la Cuenca del Duero (Gómez y col., 2004) se identificó que el arsénico, además de estar unido a óxidos e hidróxidos de hierro y a otros minerales, también se encontraba unido a la illita, que es el filosilicatos más abundante en nuestra zona de estudio. Todo ello nos lleva a pensar que el arsénico podría encontrarse en estos sedimentos preferencialmente ligado a filosilicatos mediante enlaces de adsorción mediados por cationes de las arcillas. 

CAPÍTULO VI. DISTRIBUCIÓN DE As EN SEDIMENTOS

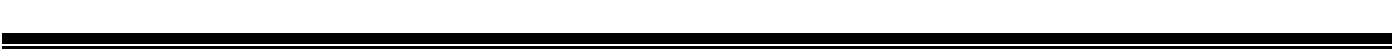





\section{VI.1. INTRODUCCION}

Aunque los niveles fondo de arsénico en sedimentos son, por término medio, del orden de 5-6 mg/kg, el valor de referencia sugerido para suelos no contaminados es de 10 mg/kg (Adriano y col, 1986; Bowen y col, 1979; Smedley y Kinniburgh, 2002; Taggart y col, 2004). Este valor es ampliamente superado en sedimentos y rocas localizadas en áreas mineralizadas con abundancia de materiales ricos en pirita $u$ otros sulfuros y en áreas sometidas a acción antrópica contaminante (vertidos industriales, combustión de carburantes, fertilizantes, pesticidas, escombreras, balsas mineras...) (Manning y col., 1998).

El riesgo potencial de suelos y sedimentos contaminados reside principalmente en los factores y mecanismos que afectan a la movilidad y disponibilidad del arsénico en los materiales sólidos. Como se discutió en el capítulo V (Estudio Geoquímico), los principales mecanismos implicados en la retención del arsénico en los sedimentos están relacionados con la adsorción sobre óxidos de hierro y manganeso y arcillas y la fijación por adsorción/complejación con la materia orgánica, mientras que los factores más importantes que afectan a la liberación de este metaloide son el pH, el potencial redox, la concentración de fósforo y otros aniones que ejercen un efecto competitivo, la fuerza iónica y otros factores como la concentración total de arsénico, el régimen de precipitaciones o el tiempo de interacción del arsénico con las partículas de sedimento.

Una gran parte de los estudios realizados sobre sedimentos se refieren a la concentración total de metales, en especial cuando el estudio se encamina a concretar niveles de referencia de los metales o contenidos fondo según diferentes litologías. El uso de la concentración total como criterio de evaluación para la determinación de los efectos potenciales de la contaminación por elementos tóxicos en sedimentos, significaría que todas las formas químicas en las que puede encontrarse el elemento causan o producen el mismo impacto sobre el medio ambiente (Thomas y col., 1994). No obstante, en los últimos años, la valoración del riesgo de contaminación (distribución, movilidad y disponibilidad biológica de los elementos químicos) se realiza teniendo en cuenta las asociaciones químicas y físicas que los metales presentan con los diferentes componentes en los sistemas naturales (Raksasataya y col., 1996; Breward y col., 1996; Keon y col., 2001; Fendorf y col., 2004, Martínez-Fernández y col., 2011; Kandakji, 2015). Este enfoque ha llevado al desarrollo de numerosas metodologías de extracción parcial (extracción simple) y secuencial de los elementos unidos a suelos, sedimentos y rocas (Rao y col., 2008).

Las cantidades de metales presentes en formas disponibles pueden determinarse mediante la utilización de extracciones simples, generando información sobre la solubilidad del elemento en un medio extractante concreto, o con procedimientos de fraccionamiento químico, con los cuales determinamos la distribución del contenido metálico en varias fracciones del material de diferente disponibilidad o solubilidad.

Los procedimientos de extracción simple consisten en la extracción de una muestra de sedimento con un único agente extractante. Se pueden clasificar agrupándolos en cuatro grandes grupos atendiendo a la naturaleza del extractante empleado: extracción 
con ácidos, con agentes complejantes, con disoluciones tampón o con disoluciones salinas no tamponadas (Rauret, 1998). La Tabla VI.1 recoge algunos de los procedimientos de extracción simple más utilizados para el caso del arsénico. Puede observarse que existe un amplio espectro de reactivos extractantes, de forma que encontramos desde ácidos muy fuertes como agua regia, ácido nítrico o ácido clorhídrico hasta disoluciones neutras de sales no tamponadas como es el caso del cloruro cálcico o nitrato sódico.

Tabla VI.1. Procedimientos de extracción simple más utilizados. Adaptado de Rauret, 1998

\begin{tabular}{|c|c|c|}
\hline GRUPO & REACTIVO EXTRACTANTE & REFERENCIA \\
\hline Extracción ácida & $\begin{array}{l}\mathrm{HNO}_{3} 0,43-2 \mathrm{M} \\
\text { Agua regia } \\
\mathrm{HCl} 0,1-1 \mathrm{M} \\
\mathrm{CH}_{3} \mathrm{COOH} 0,1 \mathrm{M} \\
\mathrm{HCl} 0,05 \mathrm{M}+\mathrm{H}_{2} \mathrm{SO}_{4} 0,0125 \mathrm{M}\end{array}$ & $\begin{array}{l}\text { Novozamski y col., } 1993 \\
\text { Colinet y col., } 1983 \\
\text { Novozamsji y col., } 1993 \\
\text { Ure y col., } 1993 \\
\text { Mulchi y col., } 1992 \\
\end{array}$ \\
\hline Agente complejante & $\begin{array}{l}\text { EDTA } 0,01-0,05 \mathrm{M} \text { a diferentes } \mathrm{pH} \\
\text { DTPA } 0,005 \mathrm{M}+\text { TEA } 0,1 \mathrm{M}\end{array}$ & $\begin{array}{l}\text { Novozamski y col., } 1993 \\
\text { Lindsay y Norwell } 1978\end{array}$ \\
\hline Disoluciones tampón & $\begin{array}{l}\mathrm{NH}_{4} \mathrm{AcO} / \mathrm{HAcO} 1 \mathrm{M} \text { tamponado a } \mathrm{pH}=7 \\
\mathrm{NH}_{4} \mathrm{AcO} / \mathrm{HAcO} 1 \mathrm{M} \text { tamponado a } \mathrm{pH}=4,8\end{array}$ & $\begin{array}{l}\text { Ure y col., } 1993 \\
\text { Novozamski y col., } 1993\end{array}$ \\
\hline $\begin{array}{l}\text { Disoluciones salinas no } \\
\text { tamponadas }\end{array}$ & $\begin{array}{l}\mathrm{CaCl}_{2} \text { (a diferentes concentraciones) } \\
\mathrm{NaNO}_{3} 0,1 \mathrm{M} \\
\mathrm{NH}_{4} \mathrm{NO}_{3} 1 \mathrm{M} \\
\mathrm{AlCl}_{3} 0,3 \mathrm{M} \\
\mathrm{BaCl}_{2} 0,1 \mathrm{M}\end{array}$ & $\begin{array}{l}\text { Novozamski y col., } 1993 \\
\text { Gupta y col., } 1993 \\
\text { Novozamski y col., } 1993 \\
\text { Hughes y Noble } 1991 \\
\text { Juste y Solda } 1988\end{array}$ \\
\hline
\end{tabular}

La porción de arsénico lixiviada depende de la fuerza o agresividad del extractante, pudiéndose considerar el grupo de disoluciones salinas el menos agresivo ya que el único efecto competitivo es el de la fuerza iónica, y el grupo más agresivo es el de los disolventes ácidos, que atacan un mayor número de fracciones minerales del sedimento liberando por tanto mayor cantidad del elemento. Para una extracción del arsénico total contenido en el sedimento sería necesario un tratamiento con una mezcla de ácido oxidante y ácido fluorhídrico para disolver los silicatos que pueden contener cantidades significativas de arsénico. Por tanto, el reactivo elegido debe ser cuidadosamente seleccionado atendiendo al grado de movilidad del arsénico que se desea simular.

Actualmente se acepta el hecho de que los extractantes no son selectivos y que cualquier variación en el procedimiento analítico tiene efectos significativos sobre los resultados obtenidos (Rauret, 1998). En base a estas consideraciones, algunos países han estudiado la posibilidad de adoptar determinados procedimientos como oficiales. Así, en Alemania se utiliza el $\mathrm{NH}_{4} \mathrm{NO}_{3}$ para la determinación de elementos traza móviles (DIN Deutches Institut für Normung, 1993).

Las extracciones químicas secuenciales constituyen una metodología operativa consistente en la exposición de una muestra sólida a una serie de soluciones reactivas de características fisicoquímicas distintas, con creciente grado de reactividad. 
La finalidad que se persigue al aplicar una metodología de extracción química secuencial es determinar, con la mayor precisión posible, la distribución de los elementos traza existentes en una muestra sólida entre fracciones de distinta naturaleza fisicoquímica. A esta distribución se le ha denominado "fraccionamiento", y se ha comprobado que el reparto elemental determinado mediante la aplicación de una metodología de este tipo tiene una relación directa con el comportamiento geoquímico y la biodisponibilidad y movilidad de los elementos químicos en condiciones naturales (Nirel y Morel, 1990).

La principal ventaja de los procedimientos de extracción secuencial respecto al uso de extractantes simples es que se consigue mayor cantidad de información sobre el origen, forma de aparición, disponibilidad biológica, fisicoquímica, movilización y transporte de los elementos (Ure y Davidson, 1995). No obstante, la información resultante de la aplicación de un método de extracción secuencial depende de factores como las propiedades químicas de los extractantes, los parámetros experimentales (concentración de los reactivos, temperatura, velocidad de agitación, tiempo de contacto...), la secuencia de etapas individuales, el tipo de suelo o matriz que influye en los fenómenos de readsorción y la heterogeneidad de las muestras.

Uno de los primeros métodos de extracción secuencial fue el desarrollado por Tessier y col., (Tessier y col., 1979). Desde entonces se han desarrollado múltiples esquemas de extracción secuencial para elementos traza (Gleyzes y col, 2002; Filgueiras y col, 2002; Zimmerman, 2010).

El gran número de métodos de extracción secuencial desarrollados impedían comparar los resultados de las extracciones secuenciales realizadas por los distintos investigadores, debido a la amplia variedad de reactivos utilizados y a las diferentes fases que se quieren evaluar (Quevauviller, 1998). Por ello, con el fin de establecer un método sencillo y estandarizado, el grupo de expertos del BCR, European Community Bureau of Reference, desarrolló un protocolo de extracción secuencial para cationes metálicos que pretende garantizar que los resultados puedan ser comparados (Ure y col, 1993; Quevauviller y col., 1997; Sahuquillo y col, 1999; Mossop y col, 2003; Pardo y col, 2004; Pardo y col, 2013).

Los procedimientos de extracción secuencial presentan ciertos inconvenientes como poca reproducibilidad, readsorción de metales, escasa selectividad, manipulación lenta y laboriosa de la muestra o concentraciones de elementos extraídos muy bajas que exigen técnicas de detección muy sensibles. A pesar de ello muchos científicos han dedicado tiempo y esfuerzo a idear procedimientos de extracción de arsénico en muestras de sedimentos para poder definir la fracción mineral que es atacada en cada una de las fases del protocolo aplicado, a qué fases está asociado el elemento, su solubilidad y disponibilidad, para así poder comprender los factores que controlan la movilidad del arsénico.

Se han documentado problemas para la reproducibilidad de las mediciones a causa de la heterogeneidad de las muestras naturales empleadas (Tessier y col., 1979). En otras ocasiones, la precisión se ve afectada por la proximidad al límite de detección de los métodos analíticos empleados para las determinaciones químicas en las soluciones reactivas (Hall y col., 1996). Como norma general, la precisión de los resultados 
obtenidos mediante un procedimiento secuencial está inversamente relacionada con el número de etapas extractivas de que consta el protocolo, debido principalmente a la manipulación del material entre una etapa y la siguiente.

El problema de la readsorción tiene lugar cuando elementos traza liberados en una etapa de un esquema de extracción secuencial se asocian a otra fracción del material sólido, previamente a la recuperación de la solución reactiva. Este proceso puede enmascarar la asociación real de los elementos traza con las fracciones sólidas de los materiales analizados, complicando de este modo la correcta interpretación de los resultados obtenidos (Kheboian y Bauer, 1987; Tipping y col., 1985; Kheboian y Bauer, 1987; Dhoum y Evans, 1988; Belzile y col., 1989; Raksasataya y col., 1996; Abollino y col., 2001; Gleyzes y col., 2002; Rao y col., 2008).

El problema de la selectividad de los reactivos continúa siendo una cuestión de gran importancia, todavía sin resolver (Yong y col., 1993), y hay autores que afirman que aún no se ha catalogado ningún reactivo totalmente específico (McCarty y col., 1998). Se ha comprobado que los reactivos más comúnmente empleados en estas metodologías no son totalmente selectivos, es decir, no son capaces de solubilizar una única fracción de los sólidos (Jones y col, 1984). Este hecho queda gráficamente reflejado en el trabajo de Ure y col., 1995, donde se puede observar que el ámbito de influencia de los reactivos se extiende más allá de los límites de una única fase, a excepción únicamente de los utilizados para extraer la fracción intercambiable (Abollino y col., 2001; Gleyzes y col., 2002; Rao y col., 2008).

Los procedimientos empleados en la conservación y preparación de la muestra son también críticos, especialmente para las muestras que se toman en ambientes reductores, ya que las fases lábiles pueden ser transformadas en otras fases durante la preparación de la muestra.

Todos estos problemas, junto con la imprecisión debida a que se analizan metales a nivel de trazas y los errores acumulados al tener varias etapas sucesivas, redundan en una disminución de la precisión de las medidas. Muchas investigaciones han estado encaminadas a minimizar los inconvenientes expuestos.

Los esquemas de extracción secuencial se han aplicado ampliamente a elementos y materiales diversos, sobre todo en campos de investigación relacionados con procesos de contaminación ambiental ya que las distintas fracciones del procedimiento pueden proporcionar información muy útil para la estimación de riesgos medioambientales.

Aunque el uso del procedimiento BCR de extracción secuencial se ha generalizado para el fraccionamiento de cationes metálicos, para el arsénico, presente en la naturaleza mayoritariamente como oxoanión, no existe un procedimiento tan ampliamente consensuado, lo cual dificulta en gran medida la comparación e interpretación de resultados. Así, en la actualidad existe una amplia variedad de protocolos de extracción secuencial de arsénico que difieren en el número de etapas involucradas, en los reactivos empleados o en las condiciones experimentales bajo las cuales se desarrollan.

La naturaleza del extractante y los diferentes procedimientos empleados han sido objeto de revisión por diferentes autores entre los que destacan Pickering (1986); Lebourg y Col (1998); Rauret (1998); Sauquillo y col (2003); Zimmerman (2010). 
En la Tabla A.IV.1 del Anexo se muestra un resumen de diferentes esquemas de extracción secuencial propuestos para extraer arsénico de sedimentos y rocas, mostrando en columnas los reactivos usados para movilizar este elemento asociado a diferentes fracciones minerales. Los distintos esquemas se diferencian sobre todo en el número de pasos que se llevan a cabo, los extractantes usados y el tiempo de agitación. Prácticamente todos los esquemas poseen tres fases, una en la cual se extrae el arsénico débilmente adsorbido, otra en la que se extrae el arsénico unido a óxidos/hidróxidos de aluminio, hierro y/o manganeso y una última fase residual, difícilmente solubilizable. Los reactivos químicos usados en las extracciones secuenciales se van introduciendo de forma que en cada paso se aumente su fuerza y variando el pH. Su elección varía según la preferencia de los autores, pero siempre intentando minimizar los fenómenos de readsorción o precipitación.

El arsénico enlazado iónicamente o intercambiable se extrae usando $\mathrm{MgCl}_{2}$ (Tessier y col., 1979), $\left(\mathrm{NH}_{4}\right)_{2} \mathrm{SO}_{4}$ (Wenzel ycol., 2002), $\mathrm{NaNO}_{3}$ o con membranas intercambiables de aniones. Todos estos extractantes se utilizan atendiendo a los fenómenos de intercambio iónico, donde el arsénico débilmente enlazado se intercambia con uno de los componentes de los extractantes utilizados o en las membranas.

Keon y col., 2001, Wenzel y col., 2002 y Cai y col., 2002 han extraído una fracción de arsénico específicamente adsorbido utilizando $\mathrm{NaH}_{2} \mathrm{PO}_{4}, \mathrm{NH}_{4} \mathrm{H}_{2} \mathrm{PO}_{4}$ y $\mathrm{KH}_{2} \mathrm{PO}_{4}$, respectivamente. El fundamento de esta fracción es el intercambio competitivo entre los aniones fosfato y arseniato. Debido a que el fosfato posee un menor tamaño y una mayor densidad de carga, el arseniato se desorbe más fácilmente que el fosfato.

Los arseniatos de calcio son estables en ambientes altamente oxidantes y alcalinos, y son además más solubles que los arseniatos de hierro o aluminio. Por eso, Van Herreweghe y col., 2003 sugieren que los arseniatos de calcio se disuelven en los primeros pasos de las extracciones con extractantes débiles.

Para extraer el arsénico asociado con los hidróxidos de hierro amorfos y/o cristalinos se usan reactivos como NaOH (Cappuyns y col., 2002; Van Herreweghe y col., 2003), oxalato/ácido oxálico (Keon y col., 2001), Ti(III)-citrato-EDTA-bicarbonato (Keon y col., 2001), $\mathrm{NH}_{4}{ }^{+}$-oxalato-ácido ascórbico (Wenzel y col., 2002) y citrato- $\mathrm{NaHCO}_{3}-\mathrm{HNO}_{3}$ (Cappuyns y col., 2002; van Herreweghe y col., 2003). Algunos de estos reactivos (oxalato, ácido ascórbico, Ti(III)) provocan una disolución reductiva de los minerales que retienen arsénico. La mayoría de estos reactivos son eficaces a la hora de extraer el arsénico asociado a los hidróxidos de hierro, pero hay que tener en cuenta que reactivos más débiles tales como $\mathrm{NaH}_{2} \mathrm{PO}_{4}$ y $\mathrm{NH}_{4} \mathrm{H}_{2} \mathrm{PO}_{4}$, que se usan para movilizar el arsénico adsorbido específicamente, pueden también extraer arsénico adsorbido a algunos minerales de hierro como la ferrihidrita y la goetita (Zeien, 1989).

Los reactivos oxidantes como $\mathrm{H}_{2} \mathrm{O}_{2}, \mathrm{HNO}_{3}$ y agua regia se emplean para extraer el arsénico relativamente insoluble (fase residual) de minerales como sulfuros y óxidos, mientras que para disolver silicatos se debe añadir, además, HF. Estos extractantes son similares a los utilizados en la extracción total de arsénico en suelos.

Los esquemas de Tessier y el esquema BCR son los más usados y los que más se han aplicado a una amplia variedad de muestras medioambientales contaminadas. A pesar 
de que ambos métodos se desarrollaron para estudiar el comportamiento de especies en forma catiónica, también han sido aplicados para el estudio de especies aniónicas, como es el caso del arsénico (Szakovav y col., 1999; Fernández y col., 2004; Vaisanen y col., 2005; Larios y col., 2008; Li y col, 2009; Baig y col.,2009; Otones y col.,2011; Ashraf y col., 2012; Alvarez y col., 2012). Otros muchos esquemas de especiación basados en esquemas para extraer metales y otros elementos que están en forma de cationes se han utilizado para realizar el fraccionamiento químico del arsénico (Ure y col., 1993; Quevauviller y col., 1994; Voigt y col., 1996). No obstante, algunos autores han reconocido el carácter aniónico del arsénico en suelos y sedimentos y han basado sus esquemas de especiación en procedimientos usados para el fósforo (Johnson y col., 1969; Gruebel y col., 1988; Cappuyns y col., 2002; Jacobs y col., 1970; Woolson y col., 1973; Gruebel y col., 1988, Manful y col., 1992; Hudson-Edwards y col., 2004). Otros autores, aún reconociendo el carácter aniónico del arsénico, han basado sus esquemas de especiación en el método de Tessier, modificando algunos pasos para tener en cuenta las peculiaridades del arsénico (Matera y col., 2003; Anawar y col., 2008). Algunos autores han desarrollado esquemas específicos para el arsénico, (Wenzel y col., 2001; Van Herreweghe y col., 2003). Estos esquemas se han basado en algunas particularidades de este elemento, como el hecho de ser más estable en un rango más pequeño de potencial y pH que el fósforo, que es más propenso a formar enlaces con el azufre y el carbono que el fósforo, y que el arsénico orgánico es menos común en suelos que el fósforo orgánico (Van Herreweghe y col., 2003; Johnson y col., 1969; O’Neill y col., 1995).

El esquema de fraccionamiento empleado en este trabajo consta de cinco extracciones secuenciales que se describen a continuación (Wenzel y col., 2001):

En la primera fracción, extraída con $\left(\mathrm{NH}_{4}\right)_{2} \mathrm{SO}_{4}$, se extrae el arsénico adsorbido a través de interacciones electroestáticas débiles con la superficie de las partículas de sedimento y aquel que puede ser extraído con procesos de intercambio iónico. Esta fracción es teóricamente la más móvil, y puede ser usada para predecir la concentración de arsénico en la solución del suelo (Wenzel y col, 2001). Tal información es útil en la valoración del riesgo medioambiental que supone el lixiviado de arsénico a aguas subterráneas y el arsénico extraído por los reactivos correspondientes a la fracción fácilmente biodisponible.

La segunda fracción, obtenida tras el tratamiento con $\mathrm{NH}_{4} \mathrm{H}_{2} \mathrm{PO}_{4}$, se corresponde con la fracción específicamente adsorbida. Se fundamenta en el intercambio competitivo entre fosfato y arseniato en la superficie del sedimento donde, a causa de su menor tamaño y mayor densidad de carga, el fosfato es adsorbido preferentemente, provocando la desorción de arseniato (Maning y Golberg, 1996). Representa una estimación del arsénico adsorbido en puntos de la superficie por los cuales presenta una alta afinidad y a los cuales se puede enlazar a través de enlaces covalentes (Stumm y col., 1995).

En la tercera fracción se extrae el arsénico unido a óxidos amorfos de Fe y Al o con bajo grado de cristalinidad. La adsorción de arseniato sobre oxihidróxidos de hierro es particularmente fuerte y las cantidades adsorbidas pueden ser apreciables incluso a bajas concentraciones de arsénico en la solución (Goldberg y col., 1986; Manning y Goldberg, 1996; Hiemstra y van Riemsdijk, 1996). La adsorción de arsénico en 
oxihidróxidos de $\mathrm{Al}$ y $\mathrm{Mn}$ también puede ser importante si estos óxidos están presentes en concentraciones altas (Peterson y Carpenter, 1983; Brannon y Patrick, 1987). Las reacciones de adsorción y desorción del arseniato sobre óxidos de hierro son particularmente importantes ya que esa fase mineral aparece frecuentemente recubriendo otras fases sólidas y porque el arseniato se adsorbe fuertemente sobre las superficies de los óxidos de hierro en condiciones ácidas o con pH próximos a los valores neutros. Sin embargo, la desorción de arseniato de dichas superficies se producirá si la disolución en contacto posee un pH alcalino.

En la fracción 4 la mezcla reductora oxalato/ácido ascórbico extrae el arsénico retenido por óxidos de Fe y Mn cristalinos, tras la disolución reductiva de los óxidos. Para que el arsénico unido a esta fracción pueda liberarse en el medio natural, los cambios medioambientales producidos han de ser muy drásticos (acidificación severa, condiciones fuertemente reductoras).

Finalmente, en la última fracción se extrae el arsénico residual, fuertemente ligado a minerales del suelo, como sulfuros u óxidos, que necesitan unas condiciones muy enérgicas para ser disueltos por lo que esta fracción es la menos disponible medioambientalmente (Manning y Goldberg, 1997).

En el método del Wenzel la readsorción de arsénico en fases minerales durante la extracción está minimizada en los dos primeros pasos ya que ni el $\left(\mathrm{NH}_{4}\right)_{2} \mathrm{SO}_{4}$ ni el $\mathrm{NH}_{4} \mathrm{H}_{2} \mathrm{PO}_{4}$ causan una disolución significativa de las fases minerales. Aunque este problema requiere mayor atención en el tercer y cuarto pasos, que involucran óxidos de hierro amorfos y cristalinos. Wenzel utiliza un exceso de concentración de oxalato durante la extracción para así minimizar los problemas de readsorción (Wenzel y col, 2001).

Se ha comprobado que los métodos utilizados para extraer el arsénico ligado a los óxidos de Fe y Mn influyen en los resultados obtenidos. Así, la mezcla reductora de oxalato y ácido ascórbico extrae arsénico enlazado a óxidos cristalinos de $\mathrm{Fe}$, mientras que la hidroxilamina, empleada en el esquema secuencial BCR, libera principalmente elementos asociados a óxidos de $\mathrm{Mn}$. Además, el arsénico es readsorbido en goetita si se utiliza hidroxilamina $\mathrm{NH}_{2} \mathrm{OH} \mathrm{HCl} 0,25 \mathrm{M}$ como agente extractante, mientras que un exceso de oxalato durante la extracción minimiza la readsorción (Wenzel y col, 2001).

Son muchos los autores que han empleado el procedimiento de extracción secuencial diseñado por Wenzel y col., 2001 (Taggart y col., 2004; Krysiak y col., 2007; Smith y col., 2008; Doušová y col., 2008; Moreno Jiménez y col., 2010). No obstante, otros autores han realizado comparaciones de métodos en sus trabajos, para poder establecer cuál de ellos es el que mejor representa las asociaciones del arsénico con las fracciones del suelo. Así, algunos autores han desarrollado trabajos para comparar los métodos convencionales (métodos de extracción para especies catiónicas), frente a métodos específicos para aniones (Tlustos y col., 2005; Muller y col., 2007; Giacomino y col., 2010; Van Herreweghe y col., 2003).

Tlustos y col., 2005 realizaron la extracción secuencial con tres métodos no específicos para la extracción de arsénico y dos métodos específicos. Los métodos no específicos utilizados fueron los descritos por Queuaviller y col., 1998, Li y col., 1995 y Zeien y col., 
1995. De los resultados obtenidos concluyeron que las fracciones de arsénico presentadas como suma de fracciones móviles dentro de estos tres métodos presentan diferencias significativas. De la extracción secuencial con dos métodos específicos para el arsénico, el método de Wenzel., 2001 y el método de Azcue y col., 1994, concluyeron que las fracciones de arsénico presentadas como suma de las fracciones móviles no difieren significativamente y están fuertemente correlacionadas entre sí $(r=0,92)$, mientras que las correlaciones con los tres métodos no específicos ensayados son prácticamente inexistentes.

Igualmente difícil es comparar las fracciones asociadas a los óxidos de los distintos métodos, encontrándose valores desde 1,9\% cuando se usó el método de Li y col., 1995, que usa hidroxilamina como agente reductor para disolver óxidos de $\mathrm{Fe}$ y $\mathrm{Mn}$, hasta 25,6\% cuando la extracción se realizó con el método de Wenzel., 2001 que emplea oxalato/ácido ascórbico.

Muller y col., 2007, compararon los métodos de Wenzel., 2001 y BCR en muestras afectadas por actividades de minería y fundición, y encontraron que el esquema diseñado por Wenzel resultó ser más conveniente que el BCR.

En el trabajo de Giacomino y col., 2010 se compara el método de Tessier., 1979, desarrollado para especies catiónicas con el método de Cai y col., 2002, desarrollado para especies aniónicas, para evaluar el fraccionamiento de arsénico. Los resultados del esquema de Tessier mostraron unos porcentajes extraídos de arsénico demasiado bajos, teniendo en cuenta que el arsénico era uno de los principales contaminantes en los suelos estudiados. Esto demuestra la importancia del carácter aniónico del arsénico y la importancia de elegir un método adaptado a la forma en que se encuentra en la naturaleza.

Los trabajos realizados por Van Herreweghe y col., 2003 sobre extracciones secuenciales desvelan que los esquemas de extracción basados en los protocolos de extracción secuencial para el fósforo proporcionan un mejor fraccionamiento y una mejor recuperación del arsénico que el esquema de tres pasos seguido en el BCR.

Larios y col., 2012 evaluaron tres procedimientos de extracción secuencial para el fraccionamiento de arsénico en sedimentos mineros muy contaminados: el procedimiento $B C R$, diseñado para el estudio de metales en forma catiónica, el procedimiento desarrollado por Manful y col., 1992, diseñado para fósforo y adaptado para arsénico y un esquema de extracción secuencial especialmente diseñado por el CIEMAT para el arsénico (Larios y col., 2012). Los resultados mostraron que el esquema BCR es inapropiado para estudiar el fraccionamiento de este oxoanión, mientras que el esquema de Manful presenta inconvenientes causados por la falta de selectividad de algunos de los reactivos utilizados como, por ejemplo, sobreestimación de arseniato adsorbido a causa de los procesos de coprecipitación, y la incapacidad para discriminar entre los oxihidróxidos amorfos y cristalinos, que son los principales responsables de la retención de arsénico. Con el procedimiento diseñado específicamente para arsénico se consiguió el fraccionamiento más adecuado, ya que las principales fases de arsénico retenidas se establecen de acuerdo con el potencial de movilización. 
Si comparamos los esquemas de fraccionamiento propuestos por el BCR y por Wenzel se pueden anotar algunas diferencias evidentes: el esquema de Wenzel utiliza más etapas de extracción, por lo que es capaz de discriminar más formas o fracciones de arsénico en el sedimento, siendo capaz de diferenciar entre arsénico no adsorbido específicamente del arsénico o débilmente adsorbido; el esquema BCR no hace tal distinción ya que en la primera fracción extrae todo el arsénico intercambiable y ligado a carbonatos. El procedimiento de Wenzel también diferencia entre el arsénico ligado a oxihidróxidos amorfos y cristalinos de metales como hierro, manganeso o aluminio, mientras que en el esquema BCR la segunda fracción extrae con hidroxilamina la fracción reducible, en la cual se entiende estarían incluidos ambos tipos de óxidos. Además, la extracción de arsénico en materiales con alto contenido en hierro parece ser incompleta cuando se utiliza como agente reductor hidroxilamina (Coetzee y col., 1993; Gleyzes y col., 2001; Larios y col., 2012), y serían necesarias condiciones más agresivas que las que plantea el esquema BCR. En el procedimiento de Wenzel se emplea oxalato amónico para extraer primeramente los óxidos amorfos y después se usa un reactivo más agresivo, oxalato amónico y ácido ascórbico a 96 ㄷ, para extraer los óxidos cristalinos. Por lo tanto, el esquema del BCR parece que subestima la asociación del arsénico con los oxihidróxidos de hierro y otros elementos.

Como se ha demostrado en los trabajos comentados, los resultados derivados de un estudio sobre la distribución de arsénico en rocas y minerales dependen del sistema de extracción secuencial que se utilice. Por dicha razón hay que elegir cuidadosamente el sistema de extracción más adecuado atendiendo al elemento que se vaya a analizar. En nuestro caso se eligió el esquema de fraccionamiento químico de Wenzel (Wenzel y col., 2001), diseñado específicamente para el arsénico que tiene en cuenta su carácter aniónico y sus propiedades químicas específicas. Permite, además, la diferenciación de las formas más móviles del arsénico, que pueden convertirse en formas biodisponibles y movilizables con el consiguiente riesgo para el medio ambiente, y las fracciones metálicas difícilmente solubilizables. La información obtenida de la aplicación del procedimiento de fraccionamiento de arsénico a las muestras de sedimentos permitirá, por un lado, conocer las formas minerales a las que aparece ligado preferentemente el arsénico en los sedimentos del acuífero investigado y, por otro, evaluar la estabilidad del arsénico en dichos materiales ante cambios ambientales drásticos, especialmente cambios relacionados con la acidez y propiedades redox del agua en contacto con los sedimentos.

\section{VI.2. MUESTREO}

Para llevar a cabo el estudio de fraccionamiento de arsénico se han seleccionado un total de 31 muestras de entre todas las muestras de sedimentos tomadas. La elección de estas muestras ha tenido en consideración que se mantenga la representatividad de las diferentes unidades geológicas presentes en la zona investigada.

En la Fig. VI.1 se indica la localización de las muestras analizadas en este estudio sobre el mapa geológico del área investigada. 


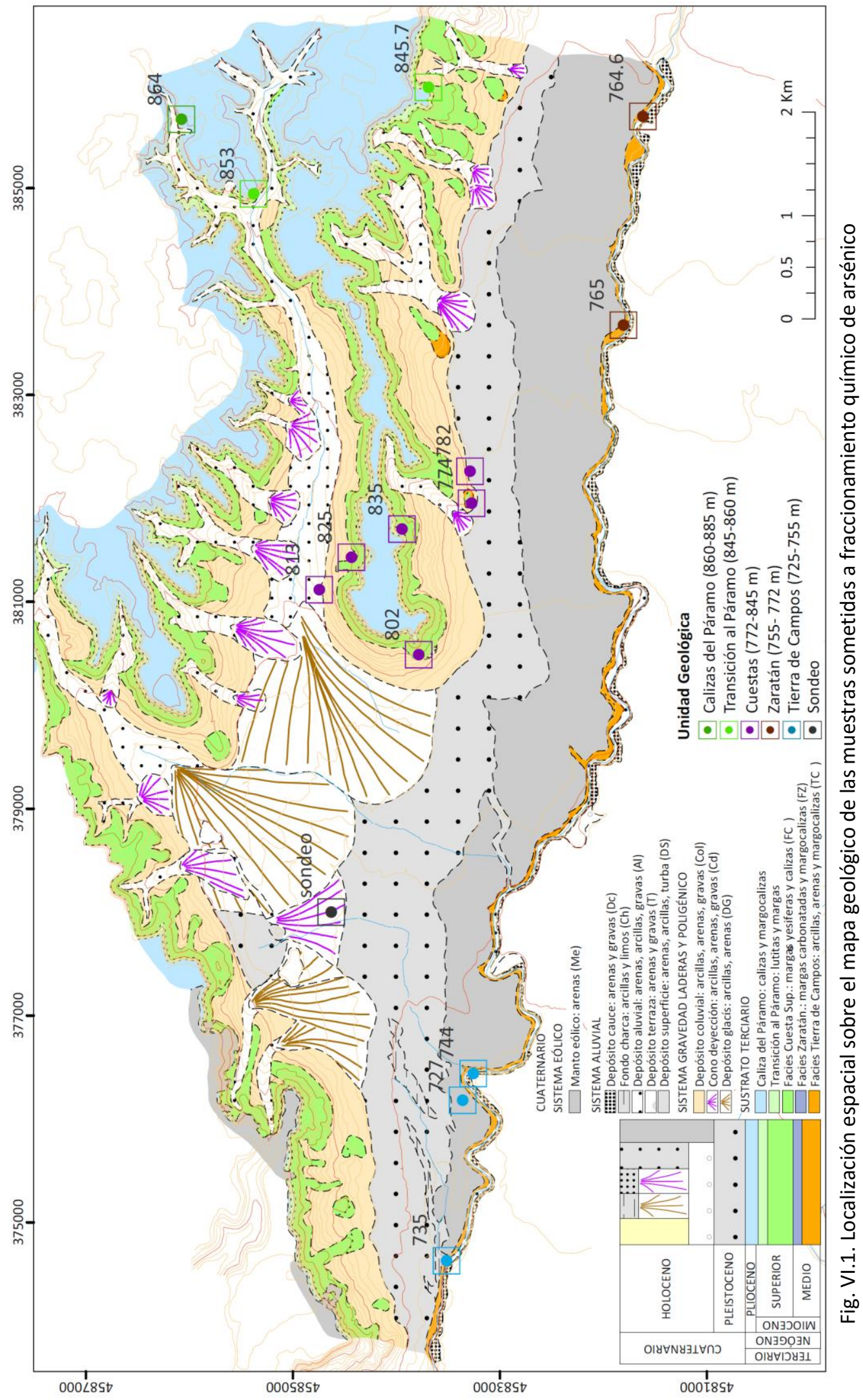




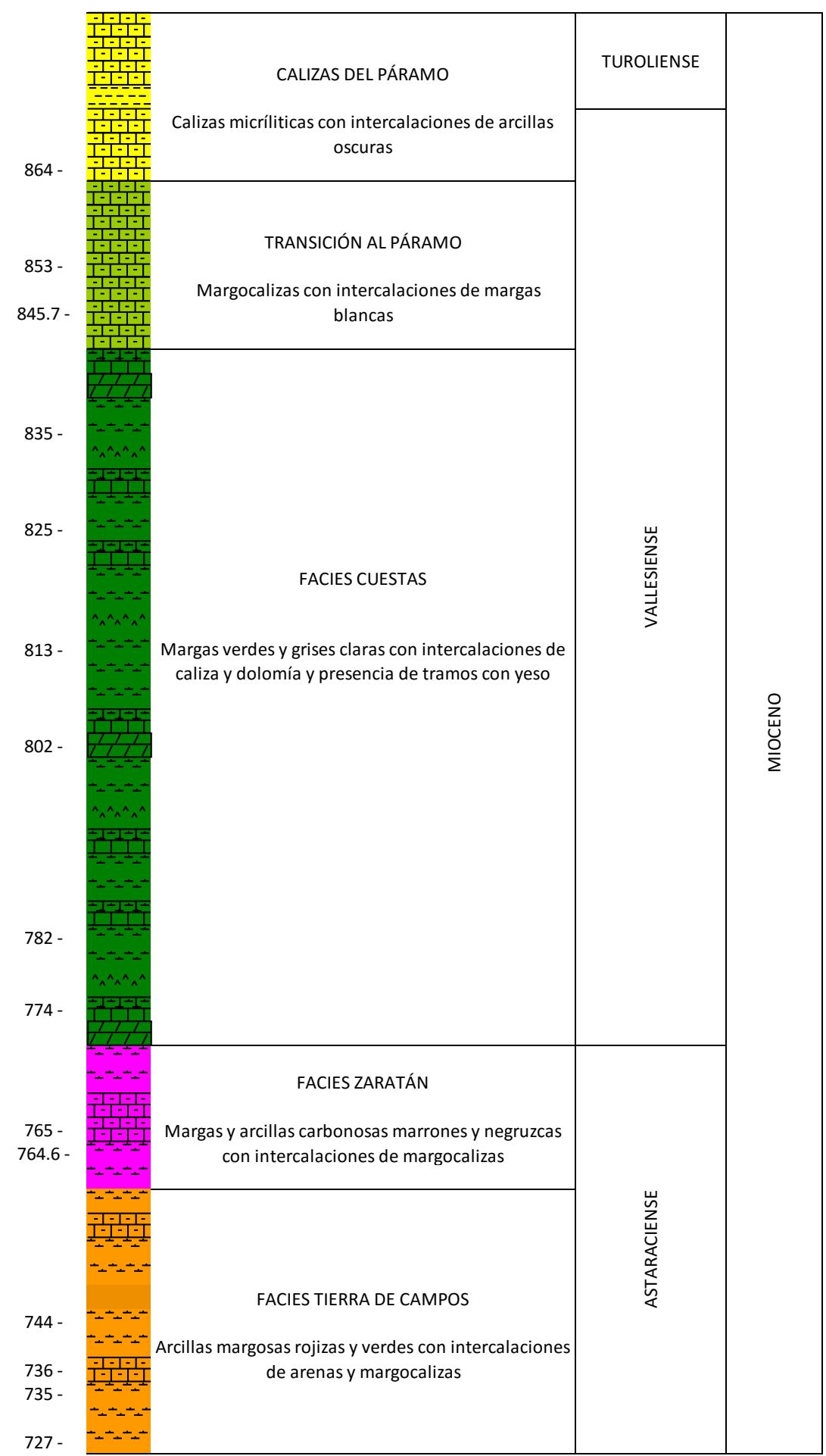

Fig. VI.2. Localización vertical sobre la columna estratigráfica de muestras elegidas para el fraccionamiento de arsénico 


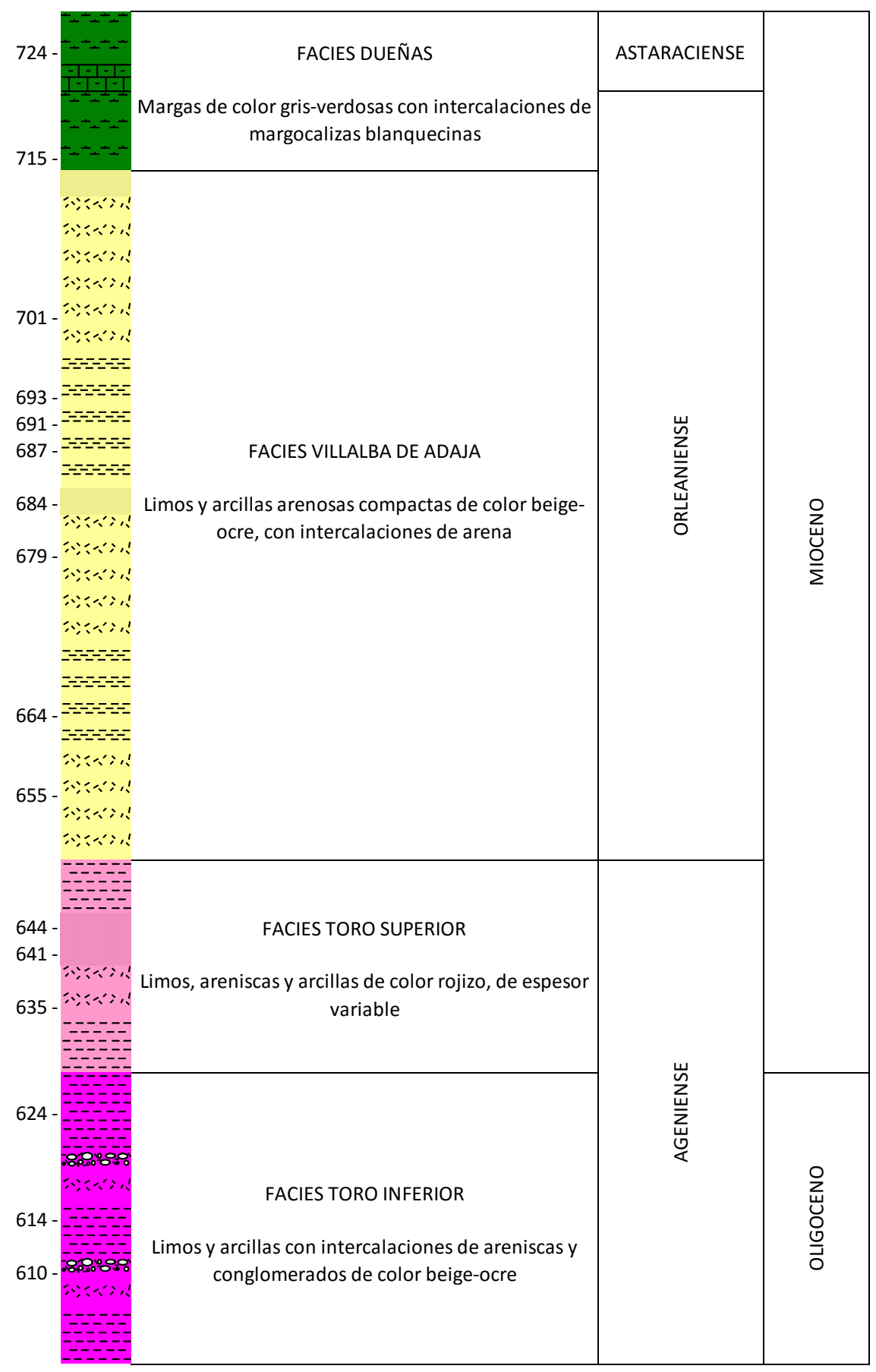

Fig. VI.2. Continuación. 
Al estar todas las muestras del sondeo localizadas sobre un mismo punto, se ha optado por representar también todas las muestras sobre una columna estratigráfica (Fig. VI.2), en la que se ha incluido una descripción visual de la composición de cada una de las unidades geológicas identificadas "in situ".

\section{VI.3. PROCEDIMIENTOS ANALÍTICOS}

\section{VI.3.1. FRACCIONAMIENTO DE ARSÉNICO EN SEDIMENTOS}

El procedimiento de extracción secuencial elegido para el fraccionamiento químico de arsénico en sedimentos consta de cinco etapas de extracción con reactivos de creciente agresividad (Wenzel y col., 2001). De esa forma se extraen secuencialmente las fracciones que se detallan a continuación: $\mathrm{E} 1$, arsénico adsorbido no específicamente, extraído con $\left(\mathrm{NH}_{4}\right)_{2} \mathrm{SO}_{4} ; \mathrm{E} 2$, arsénico adsorbido específicamente, extraído con $\mathrm{NH}_{4} \mathrm{H}_{2} \mathrm{PO}_{4}$; $\mathrm{E} 3$, arsénico enlazado a óxidos amorfos de $\mathrm{Fe}, \mathrm{Al}$ y $\mathrm{Mn}$, lixiviado con un tampón de oxalato amónico ( $\mathrm{pH} \mathrm{3,25);} \mathrm{E4,} \mathrm{arsénico} \mathrm{enlazado} \mathrm{a} \mathrm{óxidos} \mathrm{cristalinos} \mathrm{de} \mathrm{Fe}, \mathrm{Mn}$ y Al, extraído con una mezcla de oxalato amónico y ácido ascórbico ( $\mathrm{pH} 3.25$ y 90ㅡㄷ); y E5, arsénico residual fuertemente retenido, extraído por digestión ácida oxidante asistida por microondas con $\mathrm{HNO}_{3} / \mathrm{H}_{2} \mathrm{O}_{2}$. Las etapas del procedimiento, que se esquematiza en la Fig. VI.3iError! No se encuentra el origen de la referencia., se describen detalladamente a continuación:

En un tubo de centrífuga se pesa $1 \mathrm{~g}$ de suelo con precisión de $\pm 0,1 \mathrm{mg}$. Se añaden 25 $\mathrm{mL}$ de $\left(\mathrm{NH}_{4}\right)_{2} \mathrm{SO}_{4} 0,05 \mathrm{M}$ y se agita a aproximadamente $700 \mathrm{U} / \mathrm{min}$ con un agitador Selecta-P Vibromatic durante $4 \mathrm{~h}$ a fin de extraer todo el arsénico no específicamente adsorbido al suelo. Transcurrido dicho tiempo se centrifuga a $1700 \mathrm{U} / \mathrm{min}$ durante 15 min en una centrífuga ALC Cetrifuge PK 120 para separar por decantación el sobrenadante, que es trasvasado a un matraz de $50 \mathrm{~mL}$. El residuo sólido se lava por triplicado con $5 \mathrm{~mL}$ de agua desionizada y agitando enérgicamente durante unos segundos; después se centrifuga la suspensión a $4500 \mathrm{U} / \mathrm{min}$ durante 5 minutos y las porciones del líquido de lavado se separan del residuo por decantación, trasvasándolas al matraz. Finalmente, se enrasa el contenido del matraz con agua desionizada obteniéndose el extracto correspondiente a la primera fracción de arsénico, que se filtra, con un filtro de 0,45 micras de nitrato/acetato de celulosa y guarda a $4{ }^{\circ} \mathrm{C}$ en un bote de policarbonato hasta su medida.

Al residuo de sedimento resultante de la etapa anterior se le añaden $25 \mathrm{~mL}$ de $\left(\mathrm{NH}_{4}\right) \mathrm{H}_{2} \mathrm{PO}_{4}$ 0,05 $\mathrm{M}$ y se agita a $700 \mathrm{U} / \mathrm{min}$ durante $16 \mathrm{~h}$ para lixiviar la fracción de arsénico adsorbida específicamente. A continuación se centrifuga y decanta el extracto y se lava el residuo de la misma forma que en la etapa previa, recogiendo el extracto y los líquidos de lavado en un matraz de $50 \mathrm{~mL}$, que se enrasa con agua y se filtra. El extracto filtrado se conserva a $4 \stackrel{\circ}{ } \mathrm{C}$ hasta el momento del análisis. 


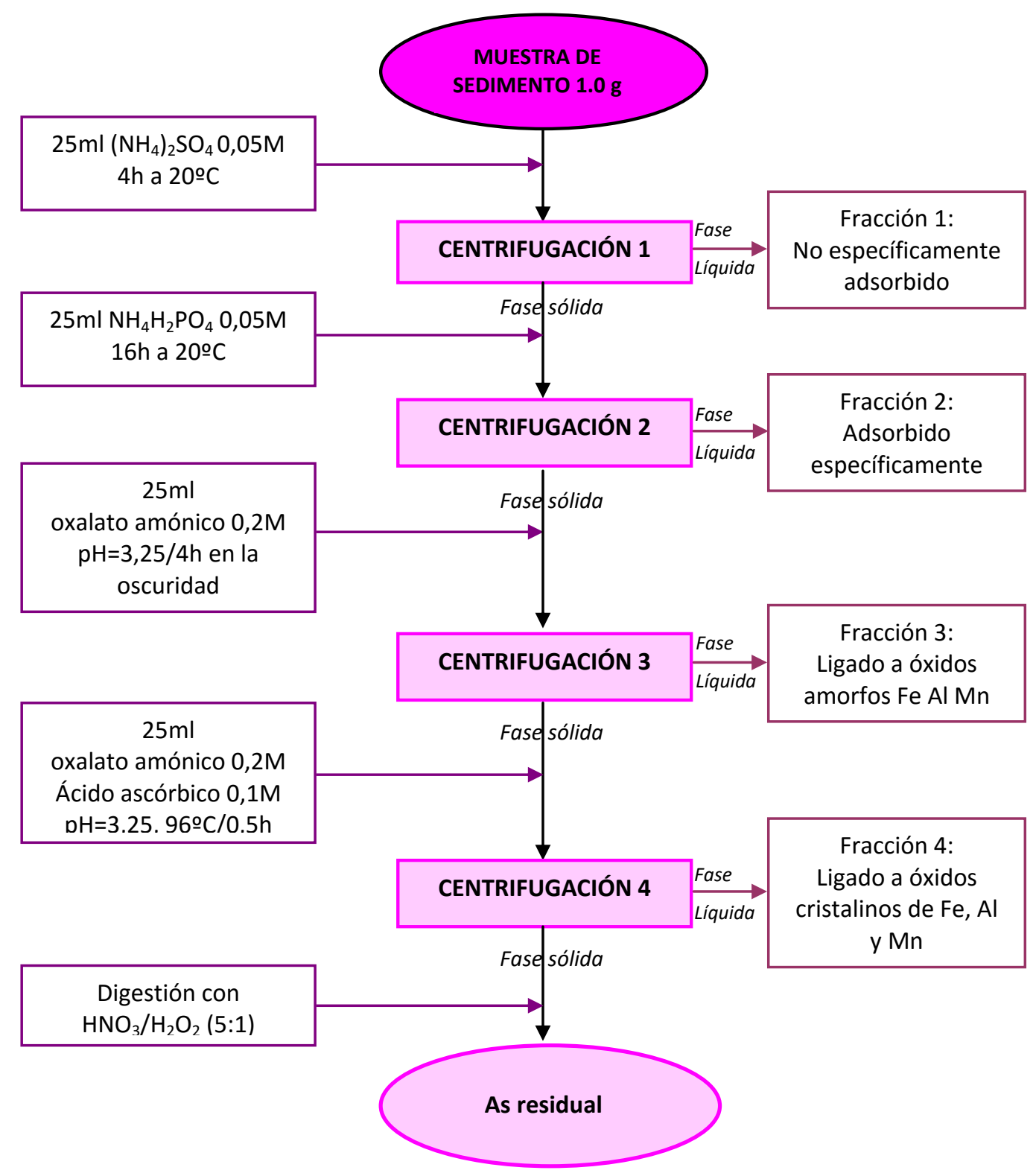

Fig. VI.3. Esquema de fraccionamiento de arsénico en sedimentos (Wenzel y col., 2001). 
El residuo sólido contenido en el tubo de centrífuga, procedente de la segunda extracción, se trata ahora con $25 \mathrm{~mL}$ de oxalato amónico $0,2 \mathrm{M}$ a pH 3,25 con el fin de extraer del suelo la fracción de arsénico ligada a hidróxidos de $\mathrm{Fe}, \mathrm{Mn}$ y $\mathrm{Al}$ poco cristalinos y/o amorfos. Los tubos se envuelven en papel de aluminio para evitar la oxidación fotoquímica del oxalato, y se agitan a $900 \mathrm{U} / \mathrm{min}$ durante $4 \mathrm{~h}$. Una vez finalizado el tiempo de agitación se centrifuga la suspensión, se decanta el extracto a un matraz de $50 \mathrm{~mL}$, y se lava por triplicado, recogiendo en el matraz los líquidos de lavado separados tras centrifugación y decantación en las condiciones habituales.

En la cuarta etapa del procedimiento se trata el residuo anterior con $25 \mathrm{~mL}$ de una mezcla de oxalato amónico $0,2 \mathrm{M}$ y ácido ascórbico $0,1 \mathrm{M}$ a $\mathrm{pH}=3,25$, que posee un poder reductor mayor que el oxalato frío empleado en la fase tercera. Después de agitar la suspensión para asegurar la perfecta mezcla de las fases, se colocan los tubos de centrifuga en un baño de agua termostatado a $96{ }^{\circ} \mathrm{C}$ durante 30 minutos con el fin de extraer la fracción de arsénico ligada a hidróxidos cristalinos de Fe, Mn y Al. Transcurrido ese tiempo se dejan enfriar las suspensiones a temperatura ambiente y se recoge el extracto como en las etapas anteriores.

Finalmente, el residuo procedente de la cuarta extracción se trasvasa a un recipiente para horno microondas de PTFE (teflón), junto con $10 \mathrm{~mL}$ de ácido nítrico concentrado $65 \%(\mathrm{~m} / \mathrm{v})$ y $2 \mathrm{~mL}$ de peróxido de hidrógeno $33 \%(\mathrm{v} / \mathrm{v})$. Una vez encamisados los vasos de reacción, se cierran herméticamente, se colocan en el rotor de un digestor de microondas MILESTONE ETHOS PLUS y se someten a un programa de calentamiento adecuado con el fin de digerir la muestra y liberar el arsénico residual ligado en formas químicas solubles en medio ácido oxidante tales como carbonatos, fosfatos, algunos sulfuros y complejos con materia orgánica. Una vez fríos los vasos de reacción, se diluye el contenido con agua y se filtra, recogiendo el filtrado en un matraz de $50 \mathrm{~mL}$ que se enrasa y guarda refrigerado.

Finalmente, la concentración de arsénico en los diferentes extractos se determina por espectrometría de absorción atómica con cámara de grafito, en las condiciones ya descritas en capítulos anteriores.

Todas las muestras se sometieron al proceso de extracción secuencial al menos por duplicado.

\section{VI.3.2. DISEÑO DE MAPAS}

El programa ArcGIS 10.2.1 ha sido utilizado para la elaboración de los mapas. 


\section{VI.4. RESULTADOS}

\section{VI.4.1. FRACCIONAMIENTO QUÍMICO DE ARSÉNICO}

En la Tabla A.IV.2 del Anexo se muestran los resultados obtenidos al aplicar el procedimiento de extracciones secuenciales de Wenzel a las 31 muestras de sedimento. La tabla incluye la concentración media de arsénico hallada en cada fracción ( $n=2)$, la desviación estándar absoluta de cada media y la desviación estándar relativa, que nos da una idea más clara de la reproducibilidad de los resultados. La tabla recoge también la concentración de arsénico total hallada como suma de las distintas fracciones y la concentración de arsénico total (pseudototal) obtenida aplicando la norma EPA 3051 (digestión con $\mathrm{HNO}_{3}$ ). Al no utilizar ácido fluorhídrico para atacar y disolver los minerales de silicato, los contenidos de arsénico determinados no son totales sino pseudotales.

La Tabla VI.2

\begin{tabular}{lrrrrr} 
& \%E1 & \%E2 & \%E3 & \%E4 & \%E5 \\
\hline$[A s]_{\text {media }}$ & 5,2 & 9,3 & 11,6 & 51,0 & 22,9 \\
{$[A s]_{\max }$} & 26,3 & 22,7 & 47,1 & 82,0 & 65,3 \\
{$[A s]_{\min }$} & 0,4 & 1,1 & 3,0 & 9,8 & 4,5 \\
\hline
\end{tabular}

muestra un resumen de los valores mínimo, medio y máximo de la concentración de arsénico en cada fracción, tanto en valor absoluto como porcentual, obtenidos al promediar los resultados de las 31 muestras. Se observa que la fracción E4, que se asimila con arsénico ligado a óxidos cristalinos o, lo que es lo mismo, arsénico extraíble por ataque con reactivos reductores en caliente, es la que contiene mayor cantidad de arsénico ( $51 \%$ del elemento total, de media).

Tabla VI.2. Rangos y media de concentraciones, en valores absolutos y porcentuales, de las diferentes fracciones.

\begin{tabular}{lccrrr} 
& E1 & E2 & E3 & \multicolumn{1}{c}{ E4 } & E5 \\
\hline$[\mathrm{As}]_{\text {media }} / \mathrm{mg} \mathrm{kg}^{-1}$ & 0,8 & 1,7 & 2,2 & 8,1 & 3,0 \\
{$[\mathrm{As}]_{\max } / \mathrm{mg} \mathrm{kg}^{-1}$} & 5,8 & 6,1 & 14,9 & 33,2 & 10,1 \\
{$[\mathrm{As}]_{\min } / \mathrm{mg} \mathrm{kg}^{-1}$} & 0,05 & 0,05 & 0,17 & 0,8 & 0,4 \\
\hline
\end{tabular}

\begin{tabular}{lrrrrr} 
& \%E1 & \%E2 & \%E3 & \%E4 & \%E5 \\
\hline$[\text { As }]_{\text {media }}$ & 5,2 & 9,3 & 11,6 & 51,0 & 22,9 \\
{$[\text { As }]_{\text {max }}$} & 26,3 & 22,7 & 47,1 & 82,0 & 65,3 \\
{$[\text { As }]_{\text {min }}$} & 0,4 & 1,1 & 3,0 & 9,8 & 4,5 \\
\hline
\end{tabular}

La Fig. VI.4 representa la concentración y la distribución de arsénico en las diferentes fracciones minerales de las 31 muestras analizadas (diagrama de barras apiladas) y las compara con las concentraciones pseudototales del elemento obtenidas según la norma EPA 3051 (gráfico de dispersión de puntos). Las muestras se han etiquetado y ordenado en función de su cota, de tal forma que las muestras con menor cota son las más profundas y a partir de la muestra 727 son muestras tomadas de sedimentos aflorantes, con la excepción de la muestra 736 que se tomó en la perforación. La figura muestra la 
enorme variabilidad que presentan las muestras tanto en contenido total de arsénico como en distribución en las diferentes fracciones. No obstante, el arsénico parece estar predominantemente ligado a la fracción E4 en la mayor parte de las muestras. Aquellas muestras con elevada concentración total de arsénico también tienen cantidades importantes de arsénico en las fracciones E2 (adsorbido específicamente), E3 (ligado a óxidos de hierro amorfos) o E5 (arsénico soluble en medio ácido fuertemente oxidante).

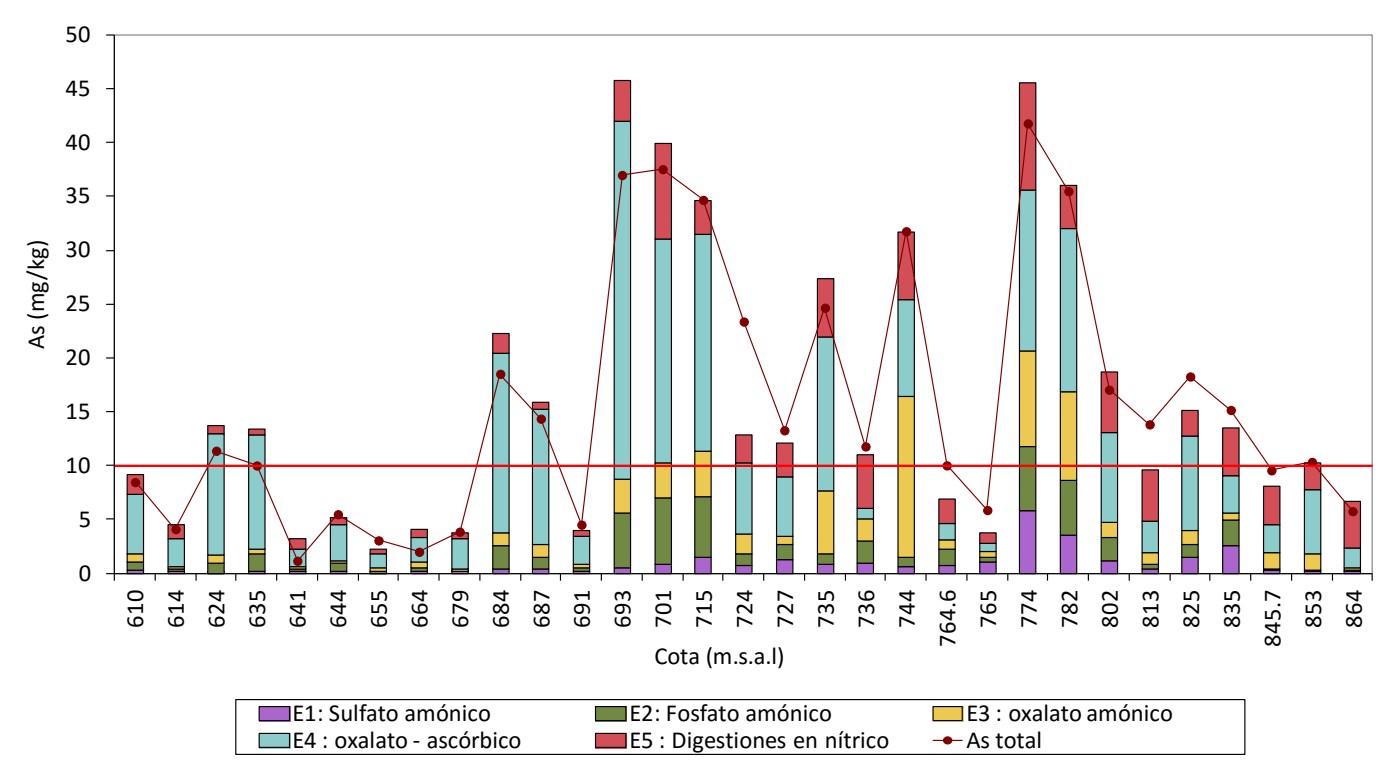

Fig. VI.4. Contenido de arsénico en las distintas fracciones extraídas de 31 muestras de sedimentos. Muestras subterráneas: 610-724; muestras superficiales: 727-864, excepto la muestra 736 que pertenece a las muestras subterráneas.

Aunque la concentración media de arsénico en la corteza terrestre es del orden de 5-6 $\mathrm{mg} / \mathrm{kg}$, se ha sugerido un valor de referencia para suelos no contaminados algo superior, de 10 mg/kg (Adriano, 1986; Bowen, 1979; Smedley y Kinniburgh, 2002, Taggar, 2004). En este estudio se ha tomado dicho valor como referencia y así se ha marcado una línea de referencia a un valor de $10 \mathrm{mg} / \mathrm{kg}$ sobre la Fig. VI.4, que señalará el límite a partir del cual consideraremos que un sedimento contiene niveles de arsénico anormalmente elevados (Smedley y Kinniburgh, 2002; Krysiak y Karczewska, 2007; Fergusson, 1990).

La distribución de arsénico en las diferentes fracciones extraídas de cada sedimento se ha representado también en un diagrama de barras porcentuales, como muestra la Fig. VI.5, en el que se puede visualizar mejor la predominancia de la fracción E4 de arsénico en los sedimentos sub-superficiales (60\% del arsénico total), mientras que en los sedimentos aflorantes la fracción E4 representa menos del $40 \%$ del arsénico total, predominando en algunas muestras concretas otras formas de arsénico (residual, adsorbido específicamente o ligado a óxidos amorfos).

Aunque si bien es cierto que gran parte del arsénico se encuentra asociado a fracciones escasamente movilizables (fracciones E3, E4 y E5), a no ser que se produzcan fuertes 
cambios ambientales, en los sedimentos aflorantes encontramos un rango de $0,36 \%$ a $26,3 \%$ del arsénico total en la fracción E1, que es la fracción más fácilmente movilizable.

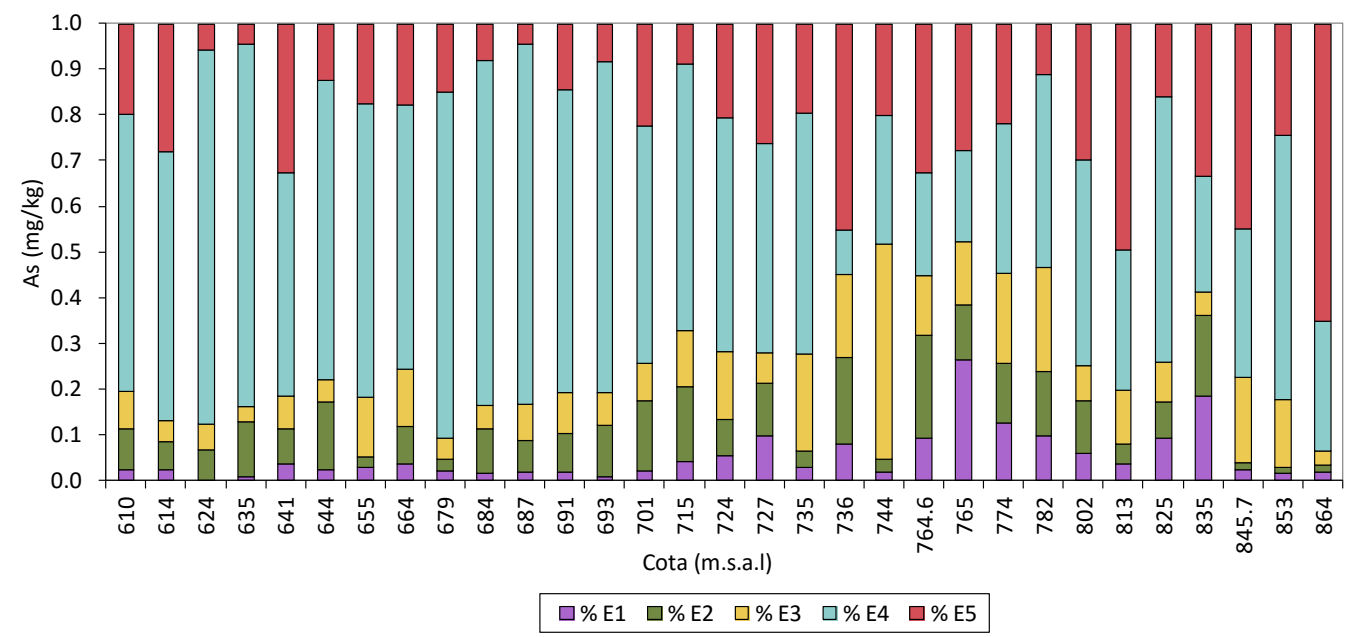

Fig. VI.5. Concentración porcentual de arsénico en las diferentes fracciones extraídas del suelo Muestras subterráneas: $610-724$; muestras superficiales: 727-864 excepto la muestra 736 que pertenece a las muestras subterráneas.

\section{VI.4.2. DISTRIBUCIÓN DEL ARSÉNICO EN LA ZONA ESTUDIADA}

Las concentraciones de arsénico en las distintas fracciones obtenidas de las muestras de sedimentos se han representado sobre un mapa geológico (Fig. VI.6) e hidrológico (Fig. VI.7) de la zona de estudio y también sobre la columna estratigráfica (Fig. VI.8), para valorar posibles orígenes geológicos del arsénico o posibles efectos de la composición geológica de los suelos en la movilidad del arsénico. Se han representado también las concentraciones de arsénico halladas en las aguas subterráneas de la zona. Se han simbolizado los pozos, sondeos y manantiales con diferentes colores en función de la unidad hidrológica en la que se ubican: verde para el acuífero carbonatado, rojo para el acuífero aluvial y azul para el acuífero detrítico profundo. Se observa que las muestras de sedimento con mayores contenidos de arsénico total se localizan en las zonas con mayores niveles de arsénico en el agua subterránea.

En cuanto a la distribución vertical del arsénico, representada en la columna estratigráfica, se observa que las muestras con mayor concentración de arsénico total están ubicadas en las facies Cuestas, Tierra de Campos, y Villalba de Adaja. 


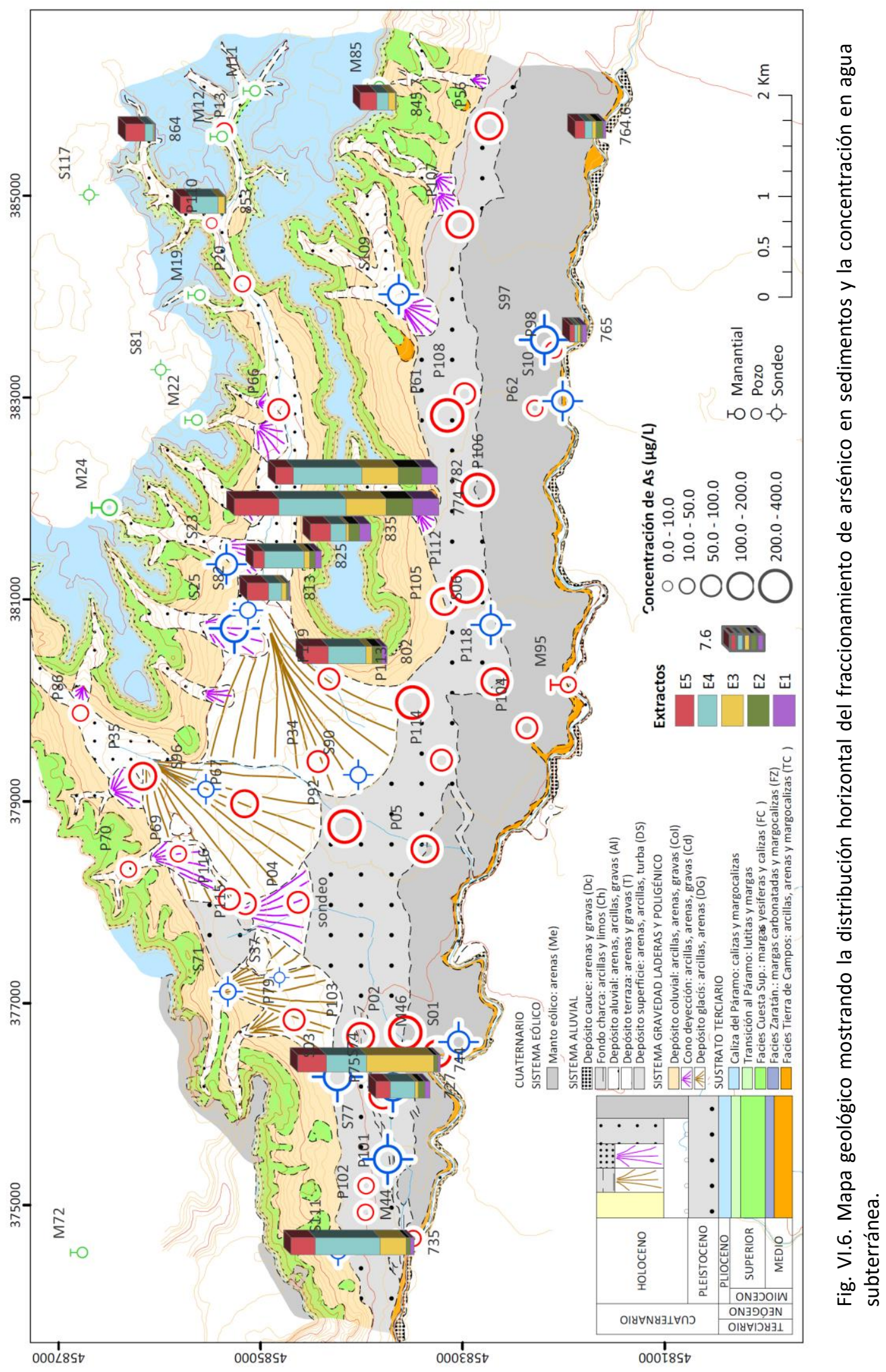




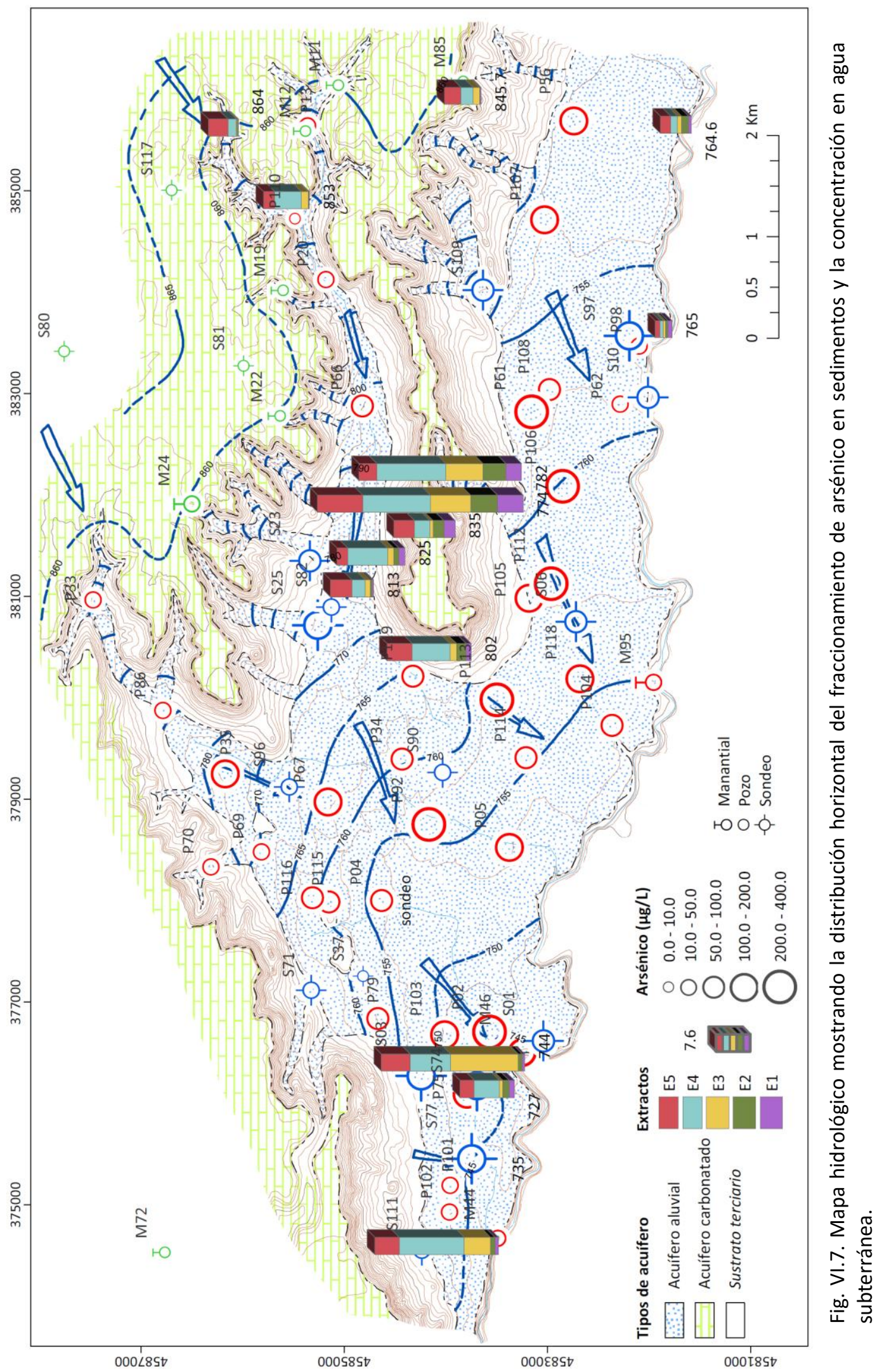




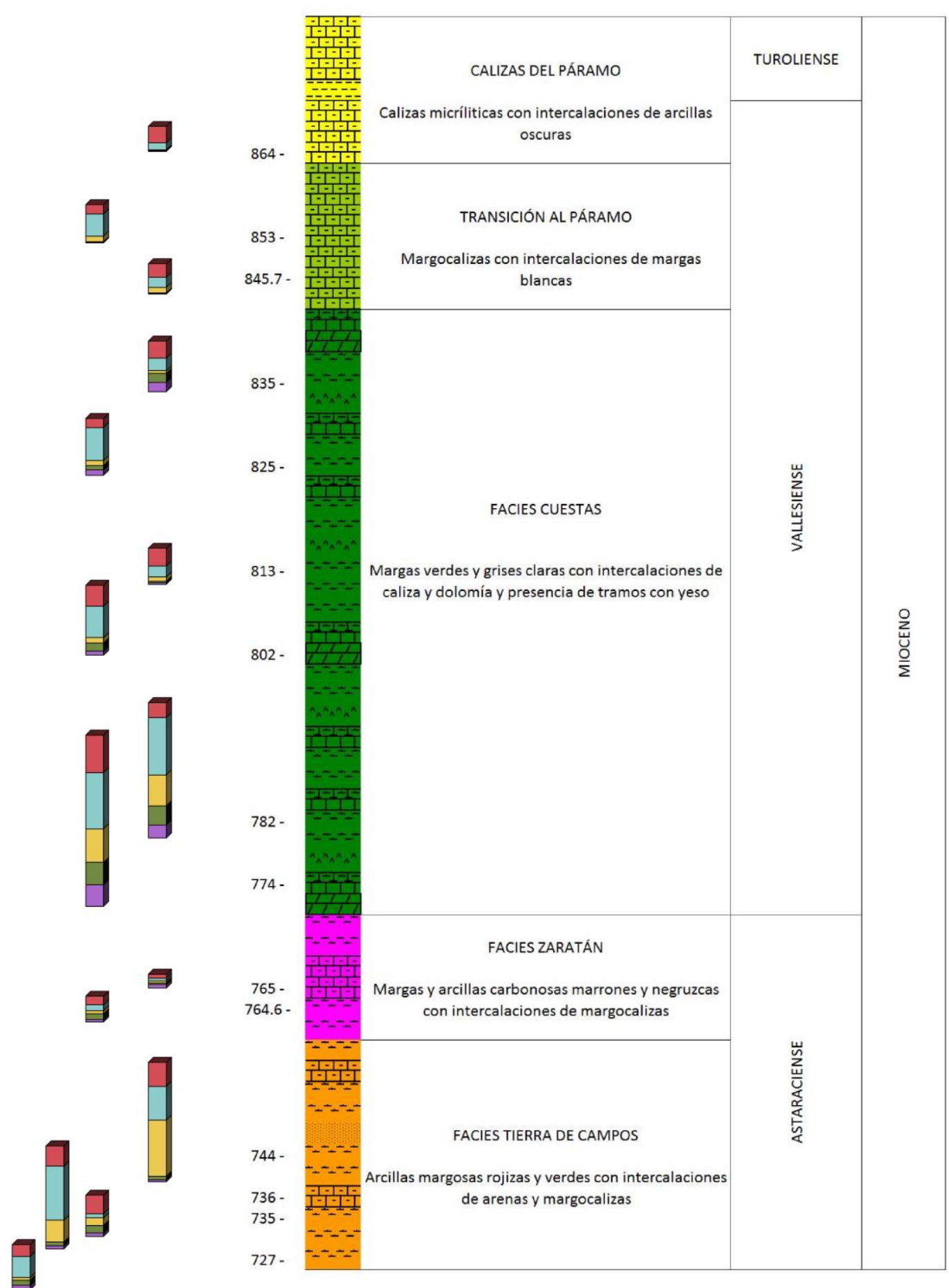

Fig. VI.8. Distribución y fraccionamiento de arsénico en sedimentos en función de la profundidad 


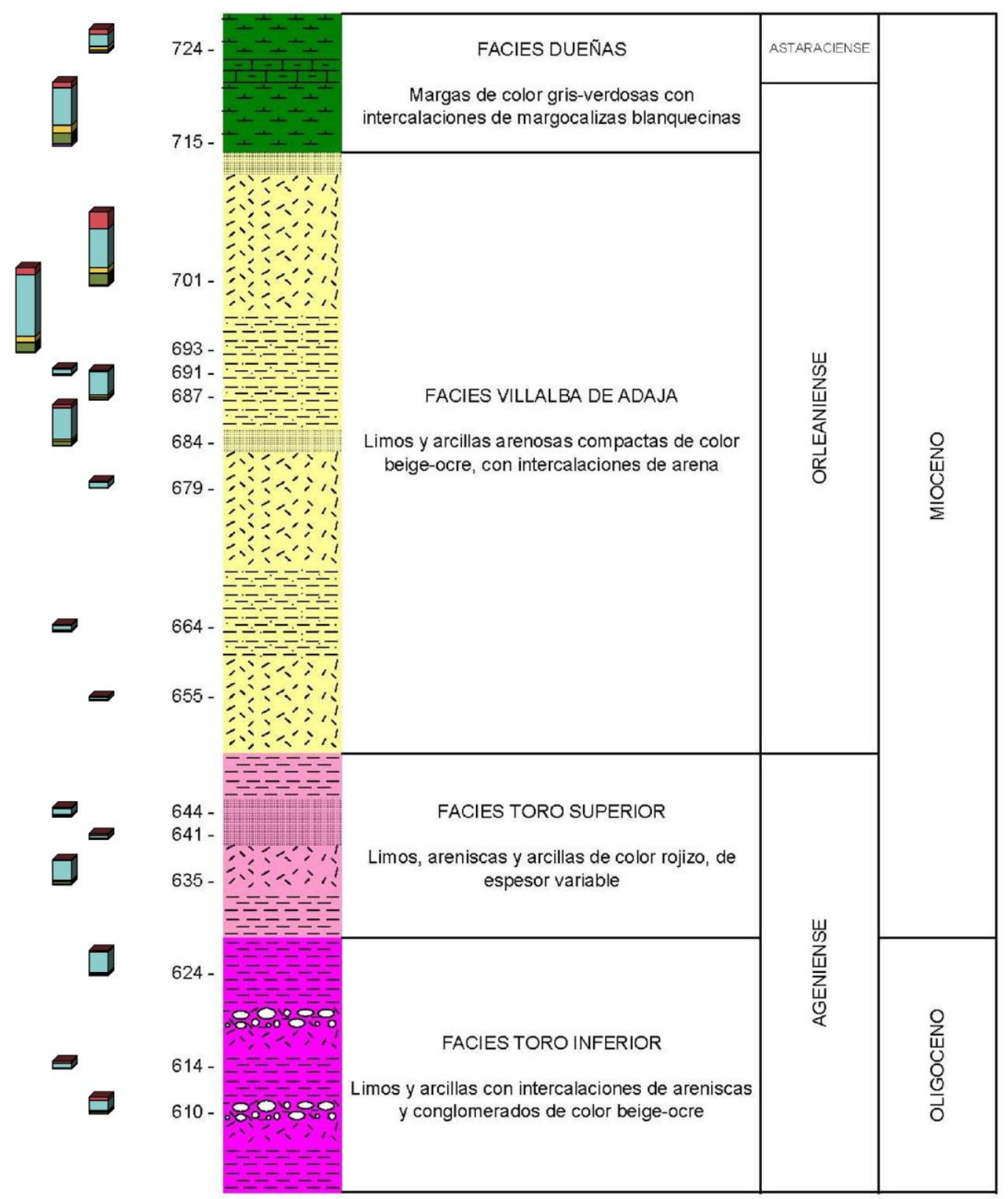

Fig. VI.8. Continuación 


\section{VI.4.3. VALIDACIÓN DE LOS DATOS OBTENIDOS}

Los resultados del fraccionamiento de arsénico en sedimentos se han validado evaluando su veracidad y precisión, esto es, su exactitud.

Al no existir materiales de referencia para la extracción secuencial de arsénico en sedimentos por el procedimiento de Wenzel, la evaluación de la veracidad se ha realizado comparando el contenido total de arsénico en los sedimentos, calculado como suma de fracciones, con la concentración determinada según la norma EPA 3051.

En la Tabla VI.3 se muestran las concentraciones de arsénico obtenidas como la suma de las fracciones [1], las concentraciones de arsénico obtenidas mediante la digestión con $\mathrm{HNO}_{3}$, norma EPA 3051 [2] y la diferencia entre el arsénico hallado como suma de fracciones y el arsénico analizado según la norma EPA 3051 [1]-[2]. Esas concentraciones ya han sido representadas gráficamente en la Fig. VI.4.

Hay que resaltar que el método de Wenzel establece que la fracción residual se extrae con una mezcla de $\mathrm{HNO}_{3}(65 \% \mathrm{~m} / \mathrm{v})$ y $\mathrm{H}_{2} \mathrm{O}_{2}(30 \% \mathrm{v} / \mathrm{v})$, mientras que en la norma EPA3051 solamente se añade $\mathrm{HNO}_{3}(65 \%)$ para extraer los elementos, entre ellos el arsénico. Teniendo en cuenta que el $\mathrm{H}_{2} \mathrm{O}_{2}$ se añade coadyuvante para la oxidación de la materia orgánica y de los sulfuros y que en los suelos analizados la cantidad de materia orgánica y de sulfuros es despreciable, consideramos que la adición de peróxido de hidrógeno hubiera sido prescindible en este estudio.

Tabla VI.3. Diferencia entre las concentraciones de arsénico medidas como suma de fracciones y concentración de arsénico total

\begin{tabular}{lccc} 
Muestra & $\begin{array}{c}{\left[\text { As] } / \mathbf{m g ~ k g}^{-1}\right.} \\
\text { Suma de fracciones } \\
{[\mathbf{1}]}\end{array}$ & $\begin{array}{c}{\left[\text { As] } / \mathbf{m g ~ k g}^{-1}\right.} \\
\text { norma EPA 3051 } \\
{[\mathbf{2}]}\end{array}$ & $\begin{array}{c}\text { [As] } / \mathbf{m g ~ k}^{-1} \\
\text { Diferencia } \\
{[\mathbf{1}]-[2]}\end{array}$ \\
\hline 610 & 9,1 & 8,5 & 0,6 \\
614 & 4,4 & 4,1 & 0,3 \\
624 & 13,8 & 11,4 & 2,4 \\
635 & 13,4 & 10,0 & 3,4 \\
641 & 3,1 & 1,2 & 1,9 \\
644 & 5,1 & 5,5 & $-0,4$ \\
655 & 2,2 & 3,0 & $-0,8$ \\
664 & 4,0 & 2,0 & 2,0 \\
679 & 3,7 & 3,9 & $-0,2$ \\
684 & 22,2 & 18,5 & 3,7 \\
687 & 15,9 & 14,4 & 1,5 \\
691 & 3,9 & 4,5 & $-0,6$ \\
693 & 45,7 & 37,0 & 8,7 \\
701 & 39,9 & 37,5 & 2,4 \\
715 & 34,5 & 34,7 & $-0,2$ \\
724 & 12,8 & 23,4 & $-10,6$ \\
727 & 12,0 & 13,3 & $-1,3$ \\
735 & 27,3 & 24,7 & 2,6 \\
736 & 11,0 & 11,8 & $-0,8$ \\
744 & 31,7 & 31,8 & $-0,1$
\end{tabular}




\begin{tabular}{lccc} 
Muestra & $\begin{array}{c}\text { [As] } / \mathbf{m g ~ k g}^{-1} \\
\text { Suma de fracciones } \\
{[1]}\end{array}$ & $\begin{array}{r}{\left[\text { As] } / \mathbf{m g ~ k g}^{-1}\right.} \\
\text { norma EPA 3051 }\end{array}$ & $\begin{array}{c}{\left[\text { As] } / \mathbf{m g ~ k g}^{-1}\right.} \\
\text { Diferencia } \\
{[1]-[2]}\end{array}$ \\
\hline 764,6 & 6,9 & 10,0 & $-3,1$ \\
765 & 3,7 & 5,9 & $-2,2$ \\
774 & 45,5 & 41,8 & 3,7 \\
782 & 35,946 & 35,48 & 0,5 \\
802 & 18,59 & 17,04 & 1,6 \\
813 & 9,519 & 13,82 & $-4,3$ \\
825 & 15,114 & 18,27 & $-3,2$ \\
835 & 13,47 & 15,16 & $-1,7$ \\
845.7 & 8,08 & 9,55 & $-1,5$ \\
853 & 10,143 & 10,33 & $-0,2$ \\
864 & 6,638 & 5,76 & 0,9 \\
\hline
\end{tabular}

Las diferencias [1]-[2] se han representado gráficamente en la Fig. VI.9 en función de la altitud, y puede observarse que no se aprecia ninguna tendencia, por lo que podemos entender que las diferencias son aleatorias.

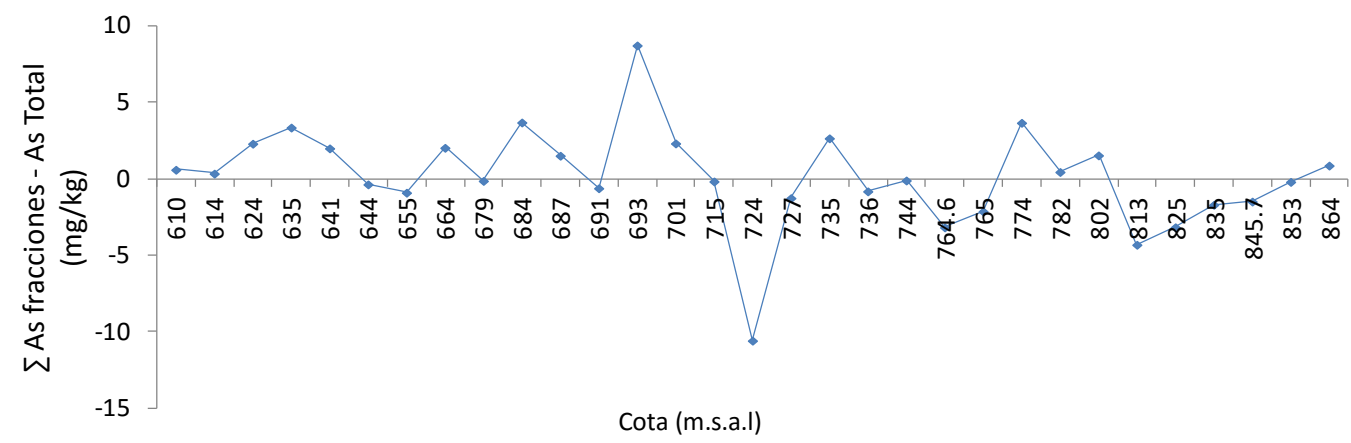

Fig. VI.9. Diferencias entre la suma de fracciones y el arsénico total analizado según norma EPA 3051

Se ha comprobado que estas diferencias no son significativas mediante una prueba de significación estadística. La prueba de normalidad de Shapiro-Wilk para el conjunto de diferencias entre la suma de fracciones y el valor de arsénico pseudototal ofrece un valor $p$ inferior a 0,05 , por lo que estas diferencias no pertenecen a una distribución normal y, por lo tanto, se aplicó la prueba no paramétrica de Wilcoxon para comprobar que no existen diferencias significativas entre las parejas de valores comparados. La prueba de Wilcoxon demostró, usando un nivel de confianza del 95\%, que no hay diferencias significativas entre el arsénico calculado como suma de fracciones y el arsénico total extraído siguiendo la norma EPA 3051. Por tanto, si los resultados de analizar el contenido total de arsénico en los sedimentos aplicando la norma EPA 3051 son considerados válidos, podremos concluir que el procedimiento de extracción 
secuencial de arsénico aplicado no está afectado por sesgo y los resultados son, por tanto, válidos.

Novoa-Muñoz y col., 2007 compararon la concentración total obtenida como suma de fracciones del procedimiento de Wenzel con la concentración de arsénico obtenida tras una extracción simple con la mezcla $\mathrm{HCl} / \mathrm{HNO}_{3} / \mathrm{HF}$, y obtuvieron en el segundo caso un incremento del $11 \%$ en la concentración de arsénico, que achacaron al empleo de $\mathrm{HF}$, capaz de disolver silicatos, insolubles en el método de Wenzel. En general, se consideran satisfactorios los resultados si las diferencias son inferiores a $\pm 10 \%$ (Tessier y col., 1980; Pickering, 1986; Yan y col., 1999).

Sarkar y col., 2007, utilizando el método de fraccionamiento basado en Chunguo y Zihui, 1988 y modificado por Sarkar y Datta, 2004, obtuvieron que la suma de las concentraciones de arsénico de todas las fracciones frente a la concentración de arsénico total obtenida según el método USEPA 3050B, el cual utiliza $\mathrm{HNO}_{3}$ y $\mathrm{H}_{2} \mathrm{O}_{2}$, fue del 63-93\%.

Dado que en nuestro trabajo no se ha empleado HF, y por tanto los silicatos cristalinos no han sido disueltos, cabe esperar que el contenido total de arsénico en los suelos sea un poco superior al estimado, aunque sin olvidar que estudios como el realizado por Goh y col., 2005 revelan que la cantidad de arsénico retenido en los silicatos es despreciable.

Para poder evaluar la precisión del método de extracción secuencial se han analizado todas las muestras por duplicado. Dado que las extracciones y medidas de arsénico se realizaron muy espaciadas en el tiempo, en nuestro caso podremos estimar la precisión en condiciones de reproducibilidad.

En el Tabla A.IV.2 se detallan los valores de la desviación estándar absoluta (s) y la desviación estándar relativa (\%DER) encontrada en las distintas fracciones de cada muestra. En la Tabla VI.4 se pueden ver los valores medios de la \%DER así como sus valores máximos y mínimos. Aunque los resultados puedan sugerir a simple vista que la reproducibilidad del método es pobre (DER superior al 15\% en muchos extractos), no lo es tanto si tenemos en cuenta la laboriosidad y dificultad del procedimiento y los bajos niveles de concentración de arsénico determinados.

Tabla VI.4. Porcentajes de la desviación estándar relativa (DER) de los resultados obtenidos

\begin{tabular}{cccc} 
& \%DER media & \%DER max & \%DER min \\
\hline Fracción 1 & 17,6 & 43,8 & 1,0 \\
Fracción 2 & 16,8 & 49,2 & 2,1 \\
Fracción 3 & 18,6 & 66,0 & 1,1 \\
Fracción 4 & 14,9 & 67,2 & 0,1 \\
Fracción 5 & 29,1 & 106,2 & 0,4 \\
\hline
\end{tabular}




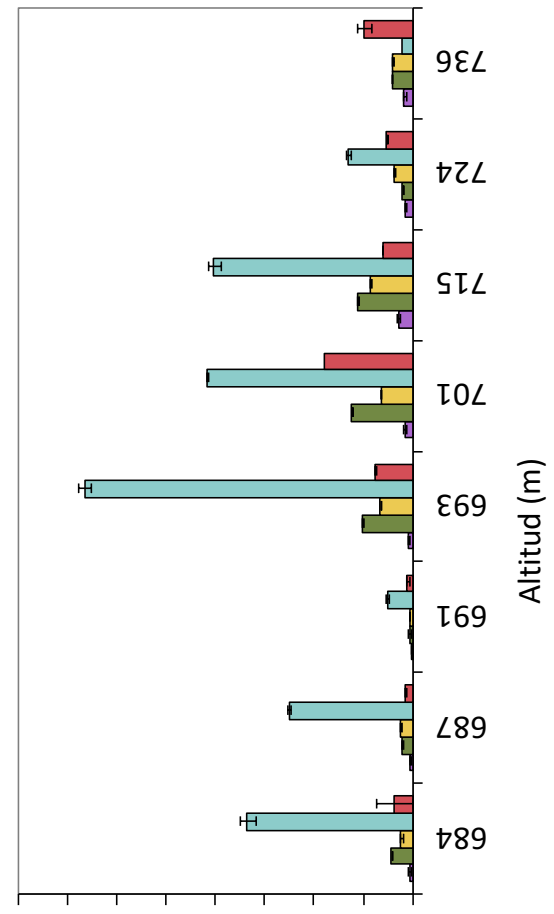

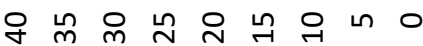

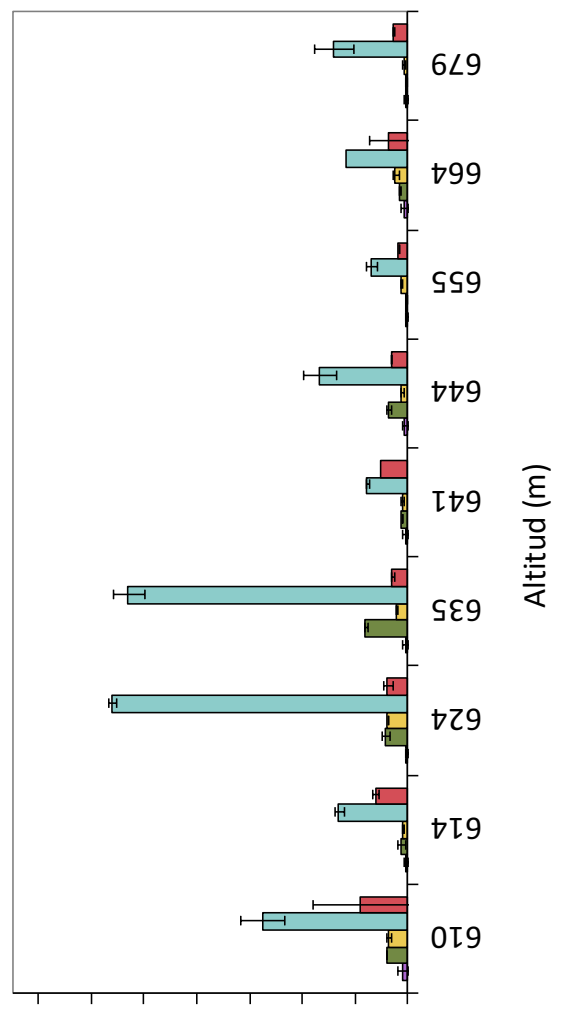

구의

$(8 y / 8 m) s \forall$

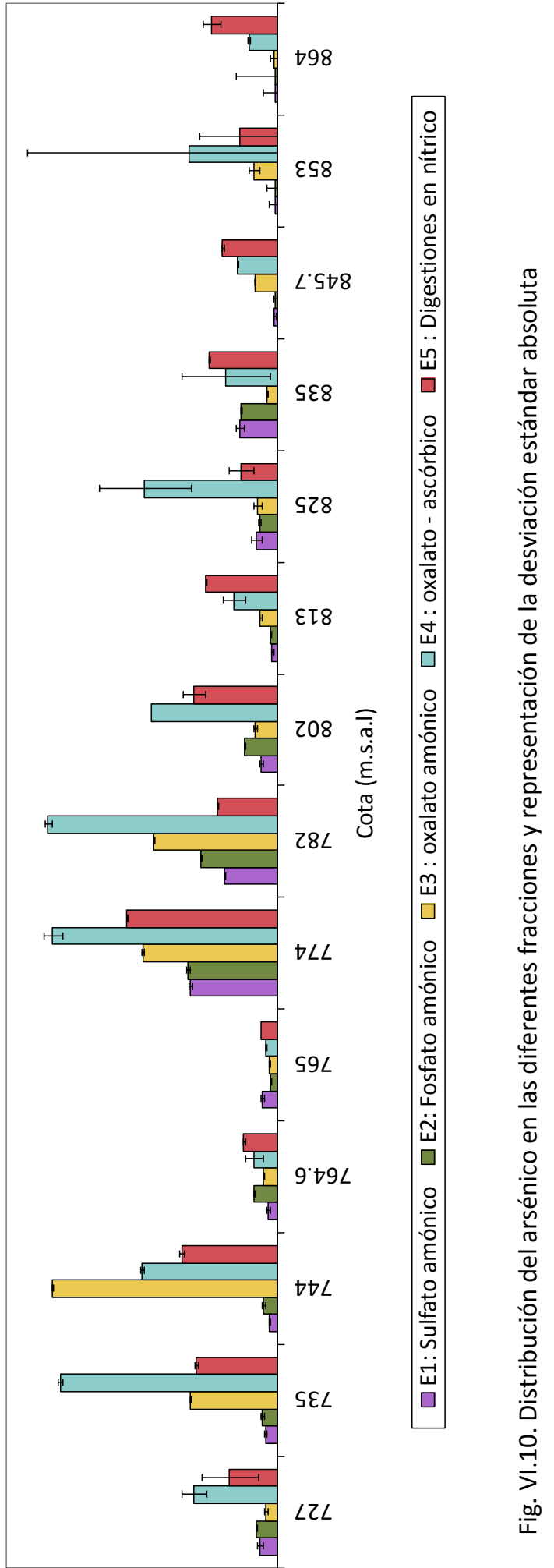

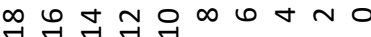

$(8 y / 8 m) s \forall$ 
En la Fig. VI.10 se muestran los contenidos medios de arsénico en cada fracción con sus correspondientes barras de error que representan la desviación estándar de la media. La escala del eje de ordenadas se ha adaptado en cada gráfico una mejor visualización.

Las desviaciones estándar relativas encontradas por otros autores varían entre menos del $5 \%$ y el $10 \%$ (Keon y col., 2001; Wenzel y col., 2001; van Herreweghe y col., 2003; Krysiak y col., 2007). No obstante, la variabilidad puede incrementarse hasta un $20 \%$ o más si se trata de muestras naturales con elevados contenidos de arsénico, debido a la heterogeneidad de las muestras (Van Herreweghe y col., 2003; Krysiak y col., 2007).

Goh y col., 2005 encontraron adecuadas reproducibilidades de su método de fraccionamiento, el cual está basado en el de Keon y col., 2001 y Matera y Hécho, 2001. Así, las desviaciones estándar relativas fueron menores al 3\% en todas las fracciones excepto para la fracción 5 , en la cual se utiliza HF y ácido bórico para la disolución de minerales de silicatos, donde la DER fue del 32\%.Aunque en nuestro estudio las DER parecen ligeramente superiores a las encontradas por los autores citados, cabe destacar que en nuestro caso los análisis se han hecho en diferentes momentos y, en el caso de algunas muestras concretas, por analistas poco experimentados (alumnos de proyectos fin de carrera y tesinas de licenciatura).

\section{VI.4.4. RELACIÓN DE LAS FRACCIONES DE ARSÉNICO CON OTRAS VARIABLES}

En la Fig. VI.11 se han representado las correlaciones bivariadas entre las fracciones del arsénico y los demás parámetros geoquímicos determinados en las muestras de sedimentos (ver capítulo V) sobre un mapa de colores para intentar revelar datos adicionales sobre sus orígenes y comportamientos en la zona estudiada.

Las correlaciones negativas se han representado en tonos fríos (azules y verdes) y las positivas en tonos cálidos (amarillos y rojos), siendo la correlación tanto más fuerte cuanto más intenso es el color.

Las Fig. VI.12 y Fig. VI.13 muestran la correlación existente entre los resultados del fraccionamiento químico del arsénico en sedimentos con las variables \% filosilicatos y hierro total, respectivamente, que son parámetros correlacionados significativamente con el contenido de arsénico total en los suelos.

La fracción E1 se correlaciona con los elementos extraíbles analizados, lo cual pone de manifiesto la débil unión de estos elementos con los componentes del suelo. La fracción E2 está muy correlacionada con la fracción E4, lo cual parece indicar que los puntos de adsorción específicos están asociados a los componentes de los suelos que retienen el arsénico en la fracción E4.

La fracción E4 presenta fuertes correlaciones con todos los metales y, como ya vimos en el capítulo $V$ (Estudio Geoquímico), estos parece que se encuentran retenidos en los filosilicatos, por lo que en esta fracción se puede estar atacando a estos minerales, lo que provocaría la disolución de los metales, incluido el hierro y el arsénico.

Las fracciones E3 y E5 muestran prácticamente similares correlaciones con el resto de los parámetros analizados. 


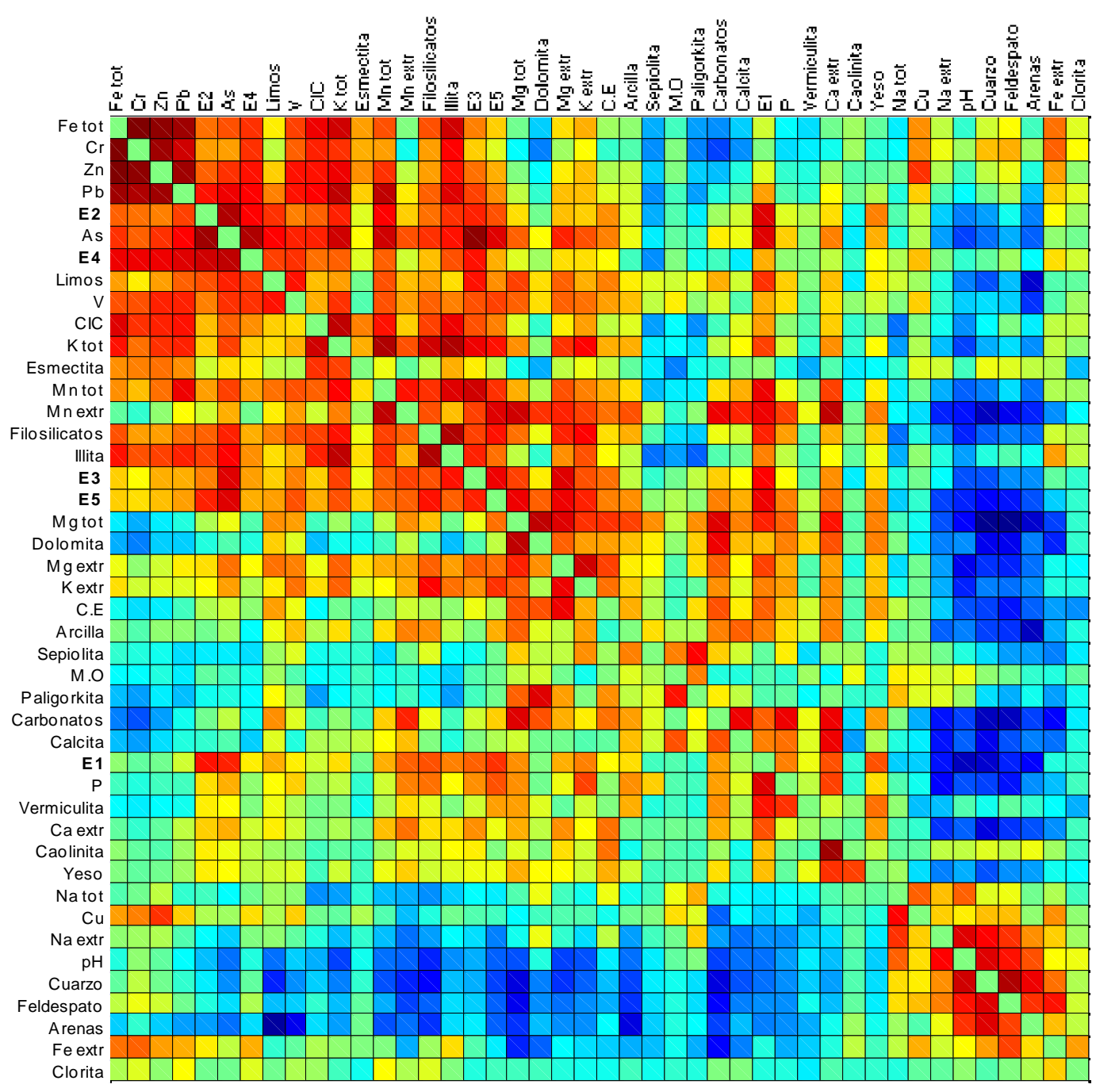

Fig. VI.11. Correlaciones bivariadas entre los distintos parámetros analizados en las muestras de suelos, representados con un mosaico de colores.

En la Fig. VI.12 se observa la buena correlación que hay entre la concentración total de arsénico y el contenido de filosilicatos, a excepción de las muestras a cotas $664 \mathrm{~m}$ (Villalba de Adaja), 724 m (Facies Dueñas), 727 m (Tierra de Campos), 736 m (Tierra de Campos) y 864 m (Calizas del Páramo), donde podría esperarse mayor concentración de arsénico atendiendo a la presencia de arcillas como fase mineral mayoritaria. Por el contrario, en las muestras a cotas $693 \mathrm{~m}$ y $701 \mathrm{~m}$ (Villalba de Adaja) los niveles de arsénico hallados son mayores a lo que cabría esperar según el porcentaje de filosilicatos que se encuentran en dichas muestras, por lo que deben existir otras formas de unión del arsénico al suelo. 


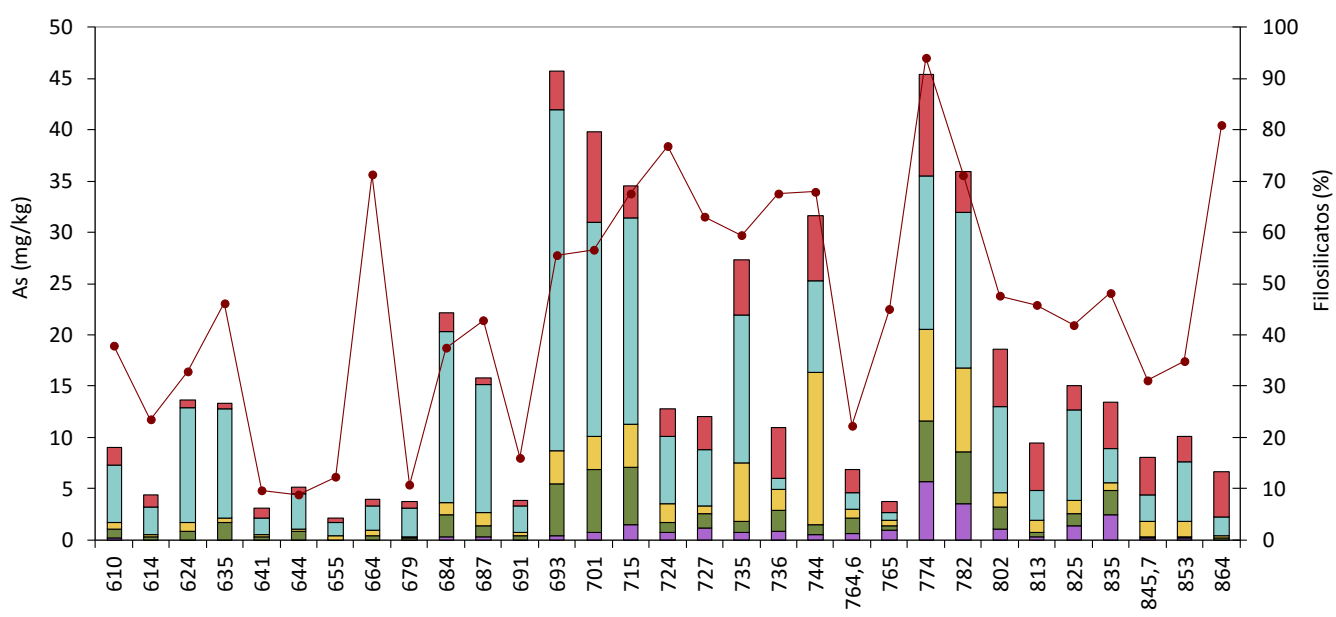

Cota (m.s.a.I)

$\square$ F1 $\square$ F2 $\square$ F3 $\square$ F4 $\square$ F5 $\quad$-Filosilicatos

Fig. VI.12. Correlación entre las fracciones de As y el contenido de filosilicatos

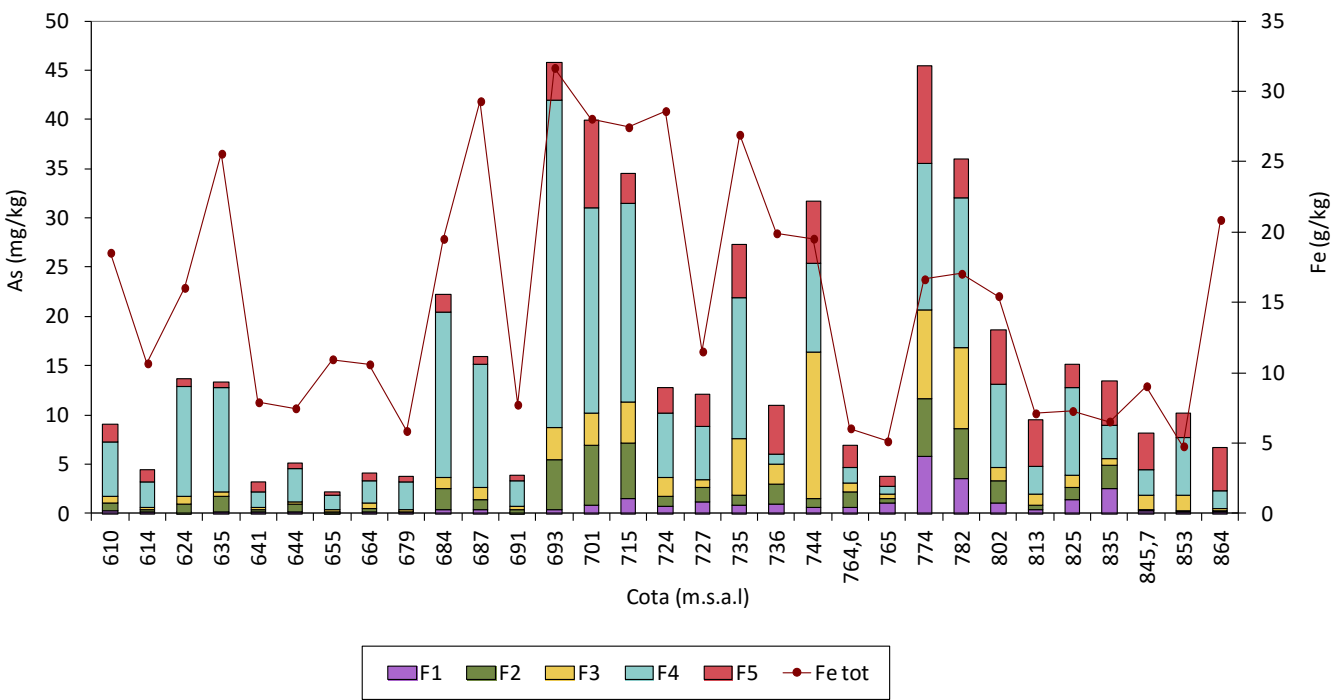

Fig. VI.13. Resultados experimentales/Fe total.

Si se representa la distribución de arsénico en las fracciones de los sedimentos frente a la concentración de hierro total se observa una correlación similar a la obtenida frente a los filosilicatos. Se observa como la concentración de hierro total con respecto a la concentración de arsénico total en las muestras del sondeo (cotas inferiores a $724 \mathrm{~m}$ ) es mayor que en los sedimentos aflorantes. Dado que en estos sedimentos el arsénico está mayoritariamente en la fracción E4, parece que esta fracción mineralógica puede constituir una parte importante en la composición de estos suelos. Por el contrario, en los sedimentos superiores, aflorantes, relación $\mathrm{Fe} / \mathrm{As}$ es inferior que en las muestras 
tomadas en cotas inferiores, lo que podría justificar que la proporción de arsénico encontrada en la fracción E4 de los sedimentos superiores sea menor que en los sedimentos profundos.

Todas estas muestras tienen un denominador común: elevados niveles de arcillas, la cuales poseen altos contenidos de hierro, el cual puede actuar como mediador para que el arsénico se quede retenido en la estructura de las arcillas.

Dado que no ha podido observarse por XRD la presencia de óxidos de hierro cristalinos en las muestras y que tampoco tenemos evidencias de que estos existan en altas concentraciones en nuestra zona de estudio, tenemos que asumir que el arsénico obtenido en las fracciones E3 y E4 puede provenir de los filosilicatos, en los cuales también hay importantes concentraciones de hierro. La Fig. VI.14 muestra la correlación entre el contenido de arsénico en distintas fracciones y la concentración de filosilicatos. Tanto los sedimentos aflorantes como los del sondeo presentan buena correlación, a excepción de algunas muestras que combinan alto contenido de filosilicatos con niveles de arsénico por debajo del nivel fondo acordado $(<10 \mathrm{mg} / \mathrm{kg})$.

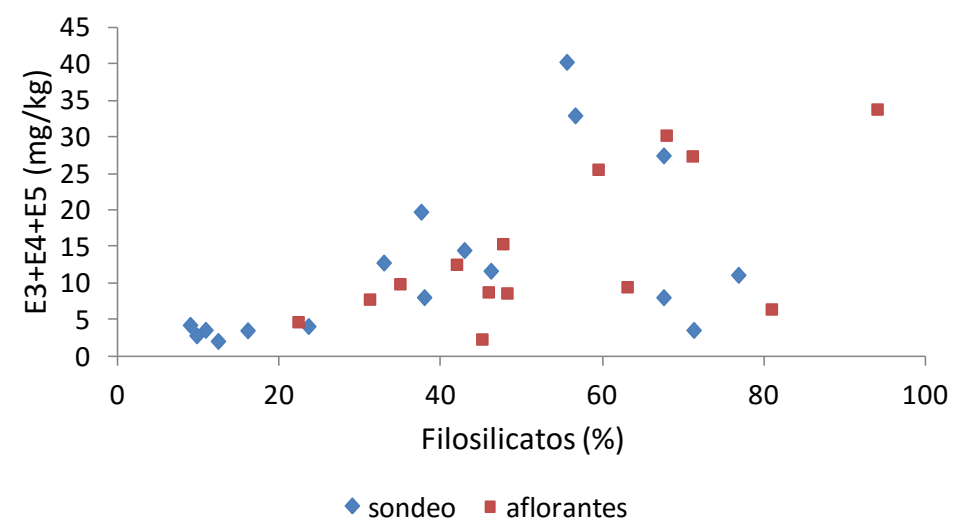

Fig. VI.14. Representación del \% filosilicatos frente a la suma de las fracciones 3,4 y5.

\section{VI.5. DISCUSIÓN DE LOS RESULTADOS}

El peligro medioambiental que puede ocasionar el arsénico depende en gran medida de las asociaciones que este contaminante presenta con los minerales del suelo. Por ello, con el estudio del fraccionamiento del arsénico se pretende entender el comportamiento geoquímico del arsénico en los acuíferos afectados y la estabilidad de las formas químicas a las que se asocia este elemento tóxico.

A grandes rasgos, podemos decir que los resultados de fraccionamiento de las distintas muestras analizadas muestran cierta homogeneidad entre las muestras con cotas inferiores a $724 \mathrm{~m}$, que podría deberse a que estas muestras sólo presentan variación vertical, ya que pertenecen al sondeo, mientras que las muestras tomadas a cotas superiores además de la variación vertical también presentan variación superficial u horizontal, por lo que las diferencias encontradas en las distintas muestras podrían 
deberse a una mayor interacción con actividades antropogénicas (fertilizantes, riego con agua contaminada...).

Analizando más en detalle los resultados obtenidos en las distintas fracciones del esquema de Wenzel, se observa que:

Las fracciones E1 y E2, que se corresponden con el arsénico que no está específicamente adsorbido al suelo y el que esta específicamente adsorbido y que representan el arsénico fácilmente intercambiable y más móvil, presentan bajos niveles de arsénico: 0,05 a 5,75 mg/kg para la fracción E1 y 0,05 a 6,14 mg/ $\mathrm{kg}$ para la fracción E2, las cuales representan un $5 \%$ y un $9 \%$ del arsénico total, respectivamente. Por lo tanto, las fracciones potencialmente más tóxicas para el medioambiente (Brandstetter y col., 2000) no parecen contribuir significativamente en la zona investigada, por lo que la disponibilidad del arsénico en los sedimentos será escasa y la liberación por efectos competitivos de otros aniones es en general un riesgo menor. La muestra con mayor contenido de arsénico en la fracción E1 $(5,75 \mathrm{mg} / \mathrm{kg}$ arsénico) pertenece a la Facies Cuestas $(774 \mathrm{~m})$, mientras que la muestra con mayor contenido en la fracción E2 pertenece a Facies Villalba de Adaja, con una concentración de arsénico de 6,14 mg/kg. A pesar de este bajo riesgo potencial de movilización, debe tenerse en cuenta que la movilización de arsénico de los suelos causada por fenómenos de intercambio iónico puede llegar a ser más importante que por disolución como resultado de cambios en el pH del medio (Pantsar-Kallio, 1997).

Autores como Novao-Muñoz y col., 2007, Moreno Jiménez y col., 2010, Krysiak y col., 2007 y Taggart y col., 2004 (que también usaron el método Wenzel para estudiar el fraccionamiento de arsénico en sedimentos) igualmente encontraron bajos niveles de arsénico en las fracciones E1 y E2.

En un estudio de fraccionamiento de arsénico por el método de extracciones secuenciales de Wenzel se analizaron suelos de viñedos de Galicia con altos contenidos de arsénico (30-219 $\mathrm{mg} / \mathrm{kg})$ y se obtuvieron valores inferiores al $4 \%$ para las fracciones móviles E1 y E2 (Novoa-Muñoz y col., 2007). En muestras de suelo de una antigua zona minera en Bustarviejo (Madrid) se hallaron valores de arsénico entre el 3-7\% para los dos primeros extractos (Moreno Jiménez y col., 2010). En suelos de antiguas zonas mineras del suroeste de Polonia, los cuales presentaban materiales con altos contenidos en arsénico, alguna de las muestras llegó a alcanzar los $43.500 \mathrm{mg} / \mathrm{kg}$ y se hallaron porcentajes inferiores al 0,01\% para la fracción E1, mientras que para la fracción E2 encontró valores entre 2,6-18\% (Krysiak y col., 2007). En los suelos tomados en la zona de Entremuros de la mina de Aznalcóllar se encontraron porcentajes en torno al $20 \%$ en las fracciones extraíbles (Taggart y col., 2004).

Otros estudios que han empleado como extractante moderado una solución de ácido acético, han mostrado la lixiviación de una proporción relativamente pequeña del arsénico en fracciones fácilmente movilizables (Luo y col., 2008).

El método de Wenzel ha sido comparado con el esquema BCR para extraer secuencialmente arsénico de suelos y sedimentos, con resultados dispares. Así, mientras que Rao y col., 2008 equiparan la fracción E1 del BCR (extracción con ácido acético) con las fracciones E1 y E2 del método Wenzel (sulfato amónico y fosfato amónico), 
interpretándolas como fracción intercambiable, en los estudios realizados por Mueller y col., 2007 y Tlustos y col., 2005 se concluye que en la fracción E1 del procedimiento BCR la cantidad de arsénico extraída es sensiblemente menor que la hallada en las dos primeras fracciones del método Wenzel.

Algunos estudios sugieren que el arsénico es más fácilmente movilizable en los suelos contaminados por fuentes antropogénicas que en la roca madre, debido probablemente a que el sedimento no ha envejecido lo suficiente y el elemento no ha tenido tiempo de incorporarse en la estructura cristalina (Chlopecka, 1996; Luo y col., 2008). Por el contrario, altos contenidos de arsénico en las fracciones fácilmente intercambiables del esquema de Wenzel suelen ser frecuentes en suelos y sedimentos contaminados por actividades mineras o industriales (Krysiak y col., 2007 y Taggart y col., 2004). De ser así, los bajos niveles de arsénico extraídos de nuestras muestras en las fracciones E1 y E2 parecen indicar que no nos encontramos ante sedimentos contaminados por la acción antrópica, sino que el arsénico en los sedimentos del acuífero tiene un origen natural.

El arsénico lixiviado en las fracciones E3 y E4 del procedimiento de extracción secuencial aplicado se relaciona con el elemento asociado a óxidos amorfos y cristalinos de hierro y aluminio que pueden ser disueltos en condiciones ácidas y reductoras (Wenzel y col., 2001). El arsénico unido a estos óxidos se puede liberar como consecuencia de cambios ambientales drásticos en el pH y/o en el potencial redox del suelo o de la interfase aguaroca. No obstante, debido al poder de autorregulación del suelo, cambios tan acusados en el $\mathrm{pH}$ o en el potencial redox del suelo no son frecuentes por lo que el arsénico ligado a esta fracción en principio puede ser considerado como de baja disponibilidad y el riesgo de que se movilice pasando al agua puede considerarse bajo.

A la vista de los resultados de este estudio, y tal como se puede observar en la Fig. VI.4, la mayor parte del arsénico se ha liberado en la fracción E4, suponiendo por término medio un $51 \%$ del arsénico total, por lo que la fracción extraíble en condiciones fuertemente reductoras y ácidas (oxalato amónico y ácido ascórbico a elevada temperatura) es la predominante en estos suelos. Atendiendo a los resultados obtenidos, se hace necesario considerar esta fracción a la hora de interpretar la geoquímica del arsénico.

A pesar de que la fracción E4 es la mayoritaria, las medidas de XRD sobre roca total no han permitido identificar las señales correspondientes a los óxidos de hierro o manganeso. Adicionalmente, las señales correspondientes a óxidos de hierro amorfos muestran picos de poca intensidad que además se solapan con picos de silicatos de alta intensidad, lo que dificulta la determinación de los mismos. No obstante, la fracción E3 no es la más abundante en nuestro caso.

En un estudio similar realizado sobre suelos ácidos $(\mathrm{pH} 4,5-6,6)$ y con una composición textural de $17-36 \%$ de arenas, $25-54 \%$ de limos y $9-28 \%$ de arcillas, se demostró que el arsénico se encuentra mayoritariamente asociado a los óxidos de hierro y después a la fracción residual (Roh Yal y col., 2011); sin embargo, como en nuestro caso, al realizar el estudio mineralógico se observó que los óxidos de hierro eran componentes minoritarios. 
La fracción E3 extraíble con oxalato amónico en frío (fracción extraíble en condiciones reductoras moderadas) contribuye con una media del $12 \%$ del As total, y presenta un rango de $0,36 \%-26,31 \%(0,17$ a $14,91 \mathrm{mg} / \mathrm{kg})$. Las mayores retenciones de arsénico en esta fracción se producen en los sedimentos de las facies que afloran a la superficie. Sin embargo, a la vista de los resultados obtenidos, se podría decir que en los suelos estudiados esta fracción no juega un papel importante en la retención de arsénico, sobre todo en las muestras subterráneas.

En la Fig. VI.4 se puede comprobar que el arsénico se extrae preferentemente en la fracción E4 para cotas inferiores a $735 \mathrm{~m}$, las cuales se corresponden con muestras subterráneas obtenidas en la perforación. No obstante, a cotas superiores a $735 \mathrm{~m}$, en las que las muestras se tomaron en la superficie, el contenido de arsénico en la fracción E4 es notablemente inferior y se incrementa el contenido de arsénico en la fracción residual E5. Otros autores han encontrado resultados similares a los de este estudio. Así, de la aplicación del esquema de Wenzel a suelos contaminados y no contaminados, se concluyó que en los extractos E3 y E4 de los suelos no contaminados había porcentajes superiores al $80 \%$ del arsénico total, mientras que en los suelos contaminados los porcentajes en estas fracciones eran del orden de 41-59\% (Moreno Jiménez y col., 2010). En otro estudio realizado en suelos del suroeste de Polonia procedentes de antiguas minas de oro se halló que la mayor proporción de arsénico se extraía en las fracciones E3 y E4, contabilizando el 23-96\% del total de arsénico (Krysiak y col., 2007).

Las arcillas minerales y su composición son factores fundamentales que afectan a la movilidad y a la disponibilidad del arsénico en suelos y rocas. El contenido de arcilla es una propiedad química de las rocas, especialmente de las sedimentarias, frecuentemente correlacionada con la retención de arsénico en las partículas del sedimento (Adriano, 2001). Como se discutió en el capítulo V (Estudio Geoquímico) existen diversas referencias que reportan que las arcillas pueden retener en su estructura al arsénico.

La fracción residual (fracción E5) representa el arsénico fuertemente retenido en minerales del suelo con una gran estabilidad. El arsénico asociado a esta fracción puede considerarse no movilizable y de limitada disponibilidad, y por tanto no constituye un potencial peligro para el medioambiente ya que se necesitan unas condiciones muy agresivas para que se produzca su liberación al medio. Por tanto, las altas contribuciones de la fracción residual deberían ser consideradas indudablemente como un beneficio según el punto de vista del peligro medioambiental.

La fracción residual, según se puede ver en la Fig. VI.4, presenta una mayor concentración de arsénico en los sedimentos aflorantes, predominantemente en los estratos de roca a mayor altitud. Por haberse tomado las muestras lejos de áreas sometidas a actividades agrícolas o ganaderas, se puede asumir que son sedimentos que no han sido expuestos a contaminación exógena y por tanto la presencia de arsénico en la fracción más estable podría estar más bien relacionada con la formación de compuestos de arsénico poco solubles, como arseniatos de calcio, con las rocas calizas que están presentes en elevada proporción en esos estratos. (S $\varnothing, 2008 ; S \varnothing, 2012)$. Cabe destacar la muestra tomada a $864 \mathrm{~m}$ de altitud, con un $65 \%$ de arsénico en la fracción residual, y que fue obtenida en un estrato de roca caliza. 
Se han representado conjuntamente, sobre el mapa geológico (Fig. VI.6) e hidrológico (Fig. VI.7), la distribución de arsénico en las muestras de sedimentos aflorantes y la concentración de arsénico en las aguas subterráneas muestreadas en pozos próximos al punto de muestreo del sedimento. Dicha representación revela que las muestras con altos contenidos en arsénico y que se tomaron en zonas arcillosas donde transcurre el flujo principal del acuífero aluvial pueden estar sometidos a una mayor interacción con el agua subterránea favoreciendo así los procesos de adsorción/desorción y la movilización del arsénico de las fracciones más disponibles.

La variabilidad en la distribución vertical es más difícil de explicar atendiendo solo a la composición mineralógica de los suelos. Los sedimentos de las cotas inferiores, menos sometidas a la acción de la atmósfera y más envejecidos, están principalmente formados por arcillas y arenas y el arsénico hallado está predominantemente ligado a la fracción E4 (fracción reducible del esquema de Wenzel). Por el contrario, en los estratos sedimentarios superiores donde la presencia de carbonatos y sulfatos es más notable, los niveles de arsénico total varían más acusadamente y la fracción residual se hace en ocasiones importante, sugiriendo una unión del arsénico a fracciones minerales tales como ciertos sulfatos insolubles, silicatos o sulfuros. 
CAPÍTULO VII. INFLUENCIA DE LAS PRÁCTICAS AGRÍCOLAS EN LA MOVILIZACIÓN Y DISPERSIÓN DE As 



\section{VII.1. INTRODUCCIÓN}

Con el fin de aportar información acerca del ciclo hidrogeoquimico del arsénico en el área estudiada, arrojando alguna luz sobre el posible origen natural o antropogénico del arsénico, se pretende investigar las variaciones estacionales que sufre el agua intersticial del suelo (agua de infiltración) como consecuencia del empleo de agua de riego contaminada por arsénico, además de estudiar la influencia que tiene el agua de riego en los suelos agrícolas.

La solución del suelo es una delgada capa acuosa que rodea las partículas edáficas, y que tiene una importancia decisiva para el desarrollo de los procesos químicos en el medio natural. La presencia de iones en esa solución se debe a varias causas: la meteorización mineral, la descomposición de la materia orgánica, la lluvia y los procesos de intercambio iónico entre dicha solución y las partículas coloidales, minerales u orgánicas del suelo. Hay que señalar que los procesos de descomposición de materia orgánica liberan iones de manera más rápida que la meteorización mineral, por lo que el primer mecanismo adquiere un papel predominante a corto plazo.

Existen dos categorías fundamentales de procesos geoquímicos de interacción agua-fase sólida, que controlarán la movilización de arsénico en el agua: reacciones de adsorcióndesorción y reacciones de precipitación-disolución de la fase sólida.

La fuerza de la adsorción de las especies arsenicales presentes en el agua, por la superficie de la fase sólida, dependerá en parte de las diferencias de carga entre las especies acuosas y la fase sólida, que juegan un papel fundamental en las interacciones electrostáticas entre las especies disueltas y la fase sólida.

Las reacciones de adsorción-desorción, que tienden a ser rápidas en la escala temporal geológica, están descritas mediante isotermas de adsorción, en la Fig. VII.1 se muestran las isotermas para los dos estados de oxidación del arsénico inorgánico sobre oxihidróxidos férricos, en la cual se puede observar que el arseniato posee una isoterma de adsorción tan acusadamente "no lineal" que provoca que su adsorción llegue a ser del orden de miles de $\mathrm{mg} / \mathrm{kg}$, incluso a concentraciones en disolución del orden de $\mu \mathrm{g} / \mathrm{L}$ (Goldberg, 1986; Manning y Goldberg, 1996; Hiemstra y van Riemsdijk, 1996). La adsorción de arsénico sobre oxihidróxidos de Al y Mn también puede ser importante, si estos óxidos están presentes en concentraciones altas (Peterson y Carpenter, 1983; Brannon y Patrick, 1987).

No obstante, en el suelo además de óxidos e oxihidróxidos de hierro, aluminio y manganeso (de Vitre y col., 1991; Sullivan y Aller, 1996) existe una gran variedad de materiales, como materia orgánica, carbonatos, arcillas, etc,... en los que tanto el arsenito como arseniato pueden ser adsorbidos en su superficie. 


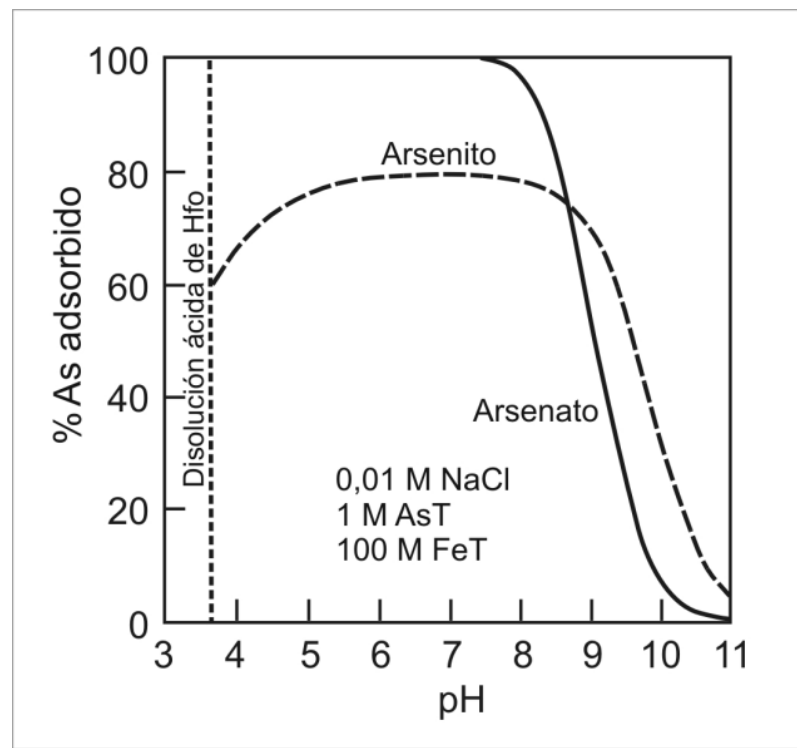

Fig. VII.1. Curvas de adsorción de $\mathrm{As}(\mathrm{III})$ y $\mathrm{As}(\mathrm{V})$, en función del pH. (Tomado de Smedley y Kinniburgh, 2001).

El arsénico también es adsorbido como As(III) y As(V) en los puntos activos de las arcillas (Manning y Goldberg, 1997), así como en la superficie de carbonatos, como la calcita, aunque la cantidad adsorbida es mucho menor que en el caso de los óxidos e oxihidróxidos de hierro (Goldberg y Glaubig, 1988). En general, aunque depende de las fases minerales presentes, la máxima adsorción de $\mathrm{As}$ (III) se produce a $\mathrm{pH}<8$, mientras que la máxima adsorción de $\mathrm{As}(\mathrm{V})$ se da $\mathrm{pH}<7$ (Raven y col., 1998).

La adsorción de arsénico puede estar condicionada por la presencia de otros iones que compiten por ocupar los puntos superficiales de intercambio.

Las reacciones de precipitación-disolución implican la formación y crecimiento de una fase mineral y su posterior destrucción. La solubilidad de un mineral puede describirse a través de su producto de solubilidad, aunque dicho valor puede variar en función del tamaño de la partícula y estado cristalino del mineral. Normalmente, la velocidad de disolución o precipitación es muy lenta, por lo que el equilibrio termodinámico es, a menudo, difícil de alcanzar en periodos cortos de tiempo.

En los procesos de coprecipitación se incorporan a la estructura mineral otros elementos que se encuentran en la solución. El proceso inverso a la coprecipitación es la codisolución que, en el caso de arsénico, dará lugar a su movilización al medio acuoso. La movilización del arsénico vendrá condicionada por la propia estabilidad del mineral con el que ha coprecipitado. El mecanismo de disolución de una fase mineral conteniendo arsénico, puede ser mucho más efectivo que la desorción, en términos de arsénico movilizado (Guo y col., 1997).Las reacciones de precipitación-disolución están controladas por la fisicoquímica de la solución, fundamentalmente $\mathrm{pH}$, temperatura, 
estado redox y concentración de especies acuosas. En la práctica, la adsorción y la coprecipitación tienen lugar al mismo tiempo (WHO, 2001).

Se ha demostrado que el arsénico proveniente de contaminación antropogénica, en general, es más móvil, y por tanto más biodisponible, que los procedentes de los sustratos geológicos (Chopecka y col., 1996 y Luo y col., 2008), lo que ha provocado el aumento de la preocupación medioambiental mundial por los elementos tóxicos y en particular por el arsénico.

La acumulación de arsénico y otros elementos tóxicos en suelos puede acarrear, a la larga, consecuencias negativas para el entorno ecológico, ya que se facilita la lixiviación de cantidades significativamente elevadas que, posteriormente, se hacen accesibles a los sistemas acuosos y a los seres vivos. Por su parte, la acumulación en tejidos vegetales puede llegar a producir daños genotóxicos en las células, peligrosos porque se incorporan al hombre a través de la cadena alimenticia (Pérez y col., 2004).

Las actividades industriales han arrojado al medio ambiente grandes cantidades de arsénico (Nriagu ycol., 1989; Jacks y Bhattacharya, 1998; Hanedar y col., 2015) fundamentalmente inorgánico. A pesar de que su uso ha ido disminuyendo gradualmente a partir de los años sesenta, debido a un mayor conocimiento de la toxicidad del arsénico (Smith y col., 1989), muchos de estos compuestos inorgánicos tales como arseniato de calcio, arseniato de plomo, arseniato de sodio y otros, se han usado en tiempos recientes (e incluso hoy en día) como insecticidas y/o pesticidas en el tratamiento de árboles, en la desinfección del ganado para el control de garrapatas, pulgas, piojos, en los tratamientos de madera y cuero, en la manufacturación de metales y aleaciones, refinamiento del petróleo, en la incineración de residuos y combustibles fósiles, etc.

En nuestra zona de estudio, hay abundantes actividades agropecuarias, las cuales utilizan los purines generados como abonos para los suelos agrícolas. Este abono natural puede contener arsénico, procedente del agua o de los piensos que consumen los animales, por lo que la deposición de dichos purines sobre los suelos agrícolas podría ser unas de las vías de entrada de arsénico a los mismos. La adición de abonos y fertilizantes sintéticos para mejorar la productividad de los campos puede ser otra vía de entrada de este contaminante. Aunque según Adriano, 2001 estos contienen niveles de arsénico inferiores a $30 \mathrm{mg} / \mathrm{kg}$, la fracción biodisponible que puede ser elevada (Beesley y Dickinson, 2010).

Los abonos y fertilizantes (ricos en fósforo) añadidos a los suelos agrícolas, modifican sus condiciones (Craig y col., 1986; Ya-Chu y col., 1994) y puede provocar la movilización o la retención de compuestos de arsénico, como ya hemos comentado. Numerosos autores han comprobado que la adición de fósforo provoca un aumento del arsénico extraíble (o disponible) en el suelo. Así, Woolson y col., 1973 demostraron que el uso de fertilizantes de fósforo en suelos contaminados por arsénico, provocaba el desplazamiento del $77 \%$ del arsénico total presente en el suelo. La competencia en la retención entre ambos aniones, fue observada también por otros investigadores como Fitz y Wenzel, 2002 y Cao y col., 2003. 
La mayoría de los campos agrícolas de la zona de estudio, se riegan con aguas procedentes de los acuíferos de la zona, lo cual puede introducir cambios sustanciales en sus condiciones originales. Como hemos visto en el capítulo IV (Estudio Hidroquímico) algunos puntos de agua de la zona poseen elevados niveles de arsénico, por lo que la sobreexplotación de estos acuíferos puede aumentar los niveles de este contaminante en los suelos agrícolas, a través de la recirculación de aguas contaminadas con arsénico. Se han reportado varios casos en los que el dilatado uso de aguas subterráneas ricas en arsénico, han provocado la aparición de concentraciones elevadas de este elemento tóxico en suelos agrícolas, originando una reducción de la productividad del suelo y la entrada de arsénico en los cultivos (Guha y col., 2000; Tanabe y col., 2001; Pandey y col., 2002; Alam y col., 2003).

El Servicio Geológico de Estados Unidos realizó un estudio sobre las aguas subterráneas de la Cuenca Willamette (Oregón) donde observaron variaciones temporales de las concentraciones de arsénico en algunos pozos, que se interpretan como ocasionadas por variaciones en el régimen de explotación.

Otras posibles vías de contaminación por arsénico son los núcleos urbanos. En nuestra zona existen tres, pero no existen indicios para pensar que puedan estar originando contaminación con arsénico en los suelos circundantes. Por su parte, la deposición atmosférica de arsénico suele provenir de actividades industriales y está en el rango comprendido entre 1-1000 $\mathrm{mg} / \mathrm{m}^{2}$ año (Schroeder y col., 1987), dependiendo de factores como humedad y proximidad a los puntos de emisión. En nuestro caso y dada la ausencia de industrias en el área de estudio, este mecanismo puede ser desechado.

El grado y fuerza de retención de arsénico en los constituyentes del suelo, y por tanto su disponibilidad, puede variar mucho con el tiempo. Quazi y col., 2010 plantean que al aumentar el tiempo de equilibrio entre el suelo y el contaminante (pesticida) se reduce la movilidad de este último y por lo tanto decrece su liberación al medio. Quazi y col., 2010, realizaron un experimento con diferentes suelos a los que añadían un pesticida arsenical para obtener información sobre los resultados de especiación en tiempos diferentes (0, 6 meses, 1 año y 3 años). A tiempo cero, la mayor parte del As era extraído en la fracción soluble, una fracción que depende del tipo de suelo, de la cantidad añadida de pesticida y del tiempo. Después de 6 meses de equilibrado entre el suelo y el pesticida, la fracción soluble disminuye, mientras que la fracción unida a óxidos de Fe y Al aumenta significativamente, con una relación directa entre los contenidos en los óxidos y los de As en esta fracción. A partir de los 6 meses, la fracción de As soluble permanece más o menos constante.

La legislación medioambiental de muchos países considera como peligrosos en suelos un contenido total de arsénico de $50 \mathrm{mg} / \mathrm{kg}$, y hace recomendaciones para su remediación en caso de que este nivel sea superado (Adriano, 2001). En Castilla y León no se ha publicado hasta el momento ninguna orden para establecer los niveles genéricos de referencia de arsénico en suelos contaminados. Por tanto, se aplica el Anexo VII del RD 9/2005, el cual especifica que las comunidades autónomas que no dispongan de niveles genéricos de referencia para metales, podrán adoptar como tales los resultantes de sumar a la concentración media el doble de la desviación típica de las concentraciones existentes en suelos de zonas próximas no contaminadas y con sustratos geológicos de 
similares características. A los efectos de evaluación de la contaminación del suelo, los valores así calculados para metales serán únicos y, por tanto, aplicables a cualquier uso del suelo y atendiendo tanto a la protección de la salud humana como a la protección de los ecosistemas.

\section{VII.2. MUESTREO}

\section{VII.2.1.SOLUCIÓN DEL SUELO}

Las cápsulas porosas se emplean para la extracción de la solución del suelo en condiciones de campo (Goulding y Webster, 1992). Gracias a su coste relativamente barato y su fácil instalación y manejo, permiten el muestreo de solución del suelo con cierta frecuencia. Constan de un tubo de PVC, en uno de cuyos extremos se coloca una cápsula cerámica porosa y en el otro, que es el que sobresale del suelo, un tapón a través del cual se aplica succión, con el fin de mantener en el interior una presión muy baja y prácticamente constante durante varios días.

La instalación de estas cápsulas consistió en introducirlas en el suelo, en un agujero de diámetro ligeramente superior al de la cápsula cerámica. Para facilitar el contacto hidráulico del elemento poroso (cápsula) con el suelo, se coloca en el fondo del agujero e inmediatamente antes de introducir la cápsula, una pasta hecha con agua y el mismo suelo o con caolín. Estudios realizados hablan del peligro que supone la compactación y formación de grietas en el suelo alrededor de las cápsulas, que disminuyen de manera sustancial la superficie de contacto cápsula-suelo y dificultan la extracción de la solución del suelo (Beckmann y col., 1992). Otro hecho a tener en cuenta, es un posible flujo preferencial que puede producirse en la zona de contacto del tubo de la cápsula con el suelo circundante, aunque su impacto sobre la representatividad de la muestra tomada es variable. Se recomienda también, que la succión que se aplica a los tubos que llevan las cápsulas sea sólo ligeramente superior a la tensión del agua en la zona del suelo donde se muestrea (Barbee y Brown, 1986).

Para la instalación de las cápsulas de succión se eligieron tres fincas, dentro de la zona de estudio (Fig. VII.2), asegurándonos de que:

- fueran representativas de la zona investigada,

- las texturas de los suelos fueran muy diferentes, para poder estudiar la influencia que ejerce el tipo de suelo en la retención del arsénico,

- sus cultivos precisaran riegos frecuentes,

- fueran irrigadas con aguas contaminadas con niveles de arsénico superiores a los $50 \mu \mathrm{g} / \mathrm{L}$. 


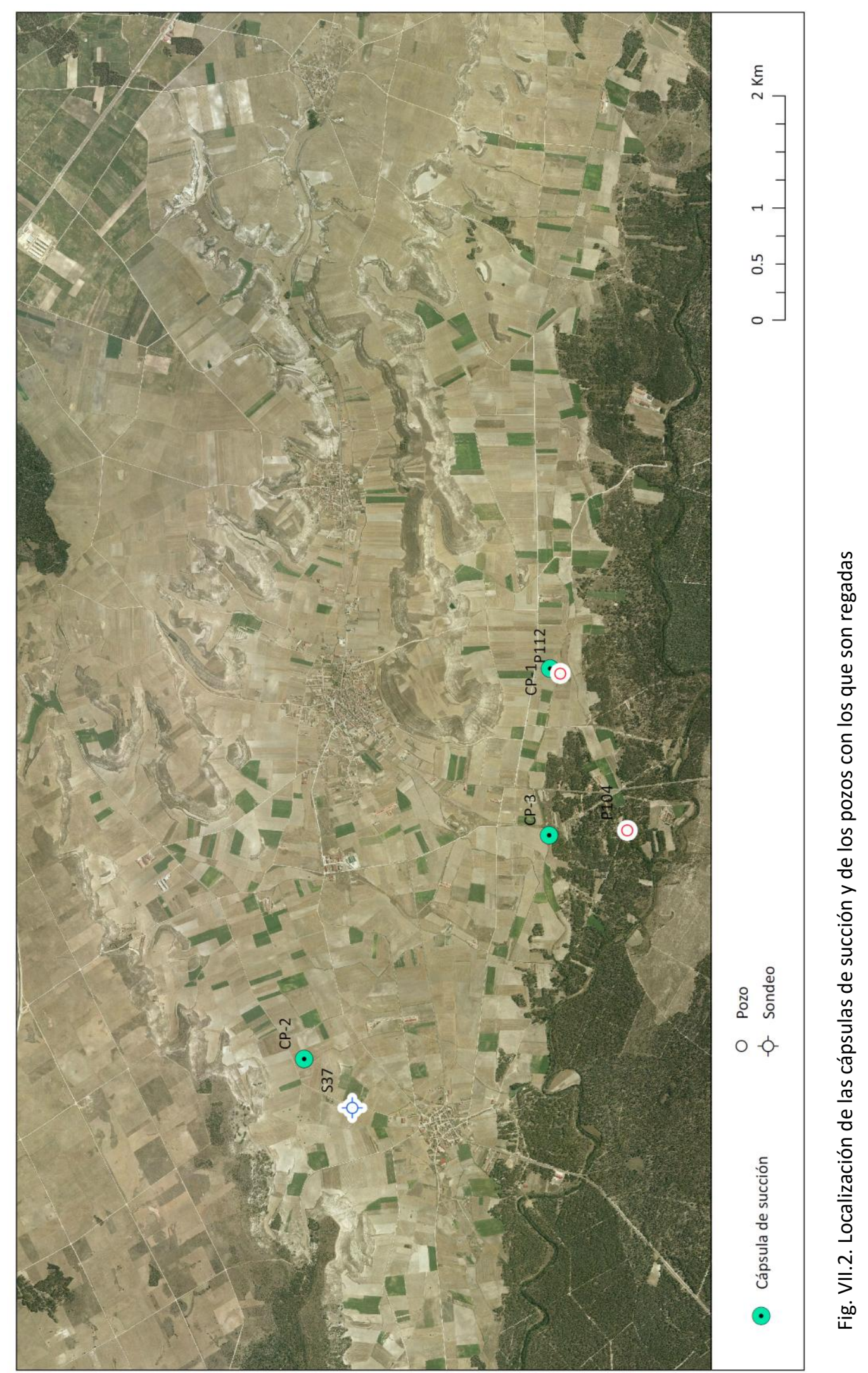


Las cápsulas se ubicaron en tres fincas con suelos de diferente textura: F1, arcilloarenosa; F2, arcillosa y F3, arenosa. Las cápsulas de succión se instalaron en julio de 2003, fecha en la cual los terrenos estaban sembrados con zanahoria en las fincas F1 y F3 y con patata en la finca F2.

Los pozos con los que se regaban las fincas (Fig. VII.2) y las concentraciones de arsénico halladas son las siguientes:

- Finca F1, irrigada con agua procedente del pozo P112 con una concentración de arsénico de aproximadamente $200 \mu \mathrm{g} / \mathrm{L}$.

- Finca F2, sondeo $S 37$ con unos $100 \mu \mathrm{g} / \mathrm{L}$ de arsénico.

- Finca F3, pozo P104 con unos $75 \mu \mathrm{g} / \mathrm{L}$ de arsénico.

Al lado de cada cápsula de succión se instaló un pluviómetro, para recoger el agua que irrigaba el suelo y, si era el caso, el agua de lluvia. El pluviómetro fue de tipo Hellmann formado por dos recipientes metálicos. El de la parte superior tiene en su interior un embudo que permite pasar el agua al recipiente inferior e impide la evaporación del agua que se almacena en el recipiente inferior. Se tuvo la precaución de colocar el pluviómetro en posición vertical, sujeto a un poste y alejado de cualquier obstáculo que pudiera hacer de pantalla e impedir la entrada de agua. Este instrumento recoge el agua de riego y el posible agua de lluvia, correspondiente a una superficie de 1 decímetro cuadrado.

Las cápsulas de succión y los pluviómetros fueron muestreados y vaciados cada 8-15 días, en el periodo comprendido entre julio de 2003 a abril de 2004.

Para obtener el agua de las cápsulas de succión se procedía a su desinstalación, pasando el agua contenida en las mismas a botes de polietileno de alta densidad, que habían sido previamente acondicionados de forma idéntica a los empleados en el muestreo de puntos de agua.

Antes de proceder al muestreo del agua del pluviómetro, se medía su volumen con una probeta graduada y de sección diez veces inferior a la de recepción del pluviómetro, con lo que es posible establecer una relación entre la altura en la probeta y la precipitación en milímetros por metro cuadrado, de manera que cada milímetro de agua en la probeta equivale a un litro por metro cuadrado. El líquido se recogió en botes de polietileno como en el caso anterior.

La codificación de las muestras incluía:

- Fecha

- Identificación de la finca

- Identificación si el agua procedía de la cápsula de succión o del pluviómetro

Adicionalmente, se tomaron muestras de suelo de las tres fincas para su caracterización a nivel superficial, a $0,5 \mathrm{~m}$ y, en el caso de la finca $F 1$, también a $1,5 \mathrm{~m}$. El procedimiento de muestreo del suelo a nivel superficial fue idéntico al utilizado en suelos agrícolas, que se describe más adelante. Para las muestras tomadas a 0,5 y 1,5 m, se utilizó una barrena manual de tamaño pequeño.

La identificación de las muestras se realizó con la siguiente codificación: 
- Fecha

- Identificación del la finca

- Identificación de la profundidad

\section{VII.2.2.SUELOS AGRICOLAS}

Se tomaron, en octubre de 2012, 12 muestras de suelos agrícolas irrigados con agua subterránea contaminada con arsénico, y sus correspondientes contra-muestras recogidas tan cerca como fue posible, pero en suelo no irrigado, al menos, en los doce meses anteriores, con objeto de ver si había diferencias significativas entre ambos tipos de suelos. La Fig. VII.3 presentan los puntos de muestreo sobre la ortofoto de la zona. Las coordenadas de cada punto se confirmaron sobre el terreno con un sistema GPS GARMIN 12XL para facilitar su localización posterior y para la realización de los mapas.

Antes de proceder a la toma de muestra en el punto elegido, se limpia la zona con una azada y se recoge la muestra con una pala recubierta de material plástico, para evitar la posible contaminación metálica. Una vez extraída una cantidad suficiente en el punto de muestreo seleccionado, se procedió a mezclar pequeñas porciones de la misma, seleccionadas aleatoriamente, para fabricar la muestra bruta, que se guarda en bolsas de plástico herméticamente cerradas.

Las bolsas se etiquetan convenientemente de acuerdo con la siguiente codificación;

- Suelos irrigados con aguas contaminadas con arsénico

- Fecha en la que se toma la muestra

- Número identificativo que se correspondía con el punto de agua (pozo o sondeo) con el que eran regados.

- Suelos no irrigados con aguas contaminadas con arsénico al menos en el último año:

- Fecha en la que se toma la muestra

- Número identificativo idéntico al de su contra-muestra.

- Un asterisco $(*)$ detrás del número identificativo.

Una vez en el laboratorio, las muestras de suelo se extendieron sobre papel de filtro en una zona ventilada, y se dejaron secar durante 48 horas para equilibrar su humedad con la del ambiente. Se redujo a continuación el tamaño de los agregados, con ayuda de un rodillo y un martillo de madera y se tamizó la muestra de suelo a través de una malla de $2 \mathrm{~mm}^{2}$ de paso de luz. La fracción tamizada se recogió y guardó dentro de bolsas herméticamente cerradas y perfectamente identificadas. Las determinaciones analíticas se llevaron a cabo sobre esta última fracción. 


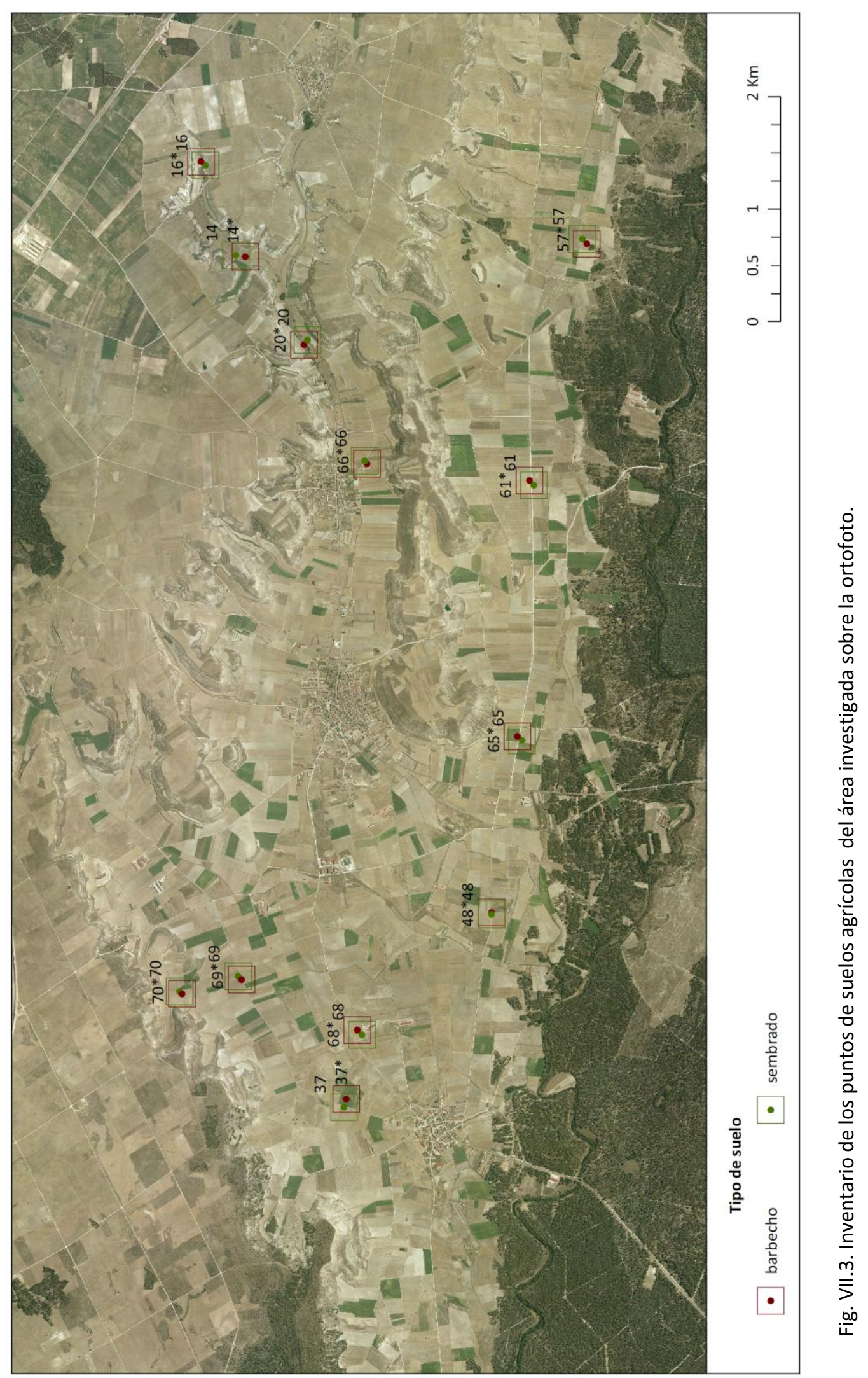




\section{VII.3. PROCEDIMIENTOS ANALÍTICOS}

Todos los procedimientos utilizados en este capítulo para la determinación de las variables físico-químicas de muestras de suelos (pH, C.E, M.O, Carbonatos, Textura, Na, $\mathrm{K}, \mathrm{Ca}$ y $\mathrm{Mg}$ intercambiables, $\mathrm{Fe}, \mathrm{As}, \mathrm{Cr}, \mathrm{Cu}, \mathrm{Mn}, \mathrm{Pb}, \mathrm{V}, \mathrm{Zn}$ y las fases minerales ) y para la determinación de las variables físico-químicas de las muestras de aguas ( $\mathrm{As}, \mathrm{Cl}^{-}, \mathrm{SO}_{4}{ }^{2-} \mathrm{y}$ $\mathrm{NO}_{3}{ }^{-}$) se encuentran ya descritos en los apartados de procedimientos del capítulo IV (Estudio Hidroquímico) y del capítulo V (Estudio Geoquímico).

\section{VII.4. RESULTADOS}

\section{VII.4.1.CÁPSULAS DE SUCCIÓN}

Se analizaron los contenidos de arsénico en las muestras de suelos recogidas en los tres puntos de muestreo. Los resultados numéricos de arsénico $(\mathrm{mg} / \mathrm{kg})$ se muestran a continuación en la Tabla VII.1 y en la Fig. VII.4 se han representado gráficamente.

Tabla VII.1. Concentraciones de arsénico de las distintas muestras de suelos tomadas en las tres fincas de estudio.

\begin{tabular}{lcc} 
MUESTRA & Profundidad $(\mathbf{m})$ & As $(\mathbf{m g} / \mathbf{k g})$ \\
\hline F1 & 0,50 & 8,58 \\
F1 & 1,00 & 1,42 \\
F1 & 1,50 & 3,28 \\
F2 & 0,50 & 15,29 \\
F2 & 1,00 & 12,07 \\
F3 & 0,50 & 0,72 \\
F3 & 1,00 & 0,53 \\
\hline
\end{tabular}

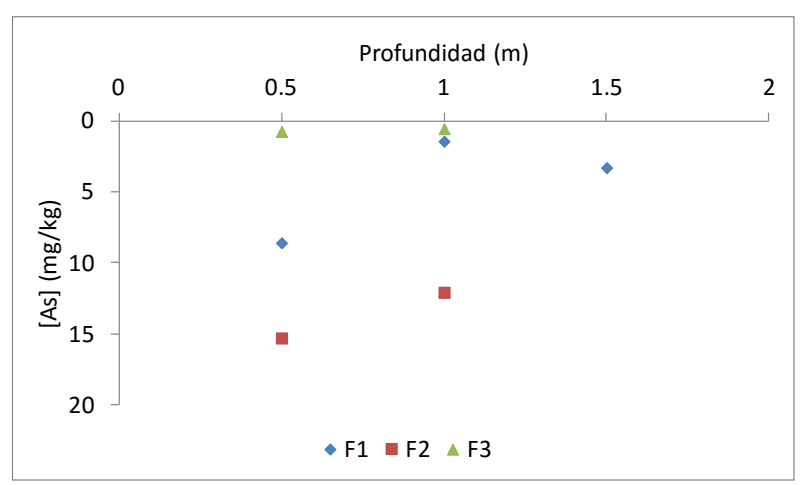

Fig. VII.4. Representación de las concentraciones de arsénico en las diferentes profundidades de suelo muestreadas. 
Las muestras de agua, obtenidas de los lisímetros y de los pluviómetros, fueron caracterizadas determinándose un total de 6 parámetros físicos y químicos en las cápsulas de succión y de 5 en los pluviómetros, que se resumen en la Tabla VII.2 junto con las unidades en las que se han expresado los resultados. Los resultados numéricos se muestran en la Tabla A.V.1, Tabla A.V.2 y Tabla A.V.3 del Anexo.

Tabla VII.2. Parámetros analíticos analizados en las cápsulas de succión y en los pluviómetros.

\begin{tabular}{lccc} 
Parámetro analítico & Cápsula de succión & Pluviómetro & Unidades \\
\hline Volumen & $x$ & $x$ & $\mathrm{~m}^{3}$ \\
Presión & $x$ & & in $\mathrm{Hg}$ \\
Aniones : $\mathrm{Cl}^{-}, \mathrm{NO}_{3}{ }^{-}, \mathrm{SO}_{4}{ }^{2-}$ & $x$ & $x$ & $\mathrm{mg} / \mathrm{L}$ \\
As (soluble en ácido nítrico) & $x$ & $x$ & $\mu \mathrm{L} / \mathrm{L}$ \\
\hline
\end{tabular}

Las siguientes figuras muestran la evolución temporal de la concentración de arsénico y cloruro en pluviómetros y cápsulas de succión, para los tres puntos muestreados.

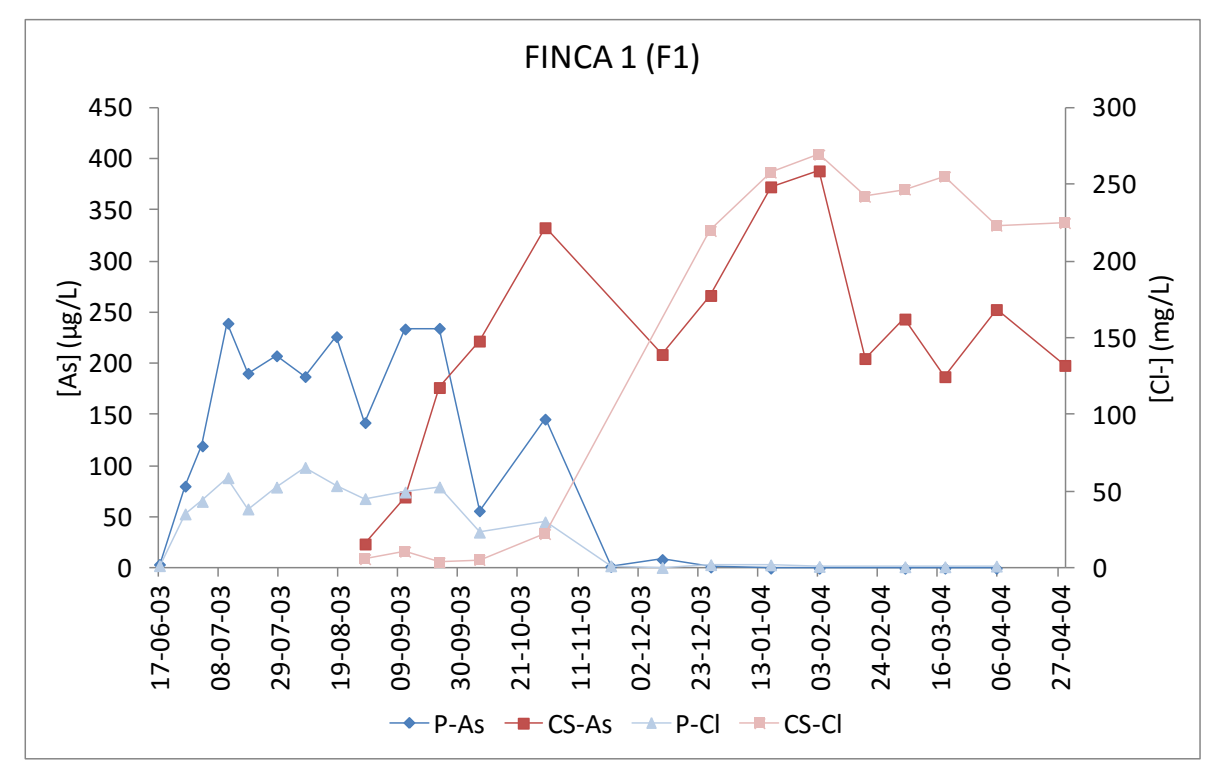

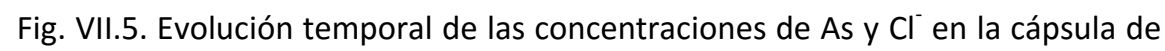
succión (CS) y pluviómetro (P) de la finca F1. 


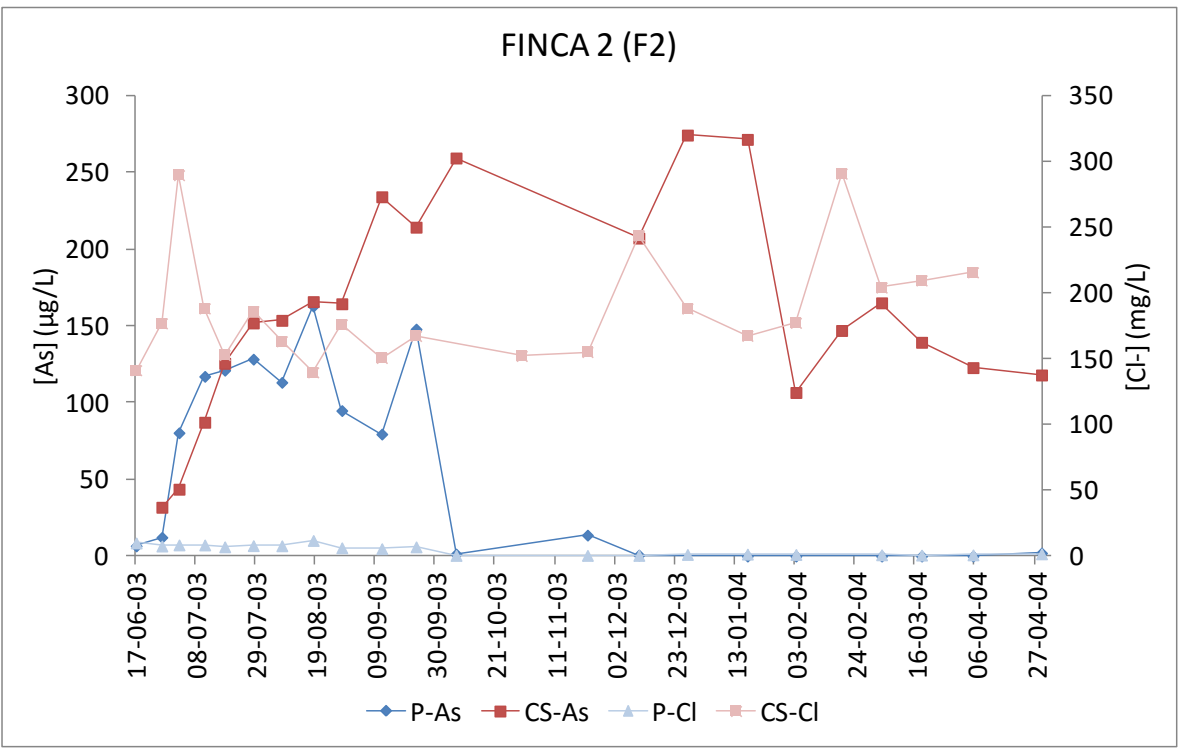

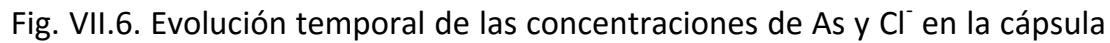
de succión (CS) y pluviómetro (P) de la finca F2.

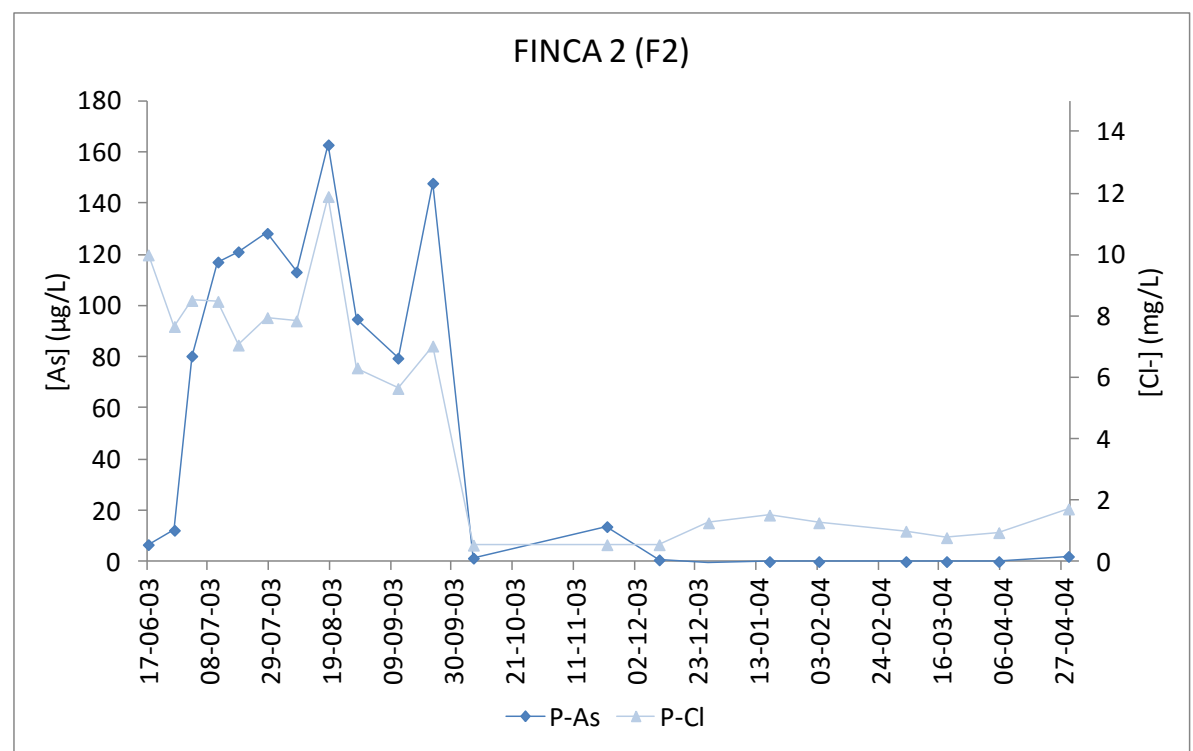

Fig. VII.7. Evolución temporal de las concentraciones de $\mathrm{As}$ y $\mathrm{Cl}^{-}$en el pluviómetro de la finca F2. 


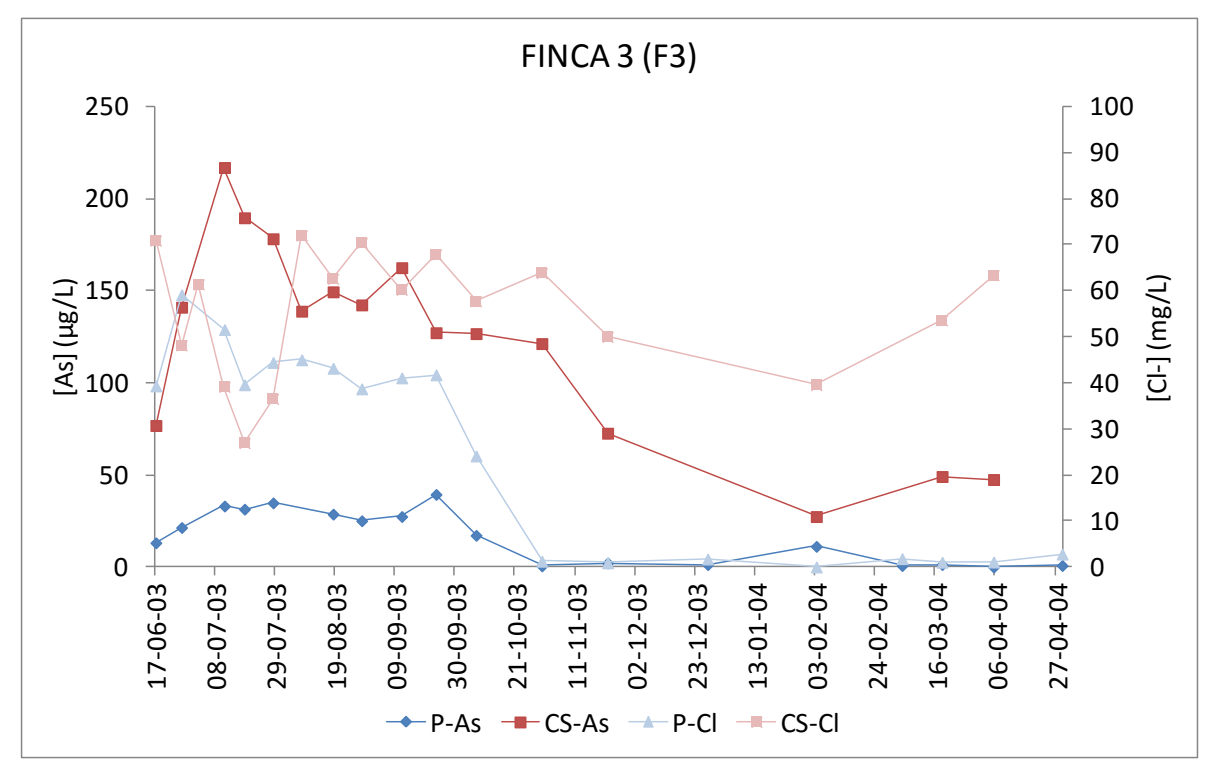

Fig. VII.8. Evolución temporal de las concentraciones de As y $\mathrm{Cl}^{-}$en la cápsula de succión (CS) y pluviómetro (P) de la finca F3.

El cloruro se emplea como trazador ambiental ya que es muy soluble, no se absorbe ni reacciona químicamente en las aguas y se determina con facilidad (Ruiz y col., 2003). En todos los casos, las variaciones temporales de arsénico y cloruro son muy similares, tanto en las cápsulas de succión como en los pluviómetros, por lo que podemos asumir que solo hay una fuente de origen para el arsénico.

En la finca F1, arcillo-arenosa, la concentración de arsénico del pluviómetro alcanza sus máximos valores (200 - $250 \mu \mathrm{g} / \mathrm{L}$ de As) durante la época de riego. Cuando finalizan los riegos, el agua del pluviómetro procede únicamente del agua de lluvia, y es, por tanto, prácticamente inexistente. Por el contrario, la concentración de arsénico de la cápsula de succión, se estabiliza en torno a $200 \mu \mathrm{g} / \mathrm{L}$ una vez ha finalizado la época de riego, apareciendo dos picos máximos que se discutirán más adelante.

En el agua del pluviómetro de la finca F2, arcillosa, muestra una variación temporal similar a la de la finca F1, mostrando las concentraciones de arsénico más elevadas, 125 $\mu \mathrm{g} / \mathrm{L}$, durante la época de riego. La concentración de arsénico en las cápsulas de succión, empieza a aumentar desde el inicio de la época de riego, hasta alcanzar $150 \mu \mathrm{g} / \mathrm{L}$ de As, llegando hasta $250 \mu \mathrm{g} / \mathrm{L}$ desde primeros de septiembre hasta mediados de enero del año siguiente, y a partir de esta fecha vuelve a estabilizarse en $150 \mu \mathrm{g} / \mathrm{L}$ de arsénico.

En la finca F3, arenosa, la concentración del pluviómetro se mantiene en torno a $40 \mathrm{\mu g} / \mathrm{L}$ de arsénico hasta la finalización de la época de riego. Una vez finalizado éste las concentraciones de arsénico son despreciables, ya que proceden solamente del agua de Iluvia. Las cápsulas de succión recogen las mayores concentraciones de arsénico durante la época de riego (en torno a $200 \mu \mathrm{g} / \mathrm{L}$ ) y, una vez finalizado el riego, las concentraciones de arsénico disminuyen gradualmente hasta $50 \mu \mathrm{g} / \mathrm{L}$ de arsénico. 


\section{VII.4.2.SUELOS AGRICOLAS}

Las 24 muestras de suelos agrícolas recogidas, fueron caracterizadas en base a un total de 27 parámetros físicos, químicos y mineralógicos, que se resumen en la Tabla VII.3, junto con las unidades en las que se han expresado los resultados. Los resultados numéricos se muestran en la Tabla A.V.4 del Anexo.

Tabla VII.3. Parámetros físico-químicos analizados en las muestras de suelos agrícolas.

\begin{tabular}{|l|l|}
\hline Parámetro analítico & Unidades \\
\hline $\mathrm{pH}$ (en extracto acuoso) & Unidades de $\mathrm{pH}$ \\
\hline Conductividad (en extracto acuoso) & $\mu \mathrm{S} / \mathrm{cm}$ \\
\hline Materia orgánica & $\%$ \\
\hline Carbonatos & $\% \mathrm{CaCO}_{3}$ \\
\hline Textura (arena, limo, arcilla) & $\%$ \\
\hline $\mathrm{Na}, \mathrm{K}, \mathrm{Ca}$ y Mg intercambiables (solubles en acetato amónico 1M) & $\mathrm{g} / \mathrm{Kg}$ \\
\hline Pintercambiable (soluble en bicarbonato sódico) & $\mathrm{mg} / \mathrm{Kg}$ \\
\hline $\begin{array}{l}\text { Metales pseudototales (solubles en ácido nítrico): } \\
\text { Mayoritarios: Fe } \\
\text { Traza: As, Cr, Cu, Mn, Pb, V, Zn }\end{array}$ & $\mathrm{g} / \mathrm{Kg}$ \\
\hline $\begin{array}{l}\text { Fases minerales: } \\
\text { Cuarzo, Plagioclasa, Ortosa, Calcita, Dolomita, Yeso, Filosilicatos }\end{array}$ & $\%$ \\
\hline
\end{tabular}

\section{VII.4.2.1DISTRIBUCIÓN ESPACIAL}

En la Fig. VII.9 se han representado, sobre la ortofoto de la zona de estudio, las concentraciones de arsénico halladas en las muestras de suelos agrícolas. Todos los valores, salvo en tres casos, son inferiores a $10 \mathrm{mg} / \mathrm{kg}$. En general, las concentraciones de arsénico en suelos sembrados y en barbecho son similares, excepto para los situados en el suroeste de la zona de estudio, donde las concentraciones de los suelos en barbecho son menores que en los sembrados.

Teniendo en cuenta que el contenido de arsénico está influenciado por la diferente composición mineralógica del suelo se han representado los contenidos mineralógicos como diagramas circulares (Fig. VII.10). Se puede apreciar que los filosilicatos son los componentes mayoritarios seguidos por el cuarzo. Todas las parejas de muestras presentan similares porcentajes de minerales, a excepción de las muestras $65-65^{*}$ y 57 - 57*, localizadas en la zona suroeste, en las que cabe destacar que el contenido en filosilicatos es menor en las muestras en barbecho que en las sembradas. 


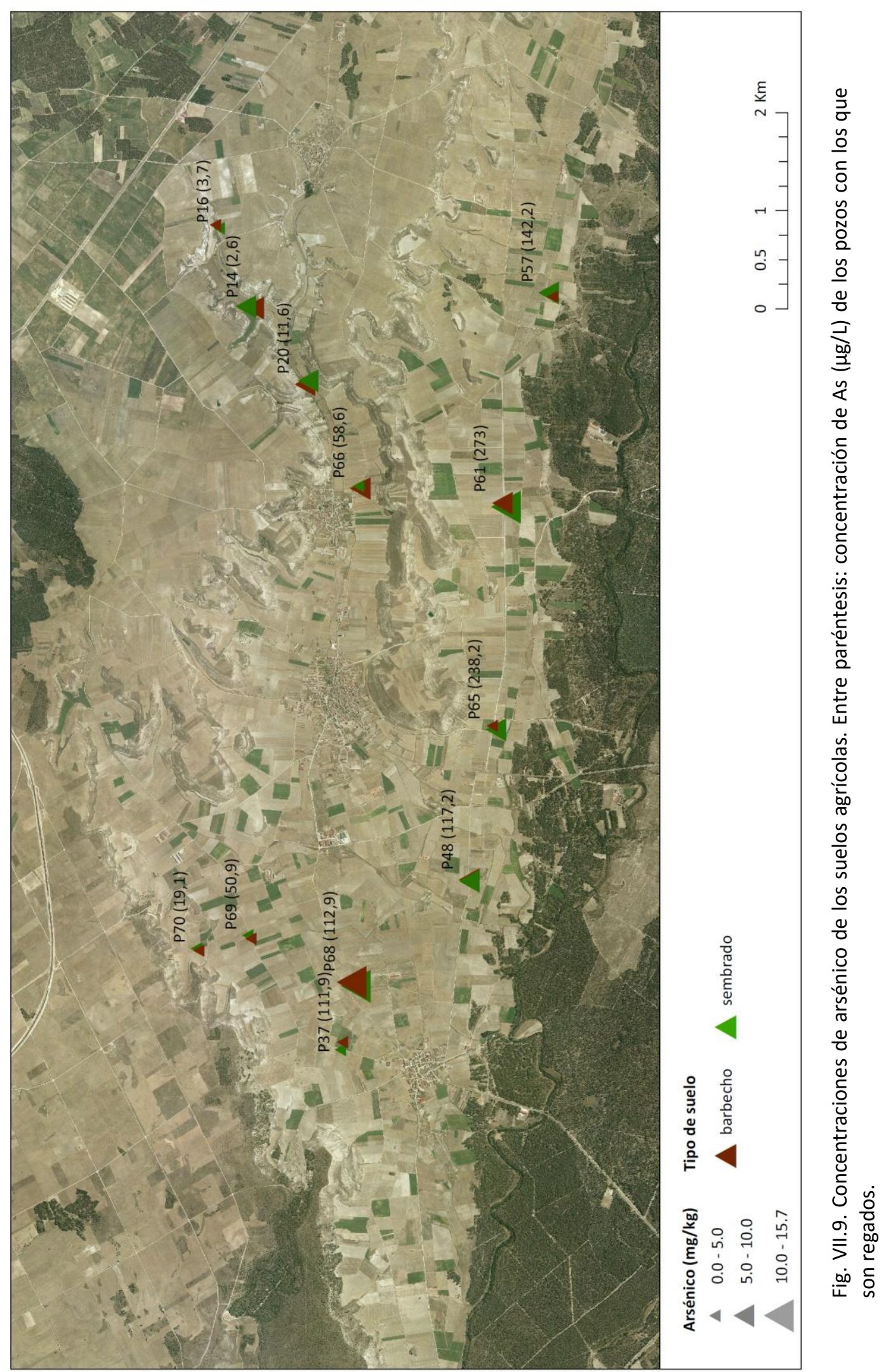




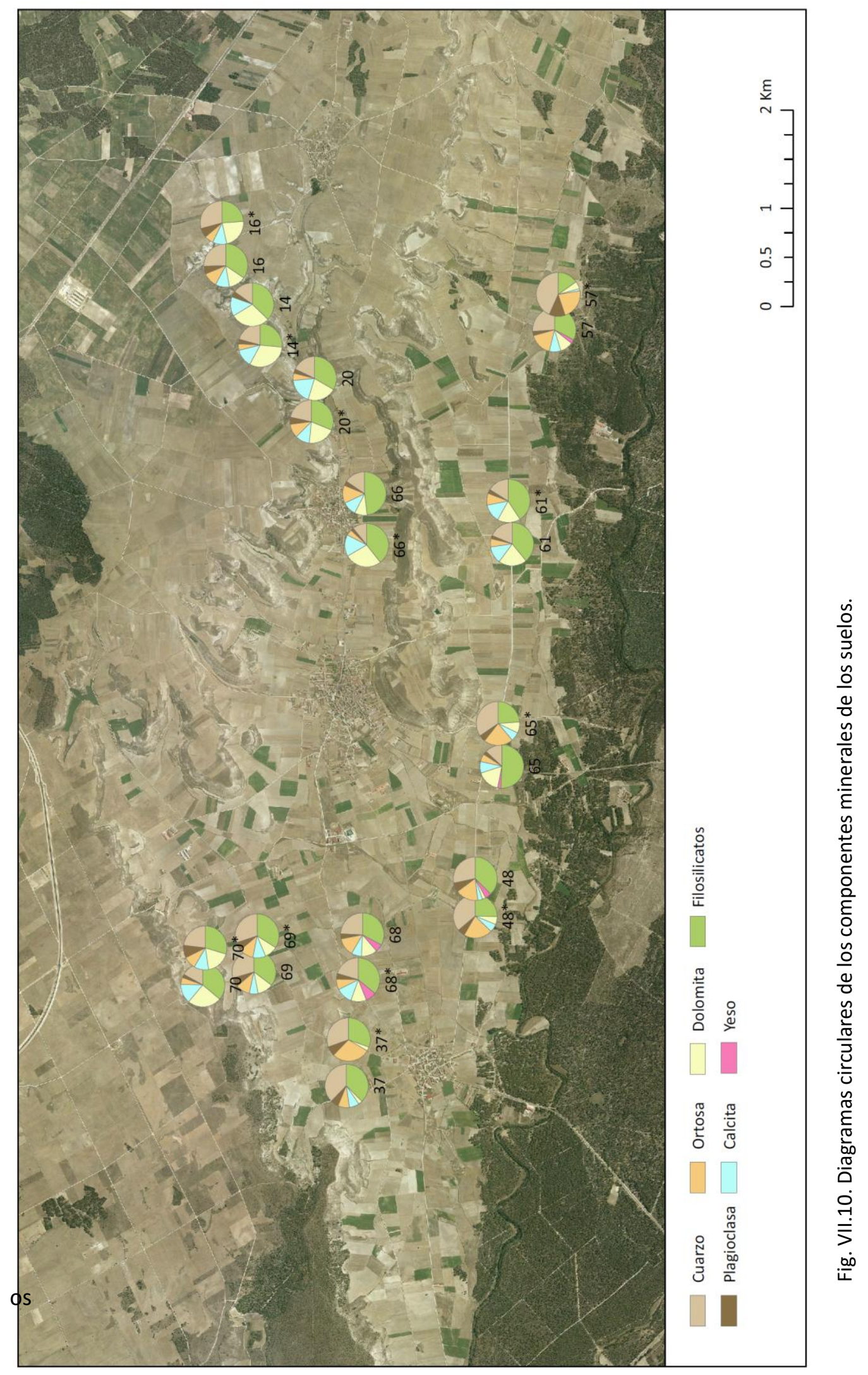


Se han comparado las concentraciones de arsénico halladas en los suelos agrícolas, con valores encontrados por otros autores para suelos no contaminados (Tabla VII.4).

Tabla VII.4. Concentraciones medias de arsénico de los suelos agrícolas, NGR y niveles propuestos por otros autores.

\begin{tabular}{lll} 
Ref & $\begin{array}{l}\text { As } \\
(\mathbf{m g} / \mathbf{k g})\end{array}$ & Observaciones \\
\hline $\begin{array}{l}\text { El presente estudio: } \\
\text { Media suelos agrícolas }\end{array}$ & 6,35 & \\
$\begin{array}{l}\text { Valores medios pubicados: } \\
\text { Taylor y McLennan, 1985 }\end{array}$ & 13 & $\begin{array}{l}\text { Rocas sedimentarias } \\
\text { Gomez y col., 2006 }\end{array}$ \\
$\begin{array}{l}\text { Garcia-Lorenzo y col., 2015 } \\
\text { Cornelis y col., 2005 }\end{array}$ & 18,8 & $\begin{array}{l}\text { Rocas con alto contenido en filosilicatos } \\
\text { (Murcia) }\end{array}$ \\
Chen y col., 2001 & $1-40$ & Suelos no contaminados \\
\end{tabular}

La media de los suelos agrícolas es similar o mas bajas que los niveles en contrados por otros autores para suelos no contaminados.

Hay que recordar que los suelos agrícolas son suelos muy alterados por la intervención humana, y que en la adsorción/desorción de arsénico influyen muchos factores que pueden hacer que en determinados momentos se favorezca la adsorción o desorción de este contaminante. Otro hecho a tener en cuenta es que los metales de zonas contaminadas suelen ser más solubles que aquellos que proceden de zonas no contaminadas (Wilcke; 1998).

\section{VII.4.2.2ESTADÍSTICA DESCRIPTIVA}

La Tabla VII.5 presenta un resumen estadístico de los resultados encontrados al analizar los suelos sembrados y en barbecho. A partir de los mismos, se pretende comprobar la existencia de alguna pauta que nos ayude a comprobar si en nuestra zona de estudio las prácticas agrícolas (aportes de fertilizantes, los riegos en el periodo estival, etc) influyen en los mecanismos de movilización del arsénico en los suelos agrícolas.

Se han calculado los mismos estadísticos que en capítulos anteriores, salvo en la prueba de normalidad, donde el valor $\mathrm{p}$ se ha obtenido a través de la prueba de normalidad de Shapiro-Wilk, más apropiado para tamaños de muestra pequeños, como es el caso. Al igual que la prueba de Kolmogorov-Smirnov nos ha permitido establecer si las variables siguen o no una distribución normal. En negrita se han señalado las variables que siguen una distribución normal (valor $p>0,05$ ).

En todos los casos se ha asignado valor cero a todos aquellos valores por debajo del límite de detección. 


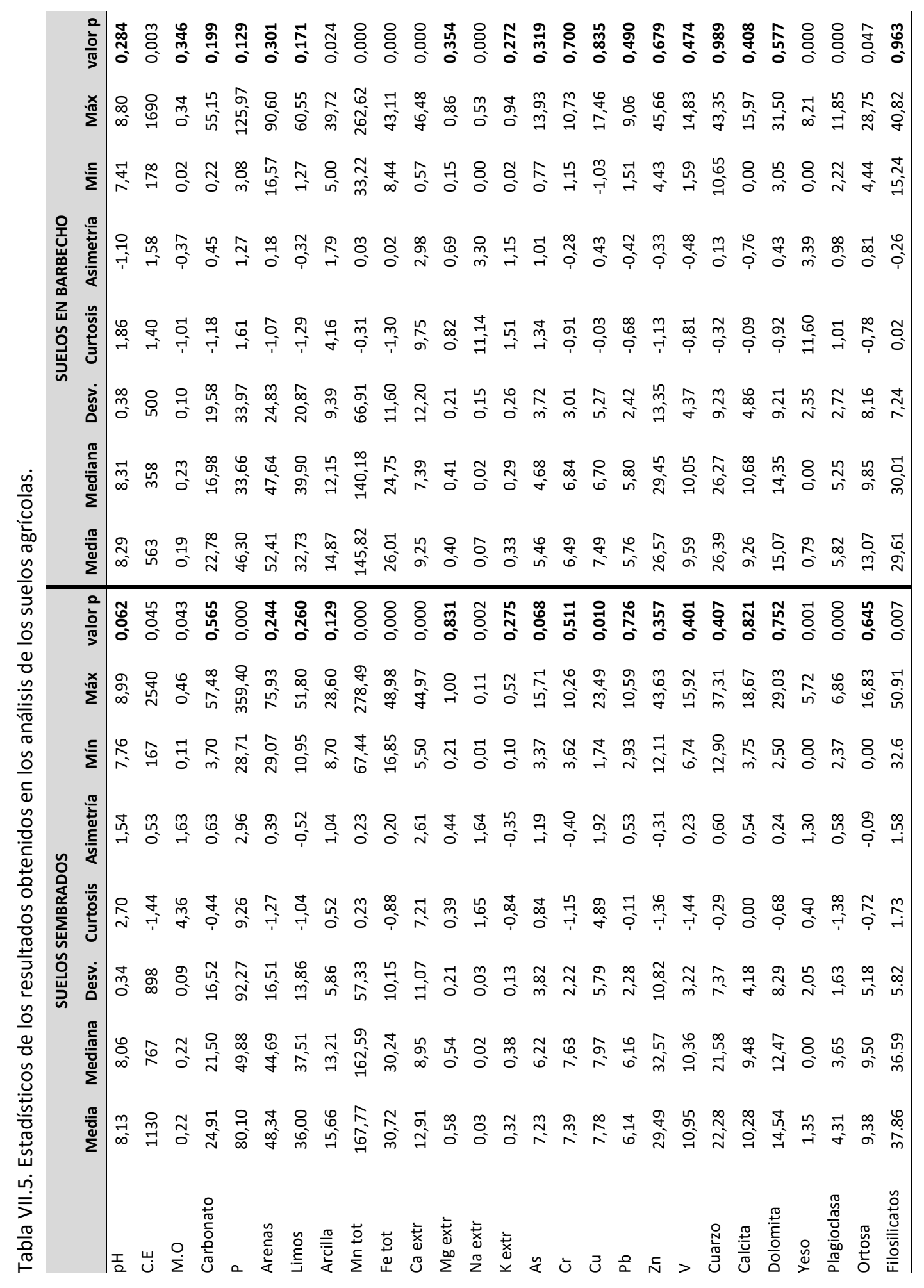



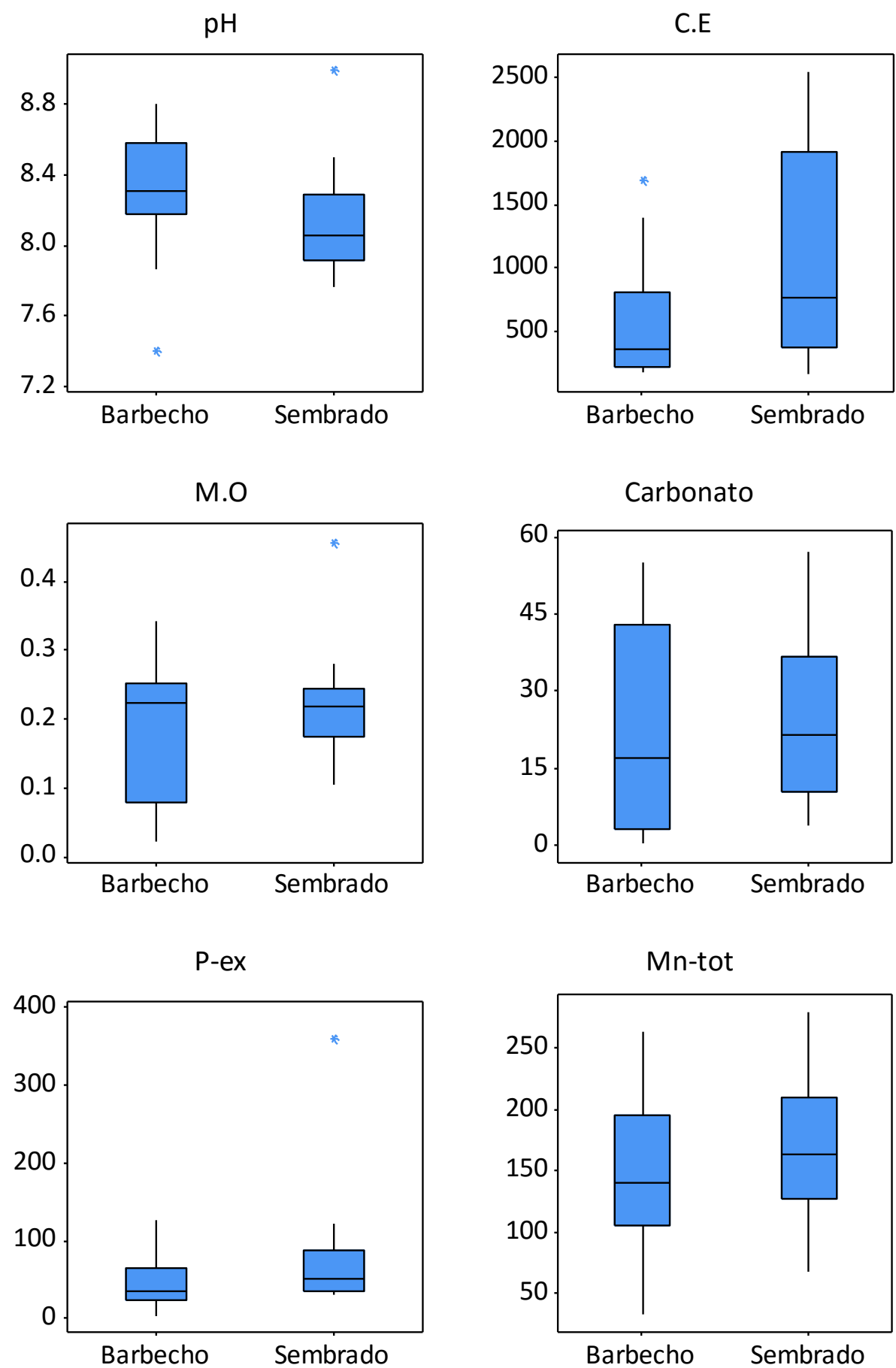

Fig. VII.11. Representación de los datos obtenidos en box-plot según pertenezcan a suelos sembrados o en barbecho. 
Fe-tot

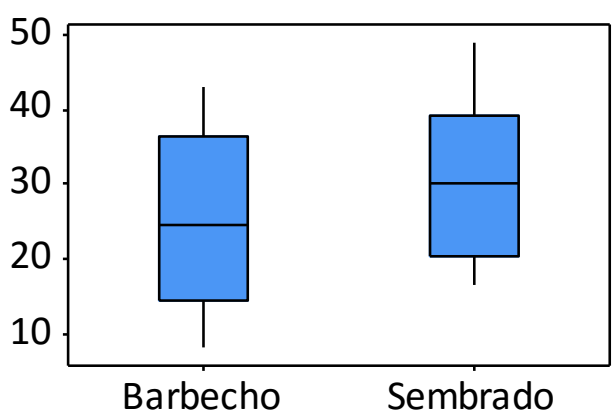

Mg-ex

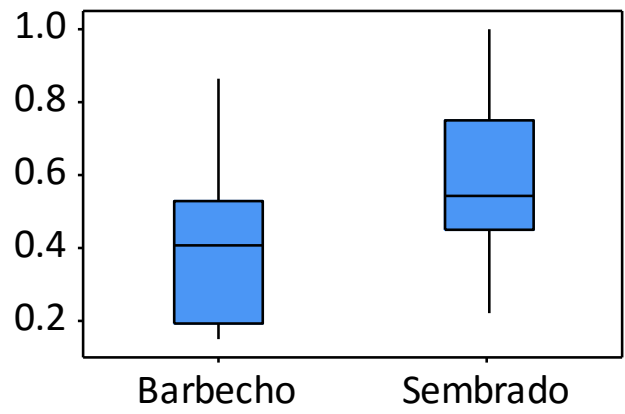

K-ex

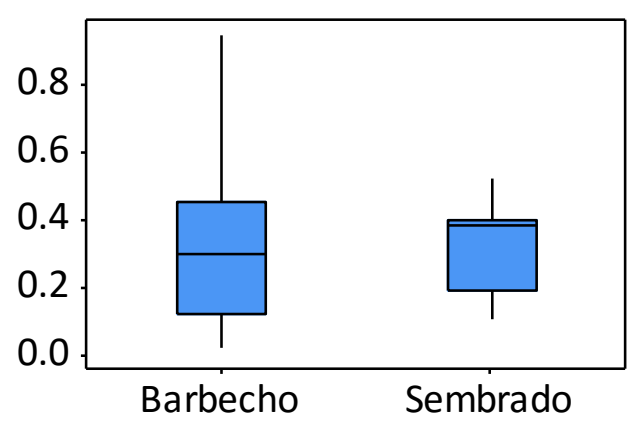

$\mathrm{Cr}$

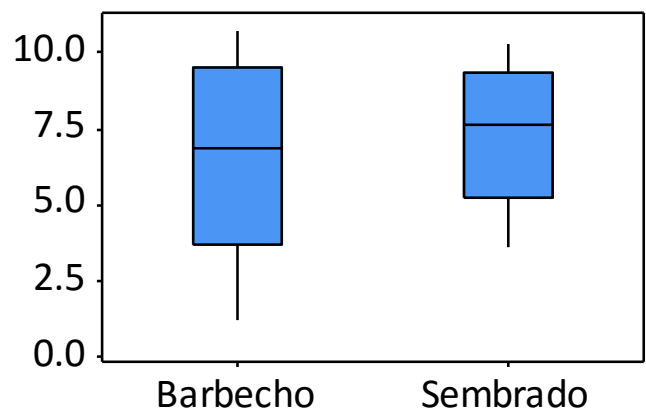

Ca-ex

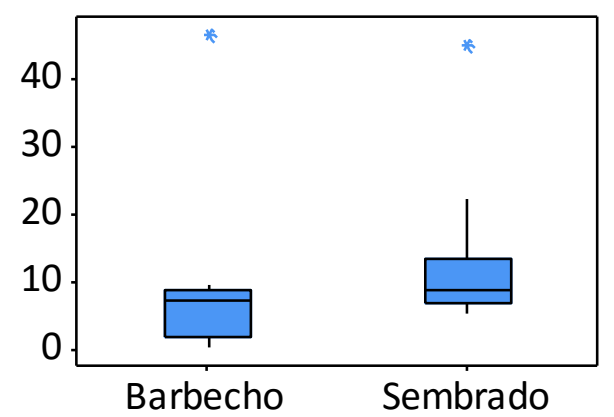

Na-ex

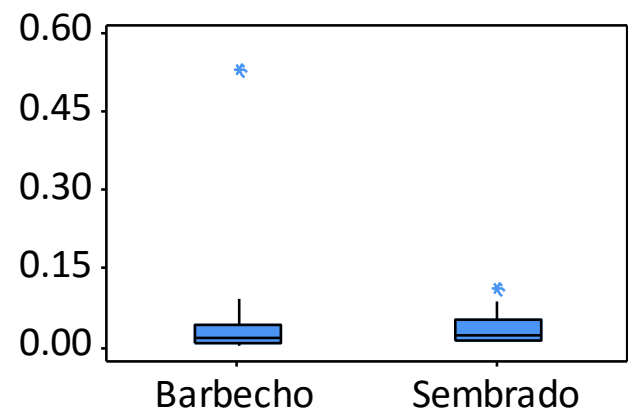

As

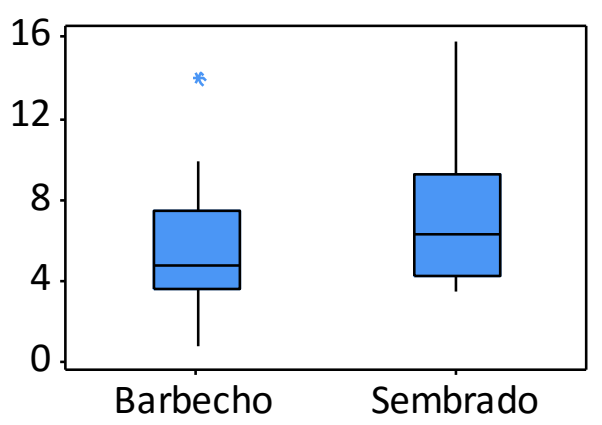

$\mathrm{Cu}$

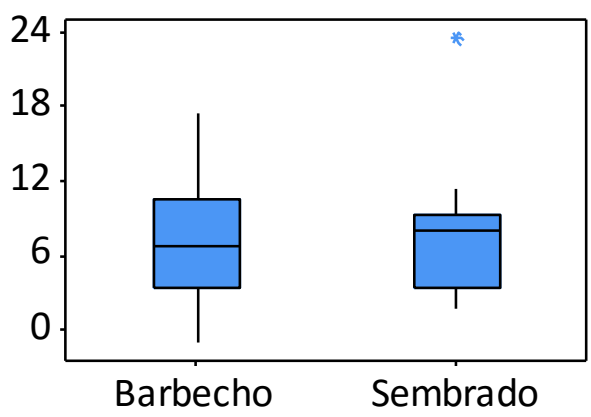

Fig. VII.11. Continuación 

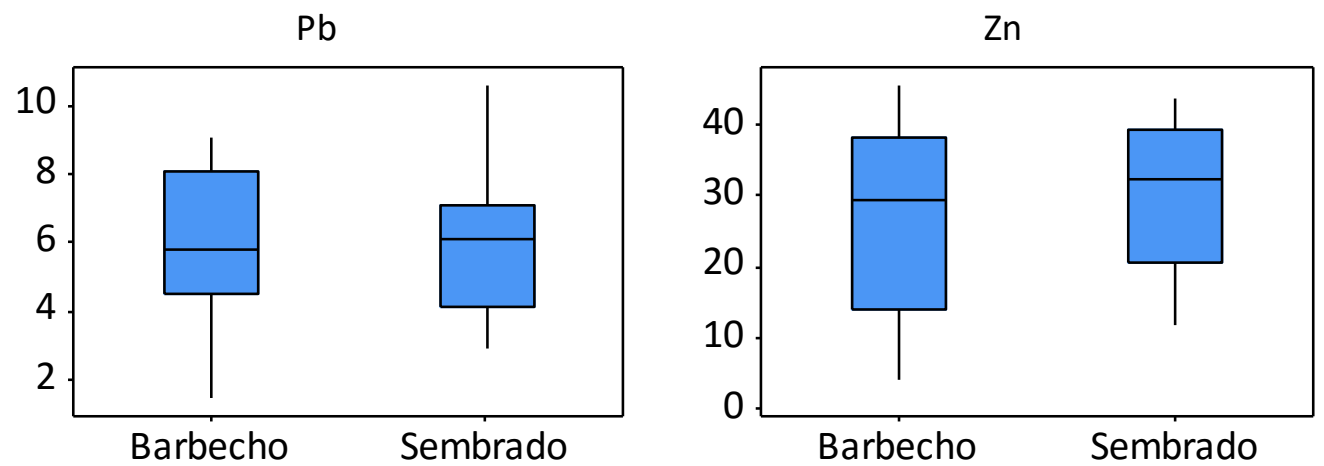

V
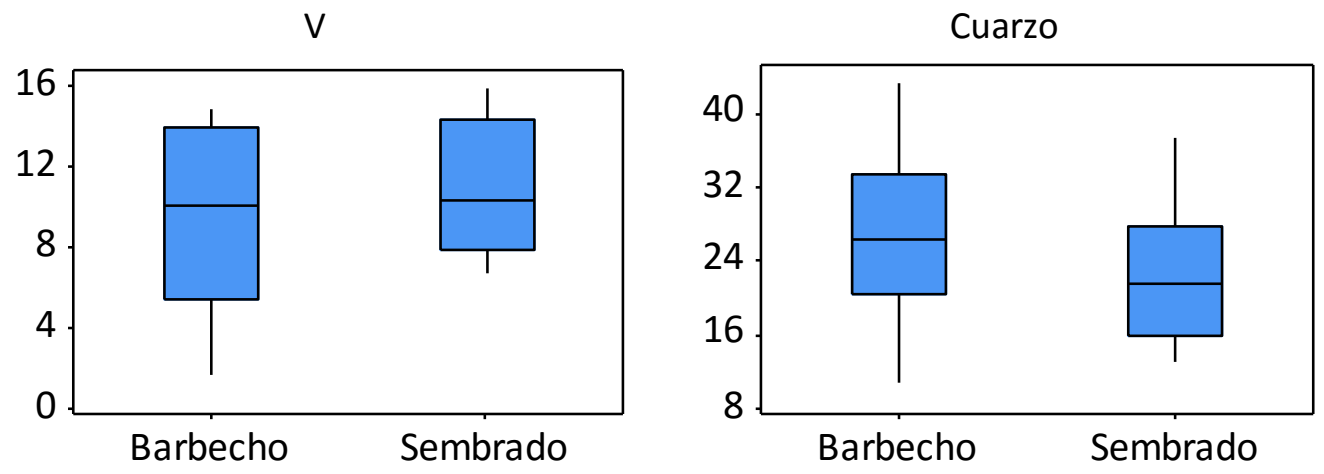

Ortosa
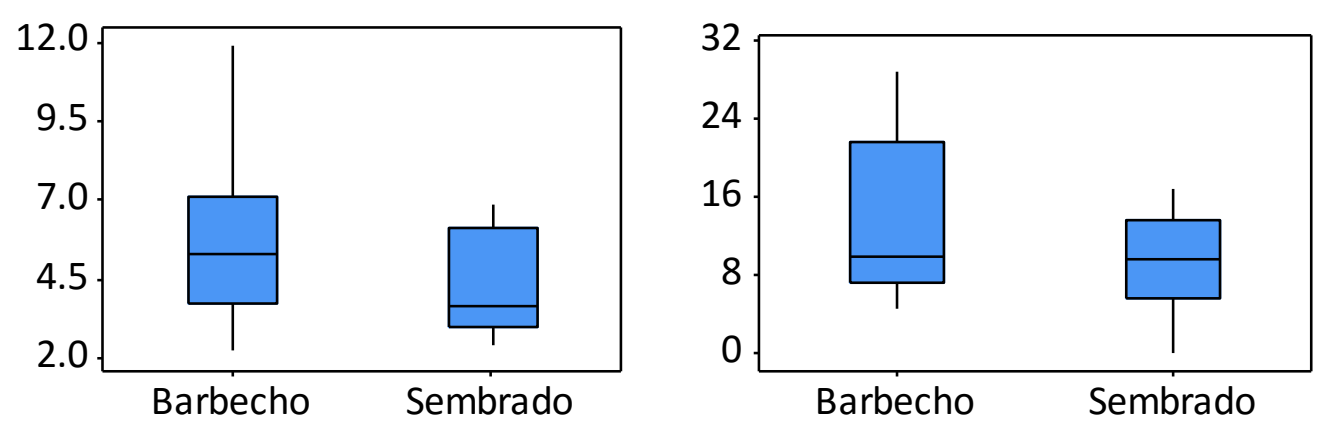

Calcita

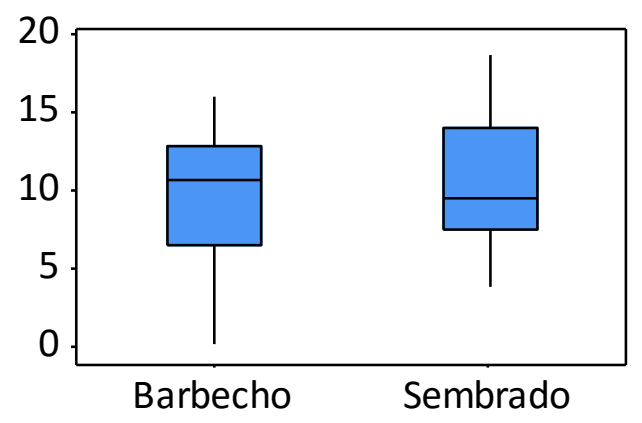

Fig. VII.11. Continuación

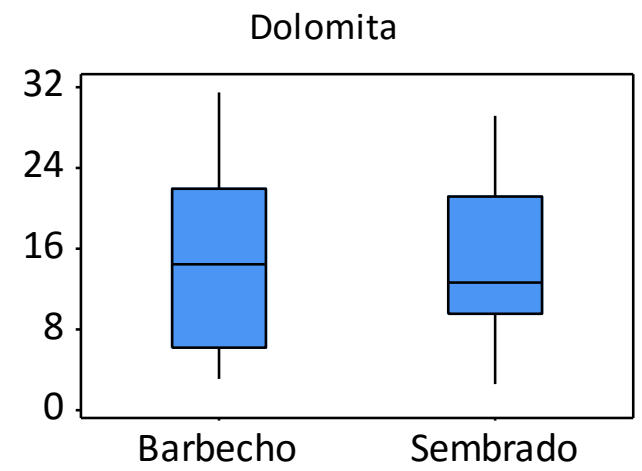


Yeso

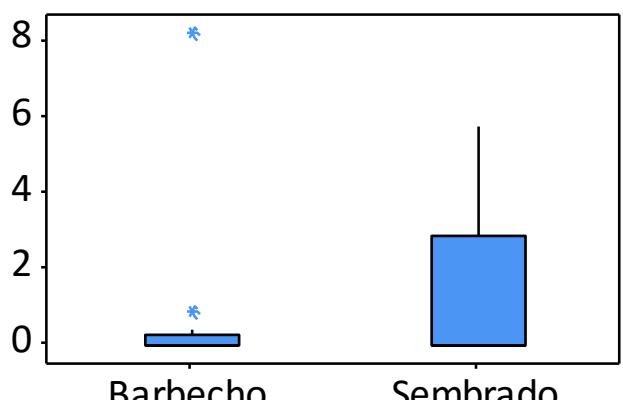

Barbecho Sembrado
Filosilicatos

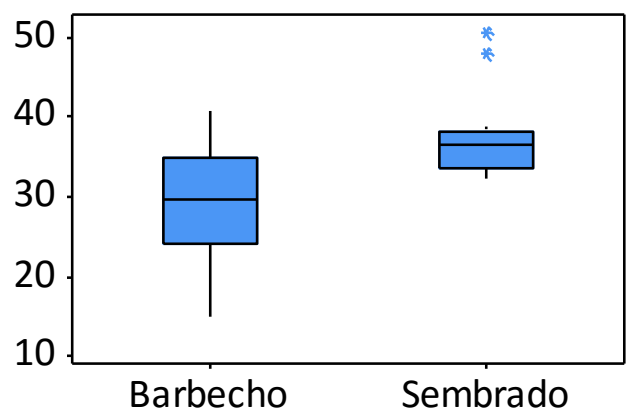

Fig. VII.11. Continuación

De la observación de los datos de la Tabla VII.5, se aprecia que los parámetros conductividad eléctrica, filosilicatos y fósforo, presentan valores de la media y la mediana superiores en suelos agrícolas sembrados respecto de sus homólogos en barbecho. También se observa esa misma diferencia, aunque no de forma tan notable, en parámetros como el calcio extraíble, y los metales (arsénico, cromo, plomo y zinc).

El manganeso y el fósforo presentan los mayores valores de desviación estándar, tanto en suelos sembrados como en barbecho. Sin embargo, el fósforo presenta la mayor dispersión en suelos sembrados, lo que puede ser debido a la distinta dosificación de los fertilizantes y abonos utilizados en las diferentes parcelas.

La Fig. VII.9 muestra los resultados experimentales en forma de diagramas de cajas y bigotes (boxplot), lo cual permite llevar a cabo una comparación rápida de las distribuciones de los diferentes parámetros analizados, correspondientes a los dos tipos de suelos estudiados.

A grandes rasgos, se puede observar que las formas y rangos de valores son similares para ambas categorías. Para comprobarlo, se ha llevado a cabo una prueba de significación que se presenta en la Tabla VII.6. Si el valor $p(1)>0,05$, entonces las diferencias entre ambos tipos de suelos siguen una distribución normal y aplicaremos la pureba $t$ de student para verificar si existen diferencias significativas. En cambio, si p(1) $<0,05$ las diferencias no siguen una distribución normal y aplicaremos la prueba de Wilcoxon. El valor $\mathrm{p}(2)$, refleja el resultado de la prueba $\mathrm{t}$ o la de Wilcoxon, según corresponda. En ambos casos, si dicho valor es inferior a 0,05, existen diferencias significativas entre suelos sembrados y en barbecho, lo cual resultar ser el caso de $\mathrm{pH}$, C.E, As y filosilicatos.

Tabla VII.6. Prueba t de medidas emparejadas (prueba de dos colas)

\begin{tabular}{cccc} 
Parámetro & Valor $\mathbf{p ~ ( 1 )}$ & Prueba & Valor $\mathbf{p ~ ( 2 )}$ \\
\hline As & 0,292 & t de Student & 0,028 \\
pH & 0,001 & Wilcoxon & 0,034 \\
C.E & 0,058 & Wilcoxon & 0,005 \\
M.O & 0,680 & t de Student & 0,219 \\
CO3 & 0,274 & t de Student & 0,633 \\
P-ex & 0,003 & Wilcoxon & 0,117 \\
Ca-ex & 0,109 & t de Student & 0,061
\end{tabular}




\begin{tabular}{lccc} 
Parámetro & Valor $\mathbf{p ~ ( 1 )}$ & Prueba & Valor $\mathbf{p ~ ( 2 )}$ \\
\hline Mg-ex & 0,952 & t de Student & 0,079 \\
Na-ex & 0,000 & Wilcoxon & 0,875 \\
K-ex & 0,303 & t de Student & 0,877 \\
Arenas & 0,755 & t de Student & 0,525 \\
Limos & 0,613 & t de Student & 0,496 \\
Arcilla & 0,014 & Wilcoxon & 0,286 \\
V & 0,252 & t de Student & 0,273 \\
Cr & 0,325 & t de Student & 0,184 \\
Mn & 0,379 & t de Student & 0,173 \\
Cu & 0,868 & t de Student & 0,895 \\
Zn & 0,557 & t de Student & 0,392 \\
Pb & 0,985 & t de Student & 0,581 \\
Fe & 0,087 & t de Student & 0,105 \\
Cuarzo & 0,336 & t de Student & 0,128 \\
Plagiocl & 0,013 & Wilcoxon & 0,195 \\
Ortosa & 0,299 & t de Student & 0,152 \\
Calcita & 0,427 & t de Student & 0,459 \\
Dolomita & 0,129 & t de Student & 0,807 \\
Yeso & 0,033 & Wilcoxon & 0,249 \\
Filosilicatos & 0,522 & t de Student & 0,006 \\
\hline
\end{tabular}

\section{VII.4.2.3 CORRELACIÓN ENTRE LOS PARÁMETROS INVESTIGADOS}

El estudio de las correlaciones existentes entre los valores experimentales de los diferentes parámetros analizados, puede ayudarnos a comprobar si las prácticas agrícolas influyen en la movilización/retención del arsénico en la zona de estudio.

En la Tabla A.V.5 y Tabla A.V.6 del Anexo se recogen los coeficientes de correlación bivariada entre los parámetros analizados en ambas categorías (suelos sembrados o en barbecho). Puesto que hay parámetros analizados en ambos tipos de suelos que no sigue una distribución normal, se han aplicado pruebas paramétricas y no paramétricas. Así, la parte inferior de las tablas muestra los coeficientes de correlación de Pearson ( $r$ ), mientras que por encima de la diagonal, se muestran los coeficientes de correlación de Spearman $\left(r_{s}\right)$, más adecuados para el caso de distribuciones no simétricas. Los valores críticos para ambos coeficientes de correlación, con un nivel de significación $\alpha=0,05$ y $n$ $2=12-2=10$ grados de libertad, son $r_{\text {crit }}=0,576$ para Pearson, $y r_{\text {crit }}=0,587$ para Spearman.

Para una mejor visualización de las correlaciones positivas y/o negativas, se han representado los mapas de colores (heat map) que aparecen en la Fig. VII.12 donde las celdas en tonos fríos (azules y verdes) corresponden a las correlaciones negativas, mientras que las de tonos cálidos (amarillos y rojos) corresponden a las positivas, siendo la correlación tanto más negativa o positiva cuanto más intenso es el color.

De la comparación de los mapas de colores de ambas categorías, cabe destacar que las correlaciones entre los parámetros estudiados son en general mayores y más positivas en los suelos en barbecho que en los suelos sembrados. Esto puede deberse a que durante las prácticas agrícolas, se introducen modificaciones en los suelos (agua de riego, abonos, fertilizantes,...) que con el tiempo terminan siendo amortiguadas por el suelo. 


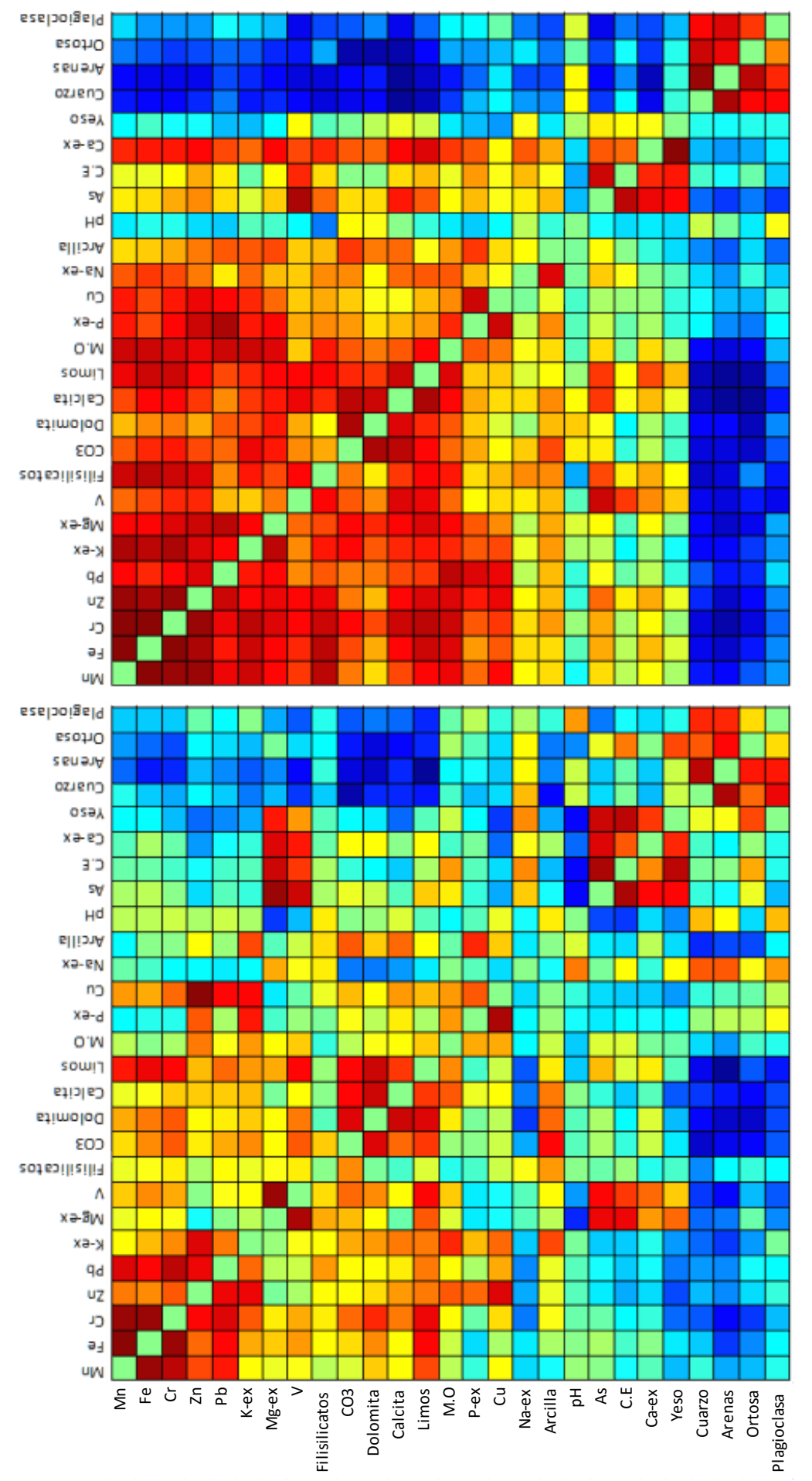

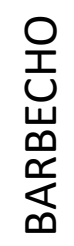

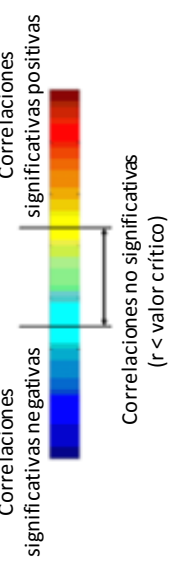

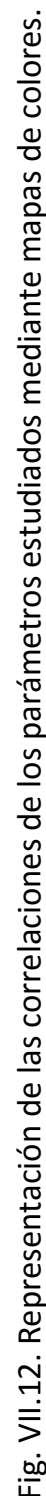


Las correlaciones, en general, son similares a las encontradas en los suelos geológicos, salvo que el arsénico, tanto en suelos sembrados como en barbecho, está ahora más correlacionado con la C.E, calcio extraíble y yesos, aunque también se encuentra correlacionado, en menor medida, con los demás metales y con los parámetros asociados a éstos.

La materia orgánica en suelos sembrados está correlacionada fuertemente con metales como el zinc y el cobre, y también con potasio y fósforo extraíbles, parámetros todos ellos relacionados con la contaminación agrícola. En los suelos en barbecho, la materia orgánica se correlaciona con todos los metales y parámetros asociados a éstos y también se pone de manifiesto la escasa correlación entre los minerales cuarzo, plagioclasa y ortosa con el resto de parámetros analizados.

La liberación de arsénico por el fosfato podría darse en suelos agrícolas donde se utilizan estos compuestos para mejorar las condiciones de los suelos agrícolas, ya que los fosfatos compiten con los arseniatos para ocupar las posiciones de adsorción en las arcilla y/o óxidos de hierro y manganeso y alterando los equilibrios que afectan a las fracciones más móviles y disponibles del suelo (Brandstetter y col 2000) lo que podría aumentar los niveles de toxicidad. Sin embargo en este estudio no se ha encontrado una clara correlación entre fosfatos y arsénico.

\section{VII.4.2.4ANÁLISIS MULTIVARIANTE}

Se ha llevado a cabo un análisis multivariante de los resultados correspondientes a los suelos agrícolas, con objeto de contrastar las agrupaciones de las variables con las obtenidas para los suelos geológicos y estudiar así las posibles diferencias entre ambos, con el fin último de comprobar si la retención o movilización del arsénico se ve influenciada por las prácticas agrícolas. El estudio se ha realizado con todos los suelos agrícolas (sembrados y en barbecho) ya que, como se ha comprobado prácticamente no existen diferencias significativas entre ambos muestreos excepto para cuatro parámetros. La textura no ha sido incluida en el análisis multivariante, ya que son más precisos los análisis mineralógicos tal y como se vio en el capítulo $\mathrm{V}$ (Estudio Geoquímico).

\section{ANÁLISIS CLÚSTER}

En los resultados obtenidos mediante el análisis clúster (Fig. VII.13), se observa como el arsénico aparece en el mismo grupo que la C.E, calcio extraíble y yeso.

\section{ANÁLISIS EN COMPONENTES PRINCIPALES}

El ACP nos va a permitir, en primer lugar, obtener información acerca de la existencia de diferentes clases de objetos (suelos) y variables (parámetros analizados) en un espacio de dimensiones más reducido y sencillo de visualizar gráficamente. En segundo término, la comparación de los resultados con los obtenidos en el ACP de las muestras estudiadas en el capítulo $V$ (Estudio Geoquímico), nos va a permitir establecer si las prácticas agrícolas pueden llegar a alterar los procesos de retención/movilización de arsénico en el suelo. 

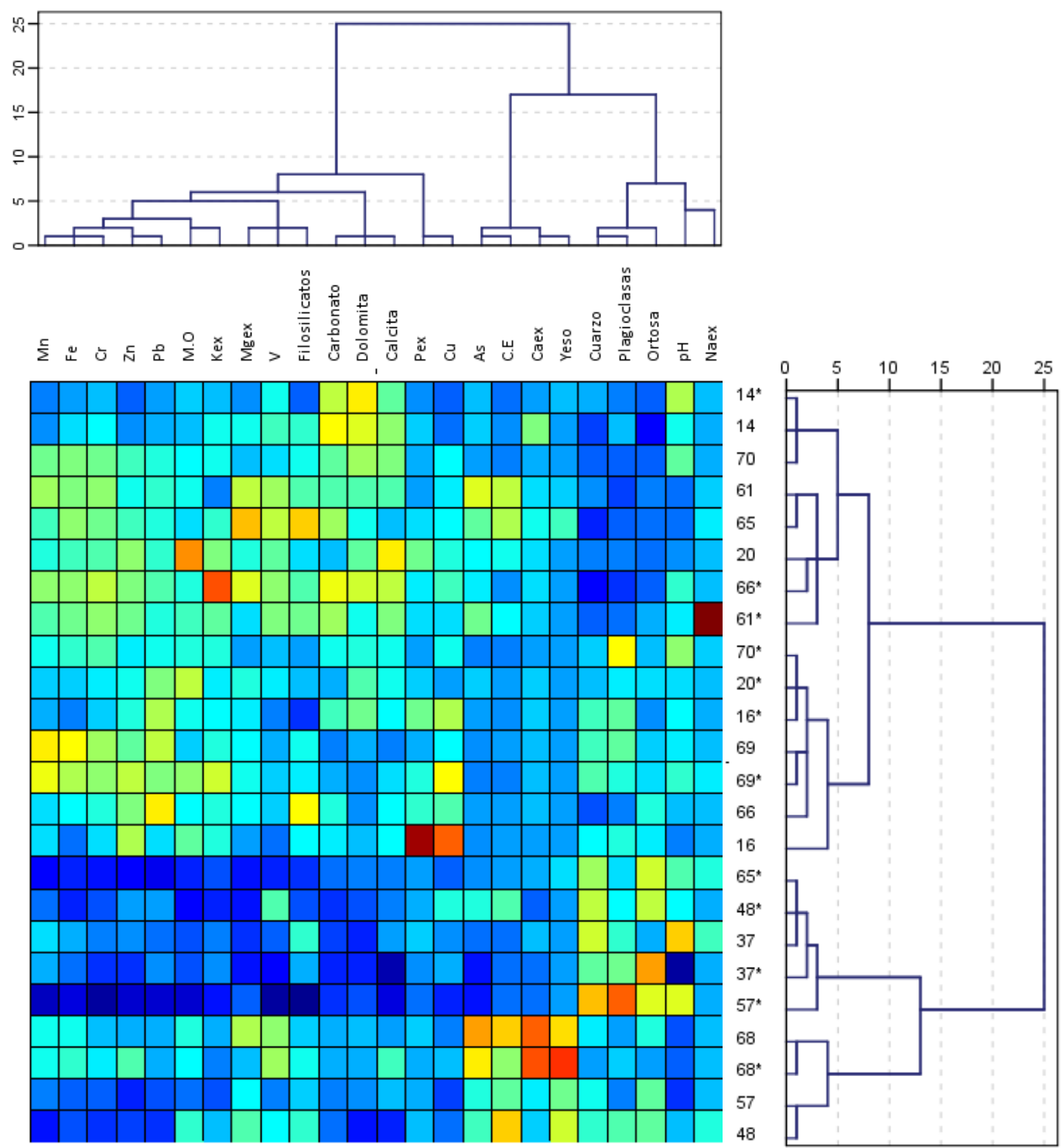

Fig. VII.13. Dendrogramas obtenidos por análisis clúster de las 24 muestras de suelos agrícolas y de los 24 parámetros analizados, complementado con un mosaico de colores que indica los niveles relativos de los parámetros en las muestras.

Para reducir la dimenionalidad de la tabla original de datos (24 muestras $\times 24$ variables), se ha optado por mantener los cinco primeros PCs cuyo autovalor es mayor que la unidad y por tanto explican más varianza que una única variable original. Estos cinco primeros PCs explican el $82,2 \%$ de la varianza contenida en el conjunto de datos, consiguiendo una importante reducción de la dimensionalidad de los datos.

La Fig. VII.14 muestra la representación de los dos primeros PCs, que explican el 61,1\% de la varianza total, y donde podemos apreciar los agrupamientos de las variables. 


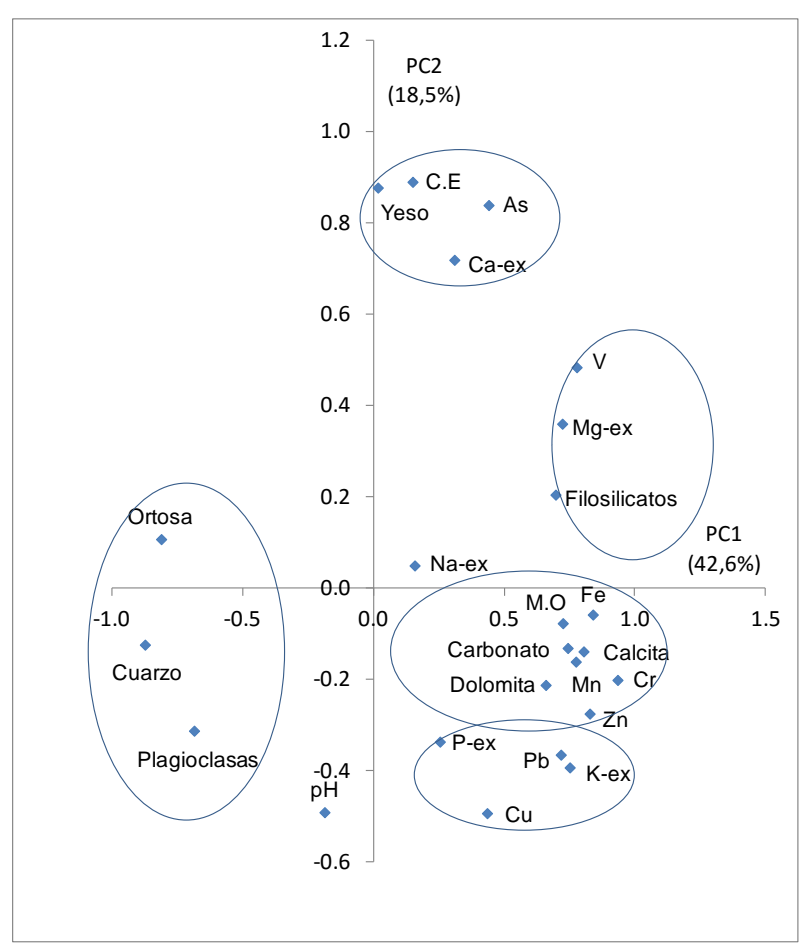

Fig. VII.14. Representación gráfica de las cargas de los dos primeros componentes principales.

El primer componente (PC1) explica el $42,6 \%$ de la varianza total de la matriz de datos y tiene una importante contribución positiva de filosilicatos, calcita, dolomita, carbonatos materia orgánica, metales totales mayoritarios (manganeso, hierro), metales extraíbles mayoritarios (magnesio y potasio) y metales traza (cromo, plomo, zinc y vanadio). También presentan una importante contribución negativa cuarzo, ortosa y plagioclasa. Por tanto, este primer componente se puede interpretar como una variable relacionada con la presencia de arcillas y carbonatos, con alta capacidad para retener metales.

El componente PC2, que explica el $18,5 \%$ de la varianza total, y contiene al elemento objeto de estudio además de otros parámetros como $\mathrm{CE}$, calcio extraíble, arsénico y yeso.

En la Fig. VII.15 se han representado los scores de las muestras (indicando con un asterisco si el suelo está en barbecho) en el nuevo sub-espacio definido por PC1 y PC2, que permite visualizar la mayor cantidad de información, para ayudarnos a reconocer la existencia de grupos de muestras con similar comportamiento. La Fig. VII.16 muestra los mismos scores, con los puntos rotulados de acuerdo a la concentración de arsénico: en azul los que tienen concentraciones entre 0 y $5 \mathrm{mg} / \mathrm{kg}$, en naranja entre 5 y $10 \mathrm{mg} / \mathrm{kg}$ y en rojo aquellas muestras con valores superiores a $10 \mathrm{mg} / \mathrm{kg}$. También se han incluido entre paréntesis, las concentraciones de arsénico de las aguas con las que se han regado los suelos agrícolas, para facilitar la interpretación de los resultados. 


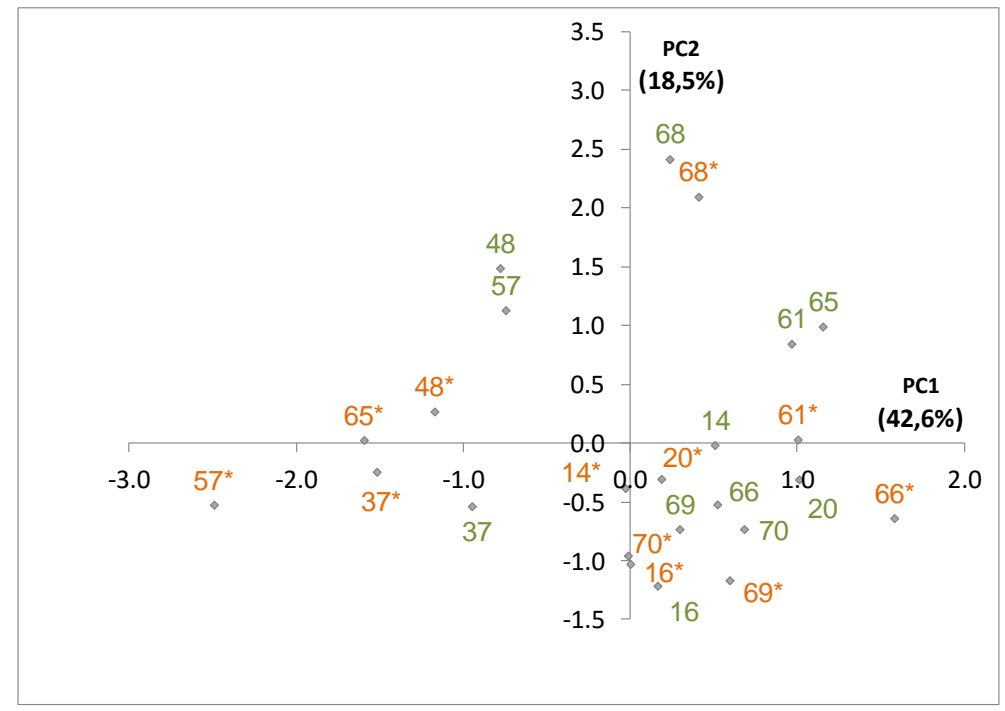

Fig. VII.15. Representación de los dos primeros scores. El asterisco identifica a las muestras que se tomaron de campos en barbecho.

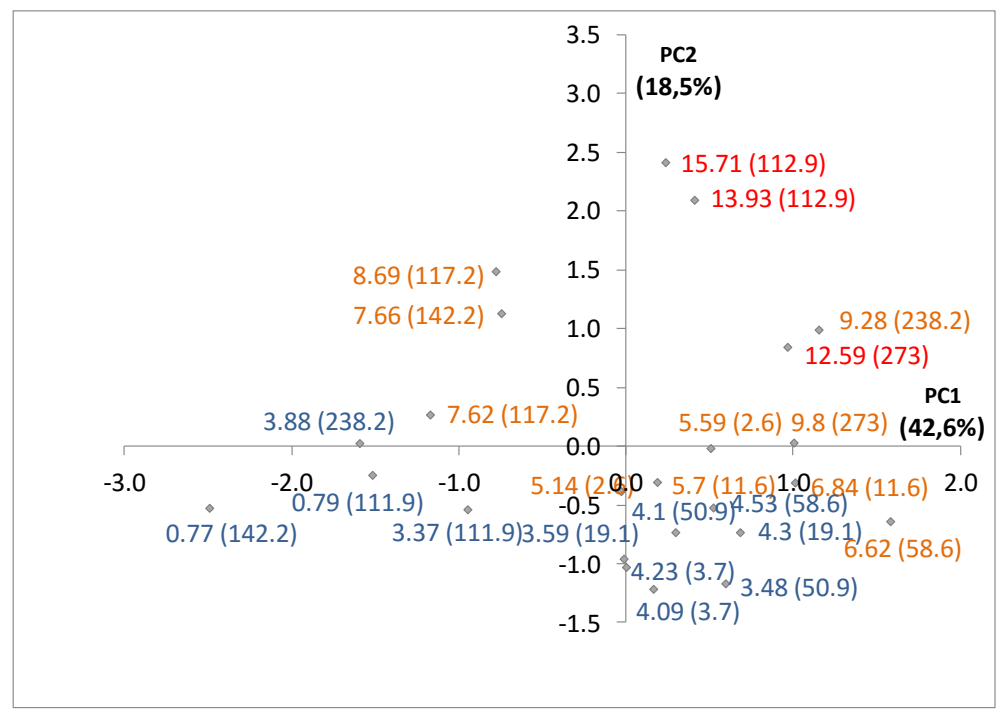

Fig. VII.16. Representación de los dos primeros scores. Identificando para cada muestra el contenido de arsénico en la muestra de suelo y entre paréntesis el contenido del agua de riego. 


\section{VII.5. DISCUSIÓN DE LOS RESULTADOS}

\section{VII.5.1.CÁPSULAS DE SUCCIÓN}

Las fincas donde se han instalado las cápsulas de succión y los pluviómetros se riegan con agua de pozos con niveles de arsénico elevados ( $>50 \mu \mathrm{g} / \mathrm{L}$ de As), según muestran los valores obtenidos en los pluviómetros en la época de riego, en la que podemos suponer que el agua procede mayoritariamente del riego, ya que las lluvias son entonces poco frecuentes. Las variaciones encontradas en los pluviómetros en los diferentes muestreos pueden deberse, bien a lluvias locales en los meses de verano que provocarían una dilución de la muestra o bien, a evaporaciones producidas por el intenso calor de los meses de verano, que produciría el aumento de la concentración de los parámetros analizados.

Los tipos de terreno de las fincas estudiadas son: arcilloso-arenosos para la finca F1; arcillosos para la finca F2 y arenoso para la finca F3. Por otro lado y según se ha comprobado en el capítulo $V$ (Estudio Geoquímico), la composición mineralógica del suelo influye en la retención de los metales, siendo los suelos arcillosos los que retienen un mayor contenido, por lo que en este estudio deberíamos observar distintos comportamientos, en función del tipo de suelo. Así, del análisis de de arsénico de los suelos de las tres fincas, se desprende que el suelo arcilloso de la finca F2 presenta concentraciones de arsénico más elevadas que el suelo, principalmente arenoso, de la finca F3, mientras que el suelo de la finca F1, arcillo-arenoso, posee una concentración intermedia.

A la vista de estos resultados, es de esperar que el arsénico procedente de la cápsula de succión de la finca F3 provenga del agua de riego, ya que el suelo apenas retiene arsénico. Por el contrario, el arsénico recogido en las cápsulas de succión de los suelos de las fincas F1 y F2 será posiblemente, una mezcla del arsénico contenido en el suelo y del procedente del agua de riego. A continuación se analizan con más detalle los resultados obtenidos para cada finca.

En la finca F1, se deja de regar el 22/11/2003, por lo que a partir de esta fecha cesa el aporte de arsénico al suelo procedente del agua de riego. No obstante, en la cápsula de succión se observa cómo se produce un aumento de la concentración de arsénico (350 $\mu \mathrm{g} / \mathrm{L}$ de As) durante los meses de invierno, que después se estabiliza en unos $200 \mu \mathrm{g} / \mathrm{L}$ de As. El aumento en época invernal puede deberse a que el arsénico aportado al suelo por el agua de riego, es ahora lixiviado por las frecuentes lluvias estacionales. A principios de febrero de 2004, los niveles de arsénico se estabilizan en un valor más pequeño $(200 \mu \mathrm{g} / \mathrm{L})$, por lo que el arsénico lixiviado a partir de esta fecha, parece proceder del que se encuentra retenido en los componentes del suelo y no del agua de riego.

En la finca F2 se observa una tendencia muy similar a la de la finca F1. Los riegos cesan el $7 / 10 / 2003$, por lo que a partir de esta fecha se deja de aportar arsénico al suelo desde el agua de riego. En la cápsula de succión se observa cómo se produce un aumento de la concentración de arsénico ( $250 \mu \mathrm{g} / \mathrm{L}$ de As) durante los meses de invierno, que después 
se estabiliza en unos $150 \mu \mathrm{g} / \mathrm{L}$ de As. El aumento hasta los $250 \mu \mathrm{g} / \mathrm{L}$ de As en la época de invierno y la posterior estabilización en febrero de 2004, se puede explicar de la misma manera que se hizo para la finca F1.

En la finca F3 se observa un comportamiento diferente a las otras dos. Se deja de regar el 30/10/2003 y a partir de esa fecha, se observa una disminución paulatina en las concentraciones de arsénico de las cápsulas de succión hasta alcanzar niveles de $50 \mu \mathrm{g} / \mathrm{L}$ de As. Esto puede atribuirse a que el arsénico de la cápsula de succión proviene en su mayoría del agua de riego y a que, en este caso, el suelo no aporta arsénico, ya que se trata de un suelo arenoso con escasa capacidad de retención, lo que se vería confirmado por el descenso de los niveles de arsénico, una vez finalizada la época de riego.

Por tanto, la composición del suelo ejerce un papel importante en la movilización/retención del arsénico y el uso de aguas contaminadas con arsénico para regadío, contribuye a la recirculación de este contaminante y al aumento de su concentración en los suelos durante las épocas de riego.

\section{VII.5.2.SUELOS AGRÍCOLAS}

De los resultados del ACP de los suelos agrícolas se desprende que los dos primeros factores, PC1 y PC2, explican más de la mitad de la información $(61,1 \%)$. Al representar gráficamente las cargas de las variables (Fig. VII.14), se pueden observar cinco agrupaciones de parámetros que coinciden con las encontradas en las correspondientes matrices de correlación Fig. VII.12 y en el Análisis Clúster de variables (Fig. VII.13).

Las agrupaciones de parámetros de los suelos agrícolas estudiados se diferencian de las encontradas para los sedimentos que no han sufrido intervención humana, analizados en el capítulo $V$ (Estudio Geoquímico). Así, en los suelos agrícolas vemos como el arsénico se separa del resto de los metales, para agruparse principalmente con la conductividad eléctrica y yesos. La correlación entre el arsénico y la conductividad eléctrica, fue encontrada también en las aguas del acuífero aluvial analizadas en la zona de estudio, que son precisamente las utilizadas para regar la mayoría de los campos agrícolas de la zona, por lo que parece que la intensa recirculación de las aguas subterráneas sobre los campos agrícolas influyen en la retención/movilización de este contaminante.

La agrupación de fósforo extraíble, potasio extraíble, cobre y plomo, con valores negativos del PC2., se puede interpretar como contaminación antropogénica debida a las prácticas agrícolas, utilización de abonos, fertilizantes... llevadas a cabo en la zona, por lo que aquellos suelos con valores elevados de PC2 negativos y PC1 positivo son los que presentarían mayor contaminación antropogénica.

Del resto de agrupaciones de variables, cabe destacar que los filosilicatos solo se agrupan con vanadio y magnesio extraíble y que el hierro y manganeso totales quedan asociados con los carbonatos y materia orgánica. Al igual que en suelos geológicos, los minerales relacionados con las arenas no se relacionan con el resto de parámetros.

Las muestras de suelos agrícolas analizadas se distribuirán con valores negativos de PC1 si se componen principalmente de arenas y con valores positivos de PC1 si los suelos 
poseen carbonatos y/o filosilicatos con alto contenido en metales. Por su parte, el PC2 discrimina entre suelos que poseen altos valores de C.E, yesos y arsénico y los que poseen elevada contaminación antropogénica (cobre, fósforo extraíble, potasio extraíble).

La Fig. VII.15 no muestra una separación clara de las muestras atendiendo al estado de siembra de las mismas, sino más bien a la composición de los suelos. Si nos fijamos en la Fig. VII.16, que incluye los niveles de arsénico del suelo y del agua de riego, se observa que los suelos arenosos apenas retienen a este elemento tóxico, a pesar de ser regados con aguas con altos niveles en el mismo. Por el contrario, en los suelos compuestos por carbonatos y filosilicatos parece existir una relación entre la cantidad de arsénico del agua de riego y los niveles encontrados en el suelo. Por tanto, se puede decir que el arsénico encontrado en los suelos, no solo depende de los niveles de arsénico del agua de riego sino también de las características del mismo, es decir de si contiene partículas donde se pueda adsorber el arsénico, si contiene algún elemento que favorezca dicha adsorción... Por tanto, y habida cuenta de la relación existente entre el arsénico de los pozos y el de los suelos (Fig. VII.16), todo parece indicar que la recirculación originada por las aguas de riego, es uno de los factores que contribuyen a la contaminación movilización por arsénico en el área de estudio. 

CONCLUSIONES 

Se ha llevado a cabo un estudio sobre la distribución de arsénico en aguas subterráneas y sedimentos de una zona delimitada de la cuenca del Duero perteneciente a la comarca Tierra de Pinares, afectada por contaminación de las aguas subterráneas por arsénico y otros elementos traza de origen natural. También se han realizado estudios encaminados a evaluar la movilidad del arsénico en los materiales sedimentarios del acuífero y para establecer el ciclo hidrológico de este elemento y su relación con el intenso uso del agua y del suelo en la zona.

Se han determinado numerosos parámetros físico-químicos y mineralógicos en un elevado número de muestras de agua subterránea, sedimentos y suelos, obtenidos en la zona investigada. Del análisis de los resultados experimentales por métodos hidrogeoquímicos clásicos y por técnicas estadísticas multivariantes se han extraído las siguientes conclusiones:

\section{Hidroquímica de las aguas subterráneas:}

- La composición química de las aguas subterráneas en el área investigada está relacionada con la unidad hidrológica de la que proceden, distinguiéndose tres tipos de aguas procedentes de otras tantas unidades acuíferas: (i) acuífero detrítico profundo, con aguas predominantemente bicarbonatadas sódicas, (ii) acuífero aluvial, superficial, con aguas sulfato-bicarbonatadas cálcico-magnésicas, y (iii) acuífero carbonatado, en el páramo, con aguas bicarbonatadas cálcico-magnésicas. Los mayores contenidos de arsénico se hallan en el acuífero aluvial y en el detrítico profundo.

- Los acuíferos aluvial y carbonatado, que en las cabeceras de los valles están conectados hidráulicamente y presentan características hidroquímicas similares (Ca$\mathrm{Mg}-\mathrm{HCO}_{3}$ ), evolucionan en el sentido del flujo del agua aumentando sus diferencias, ya que el acuífero aluvial aumenta su carácter salino con la incorporación de sulfato, nitrato, calcio y magnesio.

- El acuífero detrítico se caracteriza por niveles confinados profundos y flujos descendentes. Sus aguas bicarbonatadas sódicas tienen $\mathrm{pH}$ alcalino $(>8,5)$ y temperatura elevada y parecen indicar la existencia de procesos de hidrólisis de feldespatos.

- A pesar de tratarse de un área de estudio pequeña, la distribución de arsénico varía ampliamente: el $16 \%$ de las muestras analizadas contienen menos de $10 \mu \mathrm{g} / \mathrm{L}$ (nivel máximo tolerado para aguas destinadas al consumo humano), y pertenecen todas ellas al acuífero carbonatado; un $25 \%$ de las muestras presentaron valores de arsénico de 10-50 $\mu \mathrm{g} / \mathrm{L}$; concentraciones de arsénico de 50-200 $\mu \mathrm{g} / \mathrm{L}$ fueron halladas en el $47 \%$ de las muestras; el $12 \%$ restante de muestras presentó niveles superiores a $200 \mathrm{\mu g} / \mathrm{L}$ y procedían del acuífero aluvial.

- La correlación de arsénico con otras variables hidroquímicas fue investigada por métodos estadísticos univariantes y multivariantes y permitió elucidar los mecanismos más probables que contribuyen a la movilización y dispersión del arsénico en el medio natural. Así, los altos contenidos de As encontrados en el 
acuífero detrítico profundo podrían explicarse fundamentalmente por la existencia de procesos de desorción de As de las arcillas y, en menor medida, de los oxihidróxidos de hierro y manganeso, al pH alcalino característico de este tipo de aguas. Por su parte, el acuífero aluvial presenta mayor concentración y variabilidad en los niveles de arsénico. La elevada correlación del arsénico con las variables responsables de la salinidad del agua (conductividad eléctrica, sulfato, nitrato, cloruro, calcio y magnesio), parece estar relacionada con la recirculación existente en el acuífero aluvial por la intensa explotación de las aguas que provoca salinización. La presencia de concentraciones elevadas de sulfato en el agua subterránea del acuífero aluvial puede ejercer un efecto competitivo que se traduce en un intercambio iónico con el arseniato que facilita su desorción de los sedimentos, aumentando la concentración de arsénico en el agua.

- En muchas regiones semiáridas del planeta con elevados niveles de arsénico en las aguas subterráneas es habitual que se encuentre acompañado de otros elementos formadores de oxoaniones ( $\mathrm{Mo}, \mathrm{U}, \mathrm{V}, \mathrm{Cr}$, W...) y elementos como $\mathrm{Li}, \mathrm{Sr}, \mathrm{Ba}, \mathrm{B}$ o $\mathrm{F}$. En este estudio se han determinado solo unos pocos elementos traza geogénicos, encontrando que el arsénico se correlaciona significativamente con V y Mo. Para comprobar si los mecanismos de movilización y transporte son comunes a los elementos traza es imprescindible determinar un mayor número de elementos y ahondar en el estudio de las relaciones entre ellos.

- De los valores de potencial redox y pH puede predecirse que la especie de arsénico predominante en las aguas subterráneas es la forma oxidada $\mathrm{HAsO}_{4}{ }^{2-}$. Solo se realizó el análisis de especiación de arsénico en aguas en un reducido número de muestras (resultados no incluidos), confirmando la predicción realizada en base al diagrama de predominio de las especies solubles de arsénico.

- Del seguimiento mensual de las aguas subterráneas en la red de control se ha podido concluir que la variabilidad espacial en la composición de las aguas subterráneas es mucho más acusada que la variabilidad temporal, siendo ambas fuentes de variación significativas. La interpretación de los resultados por análisis de componentes principales de tres vías indica un aumento en verano del factor que agrupa a las variables sulfato, calcio, magnesio, nitrato, cloruro y arsénico, que parece causado por concentración salina en épocas de riego. Algunos valores máximos encontrados en algunos meses invernales podrían estar relacionados con la lixiviación por el agua de lluvia de contaminantes procedentes de los fertilizantes (nitrato). Por el contrario, el aumento en los meses estivales del factor que agrupa a bicarbonato, sodio y potasio puede ser entendido si se tiene en cuenta el empleo para el riego de aguas salinas del acuífero profundo, con altos contenidos de estos tres minerales.

\section{Geoquímica y mineralogía del acuífero:}

- El $40 \%$ de las muestras de sedimentos analizadas presentan niveles de arsénico inferiores a $10 \mathrm{mg} / \mathrm{kg}$, valor similar al nivel fondo considerado normal para rocas sedimentarias $(5-8 \mathrm{mg} / \mathrm{kg})$. En un $26 \%$ de las rocas analizadas se observaron niveles del elemento superiores a $20 \mathrm{mg} / \mathrm{kg}$, concentración que puede considerarse 
anormalmente elevada y pudiera ser la causa de los elevados niveles de arsénico en el agua.

- La variabilidad de la distribución espacial de arsénico en el agua subterránea es pareja a la variabilidad de la distribución del elemento en los materiales sedimentarios. La concentración de arsénico varió con el estrato geológico y, en consecuencia, con la composición mineral del suelo. Valores inferiores a $10 \mathrm{mg} / \mathrm{kg}$ fueron detectados en las cotas más profundas (facies Toro, constituida principalmente por limo y arcilla) y en las más elevadas (Páramo y Transición al Páramo, rocas calizas). Se hallaron concentraciones superiores a $25 \mathrm{mg} / \mathrm{kg}$ en la facies Cuestas (arcillas, yeso y margas), en facies Dueñas (margas y calizas), y en algunas muestras de la facies Villalba de Adaja (arenas y grava con intercalaciones de arcilla).

- Un análisis estadístico multivariante (ACP y métodos clúster) de los datos experimentales ha evidenciado grupos de variables fuertemente correlacionadas, como por ejemplo metales pesados $(\mathrm{Cu}, \mathrm{Cr}, \mathrm{Zn}, \mathrm{V}, \mathrm{Pb})$ con la capacidad de cambio catiónico y $\mathrm{K}$, indicando la capacidad de estos suelos para retener e intercambiar iones, o el grupo formado por $\mathrm{Mn}$ total, $\mathrm{Mg}$ y As, próximo a su vez al anterior, que parece apoyar la teoría de que el As está ligado a estos suelos por fenómenos de superficie (adsorción, cambio iónico). El As aparece además significativamente correlacionado con la fracción mineral de filosilicatos, muy abundante en las rocas de la zona, apoyando la hipótesis de que el origen del arsénico está en estas arcillas con altos niveles del elemento, y que, por procesos de desorción y cambio iónico, el elemento es movilizado pasando a contaminar el agua subterránea. En cuanto a la correlación entre muestras, el ACP ha evidenciado que, en general, éstas se agrupan de acuerdo a la unidad geológica de la que proceden, lo que indica la composición más o menos homogénea de los materiales hallados en cada unidad litoestratigráfica.

- La teoría más extendida para explicar la presencia de arsénico en este tipo de cuencas sedimentarias se basa en que el arsénico está adsorbido sobre oxihidróxidos de hierro y/o manganeso, y que se libera a elevados $\mathrm{pH}$ o por una disminución del potencial redox del agua. Esta teoría no pudo ser confirmada en este estudio ya que no se detectó la presencia de cantidades significativas de óxido férrico en casi ninguna de las muestras de sedimento analizadas.

- El fraccionamiento químico de arsénico en suelos mediante el método de Wenzel ha puesto en evidencia que la fracción predominante en casi la totalidad de las muestras es la fracción 4, soluble en la disolución ácida reductora oxalato amónico/ácido ascórbico. Por el contrario, la fracción 1, adsorbida inespecíficamente y por tanto fácilmente movilizable, es solo significativa en algunas muestras procedentes de la facies Cuestas. Esto significa que el arsénico de estos minerales es en general estable, entendido como no movilizable en condiciones normales, en las muestras procedentes de cotas no aflorantes, pero resulta más fácilmente movilizable en la facies Cuestas. Si a eso añadimos que esta Facies presenta altas concentraciones de As en los minerales del suelo y grandes cantidades de sulfato por contener yeso, podemos concluir que la facies Cuestas es una fuente potencial de arsénico para el agua. Se producirá fácilmente la desorción de arsénico por competición de altas 
concentraciones de sulfato presentes en ese estrato. Debido al reducido número de muestras analizadas procedentes de ese estrato geológico, esta conclusión es aún poco consistente y necesita ser verificada.

\section{Acción antrópica:}

- Se analizaron los contenidos de arsénico en muestras de suelos agrícolas cultivados y suelos de similares características mineralógicas mantenidos en barbecho. No se han encontrado diferencias significativas entre parejas de suelos cultivados-no cultivados, lo que parece descartar el empleo de fertilizantes como contribución significativa a la concentración de arsénico en el suelo. El efecto del empleo de pesticidas no se ha investigado.

- El efecto del agua de riego con alto contenido en arsénico sobre los niveles de arsénico en el suelo y en el agua intersticial se ha investigado mediante un experimento con cápsulas de succión, observándose que los niveles de arsénico en el agua intersticial y en el suelo se incrementan durante la temporada de riegos, disminuyendo en invierno. Este resultado parece apoyar la hipótesis de que el mecanismo principal de movilización del arsénico en este acuífero se basa en procesos de adsorción/desorción sobre partículas arcillosas del suelo. La escasez de datos experimentales limita mucho la validez de esta conclusión.

- El empleo de fertilizantes NPK y purines en agricultura, la intensa explotación a la que están sometidos los acuíferos, especialmente el aluvial y durante la época estival, junto a los importantes retornos de riego que se producen, originan una notable recirculación del agua subterránea con la consiguiente modificación de su composición química, lo que complica el estudio de los mecanismos de retención/liberación de arsénico. 
BIBLIOGRAFÍA 

Abollino, O; Aceto, M; Malandrino, M; Mentasti, E, Sarzanini, C; Barberis, R. (2002). Distribution and mobility of metals in contaminated sites. Chemometric investigation of pollutant profiles. Environ. Pollut. 119,177-193.

Abollino, O; Malandrino, M; Giacomino, A; Mentasti, E. (2011) The role of chemometrics in single and sequential extraction assays: A review Part I. Extraction procedures, uni- and bivariate techniques and multivariate variable reduction techniques for pattern recognition. Anal. Chim. Acta. 688, 104-121.

Adriano, D C. (2001). Trace Elements in Terrestrial Environments: Biogeochemistry, Bioavailability and Risks of Metals. 2nd edn, Springer Verlag, New York.

Adriano, D. (1986). Trace elements in the terrestrial environment. Springer-Verlag.

Ahmann, D; Krumholz, L R; Hemond, H H; Lovley, D R; Morel, F M M. (1997). Microbial mobilization of arsenic from sediments of the Aberjona watershed. Environ. Sci. Technol. 31, 2923-2930.

Akins, M; Lewis, R. (1976). Chemical distribution and gaseous evolution of Arsenic-74 added to soils as DSMA-74 Arsenic. Soil Sci Soc Am J. 40,655-658.

Alam, M G M; Snow, E T; Tanaka, A. (2003). Arsenic and heavy metal contamination of vegetables grown in Samta Village Bangladesh. Sci. Total Environ. 308, 83-96.

Alexandratos, V G; Elzinga, E J; Reeder, R J. (2007) Arsenate uptake by calcite: macroscopic and spectroscopic characterization of adsorption and incorporation mechanisms. Geochim. Cosmochim. Acta 71, 4172-4187.

Alvarez, M; Carrillo, G. (2012). Simultaneous determination of arsenic, cadmium, copper, chromium, nickel, lead and thallium in total digested sediment samples and available fractions by electrothermal atomization atomic absorption spectroscopy (ET AAS). Talanta 97, 505-512.

Amacher, M C; Kotuby-Amacher, J. (1994). Selective extraction of arsenic from minespoils, soils, and sediments. Agron. Abstr. 256

Anawar, H M; Akai, J; Komaki, K; Terao, H; Yosioka, T; Ishizuka, T; Safiullah, S; Kikuo, K. (2003). Geochemical occurrence of arsenic in groundwater of Bangladesh: sources and mobilization processes. J. Geochem. Explor. 77, 109-131.

Anawar, H M; Garcia-Sanchez, A; Regina, S I. (2008). Evaluation of various chemical extraction methods to estimate plant-available arsenic in mine soils. Chemosphere. 70, 1459-1467.

APHA, 1985. American Public Health Association. Standard methods for the examination of water and wastewater. 16th ed, APHA,AWWA, WPCF.

APHA-AWWA-WEF (1999). Standard Methods for the Examination of Water and Wastewater, 20th Edition. American Public Health Association, American Water Works Association, Water Environment Federation.

Appelo, C A J; Postma, D. (2005). Geochemistry, Groundwater and Pollution, 2nd Edition. CRC Press. 
Armenteros, I. (1986). Estratigrafía y sedimentología del Neógeno del sector suroriental de la depresión del Duero (Aranda de Duero-Peñafiel). (Publicación de la Tesis Doctoral). Ed. Diput. Salamanca. Serie Castilla y León, 1, 471.

Ashraf, M A; Maah, M J; Yusoff, I. (2012). Chemical Speciation and Potential Mobility of Heavy Metals in the Soil of Former Tin Mining Catchment Scientific World Journal. 125608

Azcue, M; Mudroch, A; Rosa, F; Hall, G E M. (1994). Effects of abandoned gold mine tailings on the arsenic concentrations in water and sediments of Jack of Clubs Lake, BC. Environ. Tech, 15, 669-678.

Baig, J A; Kazi, TG; Arain, M B; Shah, A Q; Sarfraz, R A; Afridi, H I; Kandhro, G A; Jamali, M K; Khan, S. (2009). Arsenic fractionation in sediments of different origins using $B C R$ sequential and single extraction methods. J Hazard Mater. 167,745-751.

Barbee y Brown (1986). Comparison between suction and free-drainage soil solution samplers. Soil Sci. 141, 1, 149-154.

Barbieri, P; Adami, G; Favretto, A; Reisenhofer, E. (1998) A chemometric survey of three sites in Muggia Bay (Northern Adriatic Sea): meteorological effects on heavy metal patterns in surface coastal waters. Fresenius J. Anal. Chem. 361, 349-352.

Baur, WH; Onishi, B M H. (1969). Arsenic In:Wedepohl, K.H.(Ed.). Handbook of Geochemistry. Springer- Verlag, Berlin. pp.33-A-1-33-0-5.

Bech, J; Poschenrieder, C; Llugany, M. (1997). Arsenic and heavy metal contamination of soil and vegetation around a copper mine in northern Peru. Science of the Total Environment. 203, 83-91.

Beckmann, T; Kücke, M; Hasenpusch, K; Altemüller, H J. (1992). Einbaubedingte Gefügeänderungen in der Bodenzone um keramische Saugkerzen. Z. Pflanzenernähr. Bodenk., 155, 247-250.

Beesley, L; Dickinson, N. (2010). Carbon and trace element mobility in an urban soil amended with green waste compost. J Soils Sedim. 10, 215-222.

Belkin, H E; Zheng, B; Finkelman, R B. (2000). Human health effects of domestic combustion of coal in rural China: a causal factor for arsenic and fluorine poisoning. In:2nd World Chinese Conf. Geological Sciences, Extended Abstr. Stanford Univ.,522-524.

Belzile, N.; Lecomte, P. y Tessier, A. (1989). Testing readsorption of trace elements during partial chemical extraction of bottom sediments. Enviran. Sci. Technol. 23,1015-1020.

Benedetto, F; Costagliola, P; Benvenuti, M; Lattanzi, P; Romanelli, M; Tanelli, Giuseppe, T. (2006). Arsenic incorporation in natural calcite lattice: Evidence from Electron Spin Echo spectroscopy Earth And Planetary Science Letters: 246, 3-4 , 458-465.

Berg, M; Tran, H C; Nguyen, T C; Pham, H V; Schertenleib, R; Giger, W. (2001). Arsenic contamination of groundwater and drinking water in Vietnam: a human health threat. Environ. Sci. Technol. 35, 2621-2626. 
Bernal, M P; Clemente, R; Walker, D J. (2009). Interactions of heavy metals with soil organic matter in relation to phytoremediation. In: Navarro-Aviño, J.P. (Ed.), Phytoremediation: the Green Salvation of the World. Research Signpost, Kerala, India, pp. 109e129.

BGS y DPHE, (2001). Arsenic contamination of groundwater inBangladesh. Kinniburgh, D.G., Smedley, P.L. (Eds.), British Geological Survey (Technical Report, WC/00/19. 4 Volumes). British Geological Survey, Keyworth.

Bhumbla, D K; Keefler, R F. (1994). Arsenic mobilization andbioavailability in soils. Niragu JO Arsenic in theEnvironment, Part I, Cycling and Characterization, John Wiley \& Sons, New York. 51-82.

Blanco, A K; Alonso, A L; Alonso, D; Jiménez de Blas, O; Santiago, M; de Miguel, B. (1998) Estudio de los niveles de plomo, cadmio, zinc y arsénico, en aguas de la provincia de Salamanca, Rev. Esp. Salud Pública. 72, 53-65.

Blarasin, M; Cabrera, A; Degiovanni, S. (2000). Hidrogeología Regional: el agua subterránea como recurso fundamental del Sur de la Prov. de Córdoba, Argentina. I Congreso Mundial Integrado de Aguas Subterráneas, I: 1-22, Fortaleza, Brasil.

Bowen H J M. (1979). Environmental Chemistry of the Elements. London. Academic Press.

Bowles, E; Hamilton-Taylor, J. (1985). Artifacts in the Use of Selective Chemical Extraction to Determine Distributions of Metals between Oxides of Manganese and Iron. Analytical Chem. 57, 1944-1946.

Boyle, D R; Turner, R J W; Hall, G E M. (1998). Anomalous arsenic concentrations in groundwaters of an island community, Bowen Island, British Columbia. Environ. Geochem. and Health, 20, 199-212.

Boyle, R W; Jonasson, I R. (1973). The geochemistry of arsenic and its use as an indicator element in geochemical prospecting. J. Geochem. Explor. 2, 251-296.

Brandstetter, A; Lombi, E; Wenzel, W.W. (2000). Arsenic-contaminated soils:I. Risk assessment. In: D.L Wise, D.J Trantolo, H.I Inyang, E.D Cichon, editors. Remediation of Harardous Waste Contaminated Soils. 2nd Ed. New York: Marcel Dekker Inc. 715-37.

Brannon, J M; Patrick, W H. (1987). Fixation, transformation, and mobilization of arsenic in sediments. Environ. Sci. Technol. 21, 450-459.

Breward, N; Williams, M; Bradley, D. (1996). Comparison of altemative extraction methods for determining particulate metal fractionation in carbonate-rich Mediterranean soils. Applied Geochem. 11, 101-104.

Bro, Rasmus; Henk, A; Kiers, L. (2003). A new efficient method for determining the number of components in PARAFAC models. Journal of Chemometrics. Volume $17,5,274-286$.

Brookins,D G. (1988). Eh-pH Diagrams for Geochemistry. Springer-Verlag, Berlin. 
Burriel, F; Lucena, F; Arribas, S; Hernández, J. (1999). Química Analítica Cualitativa. Paraninfo, Madrid. Apéndice VI.

Cai, Y; Cabrera, J C; Georgiadis, M; Jayachandran, K. (2002), Assessment of arsenic mobility in the soil of some golf courses in South Florida. The Science of the Total Environment 291, 123-134.

Calvo Revuelta, C; Álvarez-Benedi, J; Andrade-Benítez, M; Marinero-Diez, P; Bolado Rodríguez, S. (2003). Contaminación con Arsénico en Aguas Subterráneas en la Provincia de Valladolid: Variaciones Estacionales, Estudio de la Zona No Saturada del Suelo, VI, 91-98.

Cao, X; Ma, L Q; Shiralipour, A. (2003.) Effects of compost and phosphate amendments on arsenic mobility in soils and arsenic uptake by the hyperaccumulator Pteris vittata L. Environ Pollut. 126, 157-167.

Cappuyns, V; Van Herreweghe, S; Swennen, R; Ottenburgs, R; Deckers, J. (2002). Arsenic pollution at the industrial site of Reppel-Bocholt (north Belgium). Sci. Total Environ. 295, 217-240.

Carretero, M C; Vega, M; Pardo, R; Fernández, L; Barrado, E; del Barrio, V. (2004) Posible origen y dispersión de arsénico en los acuíferos de la zona de Vallelado-Mata de Cuéllar (Segovia), VIII Simposio de Hidrogeología, Zaragoza (España).

Carroll, J D; Chang, J J. (1970). Analysis of individual differences in multidimensional scaling via an n-way generalization of "Eckart-Young" decomposition. Psychometrika. 35, 283-319.

Castillo-Carrión, M; Martín, J A; Jiménez, R. (2003). Estándares de calidad de los suelos del Campo de Montiel (Ciudad Real) en función del contenido en metales pesados. Edafologia. 10, 1, 23-32.

Chang, S C; Jackson, M L. (1957). Fractionation of soil phosphorous. Soil Sci. 84, 133-144.

Chen, M; Ma, L. Q; Hoogeweg C G; Harris, W G. (2001). Arsenic background concentrations in Florida, USA, surface soils: Determination and interpretation. Environmental Forensics. 2, 2. 117-126.

Cheng, H; Hu, Y; Luo, J. (2009). Geochemical processes controlling fate and transport of arsenic in acid mine drainage (AMD) and natural systems Journal Of Hazardous Materials. 165, 1-3, 13-26.

Cheng, H; Hu, Y; Luo, J; Zhao, J. (2008). Geochemical processes controlling fate and transport of arsenic in acid mine drainage (AMD) and natural systems. J Hazar Mater. 165, 13-26.

Chlopecka, A; Bacon, J R; Wilson, M J; Kay, J. (1996). Forms of cadmium, lead and zinc in contaminated soils from southwest Poland. J. Environ. Qual. 25, 69-79.

Chunguo, C; Zihui, L. (1988). Speciation of arsenic in water, suspended solids and sediment of Xiangjiang River in China. Sci Total Environ. 77, 69-82. 
Cid, F D; Anton, R I; Pardo, R. (2011). Modelling spatial and temporal variations in the water quality of an artificial water reservoir in the semiarid Midwest of Argentina Analytica Chimica Acta. 705, 1-2, 243-252.

Clemente, R; Dickinson, N M; Lepp, N W. (2008). Mobility of metals and metalloids in a multi-element contaminated soil 20 years after cessation of the pollution source activity. Environ Pollut .155, 254-261.

Coetzee, P P. (1993). Determination and speciation of heavy metals in sediments of the Hartbeespoort Dam by sequential chemical extraction. Water SA. 19, 291-300.

Colinet, E; Gonska, H; Griepink, B; Muntau, H. (1983).The certification of the contents of cadmium, copper, mercury, lead and zinc in a calcareous loam soil. EUR Report $8833 \mathrm{EN}$, Commission of the European Communities, Luxembourg, 57.

Colmenero, J R; Rodríguez, J M; Gómez Fernández, J J; Carrasco, P. (2001). Estratigrafía del subsuelo y evolución sedimentaria del sector sur de la cuenca terciaria del Duero. Geotemas, , 3 , 129.

Cornelis, R; Caruso, J; Crews, H; and Heumann, K. (2005). Handbook of elemental speciation II. Species in the environment, food, medicine and occupational health. Chichester, UK: John Wiley and Sons.

Craig, P G. (1986). Organometallic Compounds in the Environmental. Principles and Reactions, Longman Group, Harlow. UK.

Davidson, C M; Thomas, R P; McVey, S E; Perala, R; Littlejohn, D; Ure, AM. (1994) Evaluation of a sequential extraction procedure for the speciation of heavy metals in sediments. Anal Chim Acta, 291, 277-286.

de Brouwere, K; Smolders, E; Merckx, R. (2004). Soil properties affecting solid-liquid distribution of $A s(V)$ in soils. Eur J Soil Sci. 55, 165-173

de Vicente, G; González Casado, J M; Calvo, J P; Muñoz Martín, A; Giner, J; Rodríguez Pascua, M. (1994). Evolución y estructuras alpinas en la zona del centro peninsular. Cuad. Lab. Xeol. Laxe, 1994, 19, 175.

de Vitre, R; Belzile, N; Tessier, A. (1991). Speciation and adsorption of arsenic on diagenetic iron oxyhydroxides. Limnol. Oceanog. 36, 1480-1485.

del Razo, L M; Arellano, M A; Cebrián, M E. (1990). The oxidation states of arsenic in wellwater from a chronic arsenicism area of northern Mexico. Environ. Pollut. 64, 143-153.

Delgado-Iglesias, Jaime. (2007). Estudio estratigráfico y mineralógico del terciario en el suroeste de la cuenca del duero, provincias de zamora y valladolid. colección vítor 201. Tesis Doctoral. Ediciones Universidad de Salamanca.

Dhoum, R T Y; Evans, G J. (1998). Evaluation of uranium and arsenic retention by soil from a low level radioactive waste management site using sequential extraction. Applied Geochem. 13, 415-420. 
DIN (Deutches Institut für Normung) (Ed.) Bodenbeschaffenheit. Vornorm DIN V 19730, in: Boden -Chemische odenuntersuchungsverfahren, DIN, Berlin, 1993, p. 4.

Domenech, X. (2000). Química del suelo. El impacto de los contaminatnes.3a ed. Miraguano S.A Ediciones

Doušová, B; Martaus, A; Filippi, M; Koloušek, D. (2008). Stability of Arsenic Species in Soils Contaminated Naturally and in an Anthropogenic Manner. Water Air Soil Pollut. 187, 233-241.

Drahota, P; Groesslova, Z; Kindlova, H. (2014). Selectivity assessment of an arsenic sequential extraction procedure for evaluating mobility in mine wastes. Analytica Chimica Acta. 839, 34-43.

Dunn, C.E. and Irvine, D.G. (1993). Relevance of a lithogeochemical database to epidemiological studies in central Saskatchewan, Canada. Applied Geochemistry. 2, 215-222.

Edmunds, W M; Cook, J M; Kinniburgh, D G; Miles, D L; Trafford, J M. (1989). Traceelement Occurrence in British Groundwaters. Res. Report SD/89/3. British Geological Survey. Keyworth.

Eriksson, L; Johansson, E; Kettaneh-Wold, N; Wold, S. (2001). Multi- and megavariate data analysis: Principles and applications. Umetrics Academy, Ume.

Farnfield, H R; Marcilla, A L; Ward, N I. (2012). Arsenic speciation and trace element analysis of the volcanic rio Agrio and the geothermal waters of Copahue, Argentina. Science Of The Total Environment. 433, 371-378.

Fayiga, A O; Ma, L Q; Zhou, Q. (2007). Effects of plant arsenic uptake and heavy metals on arsenic distribution in an arsenic-contaminated soil. Environmental Pollution. $147,737-742$.

Fendorf, S; La Force, M J; Li, G C. (2004). Temporal changes in soil partitioning and bioaccessibility of arsenic, chromium, and lead Journal Of Environmental Quality. 33, 6, 2049-2055.

Feng, L; Yuan-Ming, Z; Ji-Zheng, H. (2009). Microbes influence the fractionation of arsenic in paddy soils with different fertilization regimes. Science of the total Environment. 407, 2631-2640.

Fergusson, J E. (1990). The heavy elements: chemistry, environmental impact and health effects. Oxford, Pergamon Press.

Fernández, E; Jiménez, R; Lallena, A M; Aguilar, J. (2004). Evaluation of the BCR sequential extraction procedure applied for two unpolluted Spanish soils. Environ Pollut. 131, 355-364.

Fernandez, M A; Soulages, O E; Acebal, S G. (2015). Sorption of Zn(II) and Cu(II) by four Argentinean soils as affected by $\mathrm{pH}$, oxides, organic matter and clay content. Environmental earth sciences. 74,5, 4201-4214. 
Filgueiras, A; Lavilla, I; Bendicho, C. (2002). Chemical sequential extraction for metal partitioning in environmental solid samples. Journal of Environmental Monitoring. 4, 823-825.

Fitz, W J; Wenzel, WW. (2002). Arsenic transformations in the soil-rhizosphere-plant system: fundamentals and potential application to phytoremediation. JBiotechnol. 99, 259-278.

Fixen, P.E; Grove, J H. (1990). Testing soils for phosphorus. p. 161-174. In R.L. Westerman (ed.) Soil testing and plant analysis. 3rd ed. SSSA Book Ser. 3. SSSA, Madison, WI.

Forstner, U; Calmano, W; Schoer, J. (1982). Metals in sediments from the Elbe, Weser and Ems estuaries and from the German Bight: grain size effects and chemical forms. Thalassia Jugosl. 12, 30-36.

Fritzsche, A; Dienemann, H; Dudel, E G. (2006). Arsenic fixation on iron-hydroxiderich and plant litter-containing sediments in natural environments. Environmental Geochemistry. 51, 133-142.

Frost, R R; Griffin, R A, (1997). Effect of pH on adsorption of copper, zinc, and cadmium from landfill leachate by clay minerals; Journal of Environmental Science and Health. 12, 4-5, 139-156.

Gadepalle, V P; Ouki, S K; Van Herwijnen, R; Hutchings, T. (2007). Immobilization of heavy metals in soil using natural and waste materials for vegetation establishment on contaminated sites. Soil \& Sediments Contamination 16, 233251.

Gao, S; Burau, R. (1997). Environmental Factors Affecting Rates of Arsine Evolution from and Mineralization of Arsenicals in Soil. J. Environ. Qual. 26.

Gao, S; Luo, T C; Zhang, B R; Zhang, H F; Han, Y W; Zhao, Z D. (1998). Chemical composition of the continental crust as revealed by studies in East China. Geochimica et Cosmochimica Acta. 62, 1959-1975.

Gao, X; Li, P. (2012). Concentration and fractionation of trace metals in surface sediments of intertidal Bohai Bay, China. Marine Pollution Bulletin. 64, 8, 15291536.

Garay, P. (2000). El dominio triásico Espadán-Calderona. Contribución a su conocimiento geológico e hidrogeológico. Tesis Doctoral. Universidad de Valencia.

García, I; Diez, M; Martín, F; Simón, M; Dorronsoro, C. (2009). Mobility of arsenic and heavy metals in a sandy-loam textured and carbonated soil. Pedosphere. 19, 166175

Garcıa-Lorenzo, M L; Martınez-Sanchez, M J; Perez-Sirvent, C; Lopez-Sanchez, J; MolinaRuiz, J; Tudela, M L. (2015). Geogenic Distribution of Arsenic (As) and Antimony (Sb) in Soils of the Murcia Region in Spain. Environmental Forensics. 16, 88-95. 
García-Sanchez, A; Alvarez-Ayuso, E. (2003). Arsenic in soils and waters and its relation to geology and mining activities (Salamanca Province, Spain). Journal of Geochemical Exploration. 80, 69-79.

Ghosh, A; Mukiibi, M; Saez, A E; Ela, W P. (2006). Leaching of arsenic from granular ferric hydroxide residuals under mature landfill conditions. Environmental Science \& Technology. 40,19, 6070-6075.

Giacomino, A; Abollino, O; Malandrino, M. (2011).The role of chemometrics in single and sequential extraction assays: A Review. Part II. Cluster analysis, multiple linear regression, mixture resolution, experimental design and other techniques Analytica Chimica Acta. 688, 2, 122-139.

Giacomino, A; Malandrino, M; Abollino, O; Velayutham, M; Chinnathangavel, T; Mentasti, E. (2010). An approach for arsenic in a contaminated soil: speciation, fractionation, extraction and effluent decontamination. Environmental Pollution. $158,416-423$.

Giménez, M; Benitez, M; Oscila, R; Garro, O. (2006). Evaluación de la contaminación con arsénico en aguas subterráneas de la región central de la Provincia del Chaco. En: www.ambiente.gov.ar Fecha de revisión: 10/12/06.

Girouard, E; Zagury, G J. (2009). Arsenic bioaccessibility in CCA-contaminated soils: influence of soil properties, arsenic fractionation and particle-size fraction. Sci. Total Environ. 407, 2576-2585.

Gleyzes, C; Tellier, S; Astruc, M. (2002) Ph. Quevauviller (Editor), Methodologies for Soil and Sediment Fractionation Studies, Royal Society of Chemistry, Cambridge, UK, (Chapter 4).

Gleyzes, C; Tellier, S; Astruc, M. (2002). Fractionation studies of trace elements in contaminated soils and sediments: a review of sequential extraction procedures. Trends Anal Chem. 21, 451-467.

Gleyzes, C; Tellier, S; Sabrier, R; Astruc, A. (2001). Arsenic characterisation in industrial soils by chemical extractions. Environ Technol 22, 27-38.

Goh, K H; Lim T T. (2005). Arsenic fractionation in a fine soil fraction and influence of various anions on its mobility in the subsurface environment. Applied Geochemistry. 20, 229-239.

Goldberg, S. (1986). Chemical modeling of arsenate adsorption on aluminum and iron oxide minerals. Soil Sci. Soc. Am. J. 50, 1154-1157

Goldberg, S; Glaubig, R A. (1988). Anion sorption on a calcareous, montmorillonitic soilarsenic. Soil Sci. Soc. Am. J. 52,1297-1300.

Gómez, J J; Lillo, J; Sahún, B. (2006). Naturally occurring arsenic in groundwater and identification of the geochemical sources in the Duero Cenozoic Basin, Spain. Environmental Geology. 50, 1151-1170.

Goulding, K W T; Webster, C P. (1992). Methods for measuring nitrate leaching. In: Nitrate and Farming systems. Aspects of applies biology. 30, 63-69. 
Gräfe, M; Sparks, D L. (2006). Solid phase speciation of arsenic. In: Naidu R y col (eds) Managing arsenic in the environment. From soils to human health. CSIRO Pub, Collingwood, Australia, pp 75-92

Gromet, L. P., Dymek, R. F., Haskin, L. A. and Korotev, R. L. (1984) The North American Shale Composite: its compilation, major and trace element characteristics. Geochim. Cosmochim. Acta 48, 2469- 2482.

Gruebel, K A; Davis, J A; Leckie, J O. (1988). The feasibility of using sequential extraction techniques for arsenic and selenium in soils and sediments. Soil Sci. Soc. Am. J. 52, 390-397.

Guha Mazumder, D.N; Haque, R; Gosh, N; De, B K; Sandra, A; Chakraborty, D; Smith, A H. (2000). Int. J. Epidemiol. 29, 1047.

Guo, T Z; DeLaune, R D; Patrick, W H.(1997). The influence of sediment redox chemistry on chemically active forms of arsenic, cadmium, chromium, and zinc in estuarine sediment. Environ. Internat. 23, 305-316.

Gupta, S K; Aten, C. (1993). Comparison and evaluation of extraction media and their suitability in a simple model to predict the biological relevance of heavy metal concentrations in contaminated soils. International Journal of Environmental Analytical Chemistry. 51, 1-4, 25-46.

Gurzau, E S; Gurzau, A E. (2001). Arsenic in drinking water from groundwater in Transylvania, Romania. In: Chapell, W.R., Abernathy, C.O., Calderon, R.L.(Eds.). Arsenic Exposure and Health Effects IV.Elsevier,Amsterdam .181-184.

Hall, G E M; Gauthier, G; Pelchat, J C. (1996). Application of a sequential extraction scheme to ten geological certified reference materials for the determination of 20 elements Journal Of Analytical Atomic Spectrometry. 11, 9, 787-796.

Hanedar, A. (2015) Assessment of airborne heavy metal pollution in soil and lichen in the Meric-Ergene Basin, Turkey Environmental Technology: 36, 20, 2588-2602.

Harshman, R A. (1970). Foundations of the PARAFAC procedure: Model and conditions for an 'explanatory' multi-mode factor analysis. UCLA Working Papers in phonetics. 161.

Helena, B A; Pardo, R; Vega, M; Barrado, E; Fernández, J M; Fernández, L. (2000) Temporal evolution of groundwater composition in an alluvial aquifer (Pisuerga River, Spain) by principal component analysis. Wat. Res. 34, 807-816.

Hernández García, M E; Fernández Ruiz, L. (2002) Presencia de arsénico de origen natural en las aguas subterráneas del acuífero detrítico del Terciario de Madrid, Boletín Geológico y Minero. 113, 2,119-130.

Hiemstra, T; van Riemsdijk,W H. (1996). A surface structural approach to ion adsorption: the charge distribution, CD. Model. J. Colloid Interface Sci. 179, 488-508.

Hindersmann, I; Mansfeldt, T. (2014). Trace Element Solubility in a MultimetalContaminated Soil as Affected by Redox Conditions. Water air and soil pollution. 225. 
Hopke, P K. (1983). An introduction to multivariate analysis of environmental data. Natusch, D.F.S, Hopke PK(Eds). Analytical aspects of environmental chemistry. Wiley, New York, 219.

Hudson-Edwards, K A; Houghton, S L; Osborn, A. (2004). Extraction and analysis of arsenic in soils and sediments. Trends in Analytical Chemistry. 23, 745-752.

Hughes, J C; Noble, A D. (1991). Extraction of chromium, nickel and iron and the availability of chromium and nickel to plants from some serpentinite-derived soils from the eastern Transvaal as revealed by various single and sequential extraction techniques. Communications in Soil Science and Plant Analysis. 22, 17-18, 17531766.

IGME (1980). Investigación hidrogeológica de la Cuenca del Duero. Sistemas no 8 y 12. Colección Informe, 75 pp. Madrid.

IGME (1982). Mapa Geológico de España. Escala 1:50.000. Hoja de Portillo (400).

IHOBE. (1994). Investigación de la Contaminación del Suelo. Plan Director para laprotección del suelo. Gobierno Vasco.

II'yin, B V; Konarbayeva, G A. (1996). Arsenic in soils of West Siberia as related to the regional environmental monitoring. Eurasian Soil Sci. 28, 144-150.

ILL. (2005) Institute Laue Langevin http://www.ill.fr/pages/press/gb/press_releases/Arsenic.htm

Inskeep, W P; McDermott, T R; Fendorf, S. (2002). Arsenic(V)/(III) cycling in soils and natural waters: chemical and microbiological processes. Environmental Chemistry of Arsenic (Frankenberger Jr WT, ed), pp. 183-215. Marcel Dekker Inc., New York.

Jacks, G; Bhattacharya, P. (1998). Arsenic contamination in the environment due to the use of CCA-wood preservatives. Arsenic in wood preservatives, Part I.

Jacobs, L W; Syers, J K; Keeney, D R. (1970). Arsenic sorption in soils. Soil Sci. Soc. Am. Proc. 34, 750-754.

James, L F; Lazar, V A; Binns, W. (1966). Effects of sublethal doses of certain minerals on pregnant ewes and fetal development. Amer J Vet Res .27, 132-135.

Jha, PK; Vaithiyanathan, P; Subramanian, V. (1993). Mineralogical characteristics of the sediments of a Himalayan river - Yamuna river - a tributary of the Ganges. Environmental Geology. 22; 13-20

Johnson, L R; Hiltbold, A E. (1969). Arsenic content of soil and crops following use of methanearsonate herbicides. Soil Sci Soc Am Proc. 33, 279-282

Jones, C A; Langner, H W; Anderson, K; McDermott, T R; Inskeep, W P. (2000). Rates of microbially mediated arsenate reduction and solubilization. Soil Science Society of America Journal. 64, 600-608.

Jones, K C; Peterson, P J Y; Davies, B D. (1984). Extraction of silver from soils and its determination by atomic absorption spectrometry. Geoderma. 33, 157-158 
Jones, L H P; Jarvis, S C. (1981). The fate of heavy metals. In: D.J. Greenland and M. H. B. Hayes (eds.) The chemistry of soil processes. 593-620.

Juste, C; Solda, P. (1988). Changes in the cadmium, manganese, nickel and zinc bioavailability of a sewage sludge-treated sandy soil as a result of ammoniumsulfate, acid peat, lime or iron compound addition. Agronomie. 8, 897-904.

Kabata-Pendias, A; Pendias, H. (1985). Trace Elements in Soils and Plants. 315. Boca Raton, CRC Press.

Kandakji, T; Udeigwe, T K.; Athanasiou, D. (2015). Chemistry of Arsenic in Semi-Arid Alkaline Soils of the Southern High Plains, USA: Sorption Characteristics and Interactions with Soil Constituents. Water Air And Soil Pollution. 226, 9

Kavanagh, PJ; Farago, M E; Thornton, I; Braman, R S. (1997). Bioavailability of arsenic in soil and mine wastes of the Tamar valley, SW England. Chemical Speciation and Bioavailability. 9, 3, 77-81.

Keon, N E; Swartz, C H; Brabander, D J; Harvey, C; Hemond, H F. (2001). Validation of an arsenic sequential extraction method for evaluating mobility in sediments. Environmental Science \& Technology. 35, 2778-2784.

Kheboian, C; Bauer, C F. (1987). Accuracy of Selective Extraction Procedures for Metal Speciation in Model Aquatic Sediments. Anal. Chem. 59, 1417-1423.

Koyama, T; Awano, H; Shibuya, M. (1976). Studies on the relation between arsenic in soils and paddy rice growth (1) - with arsenic speciation and arsenic damage of paddy rice. Jpn. J. Soil Sci. Manure. 47,3, 85-92

Krysiak, A; Karczewska, A. (2007). Arsenic extractability in soils in the areas of former arsenic mining and smelting, SW Poland. Science of the Total Environment. 379, 190-200.

Kumpiene, J; Montesinos, I C; Lagerkvist, A; Maurice, C. (2007). Evaluationofthe critical factors controlling stability ofchromium, copper, arsenic and zinc in iron-treated soil. Chemosphere. 67, 410-417.

Langmuir, D. (1971). The geochemistry of some carbonated groundwaters in central Pensylvania. Geochim. Cosmochim. Acta. 35, 1023-1045.

Larios, R; Fernández-Martínez, R; Ordóñez, A; Loredo, J; Galán, P; Gómez, M B; Silva, V; Rucandio, M I. (2008). Arsenic geochemistry in sediments from an old mining area in Asturias (Spain). Bobos ISdSJ, Ferreira da Silva E, Rosário Pereira M (eds) Geochemistry of Arsenic International Workshop Extended Abstracts. Universidade do Porto, Facultad de Ciências, Departamento de Geología, Oporto, 25-28.

Larios, R; Fernández-Martínez, R; Rucandio, I. (2012). Comparison of three sequential extraction procedures for fractionation of arsenic from highly polluted mining sediments. Anal Bioanal Chem. 402, 2909-2921

Leardi, R; Armanino, C; Lanteri, S. (2000). Three-mode principal component analysis of monitoring data from Venice lagoon. Journal Of Chemometrics, 14, 3, 187-195. 
Lebourg, A; Sterckeman, T; Ciesielski, H; Proix, N. (1998). Trace metal speciation in three unbuffered salt solutions used to assess their bioavailability in soil. J. Environ. Qual. 27, 584-590.

Li, F; Zhenga, Y-M; Hea, J-Z. (2009). Microbes influence the fractionation of arsenic in paddy soils with different fertilization regimes. Science Of The Total Environment. 407, 2631-2640

Li, X; Coles, B J; Ramsey, M H; Thornton, I. (1995). Sequential extraction of soils formultielement analysis by ICP-AES. Chem. Geol. 124, 109-123.

Lin, Z; Puls, RW. (2000). Adsorption, desorption and oxidation of arsenic affected by clay minerals and aging process.Environ.Geol. 39, 753-759.

Lindsay, W L; Norvell, W A. (1978). Development of a DTPA soil test for zinc, iron, manganese and copper. Soil Sci. Soc. Am. J. 42:421-428.

Livesey, N T; Huang, P M. (1981). Adsorption of arsenate by soils and its relation to selected chemical properties and anions. Soil Sci. 131, 88-94.

Lockwood, C L; Mortimer, R J; Stewart, D. (2014). Mobilisation of arsenic from bauxite residue (red mud) affected soils: Effect of $\mathrm{pH}$ and redox conditions. Applied Geochemistry. 51, 268-277.

Lombi E, Wenzel WW, Sletten RS (1999) Arsenic adsorption by soils and iron-coated sand: kinetics and reversibility. J Plant Nutr Soil Sci 162:451-456

Lombi, E; Sletten, R.S; Wenzel, W.W. (2000). Sequential extracted arsenic from different size fractions of contaminate soils. Water Air Soil Pollut. 56, 155-83.

Luo, W; Lu, Y; Wang. G; Shi Y; Wang, T; Giesy, J. P. (2008). Distribution and availability of arsenic in soils from the industrialized urban area of Beijing, China. Chemosphere 72(5), 797-802.

Ma, Jie; Guo, Huaming; Lei, Mei. (2015) Arsenic Adsorption and its Fractions on Aquifer Sediment: Effect of $\mathrm{pH}$, Arsenic Species, and Iron/Manganese Minerals. Water Air And Soil Pollution, 226, 8, Número de artículo: 260.

Magalhães, M C F. (2002). Arsenic. An environmental problem limited by solubility. Pure and Applied Chemistry. 74, 1843-1850.

Mahimairaja, S; Bolan, N S; Adriano, D C; Robnson, B, (2005). Arsenic contamination and its risk management $n$ complex environmental settings. Ad. Agron. 86, 182-264.

Manful, G A. (1992).Occurrence and ecochemical behavior of arsenic in a goldsmelter impacted area in Ghana. Ph.D. Dissertation, Centrum voor Milieusanering, RUG, Ghent, Belgium.

Manning ,B.A; Fendorf,S.E; Goldberg,S, (1998), Surface structuresand stability of As(III) on goethite: spectroscopic evidence for inner-sphere complexes, Environ. Sci. Technol, 32, 2383-2388

Manning, B A., Goldberg, S. (1996). Modeling competitive adsorption of arsenate with phosphate and molybdate on oxide minerals. Soil Sci.Soc.Am.J. 60,121-131 
Manning, B A; Goldberg, S. (1997). Adsorption and stability of arsenic(III) at the clay mineral-water interface. Environ. Sci. Technol. 31, 2005-2011.

Martınez-Fernandez, M; Barciela-Alonso, M; Moreda-Piñero, A; Bermejo Barrera, P. (2011). Matrix solid phase dispersion-assisted BCR sequential extraction method for metal partitioning in surface estuarine sediments. Talanta. 83, 840-849.

Masscheleyn, P H; Delaune, R D; Patrick, WH. (1991). Effect of redox potential and pH on arsenic speciation and solubility in a contaminated soil. Environ. Sci. Technol. 25, 1414-1419.

Matera, V; Le Hecho, I; Laboudigue, A; Thomas, P; Tellier, S; Astruc, M. (2003). A methodological approach for the identification of arsenic bearing phases in polluted soils. Environmental Pollution. 126, 51-64.

Matera, V; LeHecho, I. (2001). Arsenic behavior in contaminated soils: mobility and speciation. In: Heavy metals release in soils. Selim, H. M., and Sparks. D. L. (Eds). CRC Press. Boca Raton, FL. 207-235

Matis, K A; Zoubouli's, A I; Malamar, F B; Atonso, M D R; Hudson, M J. (1997). Floatation removal of $A s(V)$ onto goethite. Environ. Pollut. 97, 23924.

McBride, M B. (1994). Environmental Chemistry of soils, vol3. Oxford University Press, 406.

McCarty, D K; Mome, J N Y; Marcus, W A. (1998). Mineralogy and trace element association in an acid mine drainage iron oxide precipitate; comparison of selective extractions. Applied Geochem. 13, 165-176.

Meglen, R. (1991).Examining large databases: A chemometric approach using principal component analysis. Journal of Chemometrics. 5, 3, 163-179.

Mench, M; Bussiere, S; Vangronsveld, J; Manceau, A. (2003). Progress in remediation and revegetation of the barren Jales gold mine spoil after in-situ treatments. Plant Soil. 249, 187-202

Mohapatra, D; Mishra, D;. Chaudhury, G R; Das, R P. (2007). Arsenic adsorption mechanism on clay minerals and its dependence on temperature. Korean J. Chem. Eng. 24, 426-430.

Montperrus, M; Bohari, Y; Bueno, M; Astruc, A; Astruc, M. (2002). Comparison of extraction procedures for arsenic speciation in environmental solid reference materials by high-performance liquid chromatographyehydride generation-atomic fluorescence spectroscopy. Applied Organometallic Chemistry. 16, 347-354.

Moptma-Miner (1995). Libro blanco de las aguas subterráneas. 135 pp. Madrid.

Moreno-Jiménez, E; Manzano, R; Esteban, E; Peñalosa, J M. (2010). The fate of arsenic in soils adjacent to an old mine site (Bustarviejo, Spain): mobility and transfer to native flora. J. Soil. Sediment. 10, 301-312. 
Mossop, K F; Davidson, C M. (2003). Comparison of original and modified BCR sequential extraction procedures for the fractionation of copper, iron, lead, manganese and zinc in soils and sediments. Anal Chim Acta. 478, 111-118.

Moyano, A; Mayorga, P; García-Sánchez, A. (2003) Contaminación de arsénico en aguas subterráneas de Castilla y León, III Congreso Iberoamericano de Física y Química Ambiental, Tlaxcala.

Mueller, K; Daus, B; Morgenstern, P. (2007). Mobilization of antimony and arsenic in soil and sediment samples - Evaluation of different leaching procedures Water Air And Soil Pollution: 183, 1-4, 427-436.

Mulchi, C L; Adamu, C A; Bell, P F; Chaney R L. (1992). Residual heavy metal concentrations in sludge amended coastal plain soils - II. Predicting metal concentrations in tobacco from soil test information . Common. Soil Sci. Plant Anal. 23, 1053-1059.

Müller, K. Daus, B. Morgenstern, P.Wennrich, R. (2007). Mobilization of antimony and arsenic in soil and sediment samples: Evaluation of different leaching procedures. Water, Air, and Soil Pollution. 183, 427-436.

Nemecz, E. (1981). Clay minerals. Budapest, Akadémiai Kiado. 547.

Nicolli, H B; Merino, M H. (2000). High contents of F, As and Se in groundwater of the Carcaraiili river basin, Argentine Pampean Plain. Emiron. Gd. In press.

Nicolli, H B; Suriano, J M; Gómez Peral, M A., Ferpozzi, L H; Baleani, O M. (1989). Groundwater contamination with arsenic and other trace elements in an area of the Pampa, Province of Cordoba, Argentina. Environ. Geol. Water Sci., 14, 3-16.

Nirel, P M; Morel, F M. (1990). Pitfall of sequential extraction. Wat. Res. 24, 8, 10551056.

Novao-Muñoz, J C; Queijeiro, J M G; Blanco, D; Alvarez, C; Garcia, E; Martinez, A. (2007). Arsenic fractionation in agricultural acis soils from NW Spain using a sequential extraction procedure. Science of total environment. 378, 18-22

Novozamski, I; Lexmon, T M; Houba, V J G. (1993). A single extraction procedure of soil for evaluation of uptake of some heavy-metals by plants. Int. J. Environ. Anal. Chem. 51, 47-58.

Nriagu, J O. (1989). A global assessment of natural sources of atmospheric trace metals. Nature. 338, 47-49.

Nriagu, J O. (1994). Arsenic in the Environment. Part I: Cycling and Characterization. John Wiley \& Sons, INC. New York. 1-417.

O'Neill, P. (1995). Arsenic. B.J. Alloway (Editor), Heavy Metals in Soils, second ed., Blackie Academic \& Professional, Glasgow, UK.

Otones, V; Álvarez-Ayuso, E; García-Sánchez, A; Santa Regina, I; Murciego, A. (2011). Arsenic distribution in soils and plants of an arsenic impacted formermining area. Environ Pollut. 159, 2637-2647. 
Oyarzun, R; Lillo, J; Higueras, P; Oyarzun, J; Maturana, H. (2004). Strong arsenic enrichment in sediments from the Elqui watershed, Northern Chile: Industrial (gold mining at El Indio-Tambo district) vs. geologic processes. J Geochem Explor. $84,53-64$.

Pandey, P K; Yadav, S; Nair, S; Bhui, A. (2002). Arsenic contamination of the environment. A new perspective from central-east India. Environ. Int. 905, 28, 235-245.

Pantsar-Kallio, M; Manninen, P K G. (1997). Speciation of mobile arsenic in soil samples as a function of $\mathrm{pH}$. The Science of the Total Environment. 204, 193-200

Pardo, R; Barrado, E. (1988). Métodos de Reconocimiento de Pautas (Pattern Recognition) en Quimiometría, Blanco M. y Cerdá V (Eds.) Cuadernos de Ciencias y Técnicas Ambientales, Universitat Autònoma de Barcelona.

Pardo, R; Helena, B A; Cazurro, C; Guerra, C; Deban, L; Guerra, C M; Vega, M. (2004). Application of two-and three-way principal component analysis to the interpretation of chemical fractionation results obtained by the use of the BCR procedure. Analytica Chimica Acta. 523-1, 125-132.

Pardo, R; Vega, M; Barrado, E. Castrillejo, Y; Sánchez, I. (2013).Three-way principal component analysis as a tool to evaluate the chemical stability of metal bearing residues from wastewater treatment by the ferrite process. Journal Of Hazardous Materials. 262, 71-82.

Pardo, R; Vega, M; Barrado, E; Castrillejo, Y; Prieto, F. (2002) Mobility and chemical fractionation of heavy metals in solids originating from the ferrite process, Quim. Anal. 20, 187-195.

Pardo, R; Vega, M; Debán, L; Cazurro, C; Carretero, C. (2008) Modelling of chemical fractionation patterns of metals in soils by two-way and three-way principal component analysis. Anal. Chim. Acta. 606, 26-36.

Pérez Moreno, F. (2004). Lixiviación y precipitación de arsénico en aguas y lodos de pozos del distribuidor general de Zimapán, Hidalgo. Universidad Autónoma del Estado de Hidalgo. Pachuca, México. 17-23.

Peterson, M L; Carpenter, R. (1983). Biogeochemical processes affecting total arsenic and arsenic species distributions in an intermittently anoxic Fjord. Mar.Chem. 12, 295-321.

Pichler, T., Veizer, J., Hall, G.E.M., 1999. Natural input of arsenic into a coral reef ecosystem by hydrothermal fuids and its removal by $\mathrm{Fe}$ (III) oxyhydroxides. Environ. Sci. Technol.33,1373-1378.

Pickering, W F. (1986). Metal speciation-Soils and sediments (A review). Ore Geology Review. 1, 83-146.

Piper, A M. (1944). A graphic procedure in the geochemical interpretation of wateranalyses. Transactions, American Geophysical Union 25, 914-920. 
Polemio, M; Senesi, N; Bufo, S A. (1982). Soil contamination by metals: A survey in industrial and rural areas of southern Italy. The Science of the Total Environment 25, 1,71-79.

Quazi, S; Datta, R; Sarkar, D. (2011). Effects of soil types and forms of arsenical pesticide on rice growth and development International Journal of Environmental Science and Technology. 8, 3, 445-460.

Quevauviller, P. (1998). Operationally defined extraction procedures for soil and sediment analysis I. Standardization. Trends Anal Chem. 17,289-298.

Quevauviller, P; Rauret, G; López-Sànchez, J; Rubio, R; Ure, A M; Muntau, H. (1997). Certification of trace metal extractable contents in a sediment reference material (CRM 601) following a three-step sequential extraction procedure. Sci Total Environ. 205,223-234.

Quevauviller, P; Ure, A; Muntau, H; Griepink, B. (1993). Improvement of Analytical Measurements within the BCR-Program - Single and Sequential Extraction Procedures applied to Soil and Sediment Analysis. Int J Environ Anal Chem. 51,129-134.

Raksasataya, M; Langdon, A G Y; Kim, N D. (1996). Assessment of the extent of lead redistribution during sequential extraction by two different methods. Analyt. Chim. Acta, 332, 1-14.

Ramis, G; García, M C. (2001) Quimiometría. Editorial Síntesis.

Rao, C R M; Sahuquillo, A J F; López Sánchez, A. (2008). Review of the Different Methods Applied in Environmental Geochemistry For Single and Sequential Extraction of Trace Elements in Soils and Related Materials. Water, Air, and Soil Pollution. 189, Issue 1-4, 291-333.

Rauret, G. (1998). Extraction procedures for the determination of heavy metals in contaminated soil and sediment. Talanta, 46, 449-455.

Rauret, G. Lopez-Sanchez, J.F. Sahuquillo, A. Rubio, R. Davidson, C. Ure, A. Quevauviller $\mathrm{Ph}$. (1998). Improvement of the BCR three step sequential extraction procedure prior to the certification of new sediment and soil reference materials. J. Environ. Monit. 1, 57-61.

Raven, K P; Jain, A. Loeppert, R H. (1998). Arsenite and arsenate adsortion on ferrihydrate: kinetics, equilibrium, and adsorption envelopes. Environmental Science and Technology. 32, 344-349.

Remucal, C K; Ginder-Vogel, M. (2014). A critical review of the reactivity of manganese oxides with organic contaminants. Environmental science-processes \& impacts. 16,$6 ; 1247-1266$

Reynolds, J G; Naylor, D V; Fendorf, S E. (1999). Arsenic sorption inphosphate-amended soils during flooding and subsequent aeration. J.Soil Science Society of America Journal. 63,5, 1149-1156. 
Robertson, F N. (1989). Arsenic in groundwater under oxidizing conditions, south-west United States. Environmental Geochemistry and Health. 11, 171-185.

Roh, Yul. (2011). Geochemical and Mineralogical Characterization of ArsenicContaminated Soil at Chonam Gold Mine, Gwangyang. Economic and Environmental Geology. 44, 3, 203-215.

Romaguera, F; Boluda, R; Fornes, F; Abad, M. (2008). Comparison of three sequential extraction procedures for trace element partitioning in three contaminated Mediterranean soils. Environmental Geochemistry and Health. 30, 2, 171-175.

Roman-Ross, G; Cuello, G J; Turrillas, X; Fernandez-Martinez, A; Charlet, L. (2006). Arsenite sorption and co-precipitation with calcite. Chemical Geology 233:328336.

Romero, F M; Armienta, M A; Carrillo, C A. (2004). Arsenic sorption by carbonate-rich aquifer material, a control on arsenic mobility at Zimapan. Mexico. Arch. Environ. Contam. Toxicol. 47, 1-13.

Roy, W R; Hassett, J J; Griffin, R A. (1986). Competitive coefficients for the adsorption of arsenate, molybdate, and phosphate mixtures by soils. Soil Sci Soc Am J. 50, 11761182.

Ruiz, J M. (2003). Utilización del balance de cloruros en la zona no saturada en la estimación de la recarga natural a un acuífero detrítico. Estudios de la Zona No Saturada del Suelo Vol VI. J. Álvarez-Benedí y P. Marinero.

Saada, A; Breeze, D; Crouzet, C; Cornu, S; Baranger, P. (2003). Adsorption of arsenic (V) on kaolinite and on kaolinite-humic acid complexes: role of humic acid nitrogen groups. Chemosphere. 51, 757-763.

Sadiq, M. (1997). Arsenic chemistry in soils: an overview of thermodynamic prediction and fi eld observations. Water Air Soil Pollut. 93, 117-136

Sahún, B; Gómez, J J; Lillo, J; Del Olmo, P. (2004). Arsénico en aguas subterráneas e interacción agua-roca: un ejemplo en la Cuenca Terciaria del Duero (Castilla y León, España). Rev. Soc. Geol. De España. 17, 137-155.

Sahuquillo, A; López-Sánchez, J F; Rubio, R; Rauret, G; Thomas, R P; Davidson, C M; Ure, AM. (1999). Use of a certified reference material for extractable trace metals to assess sources of uncertainty in the BCR three-stage sequential extraction procedure. Anal Chim Acta. 382,317-327.

Sahuquillo, A; Rigol, A; Rauret, G. (2003). Overview of the use of leaching/extraction tests for risk assessment of trace metals in contaminated soils and sediments. Trend Anal. Chem. 22, 152-159.

Salman S R; Y.H. (1999) Multivariate and principal component statistical analysis of contamination in urban and agricultural soils from north Jordan, Environ. Geol., 38: $265-270$. 
Sancha, A M; Castro, M L. (2001). Arsenic in Latin America: occurrence, exposure, health effects and remediation. In: Chapell, W. R., Abernathy, C.O., Calderon, R.L.(eds.). Arsenic Exposure and Health Effects IV. Elsevier, Amsterdam. 87-96.

Sánchez de la Torre, L. (1979). Tránsito de "Facies Tierra de Campos" a "Facies Cuestas" y depósitos de ciénagas. Zaratán. I Reun. Geol. Cuenca del Duero., Salamanca, Guía de excursiones. 758-762.

Sarkar, D; Datta, R. (2004). Arsenic fate and bioavailability in two soils contaminated with sodium arsenate pesticide. Bull Environ Contam Toxicol.72, 240-7.

Sarkar, D; Makris, KC; Vandanapu, V; Datta, R. (2007). Arsenic immobilization in soils amended with drinking-water treatment residuals. Environ Pollut. 146, 414-419.

Schroeder, W H; Dobson, M; Kane, D M; Johnson, N D, (1987). Toxic trace-elements associated with airborne particulate matter - a review. Internat. J. Air Pollut. Control Hazard. Waste Manag. 37, 1267-1285.

Seiler, H G; Sigel, A; Sigel, H. (1994). Arsenic. Handbook on Metals in Clinical and Analytical Chemistry. Marcel Dekker Inc. New York, NY, 237-253

Sharaf, M A; Illman, D L; Kowalski, B R. (1986). Chemometrics. Editors: Elving, P. J., Winefordner, J. D., and Koltho[? I. M. John Wiley \& Sons, New York: USA.

Simeonov, V; Massart, D L; Andreev, G; Tsakovski, S. (2000) Assessment of metal pollution based on multivariate statistical modeling of 'hot spot' sediments from the Black Sea. Chemosphere. 41, 1411-1417.

Singh, K P; Malik, A; Singh, V K. (2006). Multi-way data analysis of soils irrigated with wastewater - A case study. Chemometrics And Intelligent Laboratory Systems. 83, 1, 1-12.

Singh, K P; Malik, A; Sinha, S; Mohan, D; Singh V K. (2007) Exploring groundwater hydrochemistry of alluvial aquifers using multi-way modeling. Anal. Chim. Acta. 596. 171-182.

Smedley, P L; Kinniburgh, D G. (2002). A review of the source, behavior and distribution of arsenic in natural waters. Applied Geochemistry. 17, 517-568.

Smedley, P L; Kinniburgh, D G; Huq, I; Luo, Z; Nicolli, H B. (2001). International perspective on naturally occurring arsenic problems in groundwater. In: Chappell, W.R., Abernathy, C.O., Calderon, R.L. (Eds.), Arsenic Exposure and Health Effects IV. Elsevier. Amsterdam. 9-25.

Smedley, P L; Nicolli, H B; Macdonald, D M; Barros, A J; Tullio, J O. (2002). Hydrogeochemistry of arsenic and other inorganic constituents in groundwaters from La Pampa, Argentina. Applied Geochemistry. 17, 259-284.

Smedley, P L; Zhang, M; Zhang, G; Luo, Z. (2001). Arsenic and other redox-sensitive elementsin groundwaterfrom theHuhhot Basin, Inner Mongolia. In: Cidu, R. (Ed.), Water-Rock Interaction 2001, Vol. 1. Swets \& Zeitlinger, Lisse. 581-584. 
Smith, A H; Goycolea, M; Haque, R; Biggs, M L. (1998). Marked increase in bladder and lung cancer mortality in a region of northern Chile due to arsenic in drinking water. Am. J. Epidemiol. 147, 660-669.

Smith, E; Naidu, R; Alston, A.M. (1998). Arsenic in the soil environment: a review. Adv. Agron. 64, 149-195.

Smith, Euan; Naidu, Ravi; Weber, John; Juhasz, Albert, L. (2008). The impact of sequestration on the bioaccessibility of arsenic in long-term contaminated soils Chemosphere. 71, 4, 773-780.

Smolinski,A; Walczak,B; Einax,J.W. (2002). Hierarchical clustering extended with visual complements of environmental data set. Chemom.Intell. Lab. Syst. 64, 45-54.

Sø, H U; Postma, D; Jakobsen, R; Larsen, F. (2008). Sorption and desorption of arsenate and arsenite on calcite. Geochimica et Cosmochimica Acta. 72, 5871-5884.

Sø, H U; Postma, D; Jakobsen, Rs. (2012). Competitive adsorption of arsenate and phosphate onto calcite; experimental results and modeling with CCM and CDMUSIC. Geochimica Et Cosmochimica Acta. 93, 1-13.

SSPSS versión 20.0.0, tutorial

Stachowicz, M; Hiemstra, T; van Riemsdijk, W H. (2008). Multi-competitive interaction of $\mathrm{As}(\mathrm{III})$ and $\mathrm{As}(\mathrm{V})$ oxyanions with $\mathrm{Ca}^{2+}, \mathrm{Mg}^{2+}, \mathrm{PO}_{4}{ }^{3-}$, and $\mathrm{CO}_{3}{ }^{2-}$ ions on goethite. $\mathrm{J}$ Colloid Interface Sci. 320, 400-414.

Stevenson, F J. (1982). Humus chemistry. Genesis, composition, reactions. Wiley, New York.

Stumm, W. (1995). The inner-sphere surface complex - a key to understanding surface reactivity. Editado por: Huang, CP; OMelia, CR; Morgan, JJ. Aquatic chemistry: Interfacial and Interspecies Processes. Colección: Advances in Chemistry Series. 244, 1-32.

Sullivan, K A; Aller, R C. (1996). Diagenetic cycling of arsenic in Amazon shelf sediments. Geochim. Cosmochim. Acta. 60, 1465-1477

Szakova, J; Tlustos, P; Balik, J; Pavlikova, D; Vanek, V. (1999). The sequential analytical procedure as a tool for evaluation of As, Cd and Zn mobility in soil. Fresen J Anal Chem. 363,594-595.

Taggart, M A; Carlisle, M; Pain, D J; Williams, R; Osborn, D; Joyson, A; Meharg, A.A. (2004). The distribution of arsenic in soil affected by the Aznalcollar mine spill, SW Spain. Sci. Total Environ. 323, 137-52.

Tam, NFY; Wong, YS. (2000). Spatial variation of heavy metals in surface sediments of Hong Kong mangrove swamps. Environmental Pollution. 110; 2; 195-205.

Tanabe, K; Yokota, H; Hironaka, H; Tsushima, S; Kubota, Y. (2001). Appl. Organomet. Chem. 15, 245.

Tareq, S M; Safiullah, S; Anawar, H M; Rahman, M M; Ishizuka, T. (2003). Arsenic pollution in groundwater: a self-organizing complex geochemical process in the 
deltaic sedimentary environment, Bangladesh. The Science of the Total Environment. 313, 213-226.

Taylor, S R; McLennan, S M. (1985). The continental Crust: Its Composition and Evolution. Blackwell, Oxford.

Tessier, A; Campbell, P G C; Bisson, M. (1979). Sequential extraction procedure for the speciation of particulate trace metals. Anal. Chem. 51, 844-851.

Thomas, R P; Ure, AM; Davidson, C M; Littlejohn, D; Rauret, G; Rubio, R; López-Sánchez, J F. (1994). Three-stage sequential extraction procedure for the determination of metals in river sediments. Anal Chim Acta. 286, 423-429.

Tipping, E; Hetherington, N B; Hilton, J; Thompson, D W; Bowles, E; HamiltonTaylor, J. (1985). Artifacts in the use of selective chemical extraction to determine the distribution of heavy metals between oxides of manganese and iron. Anal. Chem. 57, 1944-1946.

Tlustos, P; Szakova, J; Starkova, A; Pavlikova, D. (2005). A comparison of sequential extraction procedures for fractionation of arsenic, cadmium, lead, and zinc in soil. Central European Journal of Chemistry. 3, 4, 830-851.

Tucker, L. (1996). Some mathematical notes on three-mode factor analysis. Psychometrika. 31, 279-311

Ungaro, F; Ragazzi, F. Arsenic concentration in the soils of the Brenda Plain (Norteen Italy) Mapping the probability of exceeding contamination thresholds.

Ure AM, Berrow ML (1982) The elemental constituents of soils. Environmental Chemistry, 94-204. http://dx.doi.org/10.1039/9781847555991-00094

Ure, A M. (1995). Methods of ana1ysis for heavy meta1s in soi1s. B. J. Alloway (Ed.), Heavy Metals in Soils, p. 58-102. Blackie Academic \& Professiona1, 2a edición.

Ure, A M; Davidson, C M; Thomas R P. (1995). Single and sequential extraction schemes for trace metal speciation in soil and sediment. Techniques and Instrumentation in Analytical Chemistry. 17, 505-523.

Ure, A M; Quevauviller, P; Muntau, H; Griepink, B. (1993). Speciation of heavy metals in soils and sediments. An account of the improvement and harmonization of extraction techniques undertaken under the auspices of the BCR of the Commission of the European Communities. International Journal of Environmental Analytical Chemistry. 51, 1-4, 135-151.

Vaïsänen, A; Kiljunen, A. (2005). Ultrasound-assisted sequential extraction method for the evaluation of mobility of toxic elements in contaminated soils. Int J Environ Anal Chem. 85, 1037-1049.

Van Herreweghe S, Swennen R, Vandecasteele C, Cappuyns V (2003) Solid phase speciation of arsenic by sequential extraction in standard reference materials and industrially contaminated soil samples. Environ Pollut 122, 323-342. 
Vandeginste, B G M; Massart, D L; Buydens, L M C; De Jong, S; Lewi, P-J; Smeyers-Verbeke, J. (1998). Handbook of Chemometrics and Qualimetrics: Part B. Elsevier.

Varsányi, I; Fodré, Z; Bartha, A. (1991). Arsenic in drinking water and mortality in the southern Great Plain, Hungary. Environ. Geochem. Health 13,14-22.

Vega, M; Pardo, R; Carretero, M,C; Fernández, L; Barrado, E. (2004). An investigation into the spatial and temporal evolution of hydrochemical variables of an aquifer influenced by arsenic contamination by three-way Principal Component Análisis,Euroanalysis XIII, Salamanca (España).

Vega, M; van den Berg, C M G. (1994). Determination of vanadium in sea water by catalytic adsorptive cathodic stripping voltammetry. Analytica Chimica Acta. 293, 19-28.

Vidal, M; Tent, J; Rauret, G; Roca, M C; Sauras, T Y, Vallejo, V R. (1994). Forest soil sampling for pollution assessment. Quim. Anal. 13, S70-S75.

Voigt, D E; Brantley, S L; Hennet, R J C. (1996). Chemical fixation of arsenic in contaminated soils. Applied Geochemistry. 11, 633-643

Wang, L; Huang, J. (1994). Chronic arsenism from drinking water in some areas of Xinjiang, China. In: Nriagu, J.O. (Ed.), Arsenic in the Environment, Part II: Human Health and Ecosystem Effects. John Wiley, New York. 159-172.

Wang, Z M; Chen, L D; Zhang, H P; Sun, RH. (2014) Multivariate Statistical Analysis and Risk Assessment of Heavy Metals Monitored in Surface Sediment of the Luan River and its Tributaries, China. Hum. Ecol. Risk Assess. 20, 1521-1537.

Waychunas, G A; Fuller, C C; Rea, B A; Davis, J A. (1993). Surface chemistry of ferihydrite: 1. EXAFS studies on the geometry of coprecipitated and adsorbed arsenate. Geochim Cosmochim Acta. 57:2251-2269.

Welch, A H; Watkins, S A; Helsel, D R; Focazio, M F. (2000). Arsenic in groundwater resources of the United States: U.S. Geological Survey Fact Sheet 063-00, 4p.

Weng, L; Van Riemsdijk, W H; Hiemstra, T. (2009). Effects of fulvic acids on arsenate adsorption to goethite: experiments and modelling. Environ Sci Technol. 43, 71987204.

Wenning, R J; Erickson, G A. (1994). Interpretation and analysis of complex environmental data using chemometric methods Trac-Trends In Analytical Chemistry: $13,10,446-457$

Wenzel, W W; Brandsetter, A; Wutte, H; Lombi, E; Prohaska, T; Stingeder, G; Adriano, D C. (2002). Arsenic in field-collected soil solutions and extracts of contaminated soils and its implication to soil standards. Journal of Plant Nutrition and Soil Science 165, 221-228.

Wenzel, W W; Kirchbaumer, N; Prohaska, T; Stingeder, G; Lombi, E; Adriano, DC. (2001). Arsenic fractionation in soils using an improved sequential extraction procedure, Anal. Chim. Acta. 436, 1-15. 
WHO, 2001. Environmental Health Criteria 224: Arsenic compounds 2nd edition. World

Wilcke, W; Muller, S; Kanchanakool, N. (1998) Urban soil contamination in Bangkok: heavy metal and aluminium partitioning in topsoils. Geoderma. 86, 3-4, 211-228.

Willett J. (1987). Similarity and Clustering inChemical Information Systems. JohnWiley \& Sons, Inc., New York.

Winkel, L; Casentini, B; Bardelli, F; Voegelin, A; Nikolaidis, N P; Charlet, L. (2013). Speciation of arsenic in Greek travertines: Co-precipitation of arsenate with calcite. Geochimica et Cosmochimica Acta. 106, 99-110

Woolson, E A; Axley, J H; Kearney, P C. (1973). The chemistry and phytotoxicity of arsenic in soils: II. Effects of time and phosphorus. Soil Sci. Soc. Am. Proc. 37, 254259.

Woolson, E.A. 1975. Arsenical pesticides. ACS Ser. 7, 1-176.

Xie ,Z M; Naidu, R. (2006.) Factors infl uencing bioavailability of arsenic to crops. In: Naidu R y col (eds) Managing arsenic in the environment. From soils to human health. CSIRO Pub, Collingwood, Australia. 223-234.

$\mathrm{Xu}, \mathrm{H}$; Allard, B; Grimvall, A. (1988). Influence of $\mathrm{pH}$ and organic substance on the adsorption of $\mathrm{As}(\mathrm{V})$ on geologic materials. Water Air Soil Pollut. 40, 293-305.

Ya-Chu, H. (1994). Arsenic Distribution in soils, J.O. Nriagu (Ed.), Arsenic in the Environment. I: Cycling and Charaterization, Wiley and Sons, NewYork,

Yan, X P; Kerrich, R; Hendry, M J. (2000). Distribution of arsenic(III), arsenic(V)and total inorganic arsenic in pore-waters from a thick till and clay-rich aquitard sequence, Saskatchewan,Canada.Geochim. Cosmochim.Acta. 64, 2637-2648.

Yokoyama, Y; Tanaka, K; Takahashi, Y. (2012). Differences in the immobilization of arsenite and arsenate by calcite. Geochimica Et Cosmochimica Acta. 91, 202-219.

Yolcubal, I; H. Akyol. (2008). Adsorption and transport of arsenate in carbonate-rich soils: Coupled effects of nonlinear and rate-limited sorption Chemosphere. 73, 1300-1307.

Yong, R N; Galvez-Coutier, R; Phadungchewit, Y. (1993). Se1ective sequentia1 extraction ana1ysis of heavy-meta1 retention in soil. Can. Geotech. J. 30, 834-847.

Zeien, H. (1995). Chemische Extraktionen zur Bestimmung der Bindungsformen von Schwermetallen in B"oden, Thesis (PhD, Rheinische Friedrich-WilhelmsUniversit"at Bonn.

Zeien, H; Brümmer, G W. (1989). Chemische Extraktionen zur Bestimmung von Schwermetallbildungformen in Böden. Mitt. Dtsch. Bodenk. Gesell. 59, 505 - 510.

Zhang, H; Selim, H M. (2008). Reaction and transport of arsenic in soils: equilibrium and kinetic modeling. Adv Agron. 98, 45-115.

Zimmerman, A J; Weindorf, D C. (2010). Heavy metal and trace metal analysis in soil by sequential extraction: a review of procedures. International journal of analytical chemistry. 2010. Número de artículo: 387803. 
Zollmer, V; Irion, G. (1993). Clay mineral and heavy-metal distributions in the northeastern north-sea. Marine geology. 111, 223-230. 

ANEXOS 

A.IÁREA DE ESTUDIO 

Tabla A.I.1. Inventario puntos de agua.

\begin{tabular}{|c|c|c|c|c|c|c|c|}
\hline \multirow{2}{*}{ № } & \multirow{2}{*}{ Naturaleza } & \multicolumn{2}{|c|}{ Coordenadas UTM } & \multirow{2}{*}{ Cota $(m)$} & \multirow{2}{*}{ Acuífero } & \multirow{2}{*}{ Uso } & \multirow{2}{*}{$\begin{array}{c}\text { Vol anual } \\
\left(\mathrm{Dm}^{3}\right)\end{array}$} \\
\hline & & $x$ & $\mathbf{Y}$ & & & & \\
\hline 1 & Sondeo & 376.615 & 4.583 .040 & 746,8 & Profundo & Abastecimiento & \\
\hline 2 & Pozo & 376.707 & 4.583 .570 & 748,4 & Aluvial & Agrícola & 0,4 \\
\hline 3 & Sondeo & 376.270 & 4.584 .240 & 752,9 & Profundo & Agrícola & 34,7 \\
\hline 4 & Pozo & 378.000 & 4.584 .630 & 755,9 & Aluvial & Agrícola & \\
\hline 5 & Pozo & 378.526 & 4.583 .375 & 755,1 & Aluvial & Ganadería & \\
\hline 6 & Sondeo & 380.748 & 4.582 .720 & 759,2 & Profundo & Agrícola & \\
\hline 7 & Sondeo & 381.205 & 4.582 .795 & 760,7 & Profundo & Agrícola & \\
\hline 8 & Piezómetro & 381.930 & 4.582 .815 & 762,5 & Profundo & Ninguno & \\
\hline 9 & Sondeo & 382.680 & 4.582 .740 & 764,6 & Profundo & Agrícola & \\
\hline 10 & Sondeo & 382.965 & 4.582 .010 & 760,1 & Profundo & Agrícola & \\
\hline 11 & Manantial & 386.041 & 4.585 .091 & 860,0 & Carbonatado & Ninguno & 0,3 \\
\hline 12 & Manantial & 385.590 & 4.585 .415 & 860,0 & Carbonatado & Ninguno & \\
\hline 13 & Pozo & 385.640 & 4.585 .360 & 851,3 & Aluvial & Agrícola & 13,9 \\
\hline 14 & Pozo & 384.820 & 4.585 .680 & 835,1 & Aluvial & Agrícola & 8,2 \\
\hline 15 & Manantial & 385.120 & 4.585 .835 & 860,0 & Carbonatado & Ninguno & 0,2 \\
\hline 16 & Pozo & 385.662 & 4.586 .079 & 874,6 & Carbonatado & Agrícola & 11,0 \\
\hline 17 & Pozo & 385.720 & 4.586 .150 & 860,0 & Aluvial & Agrícola & \\
\hline 18 & Pozo & 384.440 & 4.585 .975 & 870,0 & Carbonatado & Agrícola & \\
\hline 19 & Manantial & 384.018 & 4.585 .635 & 851,0 & Carbonatado & Ninguno & 6,3 \\
\hline 20 & Pozo & 384.125 & 4.585 .180 & 817,5 & Aluvial & Agrícola & 2,0 \\
\hline 21 & Pozo & 382.330 & 4.584 .720 & 793,6 & Aluvial & Agrícola & \\
\hline 22 & Manantial & 382.780 & 4.585 .665 & 860,0 & Carbonatado & Abastecimiento & 9,5 \\
\hline 23 & Sondeo & 381.350 & 4.585 .340 & 790,3 & Profundo & Abastecimiento & \\
\hline 24 & Manantial & 381.910 & 4.586 .550 & 864,0 & Carbonatado & Agrícola & 34,5 \\
\hline 25 & Sondeo & 380.715 & 4.585 .260 & 779,1 & Profundo & Agrícola & 23,2 \\
\hline 26 & Pozo & 379.800 & 4.585 .380 & 768,4 & Aluvial & Agrícola & 5,6 \\
\hline 27 & Pozo & 379.765 & 4.585 .405 & 768,8 & Aluvial & Agrícola & 6,1 \\
\hline 28 & Pozo & 379.165 & 4.585 .735 & 773,7 & Aluvial & Agrícola & 2,5 \\
\hline 29 & Pozo & 379.370 & 4.585 .755 & 774,2 & Aluvial & Agrícola & 7,1 \\
\hline 30 & Pozo & 379.250 & 4.585 .900 & 774,5 & Aluvial & Agrícola & 14,1 \\
\hline 31 & Pozo & 379.630 & 4.586 .530 & 784,9 & Aluvial & Agrícola & 5,1 \\
\hline 32 & Sondeo & 386.064 & 4.586 .926 & 883,9 & Carbonatado & Agrícola & 30,7 \\
\hline 33 & Pozo & 380.965 & 4.587 .470 & 828,0 & Aluvial & Agrícola & 27,0 \\
\hline 34 & Pozo & 379.395 & 4.584 .430 & 762,8 & Aluvial & Agrícola & 9,6 \\
\hline 35 & Pozo & 379.250 & 4.586 .170 & 779,3 & Aluvial & Agrícola & 9,0 \\
\hline 36 & Pozo & 377.230 & 4.584 .820 & 761,8 & Aluvial & Agrícola & \\
\hline 37 & Sondeo & 377.255 & 4.584 .815 & 761,7 & Profundo & Agrícola & 15,3 \\
\hline 38 & Sondeo & 377.685 & 4.584 .320 & 753,3 & Profundo & Agrícola & \\
\hline 39 & Pozo & 375.030 & 4.583 .970 & 750,3 & Aluvial & Agrícola & 21,9 \\
\hline 40 & Pozo & 382.140 & 4.582 .955 & 764,1 & Aluvial & Agrícola & 9,6 \\
\hline 41 & Pozo & 376.050 & 4.584 .950 & 750,8 & Aluvial & Agrícola & 8,9 \\
\hline 42 & Pozo & 374.795 & 4.583 .940 & 749,8 & Aluvial & Agrícola & 3,5 \\
\hline 43 & Pozo & 375.100 & 4.583 .650 & 744,3 & Aluvial & Agrícola & 5,4 \\
\hline 44 & Manantial & 374.670 & 4.583 .540 & 741,0 & Aluvial & Ninguno & 0,15 \\
\hline 45 & Pozo & 376.470 & 4.583 .800 & 747,9 & Aluvial & Agrícola & 0,3 \\
\hline 46 & Manantial & 376.500 & 4.583 .330 & 742,5 & Aluvial & Ninguno & 0,15 \\
\hline 47 & Manantial & 377.745 & 4.583 .060 & 748,0 & Aluvial & Agricola & \\
\hline 48 & Sondeo & 378.535 & 4.582 .970 & 752,2 & Profundo & Agricola & \\
\hline 49 & Pozo & 379.280 & 4.582 .960 & 756,0 & Aluvial & Agrícola & 1,5 \\
\hline 50 & Pozo & 379.140 & 4.583 .175 & 756,0 & Aluvial & Agrícola & 4,5 \\
\hline 51 & Pozo & 379.480 & 4.583 .950 & 761,3 & Aluvial & Agrícola & 10,6 \\
\hline
\end{tabular}




\begin{tabular}{|c|c|c|c|c|c|c|c|}
\hline \multirow{2}{*}{ № } & \multirow{2}{*}{ Naturaleza } & \multicolumn{2}{|c|}{ Coordenadas UTM } & \multirow{2}{*}{ Cota (m) } & \multirow{2}{*}{ Acuífero } & \multirow{2}{*}{ Uso } & \multirow{2}{*}{$\begin{array}{c}\text { Vol anual } \\
\left(\mathrm{Dm}^{3}\right)\end{array}$} \\
\hline & & $x$ & $Y$ & & & & \\
\hline 52 & Pozo & 379.250 & 4.584 .060 & 760,8 & Aluvial & Agrícola & 11,6 \\
\hline 53 & Pozo & 379.435 & 4.584 .010 & 761,8 & Aluvial & Agrícola & \\
\hline 54 & Pozo & 379.475 & 4.584 .240 & 763,2 & Aluvial & Agrícola & \\
\hline 55 & Pozo & 379.550 & 4.584 .360 & 763,5 & Aluvial & Agrícola & 20,2 \\
\hline 56 & Pozo & 385.690 & 4.582 .740 & 774,0 & Aluvial & Agrícola & 7,6 \\
\hline 57 & Pozo & 385.006 & 4.582 .723 & 771,9 & Aluvial & Agrícola & 8,6 \\
\hline 58 & Pozo & 384.840 & 4.582 .940 & 772,1 & Aluvial & Agrícola & 6,1 \\
\hline 59 & Pozo & 384.405 & 4.582 .680 & 770,1 & Aluvial & Agrícola & 1,5 \\
\hline 60 & Pozo & 383.550 & 4.583 .150 & 768,2 & Aluvial & Agrícola & 5,0 \\
\hline 61 & Pozo & 382.820 & 4.583 .155 & 766,2 & Aluvial & Agrícola & 9,1 \\
\hline 62 & Pozo & 382.895 & 4.582 .285 & 764,8 & Aluvial & Agrícola & 15,4 \\
\hline 63 & Pozo & 381.470 & 4.582 .870 & 761,6 & Aluvial & Agrícola & \\
\hline 64 & Pozo & 380.615 & 4.582 .650 & 758,8 & Aluvial & Agrícola & 5,6 \\
\hline 65 & Pozo & 380.550 & 4.583 .260 & 761,3 & Aluvial & Agrícola & 8,6 \\
\hline 66 & Pozo & 382.880 & 4.584 .820 & 800,8 & Aluvial & Agrícola & \\
\hline 67 & Pozo & 378.975 & 4.585 .160 & 765,7 & Aluvial & Agrícola & 6,1 \\
\hline 68 & Pozo & 377.935 & 4.585 .215 & 761,9 & Aluvial & Agrícola & 15,3 \\
\hline 69 & Pozo & 378.480 & 4.585 .815 & 774,1 & Aluvial & Agrícola & 4,5 \\
\hline 70 & Pozo & 378.330 & 4.586 .310 & 794,1 & Aluvial & Agrícola & 12,3 \\
\hline 71 & Sondeo & 377.115 & 4.585 .325 & 773,9 & Profundo & Agrícola & 33,6 \\
\hline $72 a$ & Manantial & 374.530 & 4.586 .800 & 860,0 & Carbonatado & Ninguno & \\
\hline $72 b$ & Manantial & 374.426 & 4.585 .857 & 830,0 & Carbonatado & Ninguno & 3,2 \\
\hline 73 & Pozo & 376.930 & 4.585 .140 & 767,5 & Aluvial & Agrícola & 5,0 \\
\hline 74 & Sondeo & 376.171 & 4.583 .691 & 746,9 & Profundo & Agrícola & \\
\hline 75 & Pozo & 376.091 & 4.583 .791 & 747,9 & Aluvial & Agrícola & 1,3 \\
\hline 76 & Pozo & 375.234 & 4.584 .119 & 752,1 & Aluvial & Agrícola & \\
\hline 77 & Sondeo & 375.454 & 4.583 .743 & 746,2 & Profundo & Agrícola & \\
\hline 78 & Pozo & 374.422 & 4.585 .829 & & Aluvial & Agrícola & \\
\hline 79 & Pozo & 376.836 & 4.584 .668 & 759,8 & Aluvial & Agrícola & 7,6 \\
\hline 80 & Sondeo & 383.417 & 4.587 .758 & 880,3 & Carbonatado & Abastecimiento & \\
\hline 81 & Sondeo & 383.276 & 4.585 .991 & 883,5 & Carbonatado & Abastecimiento & \\
\hline 82 & Sondeo & 380.896 & 4.585 .126 & 774,6 & Aluvial & Abastecimiento & \\
\hline 83 & Piezómetro & 380.969 & 482.770 & 760,2 & Aluvial & Piezómetro & \\
\hline 84 & Piezómetro & 387.151 & 4.585 .702 & 883,6 & Carbonatado & Piezómetro & \\
\hline 85 & Manantial & 386.081 & 4.583 .862 & 863,0 & Carbonatado & Ninguno & 0,5 \\
\hline 86 & Pozo & 379.875 & 4.586 .785 & 792,5 & Aluvial & Agrícola & 16,2 \\
\hline 87 & Sondeo & 381.297 & 4.587 .321 & 845,0 & Aluvial & Piezómetro & \\
\hline 88 & Pozo & 380.259 & 4.587 .161 & 805,2 & Aluvial & Agrícola & 6,1 \\
\hline 89 & Piezómetro & 379.811 & 4.583 .806 & 763,4 & Profundo & Piezómetro & \\
\hline 90 & Sondeo & 379.265 & 4.584 .032 & 760,8 & Profundo & Ganadero & \\
\hline 91 & Piezómetro & 379.496 & 4.584 .223 & 763,9 & Profundo & Ninguno & \\
\hline 92 & Pozo & 378.750 & 4.584 .169 & 758,4 & Aluvial & Ninguno & \\
\hline 93 & Pozo & 378.951 & 4.583 .125 & 755,7 & Aluvial & Agrícola & 4,5 \\
\hline 94 & Sondeo & 381.813 & 4.583 .133 & 764,4 & Profundo & Ganadero & \\
\hline 95 & Manantial & 380.153 & 4.582 .006 & 755,0 & Aluvial & Ninguno & 31,5 \\
\hline 96 & Sondeo & 379.121 & 4.585 .540 & 771,3 & Profundo & Ganadero & \\
\hline 97 & Sondeo & 383.571 & 4.582 .191 & 767,2 & Profundo & Ganadero & \\
\hline 98 & Pozo & 383.472 & 4.582 .099 & 765,8 & Aluvial & Agrícola & 0,7 \\
\hline 99 & Pozo & 382.045 & 4.584 .859 & 790,4 & Aluvial & Agrícola & 7,0 \\
\hline 100 & Pozo & 382.988 & 4.584 .860 & 801,9 & Aluvial & Agrícola & 2,5 \\
\hline 101 & Pozo & 375.192 & 4.583 .957 & 750,3 & Aluvial & Agrícola & \\
\hline 102 & Pozo & 374.929 & 4.583 .963 & 750,0 & Aluvial & Ganadero & \\
\hline
\end{tabular}




\begin{tabular}{|c|c|c|c|c|c|c|c|}
\hline \multirow{2}{*}{ № } & \multirow{2}{*}{ Naturaleza } & \multicolumn{2}{|c|}{ Coordenadas UTM } & \multirow{2}{*}{ Cota $(m)$} & \multirow{2}{*}{ Acuífero } & \multirow{2}{*}{ Uso } & \multirow{2}{*}{$\begin{array}{c}\text { Vol anual } \\
\left(\mathrm{Dm}^{3}\right)\end{array}$} \\
\hline & & $x$ & $Y$ & & & & \\
\hline 103 & Pozo & 376.674 & 4.584 .011 & 749,8 & Aluvial & Agrícola & 0,2 \\
\hline 104 & Pozo & 379.728 & 4.582 .364 & 757,1 & Aluvial & Agrícola & 11,6 \\
\hline 105 & Pozo & 380.980 & 4.583 .181 & 762,8 & Aluvial & Agrícola & 6,6 \\
\hline 106 & Pozo & 382.085 & 4.582 .851 & 763,2 & Aluvial & Agrícola & 17,2 \\
\hline 107 & Pozo & 384.717 & 4.583 .029 & 771,6 & Aluvial & Agrícola & 9,6 \\
\hline 108 & Pozo & 383.038 & 4.582 .979 & 765,4 & Aluvial & Agrícola & 15,2 \\
\hline 109 & Sondeo & 384.022 & 4.583 .634 & 780,0 & Profundo & Ganadero & \\
\hline 110 & Pozo & 384.729 & 4.585 .486 & 826,8 & Aluvial & Agrícola & 15,7 \\
\hline 111 & Sondeo & 374.550 & 4.584 .234 & 758,9 & Profundo & Agrícola & \\
\hline 112 & Pozo & 381.126 & 4.582 .963 & 760,8 & Aluvial & Agrícola & \\
\hline 113 & Pozo & 379.979 & 4.583 .498 & 759,7 & Aluvial & Ganadero & \\
\hline 114 & Pozo & 379.407 & 4.583 .210 & 757,0 & Aluvial & Agrícola & 2,1 \\
\hline 115 & Pozo & 377.986 & 4.585 .150 & 761,3 & Aluvial & Agrícola & \\
\hline 116 & Pozo & 378.029 & 4.585 .310 & 762,7 & Aluvial & Agrícola & \\
\hline 117 & Sondeo & 385.009 & 4.586 .698 & 884,9 & Carbonatado & Agrícola & 29,4 \\
\hline 118 & Pozo & 380.189 & 4.582 .681 & 758,8 & Aluvial & Ganadero & \\
\hline 119 & Pozo & 380.211 & 4.584 .325 & 768,6 & Aluvial & Agrícola & 12,6 \\
\hline 120 & Manantial & 376.386 & 4.584 .040 & 749,9 & Aluvial & Ninguno & 12,6 \\
\hline 121 & Manantial & 377.661 & 4.585 .249 & 761,3 & Aluvial & Ninguno & 14,8 \\
\hline 122 & Manantial & 779.028 & 4.585 .959 & 775,1 & Aluvial & Ninguno & 17,9 \\
\hline 123 & Manantial & 379.668 & 4.586 .590 & 786,4 & Aluvial & Ninguno & 10,9 \\
\hline 124 & Manantial & 378.696 & 4.585 .275 & 765,2 & Aluvial & Ninguno & 28,0 \\
\hline 125 & Manantial & 378.883 & 4.584 .814 & 759,8 & Aluvial & Ninguno & 15,6 \\
\hline 126 & Manantial & 380.221 & 4.585 .253 & 770,7 & Aluvial & Ninguno & 12,4 \\
\hline 127 & Manantial & 384.231 & 4.585 .285 & 816,2 & Aluvial & Ninguno & 9,3 \\
\hline
\end{tabular}



A.II ESTUDIO HIDROQUÍMICO 

Tabla A.II.1. Características hidrogeológicas y resultados analíticos del Muestreo M1.

\begin{tabular}{|c|c|c|c|c|c|c|c|c|}
\hline Etiqueta & Naturaleza & Coord. X & Coord. Y & $\begin{array}{l}\text { Cota } \\
(\mathrm{m})\end{array}$ & $\begin{array}{l}\text { Unidades } \\
\text { geológicas }\end{array}$ & $\begin{array}{c}\text { Cuenca } \\
\text { hidrológica }\end{array}$ & $\begin{array}{c}\text { U. } \\
\text { Hidro }\end{array}$ & Uso \\
\hline M11 & Manantial & 386041 & 4585091 & 860 & CA(CP-TP) & Torregutiérrez & 13 & Ninguno \\
\hline M19 & Manantial & 384018 & 4585635 & 851 & CA(CP-TP) & Horcajo-1 & 13 & Ninguno \\
\hline M22 & Manantial & 382780 & 4585665 & 860 & CP-TP & Horcajo-1 & 13 & Abastecimiento \\
\hline $\mathrm{M} 24$ & Manantial & 381910 & 4586550 & 864 & CP-TP & Horcajo-1 & 13 & Agrícola \\
\hline M72a & Manantial & 374530 & 4586800 & 860 & CP-TP & Cantalavacía & 13 & Ninguno \\
\hline M85 & Manantial & 386081 & 4583862 & 863 & CP-TP & Cega-1 & 13 & Ninguno \\
\hline M95 & Manantial & 380153 & 4582006 & 755 & ME/SA-FVA & Cega & 12 & Ninguno \\
\hline P2 & Pozo & 376707 & 4583570 & 748.4 & ME/SA-FVA & Cega & 12 & Agrícola \\
\hline P4 & Pozo & 378000 & 4584630 & 755.9 & CD/FVA & Monje & 12 & Agrícola \\
\hline P5 & Pozo & 378526 & 4583375 & 755.1 & ME/SA-FVA & Cega & 12 & Ganadería \\
\hline P13 & Pozo & 385640 & 4585360 & 851.3 & CA-FCs & Torregutiérrez & 12 & Agrícola \\
\hline P14 & Pozo & 384820 & 4585680 & 835.1 & CA-FCs & Horcajo & 12 & Agrícola \\
\hline P16 & Pozo & 385662 & 4586079 & 874.6 & CP-TP & Horcajo & 13 & Agrícola \\
\hline $\mathrm{P} 20$ & Pozo & 384125 & 4585180 & 817.5 & CA-FCs & Horcajo & 12 & Agrícola \\
\hline P33 & Pozo & 380965 & 4587470 & 828 & CA-FCs & Valdelacasa & 12 & Agrícola \\
\hline P34 & Pozo & 379395 & 4584430 & 762.8 & CD/SA-FVA & Horcajo & 12 & Agrícola \\
\hline P35 & Pozo & 379250 & 4586170 & 779.3 & $\mathrm{CD} / \mathrm{FCi}$ & Valdelacasa & 12 & Agrícola \\
\hline P36 & Pozo & 377230 & 4584820 & 761.8 & CD/FVA & Caleza & 12 & Agrícola \\
\hline P39 & Pozo & 375030 & 4583970 & 750.3 & SA-FVA & Cega & 12 & Agrícola \\
\hline $\mathrm{P} 40$ & Pozo & 382140 & 4582955 & 764.1 & SA-FVA & Cega & 12 & Agrícola \\
\hline P49 & Pozo & 379280 & 4582960 & 756 & ME-SA-FVA & Cega & 12 & Agrícola \\
\hline P52 & Pozo & 379250 & 4584060 & 760.8 & CD/SA-FVA & Horcajo & 12 & Agrícola \\
\hline P57 & Pozo & 385006 & 4582723 & 771.9 & $\mathrm{SA}-\mathrm{FCi}$ & Cega & 12 & Agrícola \\
\hline P61 & Pozo & 382820 & 4583155 & 766.2 & SA-FVA & Cega & 12 & Agrícola \\
\hline P62 & Pozo & 382895 & 4582285 & 764.8 & ME-SA-FVA & Cega & 12 & Agrícola \\
\hline P65 & Pozo & 380550 & 4583260 & 761.3 & Col-FVA & Cega & 12 & Agrícola \\
\hline P66 & Pozo & 382880 & 4584820 & 800.8 & CA-FCs & Horcajo & 12 & Agrícola \\
\hline P68 & Pozo & 377935 & 4585215 & 761.9 & CD-FVA & Valdelacasa & 12 & Agrícola \\
\hline P69 & Pozo & 378480 & 4585815 & 774.1 & $\mathrm{CD}-\mathrm{FCi}$ & Valdelacasa-1 & 12 & Agrícola \\
\hline P70 & Pozo & 378330 & 4586310 & 794.1 & CA-FCs & Valdelacasa-1 & 12 & Agrícola \\
\hline P75 & Pozo & 376091 & 4583791 & 747.9 & SA-FVA & Cega & 12 & Agrícola \\
\hline P76 & Pozo & 375234 & 4584119 & 752.1 & SA-FVA & Cega & 12 & Agrícola \\
\hline P78 & Pozo & 374422 & 4585829 & 843.7 & CA(CP-TP) & Cantalavacía & 12 & Agrícola \\
\hline P79 & Pozo & 376836 & 4584668 & 759.8 & CD-FVA & Caleza & 12 & Agrícola \\
\hline P86 & Pozo & 379875 & 4586785 & 792.5 & CA-FCs & Valdelacasa & 12 & Agrícola \\
\hline P88 & Pozo & 380259 & 4587161 & 805.2 & CA-FCs & Valdelacasa & 12 & Agrícola \\
\hline P92 & Pozo & 378750 & 4584169 & 758.4 & SA/FVA/MP & Cega & 12 & Ninguno \\
\hline P93 & Pozo & 378951 & 4583125 & 755.7 & ME/SA-FVA & Cega & 12 & Agrícola \\
\hline P98 & Pozo & 383472 & 4582099 & 765.8 & ME/SA-FVA & Cega & 12 & Agrícola \\
\hline P99 & Pozo & 382045 & 4584859 & 790.4 & $\mathrm{CA}-\mathrm{FCi}$ & Horcajo & 12 & Agrícola \\
\hline P100 & Pozo & 382988 & 4584860 & 801.9 & CA-FCs & Horcajo & 12 & Agrícola \\
\hline S1 & Sondeo & 376615 & 4583040 & 746.8 & ME/SA-FVA-MP & Cega & 17 & Abastecimiento \\
\hline S3 & Sondeo & 376270 & 4584240 & 752.9 & SA-VA-MP & Cega & 17 & Agrícola \\
\hline S6 & Sondeo & 380748 & 4582720 & 759.2 & SA-FVA-MP & Cega & 17 & Agrícola \\
\hline S10 & Sondeo & 382965 & 4582010 & 760.1 & ME/SA-FVA-MP & Cega & 17 & Agrícola \\
\hline $\mathrm{S} 23$ & Sondeo & 381350 & 4585340 & 790.3 & Col-FCi-MP & Horcajo & 17 & Abastecimiento \\
\hline S32 & Sondeo & 386064 & 4586926 & 883.9 & CP-TP & Páramo & 13 & Agrícola \\
\hline S37 & Sondeo & 377255 & 4584815 & 761.7 & CD-FVA-MP & Caleza & 17 & Agrícola \\
\hline S38 & Sondeo & 377685 & 4584320 & 753.3 & SA-FVA-MP & Cega & 17 & Agrícola \\
\hline S48 & Sondeo & 378535 & 4582970 & 752.2 & ME-SA-FVA-MP & Cega & 17 & Agricola \\
\hline S71 & Sondeo & 377115 & 4585325 & 773.9 & CD-FCs-MP & Caleza & 17 & Agrícola \\
\hline S74 & Sondeo & 376171 & 4583691 & 746.9 & SA-FVA-MP & Cega & 17 & Agrícola \\
\hline S77 & Sondeo & 375454 & 4583743 & 746.2 & SA-FVA-MP & Cega & 17 & Agrícola \\
\hline S80 & Sondeo & 383417 & 4587758 & 880.3 & CP-TP & Páramo & 13 & Abastecimiento \\
\hline S81 & Sondeo & 383276 & 4585991 & 883.5 & CP-TP & Páramo & 13 & Abastecimiento \\
\hline S82 & Sondeo & 380896 & 4585126 & 774.6 & CA-FCi-FVA-MP & Horcajo & 17 & Abastecimiento \\
\hline
\end{tabular}




\begin{tabular}{|c|c|c|c|c|c|c|c|c|}
\hline Etiqueta & Naturaleza & Coord. $\mathbf{X}$ & Coord. $\mathbf{Y}$ & $\begin{array}{c}\text { Cota } \\
(\mathbf{m})\end{array}$ & $\begin{array}{c}\text { Unidades } \\
\text { geológicas }\end{array}$ & $\begin{array}{c}\text { Cuenca } \\
\text { hidrológica }\end{array}$ & $\begin{array}{c}\text { U. } \\
\text { Hidro }\end{array}$ & Uso \\
\hline S90 & Sondeo & 379265 & 4584032 & 760.8 & CD/SA-FVA-MP & Horcajo & 17 & Ganadero \\
\hline S96 & Sondeo & 379121 & 4585540 & 771.3 & CD-FCi-FVA-MP & Valdelacasa & 17 & Ganadero \\
\hline S97 & Sondeo & 383571 & 4582191 & 767.2 & ME/SA-FVA-MP & Cega & 17 & Ganadero \\
\hline
\end{tabular}

Tabla A.II.1. Continuación

\begin{tabular}{|c|c|c|c|c|c|c|c|c|c|c|}
\hline Etiqueta & $T$ & pH & C.E & O.D & $\mathrm{SO}_{4}{ }^{2-}$ & $\mathrm{HCO}_{3}^{-}$ & $\mathrm{Cl}^{-}$ & $\mathrm{NO}_{3}^{-}$ & P-ext- & $F^{-}$ \\
\hline & $\stackrel{o}{ } \mathrm{C}$ & & $\mu \mathrm{S} / \mathrm{cm}$ & $\mathrm{mg} / \mathrm{L}$ & $m g / L$ & $\mathrm{mg} / \mathrm{L}$ & $\mathrm{mg} / \mathrm{L}$ & $m g / L$ & $m g / L$ & $\mathrm{mg} / \mathrm{L}$ \\
\hline M11 & 22,3 & 7,58 & 951 & 10,7 & 88,6 & 395,3 & 52,4 & 118,8 & 0,1 & 0,6 \\
\hline M19 & 16,2 & 7,31 & 590 & 7,0 & 37,2 & 362,3 & 10,8 & 67,0 & 0,0 & 0,6 \\
\hline $\mathrm{M} 22$ & 13,7 & 7,57 & 390 & 10,5 & 8,0 & 292,2 & 5,1 & 36,3 & 0,0 & 0,7 \\
\hline $\mathrm{M} 24$ & 13,4 & 8,09 & 481 & 9,4 & 18,2 & 288,2 & 8,0 & 53,1 & 0,0 & 0,6 \\
\hline M72a & 14,0 & 7,45 & 440 & 8,9 & 13,5 & 294,2 & 8,4 & 58,6 & 0,0 & 0,4 \\
\hline M85 & 16,6 & 7,85 & 386 & 8,9 & 6,5 & 299,2 & 3,9 & 36,0 & 0,0 & 0,6 \\
\hline M95 & 16,2 & 7,71 & 1208 & 7,9 & 694,0 & 204,1 & 7,9 & 0,0 & 0,1 & 0,5 \\
\hline P2 & 15,7 & 7,35 & 2755 & 5,5 & 1609,5 & 363,3 & 64,9 & 295,4 & 0,2 & 0,9 \\
\hline P4 & 16,0 & 7,42 & 2627 & 7,0 & 1789,0 & 199,1 & 32,4 & 141,8 & 0,1 & 2,0 \\
\hline P5 & 19,0 & 7,12 & 1941 & 2,8 & 784,5 & 480,3 & 41,3 & 133,5 & 0,9 & 1,0 \\
\hline P13 & 12,6 & 7,36 & 649 & 9,5 & 49,4 & 431,3 & 28,5 & 39,2 & 0,1 & 0,8 \\
\hline P14 & 12,7 & 7,38 & 454 & 8,9 & 27,1 & 361,3 & 6,8 & 31,8 & 0,0 & 0,7 \\
\hline P16 & 16,0 & 7,81 & 381 & 9,3 & 7,4 & 279,2 & 3,4 & 26,1 & 0,0 & 0,7 \\
\hline P20 & 13,6 & 7,48 & 690 & 5,4 & 147,0 & 397,3 & 12,5 & 35,6 & 0,0 & 0,9 \\
\hline P33 & 20,1 & 7,70 & 1268 & 9,0 & 796,3 & 283,2 & 11,2 & 56,2 & 0,0 & 1,1 \\
\hline P34 & 15,1 & 7,15 & 2890 & 9,1 & 1661,2 & 297,2 & 99,2 & 386,6 & 0,0 & 1,5 \\
\hline P35 & 18,7 & 6,27 & 2490 & 10,7 & 1615,7 & 249,2 & 25,8 & 111,7 & 0,0 & 1,2 \\
\hline P36 & 19,5 & 6,54 & 1670 & 9,8 & 785,7 & 236,2 & 37,0 & 234,0 & 0,1 & 1,2 \\
\hline P39 & 15,7 & 7,39 & 1486 & 9,4 & 553,9 & 296,2 & 41,4 & 268,8 & 0,0 & 1,0 \\
\hline P40 & 16,9 & 7,37 & 2994 & 5,5 & 2175,0 & 255,2 & 40,0 & 74,7 & 0,1 & 1,4 \\
\hline P49 & 17,5 & 7,38 & 1865 & 3,3 & 989,3 & 317,2 & 50,0 & 56,7 & 0,6 & 0,3 \\
\hline P52 & 15,2 & 7,27 & 2674 & 10,9 & 1706,7 & 229,2 & 58,1 & 241,7 & 0,0 & 1,8 \\
\hline P57 & 13,4 & 7,09 & 2584 & 6,0 & 1701,1 & 232,2 & 44,2 & 291,0 & 0,0 & 1,5 \\
\hline P61 & 13,9 & 7,34 & 2796 & 8,4 & 2196,5 & 200,1 & 33,9 & 76,2 & 0,1 & 1,7 \\
\hline P62 & 15,8 & 7,08 & 867 & 5,2 & 468,2 & 156,1 & 5,7 & 13,9 & 0,1 & 0,4 \\
\hline P65 & 13,9 & 7,19 & 2984 & 8,1 & 2218,0 & 284,2 & 53,6 & 197,8 & 0,1 & 2,0 \\
\hline P66 & 14,0 & 7,06 & 1290 & 5,7 & 583,8 & 337,2 & 22,8 & 115,5 & 0,0 & 1,3 \\
\hline P68 & 13,1 & 7,33 & 2225 & 9,5 & 1632,7 & 197,1 & 25,3 & 118,1 & 0,0 & 1,9 \\
\hline P69 & 13,9 & 7,56 & 1605 & 8,8 & 1006,1 & 210,1 & 14,2 & 71,3 & 0,0 & 1,0 \\
\hline P70 & 14,3 & 7,53 & 764 & 8,4 & 276,0 & 294,2 & 6,3 & 48,5 & 0,0 & 0,9 \\
\hline P75 & 21,2 & 8,32 & 3215 & 17,1 & 1869,0 & 322,2 & 53,6 & 119,1 & 0,1 & 0,9 \\
\hline P76 & 14,4 & 7,58 & 1221 & 10,2 & 425,4 & 317,2 & 35,9 & 198,5 & 0,1 & 0,5 \\
\hline P78 & 17,4 & 7,64 & 560 & 10,2 & 40,9 & 350,2 & 8,6 & 34,7 & 0,1 & 0,9 \\
\hline P79 & 16,5 & 7,41 & 2018 & 10,0 & 1179,2 & 236,2 & 20,8 & 162,2 & 0,1 & 1,3 \\
\hline P86 & 12,9 & 7,32 & 1798 & 9,0 & 1256,9 & 236,2 & 14,9 & 63,4 & 0,0 & 1,4 \\
\hline P88 & 18,0 & 7,66 & 1626 & 9,5 & 901,3 & 258,2 & 13,7 & 58,4 & 0,0 & 1,1 \\
\hline P92 & 20,2 & 7,86 & 3443 & 11,0 & 2155,4 & 262,2 & 66,9 & 226,8 & 0,0 & 1,6 \\
\hline P93 & 17,5 & 7,18 & 2784 & 5,1 & 1572,4 & 408,3 & 93,9 & 80,1 & 0,6 & 1,1 \\
\hline P98 & 15,9 & 6,68 & 1504 & 3,5 & 979,2 & 140,1 & 12,3 & 18,1 & 0,1 & 0,5 \\
\hline P99 & 14,3 & 7,35 & 1468 & 6,2 & 770,0 & 349,2 & 20,1 & 62,1 & 0,2 & 1,2 \\
\hline P100 & 13,8 & 7,43 & 1288 & 5,8 & 660,2 & 312,2 & 17,4 & 62,5 & 0,0 & 1,3 \\
\hline S1 & 16,3 & 9,45 & 306 & 2,3 & 6,9 & 240,2 & 4,6 & 3,0 & 0,1 & 0,5 \\
\hline S3 & 23,1 & 9,37 & 491 & 7,5 & 12,8 & 292,2 & 9,7 & 4,2 & 0,0 & 1,2 \\
\hline S6 & 27,6 & 9,05 & 746 & 2,5 & 13,8 & 469,3 & 7,0 & 0,8 & 0,0 & 4,6 \\
\hline S10 & 32,9 & 8,84 & 1214 & 4,3 & 54,0 & 633,4 & 13,3 & 0,0 & 0,0 & 4,1 \\
\hline $\mathrm{S} 23$ & 21,9 & 8,96 & 716 & 0,8 & 220,5 & 208,1 & 7,2 & 0,6 & 0,0 & 0,4 \\
\hline S32 & 16,0 & 7,60 & 481 & 9,0 & 10,2 & 333,2 & 6,7 & 39,9 & 0,0 & 0,6 \\
\hline S37 & 20,1 & 9,47 & 412 & 4,8 & 13,3 & 276,2 & 7,1 & 4,8 & 0,1 & 0,5 \\
\hline
\end{tabular}




\begin{tabular}{|c|c|c|c|c|c|c|c|c|c|c|}
\hline Etiqueta & $\mathbf{T}$ & $\mathbf{p H}$ & $\mathbf{C . E}$ & $\mathbf{O . D}$ & $\mathbf{S O}_{4}{ }^{2-}$ & $\mathbf{H C O}_{3}{ }^{-}$ & $\mathbf{C l}^{-}$ & $\mathbf{N O}_{3}^{-}$ & $\mathbf{P}_{-\mathbf{e x t}}$ & $\mathbf{F}^{-}$ \\
\hline & ${ }^{\circ} \mathrm{C}$ & & $\mu \mathrm{S} / \mathrm{cm}$ & $\mathrm{mg} / \mathrm{L}$ & $\mathrm{mg} / \mathrm{L}$ & $\mathrm{mg} / \mathrm{L}$ & $\mathrm{mg} / \mathrm{L}$ & $\mathrm{mg} / \mathrm{L}$ & $\mathrm{mg} / \mathrm{L}$ & $\mathrm{mg} / \mathrm{L}$ \\
\hline $\mathrm{S} 38$ & 19,6 & 7,31 & 824 & 7,9 & 269,7 & 268,2 & 9,5 & 5,1 & 0,1 & 0,6 \\
\hline $\mathrm{S} 48$ & 16,8 & 8,06 & 1716 & 2,9 & 1040,5 & 168,1 & 21,1 & 0,5 & 0,0 & 0,4 \\
\hline $\mathrm{S} 71$ & 22,2 & 9,14 & 484 & 3,4 & 35,5 & 279,2 & 7,8 & 4,9 & 0,1 & 0,7 \\
\hline $\mathrm{S} 74$ & 23,1 & 9,08 & 894 & 5,3 & 241,4 & 308,2 & 16,1 & 17,8 & 0,0 & 0,9 \\
\hline $\mathrm{S} 77$ & 18,7 & 9,46 & 366 & 5,8 & 13,8 & 264,2 & 6,6 & 3,9 & 0,0 & 0,6 \\
\hline $\mathrm{S} 80$ & 14,6 & 7,45 & 425 & 9,8 & 13,1 & 319,2 & 5,7 & 39,5 & 0,0 & 0,9 \\
\hline $\mathrm{S} 81$ & 14,0 & 7,52 & 355 & 11,5 & 7,0 & 315,2 & 4,5 & 28,6 & 0,0 & 0,9 \\
\hline $\mathrm{S} 82$ & 21,0 & 8,99 & 865 & 4,0 & 258,5 & 224,2 & 5,3 & 0,1 & 0,0 & 0,6 \\
\hline $\mathrm{S} 90$ & 16,7 & 8,14 & 678 & 5,7 & 166,0 & 265,2 & 21,8 & 1,0 & 0,0 & 0,8 \\
\hline $\mathrm{S} 96$ & 20,5 & 8,73 & 795 & 5,5 & 259,5 & 194,1 & 8,4 & 0,0 & 0,0 & 0,6 \\
\hline $\mathrm{S} 97$ & 20,0 & 7,01 & 1531 & 3,4 & 754,0 & 176,1 & 17,0 & 2,0 & 0,0 & 0,8 \\
\hline
\end{tabular}

Tabla A.II.1. Continuación.

\begin{tabular}{|c|c|c|c|c|c|c|c|c|}
\hline Etiqueta & $\mathrm{Ca}$ & Mg & $\mathrm{Na}$ & K & $\mathrm{Fe}$ & Mn & As tot & Mo \\
\hline & $\mathrm{mg} / \mathrm{L}$ & $\mathrm{mg} / \mathrm{L}$ & $\mathrm{mg} / \mathrm{L}$ & $\mathrm{mg} / \mathrm{L}$ & $\mu g / L$ & $\mu g / L$ & $\mu g / L$ & $\mu g / L$ \\
\hline M11 & 114,0 & 51,4 & 24,0 & 46,0 & 22,5 & 8,5 & 7,9 & 0,0 \\
\hline M19 & 92,4 & 41,5 & 3,7 & 0,2 & 2,3 & 0,0 & 7,4 & 0,0 \\
\hline $\mathrm{M} 22$ & 63,8 & 36,1 & 2,3 & 0,6 & 7,9 & 0,0 & 4,9 & 0,0 \\
\hline M24 & 61,6 & 38,2 & 3,0 & 0,9 & 1,7 & 0,0 & 9,2 & 0,0 \\
\hline M72a & 103,0 & 16,0 & 3,3 & 0,8 & 0,0 & 0,0 & 2,0 & 0,0 \\
\hline M85 & 52,5 & 29,9 & 4,4 & 1,4 & 1,2 & 0,0 & 4,1 & 0,0 \\
\hline M95 & 181,0 & 97,0 & 12,3 & 3,0 & 177,5 & 106,9 & 19,3 & 0,9 \\
\hline P2 & 300,0 & 281,0 & 56,0 & 18,8 & 296,3 & 68,4 & 384,7 & 37,0 \\
\hline $\mathrm{P} 4$ & 482,0 & 144,0 & 14,1 & 1,7 & 66,7 & 3,9 & 102,6 & 4,3 \\
\hline P5 & 234,0 & 124,0 & 50,0 & 10,0 & 7,1 & 14,1 & 208,1 & 12,4 \\
\hline P13 & 102,0 & 48,9 & 16,0 & 8,8 & 13,7 & 1,2 & 12,9 & 0,0 \\
\hline P14 & 72,5 & 34,8 & 3,2 & 0,8 & 12,8 & 0,4 & 2,6 & 0,0 \\
\hline P16 & 69,8 & 26,6 & 2,0 & 0,2 & 0,2 & 0,0 & 3,7 & 0,0 \\
\hline $\mathrm{P} 20$ & 117,0 & 45,6 & 7,2 & 1,4 & 3,7 & 0,1 & 11,6 & 0,0 \\
\hline P33 & 358,0 & 90,4 & 5,9 & 1,1 & 24,8 & 2,3 & 31,9 & 5,4 \\
\hline P34 & 563,0 & 146,0 & 40,8 & 4,1 & 2,1 & 0,0 & 86,2 & 6,4 \\
\hline P35 & 566,0 & 131,0 & 14,6 & 3,0 & 3,2 & 0,2 & 100,2 & 8,2 \\
\hline P36 & 290,0 & 112,0 & 32,3 & 1,5 & 4,0 & 0,2 & 96,5 & 2,3 \\
\hline P39 & 191,0 & 146,0 & 16,1 & 3,4 & 10,3 & 1,4 & 49,4 & 2,2 \\
\hline $\mathrm{P} 40$ & 499,0 & 212,0 & 14,0 & 6,5 & 174,2 & 145,6 & 86,2 & 12,0 \\
\hline P49 & 255,0 & 132,0 & 50,6 & 12,8 & 22,5 & 35,8 & 27,1 & 2,6 \\
\hline P52 & 546,0 & 189,0 & 39,8 & 4,3 & 8,9 & 0,3 & 118,0 & 1,9 \\
\hline P57 & 445,0 & 146,0 & 13,8 & 3,0 & 6,6 & 0,0 & 142,2 & 5,4 \\
\hline P61 & 340,0 & 197,0 & 13,6 & 3,8 & 25,5 & 8,8 & 273,0 & 6,9 \\
\hline P62 & 123,0 & 63,0 & 16,1 & 2,6 & 147,9 & 89,5 & 11,6 & 1,7 \\
\hline P65 & 399,0 & 221,0 & 46,0 & 4,7 & 22,9 & 0,3 & 238,2 & 3,8 \\
\hline P66 & 267,0 & 88,1 & 5,3 & 4,3 & 9,0 & 0,1 & 58,6 & 0,6 \\
\hline P68 & 358,0 & 135,0 & 10,3 & 3,1 & 14,4 & 0,3 & 112,9 & 6,4 \\
\hline P69 & 284,0 & 80,2 & 6,8 & 1,9 & 3,1 & 0,0 & 50,9 & 2,4 \\
\hline P70 & 132,0 & 34,0 & 5,2 & 1,5 & 12,1 & 0,3 & 19,1 & 0,5 \\
\hline P75 & 340,0 & 303,0 & 68,3 & 7,0 & 3,5 & 0,2 & 103,8 & 8,0 \\
\hline P76 & 184,0 & 116,0 & 16,4 & 2,5 & 28,3 & 3,1 & 27,0 & 0,7 \\
\hline P78 & 85,9 & 32,6 & 6,3 & 1,3 & 5,2 & 2,8 & 6,0 & 0,0 \\
\hline P79 & 413,0 & 118,0 & 16,7 & 1,9 & 65,8 & 2,9 & 84,5 & 1,5 \\
\hline P86 & 487,0 & 111,0 & 7,1 & 1,7 & 81,7 & 2,6 & 47,6 & 2,4 \\
\hline P88 & 331,0 & 77,0 & 6,0 & 1,5 & 50,9 & 3,1 & 40,0 & 1,3 \\
\hline P92 & 530,0 & 261,0 & 28,9 & 5,5 & 26,0 & 1,2 & 139,5 & 3,5 \\
\hline P93 & 378,0 & 193,0 & 100,0 & 15,6 & 4,1 & 53,7 & 210,6 & 5,3 \\
\hline P98 & 253,0 & 89,3 & 12,7 & 2,3 & 404,1 & 101,0 & 26,1 & 8,6 \\
\hline P99 & 255,0 & 73,8 & 7,6 & 4,3 & 6,2 & 11,2 & 99,6 & 1,6 \\
\hline
\end{tabular}


Hidrogeoquímica de aguas subterráneas de un sector de la Cuenca del Duero con altos niveles de arsénico

\begin{tabular}{|c|c|c|c|c|c|c|c|c|}
\hline Etiqueta & $\mathbf{C a}$ & $\mathbf{M g}$ & $\mathbf{N a}$ & $\mathbf{K}$ & $\mathbf{F e}$ & $\mathbf{M n}$ & As tot & Mo \\
\hline & $m g / L$ & $m g / L$ & $m g / L$ & $m g / L$ & $\mu g / L$ & $\mu g / L$ & $\mu g / L$ & $\mu g / L$ \\
\hline P100 & 254,0 & 72,8 & 5,5 & 2,1 & 4,6 & 0,2 & 64,5 & 1,2 \\
\hline S1 & 1,1 & 0,1 & 83,4 & 0,5 & 65,2 & 0,7 & 61,0 & 0,0 \\
\hline S3 & 1,6 & 0,0 & 112,5 & 1,2 & 0,0 & 0,0 & 122,9 & 0,0 \\
\hline S6 & 3,5 & 0,5 & 168,0 & 0,9 & 11,5 & 0,0 & 38,2 & 4,8 \\
\hline S10 & 0,9 & 0,0 & 213,0 & 1,6 & 21,8 & 0,2 & 70,6 & 0,6 \\
\hline S23 & 12,5 & 5,9 & 162,0 & 1,6 & 375,0 & 10,1 & 51,5 & 1,8 \\
\hline S32 & 77,8 & 30,3 & 2,6 & 0,8 & 3,8 & 0,2 & 2,0 & 0,0 \\
\hline S37 & 1,8 & 0,0 & 96,3 & 0,9 & 3,9 & 0,0 & 111,9 & 0,0 \\
\hline S38 & 21,7 & 55,7 & 96,5 & 2,5 & 24,9 & 0,0 & 112,1 & 1,5 \\
\hline S48 & 142,0 & 140,0 & 105,0 & 5,9 & 135,1 & 17,0 & 117,2 & 2,7 \\
\hline S71 & 6,7 & 2,3 & 104,0 & 0,8 & 2,8 & 0,0 & 121,7 & 0,0 \\
\hline S74 & 15,8 & 50,7 & 113,0 & 2,9 & 4,1 & 0,7 & 175,0 & 0,5 \\
\hline S77 & 1,8 & 0,7 & 98,1 & 0,9 & 1,9 & 0,0 & 98,3 & 0,0 \\
\hline S80 & 69,3 & 38,3 & 3,0 & 0,6 & 7,0 & 0,0 & 6,5 & 0,0 \\
\hline S81 & 58,6 & 33,4 & 2,0 & 0,0 & 2,9 & 0,0 & 6,6 & 0,0 \\
\hline S82 & 2,3 & 0,0 & 159,0 & 1,1 & 9,4 & 0,0 & 45,0 & 2,5 \\
\hline S90 & 26,6 & 15,3 & 135,0 & 2,8 & 24,6 & 0,1 & 48,1 & 0,5 \\
\hline S96 & 16,0 & 9,6 & 142,0 & 2,6 & 23,3 & 0,0 & 34,6 & 1,7 \\
\hline S97 & 94,6 & 48,5 & 177,0 & 3,5 & 321,3 & 11,7 & 65,4 & 1,5 \\
\hline
\end{tabular}


Tabla A.II.2. Características hidrogeológicas y resultados analíticos del Muestreo M2.

\begin{tabular}{|c|c|c|c|c|c|c|c|c|}
\hline Etiqueta & Naturaleza & Coord. X & Coord. Y & $\begin{array}{l}\text { Cota } \\
(\mathrm{m})\end{array}$ & $\begin{array}{l}\text { Unidades } \\
\text { geológicas }\end{array}$ & $\begin{array}{l}\text { Cuenca } \\
\text { hidrológica }\end{array}$ & $\begin{array}{c}\text { U. } \\
\text { Hidro } \\
\text { g. }\end{array}$ & Uso \\
\hline M44 & Manantial & 374670 & 4583540 & 741 & ME-SA-FVA & Cega & 12 & Ninguno \\
\hline M46 & Manantial & 376500 & 4583330 & 742.5 & ME-SA-FVA & Cega & 12 & Ninguno \\
\hline M95 & Manantial & 380153 & 4582006 & 755 & ME/SA-FVA & Cega & 12 & Ninguno \\
\hline P101 & Pozo & 375192 & 4583957 & 750.3 & SA-FVA & Cega & 12 & Agrícola \\
\hline P102 & Pozo & 374929 & 4583963 & 750 & SA-FVA & Cega & 12 & Ganadero \\
\hline P103 & Pozo & 376674 & 4584011 & 749.8 & SA-FVA & Cega & 12 & Agrícola \\
\hline P104 & Pozo & 379728 & 4582364 & 757.1 & ME-SA-FVA & Cega & 12 & Agrícola \\
\hline P105 & Pozo & 380980 & 4583181 & 762.8 & SA-FVA & Cega & 12 & Agrícola \\
\hline P106 & Pozo & 382085 & 4582851 & 763.2 & ME-SA-FVA & Cega & 12 & Agrícola \\
\hline P107 & Pozo & 384717 & 4583029 & 771.6 & SA-FVA & Cega & 12 & Agrícola \\
\hline P108 & Pozo & 383038 & 4582979 & 765.4 & SA-FVA & Cega & 12 & Agrícola \\
\hline P110 & Pozo & 384729 & 4585486 & 826.8 & CA-FCs & Horcajo & 12 & Agrícola \\
\hline P112 & Pozo & 381126 & 4582963 & 760.8 & SA-FVA & Cega & 12 & Agrícola \\
\hline P113 & Pozo & 379979 & 4583498 & 759.7 & SA-FVA & Cega & 12 & Ganadero \\
\hline P114 & Pozo & 379407 & 4583210 & 757 & SA-FVA & Cega & 12 & Agrícola \\
\hline P115 & Pozo & 377986 & 4585150 & 761.3 & CD-FVA & Valdelacasa & 12 & Agrícola \\
\hline P116 & Pozo & 378029 & 4585310 & 762.7 & CD-FVA & Valdelacasa & 12 & Agrícola \\
\hline P118 & Pozo & 380189 & 4582681 & 758.8 & CD-FVA & Cega & 12 & Ganadero \\
\hline P119 & Pozo & 380211 & 4584325 & 768.6 & SA-FVA & Horcajo & 12 & Agrícola \\
\hline P13 & Pozo & 385640 & 4585360 & 851.3 & CA-FCs & Torregutiérrez & 12 & Agrícola \\
\hline P2 & Pozo & 376707 & 4583570 & 748.4 & ME/SA-FVA & Cega & 12 & Agrícola \\
\hline $\mathrm{P} 20$ & Pozo & 384125 & 4585180 & 817.5 & CA-FCs & Horcajo & 12 & Agrícola \\
\hline P33 & Pozo & 380965 & 4587470 & 828 & CA-FCs & Valdelacasa & 12 & Agrícola \\
\hline P34 & Pozo & 379395 & 4584430 & 762.8 & CD/SA-FVA & Horcajo & 12 & Agrícola \\
\hline P35 & Pozo & 379250 & 4586170 & 779.3 & $\mathrm{CD} / \mathrm{FCi}$ & Valdelacasa & 12 & Agrícola \\
\hline P4 & Pozo & 378000 & 4584630 & 755.9 & CD/FVA & Monje & 12 & Agrícola \\
\hline P5 & Pozo & 378526 & 4583375 & 755.1 & ME/SA-FVA & Cega & 12 & Ganadería \\
\hline P56 & Pozo & 385690 & 4582740 & 774 & $\mathrm{SA}-\mathrm{FCi}$ & Cega & 12 & Agrícola \\
\hline P61 & Pozo & 382820 & 4583155 & 766.2 & SA-FVA & Cega & 12 & Agrícola \\
\hline P62 & Pozo & 382895 & 4582285 & 764.8 & ME-SA-FVA & Cega & 12 & Agrícola \\
\hline P66 & Pozo & 382880 & 4584820 & 800.8 & CA-FCs & Horcajo & 12 & Agrícola \\
\hline P67 & Pozo & 378975 & 4585160 & 765.7 & CD-FVA & Valdelacasa & 12 & Agrícola \\
\hline P69 & Pozo & 378480 & 4585815 & 774.1 & $\mathrm{CD}-\mathrm{FCi}$ & Valdelacasa-1 & 12 & Agrícola \\
\hline $\mathrm{P} 70$ & Pozo & 378330 & 4586310 & 794.1 & CA-FCs & Valdelacasa-1 & 12 & Agrícola \\
\hline P75 & Pozo & 376091 & 4583791 & 747.9 & SA-FVA & Cega & 12 & Agrícola \\
\hline P79 & Pozo & 376836 & 4584668 & 759.8 & CD-FVA & Caleza & 12 & Agrícola \\
\hline P86 & Pozo & 379875 & 4586785 & 792.5 & CA-FCs & Valdelacasa & 12 & Agrícola \\
\hline P92 & Pozo & 378750 & 4584169 & 758.4 & SA/FVA/MP & Cega & 12 & Ninguno \\
\hline P98 & Pozo & 383472 & 4582099 & 765.8 & ME/SA-FVA & Cega & 12 & Agrícola \\
\hline M11 & Manantial & 386041 & 4585091 & 860 & $\mathrm{CA}(\mathrm{CP}-\mathrm{TP})$ & Torregutiérrez & 13 & Ninguno \\
\hline M12 & Manantial & 385590 & 4585415 & 860 & CP-TP & Torregutiérrez & 13 & Ninguno \\
\hline M19 & Manantial & 384018 & 4585635 & 851 & $\mathrm{CA}(\mathrm{CP}-\mathrm{TP})$ & Horcajo-1 & 13 & Ninguno \\
\hline M22 & Manantial & 382780 & 4585665 & 860 & CP-TP & Horcajo-1 & 13 & Abastecimiento \\
\hline $\mathrm{M} 24$ & Manantial & 381910 & 4586550 & 864 & CP-TP & Horcajo-1 & 13 & Agrícola \\
\hline M72a & Manantial & 374530 & 4586800 & 860 & CP-TP & Cantalavacía & 13 & Ninguno \\
\hline M85 & Manantial & 386081 & 4583862 & 863 & CP-TP & Cega-1 & 13 & Ninguno \\
\hline S117 & Sondeo & 385009 & 4586698 & 884.9 & CP-TP & Páramo & 13 & Agrícola \\
\hline $\mathrm{S} 80$ & Sondeo & 383417 & 4587758 & 880.3 & CP-TP & Páramo & 13 & Abastecimiento \\
\hline S81 & Sondeo & 383276 & 4585991 & 883.5 & CP-TP & Páramo & 13 & Abastecimiento \\
\hline S1 & Sondeo & 376615 & 4583040 & 746.8 & ME/SA-FVA-MP & Cega & 17 & Abastecimiento \\
\hline S10 & Sondeo & 382965 & 4582010 & 760.1 & ME/SA-FVA-MP & Cega & 17 & Agrícola \\
\hline S109 & Sondeo & 384022 & 4583634 & 780 & CA-FVA & Cega & 17 & Ganadero \\
\hline S111 & Sondeo & 374550 & 4584234 & 758.9 & Col-Fci & Cega & 17 & Agrícola \\
\hline S23 & Sondeo & 381350 & 4585340 & 790.3 & Col-FCi-MP & Horcajo & 17 & Abastecimiento \\
\hline S25 & Sondeo & 380715 & 4585260 & 779.1 & CD-FCi-FVA-MP & Horcajo-1 & 17 & Agrícola \\
\hline
\end{tabular}




\begin{tabular}{|c|c|c|c|c|c|c|c|c|}
\hline Etiqueta & Naturaleza & Coord. $\mathbf{X}$ & Coord. $\mathbf{Y}$ & $\begin{array}{c}\text { Cota } \\
(\mathbf{m})\end{array}$ & $\begin{array}{c}\text { Unidades } \\
\text { geológicas }\end{array}$ & $\begin{array}{c}\text { Cuenca } \\
\text { hidrológica }\end{array}$ & $\begin{array}{c}\text { U. } \\
\text { Hidro } \\
\mathbf{g} .\end{array}$ & $\begin{array}{c}\text { Uso } \\
\text { S3 }\end{array}$ \\
Sondeo & 376270 & 4584240 & 752.9 & SA-VA-MP & Cega & 17 & Agrícola \\
\hline S37 & Sondeo & 377255 & 4584815 & 761.7 & CD-FVA-MP & Caleza & 17 & Agrícola \\
\hline S6 & Sondeo & 380748 & 4582720 & 759.2 & SA-FVA-MP & Cega & 17 & Agrícola \\
\hline S71 & Sondeo & 377115 & 4585325 & 773.9 & CD-FCs-MP & Caleza & 17 & Agrícola \\
\hline S74 & Sondeo & 376171 & 4583691 & 746.9 & SA-FVA-MP & Cega & 17 & Agrícola \\
\hline S77 & Sondeo & 375454 & 4583743 & 746.2 & SA-FVA-MP & Cega & 17 & Agrícola \\
\hline S82 & Sondeo & 380896 & 4585126 & 774.6 & CA-FCi-FVA-MP & Horcajo & 17 & Abastecimiento \\
\hline S90 & Sondeo & 379265 & 4584032 & 760.8 & CD/SA-FVA-MP & Horcajo & 17 & Ganadero \\
\hline S96 & Sondeo & 379121 & 4585540 & 771.3 & CD-FCi-FVA-MP & Valdelacasa & 17 & Ganadero \\
\hline S97 & Sondeo & 383571 & 4582191 & 767.2 & ME/SA-FVA-MP & Cega & 17 & Ganadero \\
\hline
\end{tabular}

Tabla A.II.2. Continuación.

\begin{tabular}{|c|c|c|c|c|c|c|c|c|c|c|c|c|}
\hline Muestra & $\mathbf{T}$ & pH & C.E & O.D & $\mathrm{SO}_{4}{ }^{2-}$ & $\mathrm{HCO}_{3}^{-}$ & $\mathrm{Cl}^{-}$ & $\mathrm{SiO}_{2}$ & $\mathrm{NO}_{3}^{-}$ & $\mathrm{NO}_{2}^{-}$ & $\mathbf{P}$ & $\mathbf{F}^{-}$ \\
\hline & ${ }^{o} \mathrm{C}$ & & $\mu S / \mathrm{cm}$ & $\mathrm{mg} / \mathrm{L}$ & $\mathrm{mg} / \mathrm{L}$ & $\mathrm{mg} / \mathrm{L}$ & $m g / L$ & $\mathrm{mg} / \mathrm{L}$ & $\mathrm{mg} / \mathrm{L}$ & $\mathrm{mg} / \mathrm{L}$ & $\mathrm{mg} / \mathrm{L}$ & $\mathrm{mg} / \mathrm{L}$ \\
\hline M44 & 13,8 & 7,86 & 1333 & 6,0 & 632,9 & 330,3 & 50,6 & 22,8 & 280,8 & 0,15 & 0,22 & 0,5 \\
\hline M46 & 19,6 & 8,29 & 2657 & 6,3 & 1792,8 & 442,4 & 84,0 & 29,6 & 149,1 & 3,87 & 0,36 & 1,2 \\
\hline M95 & 15,0 & 7,57 & 1000 & 7,5 & 748,4 & 237,4 & 9,1 & 23,1 & 0,0 & 0,01 & 0,06 & 0,5 \\
\hline P101 & 14,7 & 7,42 & 1443 & 5,5 & 627,7 & 339,2 & 50,8 & 25,2 & 373,0 & 0,49 & 0,08 & 0,5 \\
\hline P102 & 17,7 & 7,75 & 1186 & 10,0 & 407,7 & 251,0 & 43,1 & 33,6 & 325,9 & 0,45 & 0,02 & 0,9 \\
\hline P103 & 12,6 & 6,95 & 3125 & 3,0 & 1917,2 & 362,1 & 55,5 & 52,8 & 297,7 & 0,14 & 0,08 & 0,9 \\
\hline P104 & 14,4 & 7,14 & 2016 & 6,5 & 1789,2 & 293,6 & 38,4 & 15,6 & 1,8 & 0,02 & 0,05 & 0,6 \\
\hline P105 & 18,2 & 7,92 & 2728 & 15,9 & 2164,9 & 308,8 & 46,6 & 43,0 & 179,0 & 0,04 & 0,09 & 1,3 \\
\hline P106 & 13,6 & 7,1 & 2340 & 5,4 & 2282,5 & 357,9 & 33,5 & 30,2 & 62,1 & 0,05 & 2,22 & 1,3 \\
\hline P107 & 14,1 & 7,35 & 2324 & 6,3 & 1943,1 & 273,7 & 41,3 & 62,7 & 277,1 & 0,01 & 0,05 & 1,1 \\
\hline P108 & 12,5 & 6,89 & 2282 & 0,9 & 2265,7 & 251,0 & 30,9 & 16,2 & 26,9 & 0,16 & 0,04 & 1,2 \\
\hline P110 & 12,3 & 7,42 & 417 & 11,2 & 49,2 & 339,2 & 4,8 & 55,1 & 37,5 & 0,09 & 0,03 & 0,6 \\
\hline P112 & 18,3 & 7,06 & 2693 & 3,0 & 2265,7 & 246,0 & 41,3 & 38,8 & 26,9 & 0,08 & 0,15 & 1,3 \\
\hline P113 & 18,9 & 7,48 & 2801 & 10,3 & 2037,5 & 267,8 & 73,0 & 66,5 & 247,3 & 0,01 & 0,14 & 1,5 \\
\hline P114 & 20,6 & 7,7 & 1617 & 2,3 & 856,5 & 304,5 & 47,5 & 61,6 & 28,7 & 9,51 & 0,81 & 0,9 \\
\hline P115 & 12,7 & 7,37 & 1849 & 7,2 & 1574,4 & 262,0 & 23,6 & 63,2 & 130,8 & 0,01 & 0,02 & 2,5 \\
\hline P116 & 16,5 & 7,82 & 1960 & 10,3 & 1634,4 & 242,1 & 21,8 & 55,6 & 107,9 & 0,12 & 0,04 & 1,2 \\
\hline P118 & 13,8 & 7,11 & 2694 & 4,4 & 2862,9 & 341,6 & 32,7 & 25,0 & 1,8 & 0,03 & 0,12 & 0,8 \\
\hline P119 & 15,1 & 7,68 & 1581 & 6,5 & 1123,8 & 354,6 & 32,2 & 69,6 & 136,0 & 0,01 & 0,13 & 1,4 \\
\hline P13 & 12,8 & 7,33 & 529 & 12,2 & 49,7 & 379,9 & 24,4 & 42,9 & 68,9 & 0,17 & 0,19 & 0,8 \\
\hline P2 & 11,9 & 7,07 & 2234 & 1,4 & 1607,4 & 391,8 & 54,2 & 32,3 & 321,9 & 0,13 & 0,19 & 1,3 \\
\hline P20 & 14,1 & 7,55 & 648 & 6,6 & 159,3 & 540,4 & 15,5 & 54,8 & 38,7 & 0,02 & 0,04 & 1,0 \\
\hline P33 & 15,4 & 7,58 & 1014 & 9,2 & 630,1 & 306,5 & 10,3 & 59,2 & 52,3 & 0,03 & 0,01 & 1,0 \\
\hline P34 & 16,1 & 7,36 & 2600 & 7,2 & 1756,0 & 340,4 & 94,7 & 77,1 & 488,6 & 0,15 & 0,06 & 1,2 \\
\hline P35 & 13,6 & 7,23 & 1943 & 13,2 & 1628,8 & 244,0 & 27,4 & 65,3 & 114,5 & 0,16 & 0,03 & 1,1 \\
\hline $\mathrm{P} 4$ & 12,5 & 7,39 & 2018 & 8,8 & 1765,0 & 260,8 & 29,2 & 84,1 & 164,4 & 0,02 & 0,07 & 1,4 \\
\hline P5 & 14,8 & 7,21 & 1761 & 1,7 & 1216,9 & 511,2 & 39,7 & 47,1 & 69,1 & 0,09 & 1,69 & 1,2 \\
\hline P56 & 12,2 & 7,28 & 1853 & 11,1 & 1663,6 & 213,3 & 28,7 & 61,0 & 112,1 & 0,00 & 0,06 & 1,4 \\
\hline P61 & 16,9 & 7,49 & 2495 & 4,7 & 2060,3 & 316,4 & 32,3 & 38,9 & 148,7 & 0,05 & 0,11 & 1,6 \\
\hline P62 & 15,1 & 7,31 & 677 & 6,9 & 373,4 & 219,9 & 3,7 & 18,0 & 27,0 & 0,11 & 0,14 & 0,6 \\
\hline P66 & 13,0 & 7,18 & 1195 & 4,7 & 766,8 & 394,2 & 20,3 & 66,0 & 142,0 & 0,02 & 0,04 & 1,2 \\
\hline P67 & 13,0 & 7,29 & 2197 & 7,7 & 1973,5 & 303,0 & 40,7 & 68,2 & 208,4 & 0,00 & 0,06 & 1,7 \\
\hline P69 & 14,6 & 7,48 & 1120 & 6,3 & 772,5 & 286,6 & 9,4 & 60,0 & 73,8 & 0,04 & 0,04 & 0,9 \\
\hline $\mathrm{P} 70$ & 14,8 & 7,58 & 785 & 7,7 & 408,3 & 299,4 & 6,5 & 62,0 & 58,4 & 0,03 & 0,02 & 0,8 \\
\hline P75 & 20,3 & 8,04 & 2623 & 8,9 & 1743,6 & 364,9 & 58,8 & 14,2 & 323,6 & 0,35 & 0,07 & 0,6 \\
\hline P79 & 12,8 & 7,2 & 1589 & 7,9 & 1280,3 & 232,1 & 18,3 & 57,7 & 147,8 & 0,33 & 0,06 & 1,0 \\
\hline P86 & 16,4 & 7,92 & 1674 & 10,0 & 1290,6 & 321,7 & 11,7 & 67,9 & 57,4 & 0,12 & 0,03 & 1,3 \\
\hline P92 & 21,6 & 7,9 & 3060 & 7,6 & 2257,7 & 335,7 & 61,5 & 74,2 & 240,1 & 0,31 & 0,10 & 1,4 \\
\hline P98 & 14,5 & 6,72 & 1258 & 1,2 & 1032,4 & 195,4 & 18,7 & 26,0 & 1,4 & 0,03 & 0,03 & 0,5 \\
\hline
\end{tabular}




\begin{tabular}{|c|c|c|c|c|c|c|c|c|c|c|c|c|}
\hline Muestra & $\mathbf{T}$ & $\mathrm{pH}$ & C.E & O.D & $\mathrm{SO}_{4}{ }^{2-}$ & $\mathrm{HCO}_{3}{ }^{-}$ & $\mathrm{Cl}^{-}$ & $\mathrm{SiO}_{2}$ & $\mathrm{NO}_{3}^{-}$ & $\mathrm{NO}_{2}^{-}$ & $\mathbf{P}$ & $F^{-}$ \\
\hline & $\stackrel{\circ}{ } \mathrm{C}$ & & $\mu \mathrm{S} / \mathrm{cm}$ & $\mathrm{mg} / \mathrm{L}$ & $\mathrm{mg} / \mathrm{L}$ & $m g / L$ & $\mathrm{mg} / \mathrm{L}$ & $\mathrm{mg} / \mathrm{L}$ & $m g / L$ & $\mathrm{mg} / \mathrm{L}$ & $\mathrm{mg} / \mathrm{L}$ & $\mathrm{mg} / \mathrm{L}$ \\
\hline M11 & 12,3 & 7,12 & 753 & 1,7 & 95,8 & 450,3 & 45,3 & 57,6 & 123,5 & 0,26 & 0,11 & 0,6 \\
\hline M12 & 15,8 & 8,07 & 310 & 20,0 & 9,7 & 270,8 & 4,2 & 50,8 & 33,2 & 0,01 & 0,02 & 0,7 \\
\hline M19 & 13,3 & 7,18 & 500 & 3,5 & 60,9 & 416,6 & 10,3 & 46,8 & 38,4 & 0,17 & 0,14 & 0,9 \\
\hline M22 & 13,4 & 7,67 & 327 & 10,5 & 9,8 & 302,1 & 3,6 & 43,9 & 39,9 & 0,00 & 0,02 & 0,6 \\
\hline M24 & 13,2 & 7,69 & 363 & 8,9 & 21,8 & 349,7 & 9,5 & 37,0 & 63,1 & 0,00 & 0,03 & 0,6 \\
\hline M72a & 13,0 & 7,36 & 378 & 6,1 & 15,1 & 310,5 & 8,1 & 29,9 & 62,0 & 0,00 & 0,00 & 0,3 \\
\hline M85 & 16,5 & 7,98 & 326 & 10,7 & 6,6 & 274,8 & 2,0 & 41,4 & 36,5 & 0,00 & 0,00 & 0,6 \\
\hline S117 & 17,3 & 7,57 & 368 & 6,6 & 7,4 & 374,3 & 3,1 & 47,7 & 26,9 & 0,00 & 0,04 & 0,8 \\
\hline S80 & 14,2 & 7,69 & 360 & 5,7 & 9,4 & 320,6 & 5,0 & 37,5 & 46,3 & 0,00 & 0,00 & 0,8 \\
\hline S81 & 14,0 & 7,64 & 299 & 7,0 & 13,1 & 327,5 & 3,3 & 44,6 & 29,4 & 0,06 & 0,00 & 0,9 \\
\hline S1 & 23,2 & 9,49 & 237 & 2,6 & 7,3 & 227,3 & 4,5 & 11,6 & 1,9 & 0,01 & 0,02 & 1,0 \\
\hline S10 & 24,2 & 8,86 & 890 & 4,0 & 61,0 & 732,2 & 11,9 & 17,0 & 0,0 & 0,00 & 0,05 & 4,3 \\
\hline S109 & 15,8 & 8,61 & 829 & 8,1 & 426,9 & 202,4 & 5,3 & 9,0 & 0,5 & 0,01 & 0,01 & 0,6 \\
\hline S111 & 19,6 & 8,78 & 330 & 3,5 & 37,3 & 202,4 & 5,9 & 11,7 & 22,7 & 0,02 & 0,04 & 0,5 \\
\hline $\mathrm{S} 23$ & 21,1 & 9,75 & 376 & 3,1 & 15,8 & 349,7 & 5,6 & 14,4 & 0,0 & 0,07 & 0,11 & 0,5 \\
\hline S25 & 23,7 & 9,19 & 511 & 2,3 & 96,7 & 238,1 & 6,9 & 18,2 & 8,5 & 0,08 & 0,14 & 0,5 \\
\hline S3 & 23,3 & 9,23 & 389 & 3,8 & 51,6 & 303,1 & 9,3 & 27,8 & 11,0 & 0,00 & 0,09 & 0,7 \\
\hline S37 & 18,8 & 7,51 & 1234 & 6,0 & 445,3 & 300,2 & 34,9 & 34,9 & 242,0 & 0,28 & 0,00 & 0,7 \\
\hline S6 & 23,3 & 8,97 & 740 & 2,1 & 19,3 & 666,7 & 4,5 & 15,5 & 0,0 & 0,00 & 0,02 & 6,4 \\
\hline S71 & 21,6 & 7,73 & 1306 & 7,9 & 797,7 & 226,2 & 9,1 & 48,4 & 31,5 & 0,00 & 0,03 & 0,9 \\
\hline S74 & 23,2 & 9,3 & 890 & 5,1 & 741,6 & 303,1 & 27,4 & 14,2 & 67,4 & 0,01 & 0,07 & 1,0 \\
\hline S77 & 19,3 & 9,47 & 329 & 4,8 & 16,1 & 312,3 & 7,2 & 13,4 & 3,9 & 0,00 & 0,08 & 0,5 \\
\hline S82 & 20,0 & 8,97 & 596 & 1,9 & 311,0 & 252,7 & 3,9 & 10,8 & 0,0 & 0,00 & 0,01 & 0,6 \\
\hline S90 & 15,7 & 8,14 & 606 & 5,4 & 263,2 & 313,5 & 23,2 & 12,1 & 9,1 & 0,00 & 0,03 & 1,0 \\
\hline S96 & 19,3 & 8,78 & 607 & 3,8 & 201,9 & 243,3 & 3,8 & 10,7 & 0,4 & 0,00 & 0,02 & 1,2 \\
\hline S97 & 21,2 & 6,8 & 227 & 1,7 & 424,1 & 231,1 & 7,0 & 17,7 & 0,0 & 0,00 & 0,02 & 0,7 \\
\hline
\end{tabular}

Tabla A.II.2. Continuación.

\begin{tabular}{|c|c|c|c|c|c|c|c|c|c|}
\hline Muestra & $\mathrm{Ca}$ & $\mathrm{Mg}$ & $\mathrm{Na}$ & K & $\mathrm{Fe}$ & $\mathrm{Mn}$ & As & Mo & V \\
\hline & $\mathrm{mg} / \mathrm{L}$ & $\mathrm{mg} / \mathrm{L}$ & $\mathrm{mg} / \mathrm{L}$ & $\mathrm{mg} / \mathrm{L}$ & $\mu g / L$ & $\mu g / L$ & $\mu g / L$ & $\mu g / L$ & $\mu g / L$ \\
\hline M44 & 214,0 & 115,0 & 20,1 & 2,5 & 17,3 & 3,9 & 29,3 & 1,2 & 11,9 \\
\hline M46 & 273,0 & 230,0 & 78,9 & 19,0 & 55,9 & 45,4 & 171,4 & 15,6 & 77,4 \\
\hline M95 & 208,0 & 119,0 & 14,2 & 3,2 & 146,0 & 119,7 & 17,9 & 1,8 & 0,2 \\
\hline P101 & 186,0 & 110,0 & 31,6 & 2,7 & 15,7 & 3,2 & 30,6 & 2,8 & 14,5 \\
\hline P102 & 139,0 & 79,3 & 9,7 & 2,1 & 8,1 & 1,2 & 36,7 & 1,5 & 8,9 \\
\hline P103 & 452,0 & 176,0 & 30,4 & 12,5 & 17,1 & 3,6 & 142,2 & 5,4 & 45,6 \\
\hline P104 & 503,0 & 248,0 & 35,1 & 10,5 & 626,0 & 234,0 & 75,2 & 5,7 & 0,9 \\
\hline P105 & 426,0 & 182,0 & 26,0 & 4,8 & 35,4 & 2,8 & 196,2 & 1,6 & 6,1 \\
\hline P106 & 370,0 & 187,0 & 24,6 & 22,8 & 9,8 & 3,0 & 231,2 & 21,9 & 27,6 \\
\hline P107 & 483,0 & 132,0 & 8,5 & 2,4 & 26,3 & 1,9 & 119,9 & 4,7 & 43,4 \\
\hline P108 & 693,0 & 309,0 & 27,9 & 5,2 & 272,0 & 149,0 & 67,3 & 17,7 & 1,5 \\
\hline P110 & 61,8 & 33,7 & 2,1 & 0,6 & 9,5 & 1,1 & 7,1 & 0,2 & 8,4 \\
\hline P112 & 568,0 & 308,0 & 22,5 & 6,2 & 15,6 & 7,4 & 214,4 & 7,7 & 30,3 \\
\hline P113 & 637,0 & 266,0 & 45,1 & 18,2 & 12,0 & 1,2 & 211,4 & 6,0 & 74,9 \\
\hline P114 & 316,0 & 115,0 & 43,6 & 9,1 & 53,7 & 43,9 & 52,5 & 2,9 & 18,5 \\
\hline P115 & 842,0 & 248,0 & 24,2 & 4,6 & 63,2 & 2,7 & 80,5 & 8,2 & 35,0 \\
\hline P116 & 512,0 & 157,0 & 13,2 & 3,1 & 29,2 & 1,1 & 67,6 & 8,6 & 42,2 \\
\hline P118 & 630,0 & 412,0 & 39,0 & 10,5 & 450,0 & 217,0 & 152,0 & 8,1 & 24,7 \\
\hline P119 & 457,0 & 156,0 & 31,6 & 17,1 & 17,5 & 1,0 & 78,9 & 2,9 & 22,0 \\
\hline $\mathrm{P} 13$ & 73,8 & 39,1 & 10,5 & 6,9 & 7,0 & 0,9 & 16,6 & 0,5 & 9,0 \\
\hline P2 & 298,0 & 198,0 & 58,4 & 21,6 & 15,6 & 7,3 & 357,0 & 25,2 & 98,3 \\
\hline P20 & 161,0 & 66,7 & 6,9 & 1,1 & 52,7 & 2,8 & 13,6 & 6,1 & 9,1 \\
\hline P33 & 218,0 & 51,3 & 3,4 & 2,1 & 9,5 & 1,7 & 28,7 & 0,4 & 19,7 \\
\hline P34 & 706,0 & 225,0 & 57,2 & 5,1 & 9,8 & 0,5 & 58,0 & 3,2 & 24,8 \\
\hline
\end{tabular}




\begin{tabular}{|c|c|c|c|c|c|c|c|c|c|}
\hline Muestra & $\mathrm{Ca}$ & $\mathrm{Mg}$ & $\mathrm{Na}$ & $\mathrm{K}$ & $\mathrm{Fe}$ & $\mathrm{Mn}$ & As & Mo & $\mathrm{V}$ \\
\hline & $\mathrm{mg} / \mathrm{L}$ & $\mathrm{mg} / \mathrm{L}$ & $\mathrm{mg} / \mathrm{L}$ & $\mathrm{mg} / \mathrm{L}$ & $\mu g / L$ & $\mu g / L$ & $\mu g / L$ & $\mu g / L$ & $\mu g / L$ \\
\hline P35 & 404,0 & 111,0 & 10,2 & 2,2 & 35,3 & 3,4 & 111,6 & 0,9 & 33,8 \\
\hline P4 & 961,0 & 286,0 & 31,9 & 2,8 & 71,1 & 1,4 & 69,1 & 7,9 & 32,0 \\
\hline P5 & 416,0 & 189,0 & 73,5 & 21,1 & 7,5 & 13,0 & 173,1 & 6,9 & 50,8 \\
\hline P56 & 406,0 & 123,0 & 12,0 & 2,7 & 16,6 & 0,5 & 142,2 & 1,1 & 43,1 \\
\hline P61 & 553,0 & 351,0 & 78,2 & 2,9 & 39,1 & 4,3 & 223,2 & 4,4 & 31,4 \\
\hline P62 & 94,0 & 46,2 & 16,1 & 2,4 & 70,6 & 23,8 & 18,9 & 1,1 & 8,4 \\
\hline P66 & 331,0 & 110,0 & 7,4 & 4,2 & 18,2 & 0,9 & 54,5 & 3,2 & 31,1 \\
\hline P67 & 737,0 & 245,0 & 27,5 & 3,0 & 53,3 & 2,7 & 146,0 & 6,4 & 31,1 \\
\hline P69 & 489,0 & 135,0 & 11,4 & 2,9 & 55,4 & 1,6 & 42,6 & 5,0 & 37,7 \\
\hline P70 & 200,0 & 56,7 & 5,6 & 1,5 & 15,8 & 0,8 & 17,6 & 1,8 & 21,9 \\
\hline P75 & 355,0 & 400,0 & 40,3 & 6,9 & 10,0 & 0,9 & 105,5 & 18,0 & 22,9 \\
\hline P79 & 331,0 & 91,3 & 17,4 & 2,4 & 63,5 & 5,7 & 93,1 & 1,4 & 32,3 \\
\hline P86 & 522,0 & 133,0 & 9,8 & 2,8 & 53,8 & 1,9 & 44,2 & 17,6 & 29,9 \\
\hline P92 & 1020,0 & 476,0 & 72,3 & 10,3 & 58,0 & 3,5 & 224,6 & 7,8 & 37,6 \\
\hline P98 & 315,0 & 131,0 & 17,4 & 1,7 & 1220,0 & 172,0 & 26,9 & 3,2 & 1,0 \\
\hline M11 & 120,0 & 50,7 & 21,1 & 44,9 & 9,6 & 5,4 & 8,6 & 0,6 & 8,0 \\
\hline M12 & 54,1 & 28,3 & 1,9 & 0,7 & 16,5 & 0,5 & 5,2 & 0,3 & 11,6 \\
\hline M19 & 94,1 & 42,5 & 4,1 & 0,8 & 8,1 & 20,6 & 8,9 & 0,2 & 8,4 \\
\hline $\mathrm{M} 22$ & 99,2 & 57,5 & 5,5 & 1,1 & 37,8 & 3,1 & 7,5 & 1,0 & 6,2 \\
\hline $\mathrm{M} 24$ & 73,8 & 41,8 & 3,2 & 0,0 & 7,6 & 0,1 & 12,2 & 1,5 & 5,6 \\
\hline M72a & 87,3 & 17,2 & 4,0 & 0,0 & 0,8 & 0,0 & 2,5 & 0,4 & 2,3 \\
\hline M85 & 47,2 & 26,0 & 4,2 & 0,8 & 5,1 & 0,0 & 3,9 & 0,3 & 5,7 \\
\hline S117 & 75,3 & 31,7 & 2,2 & 0,2 & 15,8 & 1,0 & 2,7 & 0,0 & 1,2 \\
\hline $\mathrm{S} 80$ & 79,1 & 29,7 & 2,4 & 0,8 & 109,0 & 2,1 & 3,9 & 0,8 & 4,5 \\
\hline $\mathrm{S} 81$ & 60,8 & 31,4 & 2,0 & 0,3 & 279,0 & 8,0 & 3,6 & 0,0 & 6,4 \\
\hline S1 & 1,9 & 0,3 & 89,7 & 0,4 & 8,2 & 0,2 & 57,6 & 0,1 & 35,4 \\
\hline $\mathrm{S} 10$ & 1,0 & 0,3 & 233,0 & 0,9 & 14,5 & 0,6 & 76,8 & 1,0 & 30,3 \\
\hline S109 & 29,3 & 13,5 & 235,0 & 1,9 & 1120,0 & 18,4 & 54,8 & 2,2 & 29,1 \\
\hline S111 & 12,7 & 8,4 & 73,3 & 1,4 & 155,0 & 4,9 & 32,5 & 1,1 & 16,9 \\
\hline $\mathrm{S} 23$ & 4,2 & 0,0 & 118,0 & 0,4 & 3310,0 & 110,0 & 80,0 & 0,3 & 32,9 \\
\hline $\mathrm{S} 25$ & 23,6 & 9,7 & 115,0 & 1,1 & 1110,0 & 26,9 & 122,9 & 1,5 & 98,3 \\
\hline S3 & 12,0 & 6,2 & 135,0 & 0,4 & 0,0 & 0,1 & 149,6 & 0,5 & 80,2 \\
\hline S37 & 173,0 & 72,9 & 138,0 & 2,1 & 46,4 & 31,5 & 9,1 & 0,3 & 7,8 \\
\hline S6 & 1,4 & 0,5 & 198,0 & 0,8 & 13,6 & 0,5 & 67,6 & 1,2 & 34,6 \\
\hline $\mathrm{S} 71$ & 216,0 & 70,9 & 107,0 & 2,8 & 57,0 & 1,0 & 48,0 & 1,7 & 26,4 \\
\hline $\mathrm{S} 74$ & 60,5 & 166,0 & 180,0 & 6,7 & 25,3 & 0,3 & 190,5 & 2,7 & 73,5 \\
\hline $\mathrm{S} 77$ & 2,5 & 0,5 & 118,0 & 0,5 & 7,0 & 0,0 & 116,4 & 4,1 & 69,0 \\
\hline S82 & 7,3 & 0,3 & 423,0 & 3,0 & 282,0 & 4,5 & 38,0 & 9,2 & 37,0 \\
\hline $\mathrm{S} 90$ & 52,5 & 30,0 & 163,0 & 3,6 & 106,0 & 1,2 & 49,7 & 5,0 & 17,4 \\
\hline S96 & 21,3 & 10,0 & 243,0 & 2,5 & 62,1 & 2,0 & 34,1 & 5,1 & 5,8 \\
\hline S97 & 72,2 & 39,8 & 162,0 & 2,2 & 344,0 & 104,3 & 126,3 & 1,9 & 32,1 \\
\hline
\end{tabular}


Tabla A.II.3. Valor del índice de cambio de bases para los puntos de agua del muestreo M1 y M2.

\begin{tabular}{|c|c|c|}
\hline Muestra & icb (M1) & icb (M2) \\
\hline M11 & $-0,50$ & $-0,62$ \\
\hline M12 & -- & 0,15 \\
\hline M19 & 0,45 & 0,32 \\
\hline M22 & 0,20 & $-1,63$ \\
\hline M24 & 0,32 & 0,48 \\
\hline M44 & -- & 0,34 \\
\hline M46 & -- & $-0,65$ \\
\hline M72 & -- & 0,24 \\
\hline M85 & $-1,07$ & $-2,60$ \\
\hline M95 & $-1,75$ & $-1,73$ \\
\hline P02 & -- & $-1,02$ \\
\hline P04 & -- & $-0,77$ \\
\hline P05 & -- & $-2,34$ \\
\hline P101 & -- & $-0,01$ \\
\hline P102 & -- & 0,61 \\
\hline P103 & -- & $-0,05$ \\
\hline P104 & -- & $-0,66$ \\
\hline P105 & -- & 0,05 \\
\hline P106 & -- & $-0,75$ \\
\hline P107 & -- & 0,63 \\
\hline P108 & -- & $-0,54$ \\
\hline P110 & -- & 0,21 \\
\hline P112 & -- & 0,02 \\
\hline P113 & -- & $-0,18$ \\
\hline P114 & -- & $-0,59$ \\
\hline P115 & -- & $-0,76$ \\
\hline P116 & -- & $-0,06$ \\
\hline P118 & -- & $-1,13$ \\
\hline P119 & -- & $-0,99$ \\
\hline P13 & $-0,15$ & 0,08 \\
\hline P20 & 0,01 & 0,25 \\
\hline & & \\
\hline & & \\
\hline
\end{tabular}

\begin{tabular}{|c|c|c|}
\hline Muestra & icb (M1) & icb (M2) \\
\hline P33 & 0,10 & 0,31 \\
\hline P34 & 0,33 & 0,02 \\
\hline P35 & 0,02 & 0,35 \\
\hline P56 & -- & 0,27 \\
\hline P61 & 0,28 & $-2,81$ \\
\hline P62 & $-3,77$ & $-6,30$ \\
\hline P66 & 0,47 & 0,25 \\
\hline P67 & -- & $-0,11$ \\
\hline P69 & 0,14 & $-1,15$ \\
\hline P70 & $-0,49$ & $-0,54$ \\
\hline P75 & $-1,08$ & $-0,16$ \\
\hline P79 & $-0,32$ & $-0,59$ \\
\hline P86 & 0,16 & $-0,51$ \\
\hline P92 & 0,26 & $-0,96$ \\
\hline P98 & $-0,76$ & $-0,52$ \\
\hline S01 & -- & $-29,82$ \\
\hline S03 & -- & $-21,42$ \\
\hline S06 & -- & $-67,01$ \\
\hline S10 & $-23,81$ & $-29,26$ \\
\hline S109 & -- & $-67,70$ \\
\hline S111 & -- & $-18,37$ \\
\hline S117 & -- & $-0,15$ \\
\hline S23 & $-33,90$ & $-31,56$ \\
\hline S25 & -- & $-24,85$ \\
\hline S37 & $-20,03$ & $-5,15$ \\
\hline S71 & $-19,65$ & $-17,41$ \\
\hline S74 & $-9,99$ & $-9,35$ \\
\hline S77 & $-22,05$ & $-24,34$ \\
\hline S80 & 0,09 & 0,11 \\
\hline S81 & 0,31 & $-0,02$ \\
\hline & & \\
\hline & & -26 \\
\hline
\end{tabular}

\begin{tabular}{|c|c|c|}
\hline Muestra & icb (M1) & icb (M2) \\
\hline S82 & $-45,45$ & $-166,96$ \\
\hline S90 & $-8,67$ & $-9,98$ \\
\hline S96 & $-25,35$ & $-98,21$ \\
\hline S97 & $-15,24$ & $-34,97$ \\
\hline M72a & 0,31 & -- \\
\hline P100 & 0,40 & -- \\
\hline P14 & 0,17 & -- \\
\hline P16 & 0,04 & -- \\
\hline P2 & $-0,59$ & -- \\
\hline P36 & $-0,38$ & -- \\
\hline P39 & 0,33 & -- \\
\hline P4 & 0,28 & -- \\
\hline P40 & 0,31 & -- \\
\hline P49 & $-0,79$ & -- \\
\hline P5 & $-1,09$ & -- \\
\hline P52 & $-0,12$ & -- \\
\hline P57 & 0,46 & -- \\
\hline P65 & $-0,40$ & -- \\
\hline P68 & 0,26 & -- \\
\hline P76 & 0,23 & -- \\
\hline P78 & $-0,27$ & -- \\
\hline P88 & 0,23 & -- \\
\hline P93 & $-0,79$ & -- \\
\hline P99 & 0,22 & -- \\
\hline S1 & $-27,06$ & -- \\
\hline S3 & $-17,00$ & -- \\
\hline S32 & 0,30 & -- \\
\hline S38 & $-14,90$ & -- \\
\hline S48 & $-6,93$ & -- \\
\hline S6 & $-36,13$ & -- \\
\hline & & \\
\hline & \\
\hline
\end{tabular}


Tabla A.II.4. Índices de saturación de los puntos de agua del muestreo M1.

\begin{tabular}{|c|c|c|c|c|c|c|c|c|c|c|}
\hline ID & $\begin{array}{c}\text { I.S } \\
\text { Anhydrita }\end{array}$ & $\begin{array}{c}\text { I.S } \\
\text { Aragonito }\end{array}$ & $\begin{array}{c}\text { I.S } \\
\text { Calcita }\end{array}$ & $\begin{array}{c}\text { I.S } \\
\text { Dolomita }\end{array}$ & $\begin{array}{c}\text { I.S } \\
\text { Fluorita }\end{array}$ & $\begin{array}{l}\text { I.S } \\
\text { Yeso }\end{array}$ & $\begin{array}{l}\text { I.S } \\
\text { Halita }\end{array}$ & $\begin{array}{c}\text { I.S } \\
\text { Hematita }\end{array}$ & $\begin{array}{c}\text { I.S } \\
\text { Pirita }\end{array}$ & $\begin{array}{c}\text { I.S } \\
\text { Siderita }\end{array}$ \\
\hline M19 & $-2,242$ & 0,029 & 0,180 & 0,240 & $-1,310$ & $-1,995$ & $-8,968$ & 19,000 & $-96,538$ & 0,585 \\
\hline M22 & $-2,997$ & 0,031 & 0,183 & 0,307 & $-1,300$ & $-2,746$ & $-9,489$ & 21,037 & $-100,682$ & 1,113 \\
\hline M24 & $-2,669$ & 0,508 & 0,661 & 1,298 & $-1,378$ & $-2,417$ & $-9,169$ & 20,453 & $-110,019$ & $-0,216$ \\
\hline M72 & $-2,579$ & 0,123 & 0,275 & $-0,066$ & $-1,586$ & $-2,328$ & $-9,116$ & $-999,999$ & $-999,999$ & $-999,999$ \\
\hline M85 & $-3,151$ & 0,293 & 0,443 & 0,876 & $-1,559$ & $-2,905$ & $-9,319$ & 19,893 & $-107,920$ & $-0,144$ \\
\hline M95 & $-0,946$ & $-0,223$ & $-0,073$ & $-0,187$ & $-1,436$ & $-0,699$ & $-8,630$ & 24,100 & $-99,292$ & 1,533 \\
\hline P100 & $-0,810$ & 0,307 & 0,459 & 0,569 & $-0,381$ & $-0,559$ & $-8,635$ & 19,830 & $-95,119$ & 0,785 \\
\hline P13 & $-2,102$ & 0,120 & 0,273 & 0,395 & $-1,024$ & $-1,849$ & $-7,912$ & 20,405 & $-95,073$ & 1,429 \\
\hline P14 & $-2,434$ & $-0,043$ & 0,110 & 0,071 & $-1,206$ & $-2,181$ & $-9,219$ & 20,532 & $-95,863$ & 1,380 \\
\hline P16 & $-2,975$ & 0,339 & 0,489 & 0,785 & $-1,259$ & $-2,728$ & $-9,719$ & 18,465 & $-107,526$ & $-0,779$ \\
\hline $\mathrm{P} 2$ & $-0,636$ & 0,105 & 0,256 & 0,711 & $-0,899$ & $-0,389$ & $-7,116$ & 23,099 & $-92,298$ & 2,387 \\
\hline P20 & $-1,593$ & 0,260 & 0,412 & 0,602 & $-0,889$ & $-1,342$ & $-8,620$ & 19,924 & $-97,067$ & 0,868 \\
\hline P33 & $-0,653$ & 0,708 & 0,855 & 1,395 & $-0,537$ & $-0,416$ & $-8,815$ & 22,304 & $-101,529$ & 1,085 \\
\hline P34 & $-0,329$ & 0,208 & 0,359 & 0,349 & $-0,158$ & $-0,081$ & $-7,066$ & 17,614 & $-90,907$ & 0,122 \\
\hline P35 & $-0,307$ & $-0,667$ & $-0,518$ & $-1,408$ & $-0,340$ & $-0,067$ & $-8,091$ & 13,286 & $-77,819$ & $-0,524$ \\
\hline P36 & $-0,762$ & $-0,599$ & $-0,451$ & $-1,039$ & $-0,552$ & $-0,524$ & $-7,569$ & 15,320 & $-82,754$ & $-0,094$ \\
\hline P39 & $-1,055$ & 0,134 & 0,284 & 0,676 & $-0,819$ & $-0,808$ & $-7,808$ & 20,517 & $-95,040$ & 1,079 \\
\hline P4 & $-0,339$ & 0,211 & 0,361 & 0,426 & 0,015 & $-0,092$ & $-8,004$ & 22,188 & $-94,006$ & 1,612 \\
\hline $\mathrm{P} 40$ & $-0,314$ & 0,170 & 0,320 & 0,509 & $-0,369$ & $-0,069$ & $-7,931$ & 22,835 & $-93,034$ & 1,996 \\
\hline P49 & $-0,733$ & 0,234 & 0,383 & 0,728 & $-1,750$ & $-0,490$ & $-7,237$ & 21,245 & $-94,731$ & 1,383 \\
\hline P5 & $-0,848$ & 0,180 & 0,328 & 0,649 & $-0,808$ & $-0,608$ & $-7,327$ & 19,038 & $-91,688$ & 0,932 \\
\hline P52 & $-0,331$ & 0,204 & 0,355 & 0,468 & $-0,044$ & $-0,083$ & $-7,304$ & 19,590 & $-92,231$ & 0,747 \\
\hline P57 & $-0,384$ & $-0,080$ & 0,072 & $-0,147$ & $-0,236$ & $-0,133$ & $-7,876$ & 18,096 & $-88,730$ & 0,466 \\
\hline P61 & $-0,415$ & $-0,053$ & 0,099 & 0,161 & $-0,300$ & $-0,164$ & $-7,999$ & 20,692 & $-92,139$ & 1,165 \\
\hline P62 & $-1,224$ & $-0,672$ & $-0,522$ & $-1,110$ & $-1,694$ & $-0,976$ & $-8,648$ & 21,363 & $-88,821$ & 1,763 \\
\hline P65 & $-0,373$ & 0,017 & 0,169 & 0,282 & $-0,080$ & $-0,122$ & $-7,279$ & 19,729 & $-89,818$ & 1,137 \\
\hline P66 & $-0,857$ & $-0,001$ & 0,151 & 0,017 & $-0,392$ & $-0,607$ & $-8,538$ & 18,424 & $-89,026$ & 0,843 \\
\hline P68 & $-0,451$ & 0,004 & 0,156 & 0,076 & $-0,044$ & $-0,199$ & $-8,230$ & 20,125 & $-92,117$ & 0,947 \\
\hline P69 & $-0,640$ & 0,260 & 0,412 & 0,472 & $-0,614$ & $-0,389$ & $-8,640$ & 20,039 & $-97,185$ & 0,446 \\
\hline P70 & $-1,294$ & 0,207 & 0,358 & 0,327 & $-0,838$ & $-1,044$ & $-9,063$ & 21,227 & $-97,107$ & 1,246 \\
\hline P75 & $-0,510$ & 1,218 & 1,365 & 2,975 & $-1,010$ & $-0,277$ & $-7,117$ & 20,715 & $-113,962$ & $-0,980$ \\
\hline P76 & $-1,134$ & 0,331 & 0,483 & 0,970 & $-1,289$ & $-0,884$ & $-7,848$ & 22,089 & $-97,508$ & 1,565 \\
\hline P78 & $-2,202$ & 0,337 & 0,486 & 0,799 & $-0,970$ & $-1,958$ & $-8,835$ & 20,919 & $-102,216$ & 0,807 \\
\hline P79 & $-0,509$ & 0,282 & 0,432 & 0,556 & $-0,365$ & $-0,264$ & $-8,109$ & 22,231 & $-94,325$ & 1,711 \\
\hline P86 & $-0,420$ & 0,216 & 0,369 & 0,279 & $-0,155$ & $-0,168$ & $-8,615$ & 21,612 & $-91,398$ & 1,766 \\
\hline P88 & $-0,628$ & 0,521 & 0,670 & 0,961 & $-0,554$ & $-0,386$ & $-8,719$ & 22,885 & $-99,486$ & 1,488 \\
\hline P92 & $-0,297$ & 0,817 & 0,964 & 1,903 & $-0,302$ & $-0,061$ & $-7,403$ & 22,455 & $-103,875$ & 0,756 \\
\hline P93 & $-0,490$ & 0,242 & 0,391 & 0,740 & $-0,646$ & $-0,247$ & $-6,693$ & 18,651 & $-91,946$ & 0,592 \\
\hline P98 & $-0,787$ & $-0,941$ & $-0,791$ & $-1,806$ & $-1,332$ & $-0,540$ & $-8,450$ & 19,766 & $-81,639$ & 1,662 \\
\hline P99 & $-0,765$ & 0,259 & 0,411 & 0,486 & $-0,481$ & $-0,514$ & $-8,434$ & 19,711 & $-93,740$ & 0,904 \\
\hline S1 & $-4,667$ & $-0,259$ & $-0,109$ & $-0,883$ & $-3,224$ & $-4,421$ & $-7,950$ & 22,747 & $-136,459$ & $-2,378$ \\
\hline $\mathrm{S} 10$ & $-4,041$ & $-0,136$ & 0,002 & $-999,999$ & $-1,921$ & $-3,858$ & $-7,161$ & 21,371 & $-130,346$ & $-1,890$ \\
\hline $\mathrm{S} 23$ & $-2,627$ & $-258,163$ & $-258,017$ & $-516,073$ & $-2,628$ & $-2,396$ & $-7,448$ & 24,391 & $-126,086$ & $-259,129$ \\
\hline S3 & $-4,376$ & 0,174 & 0,319 & $-999,999$ & $-2,575$ & $-4,148$ & $-7,527$ & $-999,999$ & $-999,999$ & $-999,999$ \\
\hline S32 & $-2,820$ & 0,235 & 0,386 & 0,588 & $-1,320$ & $-2,573$ & $-9,325$ & 20,544 & $-102,254$ & 0,753 \\
\hline S37 & $-4,300$ & 0,240 & 0,387 & $-999,999$ & $-3,221$ & $-4,063$ & $-7,720$ & 19,988 & $-139,219$ & $-3,654$ \\
\hline S38 & $-2,042$ & $-0,748$ & $-0,600$ & $-0,515$ & $-2,002$ & $-1,804$ & $-7,627$ & 21,363 & $-94,968$ & 1,460 \\
\hline S48 & $-0,917$ & $-0,414$ & $-0,264$ & $-0,297$ & $-1,726$ & $-0,672$ & $-7,282$ & 24,107 & $-105,805$ & 0,420 \\
\hline S6 & $-4,032$ & 0,470 & 0,612 & 0,766 & $-1,139$ & $-3,823$ & $-7,519$ & 20,931 & $-133,724$ & $-2,422$ \\
\hline S71 & $-3,273$ & 0,613 & 0,759 & 1,405 & $-2,359$ & $-3,043$ & $-7,653$ & 19,961 & $-132,976$ & $-3,049$ \\
\hline S74 & $-2,262$ & 0,844 & 0,989 & 2,829 & $-1,886$ & $-2,035$ & $-7,338$ & 20,286 & $-130,588$ & $-2,822$ \\
\hline S77 & $-4,279$ & 0,208 & 0,356 & 0,597 & $-3,106$ & $-4,039$ & $-7,737$ & 19,491 & $-138,686$ & $-3,824$ \\
\hline $\mathrm{S} 80$ & $-2,765$ & $-0,008$ & 0,144 & 0,232 & $-1,072$ & $-2,515$ & $-9,334$ & 20,522 & $-98,624$ & 1,091 \\
\hline S81 & $-3,077$ & $-0,007$ & 0,145 & 0,237 & $-1,087$ & $-2,826$ & $-9,608$ & 19,986 & $-100,475$ & 0,713 \\
\hline S82 & $-2,961$ & $-0,173$ & $-0,026$ & $-999,999$ & $-3,023$ & $-2,727$ & $-7,656$ & 21,232 & $-127,359$ & $-2,161$ \\
\hline S90 & $-2,071$ & 0,129 & 0,279 & 0,554 & $-1,576$ & $-1,825$ & $-7,099$ & 22,647 & $-109,223$ & 0,548 \\
\hline
\end{tabular}




\begin{tabular}{|c|c|c|c|c|c|c|c|c|c|c|}
\hline ID & $\begin{array}{c}\text { I.S } \\
\text { Anhydrita }\end{array}$ & $\begin{array}{c}\text { I.S } \\
\text { Aragonito }\end{array}$ & $\begin{array}{c}\text { I.S } \\
\text { Calcita }\end{array}$ & $\begin{array}{c}\text { I.S } \\
\text { Dolomita }\end{array}$ & $\begin{array}{c}\text { I.S } \\
\text { Fluorita }\end{array}$ & $\begin{array}{c}\text { I.S } \\
\text { Yeso }\end{array}$ & $\begin{array}{c}\text { I.S } \\
\text { Halita }\end{array}$ & $\begin{array}{c}\text { I.S } \\
\text { Hematita }\end{array}$ & $\begin{array}{c}\text { I.S } \\
\text { Pirita }\end{array}$ & $\begin{array}{c}\text { I.S } \\
\text { Siderita }\end{array}$ \\
\hline S96 & $-2,120$ & 0,321 & 0,468 & 1,005 & $-2,183$ & $-1,884$ & $-7,502$ & 22,245 & $-121,752$ & $-1,210$ \\
\hline S97 & $-1,199$ & $-0,829$ & $-0,681$ & $-1,373$ & $-1,305$ & $-0,962$ & $-7,154$ & 22,034 & $-88,467$ & 2,060 \\
\hline
\end{tabular}

Tabla A. II.5. Índices de saturación de los puntos de agua del muestreo M2.

\begin{tabular}{|c|c|c|c|c|c|c|c|c|c|c|c|}
\hline & $\begin{array}{c}\text { I.S } \\
\text { Anhydrita }\end{array}$ & $\begin{array}{c}\text { I.S } \\
\text { Aragonito }\end{array}$ & $\begin{array}{c}\text { I.S } \\
\text { Calcita }\end{array}$ & $\begin{array}{c}\text { I.S } \\
\text { Dolomita }\end{array}$ & $\begin{array}{c}\text { I.S } \\
\text { Fluorita }\end{array}$ & $\begin{array}{c}\text { I.S } \\
\text { Goetita }\end{array}$ & $\begin{array}{l}\text { I.S } \\
\text { Yeso }\end{array}$ & $\begin{array}{l}\text { I.S } \\
\text { Halita }\end{array}$ & $\begin{array}{c}\text { I.S } \\
\text { Hematita }\end{array}$ & $\begin{array}{c}\text { I.S } \\
\text { Pirita }\end{array}$ & $\begin{array}{c}\text { I.S } \\
\text { Siderita }\end{array}$ \\
\hline M44 & $-0,946$ & \begin{tabular}{|l|}
0,637 \\
\end{tabular} & 0,790 & 1,505 & $-1,404$ & 10,16 & $-0,696$ & $-7,62$ & 22,3 & $-102,2$ & 1,137 \\
\hline M95 & $-0,870$ & 0,099 & 0,250 & 0,471 & $-1,350$ & 10,79 & $-0,621$ & $-8,51$ & 23,5 & $-96,4$ & 2,021 \\
\hline P101 & $-1,013$ & 0,177 & 0,329 & 0,639 & $-1,438$ & 9,47 & $-0,764$ & $-7,43$ & 20,9 & $-94,9$ & 1,314 \\
\hline P102 & $-1,239$ & 0,343 & 0,492 & 0,994 & $-1,043$ & 9,73 & $-0,996$ & $-8,01$ & 21,4 & $-102,4$ & 0,654 \\
\hline P103 & $-0,360$ & $-0,059$ & 0,094 & $-0,041$ & $-0,721$ & 7,98 & $-0,107$ & $-7,44$ & 17,9 & $-85,8$ & 0,880 \\
\hline P104 & $-0,411$ & $-0,022$ & 0,130 & 0,162 & $-1,048$ & 10,26 & $-0,161$ & $-7,54$ & 22,5 & $-88,1$ & 2,440 \\
\hline P105 & $-0,347$ & 0,820 & 0,969 & 1,827 & $-0,512$ & 10,42 & $-0,106$ & $-7,60$ & 22,8 & $-103,9$ & 0,990 \\
\hline P106 & $-0,373$ & $-0,007$ & 0,145 & 0,189 & $-0,479$ & 8,22 & $-0,122$ & $-7,75$ & 18,4 & $-88,6$ & 0,777 \\
\hline P107 & $-0,318$ & 0,265 & 0,416 & 0,473 & $-0,472$ & 9,42 & $-0,068$ & $-8,12$ & 20,8 & $-92,5$ & 1,319 \\
\hline P108 & $-0,204$ & $-0,170$ & $-0,017$ & $-0,203$ & $-0,358$ & 9,02 & 0,049 & $-7,74$ & 20,0 & $-83,6$ & 1,812 \\
\hline P110 & $-2,235$ & $-0,106$ & 0,048 & $-0,006$ & $-1,328$ & 9,24 & $-1,982$ & $-9,56$ & 20,4 & $-96,0$ & 1,247 \\
\hline P112 & $-0,257$ & 0,049 & 0,198 & 0,389 & $-0,453$ & 8,62 & $-0,015$ & $-7,71$ & 19,2 & $-89,5$ & 0,854 \\
\hline P113 & $-0,257$ & 0,558 & 0,706 & 1,301 & $-0,268$ & 9,56 & $-0,017$ & $-7,17$ & 21,1 & $-96,9$ & 0,950 \\
\hline P115 & $-0,237$ & 0,488 & 0,641 & 0,933 & 0,444 & 9,81 & 0,016 & $-7,91$ & 21,6 & $-92,3$ & 1,677 \\
\hline P116 & $-0,342$ & 0,733 & 0,883 & 1,488 & $-0,404$ & 10,33 & $-0,097$ & $-8,20$ & 22,6 & $-101,7$ & 1,078 \\
\hline P118 & $-0,205$ & 0,083 & 0,235 & 0,488 & $-0,864$ & 9,93 & 0,046 & $-7,59$ & 21,8 & $-87,2$ & 2,311 \\
\hline P119 & $-0,506$ & 0,771 & 0,922 & 1,594 & $-0,261$ & 9,98 & $-0,257$ & $-7,64$ & 21,9 & $-99,1$ & 1,279 \\
\hline P13 & $-2,198$ & $-0,083$ & 0,070 & 0,035 & $-1,100$ & 8,89 & $-1,945$ & $-8,16$ & 19,7 & $-94,9$ & 1,093 \\
\hline P2 & $-0,571$ & $-0,071$ & 0,083 & 0,157 & $-0,528$ & 8,26 & $-0,318$ & $-7,16$ & 18,5 & $-87,6$ & 0,992 \\
\hline P20 & $-1,502$ & 0,548 & 0,700 & 1,213 & $-0,735$ & 10,27 & $-1,251$ & $-8,56$ & 22,5 & $-97,4$ & 2,081 \\
\hline P33 & $-0,861$ & 0,413 & 0,564 & 0,718 & $-0,632$ & 9,61 & $-0,612$ & $-9,06$ & 21,2 & $-97,9$ & 1,072 \\
\hline P34 & $-0,275$ & 0,561 & 0,711 & 1,159 & $-0,314$ & 9,11 & $-0,029$ & $-6,95$ & 20,2 & $-94,1$ & 0,974 \\
\hline P35 & $-0,406$ & 0,051 & 0,203 & 0,040 & $-0,500$ & 9,22 & $-0,155$ & $-8,20$ & 20,4 & $-90,3$ & 1,344 \\
\hline P4 & $-0,173$ & 0,533 & 0,686 & 1,026 & $-0,052$ & 9,89 & 0,080 & $-7,71$ & 21,7 & $-92,5$ & 1,715 \\
\hline P5 & $-0,525$ & 0,422 & 0,573 & 1,015 & $-0,408$ & 8,54 & $-0,276$ & $-7,19$ & 19,0 & $-91,5$ & 0,964 \\
\hline P56 & $-0,396$ & 0,026 & 0,179 & 0,014 & $-0,289$ & 8,96 & $-0,143$ & $-8,11$ & 19,9 & $-90,9$ & 0,992 \\
\hline P61 & $-0,319$ & 0,537 & 0,687 & 1,419 & $-0,267$ & 10,03 & $-0,075$ & $-7,28$ & 22,0 & $-95,8$ & 1,551 \\
\hline P62 & $-1,333$ & $-0,323$ & $-0,172$ & $-0,441$ & $-1,315$ & 9,96 & $-1,084$ & $-8,81$ & 21,9 & $-92,7$ & 1,816 \\
\hline P66 & $-0,712$ & 0,220 & 0,372 & 0,449 & $-0,406$ & 8,79 & $-0,460$ & $-8,45$ & 19,5 & $-90,2$ & 1,262 \\
\hline P67 & $-0,204$ & 0,400 & 0,552 & 0,815 & 0,026 & 9,51 & 0,048 & $-7,63$ & 21,0 & $-91,0$ & 1,594 \\
\hline P69 & $-0,600$ & 0,533 & 0,684 & 1,018 & $-0,520$ & 10,16 & $-0,350$ & $-8,61$ & 22,3 & $-95,3$ & 1,770 \\
\hline P70 & $-1,042$ & 0,396 & 0,548 & 0,756 & $-0,861$ & 9,83 & $-0,793$ & $-9,03$ & 21,6 & $-97,8$ & 1,312 \\
\hline P75 & $-0,560$ & 1,010 & 1,157 & 2,654 & $-1,338$ & 9,85 & $-0,325$ & $-7,31$ & 21,7 & $-107,9$ & 0,167 \\
\hline P79 & $-0,540$ & $-0,069$ & 0,084 & $-0,209$ & $-0,564$ & 9,37 & $-0,288$ & $-8,13$ & 20,7 & $-89,4$ & 1,569 \\
\hline P86 & $-0,398$ & 0,968 & 1,118 & 1,878 & $-0,242$ & 10,64 & $-0,152$ & $-8,59$ & 23,2 & $-103,4$ & 1,286 \\
\hline P92 & $-0,135$ & 1,178 & 1,325 & 2,624 & $-0,294$ & 10,57 & 0,096 & $-7,07$ & 23,1 & $-105,1$ & 0,958 \\
\hline P98 & $-0,815$ & $-0,851$ & $-0,700$ & $-1,570$ & $-1,320$ & 9,38 & $-0,565$ & $-8,16$ & 20,7 & $-81,5$ & 2,133 \\
\hline M12 & $-2,954$ & 0,443 & 0,593 & 1,129 & $-1,287$ & 10,18 & $-2,707$ & $-9,66$ & 22,3 & $-110,2$ & 0,600 \\
\hline M19 & $-2,024$ & $-0,085$ & 0,067 & $-0,030$ & $-0,878$ & 8,56 & $-1,772$ & $-8,94$ & 19,1 & $-92,4$ & 1,081 \\
\hline $\mathrm{M} 22$ & $-2,800$ & 0,264 & 0,416 & 0,778 & $-1,224$ & 10,36 & $-2,548$ & $-9,28$ & 22,7 & $-101,6$ & 1,714 \\
\hline M24 & $-2,542$ & 0,254 & 0,407 & 0,746 & $-1,283$ & 9,67 & $-2,290$ & $-9,08$ & 21,3 & $-101,8$ & 1,101 \\
\hline M72 & $-2,590$ & $-0,028$ & 0,125 & $-0,280$ & $-1,786$ & 8,07 & $-2,338$ & $-9,05$ & 18,1 & $-97,3$ & 0,125 \\
\hline M85 & $-3,165$ & 0,338 & 0,488 & 0,950 & $-1,470$ & 9,65 & $-2,919$ & $-9,63$ & 21,3 & $-109,6$ & 0,243 \\
\hline S117 & $-2,974$ & 0,252 & 0,401 & 0,673 & $-1,167$ & 9,88 & $-2,729$ & $-9,74$ & 21,7 & $-101,9$ & 1,387 \\
\hline $\mathrm{S} 80$ & $-2,860$ & 0,167 & 0,319 & 0,409 & $-1,008$ & 10,85 & $-2,609$ & $-9,49$ & 23,7 & $-101,8$ & 2,083 \\
\hline S81 & $-2,842$ & $-0,199$ & $-0,047$ & $-0,188$ & $-1,043$ & 11,22 & $-2,591$ & $-9,75$ & 24,4 & $-100,1$ & 2,358 \\
\hline S1 & $-4,508$ & 0,226 & 0,371 & 0,362 & $-2,643$ & 9,19 & $-4,281$ & $-7,95$ & 20,4 & $-141,1$ & $-3,755$ \\
\hline S10 & $-4,002$ & $-0,126$ & 0,019 & $-0,181$ & $-1,744$ & 9,76 & $-3,779$ & $-7,15$ & 21,5 & $-127,3$ & $-1,370$ \\
\hline S109 & $-2,676$ & -261 & -260 & -521 & $-2,607$ & 11,97 & $-2,429$ & $-7,39$ & 25,9 & $-116,3$ & -259 \\
\hline
\end{tabular}


Hidrogeoquímica de aguas subterráneas de un sector de la Cuenca del Duero con altos niveles de arsénico

\begin{tabular}{|c|c|c|c|c|c|c|c|c|c|c|c|}
\hline & $\begin{array}{c}\text { I.S } \\
\text { Anhydrita }\end{array}$ & $\begin{array}{c}\text { I.S } \\
\text { Aragonito }\end{array}$ & $\begin{array}{c}\text { I.S } \\
\text { Calcita }\end{array}$ & $\begin{array}{c}\text { I.S } \\
\text { Dolomita }\end{array}$ & $\begin{array}{c}\text { I.S } \\
\text { Fluorita }\end{array}$ & $\begin{array}{c}\text { I.S } \\
\text { Goetita }\end{array}$ & $\begin{array}{c}\text { I.S } \\
\text { Yeso }\end{array}$ & $\begin{array}{c}\text { I.S } \\
\text { Halita }\end{array}$ & $\begin{array}{c}\text { I.S } \\
\text { Hematita }\end{array}$ & $\begin{array}{c}\text { I.S } \\
\text { Pirita }\end{array}$ & $\begin{array}{c}\text { I.S } \\
\text { Siderita }\end{array}$ \\
\hline S111 & $-2,631$ & -255 & -255 & -511 & $-2,023$ & 10,97 & $-2,393$ & $-7,91$ & 23,9 & $-123,1$ & -256 \\
\hline S23 & $-5,572$ & -262 & -261 & -525 & $-4,209$ & 11,61 & $-5,339$ & $-7,66$ & 25,2 & $-144,1$ & -263 \\
\hline S25 & $-3,519$ & -260 & -260 & -521 & $-3,009$ & 11,47 & $-3,294$ & $-7,59$ & 24,9 & $-132,3$ & -262 \\
\hline S3 & $-2,925$ & 0,937 & 1,082 & 2,244 & $-2,208$ & 7,44 & $-2,699$ & $-7,48$ & 16,9 & $-136,4$ & $-4,811$ \\
\hline S37 & $-1,132$ & 0,256 & 0,404 & 0,701 & $-1,103$ & 10,25 & $-0,892$ & $-6,95$ & 22,5 & $-97,7$ & 1,652 \\
\hline S6 & $-4,357$ & 0,056 & 0,201 & 0,331 & $-1,245$ & 9,72 & $-4,131$ & $-7,64$ & 21,4 & $-130,0$ & $-1,640$ \\
\hline S71 & $-0,808$ & 0,382 & 0,528 & 0,870 & $-0,897$ & 10,52 & $-0,576$ & $-7,64$ & 23,0 & $-102,2$ & 1,157 \\
\hline S74 & $-1,438$ & 1,305 & 1,450 & 3,673 & $-1,461$ & 9,79 & $-1,211$ & $-6,95$ & 21,6 & $-133,5$ & $-2,864$ \\
\hline S77 & $-4,102$ & 0,400 & 0,548 & 0,721 & $-3,042$ & 9,28 & $-3,863$ & $-7,62$ & 20,5 & $-138,5$ & $-3,295$ \\
\hline S82 & $-1,523$ & -258 & -258 & -518 & $-1,641$ & 11,13 & $-1,286$ & $-7,39$ & 24,2 & $-125,1$ & -260 \\
\hline S90 & $-1,665$ & 0,280 & 0,431 & 0,841 & $-1,119$ & 11,00 & $-1,417$ & $-7,00$ & 24,0 & $-107,8$ & 1,165 \\
\hline S96 & $-2,112$ & 0,460 & 0,608 & 1,165 & $-1,373$ & 10,58 & $-1,873$ & $-7,61$ & 23,1 & $-122,0$ & $-0,836$ \\
\hline S97 & $-1,500$ & $-0,940$ & $-0,794$ & $-1,549$ & $-1,450$ & 9,55 & $-1,267$ & $-7,57$ & 21,1 & $-85,9$ & 2,094 \\
\hline
\end{tabular}


Tabla A.II.6. Características físico-químicas de los puntos de agua del muestreo de los puntos de control.

\begin{tabular}{|c|c|c|c|c|c|c|c|c|c|}
\hline Fecha & Muestra & $\mathrm{pH}$ & $\begin{array}{c}\text { C.E } \\
\mu \mathrm{S} / \mathrm{cm}\end{array}$ & $\begin{array}{c}\text { O.D } \\
\mathrm{mg} / \mathrm{L}\end{array}$ & $\begin{array}{c}\mathrm{SO} 42- \\
\mathrm{mg} / \mathrm{L}\end{array}$ & $\begin{array}{c}\mathrm{HCO}- \\
\mathrm{mg} / \mathrm{L}\end{array}$ & $\begin{array}{c}\mathrm{Cl}- \\
\mathrm{mg} / \mathrm{L}\end{array}$ & $\begin{array}{l}\text { NO3- } \\
\mathrm{mg} / \mathrm{L}\end{array}$ & $\begin{array}{c}\mathrm{F}- \\
m g / L\end{array}$ \\
\hline \multirow[t]{9}{*}{ nov-02 } & M24 & 8,16 & 430 & 8,8 & 17,1 & 274,2 & 8,4 & 56,8 & 0,7 \\
\hline & P20 & 7,25 & 821 & 1,1 & 221,6 & 383,3 & 18,3 & 44,4 & 0,8 \\
\hline & P86 & 7,37 & 1845 & 7,5 & 1233,0 & 212,1 & 16,1 & 63,8 & 1,1 \\
\hline & P34 & 7,32 & 2730 & 8,2 & 1663,6 & 265,2 & 95,9 & 388,4 & 1,4 \\
\hline & P61 & 7,49 & 2810 & 6,1 & 2203,5 & 208,1 & 33,5 & 77,8 & 1,7 \\
\hline & M95 & 7,75 & 1171 & 7,6 & 831,4 & 178,1 & 8,3 & 0,0 & 0,3 \\
\hline & S90 & 8,17 & 672 & 5,7 & 177,6 & 239,2 & 21,3 & 2,9 & 0,8 \\
\hline & P5 & 7,28 & 1981 & 2,5 & 986,1 & 429,3 & 51,5 & 86,7 & 1,0 \\
\hline & P75 & 7,80 & 2634 & 7,5 & 1627,5 & 313,2 & 67,0 & 296,3 & 0,6 \\
\hline \multirow[t]{9}{*}{ dic-02 } & M24 & 8,01 & 428 & 8,6 & 17,0 & 270,2 & 7,8 & 52,5 & 0,6 \\
\hline & P20 & 7,16 & 829 & 1,3 & 222,5 & 383,3 & 17,3 & 45,0 & 0,8 \\
\hline & P86 & 7,17 & 1845 & 7,8 & 1237,3 & 222,2 & 13,2 & 60,4 & 1,1 \\
\hline & P34 & 7,18 & 2634 & 8,6 & 1586,8 & 271,2 & 86,4 & 390,8 & 1,4 \\
\hline & P61 & 7,32 & 2727 & 6,2 & 2205,9 & 210,1 & 31,3 & 82,5 & 1,5 \\
\hline & M95 & 7,71 & 1135 & 7,4 & 818,6 & 174,1 & 8,5 & 0,0 & 0,4 \\
\hline & S90 & 8,03 & 772 & 3,4 & 228,5 & 279,2 & 21,9 & 6,0 & 0,8 \\
\hline & P5 & 7,28 & 1935 & 3,5 & 1068,1 & 434,3 & 51,6 & 69,0 & 1,1 \\
\hline & P75 & 7,38 & 2717 & 4,5 & 1763,0 & 334,2 & 70,2 & 310,0 & 0,7 \\
\hline \multirow[t]{9}{*}{ ene-03 } & M24 & 8,05 & 445 & 8,4 & 17,2 & 275,2 & 7,8 & 51,2 & 0,8 \\
\hline & P20 & 7,22 & 857 & 1,3 & 220,2 & 381,3 & 23,0 & 45,4 & 1,3 \\
\hline & P86 & 7,19 & 1917 & 7,6 & 1260,0 & 233,2 & 12,8 & 58,6 & 1,3 \\
\hline & P34 & 7,41 & 2777 & 8,5 & 1663,0 & 266,2 & 95,4 & 391,1 & 1,6 \\
\hline & P61 & 7,39 & 2810 & 6,3 & 2283,4 & 214,1 & 31,4 & 88,0 & 1,9 \\
\hline & M95 & 7,77 & 1141 & 7,2 & 684,7 & 176,1 & 8,1 & 0,0 & 0,5 \\
\hline & S90 & 8,1 & 656,3 & 3,7 & 228,5 & 260,8 & 21,9 & 6,0 & 0,9 \\
\hline & P5 & 7,27 & 1768 & 2,9 & 1015,2 & 420,3 & 45,0 & 58,4 & 1,1 \\
\hline & P75 & 7,29 & 3149 & 2,4 & 1977,0 & 334,2 & 70,4 & 291,1 & 0,7 \\
\hline \multirow[t]{9}{*}{ feb-03 } & M24 & 7,91 & 405 & 9,3 & 19,2 & 297,2 & 8,7 & 54,7 & 0,7 \\
\hline & P20 & 7,23 & 759 & 1,6 & 210,7 & 416,3 & 17,6 & 48,1 & 0,9 \\
\hline & P86 & 7,22 & 1694 & 9,0 & 1284,7 & 266,2 & 13,3 & 58,3 & 1,2 \\
\hline & P34 & 7,31 & 2706 & 9,9 & 1839,4 & 301,2 & 146,5 & 443,6 & 1,5 \\
\hline & P61 & 7,53 & 2380 & 8,2 & 2228,7 & 242,2 & 32,3 & 99,3 & 1,7 \\
\hline & M95 & 7,74 & 1051 & 7,3 & 750,3 & 203,1 & 8,3 & 0,0 & 0,4 \\
\hline & S90 & 8,06 & 698 & 3,1 & 228,5 & 264,2 & 21,9 & 6,0 & 0,9 \\
\hline & P5 & 7,20 & 1529 & 2,9 & 977,2 & 437,3 & 42,5 & 67,8 & 1,1 \\
\hline & P75 & 7,43 & 2700 & 4,8 & 2006,4 & 358,2 & 72,0 & 304,4 & 0,6 \\
\hline \multirow[t]{9}{*}{ mar-03 } & M24 & 7,87 & 388 & 9,1 & 21,7 & 281,2 & 9,3 & 59,7 & 0,7 \\
\hline & P20 & 7,10 & 686 & 2,2 & 194,7 & 402,3 & 16,1 & 48,8 & 1,0 \\
\hline & P86 & 7,20 & 1598 & 9,7 & 1336,6 & 284,2 & 16,9 & 65,3 & 1,3 \\
\hline & P34 & 7,34 & 2515 & 11,3 & 1821,8 & 287,2 & 146,4 & 443,1 & 1,6 \\
\hline & P61 & 7,63 & 2295 & 10,8 & 2262,0 & 232,2 & 30,9 & 98,6 & 2,2 \\
\hline & M95 & 7,76 & 1020 & 6,4 & 768,4 & 185,1 & 8,6 & 0,0 & 0,4 \\
\hline & S90 & 8,03 & 753 & 3,7 & 286,7 & 256,2 & 22,7 & 10,5 & 0,9 \\
\hline & P5 & 7,31 & 1546 & 4,3 & 1128,2 & 429,3 & 42,9 & 72,8 & 1,1 \\
\hline & P75 & 7,40 & 2550 & 6,1 & 1980,4 & 342,2 & 67,5 & 308,3 & 0,6 \\
\hline \multirow[t]{9}{*}{ abr-03 } & M24 & 8,04 & 390 & 9,1 & 21,5 & 276,7 & 9,2 & 59,7 & 0,7 \\
\hline & P20 & 7,53 & 623 & 8,3 & 121,0 & 395,1 & 12,7 & 39,5 & 1,3 \\
\hline & P86 & 7,04 & 1564 & 7,0 & 1270,1 & 279,7 & 15,5 & 58,7 & 1,5 \\
\hline & P34 & 7,22 & 2529 & 9,7 & 1755,2 & 282,6 & 106,6 & 441,9 & 2,0 \\
\hline & P61 & 7,69 & 2344 & 12,1 & 2218,3 & 247,4 & 30,9 & 109,9 & 2,7 \\
\hline & M95 & 7,71 & 1021 & 8,3 & 713,3 & 189,7 & 9,4 & 0,0 & 0,4 \\
\hline & S90 & 7,91 & 764 & 3,7 & 268,6 & 253,3 & 21,8 & 10,8 & 0,9 \\
\hline & P5 & 7,26 & 1690 & 3,5 & 1155,4 & 425,4 & 45,9 & 73,3 & 1,3 \\
\hline & P75 & 7,84 & 2477 & 12,1 & 1817,0 & 347,2 & 65,4 & 229,6 & 0,6 \\
\hline
\end{tabular}


Tabla A.II.6. Continuación.

\begin{tabular}{|c|c|c|c|c|c|c|c|c|c|}
\hline Fecha & Muestra & $\mathrm{pH}$ & $\begin{array}{c}\text { C.E } \\
\mu S / \mathrm{cm} \\
\end{array}$ & $\begin{array}{c}\text { O.D } \\
\mathrm{mg} / \mathrm{L}\end{array}$ & $\begin{array}{c}\mathrm{SO} 42- \\
\mathrm{mg} / \mathrm{L}\end{array}$ & $\begin{array}{c}\mathrm{HCO}- \\
\mathrm{mg} / \mathrm{L} \\
\end{array}$ & $\begin{array}{c}\mathrm{Cl}- \\
m g / L\end{array}$ & $\begin{array}{l}\text { NO3- } \\
\mathrm{mg} / \mathrm{L}\end{array}$ & $\begin{array}{c}\mathrm{F}- \\
\mathrm{mg} / \mathrm{L} \\
\end{array}$ \\
\hline \multirow[t]{9}{*}{ may-03 } & M24 & 7,95 & 414 & 9,7 & 22,3 & 297,5 & 8,6 & 61,1 & 0,6 \\
\hline & P20 & 7,59 & 696 & 10,0 & 139,1 & 430,0 & 15,8 & 41,7 & 0,8 \\
\hline & P86 & 7,24 & 1667 & 8,5 & 1297,6 & 285,7 & 13,4 & 56,2 & 1,1 \\
\hline & P34 & 7,34 & 2674 & 9,0 & 1809,3 & 289,6 & 103,0 & 429,5 & 1,4 \\
\hline & P61 & 7,68 & 2564 & 11,4 & 2243,9 & 262,0 & 30,8 & 116,9 & 2,0 \\
\hline & M95 & 7,75 & 1071 & 9,2 & 725,5 & 194,7 & 8,3 & 0,0 & 0,3 \\
\hline & S90 & 8,04 & 823 & 3,6 & 267,1 & 261,0 & 21,8 & 9,9 & 0,8 \\
\hline & P5 & 7,26 & 1128 & 4,1 & 1186,3 & 424,1 & 42,6 & 75,2 & 1,0 \\
\hline & P75 & 7,66 & 2646 & 9,2 & 1829,9 & 335,1 & 65,0 & 307,0 & 0,5 \\
\hline \multirow[t]{9}{*}{ jun-03 } & M24 & 7,69 & 363 & 8,9 & 21,8 & 285,3 & 9,5 & 63,1 & 0,6 \\
\hline & P20 & 7,55 & 648 & 6,6 & 159,3 & 440,9 & 15,5 & 38,7 & 1,0 \\
\hline & P86 & 7,92 & 1674 & 10,0 & 1290,6 & 262,4 & 11,7 & 57,4 & 1,3 \\
\hline & P34 & 7,36 & 2600 & 7,2 & 1756,0 & 277,7 & 94,7 & 488,6 & 1,2 \\
\hline & P61 & 7,49 & 2495 & 4,7 & 2060,3 & 308,2 & 32,3 & 148,7 & 1,6 \\
\hline & M95 & 7,57 & 1000 & 7,5 & 748,4 & 193,7 & 9,1 & 0,0 & 0,5 \\
\hline & S90 & 8,14 & 606 & 5,4 & 263,2 & 255,8 & 23,2 & 9,1 & 1,0 \\
\hline & P5 & 7,21 & 1761 & 1,7 & 1216,9 & 417,0 & 39,7 & 69,1 & 1,2 \\
\hline & P75 & 8,04 & 2623 & 8,9 & 1743,6 & 297,7 & 58,8 & 323,6 & 0,6 \\
\hline \multirow[t]{9}{*}{ jul-03 } & M24 & 7,97 & 303 & 9,5 & 22,1 & 290,6 & 9,6 & 63,9 & 0,7 \\
\hline & P20 & 7,64 & 544 & 6,5 & 156,1 & 439,8 & 16,1 & 36,5 & 0,8 \\
\hline & P86 & 8,00 & 1484 & 11,4 & 1371,1 & 258,0 & 17,7 & 65,0 & 1,3 \\
\hline & P34 & 7,46 & 2370 & 9,1 & 1842,8 & 275,7 & 109,5 & 490,5 & 1,3 \\
\hline & P61 & 7,34 & 1995 & 6,9 & 2338,3 & 254,0 & 38,4 & 108,3 & 1,4 \\
\hline & M95 & 7,63 & 846 & 8,1 & 788,3 & 201,6 & 9,3 & 0,0 & 0,5 \\
\hline & S90 & 8,07 & 530 & 3,1 & 226,3 & 267,8 & 23,3 & 5,0 & 0,9 \\
\hline & P5 & 7,27 & 1526 & 2,5 & 1229,7 & 438,8 & 55,5 & 62,5 & 1,1 \\
\hline & P75 & 8,22 & 2334 & 14,4 & 1990,2 & 338,0 & 71,0 & 305,9 & 0,6 \\
\hline \multirow[t]{9}{*}{ ago-03 } & $\mathrm{M} 24$ & 8,03 & 298 & 3,6 & 22,0 & 283,7 & 8,9 & 64,6 & 0,8 \\
\hline & P20 & 7,31 & 551 & 3,2 & 184,9 & 442,7 & 15,0 & 35,5 & 1,5 \\
\hline & P86 & 7,73 & 1406 & 3,5 & 1367,4 & 260,1 & 15,4 & 68,2 & 1,6 \\
\hline & P34 & 7,27 & 2447 & 3,4 & 1829,8 & 293,5 & 96,1 & 490,1 & 1,5 \\
\hline & P61 & 7,29 & 2569 & 1,6 & 2356,8 & 252,2 & 36,6 & 111,1 & 2,0 \\
\hline & M95 & 8,03 & 839 & 3,4 & 771,0 & 199,2 & 9,0 & 0,0 & 0,6 \\
\hline & S90 & 8,28 & 521 & 1,4 & 220,9 & 266,0 & 22,9 & 3,9 & 1,0 \\
\hline & P5 & 7,14 & 1588 & 0,8 & 581,1 & 442,7 & 31,7 & 70,1 & 1,1 \\
\hline & P75 & 8,71 & 2391 & 5,0 & 1940,3 & 338,6 & 67,0 & 313,7 & 1,0 \\
\hline \multirow[t]{9}{*}{ sep-03 } & M24 & 8,14 & 293 & 9,1 & 22,0 & 288,6 & 8,7 & 64,9 & 0,7 \\
\hline & P20 & 7,54 & 501 & 6,8 & 141,6 & 427,0 & 17,2 & 33,4 & 0,8 \\
\hline & P86 & 7,49 & 1462 & 6,3 & 1334,2 & 268,9 & 14,7 & 68,2 & 1,2 \\
\hline & P34 & 7,15 & 2199 & 7,9 & 1767,0 & 290,5 & 96,3 & 487,9 & 1,5 \\
\hline & P61 & 7,56 & 2157 & 6,6 & 2323,8 & 247,3 & 39,9 & 117,7 & 1,6 \\
\hline & M95 & 7,60 & 923 & 5,6 & 760,4 & 203,2 & 9,1 & 0,0 & 0,5 \\
\hline & S90 & 8,17 & 531 & 3,4 & 200,3 & 263,0 & 19,5 & 3,2 & 0,8 \\
\hline & P5 & 7,31 & 1913 & 2,3 & 1353,9 & 439,7 & 65,1 & 72,3 & 1,1 \\
\hline & P75 & 7,83 & 2171 & 6,8 & 1680,7 & 343,5 & 80,2 & 320,4 & 0,7 \\
\hline \multirow[t]{9}{*}{ oct-03 } & M24 & 7,84 & 319 & 9,7 & 21,8 & 290,7 & 9,6 & 64,6 & 0,8 \\
\hline & P20 & 7,73 & 508 & 6,7 & 136,0 & 411,2 & 12,2 & 33,3 & 0,9 \\
\hline & P86 & 7,18 & 1400 & 6,2 & 1354,1 & 261,4 & 16,1 & 67,2 & 1,2 \\
\hline & P34 & 7,24 & 2088 & 7,1 & 1821,9 & 283,9 & 110,0 & 473,0 & 1,3 \\
\hline & P61 & 7,20 & 2029 & 5,8 & 2313,6 & 227,3 & 39,2 & 88,3 & 1,4 \\
\hline & M95 & 7,62 & 879 & 7,9 & 774,9 & 196,1 & 10,7 & 0,0 & 0,8 \\
\hline & S90 & 7,93 & 527 & 2,8 & 208,0 & 258,5 & 20,9 & 3,1 & 0,9 \\
\hline & P5 & 7,06 & 1688 & 1,8 & 740,1 & 403,8 & 54,3 & 94,5 & 0,9 \\
\hline & P75 & 7,73 & 1924 & 8,1 & 1631,8 & 343,4 & 68,6 & 310,5 & 0,9 \\
\hline
\end{tabular}


Tabla A.II.6. Continuación.

\begin{tabular}{|c|c|c|c|c|c|c|c|c|c|}
\hline Fecha & Muestra & $\begin{array}{c}\mathrm{Ca} \\
\mathrm{mg} / \mathrm{L}\end{array}$ & $\begin{array}{c}\mathrm{Mg} \\
\mathrm{mg} / \mathrm{L}\end{array}$ & $\begin{array}{c}\mathrm{Na} \\
\mathrm{mg} / \mathrm{L}\end{array}$ & $\begin{array}{c}\mathrm{K} \\
\mathrm{mg} / \mathrm{L}\end{array}$ & $\begin{array}{c}\mathrm{Fe} \\
\mathrm{ug} / \mathrm{L}\end{array}$ & $\begin{array}{c}\mathrm{Mn} \\
\mathrm{ug} / \mathrm{L}\end{array}$ & $\begin{array}{c}\text { As } \\
\mu \mathrm{g} / \mathrm{L}\end{array}$ & $\begin{array}{l}\text { Mo } \\
\text { ug/L }\end{array}$ \\
\hline \multirow[t]{9}{*}{ nov-02 } & M24 & 54,7 & 32,1 & 2,2 & 0,9 & 11,2 & 0,9 & 9,9 & 0,0 \\
\hline & P20 & 126,0 & 48,1 & 6,3 & 1,8 & 13,3 & 0,8 & 17,3 & 0,1 \\
\hline & P86 & 375,0 & 92,2 & 5,7 & 1,6 & 14,7 & 0,5 & 38,4 & 3,3 \\
\hline & P34 & 444,0 & 142,0 & 25,5 & 5,6 & 46,7 & 0,7 & 68,7 & 2,5 \\
\hline & P61 & 467,0 & 226,0 & 16,1 & 2,3 & 71,7 & 2,1 & 187,6 & 8,2 \\
\hline & M95 & 174,0 & 96,0 & 11,2 & 2,9 & 560,0 & 203,1 & 29,6 & 9,0 \\
\hline & S90 & 21,4 & 12,5 & 95,2 & 2,0 & 68,3 & 1,5 & 36,9 & 1,3 \\
\hline & P5 & 273,0 & 139,0 & 52,0 & 14,4 & 25,1 & 20,5 & 164,4 & 35,2 \\
\hline & P75 & 242,0 & 258,0 & 25,4 & 4,4 & 34,2 & 3,9 & 88,2 & 18,3 \\
\hline \multirow[t]{9}{*}{ dic-02 } & M24 & 51,6 & 27,9 & 1,8 & 1,2 & 5,5 & 0,2 & 9,9 & 0,0 \\
\hline & P20 & 145,0 & 55,6 & 7,3 & 2,1 & 11,4 & 1,3 & 17,5 & 1,0 \\
\hline & P86 & 358,0 & 91,3 & 5,7 & 1,2 & 10,0 & 0,7 & 39,2 & 12,6 \\
\hline & P34 & 533,0 & 139,0 & 30,4 & 5,8 & 30,0 & 2,1 & 71,2 & 2,9 \\
\hline & P61 & 396,0 & 216,0 & 19,3 & 2,5 & 35,6 & 2,3 & 195,6 & 6,3 \\
\hline & M95 & 174,0 & 100,0 & 10,6 & 3,5 & 702,0 & 150,3 & 32,4 & 1,3 \\
\hline & S90 & 27,3 & 16,2 & 104,0 & 2,6 & 17,5 & 1,0 & 40,8 & 0,9 \\
\hline & P5 & 323,0 & 159,0 & 61,0 & 16,2 & 30,6 & 13,0 & 165,5 & 16,7 \\
\hline & P75 & 296,0 & 290,0 & 36,6 & 6,4 & 14,4 & 3,7 & 92,2 & 32,5 \\
\hline \multirow[t]{9}{*}{ ene-03 } & $\mathrm{M} 24$ & 80,6 & 42,8 & 3,3 & 1,8 & 3,2 & 0,0 & 10,2 & 0,2 \\
\hline & P20 & 185,0 & 68,0 & 8,9 & 2,9 & 10,9 & 0,4 & 16,3 & 0,2 \\
\hline & P86 & 532,0 & 118,0 & 7,6 & 2,5 & 3,3 & 0,0 & 54,3 & 6,1 \\
\hline & P34 & 769,0 & 207,0 & 47,7 & 6,1 & 31,8 & 0,8 & 64,0 & 4,0 \\
\hline & P61 & 645,0 & 282,0 & 23,1 & 3,6 & 43,0 & 9,5 & 171,8 & 6,7 \\
\hline & M95 & 220,0 & 120,0 & 12,5 & 3,7 & 626 & 142,2 & 27,1 & 1,5 \\
\hline & S90 & 39,0 & 22,0 & 133,9 & 3,0 & 67,0 & 1,0 & 44,2 & 1,5 \\
\hline & P5 & 393,0 & 154,0 & 62,3 & 17,3 & 20,7 & 15,0 & 149,0 & 4,3 \\
\hline & P75 & 458,0 & 368,0 & 46,0 & 8,5 & 6,1 & 2,1 & 78,9 & 6,4 \\
\hline \multirow[t]{9}{*}{ feb-03 } & M24 & 64,7 & 35,6 & 2,8 & 1,3 & 4,5 & 0,0 & 12,2 & 1,1 \\
\hline & P20 & 156,0 & 55,6 & 8,5 & 2,5 & 4,2 & 0,0 & 16,9 & 0,8 \\
\hline & P86 & 525,0 & 106,0 & 7,3 & 2,6 & 16,4 & 0,6 & 44,0 & 6,1 \\
\hline & P34 & 829,0 & 205,0 & 53,8 & 7,3 & 5,8 & 0,0 & 77,9 & 5,8 \\
\hline & P61 & 633,0 & 248,0 & 21,5 & 2,8 & 7,6 & 0,2 & 193,9 & 6,9 \\
\hline & M95 & 203,0 & 102,0 & 12,1 & 4,0 & 467,0 & 206,5 & 20,9 & 2,5 \\
\hline & s90 & 51,2 & 27,0 & 130,0 & 3,8 & 55,9 & 0,6 & 40,7 & 1,8 \\
\hline & P5 & 364,0 & 141,0 & 48,8 & 13,5 & 3,7 & 9,4 & 151,2 & 5,1 \\
\hline & P75 & 397,0 & 315,0 & 36,2 & 6,7 & 3,6 & 1,7 & 77,4 & 7,1 \\
\hline \multirow[t]{9}{*}{ mar-03 } & M24 & 71,5 & 43,1 & 3,0 & 1,0 & 3,2 & 0,0 & 11,3 & 1,2 \\
\hline & P20 & 159,0 & 62,8 & 8,6 & 2,0 & 5,9 & 0,0 & 16,6 & 1,2 \\
\hline & P86 & 541,0 & 131,0 & 7,8 & 2,9 & 21,3 & 0,0 & 44,9 & 2,2 \\
\hline & P34 & 848,0 & 226,0 & 59,2 & 9,4 & 2,4 & 0,0 & 72,8 & 2,0 \\
\hline & P61 & 666,0 & 301,0 & 22,0 & 1,9 & 6,8 & 0,3 & 240,8 & 2,6 \\
\hline & M95 & 196,0 & 118,0 & 12,1 & 4,4 & 547,8 & 185,1 & 25,3 & 2,5 \\
\hline & S90 & 45,1 & 26,8 & 137,0 & 3,2 & 53,4 & 0,6 & 49,4 & 1,9 \\
\hline & P5 & 456,0 & 177,0 & 60,7 & 17,3 & 6,1 & 6,6 & 186,7 & 7,1 \\
\hline & P75 & 417,0 & 377,0 & 39,0 & 8,7 & 3,5 & 1,9 & 76,3 & 9,1 \\
\hline \multirow[t]{9}{*}{ abr-03 } & M24 & 69,1 & 38,7 & 1,9 & 0,5 & 1,2 & 0,0 & 12,2 & 0,0 \\
\hline & P20 & 129,0 & 51,7 & 5,5 & 1,4 & 12,3 & 1,0 & 15,4 & 0,0 \\
\hline & P86 & 478,0 & 109,0 & 6,7 & 1,6 & 6,5 & 0,0 & 49,1 & 2,3 \\
\hline & P34 & 799,0 & 204,0 & 48,9 & 5,0 & 15,0 & 0,8 & 71,0 & 1,7 \\
\hline & P61 & 478,0 & 226,0 & 17,0 & 2,3 & 7,8 & 1,0 & 212,3 & 2,7 \\
\hline & M95 & 193,0 & 106,0 & 11,0 & 2,3 & 316,0 & 116,0 & 20,0 & 2,5 \\
\hline & S90 & 50,4 & 26,8 & 131,0 & 3,0 & 169,0 & 1,6 & 46,5 & 2,3 \\
\hline & P5 & 367,0 & 169,0 & 57,1 & 14,6 & 8,8 & 10,2 & 140,2 & 9,0 \\
\hline & P75 & 336,0 & 314,0 & 28,6 & 4,9 & 37,5 & 2,0 & 77,3 & 11,3 \\
\hline
\end{tabular}


Tabla A.II.6. Continuación.

\begin{tabular}{|c|c|c|c|c|c|c|c|c|c|}
\hline Fecha & Muestra & $\begin{array}{c}\mathrm{Ca} \\
\mathrm{mg} / \mathrm{L}\end{array}$ & $\begin{array}{c}\mathrm{Mg} \\
\mathrm{mg} / \mathrm{L}\end{array}$ & $\begin{array}{c}\mathrm{Na} \\
\mathrm{mg} / \mathrm{L}\end{array}$ & $\begin{array}{c}\mathrm{K} \\
\mathrm{mg} / \mathrm{L}\end{array}$ & $\begin{array}{c}\mathrm{Fe} \\
\mathrm{ug} / \mathrm{L}\end{array}$ & $\begin{array}{c}\mathrm{Mn} \\
\mathrm{ug} / \mathrm{L}\end{array}$ & $\begin{array}{c}\text { As } \\
\mu \mathrm{g} / \mathrm{L}\end{array}$ & $\begin{array}{l}\text { Mo } \\
\text { ug/L }\end{array}$ \\
\hline \multirow[t]{9}{*}{ may-03 } & M24 & 56,1 & 34,0 & 2,6 & 0,3 & 3,4 & 0,1 & 14,5 & 0,0 \\
\hline & P20 & 119,0 & 53,1 & 7,3 & 3,2 & 7,9 & 0,6 & 19,4 & 0,5 \\
\hline & P86 & 354,0 & 88,8 & 8,4 & 1,8 & 9,2 & 0,7 & 51,6 & 1,3 \\
\hline & P34 & 538,0 & 155,0 & 53,9 & 7,2 & 2,4 & 0,1 & 95,0 & 1,0 \\
\hline & P61 & 392,0 & 182,0 & 25,4 & 2,8 & 3,7 & 1,4 & 276,8 & 1,0 \\
\hline & M95 & 137,0 & 77,6 & 12,0 & 2,5 & 280,2 & 128,5 & 21,4 & 1,0 \\
\hline & S90 & 49,9 & 27,0 & 124,0 & 2,8 & 194,7 & 2,6 & 46,0 & 1,0 \\
\hline & P5 & 271,0 & 117,0 & 58,3 & 15,1 & 7,5 & 4,3 & 225,7 & 4,9 \\
\hline & P75 & 261,0 & 227,0 & 34,1 & 5,2 & 3,3 & 1,4 & 106,2 & 6,8 \\
\hline \multirow[t]{9}{*}{ jun-03 } & M24 & 73,8 & 41,8 & 3,2 & 0,0 & 7,6 & 0,1 & 12,2 & 1,5 \\
\hline & P20 & 161,0 & 66,7 & 6,9 & 1,1 & 52,7 & 2,8 & 13,6 & 6,1 \\
\hline & P86 & 522,0 & 133,0 & 9,8 & 2,8 & 53,8 & 1,9 & 44,2 & 17,6 \\
\hline & P34 & 706,0 & 225,0 & 57,2 & 5,1 & 9,8 & 0,5 & 58,0 & 3,2 \\
\hline & P61 & 553,0 & 351,0 & 78,2 & 2,9 & 39,1 & 4,3 & 223,2 & 4,4 \\
\hline & M95 & 208,0 & 119,0 & 14,2 & 3,2 & 146,0 & 119,7 & 17,9 & 1,8 \\
\hline & S90 & 52,5 & 30,0 & 163,0 & 3,6 & 106,0 & 1,2 & 49,7 & 5,0 \\
\hline & P5 & 416,0 & 189,0 & 73,5 & 21,1 & 7,5 & 13 & 173,1 & 6,9 \\
\hline & P75 & 355,0 & 400,0 & 40,3 & 6,9 & 10,0 & 0,9 & 105,5 & 18,0 \\
\hline \multirow[t]{9}{*}{ jul-03 } & M24 & 75,3 & 42,5 & 3,1 & 0,4 & 11,7 & 0,0 & 8,7 & 0,0 \\
\hline & P20 & 167,0 & 71,3 & 6,5 & 0,9 & 74,4 & 1,1 & 13,3 & 0,2 \\
\hline & P86 & 555,0 & 131,0 & 9,9 & 2,5 & 11,3 & 0,7 & 40,5 & 3,5 \\
\hline & P34 & 758,0 & 223,0 & 63,1 & 6,5 & 11,0 & 1,4 & 70,1 & 1,8 \\
\hline & P61 & 713,0 & 327,0 & 42,4 & 4,0 & 38,8 & 14,3 & 236,2 & 2,9 \\
\hline & M95 & 230,0 & 127,0 & 14,5 & 3,2 & 284,8 & 144,2 & 16,4 & 1,3 \\
\hline & S90 & 42,2 & 24,1 & 155,0 & 3,4 & 58,0 & 1,1 & 47,0 & 1,2 \\
\hline & P5 & 403,0 & 183,0 & 76,0 & 26,4 & 4,2 & 28,4 & 178,4 & 8,9 \\
\hline & P75 & 438,0 & 396,0 & 53,1 & 8,7 & 15,4 & 1,5 & 92,7 & 8,7 \\
\hline \multirow[t]{9}{*}{ ago-03 } & M24 & 77,1 & 42,8 & 3,1 & 0,8 & 4,7 & 0,4 & 8,8 & 0,0 \\
\hline & P20 & 161,0 & 65,3 & 7,5 & 1,5 & 1,6 & 0,8 & 12,4 & 0,4 \\
\hline & P86 & 587,0 & 133,0 & 10,0 & 2,6 & 6,9 & 1,2 & 37,3 & 4,7 \\
\hline & P34 & 750,0 & 222,0 & 63,9 & 5,8 & 6,2 & 1,1 & 77,0 & 4,4 \\
\hline & P61 & 671,0 & 316,0 & 36,6 & 3,8 & 17,5 & 14,5 & 232,2 & 5,5 \\
\hline & M95 & 226,0 & 125,0 & 13,8 & 3,6 & 329,0 & 181,0 & 19,3 & 1,5 \\
\hline & S90 & 39,4 & 22,8 & 152,0 & 3,1 & 17,2 & 0,4 & 40,0 & 1,0 \\
\hline & P5 & 284,0 & 89,6 & 35,7 & 66,7 & 4,9 & 4,8 & 128,4 & 9,6 \\
\hline & P75 & 409,0 & 375,0 & 48,9 & 8,5 & 12,1 & 2,1 & 85,3 & 7,6 \\
\hline \multirow[t]{9}{*}{ sep-03 } & M24 & 76,5 & 41,3 & 3,2 & 0,6 & 4,9 & 0,1 & 10,6 & 0,0 \\
\hline & P20 & 140,0 & 56,7 & 5,5 & 0,9 & 11,6 & 0,9 & 16,1 & 0,2 \\
\hline & P86 & 589,0 & 137,0 & 11,0 & 2,3 & 12,6 & 0,3 & 51,7 & 4,1 \\
\hline & P34 & 751,0 & 218,0 & 56,9 & 6,0 & 19,0 & 0,8 & 88,1 & 2,1 \\
\hline & P61 & 655,0 & 308,0 & 36,6 & 4,4 & 16,0 & 13,4 & 251,6 & 4,4 \\
\hline & M95 & 227,0 & 122,0 & 14,1 & 3,5 & 364,0 & 187,0 & 24,0 & 1,5 \\
\hline & S90 & 37,0 & 20,8 & 160,0 & 3,3 & 23,6 & 0,5 & 47,5 & 1,1 \\
\hline & P5 & 408,0 & 210,0 & 83,6 & 25,3 & 8,4 & 61,1 & 218,5 & 7,3 \\
\hline & P75 & 373,0 & 343,0 & 39,6 & 7,1 & 14,0 & 1,6 & 92,7 & 6,8 \\
\hline \multirow[t]{9}{*}{ oct-03 } & M24 & 53,7 & 32,8 & 3,2 & 1,0 & 3,2 & 0,0 & 11,1 & 0,0 \\
\hline & P20 & 93,1 & 41,3 & 5,9 & 1,8 & 8,9 & 0,4 & 16,4 & 1,3 \\
\hline & P86 & 381,0 & 96,5 & 8,1 & 2,1 & 24,6 & 0,6 & 58,9 & 11,0 \\
\hline & P34 & 469,0 & 140,0 & 45,4 & 5,5 & 8,9 & 0,9 & 95,7 & 11,8 \\
\hline & P61 & 429,0 & 213,0 & 23,1 & 3,5 & 26,1 & 27,5 & 205,3 & 13,9 \\
\hline & M95 & 160,0 & 93,2 & 12,6 & 3,3 & 606,0 & 251,8 & 33,2 & 0,7 \\
\hline & S90 & 24,9 & 15,0 & 120,0 & 2,8 & 16,0 & 0,5 & 38,2 & 0,0 \\
\hline & P5 & 212,0 & 76,3 & 53,1 & 51,3 & 8,5 & 5,1 & 190,0 & 5,4 \\
\hline & P75 & 258,0 & 252,0 & 33,1 & 6,6 & 12,8 & 3,2 & 152,3 & 7,0 \\
\hline
\end{tabular}


A.III ESTUDIO GEOQUÍMICO 

Tabla A.III.1. Identificación y resultados físico-químicos de las muestras de suelos.

\begin{tabular}{|c|c|c|c|c|c|c|c|c|c|}
\hline Cota & Fecha & Coord X & Coord Y & unidad geologica & Procede & Textura & Arenas & Limos & Arcilla \\
\hline$m$ & & & & & & & $\%$ & $\%$ & $\%$ \\
\hline 603 & $10 / 08 / 2004$ & 378000 & 4584630 & Toro Inferior & columna & Franco & 53,2 & 24,6 & 22,2 \\
\hline 604 & $10 / 08 / 2004$ & 378000 & 4584630 & Toro Inferior & columna & Franco & 60,5 & 16,7 & 22,8 \\
\hline 610 & $10 / 08 / 2004$ & 378000 & 4584630 & Toro Inferior & columna & Franco & 37,0 & 43,8 & 19,2 \\
\hline 614 & $10 / 08 / 2004$ & 378000 & 4584630 & Toro Inferior & columna & Franco & 67,9 & 7,1 & 25,0 \\
\hline 619 & $10 / 08 / 2004$ & 378000 & 4584630 & Toro Inferior & columna & Franco & 49,0 & 28,2 & 22,8 \\
\hline 624 & $10 / 08 / 2004$ & 378000 & 4584630 & Toro Inferior & columna & Franco-arenoso & 46,3 & 40,4 & 13,3 \\
\hline 630 & $10 / 08 / 2004$ & 378000 & 4584630 & Toro Superior & columna & Franco & 56,2 & 27,8 & 16,0 \\
\hline 635 & $10 / 08 / 2004$ & 378000 & 4584630 & Toro Superior & columna & Franco-arcilloso & 12,2 & 61,6 & 26,2 \\
\hline 641 & $10 / 08 / 2004$ & 378000 & 4584630 & Toro Superior & columna & Franco & 68,0 & 17,9 & 14,1 \\
\hline 644 & $10 / 08 / 2004$ & 378000 & 4584630 & Toro Superior & columna & Franco & 69,1 & 16,4 & 14,6 \\
\hline 647 & $10 / 08 / 2004$ & 378000 & 4584630 & Toro Superior & columna & Franco & 29,5 & 46,3 & 24,2 \\
\hline 651 & $10 / 08 / 2004$ & 378000 & 4584630 & Villalba de Adaja & columna & Franco & 69,1 & 14,9 & 16,1 \\
\hline 655 & $10 / 08 / 2004$ & 378000 & 4584630 & Villalba de Adaja & columna & Franco & 64,1 & 18,7 & 17,3 \\
\hline 659 & $10 / 08 / 2004$ & 378000 & 4584630 & Villalba de Adaja & columna & Franco & 62,9 & 21,6 & 15,5 \\
\hline 664 & $10 / 08 / 2004$ & 378000 & 4584630 & Villalba de Adaja & columna & Franco-arenoso & 68,1 & 19,8 & 12,1 \\
\hline 668 & $10 / 08 / 2004$ & 378000 & 4584630 & Villalba de Adaja & columna & Franco-arcilloso & 59,7 & 15,1 & 25,2 \\
\hline 672 & $10 / 08 / 2004$ & 378000 & 4584630 & Villalba de Adaja & columna & Franco-arenoso & 65,7 & 24,3 & 10,0 \\
\hline 679 & $10 / 08 / 2004$ & 378000 & 4584630 & Villalba de Adaja & columna & Franco-arenoso & 72,7 & 15,1 & 12,2 \\
\hline 684 & $10 / 08 / 2004$ & 378000 & 4584630 & Villalba de Adaja & columna & Arenoso & 53,2 & 38,3 & 8,5 \\
\hline 687 & $10 / 08 / 2004$ & 378000 & 4584630 & Villalba de Adaja & columna & Franco-arcilloso & 20,0 & 53,4 & 26,7 \\
\hline 691 & $10 / 08 / 2004$ & 378000 & 4584630 & Villalba de Adaja & columna & Arenoso & 71,8 & 22,5 & 5,7 \\
\hline 693 & $10 / 08 / 2004$ & 378000 & 4584630 & Villalba de Adaja & columna & Franco-arenoso & 18,6 & 71,0 & 10,4 \\
\hline 695 & $10 / 08 / 2004$ & 378000 & 4584630 & Villalba de Adaja & columna & Franco & 44,5 & 38,9 & 16,6 \\
\hline 701 & $10 / 08 / 2004$ & 378000 & 4584630 & Villalba de Adaja & columna & Franco & 15,4 & 65,2 & 19,7 \\
\hline 704 & $10 / 08 / 2004$ & 378000 & 4584630 & Villalba de Adaja & columna & Franco & 27,7 & 52,5 & 19,8 \\
\hline 708 & $10 / 08 / 2004$ & 378000 & 4584630 & Villalba de Adaja & columna & Franco-arcilloso & 46,6 & 28,3 & 25,1 \\
\hline 713 & $10 / 08 / 2004$ & 378000 & 4584630 & Dueñas & columna & Franco & 59,5 & 25,2 & 15,3 \\
\hline 715 & $10 / 08 / 2004$ & 378000 & 4584630 & Dueñas & columna & Franco-arcilloso & 19,5 & 53,0 & 27,6 \\
\hline 720 & $10 / 08 / 2004$ & 378000 & 4584630 & Dueñas & columna & Franco-arenoso & 65,3 & 22,3 & 12,4 \\
\hline 724 & $10 / 08 / 2004$ & 378000 & 4584630 & Dueñas & columna & Arcilloso & 9,9 & 46,4 & 43,8 \\
\hline 727 & $17 / 10 / 2002$ & 376479 & 4583361 & Tierra de Campos & aflorante & Arcilloso & 6,9 & 45,3 & 47,8 \\
\hline 729 & $10 / 08 / 2004$ & 378000 & 4584630 & Tierra de Campos & columna & Arenoso & 48,0 & 44,7 & 7,4 \\
\hline 735 & $19 / 02 / 2004$ & 374631 & 4583519 & Tierra de Campos & aflorante & Franco & 32,0 & 46,1 & 22,0 \\
\hline 736 & $10 / 08 / 2004$ & 378000 & 4584630 & Tierra de Campos & columna & Franco & 36,4 & 43,9 & 19,7 \\
\hline 744 & $17 / 10 / 2002$ & 376440 & 4583260 & Tierra de Campos & aflorante & Franco-arcilloso & 25,2 & 46,0 & 28,8 \\
\hline 747 & $10 / 08 / 2004$ & 378000 & 4584630 & Tierra de Campos & columna & Franco-arenoso & 39,9 & 47,1 & 13,0 \\
\hline 751 & $04 / 03 / 2004$ & 383474 & 4582001 & Tierra de Campos & aflorante & Arenoso & 66,6 & 25,2 & 8,2 \\
\hline 755 & $04 / 03 / 2004$ & 383474 & 4582001 & Tierra de Campos & aflorante & Franco & 15,5 & 68,8 & 15,7 \\
\hline 762 & $19 / 02 / 2004$ & 383672 & 4581809 & Zaratán & aflorante & Franco-arcilloso & 1,6 & 69,1 & 29,3 \\
\hline 764,6 & $05 / 11 / 2005$ & 385690 & 4581620 & Zaratán & aflorante & Arcilloso & 18,2 & 44,5 & 37,2 \\
\hline 765,1 & $17 / 10 / 2002$ & 381928 & 4583271 & Zaratán & aflorante & Arcilloso & 10,6 & 34,8 & 54,7 \\
\hline 765 & $19 / 02 / 2004$ & 383672 & 4581809 & Zaratán & aflorante & Arcilloso & 0,7 & 60,6 & 38,7 \\
\hline 766 & $05 / 11 / 2005$ & 385690 & 4581620 & Zaratán & aflorante & Arcilloso & 2,6 & 64,1 & 33,3 \\
\hline 768 & $05 / 11 / 2005$ & 385690 & 4581620 & Zaratán & aflorante & Franco & 39,3 & 36,3 & 24,4 \\
\hline 774 & $17 / 10 / 2002$ & 381952 & 4583274 & Cuestas & aflorante & Arcilloso & 3,7 & 54,3 & 42,0 \\
\hline 782 & $17 / 10 / 2002$ & 381963 & 4583290 & Cuestas & aflorante & Franco-arenoso & 30,2 & 58,7 & 11,1 \\
\hline 792 & $19 / 02 / 2004$ & 382895 & 4585923 & Cuestas & aflorante & Arenoso & 36,0 & 54,3 & 9,8 \\
\hline 802 & $17 / 10 / 2002$ & 380488 & 4583787 & Cuestas & aflorante & Arcilloso & 0,9 & 46,8 & 52,3 \\
\hline 813 & $04 / 03 / 2004$ & 381316 & 4584747 & Cuestas & aflorante & Franco & 52,8 & 25,9 & 21,3 \\
\hline 825 & $04 / 03 / 2004$ & 381330 & 4584436 & Cuestas & aflorante & Franco-arcilloso & 4,1 & 66,4 & 29,4 \\
\hline 835 & $17 / 10 / 2002$ & 381701 & 4583946 & Cuestas & aflorante & Arcilloso & 4,6 & 50,4 & 45,0 \\
\hline 844 & $17 / 10 / 2002$ & 381696 & 4583962 & Cuestas & aflorante & Arcilloso & 0,2 & 64,7 & 35,0 \\
\hline 845,7 & $05 / 11 / 2005$ & 385974 & 4583690 & Transición al Páramo & aflorante & Arcilloso & 8,8 & 49,9 & 41,3 \\
\hline 853 & $17 / 10 / 2002$ & 384945 & 4585379 & Transición al Páramo & aflorante & Franco & 16,2 & 70,6 & 13,2 \\
\hline 864 & $17 / 10 / 2002$ & 385662 & 4586079 & Calizas del Páramo & aflorante & Arcilloso & 10,3 & 29,7 & 60,0 \\
\hline 868,7 & $05 / 11 / 2005$ & 385988 & 4583843 & Calizas del Páramo & aflorante & Franco & 42,0 & 40,7 & 17,3 \\
\hline 873 & $04 / 03 / 2004$ & 385662 & 4586079 & Calizas del Páramo & aflorante & Franco & 24,3 & 58,6 & 17,2 \\
\hline
\end{tabular}


Tabla A.III.1. Continuación.

\begin{tabular}{|c|c|c|c|c|c|c|c|c|c|c|c|}
\hline Cota & $\mathrm{pH}$ & Cond & M.O & Carbonato & $\mathrm{ClC}$ & $\mathrm{P}$ & $\mathrm{Mg}$ tot & Na tot & $\mathrm{K}$ tot & $\mathrm{Mn}$ tot & Fe tot \\
\hline$m$ & & $\mu S / \mathrm{cm}$ & $\%$ & $\% \mathrm{CaCO} 3$ & meq $\mathrm{Na} / 100 \mathrm{~g}$ & $\mathrm{mg} / \mathrm{kg}$ & $\mathrm{g} / \mathrm{kg}$ & $\mathrm{g} / \mathrm{kg}$ & $\mathrm{g} / \mathrm{kg}$ & $\mathrm{mg} / \mathrm{kg}$ & $\mathrm{g} / \mathrm{kg}$ \\
\hline 603 & 9,85 & 435,7 & 0,02 & 5,2 & 11,0 & 1,9 & 14,9 & 3,4 & 2,0 & 170 & 11,9 \\
\hline 604 & 10,20 & 475,4 & 0,09 & 0,9 & 12,2 & 3,4 & 5,0 & 1,0 & 2,6 & 147 & 11,6 \\
\hline 610 & 10,02 & 359,0 & 0,12 & 0,5 & 19,7 & 0,6 & 8,2 & 1,7 & 3,9 & 168 & 18,5 \\
\hline 614 & 10,14 & 298,0 & 0,03 & 0,8 & 8,2 & 1,2 & 3,2 & 3,0 & 2,7 & 106 & 10,7 \\
\hline 619 & 10,07 & 407,0 & 0,00 & 0,8 & 12,4 & 1,0 & 3,9 & 0,9 & 3,0 & 150 & 9,9 \\
\hline 624 & 10,25 & 397,0 & 0,00 & 11,4 & 16,8 & 1,7 & 6,6 & 4,8 & 4,0 & 170 & 16,0 \\
\hline 630 & 10,05 & 387,0 & 0,11 & 0,6 & 15,3 & 0,8 & 8,0 & 1,3 & 4,6 & 179 & 19,4 \\
\hline 635 & 9,58 & 378,7 & 0,04 & 0,7 & 19,8 & 1,3 & 9,6 & 4,9 & 5,4 & 193 & 25,6 \\
\hline 641 & 10,12 & 341,7 & 0,09 & 1,0 & 9,2 & 0,6 & 2,2 & 0,8 & 2,2 & 110 & 7,9 \\
\hline 644 & 9,54 & 408,3 & 0,01 & 1,3 & 5,4 & 3,3 & 1,2 & 4,2 & 1,7 & 58 & 7,5 \\
\hline 647 & 9,98 & 397,7 & 0,00 & 0,5 & 20,8 & 2,5 & 8,9 & 6,3 & 4,6 & 271 & 22,2 \\
\hline 651 & 9,95 & 365,0 & 0,01 & 0,8 & 8,1 & 1,4 & 1,8 & 2,9 & 2,0 & 54 & 7,0 \\
\hline 655 & 9,68 & 368,3 & 0,01 & 1,4 & 15,4 & 1,0 & 5,9 & 0,9 & 3,5 & 91 & 10,9 \\
\hline 659 & 10,06 & 322,7 & 0,02 & 0,7 & 8,4 & 1,2 & 3,1 & 2,8 & 2,2 & 85 & 8,7 \\
\hline 664 & 9,33 & 266,3 & 0,00 & 0,9 & 9,8 & 1,7 & 5,5 & 0,7 & 2,8 & 89 & 10,6 \\
\hline 668 & 8,89 & 353,7 & 0,02 & 1,6 & 16,4 & 2,4 & 7,1 & 3,9 & 5,3 & 143 & 15,6 \\
\hline 672 & 9,33 & 296,3 & 0,16 & 0,9 & 11,3 & 0,9 & 4,9 & 0,6 & 2,3 & 106 & 11,1 \\
\hline 679 & 9,29 & 310,0 & 0,02 & 1,0 & 6,6 & 1,3 & 1,6 & 2,0 & 1,5 & 77 & 5,8 \\
\hline 684 & 9,18 & 301,0 & 0,07 & 0,6 & 16,5 & 1,0 & 10,0 & 0,7 & 5,2 & 181 & 19,5 \\
\hline 687 & 9,13 & 381,0 & 0,04 & 1,6 & 16,5 & 1,3 & 11,0 & 3,2 & 6,5 & 227 & 29,3 \\
\hline 691 & 9,28 & 300,3 & 0,03 & 1,5 & 4,7 & 1,6 & 2,8 & 2,6 & 2,2 & 80 & 7,7 \\
\hline 693 & 8,80 & 341,3 & 0,03 & 0,9 & 22,5 & 2,3 & 14,6 & 0,8 & 6,7 & 267 & 31,7 \\
\hline 695 & 9,27 & 367,3 & 0,03 & 18,5 & \begin{tabular}{|l|}
15,1 \\
\end{tabular} & 2,2 & 9,0 & 3,0 & 6,4 & 264 & 13,9 \\
\hline 701 & 9,23 & 415,0 & 0,10 & 1,2 & 17,1 & 2,6 & 11,9 & 3,3 & 6,4 & 207 & 28,0 \\
\hline 704 & 8,94 & 405,0 & 0,01 & 1,2 & 26,9 & 1,0 & 17,0 & 0,9 & 14,5 & 243 & 30,9 \\
\hline 708 & 10,22 & 592,7 & 0,04 & 9,0 & 16,5 & 2,5 & 11,9 & 3,0 & 5,1 & 307 & 31,8 \\
\hline 713 & 8,89 & 420,7 & 0,03 & 6,3 & 13,6 & 1,4 & 7,5 & 3,5 & 7,8 & 206 & 13,0 \\
\hline 715 & 8,30 & 414,7 & 0,03 & 0,8 & 24,1 & 0,7 & 13,9 & 0,7 & 11,9 & 224 & 27,4 \\
\hline 720 & 8,61 & 656,7 & 0,03 & 7,3 & 28,4 & 1,4 & 29,2 & 3,7 & 14,5 & 280 & 35,6 \\
\hline 724 & 8,34 & 595,7 & 0,00 & 9,2 & 27,3 & 1,3 & 29,3 & 0,9 & 18,3 & 270 & 28,6 \\
\hline 727 & 8,76 & 530,0 & 0,01 & 54,1 & 11,3 & 3,6 & 37,7 & 1,0 & 7,7 & 497 & 11,5 \\
\hline 729 & 8,57 & 671,3 & 0,03 & 12,5 & 22,6 & 1,5 & 32,3 & 2,9 & 11,5 & 375 & 18,9 \\
\hline 735 & 8,44 & 335,0 & 0,01 & 25,9 & 32,2 & 2,9 & 27,8 & 0,7 & 17,1 & 316 & 26,9 \\
\hline 736 & 8,18 & 800,7 & 0,00 & 18,7 & 29,5 & 1,8 & 22,7 & 0,6 & 15,1 & 304 & 19,9 \\
\hline 744 & 8,64 & 550,0 & 0,05 & 26,3 & 17,4 & 8,9 & 25,9 & 0,9 & 14,4 & 359 & 19,5 \\
\hline 747 & 8,11 & 1632,3 & 0,11 & \begin{tabular}{|l|}
3,4 \\
\end{tabular} & 35,2 & 1,5 & 19,9 & 3,3 & 17,0 & 226 & 31,8 \\
\hline 751 & 8,67 & 393,0 & 0,10 & 5,5 & 17,1 & 1,6 & 15,4 & 3,5 & 3,7 & 111 & 9,4 \\
\hline 755 & 8,31 & 1620,0 & 0,13 & 21,0 & 29,4 & 4,8 & 30,7 & 0,3 & 7,7 & 120 & 23,2 \\
\hline 762 & 8,72 & 442,7 & 0,43 & \begin{tabular}{|l|}
23,4 \\
\end{tabular} & 4,0 & 1,9 & 121,7 & 4,2 & 1,3 & 188 & 4,2 \\
\hline 764,6 & 8,50 & \begin{tabular}{|l|}
816,3 \\
\end{tabular} & 1,13 & 24,1 & 9,4 & 2,7 & 29,7 & 2,8 & 3,6 & 113 & 6,0 \\
\hline 765,1 & 8,80 & 2015,0 & 0,09 & 46,8 & 8,5 & 3,0 & 87,0 & 1,2 & 0,4 & 76 & 6,8 \\
\hline 765 & 8,46 & 170,0 & 0,04 & \begin{tabular}{|l|}
58,4 \\
\end{tabular} & 10,5 & 10,4 & 24,2 & 1,0 & 3,2 & 198 & 5,1 \\
\hline 766 & 8,72 & 686,0 & 0,24 & 20,9 & 6,0 & 1,6 & 95,8 & 4,0 & 3,3 & 236 & 8,7 \\
\hline 768 & 8,80 & 1089,3 & 0,63 & 18,2 & \begin{tabular}{|l|}
3,1 \\
\end{tabular} & 1,8 & 6,6 & 3,1 & 0,7 & 476 & 1,5 \\
\hline 774 & 8,64 & 530,0 & 0,03 & 34,4 & 19,2 & 27,6 & 77,7 & 1,4 & 11,0 & 262 & 16,6 \\
\hline 782 & 8,24 & 2690,0 & 0,01 & 39,5 & 12,4 & 4,5 & 72,7 & 1,7 & 6,6 & 275 & 17,0 \\
\hline 792 & 7,88 & 2010,0 & 0,03 & 17,5 & 22,8 & 3,0 & 50,7 & 0,7 & 4,6 & 166 & 10,3 \\
\hline 802 & 8,34 & 750,0 & 0,02 & 52,3 & 12,7 & 1,3 & 77,6 & 1,6 & 10,8 & 261 & 15,4 \\
\hline 813 & 8,59 & 330,0 & 0,03 & 53,9 & 20,6 & 4,2 & 68,1 & 0,7 & 4,8 & 164 & 7,1 \\
\hline 825 & 8,21 & 980,0 & 0,01 & 60,1 & 17,7 & 10,9 & 64,9 & 0,9 & 3,3 & 219 & 7,3 \\
\hline 835 & 8,45 & 575,0 & 0,02 & 63,3 & 11,9 & 7,5 & 67,2 & 1,1 & 3,3 & 175 & 6,5 \\
\hline 844 & 9,37 & 200,0 & 0,03 & 71,6 & 14,1 & 3,4 & 103,8 & 1,0 & 3,5 & 155 & 7,4 \\
\hline 845,7 & 9,34 & 379,3 & 0,46 & 21,1 & 8,0 & 1,2 & 101,9 & 3,2 & 3,0 & 168 & 9,0 \\
\hline 853 & 8,95 & 3665,0 & 0,05 & 66,4 & 4,0 & 2,9 & 101,8 & 4,1 & 2,7 & 81 & 4,8 \\
\hline 864 & 8,29 & 400,0 & 0,04 & 8,7 & 15,4 & 11,5 & 72,1 & 0,6 & 5,6 & 57 & 20,9 \\
\hline 868,7 & 9,27 & 282,7 & 0,25 & 24,1 & 1,8 & 1,8 & 136,0 & 3,5 & 0,4 & 84 & 2,2 \\
\hline 873 & 9,33 & 275,0 & 0,11 & 62,1 & 4,0 & 3,2 & 56,3 & 0,3 & 0,2 & 90 & 1,0 \\
\hline
\end{tabular}


Tabla A.III.1. Continuación.

\begin{tabular}{|c|c|c|c|c|c|c|c|c|c|c|c|c|c|c|}
\hline Cota & MnT & $\mathrm{FeT}$ & Ca ext & Mg ex & Na ex & K ex & Mn ex & Fe ex & As & $\mathrm{Cr}$ & $\mathrm{Cu}$ & $\mathrm{Pb}$ & $\mathrm{Zn}$ & V \\
\hline$m$ & $\mathrm{mg} / \mathrm{kg}$ & $\mathrm{g} / \mathrm{kg}$ & $\mathrm{g} / \mathrm{kg}$ & $\mathrm{g} / \mathrm{kg}$ & $g / k g$ & $\mathrm{~g} / \mathrm{kg}$ & $\mathrm{mg} / \mathrm{kg}$ & $\mathrm{mg} / \mathrm{kg}$ & $\mathrm{mg} / \mathrm{kg}$ & $\mathrm{mg} / \mathrm{kg}$ & $\mathrm{mg} / \mathrm{kg}$ & $\mathrm{mg} / \mathrm{kg}$ & $\mathrm{mg} / \mathrm{kg}$ & $\mathrm{mg} / \mathrm{kg}$ \\
\hline 603 & 170 & 11,9 & 6,1 & 0,14 & 1,00 & 0,18 & 72,7 & 24,8 & 13,5 & 11,3 & 17,7 & 14,3 & 45,6 & 14,7 \\
\hline 604 & 147 & 11,6 & 2,6 & 0,15 & 1,01 & 0,17 & 52,3 & 16,9 & 13,5 & 10,6 & 5,6 & 6,7 & 26,5 & 13,8 \\
\hline 610 & 168 & 18,5 & 2,3 & 0,15 & 1,36 & 0,21 & 50,7 & 23,1 & 8,5 & 15,5 & 8,3 & 6,3 & 42,4 & 13,7 \\
\hline 614 & 106 & 10,7 & 1,6 & 0,11 & 0,49 & 0,11 & 18,1 & 38,1 & 4,1 & 10,8 & 14,1 & 4,9 & 33,2 & 10,7 \\
\hline 619 & 150 & 9,9 & 1,2 & 0,11 & 0,72 & 0,15 & 26,1 & 11,3 & 8,4 & 8,4 & 4,0 & 6,5 & 19,8 & 9,0 \\
\hline 624 & 170 & 16,0 & 8,2 & 0,19 & 1,02 & 0,24 & 37,4 & 12,7 & 111,4 & 15,0 & 22,3 & 7,0 & 57,6 & 15,1 \\
\hline 630 & 179 & 19,4 & 2,1 & 0,16 & 0,98 & 0,16 & 25,6 & 21,6 & 9,3 & 15,7 & 7,3 & 8,1 & 44,3 & 19,3 \\
\hline 635 & 193 & 25,6 & 2,1 & 0,20 & 1,36 & 0,24 & 8,8 & 31,6 & 10,0 & 20,1 & 21,6 & 11,7 & 66,9 & 22,5 \\
\hline 641 & 110 & 7,9 & 1,7 & 0,17 & 0,62 & 0,12 & 1,7 & 7,8 & 1,2 & 14,4 & 5,1 & 5,7 & 29,6 & 12,6 \\
\hline 644 & 58 & 7,5 & 1,6 & 0,14 & 0,77 & 0,13 & 10,4 & 19,1 & 5,5 & 10,8 & 17,0 & 3,2 & 34,1 & 9,7 \\
\hline 647 & 271 & 22,2 & 2,0 & 0,31 & 1,28 & 0,24 & 137,2 & 27,5 & \begin{tabular}{|l|}
18,4 \\
\end{tabular} & 20,6 & 11,2 & 11,3 & 50,7 & 22,8 \\
\hline 651 & 54 & 7,0 & 1,3 & 0,14 & 0,48 & 0,13 & 8,6 & 38,6 & 5,1 & 7,7 & 17,6 & 3,8 & 51,1 & 6,3 \\
\hline 655 & 91 & 10,9 & 1,8 & 0,25 & 0,60 & 0,18 & 11,4 & 9,9 & 3,0 & 9,9 & 4,9 & 4,4 & 22,6 & 5,7 \\
\hline 659 & 85 & 8,7 & 1,5 & 0,21 & 1,20 & 0,15 & 9,5 & 26,7 & 3,3 & 10,6 & 17,6 & 3,8 & 38,9 & 6,6 \\
\hline 664 & 89 & 10,6 & 1,2 & 0,28 & 0,43 & 0,13 & 5,7 & 36,3 & 2,0 & 13,7 & 3,3 & 2,8 & 21,2 & 8,2 \\
\hline 668 & 143 & 15,6 & 2,5 & 0,56 & 0,17 & 0,28 & 14,2 & 42,8 & 11,8 & 16,0 & 19,1 & 8,9 & 46,6 & 12,1 \\
\hline 672 & 106 & 11,1 & 1,1 & 0,33 & 0,34 & 0,12 & 22,0 & 11,6 & 8,5 & 10,2 & 5,2 & 5,7 & 22,1 & 9,2 \\
\hline 679 & 77 & 5,8 & 0,9 & 0,36 & 0,28 & 0,12 & 12,9 & 28,6 & 3,9 & 9,3 & 13,6 & 2,9 & 31,7 & 8,5 \\
\hline 684 & 181 & 19,5 & 1,5 & 0,80 & 0,42 & 0,20 & 15,6 & 22,6 & 18,5 & 18,1 & 9,5 & 10,9 & 42,7 & 16,6 \\
\hline 687 & 227 & 29,3 & 2,3 & 0,83 & 0,40 & 0,30 & 11,4 & 33,6 & 14,4 & 23,8 & 24,3 & 12,7 & 67,1 & 19,5 \\
\hline 691 & 80 & 7,7 & 2,1 & 0,82 & 0,42 & 0,29 & 10,6 & 31,7 & 4,5 & 8,6 & 14,6 & 3,2 & 29,1 & 7,3 \\
\hline 693 & 267 & 31,7 & 2,3 & 1,36 & 0,43 & 0,19 & 17,4 & 37,5 & 37,0 & 22,9 & 16,0 & 15,1 & 67,8 & 24,1 \\
\hline 695 & 264 & 13,9 & 6,1 & 0,84 & 0,25 & 0,34 & 202,6 & 19,3 & 9,9 & 14,5 & 23,2 & 7,1 & 52,0 & 11,2 \\
\hline 701 & 207 & 28,0 & 1,3 & 0,87 & 0,31 & 0,30 & 13,0 & 27,0 & 37,5 & 27,5 & 20,3 & 16,0 & 75,5 & 22,9 \\
\hline 704 & 243 & 30,9 & 2,9 & 1,34 & 0,36 & 0,38 & 12,0 & 34,5 & 20,7 & 24,2 & 16,6 & 13,0 & 68,5 & 18,4 \\
\hline 708 & 307 & 31,8 & 5,7 & 0,96 & 0,30 & 0,27 & 143,7 & 12,8 & 48,0 & 26,2 & 24,7 & 15,0 & 72,2 & 23,6 \\
\hline 713 & 206 & 13,0 & 5,5 & 0,86 & 0,46 & 0,36 & 108,0 & 14,4 & 10,5 & 15,7 & 20,0 & 7,4 & 102,7 & 7,1 \\
\hline 715 & 224 & 27,4 & 2,0 & 1,41 & 0,68 & 0,34 & 21,3 & 30,6 & 34,7 & 20,5 & 11,8 & 11,4 & 62,0 & 16,6 \\
\hline 720 & 280 & 35,6 & 6,1 & 1,72 & 0,46 & 0,68 & 82,0 & 12,7 & 22,8 & 21,3 & 19,8 & 14,3 & 80,6 & 22,6 \\
\hline 724 & 270 & 28,6 & 2,9 & 2,13 & 0,26 & 0,54 & 73,8 & 27,7 & 23,4 & 17,4 & 11,2 & 12,3 & 58,7 & 13,3 \\
\hline 727 & 497 & 11,5 & 8,9 & 1,41 & 0,12 & 0,34 & 496,2 & 18,7 & 13,3 & 13,0 & 10,5 & 13,5 & 40,4 & 22,6 \\
\hline 729 & 375 & 18,9 & 5,9 & 1,47 & 0,42 & 0,67 & 260,0 & 0,5 & 9,3 & 17,5 & 26,6 & 15,2 & 102,3 & 26,7 \\
\hline 735 & 316 & 26,9 & 7,2 & 2,52 & 0,06 & 0,51 & 212,6 & 15,6 & 24,7 & 22,7 & 11,6 & 13,4 & 70,1 & 19,2 \\
\hline 736 & 304 & 19,9 & 3,0 & 2,14 & 0,27 & 0,50 & 184,0 & 16,4 & 11,8 & 13,7 & 7,1 & 9,9 & 44,1 & 11,7 \\
\hline 744 & 359 & 19,5 & 6,6 & 1,79 & 0,19 & 0,47 & 373,8 & 12,4 & 31,8 & 15,1 & 10,2 & 9,9 & 60,9 & 22,9 \\
\hline 747 & 226 & 31,8 & 5,2 & 3,79 & 0,13 & 1,03 & 13,5 & 13,1 & 51,0 & 20,2 & 20,9 & 15,5 & 98,1 & 15,6 \\
\hline 751 & 111 & 9,4 & 6,4 & 1,07 & 0,04 & 0,33 & 9,0 & 30,6 & 2,6 & 7,8 & 15,8 & 5,9 & 56,2 & 8,5 \\
\hline 755 & 120 & 23,2 & 5,7 & 2,42 & 0,09 & 0,33 & 123,3 & 15,0 & 7,1 & 14,1 & 14,5 & 14,9 & 57,0 & 8,6 \\
\hline 762 & 188 & 4,2 & 2,8 & 0,99 & 0,03 & 0,13 & 153,8 & 24,1 & 4,5 & 4,1 & 16,8 & 3,3 & 21,1 & 7,3 \\
\hline 764,6 & 113 & 6,0 & 5,7 & 0,86 & 0,04 & 0,19 & 32,7 & 10,9 & 10,0 & 7,8 & 17,9 & 2,8 & 24,5 & 11,4 \\
\hline 765,1 & 76 & 6,8 & 41,8 & 1,40 & 0,10 & 0,05 & 45,1 & 0,5 & 15,0 & 1,2 & 3,3 & 1,0 & 10,7 & 4,4 \\
\hline 765 & 198 & 5,1 & 6,4 & 0,29 & 0,15 & 0,21 & 178,9 & 10,6 & 5,9 & 6,4 & 3,6 & 4,3 & 24,4 & 11,2 \\
\hline 766 & 236 & 8,7 & 2,8 & 1,45 & 0,05 & 0,22 & 221,5 & 24,4 & 11,0 & 8,3 & 14,3 & 5,6 & 37,1 & 9,0 \\
\hline 768 & 476 & 1,5 & 6,7 & 0,60 & 0,45 & 0,23 & 521,6 & 29,9 & 6,5 & 1,7 & 10,5 & 0,9 & 47,5 & 2,4 \\
\hline 774 & 262 & 16,6 & 7,6 & 2,14 & 0,04 & 0,87 & 292,3 & 13,3 & 41,8 & 14,3 & 7,5 & 7,3 & 43,5 & 22,4 \\
\hline 782 & 275 & 17,0 & 41,6 & 3,19 & 0,12 & 0,53 & 264,0 & 22,2 & 35,5 & 12,6 & 9,3 & 10,2 & 38,2 & 18,3 \\
\hline 792 & 166 & 10,3 & 49,0 & 0,43 & 0,01 & 0,13 & 134,5 & 6,0 & 15,2 & 10,0 & 5,4 & 4,9 & 22,4 & 19,3 \\
\hline 802 & 261 & 15,4 & 4,9 & 0,96 & 0,02 & 0,35 & 226,9 & 9,5 & 17,0 & 13,6 & 7,2 & 7,2 & 45,6 & 21,2 \\
\hline 813 & 164 & 7,1 & 7,5 & 0,65 & 0,02 & 0,35 & 129,9 & 6,5 & 13,8 & 8,9 & 3,9 & 4,0 & 25,9 & 10,5 \\
\hline 825 & 219 & 7,3 & 7,8 & 0,46 & 0,01 & 0,12 & 159,3 & 6,2 & 18,3 & 7,6 & 5,1 & 5,5 & 27,9 & 18,8 \\
\hline 835 & 175 & 6,5 & 6,9 & 0,88 & 0,01 & 0,28 & 152,8 & 10,4 & 15,2 & 7,3 & 4,1 & 5,2 & 21,8 & 11,0 \\
\hline 844 & 155 & 7,4 & 4,0 & 2,23 & 0,04 & 0,20 & 141,6 & 10,2 & 9,0 & 7,2 & 6,4 & 3,8 & 25,2 & 28,0 \\
\hline 845,7 & 168 & 9,0 & 5,1 & 1,91 & 1,10 & 0,13 & 107,0 & 9,4 & 9,6 & 8,6 & 20,8 & 5,0 & 41,9 & 18,0 \\
\hline 853 & 81 & 4,8 & 1,7 & 3,87 & 1,19 & 0,69 & 49,5 & 2,8 & 10,3 & 6,2 & 6,4 & 2,7 & 19,0 & 20,1 \\
\hline 864 & 57 & 20,9 & 2,5 & 1,65 & 0,05 & 0,94 & 59,2 & 10,2 & 5,8 & 16,9 & 16,6 & 5,4 & 43,4 & 24,7 \\
\hline 868,7 & 84 & 2,2 & 3,3 & 1,64 & 0,10 & 0,03 & 74,6 & 20,3 & 14,9 & 3,5 & 12,5 & 2,5 & 57,1 & 18,4 \\
\hline 873 & 90 & 1,0 & 6,7 & 0,34 & 0,01 & 0,01 & 47,0 & 0,8 & 3,6 & 1,4 & 0,0 & 1,7 & 9,8 & 5,2 \\
\hline
\end{tabular}


Tabla A.III.1. Cont. Filos: Filosilicatos; Feldes: Feldespatos; Esmec: Esmectita; Caol: Caolinita; Sepiol: Sepiolita; Palig: Paligorkita; Vermic: Vermiculita.

\begin{tabular}{|c|c|c|c|c|c|c|c|c|c|c|c|c|c|}
\hline Cota & Cuarzo & Filos & Feldes & Calcita & Dolomita & Yeso & Illita & Clorita & Esmec & Caol & Sepiol & Palig & Vermic \\
\hline$m$ & $\%$ & $\%$ & $\%$ & $\%$ & $\%$ & $\%$ & $\%$ & $\%$ & $\%$ & $\%$ & $\%$ & $\%$ & $\%$ \\
\hline 603 & 62,5 & 31,3 & 6,3 & 0,0 & 0,0 & 0,0 & 22,7 & 8,5 & 0,0 & 0,0 & 0,0 & 0,0 & 0,0 \\
\hline 604 & 75,8 & 21,3 & 2,8 & 0,0 & 0,0 & 0,0 & 12,3 & 9,1 & 0,0 & 0,0 & 0,0 & 0,0 & 0,0 \\
\hline 610 & 46,3 & 37,9 & 15,8 & 0,0 & 0,0 & 0,0 & 23,8 & 0,0 & 0,0 & 2,5 & 0,0 & 0,0 & 11,6 \\
\hline 614 & 64,7 & 23,5 & 11,8 & 0,0 & 0,0 & 0,0 & 16,7 & 4,5 & 0,0 & 2,3 & 0,0 & 0,0 & 0,0 \\
\hline 619 & 81,6 & 12,2 & 6,1 & 0,0 & 0,0 & 0,0 & 10,6 & 0,0 & 1,6 & 0,0 & 0,0 & 0,0 & 0,0 \\
\hline 624 & 47,4 & 32,9 & 11,5 & 8,2 & 0,0 & 0,0 & 29,6 & 0,0 & 3,2 & 0,0 & 0,0 & 0,0 & 0,0 \\
\hline 630 & 57,1 & 28,6 & 14,3 & 0,0 & 0,0 & 0,0 & 19,9 & 0,0 & 8,6 & 0,0 & 0,0 & 0,0 & 0,0 \\
\hline 635 & 42,3 & 46,2 & 11,5 & 0,0 & 0,0 & 0,0 & 29,8 & 16,3 & 0,0 & 0,0 & 0,0 & 0,0 & 0,0 \\
\hline 641 & 80,6 & 9,7 & 9,7 & 0,0 & 0,0 & 0,0 & 7,2 & 0,0 & 0,0 & 0,5 & 0,0 & 0,0 & 2,0 \\
\hline 644 & 86,7 & 8,9 & 4,4 & 0,0 & 0,0 & 0,0 & 8,2 & 0,0 & 0,7 & 0,0 & 0,0 & 0,0 & 0,0 \\
\hline 647 & 48,5 & 48,5 & 2,9 & 0,0 & 0,0 & 0,0 & 37,2 & 0,0 & 11,3 & 0,0 & 0,0 & 0,0 & 0,0 \\
\hline 651 & 70,6 & 21,2 & 7,9 & 0,3 & 0,0 & 0,0 & 17,7 & 0,0 & 0,0 & 1,1 & 0,0 & 0,0 & 2,4 \\
\hline 655 & 79,5 & 12,3 & 8,2 & 0,0 & 0,0 & 0,0 & 10,4 & 0,0 & 1,9 & 0,0 & 0,0 & 0,0 & 0,0 \\
\hline 659 & 71,6 & 19,2 & 9,2 & 0,0 & 0,0 & 0,0 & 10,9 & 7,2 & 0,0 & 1,1 & 0,0 & 0,0 & 0,0 \\
\hline 664 & 24,7 & 71,3 & 4,0 & 0,0 & 0,0 & 0,0 & 44,8 & 26,5 & 0,0 & 0,0 & 0,0 & 0,0 & 0,0 \\
\hline 668 & 53,3 & 33,3 & 13,3 & 0,0 & 0,0 & 0,0 & 28,3 & 0,0 & 5,1 & 0,0 & 0,0 & 0,0 & 0,0 \\
\hline 672 & 71,4 & 19,0 & 9,5 & 0,0 & 0,0 & 0,0 & 15,4 & 0,0 & 3,7 & 0,0 & 0,0 & 0,0 & 0,0 \\
\hline 679 & 76,6 & 10,8 & 12,6 & 0,0 & 0,0 & 0,0 & 7,1 & 0,0 & 0,0 & 0,0 & 0,0 & 0,0 & 3,7 \\
\hline 684 & 55,0 & 37,5 & 7,5 & 0,0 & 0,0 & 0,0 & 25,0 & 12,5 & 0,0 & 0,0 & 0,0 & 0,0 & 0,0 \\
\hline 687 & 46,4 & 42,9 & 10,7 & 0,0 & 0,0 & 0,0 & 30,0 & 12,9 & 0,0 & 0,0 & 0,0 & 0,0 & 0,0 \\
\hline 691 & 59,2 & 16,0 & 24,0 & 0,4 & 0,4 & 0,0 & 10,5 & 0,0 & 0,0 & 0,0 & 0,0 & 0,0 & 5,5 \\
\hline 693 & 33,3 & 55,6 & 11,1 & 0,0 & 0,0 & 0,0 & 30,1 & 25,5 & 0,0 & 0,0 & 0,0 & 0,0 & 0,0 \\
\hline 695 & 27,2 & 55,7 & 5,9 & 11,1 & 0,0 & 0,0 & 46,3 & 0,0 & 9,4 & 0,0 & 0,0 & 0,0 & 0,0 \\
\hline 701 & 37,7 & 56,6 & 5,7 & 0,0 & 0,0 & 0,0 & 47,5 & 0,0 & 9,1 & 0,0 & 0,0 & 0,0 & 0,0 \\
\hline 704 & 19,5 & 76,8 & 3,7 & 0,0 & 0,0 & 0,0 & 57,1 & 0,0 & 5,3 & 14,4 & 0,0 & 0,0 & 0,0 \\
\hline 708 & 30,5 & 61,0 & 4,3 & 4,0 & 0,3 & 0,0 & 44,6 & 9,6 & 6,8 & 0,0 & 0,0 & 0,0 & 0,0 \\
\hline 713 & 43,6 & 36,4 & 20,0 & 0,0 & 0,0 & 0,0 & 34,6 & 0,0 & 1,8 & 0,0 & 0,0 & 0,0 & 0,0 \\
\hline 715 & 27,0 & 67,6 & 5,4 & 0,0 & 0,0 & 0,0 & 62,3 & 0,0 & 5,3 & 0,0 & 0,0 & 0,0 & 0,0 \\
\hline 720 & 9,5 & 71,1 & 2,4 & 14,2 & 2,8 & 0,0 & 65,9 & 0,0 & 5,2 & 0,0 & 0,0 & 0,0 & 0,0 \\
\hline 724 & 13,0 & 76,8 & 1,0 & 9,1 & 0,0 & 0,0 & 72,3 & 0,0 & 4,5 & 0,0 & 0,0 & 0,0 & 0,0 \\
\hline 727 & 6,0 & 63,1 & 0,0 & 28,0 & 2,9 & 0,0 & 33,4 & 29,6 & 0,0 & 0,0 & 0,0 & 0,0 & 0,0 \\
\hline 729 & 4,0 & 59,5 & 0,4 & 36,1 & 0,0 & 0,0 & 46,9 & 0,0 & 12,6 & 0,0 & 0,0 & 0,0 & 0,0 \\
\hline 735 & 7,7 & 59,5 & 5,0 & 27,2 & 0,7 & 0,0 & 35,1 & 0,0 & 24,4 & 0,0 & 0,0 & 0,0 & 0,0 \\
\hline 736 & 3,4 & 67,6 & 0,3 & 28,7 & 0,0 & 0,0 & 60,5 & 0,0 & 7,1 & 0,0 & 0,0 & 0,0 & 0,0 \\
\hline 744 & 11,5 & 67,9 & 0,0 & 20,4 & 0,1 & 0,0 & 65,2 & 0,0 & 0,0 & 0,0 & 0,0 & 0,0 & 2,7 \\
\hline 747 & 6,8 & 89,1 & 0,8 & 3,3 & 0,0 & 0,0 & 83,6 & 0,0 & 5,5 & 0,0 & 0,0 & 0,0 & 0,0 \\
\hline 751 & 47,8 & 40,5 & 4,0 & 6,1 & 1,6 & 0,0 & 23,0 & 17,5 & 0,0 & 0,0 & 0,0 & 0,0 & 0,0 \\
\hline 755 & 16,7 & 60,0 & 6,3 & 8,8 & 8,3 & 0,0 & 24,0 & 0,0 & 0,0 & 0,0 & 0,0 & 0,0 & 36,0 \\
\hline 762 & 2,8 & 20,7 & 0,5 & 0,0 & 76,0 & 0,0 & 0,0 & 0,0 & 0,0 & 0,0 & 7,6 & 13,0 & 0,0 \\
\hline 764,6 & 2,6 & 22,3 & 0,0 & 75,1 & 0,0 & 0,0 & 4,3 & 0,0 & 0,0 & 0,0 & 6,1 & 11,9 & 0,0 \\
\hline 765,1 & 0,1 & 0,8 & 0,0 & 20,9 & 64,5 & 13,7 & 0,4 & 0,0 & 0,0 & 0,0 & 0,0 & 0,0 & 0,3 \\
\hline 765 & 3,6 & 45,0 & 1,8 & 49,5 & 0,0 & 0,0 & 9,5 & 0,0 & 0,0 & 0,0 & 35,6 & 0,0 & 0,0 \\
\hline 766 & 2,5 & 23,2 & 0,0 & 0,0 & 74,3 & 0,0 & 6,7 & 0,0 & 0,0 & 0,6 & 3,7 & 12,2 & 0,0 \\
\hline 768 & 0,8 & 7,6 & 0,0 & 91,6 & 0,0 & 0,0 & 5,1 & 2,5 & 0,0 & 0,0 & 0,0 & 0,0 & 0,0 \\
\hline 774 & 3,1 & 94,0 & 0,0 & 1,3 & 0,9 & 0,6 & 61,1 & 0,0 & 0,0 & 0,0 & 0,0 & 0,0 & 32,9 \\
\hline 782 & 2,0 & 71,1 & 0,0 & 0,0 & 13,9 & 13,0 & 60,5 & 0,0 & 0,0 & 10,7 & 0,0 & 0,0 & 0,0 \\
\hline 792 & 1,4 & 56,4 & 0,0 & 6,5 & 12,5 & 23,2 & 32,1 & 0,0 & 24,2 & 0,0 & 0,0 & 0,0 & 0,0 \\
\hline 802 & 1,0 & 47,6 & 0,0 & 5,6 & 30,6 & 15,3 & 27,6 & 0,0 & 0,0 & 0,0 & 0,0 & 0,0 & 20,0 \\
\hline 813 & 1,7 & 45,8 & 0,0 & 32,1 & 20,4 & 0,0 & 14,2 & 31,6 & 0,0 & 0,0 & 0,0 & 0,0 & 0,0 \\
\hline 825 & 1,5 & 41,9 & 0,0 & 34,6 & 22,0 & 0,0 & 18,0 & 0,0 & 0,0 & 0,0 & 0,0 & 0,0 & 23,9 \\
\hline 835 & 0,1 & 48,2 & 0,0 & 31,7 & 19,6 & 0,5 & 14,9 & 0,0 & 0,0 & 0,0 & 0,0 & 0,0 & 33,2 \\
\hline 844 & 1,2 & 55,6 & 0,0 & 0,9 & 42,2 & 0,0 & 34,5 & 0,0 & 0,0 & 1,1 & 20,0 & 0,0 & 0,0 \\
\hline 845,7 & 2,9 & 31,1 & 0,0 & 2,5 & 63,5 & 0,0 & 5,0 & 0,0 & 0,0 & 0,0 & 9,0 & 17,1 & 0,0 \\
\hline 853 & 6,8 & 34,9 & 0,0 & 0,0 & 58,3 & 0,0 & 5,2 & 0,0 & 0,0 & 0,0 & 15,0 & 14,3 & 0,0 \\
\hline 864 & 15,8 & 80,9 & 0,0 & 0,0 & 3,2 & 0,0 & 27,5 & 0,0 & 0,0 & 0,8 & 52,6 & 0,0 & 0,0 \\
\hline
\end{tabular}




\begin{tabular}{|l|l|l|l|l|l|l|l|l|l|l|l|l|l|}
\hline Cota & Cuarzo & Filos & Feldes & Calcita & Dolomita & Yeso & Illita & Clorita & Esmec & Caol & Sepiol & Palig & Vermic \\
\hline$m$ & $\%$ & $\%$ & $\%$ & $\%$ & $\%$ & $\%$ & $\%$ & $\%$ & $\%$ & $\%$ & $\%$ & $\%$ & $\%$ \\
\hline 868,7 & 0,9 & 23,6 & 0,0 & 0,0 & 75,5 & 0,0 & 0,0 & 0,0 & 0,0 & 0,0 & 7,6 & 16,0 & 0,0 \\
\hline 873 & 2,3 & 11,6 & 0,0 & 54,1 & 32,0 & 0,0 & 0,0 & 0,0 & 0,0 & 0,0 & 0,0 & 11,6 & 0,0 \\
\hline
\end{tabular}

Tabla A.III.2. Matriz de correlación de los parámetros investigados. En la diagonal superior se presentan las correlaciones de Spearman y en la diagonal inferior las de Pearson.

\begin{tabular}{|c|c|c|c|c|c|c|c|c|c|c|c|c|}
\hline & Fe tot & $\mathrm{Cr}$ & $\mathrm{Pb}$ & As & V & Esmectita & Mg extr & K extr & Filosilicatos & Illita & C.I.C & $\mathrm{K}$ tot \\
\hline Fe tot & & 0,94 & 0,89 & 0,58 & 0,57 & 0,52 & 0,27 & 0,57 & 0,68 & 0,82 & 0,80 & 0,74 \\
\hline $\mathrm{Cr}$ & 0,93 & & 0,84 & 0,58 & 0,56 & 0,54 & 0,14 & 0,41 & 0,60 & 0,76 & 0,68 & 0,63 \\
\hline $\mathrm{Pb}$ & 0,87 & 0,84 & & 0,63 & 0,58 & 0,48 & 0,31 & 0,44 & 0,63 & 0,76 & 0,73 & 0,68 \\
\hline As & 0,66 & 0,50 & 0,61 & & 0,60 & 0,33 & 0,50 & 0,48 & 0,60 & 0,60 & 0,52 & 0,58 \\
\hline V & 0,55 & 0,58 & 0,57 & 0,53 & & 0,24 & 0,36 & 0,43 & 0,63 & 0,55 & 0,41 & 0,42 \\
\hline Esmectita & 0,37 & 0,41 & 0,36 & 0,25 & 0,29 & & 0,10 & 0,18 & 0,30 & 0,36 & 0,53 & 0,42 \\
\hline Mg extr & 0,31 & 0,13 & 0,27 & 0,48 & 0,38 & 0,07 & & 0,63 & 0,59 & 0,37 & 0,36 & 0,55 \\
\hline K extr & 0,50 & 0,50 & 0,56 & 0,48 & 0,43 & 0,29 & 0,70 & & 0,73 & 0,67 & 0,54 & 0,70 \\
\hline Filosilicatos & 0,67 & 0,61 & 0,62 & 0,63 & 0,62 & 0,31 & 0,56 & 0,73 & & 0,86 & 0,72 & 0,77 \\
\hline Illita & 0,76 & 0,69 & 0,69 & 0,68 & 0,49 & 0,53 & 0,47 & 0,66 & 0,87 & & 0,75 & 0,85 \\
\hline C.I.C & 0,80 & 0,70 & 0,75 & 0,56 & 0,49 & 0,54 & 0,31 & 0,58 & 0,73 & 0,78 & & 0,85 \\
\hline $\mathrm{K}$ tot & 0,82 & 0,75 & 0,79 & 0,62 & 0,56 & 0,48 & 0,54 & 0,80 & 0,83 & 0,86 & 0,82 & \\
\hline $\mathrm{pH}$ & $-0,13$ & $-0,02$ & $-0,18$ & $-0,40$ & $-0,16$ & $-0,07$ & $-0,67$ & $-0,54$ & $-0,54$ & $-0,32$ & $-0,40$ & $-0,52$ \\
\hline Cuarzo & $-0,03$ & 0,13 & $-0,04$ & $-0,31$ & $-0,29$ & 0,16 & $-0,60$ & $-0,37$ & $-0,32$ & $-0,01$ & $-0,19$ & $-0,34$ \\
\hline Arenas & $-0,03$ & 0,09 & $-0,11$ & $-0,39$ & $-0,38$ & 0,18 & $-0,52$ & $-0,26$ & $-0,36$ & $-0,07$ & $-0,11$ & $-0,27$ \\
\hline Feldespato & 0,12 & 0,25 & 0,05 & $-0,23$ & $-0,23$ & 0,20 & $-0,43$ & $-0,25$ & $-0,32$ & 0,06 & $-0,05$ & $-0,17$ \\
\hline $\mathrm{Na}$ extr & 0,09 & 0,30 & 0,13 & $-0,19$ & 0,00 & 0,13 & $-0,30$ & $-0,13$ & $-0,25$ & 0,00 & $-0,09$ & $-0,20$ \\
\hline $\mathrm{Cu}$ & 0,44 & 0,49 & 0,43 & 0,19 & 0,23 & 0,26 & 0,08 & 0,24 & 0,16 & 0,27 & 0,18 & 0,21 \\
\hline $\mathrm{Zn}$ & 0,71 & 0,71 & 0,73 & 0,49 & 0,44 & 0,43 & 0,29 & 0,49 & 0,50 & 0,65 & 0,57 & 0,63 \\
\hline $\mathrm{Na}$ tot & $-0,07$ & 0,00 & 0,00 & 0,00 & 0,04 & 0,03 & $-0,09$ & 0,05 & $-0,21$ & $-0,11$ & $-0,21$ & $-0,17$ \\
\hline Fe extr & 0,24 & 0,32 & 0,19 & $-0,03$ & $-0,13$ & $-0,02$ & $-0,23$ & $-0,18$ & 0,04 & 0,20 & $-0,02$ & $-0,01$ \\
\hline Clorita & 0,07 & 0,14 & 0,16 & 0,01 & 0,08 & $-0,33$ & $-0,15$ & $-0,11$ & 0,13 & 0,00 & 0,03 & $-0,09$ \\
\hline Caolinita & 0,19 & 0,17 & 0,13 & 0,14 & 0,09 & $-0,03$ & 0,18 & 0,10 & 0,23 & 0,25 & 0,11 & 0,18 \\
\hline Ca extr & $-0,10$ & $-0,16$ & 0,09 & 0,37 & 0,14 & $-0,02$ & 0,40 & 0,30 & 0,30 & 0,15 & 0,05 & $-0,03$ \\
\hline Yeso & $-0,08$ & $-0,15$ & $-0,12$ & 0,12 & 0,07 & $-0,09$ & 0,08 & $-0,06$ & 0,04 & 0,08 & 0,01 & $-0,01$ \\
\hline C.E & 0,17 & 0,02 & 0,25 & 0,44 & 0,17 & 0,15 & 0,43 & 0,42 & 0,27 & 0,21 & 0,23 & 0,31 \\
\hline $\mathrm{Mn}$ tot & 0,55 & 0,50 & 0,67 & 0,63 & 0,49 & 0,37 & 0,40 & 0,56 & 0,58 & 0,63 & 0,37 & 0,55 \\
\hline Mn extr & $-0,11$ & $-0,13$ & 0,13 & 0,37 & 0,29 & 0,05 & 0,27 & 0,24 & 0,34 & 0,18 & $-0,01$ & 0,22 \\
\hline M.O & $-0,21$ & $-0,22$ & $-0,19$ & $-0,11$ & $-0,06$ & $-0,30$ & 0,14 & $-0,17$ & $-0,26$ & $-0,42$ & $-0,27$ & $-0,26$ \\
\hline Calcita & $-0,29$ & $-0,36$ & $-0,21$ & $-0,11$ & $-0,21$ & 0,03 & $-0,03$ & $-0,02$ & $-0,10$ & 0,05 & $-0,08$ & $-0,01$ \\
\hline $\mathrm{Mg}$ tot & $-0,09$ & $-0,24$ & $-0,01$ & 0,38 & 0,36 & $-0,19$ & 0,72 & 0,29 & 0,38 & 0,02 & $-0,24$ & 0,21 \\
\hline Dolomita & $-0,43$ & $-0,53$ & $-0,41$ & $-0,12$ & $-0,04$ & $-0,35$ & 0,30 & $-0,20$ & $-0,26$ & $-0,26$ & $-0,43$ & $-0,32$ \\
\hline Paligorkita & $-0,40$ & $-0,43$ & $-0,36$ & $-0,17$ & $-0,08$ & $-0,19$ & 0,24 & $-0,17$ & $-0,29$ & $-0,44$ & $-0,46$ & $-0,30$ \\
\hline Carbonato & $-0,37$ & $-0,46$ & $-0,22$ & 0,18 & 0,09 & $-0,23$ & 0,57 & 0,24 & 0,18 & $-0,11$ & $-0,12$ & 0,05 \\
\hline Limos & 0,13 & 0,03 & 0,23 & 0,43 & 0,41 & $-0,06$ & 0,54 & 0,28 & 0,41 & 0,17 & 0,22 & 0,32 \\
\hline $\mathrm{P}$ & $-0,19$ & $-0,24$ & $-0,10$ & 0,24 & 0,20 & $-0,20$ & 0,32 & 0,20 & 0,27 & 0,03 & 0,01 & 0,02 \\
\hline Vermiculita & $-0,03$ & $-0,08$ & 0,02 & 0,11 & 0,02 & $-0,19$ & 0,10 & 0,13 & 0,20 & 0,01 & 0,14 & 0,07 \\
\hline Arcilla & $-0,07$ & $-0,13$ & $-0,05$ & 0,21 & 0,16 & $-0,23$ & 0,16 & 0,07 & 0,11 & $-0,07$ & $-0,10$ & 0,07 \\
\hline Sepiolita & $-0,14$ & $-0,15$ & $-0,24$ & $-0,19$ & 0,21 & $-0,16$ & 0,18 & 0,26 & 0,14 & $-0,16$ & $-0,16$ & $-0,13$ \\
\hline
\end{tabular}


Tabla A.III.2. Continuación. Felde:Feldespatos; Caolini:Caolinita.

\begin{tabular}{|c|c|c|c|c|c|c|c|c|c|c|c|c|c|c|}
\hline & $\mathrm{pH}$ & Cuarzo & Arenas & Felde & $\begin{array}{l}\mathrm{Na} \\
\text { ex }\end{array}$ & $\mathrm{Cu}$ & $\mathrm{Zn}$ & $\begin{array}{l}\mathrm{Na} \\
\text { tot }\end{array}$ & $\begin{array}{l}\mathrm{Fe} \\
\text { extr }\end{array}$ & Clorita & Caolin & $\begin{array}{l}\mathrm{Ca} \\
\mathrm{ex}\end{array}$ & Yeso & C.E \\
\hline Fe tot & $-0,14$ & 0,22 & $-0,10$ & 0,29 & 0,22 & 0,42 & 0,74 & 0,01 & 0,27 & 0,10 & $-0,02$ & $-0,05$ & $-0,09$ & $-0,04$ \\
\hline $\mathrm{Cr}$ & 0,01 & 0,33 & 0,02 & 0,41 & 0,17 & 0,49 & 0,75 & 0,07 & 0,29 & 0,12 & $-0,01$ & $-0,21$ & $-0,18$ & $-0,18$ \\
\hline $\mathrm{Pb}$ & $-0,15$ & 0,16 & $-0,12$ & 0,24 & 0,05 & 0,47 & 0,74 & 0,04 & 0,17 & 0,12 & $-0,11$ & $-0,09$ & $-0,09$ & $-0,02$ \\
\hline As & $-0,29$ & $-0,35$ & $-0,29$ & $-0,28$ & $-0,19$ & 0,14 & 0,48 & $-0,04$ & $-0,01$ & $-0,03$ & $-0,21$ & 0,18 & 0,33 & 0,21 \\
\hline V & $-0,14$ & $-0,18$ & $-0,38$ & $-0,21$ & 0,04 & 0,23 & 0,42 & 0,04 & $-0,13$ & 0,02 & $-0,01$ & 0,02 & 0,06 & 0,06 \\
\hline Esmectita & $-0,19$ & $-0,12$ & 0,07 & $-0,05$ & $-0,06$ & 0,13 & 0,32 & $-0,01$ & $-0,11$ & $-0,22$ & $-0,23$ & 0,29 & 0,29 & 0,08 \\
\hline Mg extr & $-0,58$ & $-0,61$ & $-0,42$ & $-0,54$ & $-0,46$ & 0,12 & 0,30 & $-0,06$ & $-0,21$ & $-0,24$ & $-0,07$ & 0,19 & 0,19 & 0,60 \\
\hline K extr & 0,50 & $-0,22$ & $-0,20$ & $-0,18$ & $-0,18$ & 0,29 & 0,54 & 0,01 & $-0,01$ & $-0,08$ & $-0,05$ & $-0,01$ & 0,07 & 0,32 \\
\hline Filosilicatos & $-0,52$ & $-0,49$ & $-0,36$ & $-0,26$ & $-0,27$ & 0,17 & 0,50 & $-0,20$ & 0,01 & 0,02 & 0,01 & 0,08 & 0,15 & 0,12 \\
\hline Illita & $-0,35$ & $-0,24$ & $-0,09$ & $-0,13$ & $-0,13$ & 0,26 & 0,62 & $-0,08$ & 0,13 & 0,02 & 0,00 & 0,07 & 0,03 & 0,08 \\
\hline C.I.C & $-0,38$ & $-0,03$ & $-0,14$ & 0,09 & $-0,07$ & 0,15 & 0,57 & $-0,26$ & 0,00 & $-0,01$ & $-0,12$ & 0,22 & 0,02 & 0,03 \\
\hline $\mathrm{K}$ tot & $-0,50$ & $-0,14$ & $-0,20$ & $-0,03$ & $-0,13$ & 0,28 & 0,66 & $-0,19$ & 0,04 & $-0,06$ & $-0,08$ & 0,25 & 0,06 & 0,05 \\
\hline $\mathrm{pH}$ & & 0,65 & 0,48 & 0,54 & 0,67 & 0,09 & $-0,12$ & 0,29 & 0,23 & 0,23 & 0,18 & $-0,50$ & $-0,37$ & $-0,51$ \\
\hline Cuarzo & 0,73 & & 0,71 & 0,83 & 0,54 & 0,11 & $-0,06$ & 0,15 & 0,38 & 0,17 & 0,09 & $-0,37$ & $-0,46$ & $-0,38$ \\
\hline Arenas & 0,50 & 0,70 & & 0,60 & 0,45 & 0,11 & 0,04 & 0,08 & 0,29 & 0,20 & 0,03 & $-0,42$ & $-0,31$ & $-0,23$ \\
\hline Feldespatos & 0,49 & 0,69 & 0,54 & & 0,41 & 0,26 & 0,17 & 0,16 & 0,46 & 0,14 & 0,05 & $-0,30$ & $-0,40$ & $-0,34$ \\
\hline $\mathrm{Na}$ extr & 0,67 & 0,67 & 0,29 & 0,59 & & 0,24 & 0,19 & 0,40 & 0,32 & 0,16 & 0,10 & $-0,29$ & $-0,40$ & $-0,05$ \\
\hline $\mathrm{Cu}$ & 0,09 & 0,22 & & 0,32 & 0,16 & & 0,71 & & 0,34 & 0,07 & 0,01 & & $-0,33$ & $-0,16$ \\
\hline $\mathrm{Zn}$ & $-0,14$ & 0,10 & 0,06 & 0,27 & 0,06 & 0,72 & & 0,32 & 0,21 & 0,07 & $-0,06$ & $-0,19$ & $-0,24$ & $-0,11$ \\
\hline $\mathrm{Na}$ tot & 0,29 & 0,10 & 0,12 & 0,14 & 0,32 & 0,61 & 0,28 & & 0,28 & 0,00 & $-0,05$ & $-0,05$ & $-0,12$ & 0,03 \\
\hline Fe extr & 0,22 & 0,42 & 0,26 & 0,53 & 0,19 & 0,38 & 0,36 & 0,28 & & 0,36 & 0,19 & $-0,31$ & $-0,30$ & $-0,33$ \\
\hline Clorita & 0,06 & 0,04 & 0,10 & 0,02 & 0,02 & $-0,01$ & 0,00 & $-0,11$ & 0,27 & & $-0,08$ & $-0,08$ & $-0,13$ & $-0,19$ \\
\hline Caoli & $-0,04$ & $-0,07$ & $-0,03$ & $-0,04$ & $-0,02$ & 0,02 & 0,06 & $-0,12$ & 0,22 & $-0,11$ & & 0,24 & 0,17 & 0,18 \\
\hline Ca extr & $-0,37$ & $-0,69$ & $-0,17$ & $-0,57$ & $-0,56$ & $-0,07$ & 0,08 & $-0,17$ & $-0,43$ & $-0,04$ & $-0,19$ & & 0,43 & 0,59 \\
\hline Yeso & $-0,34$ & $-0,27$ & $-0,17$ & $-0,24$ & $-0,25$ & $-0,26$ & $-0,21$ & $-0,18$ & $-0,25$ & $-0,19$ & 0,01 & 0,85 & & 0,51 \\
\hline C.E & $-0,39$ & $-0,41$ & $-0,35$ & $-0,47$ & $-0,19$ & 0,09 & 0,13 & 0,14 & $-0,28$ & $-0,21$ & $-0,16$ & 0,43 & 0,41 & \\
\hline & $-0,32$ & $-0,33$ & $-0,33$ & $-0,20$ & & & & 0,00 & 0,05 & 0,07 & $-0,17$ & 0,43 & 0,06 & 0,03 \\
\hline Mn ex & $-0,38$ & $-0,67$ & $-0,39$ & $-0,62$ & $-0,32$ & $-0,14$ & 0,04 & $-0,09$ & $-0,39$ & $-0,19$ & $-0,13$ & 0,23 & 0,31 & 0,16 \\
\hline M.O & $-0,11$ & $-0,22$ & $-0,15$ & $-0,15$ & $-0,15$ & 0,08 & $-0,06$ & 0,11 & $-0,17$ & 0,00 & $-0,06$ & 0,04 & $-0,09$ & 0,05 \\
\hline Calcita & $-0,35$ & $-0,48$ & $-0,23$ & $-0,40$ & $-0,33$ & $-0,19$ & $-0,13$ & $-0,16$ & $-0,32$ & $-0,09$ & $-0,32$ & 0,12 & 0,17 & 0,06 \\
\hline $\mathrm{Mg}$ tot & $-0,40$ & $-0,86$ & $-0,62$ & $-0,79$ & $-0,62$ & $-0,14$ & $-0,09$ & $-0,06$ & $-0,47$ & $-0,20$ & $-0,05$ & 0,59 & 0,38 & 0,35 \\
\hline Dolomita & $-0,16$ & $-0,48$ & $-0,45$ & $-0,43$ & $-0,19$ & $-0,17$ & $-0,33$ & 0,15 & $-0,30$ & $-0,17$ & 0,00 & 0,20 & 0,40 & 0,30 \\
\hline Paligorkita & $-0,04$ & $-0,35$ & $-0,30$ & $-0,32$ & $-0,01$ & 0,03 & $-0,23$ & 0,27 & $-0,20$ & $-0,17$ & $-0,08$ & $-0,08$ & $-0,10$ & 0,18 \\
\hline Carbonato & $-0,42$ & $-0,81$ & $-0,60$ & $-0,76$ & $-0,70$ & $-0,24$ & $-0,23$ & $-0,09$ & $-0,59$ & $-0,23$ & $-0,18$ & 0,74 & 0,36 & 0,36 \\
\hline Limos & $-0,49$ & $-0,61$ & $-0,85$ & $-0,44$ & $-0,36$ & $-0,03$ & 0,07 & $-0,06$ & $-0,18$ & $-0,18$ & $-0,08$ & 0,33 & 0,21 & 0,35 \\
\hline $\mathrm{P}$ & $-0,31$ & $-0,50$ & $-0,43$ & $-0,59$ & $-0,56$ & $-0,19$ & $-0,19$ & $-0,10$ & $-0,32$ & $-0,02$ & $-0,18$ & 0,59 & 0,28 & 0,05 \\
\hline & $-0,26$ & $-0,21$ & $-0,33$ & $-0,09$ & $-0,23$ & $-0,22$ & $-0,09$ & $-0,25$ & $-0,19$ & $-0,17$ & $-0,07$ & 0,00 & 0,07 & 0,11 \\
\hline Arcilla & $-0,26$ & $-0,41$ & $-0,70$ & $-0,44$ & $-0,27$ & $-0,11$ & $-0,11$ & $-0,01$ & $-0,14$ & $-0,07$ & 0,03 & 0,25 & 0,18 & $-0,05$ \\
\hline Sepiolita & $-0,19$ & $-0,25$ & $-0,36$ & $-0,25$ & $-0,14$ & $-0,05$ & $-0,18$ & $-0,10$ & $-0,23$ & $-0,15$ & $-0,03$ & $-0,08$ & $-0,08$ & 0,01 \\
\hline
\end{tabular}


Tabla A.III.2. Cont. Sepiol: Sepiolita; Palig: Paligorkita; Vermic: Vermiculita; Carb. : Carbonatos.

\begin{tabular}{|c|c|c|c|c|c|c|c|c|c|c|c|c|c|}
\hline & $\begin{array}{l}\mathrm{Mn} \\
\text { tot }\end{array}$ & $\begin{array}{l}\text { Mn } \\
\text { extr }\end{array}$ & M.O & Calcita & $\begin{array}{l}\mathrm{Mg} \\
\text { tot }\end{array}$ & Dolomita & Palig & Carb. & Limos & $\begin{array}{l}\text { P } \\
\text { extr }\end{array}$ & Vermic & Arcilla & Sepiol \\
\hline Fe tot & 0,40 & $-0,02$ & $-0,30$ & $-0,18$ & $-0,32$ & $-0,35$ & $-0,46$ & $-0,41$ & 0,18 & $-0,06$ & $-0,16$ & $-0,07$ & $-0,39$ \\
\hline $\mathrm{Cr}$ & 0,36 & $-0,14$ & $-0,33$ & $-0,26$ & $-0,43$ & $-0,47$ & $-0,46$ & $-0,48$ & 0,08 & $-0,07$ & $-0,18$ & $-0,14$ & $-0,41$ \\
\hline $\mathrm{Pb}$ & 0,54 & 0,08 & $-0,30$ & $-0,06$ & $-0,29$ & $-0,29$ & $-0,42$ & $-0,29$ & 0,24 & $-0,07$ & $-0,13$ & $-0,11$ & $-0,40$ \\
\hline As & 0,46 & 0,17 & $-0,14$ & 0,12 & 0,05 & 0,11 & $-0,14$ & 0,00 & 0,34 & 0,28 & $-0,02$ & 0,07 & $-0,19$ \\
\hline V & 0,41 & 0,19 & $-0,22$ & $-0,03$ & 0,21 & 0,10 & $-0,10$ & 0,12 & 0,40 & 0,24 & $-0,12$ & 0,17 & 0,13 \\
\hline Esmectita & 0,29 & 0,09 & $-0,17$ & 0,01 & $-0,16$ & $-0,21$ & $-0,28$ & $-0,16$ & 0,07 & $-0,13$ & $-0,38$ & $-0,23$ & $-0,32$ \\
\hline Mg extr & 0,27 & 0,47 & 0,01 & 0,30 & 0,49 & 0,52 & 0,25 & 0,35 & 0,49 & 0,19 & 0,01 & 0,11 & 0,31 \\
\hline K extr & 0,34 & 0,36 & $-0,17$ & 0,21 & 0,11 & 0,02 & $-0,23$ & 0,06 & 0,17 & 0,40 & $-0,05$ & 0,13 & $-0,05$ \\
\hline Filosilicatos & 0,47 & 0,26 & $-0,30$ & 0,18 & 0,08 & 0,05 & $-0,29$ & 0,08 & 0,38 & 0,39 & $-0,06$ & 0,15 & $-0,07$ \\
\hline Illita & 0,51 & 0,18 & $-0,35$ & $-0,17$ & $-0,19$ & $-0,42$ & $-0,55$ & $-0,17$ & 0,16 & 0,16 & $-0,10$ & $-0,05$ & $-0,40$ \\
\hline C.I.C & 0,53 & 0,12 & $-0,31$ & 0,17 & 0,09 & $-0,21$ & $-0,51$ & $-0,19$ & 0,26 & 0,06 & $-0,03$ & $-0,06$ & $-0,39$ \\
\hline $\mathrm{K}$ tot & 0,69 & 0,28 & $-0,24$ & 0,17 & $-0,10$ & $-0,14$ & $-0,36$ & $-0,08$ & 0,22 & 0,11 & $-0,08$ & 0,07 & $-0,25$ \\
\hline $\mathrm{pH}$ & $-0,37$ & $-0,46$ & $-0,02$ & $-0,48$ & $-0,60$ & $-0,36$ & 0,00 & $-0,54$ & $-0,48$ & $-0,40$ & $-0,12$ & $-0,17$ & $-0,11$ \\
\hline Cuarzo & $-0,44$ & $-0,56$ & $-0,26$ & $-0,60$ & $-0,70$ & $-0,69$ & $-0,36$ & $-0,69$ & $-0,66$ & $-0,33$ & $-0,09$ & $-0,43$ & $-0,37$ \\
\hline Arenas & $-0,38$ & $-0,55$ & $-0,18$ & $-0,30$ & $-0,77$ & $-0,50$ & $-0,30$ & $-0,61$ & $-0,85$ & $-0,40$ & $-0,10$ & $-0,70$ & $-0,47$ \\
\hline Feldespato & $-0,29$ & $-0,47$ & $-0,22$ & $-0,52$ & $-0,61$ & $-0,67$ & $-0,40$ & $-0,58$ & $-0,41$ & $-0,33$ & $-0,01$ & $-0,45$ & $-0,42$ \\
\hline Na extr & $-0,14$ & $-0,43$ & $-0,10$ & $-0,52$ & $-0,38$ & $-0,60$ & $-0,15$ & $-0,44$ & $-0,20$ & $-0,33$ & $-0,21$ & $-0,26$ & $-0,19$ \\
\hline $\mathrm{Cu}$ & 0,17 & $-0,10$ & 0,12 & $-0,13$ & $-0,22$ & $-0,25$ & 0,05 & $-0,47$ & $-0,04$ & $-0,23$ & $-0,25$ & $-0,16$ & 0,01 \\
\hline Zn & 0,47 & 0,07 & $-0,14$ & $-0,01$ & $-0,27$ & $-0,31$ & $-0,28$ & $-0,39$ & 0,07 & $-0,13$ & $-0,13$ & $-0,21$ & $-0,29$ \\
\hline $\mathrm{Na}$ tot & 0,04 & $-0,07$ & 0,18 & $-0,22$ & $-0,02$ & $-0,03$ & 0,27 & $-0,26$ & $-0,05$ & $-0,23$ & $-0,19$ & $-0,16$ & 0,16 \\
\hline Fe extr & 0,00 & $-0,22$ & $-0,07$ & $-0,47$ & $-0,43$ & $-0,46$ & $-0,20$ & $-0,58$ & $-0,20$ & $-0,27$ & $-0,14$ & $-0,22$ & $-0,26$ \\
\hline Clorita & 0,15 & 0,03 & $-0,13$ & $-0,01$ & $-0,14$ & $-0,16$ & $-0,21$ & $-0,02$ & $-0,09$ & $-0,09$ & $-0,29$ & $-0,07$ & $-0,24$ \\
\hline Caolinita & 0,07 & $-0,01$ & $-0,10$ & $-0,14$ & 0,02 & $-0,05$ & $-0,05$ & $-0,03$ & 0,11 & $-0,05$ & 0,06 & $-0,10$ & 0,16 \\
\hline Ca extr & 0,08 & 0,67 & $-0,03$ & 0,73 & 0,29 & 0,48 & 0,01 & 0,30 & 0,17 & 0,12 & 0,10 & 0,08 & 0,00 \\
\hline Yeso & 0,00 & 0,14 & $-0,09$ & $-0,04$ & 0,27 & 0,21 & $-0,13$ & 0,23 & 0,13 & 0,00 & 0,39 & 0,13 & $-0,15$ \\
\hline C.E & 0,39 & 0,44 & 0,05 & 0,29 & 0,40 & 0,24 & 0,05 & 0,35 & 0,33 & 0,28 & 0,14 & 0,19 & $-0,07$ \\
\hline Mn tot & & 0,63 & 0,01 & 0,32 & $-0,04$ & $-0,06$ & $-0,20$ & 0,14 & 0,33 & 0,10 & $-0,14$ & 0,16 & $-0,22$ \\
\hline Mn extr & 0,79 & & 0,13 & 0,53 & 0,28 & 0,46 & 0,12 & 0,47 & 0,29 & 0,36 & 0,08 & 0,33 & 0,20 \\
\hline M.O & $-0,15$ & 0,03 & & 0,03 & 0,25 & 0,26 & 0,50 & 0,10 & 0,18 & $-0,01$ & 0,02 & 0,03 & 0,39 \\
\hline Calcita & 0,37 & 0,50 & 0,53 & & 0,05 & 0,28 & $-0,01$ & 0,45 & 0,16 & 0,14 & 0,19 & 0,21 & $-0,03$ \\
\hline $\mathrm{Mg}$ tot & 0,25 & 0,61 & 0,20 & 0,37 & & 0,81 & 0,49 & 0,68 & 0,51 & 0,30 & 0,02 & 0,45 & 0,53 \\
\hline Dolomita & $-0,18$ & 0,10 & 0,26 & $-0,04$ & 0,88 & & 0,51 & 0,51 & 0,40 & $-0,03$ & 0,22 & 0,30 & 0,44 \\
\hline Paligorkita & $-0,21$ & $-0,02$ & 0,57 & 0,11 & 0,65 & 0,76 & & 0,28 & 0,33 & $-0,09$ & $-0,19$ & 0,11 & 0,19 \\
\hline Carbonato & 0,19 & 0,67 & 0,04 & 0,66 & 0,78 & 0,73 & 0,36 & & 0,47 & 0,67 & 0,16 & 0,39 & 0,40 \\
\hline Limos & 0,42 & 0,42 & 0,13 & 0,20 & 0,68 & 0,42 & 0,32 & 0,50 & & 0,25 & 0,02 & 0,28 & 0,33 \\
\hline $\mathrm{P}$ & 0,09 & 0,52 & $-0,09$ & 0,45 & 0,48 & 0,47 & 0,04 & 0,39 & 0,35 & & 0,14 & 0,30 & 0,23 \\
\hline Vermiculita & 0,00 & 0,20 & $-0,08$ & 0,06 & 0,20 & 0,02 & $-0,13$ & 0,33 & 0,27 & 0,57 & & 0,26 & $-0,11$ \\
\hline Arcilla & 0,20 & 0,40 & 0,17 & 0,22 & 0,43 & 0,28 & 0,15 & 0,45 & 0,22 & 0,41 & 0,14 & & 0,35 \\
\hline Sepiolita & $-0,21$ & 0,01 & 0,08 & 0,06 & 0,36 & 0,20 & 0,68 & 0,27 & 0,17 & 0,32 & $-0,22$ & 0,44 & \\
\hline
\end{tabular}






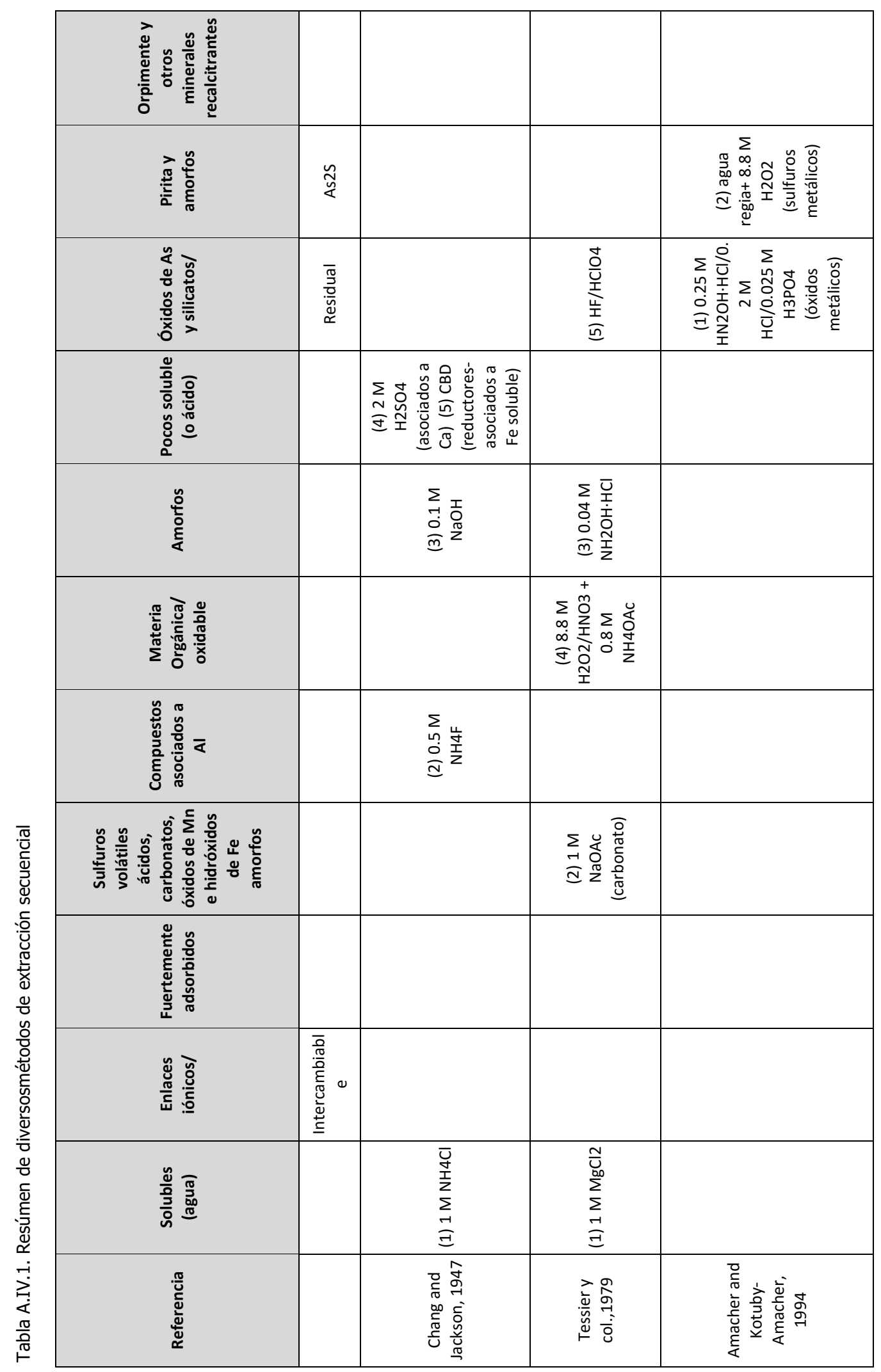




\begin{tabular}{|c|c|c|c|c|}
\hline 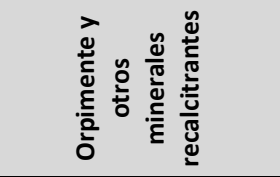 & & & & \\
\hline 을 & & & & \\
\hline 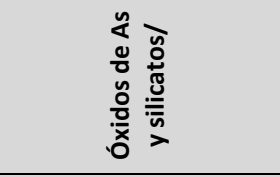 & 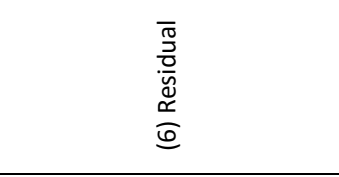 & 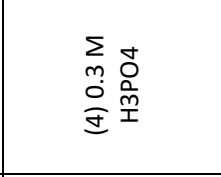 & & \\
\hline 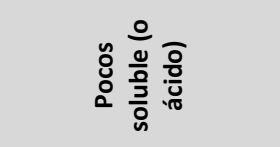 & $\begin{array}{l}\stackrel{0}{0} \\
\stackrel{N}{\underline{T}} \\
\underline{\underline{n}}\end{array}$ & & & \\
\hline 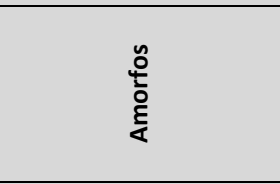 & 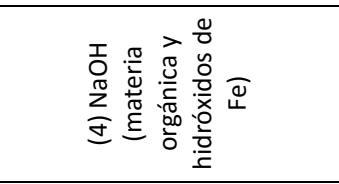 & 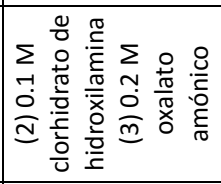 & 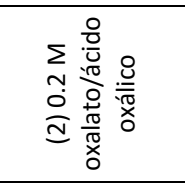 & \\
\hline 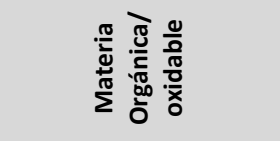 & & & & \\
\hline 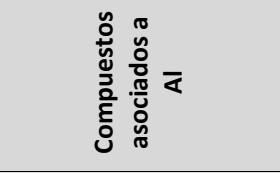 & 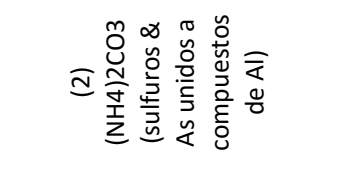 & & & \\
\hline 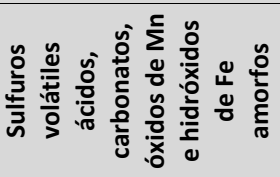 & 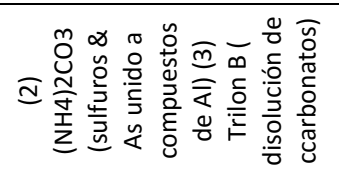 & & & \\
\hline 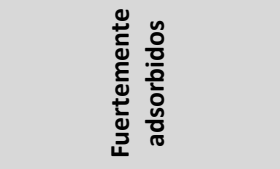 & & & & \\
\hline 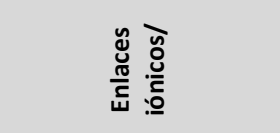 & & & & 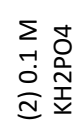 \\
\hline 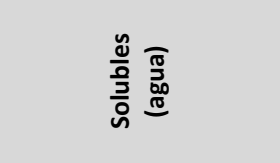 & $\begin{array}{l}\overline{\bar{y}} \\
\text { 紊 } \\
\text { I }\end{array}$ & 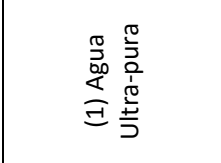 & 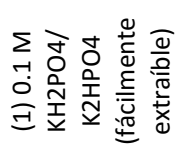 & 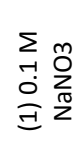 \\
\hline 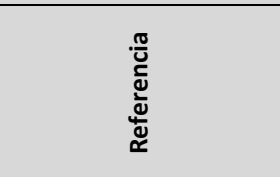 & 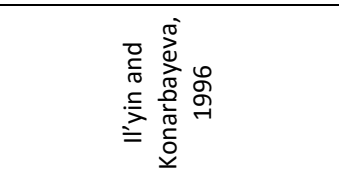 & 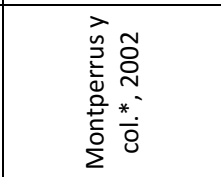 & 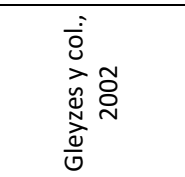 & 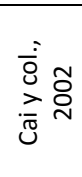 \\
\hline
\end{tabular}




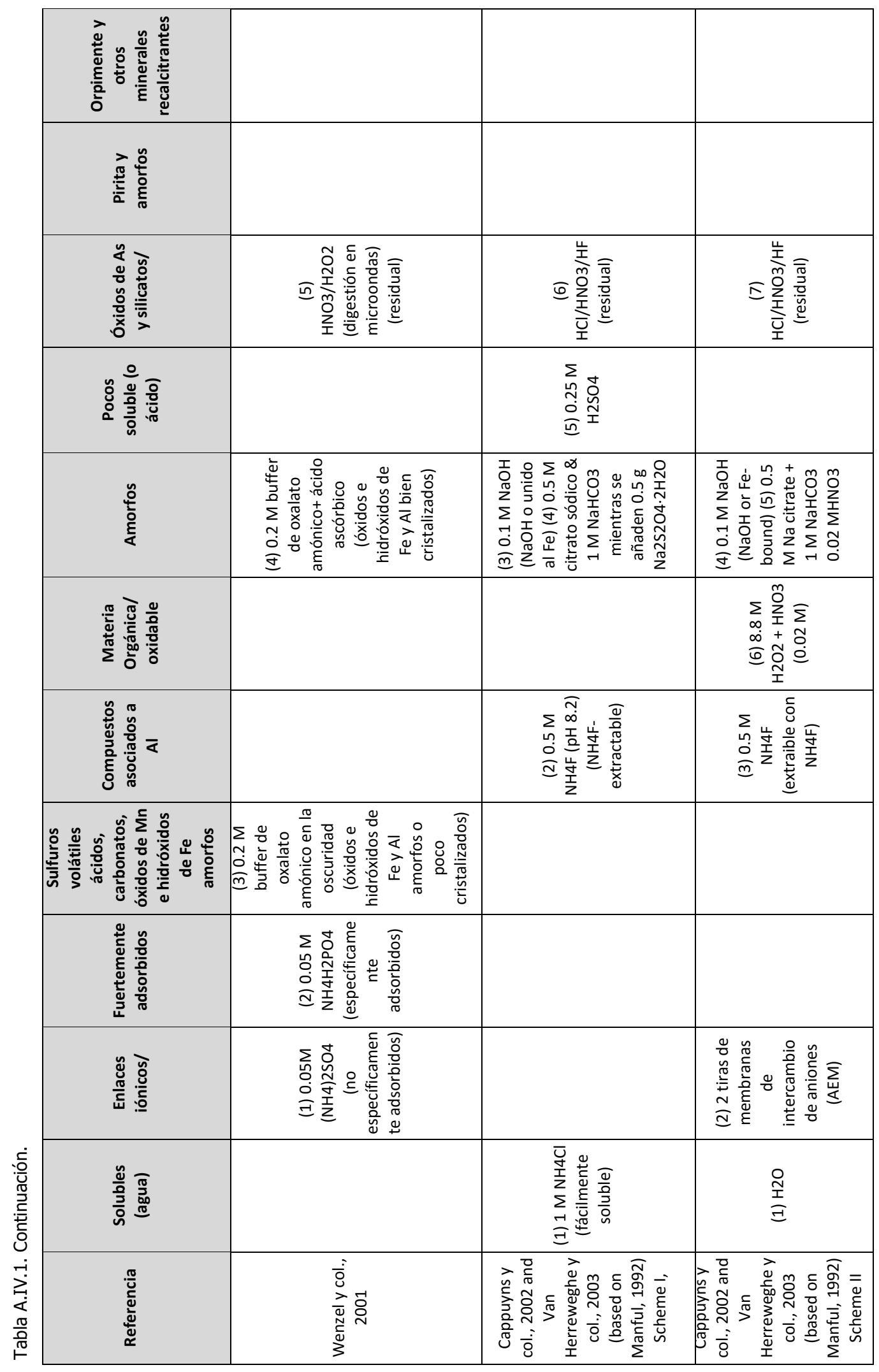


$\bar{m} \frac{0}{b}$ g

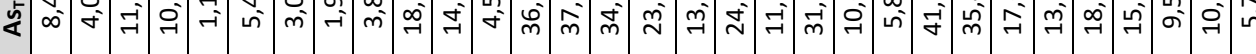

盷

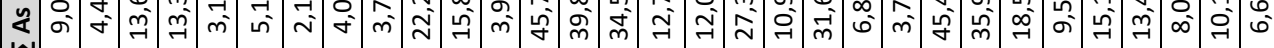

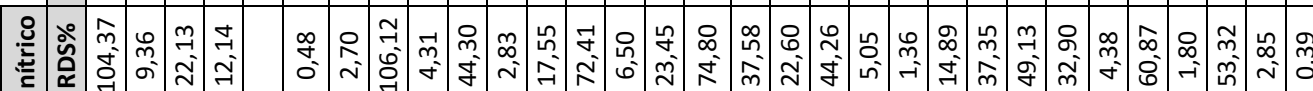

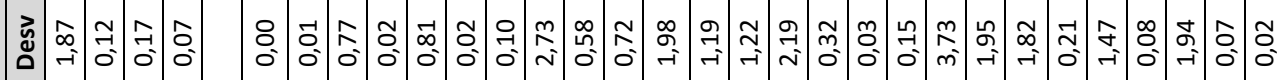
舟

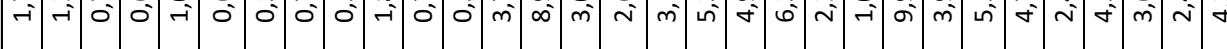

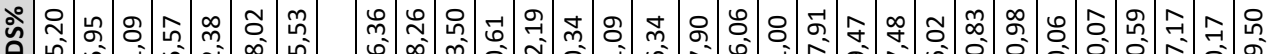
包

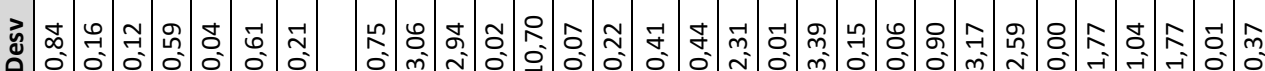

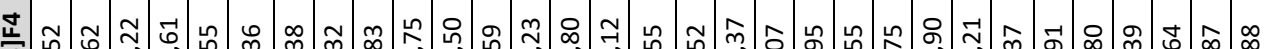

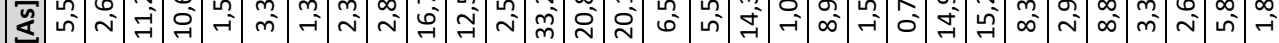

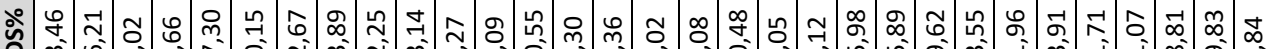

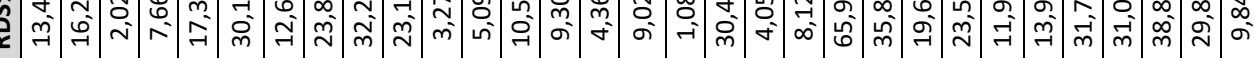

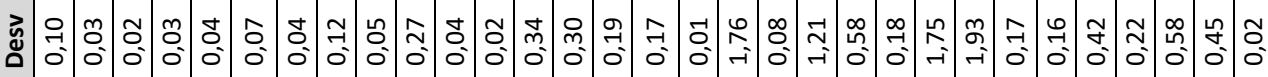

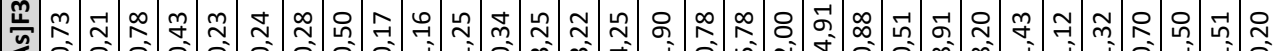

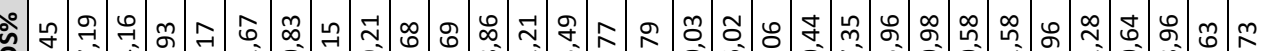

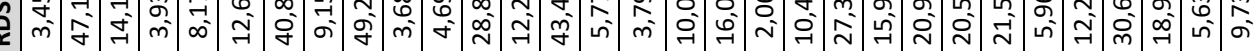

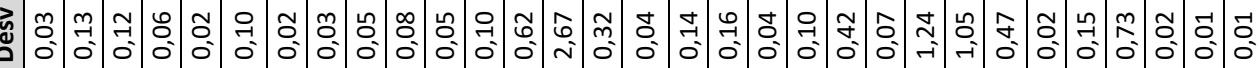

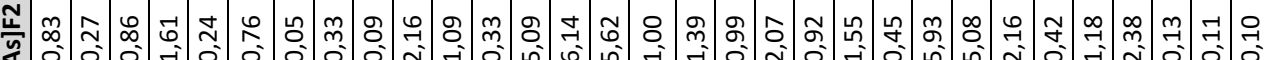

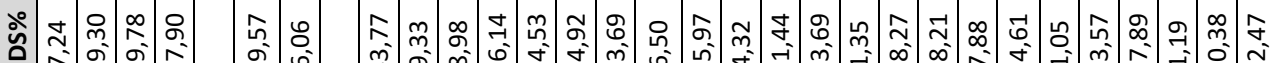

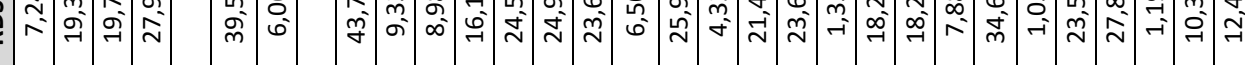

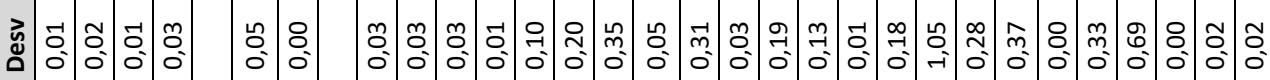

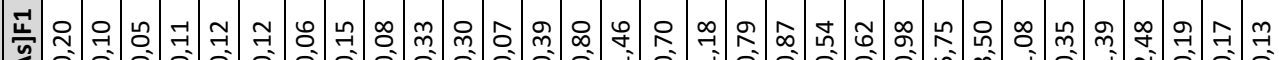

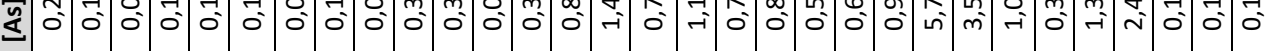

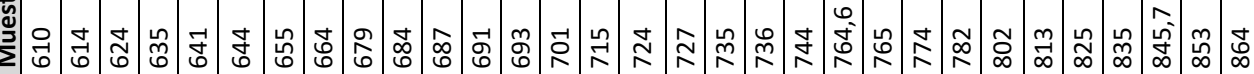


Tabla A.IV.3. Matriz de correlación de los parámetros investigados en el capítulo VI. Distribución de arsénico en sedimentos.

\begin{tabular}{|c|c|c|c|c|c|c|c|c|c|c|c|c|}
\hline & Fe tot & $\mathrm{Cr}$ & $\mathrm{Zn}$ & $\mathrm{Pb}$ & E2 & As & E4 & Limos & V & $\mathrm{CIC}$ & $\mathrm{K}$ tot & Esmectita \\
\hline Fe tot & & 0,922 & 0,888 & 0,856 & 0,484 & 0,536 & 0,594 & 0,272 & 0,565 & 0,715 & 0,767 & 0,413 \\
\hline $\mathrm{Cr}$ & 0,927 & & 0,862 & 0,784 & 0,407 & 0,417 & 0,602 & 0,129 & 0,510 & 0,628 & 0,613 & 0,379 \\
\hline $\mathrm{Zn}$ & 0,913 & 0,896 & & 0,850 & 0,517 & 0,591 & 0,668 & 0,321 & 0,646 & 0,653 & 0,721 & 0,423 \\
\hline $\mathrm{Pb}$ & 0,866 & 0,842 & 0,860 & & 0,669 & 0,702 & 0,698 & 0,460 & 0,668 & 0,683 & 0,789 & 0,333 \\
\hline E2 & 0,515 & 0,496 & 0,464 & 0,586 & & 0,821 & 0,679 & 0,594 & 0,452 & 0,522 & 0,633 & 0,179 \\
\hline As & 0,607 & 0,522 & 0,599 & 0,679 & 0,862 & & 0,817 & 0,681 & 0,621 & 0,624 & 0,758 & 0,224 \\
\hline E4 & 0,720 & 0,715 & 0,704 & 0,746 & 0,775 & 0,812 & & 0,564 & 0,612 & 0,481 & 0,516 & 0,166 \\
\hline Limos & 0,395 & 0,273 & 0,408 & 0,515 & 0,538 & 0,620 & 0,574 & & 0,646 & 0,344 & 0,405 & $-0,031$ \\
\hline V & 0,558 & 0,538 & 0,626 & 0,629 & 0,452 & 0,607 & 0,605 & 0,668 & & 0,381 & 0,590 & $-0,075$ \\
\hline $\mathrm{CIC}$ & 0,739 & 0,601 & 0,634 & 0,653 & 0,349 & 0,514 & 0,446 & 0,327 & 0,295 & & 0,806 & 0,448 \\
\hline $\mathrm{K}$ tot & 0,647 & 0,477 & 0,598 & 0,625 & 0,328 & 0,585 & 0,319 & 0,293 & 0,374 & 0,781 & & 0,380 \\
\hline Esmectita & 0,437 & 0,467 & 0,484 & 0,446 & 0,145 & 0,283 & 0,251 & 0,112 & 0,104 & 0,612 & 0,577 & \\
\hline Mn total & 0,442 & 0,344 & 0,494 & 0,725 & 0,392 & 0,587 & 0,395 & 0,492 & 0,534 & 0,528 & 0,693 & 0,286 \\
\hline Mn extr & $-0,050$ & $-0,136$ & 0,035 & 0,244 & 0,158 & 0,367 & $-0,008$ & 0,278 & 0,395 & 0,160 & 0,462 & 0,074 \\
\hline Filosilicatos & 0,539 & 0,402 & 0,401 & 0,502 & 0,512 & 0,640 & 0,369 & 0,454 & 0,559 & 0,570 & 0,673 & 0,212 \\
\hline Illita & 0,671 & 0,538 & 0,568 & 0,625 & 0,571 & 0,695 & 0,438 & 0,299 & 0,378 & 0,633 & 0,790 & 0,290 \\
\hline E3 & 0,334 & 0,243 & 0,387 & 0,368 & 0,455 & 0,741 & 0,411 & 0,326 & 0,453 & 0,321 & 0,573 & 0,202 \\
\hline E5 & 0,314 & 0,291 & 0,351 & 0,392 & 0,619 & 0,736 & 0,375 & 0,409 & 0,559 & 0,391 & 0,538 & 0,310 \\
\hline $\mathrm{Mg}$ tot & $-0,231$ & $-0,360$ & $-0,232$ & $-0,170$ & 0,085 & 0,219 & $-0,073$ & 0,421 & 0,398 & $-0,092$ & 0,075 & $-0,141$ \\
\hline Dolomita & $-0,364$ & $-0,431$ & $-0,289$ & $-0,293$ & $-0,161$ & $-0,063$ & $-0,153$ & 0,308 & 0,180 & $-0,321$ & $-0,187$ & $-0,175$ \\
\hline Mg extr & 0,220 & 0,051 & 0,153 & 0,263 & 0,280 & 0,490 & 0,233 & 0,480 & 0,453 & 0,214 & 0,514 & 0,286 \\
\hline K extr & 0,284 & 0,150 & 0,177 & 0,171 & 0,241 & 0,398 & 0,098 & 0,273 & 0,492 & 0,304 & 0,516 & 0,185 \\
\hline C.E & $-0,180$ & $-0,278$ & $-0,245$ & $-0,107$ & 0,107 & 0,161 & 0,039 & 0,409 & 0,209 & $-0,225$ & $-0,030$ & $-0,101$ \\
\hline Arcilla & 0,023 & $-0,086$ & 0,036 & 0,038 & $-0,004$ & 0,065 & $-0,219$ & 0,199 & 0,362 & 0,085 & 0,292 & $-0,086$ \\
\hline Sepiolita & $-0,123$ & $-0,166$ & $-0,181$ & $-0,259$ & $-0,252$ & $-0,252$ & $-0,274$ & 0,070 & 0,185 & $-0,173$ & $-0,158$ & $-0,131$ \\
\hline M.O & $-0,227$ & $-0,217$ & $-0,166$ & $-0,233$ & $-0,052$ & $-0,110$ & $-0,181$ & 0,060 & $-0,080$ & $-0,224$ & $-0,183$ & $-0,109$ \\
\hline Paligorkita & $-0,334$ & $-0,375$ & $-0,250$ & $-0,320$ & $-0,200$ & $-0,156$ & $-0,204$ & 0,229 & 0,060 & $-0,374$ & $-0,229$ & $-0,124$ \\
\hline $\mathrm{CO}$ & $-0,437$ & $-0,525$ & $-0,386$ & $-0,181$ & $-0,016$ & 0,115 & $-0,178$ & 0,428 & 0,179 & $-0,107$ & 0,046 & $-0,090$ \\
\hline Calcita & $-0,326$ & $-0,382$ & $-0,268$ & $-0,148$ & $-0,133$ & $-0,065$ & $-0,292$ & 0,184 & $-0,151$ & 0,095 & 0,091 & 0,110 \\
\hline E1 & 0,044 & $-0,039$ & $-0,009$ & 0,146 & 0,657 & 0,623 & 0,266 & 0,367 & 0,264 & 0,162 & 0,289 & $-0,008$ \\
\hline$P$ & $-0,102$ & $-0,154$ & $-0,104$ & $-0,101$ & 0,293 & 0,373 & 0,048 & 0,241 & 0,317 & 0,061 & 0,130 & $-0,129$ \\
\hline Vermiculita & $-0,204$ & $-0,246$ & $-0,210$ & $-0,176$ & 0,253 & 0,224 & 0,002 & 0,201 & 0,091 & $-0,007$ & 0,008 & $-0,178$ \\
\hline Ca extr & $-0,038$ & $-0,135$ & $-0,055$ & 0,117 & 0,323 & 0,371 & 0,148 & 0,259 & 0,157 & $-0,001$ & 0,089 & $-0,024$ \\
\hline Caolinita & 0,028 & $-0,046$ & $-0,071$ & 0,060 & 0,265 & 0,217 & 0,111 & 0,064 & 0,045 & $-0,089$ & $-0,053$ & $-0,107$ \\
\hline Yeso & 0,018 & $-0,044$ & $-0,008$ & 0,056 & 0,277 & 0,234 & 0,124 & 0,147 & 0,192 & $-0,098$ & 0,145 & $-0,105$ \\
\hline $\mathrm{Na}$ tot & $-0,087$ & $-0,017$ & 0,132 & $-0,126$ & $-0,106$ & $-0,203$ & $-0,028$ & 0,069 & 0,046 & $-0,400$ & $-0,388$ & $-0,125$ \\
\hline $\mathrm{Cu}$ & 0,419 & 0,458 & 0,596 & 0,322 & 0,087 & 0,062 & 0,288 & 0,096 & 0,313 & $-0,023$ & $-0,058$ & 0,081 \\
\hline $\mathrm{Na}$ extr & 0,046 & 0,067 & 0,106 & $-0,088$ & $-0,204$ & $-0,294$ & $-0,002$ & 0,025 & $-0,038$ & $-0,153$ & $-0,320$ & $-0,136$ \\
\hline $\mathrm{pH}$ & $-0,157$ & 0,031 & $-0,050$ & $-0,219$ & $-0,339$ & $-0,475$ & $-0,152$ & $-0,475$ & $-0,309$ & $-0,368$ & $-0,544$ & $-0,185$ \\
\hline Cuarzo & $-0,039$ & 0,134 & $-0,011$ & $-0,142$ & $-0,234$ & $-0,403$ & $-0,056$ & $-0,607$ & $-0,413$ & $-0,294$ & $-0,437$ & $-0,120$ \\
\hline Feldespato & 0,122 & 0,214 & 0,147 & $-0,010$ & $-0,145$ & $-0,280$ & 0,105 & $-0,334$ & $-0,299$ & $-0,127$ & $-0,336$ & $-0,034$ \\
\hline Arenas & $-0,294$ & $-0,143$ & $-0,310$ & $-0,387$ & $-0,379$ & $-0,478$ & $-0,281$ & $-0,825$ & $-0,682$ & $-0,281$ & $-0,376$ & $-0,029$ \\
\hline Fe extr & 0,491 & 0,506 & 0,404 & 0,382 & 0,254 & 0,124 & 0,388 & $-0,121$ & $-0,057$ & 0,097 & 0,041 & 0,018 \\
\hline Clorita & 0,106 & 0,176 & 0,036 & 0,228 & $-0,005$ & $-0,018$ & 0,191 & $-0,026$ & 0,107 & 0,080 & $-0,097$ & $-0,201$ \\
\hline
\end{tabular}


Tabla A.IV.3. Continuación.

\begin{tabular}{|c|c|c|c|c|c|c|c|c|c|c|c|}
\hline & Mn total & Mn extr & Filosilicatos & Illita & E3 & E5 & $\mathrm{Mg}$ tot & Dolomita & Mg extr & K extr & C.E \\
\hline Fe tot & 0,560 & 0,022 & 0,554 & 0,779 & 0,463 & 0,311 & $-0,025$ & $-0,299$ & 0,288 & 0,376 & 0,058 \\
\hline $\mathrm{Cr}$ & 0,402 & $-0,178$ & 0,419 & 0,676 & 0,310 & 0,186 & $-0,226$ & $-0,438$ & 0,080 & 0,233 & $-0,118$ \\
\hline$Z n$ & 0,589 & 0,113 & 0,408 & 0,661 & 0,500 & 0,379 & 0,004 & $-0,220$ & 0,275 & 0,350 & 0,084 \\
\hline $\mathrm{Pb}$ & 0,798 & 0,251 & 0,513 & 0,731 & 0,561 & 0,433 & 0,120 & $-0,132$ & 0,342 & 0,357 & 0,174 \\
\hline E2 & 0,696 & 0,319 & 0,500 & 0,600 & 0,643 & 0,533 & 0,280 & $-0,029$ & 0,343 & 0,319 & 0,422 \\
\hline As & 0,772 & 0,542 & 0,606 & 0,657 & 0,881 & 0,734 & 0,526 & 0,236 & 0,620 & 0,548 & 0,473 \\
\hline E4 & 0,530 & 0,146 & 0,358 & 0,560 & 0,648 & 0,367 & 0,177 & 0,056 & 0,302 & 0,297 & 0,224 \\
\hline Limos & 0,553 & 0,362 & 0,418 & 0,306 & 0,658 & 0,431 & 0,584 & 0,295 & 0,508 & 0,368 & 0,465 \\
\hline V & 0,538 & 0,394 & 0,523 & 0,462 & 0,543 & 0,582 & 0,508 & 0,301 & 0,513 & 0,490 & 0,405 \\
\hline $\mathrm{ClC}$ & 0,649 & 0,310 & 0,588 & 0,704 & 0,553 & 0,456 & 0,175 & $-0,142$ & 0,263 & 0,404 & 0,131 \\
\hline $\mathrm{K}$ tot & 0,841 & 0,559 & 0,767 & 0,831 & 0,728 & 0,665 & 0,420 & 0,042 & 0,611 & 0,687 & 0,378 \\
\hline Esmectita & 0,221 & $-0,039$ & 0,129 & 0,377 & 0,264 & 0,125 & $-0,198$ & $-0,343$ & 0,136 & 0,201 & 0,137 \\
\hline Mn total & & 0,646 & 0,612 & 0,731 & 0,774 & 0,592 & 0,389 & 0,093 & 0,535 & 0,449 & 0,371 \\
\hline Mn extr & 0,799 & & 0,538 & 0,343 & 0,575 & 0,739 & 0,759 & 0,597 & 0,628 & 0,577 & 0,481 \\
\hline Filosilicatos & 0,582 & 0,509 & & 0,840 & 0,575 & 0,662 & 0,501 & 0,199 & 0,623 & 0,688 & 0,303 \\
\hline Illita & 0,604 & 0,379 & 0,823 & & 0,619 & 0,483 & 0,131 & $-0,119$ & 0,427 & 0,539 & 0,234 \\
\hline $\mathrm{E} 3$ & 0,526 & 0,562 & 0,538 & 0,648 & & 0,722 & 0,570 & 0,276 & 0,743 & 0,552 & 0,498 \\
\hline E5 & 0,477 & 0,524 & 0,649 & 0,517 & 0,627 & & 0,726 & 0,507 & 0,706 & 0,622 & 0,470 \\
\hline $\mathrm{Mg}$ tot & 0,134 & 0,435 & 0,345 & $-0,022$ & 0,194 & 0,485 & & 0,786 & 0,749 & 0,604 & 0,591 \\
\hline Dolomita & $-0,094$ & 0,112 & $-0,094$ & $-0,322$ & $-0,064$ & 0,131 & 0,807 & & 0,527 & 0,398 & 0,403 \\
\hline Mg extr & 0,370 & 0,417 & 0,523 & 0,419 & 0,515 & 0,489 & 0,620 & 0,442 & & 0,763 & 0,561 \\
\hline K extr & 0,232 & 0,389 & 0,691 & 0,484 & 0,444 & 0,591 & 0,526 & 0,095 & 0,726 & & 0,480 \\
\hline C.E & 0,001 & 0,158 & 0,092 & 0,040 & 0,197 & 0,086 & 0,549 & 0,550 & 0,704 & 0,391 & \\
\hline Arcilla & 0,296 & 0,453 & 0,425 & 0,114 & 0,022 & 0,370 & 0,512 & 0,192 & 0,129 & 0,395 & $-0,143$ \\
\hline Sepiolita & $-0,272$ & $-0,023$ & 0,173 & $-0,210$ & $-0,173$ & $-0,012$ & 0,313 & 0,127 & 0,136 & 0,420 & 0,067 \\
\hline M.O & $-0,179$ & $-0,133$ & $-0,247$ & $-0,307$ & $-0,084$ & $-0,022$ & 0,116 & 0,148 & $-0,012$ & $-0,176$ & 0,018 \\
\hline Paligorkita & $-0,226$ & $-0,098$ & $-0,232$ & $-0,381$ & $-0,090$ & $-0,021$ & 0,510 & 0,737 & 0,392 & 0,008 & 0,441 \\
\hline $\mathrm{CO} 3$ & 0,333 & 0,639 & 0,213 & $-0,110$ & 0,139 & 0,320 & 0,735 & 0,552 & 0,377 & 0,273 & 0,480 \\
\hline Calcita & 0,238 & 0,354 & 0,014 & $-0,158$ & $-0,001$ & 0,084 & 0,144 & $-0,026$ & $-0,026$ & $-0,073$ & $-0,041$ \\
\hline E1 & 0,385 & 0,531 & 0,558 & 0,454 & 0,513 & 0,616 & 0,443 & 0,014 & 0,390 & 0,474 & 0,229 \\
\hline$P$ & 0,160 & 0,462 & 0,495 & 0,223 & 0,444 & 0,559 & 0,435 & $-0,023$ & 0,212 & 0,561 & 0,029 \\
\hline Vermiculita & 0,093 & 0,297 & 0,181 & 0,020 & 0,138 & 0,400 & 0,400 & 0,167 & $-0,034$ & 0,155 & $-0,003$ \\
\hline Ca extr & 0,335 & 0,480 & 0,291 & 0,286 & 0,428 & 0,198 & 0,376 & 0,126 & 0,420 & 0,230 & 0,489 \\
\hline Caolinita & 0,080 & 0,175 & 0,154 & 0,231 & 0,277 & 0,020 & 0,169 & 0,024 & 0,303 & 0,141 & 0,479 \\
\hline Yeso & 0,203 & 0,311 & 0,158 & 0,183 & 0,202 & 0,214 & 0,371 & 0,249 & 0,243 & 0,149 & 0,377 \\
\hline $\mathrm{Na}$ tot & $-0,331$ & $-0,353$ & $-0,424$ & $-0,306$ & $-0,219$ & $-0,256$ & $-0,071$ & 0,205 & $-0,116$ & $-0,178$ & 0,202 \\
\hline $\mathrm{Cu}$ & $-0,068$ & $-0,325$ & $-0,146$ & $-0,029$ & $-0,076$ & $-0,101$ & $-0,228$ & $-0,105$ & $-0,086$ & $-0,083$ & $-0,195$ \\
\hline $\mathrm{Na}$ extr & $-0,328$ & $-0,473$ & $-0,373$ & $-0,226$ & $-0,263$ & $-0,444$ & $-0,199$ & 0,210 & $-0,130$ & $-0,270$ & 0,114 \\
\hline $\mathrm{pH}$ & $-0,455$ & $-0,507$ & $-0,622$ & $-0,404$ & $-0,359$ & $-0,500$ & $-0,523$ & $-0,148$ & $-0,558$ & $-0,520$ & $-0,257$ \\
\hline Cuarzo & $-0,516$ & $-0,620$ & $-0,667$ & $-0,338$ & $-0,352$ & $-0,566$ & $-0,733$ & $-0,427$ & $-0,582$ & $-0,488$ & $-0,336$ \\
\hline Feldespato & $-0,346$ & $-0,557$ & $-0,505$ & $-0,259$ & $-0,307$ & $-0,511$ & $-0,687$ & $-0,407$ & $-0,483$ & $-0,422$ & $-0,345$ \\
\hline Arenas & $-0,520$ & $-0,459$ & $-0,568$ & $-0,278$ & $-0,244$ & $-0,503$ & $-0,595$ & $-0,330$ & $-0,415$ & $-0,422$ & $-0,209$ \\
\hline Fe extr & 0,007 & $-0,360$ & 0,076 & 0,297 & $-0,067$ & $-0,247$ & $-0,610$ & $-0,496$ & $-0,223$ & $-0,268$ & $-0,297$ \\
\hline Clorita & 0,240 & 0,089 & 0,170 & 0,006 & $-0,165$ & $-0,105$ & $-0,101$ & $-0,098$ & $-0,172$ & $-0,180$ & $-0,193$ \\
\hline
\end{tabular}


Tabla A.IV.3. Continuación.

\begin{tabular}{|c|c|c|c|c|c|c|c|c|c|c|c|}
\hline & Arcilla & Sepiolita & M.O & Paligorkita & $\mathrm{CO} 3$ & Calcita & E1 & $P$ & Vermiculita & Ca extr & Caolinita \\
\hline Fe tot & 0,052 & $-0,351$ & $-0,096$ & $-0,384$ & $-0,421$ & $-0,309$ & 0,158 & $-0,213$ & $-0,274$ & $-0,019$ & 0,067 \\
\hline $\mathrm{Cr}$ & $-0,074$ & $-0,399$ & 0,010 & $-0,438$ & $-0,567$ & $-0,426$ & 0,016 & $-0,281$ & $-0,240$ & $-0,196$ & 0,070 \\
\hline $\mathrm{Zn}$ & 0,127 & $-0,313$ & 0,008 & $-0,297$ & $-0,314$ & $-0,165$ & 0,167 & $-0,136$ & $-0,166$ & 0,063 & $-0,074$ \\
\hline $\mathrm{Pb}$ & 0,165 & $-0,419$ & $-0,091$ & $-0,396$ & $-0,153$ & $-0,065$ & 0,419 & $-0,071$ & $-0,141$ & 0,225 & $-0,028$ \\
\hline E2 & 0,168 & $-0,370$ & $-0,067$ & $-0,232$ & 0,062 & 0,156 & 0,739 & 0,175 & 0,096 & 0,306 & $-0,201$ \\
\hline As & 0,203 & $-0,251$ & $-0,037$ & $-0,123$ & 0,272 & 0,207 & 0,742 & 0,333 & 0,048 & 0,449 & $-0,238$ \\
\hline E4 & $-0,101$ & $-0,404$ & 0,006 & $-0,191$ & $-0,104$ & $-0,234$ & 0,367 & 0,040 & 0,003 & 0,134 & $-0,140$ \\
\hline Limos & 0,252 & 0,183 & 0,148 & 0,200 & 0,378 & 0,156 & 0,606 & 0,316 & 0,002 & 0,359 & $-0,255$ \\
\hline $\mathrm{V}$ & 0,347 & 0,128 & 0,269 & 0,043 & 0,146 & $-0,069$ & 0,373 & 0,283 & $-0,034$ & 0,292 & 0,027 \\
\hline $\mathrm{CIC}$ & 0,179 & $-0,377$ & $-0,222$ & $-0,416$ & $-0,090$ & 0,184 & 0,396 & 0,027 & $-0,080$ & 0,320 & $-0,124$ \\
\hline $\mathrm{K}$ tot & 0,375 & $-0,246$ & $-0,220$ & $-0,272$ & 0,125 & 0,222 & 0,585 & 0,141 & $-0,140$ & 0,442 & $-0,127$ \\
\hline Esmectita & $-0,056$ & $-0,254$ & $-0,444$ & $-0,190$ & $-0,133$ & 0,022 & 0,045 & $-0,147$ & $-0,365$ & $-0,073$ & $-0,254$ \\
\hline Mn total & 0,302 & $-0,339$ & $-0,240$ & $-0,254$ & 0,283 & 0,373 & 0,715 & 0,196 & 0,006 & 0,562 & $-0,184$ \\
\hline Mn extr & 0,548 & 0,125 & $-0,141$ & 0,029 & 0,721 & 0,637 & 0,713 & 0,565 & 0,207 & 0,808 & $-0,006$ \\
\hline Filosilicatos & 0,382 & $-0,073$ & $-0,259$ & $-0,291$ & 0,213 & 0,141 & 0,626 & 0,416 & $-0,059$ & 0,373 & 0,001 \\
\hline Illita & 0,137 & $-0,476$ & $-0,390$ & $-0,511$ & $-0,077$ & $-0,023$ & 0,472 & 0,127 & $-0,079$ & 0,226 & $-0,043$ \\
\hline E3 & 0,116 & $-0,121$ & $-0,021$ & 0,127 & 0,324 & 0,234 & 0,683 & 0,237 & $-0,033$ & 0,437 & $-0,255$ \\
\hline E5 & 0,446 & 0,034 & 0,084 & 0,029 & 0,456 & 0,364 & 0,716 & 0,467 & 0,129 & 0,492 & $-0,020$ \\
\hline Mg tot & 0,574 & 0,437 & 0,127 & 0,422 & 0,735 & 0,454 & 0,643 & 0,506 & 0,061 & 0,646 & $-0,078$ \\
\hline Dolomita & 0,358 & 0,266 & 0,049 & 0,324 & 0,729 & 0,344 & 0,352 & 0,472 & 0,315 & 0,538 & $-0,016$ \\
\hline Mg extr & 0,270 & 0,233 & $-0,064$ & 0,299 & 0,509 & 0,237 & 0,582 & 0,380 & $-0,073$ & 0,416 & $-0,165$ \\
\hline K extr & 0,322 & 0,119 & $-0,099$ & $-0,040$ & 0,443 & 0,181 & 0,450 & 0,419 & $-0,062$ & 0,427 & $-0,049$ \\
\hline C.E & 0,379 & 0,085 & $-0,089$ & 0,294 & 0,535 & 0,266 & 0,527 & 0,339 & 0,142 & 0,425 & $-0,066$ \\
\hline Arcilla & & 0,302 & 0,082 & 0,087 & 0,454 & 0,504 & 0,474 & 0,306 & 0,162 & 0,452 & $-0,087$ \\
\hline Sepiolita & 0,457 & & 0,473 & 0,686 & 0,321 & 0,156 & $-0,054$ & 0,252 & $-0,274$ & 0,063 & 0,059 \\
\hline M.O & 0,189 & 0,083 & & 0,463 & $-0,151$ & $-0,159$ & $-0,087$ & $-0,121$ & 0,079 & $-0,217$ & 0,214 \\
\hline Paligorkita & 0,112 & 0,183 & 0,667 & & 0,267 & 0,128 & $-0,079$ & $-0,047$ & $-0,205$ & 0,011 & $-0,143$ \\
\hline $\mathrm{CO} 3$ & 0,415 & 0,176 & $-0,004$ & 0,227 & & 0,711 & 0,520 & 0,709 & 0,197 & 0,719 & $-0,262$ \\
\hline Calcita & 0,335 & 0,141 & 0,536 & 0,181 & 0,542 & & 0,460 & 0,487 & 0,186 & 0,721 & $-0,394$ \\
\hline E1 & 0,291 & $-0,112$ & $-0,085$ & $-0,140$ & 0,415 & 0,088 & & 0,463 & 0,199 & 0,551 & $-0,125$ \\
\hline $\mathrm{P}$ & 0,423 & 0,307 & $-0,085$ & $-0,114$ & 0,406 & 0,174 & 0,744 & & 0,124 & 0,577 & $-0,136$ \\
\hline Vermiculita & 0,365 & $-0,157$ & $-0,115$ & $-0,150$ & 0,446 & 0,102 & 0,647 & 0,607 & & 0,157 & 0,049 \\
\hline Ca extr & $-0,018$ & $-0,056$ & $-0,021$ & $-0,044$ & 0,387 & 0,115 & 0,542 & 0,187 & 0,064 & & $-0,039$ \\
\hline Caolinita & $-0,183$ & $-0,031$ & $-0,065$ & $-0,090$ & 0,062 & $-0,174$ & 0,350 & $-0,018$ & $-0,076$ & 0,863 & \\
\hline Yeso & 0,150 & $-0,092$ & $-0,088$ & $-0,088$ & 0,304 & $-0,120$ & 0,340 & $-0,035$ & 0,210 & 0,615 & 0,586 \\
\hline $\mathrm{Na}$ tot & $-0,200$ & $-0,095$ & 0,204 & 0,371 & $-0,168$ & $-0,208$ & $-0,234$ & $-0,215$ & $-0,179$ & $-0,083$ & $-0,018$ \\
\hline $\mathrm{Cu}$ & $-0,010$ & 0,011 & 0,287 & 0,193 & $-0,503$ & $-0,216$ & $-0,287$ & $-0,247$ & $-0,370$ & $-0,128$ & $-0,071$ \\
\hline $\mathrm{Na}$ extr & $-0,375$ & $-0,104$ & $-0,010$ & 0,330 & $-0,389$ & $-0,483$ & $-0,422$ & $-0,424$ & $-0,293$ & $-0,276$ & $-0,044$ \\
\hline $\mathrm{pH}$ & $-0,475$ & $-0,248$ & $-0,042$ & 0,003 & $-0,560$ & $-0,469$ & $-0,461$ & $-0,380$ & $-0,237$ & $-0,335$ & $-0,071$ \\
\hline Cuarzo & $-0,563$ & $-0,235$ & $-0,187$ & $-0,284$ & $-0,736$ & $-0,535$ & $-0,466$ & $-0,404$ & $-0,293$ & $-0,388$ & $-0,086$ \\
\hline Feldespato & $-0,577$ & $-0,264$ & $-0,169$ & $-0,281$ & $-0,658$ & $-0,444$ & $-0,413$ & $-0,411$ & $-0,187$ & $-0,318$ & $-0,047$ \\
\hline Arenas & $-0,718$ & $-0,313$ & $-0,151$ & $-0,228$ & $-0,544$ & $-0,325$ & $-0,429$ & $-0,415$ & $-0,353$ & $-0,174$ & 0,060 \\
\hline Fe extr & $-0,345$ & $-0,319$ & $-0,200$ & $-0,359$ & $-0,659$ & $-0,435$ & $-0,153$ & $-0,345$ & $-0,288$ & $-0,146$ & 0,117 \\
\hline Clorita & $-0,111$ & $-0,177$ & $-0,140$ & $-0,169$ & 0,013 & 0,004 & $-0,164$ & $-0,152$ & $-0,242$ & $-0,065$ & $-0,127$ \\
\hline
\end{tabular}


Tabla A.IV.3. Continuación.

\begin{tabular}{|c|c|c|c|c|c|c|c|c|c|c|}
\hline & Yeso & Na tot & $\mathrm{Cu}$ & Na extr & $\mathrm{pH}$ & Cuarzo & Feldespato & Arenas & Fe extr & Clorita \\
\hline Fe tot & $-0,053$ & $-0,242$ & 0,423 & 0,125 & $-0,143$ & 0,163 & 0,229 & $-0,098$ & 0,494 & 0,170 \\
\hline $\mathrm{Cr}$ & $-0,150$ & $-0,207$ & 0,429 & 0,216 & 0,053 & 0,352 & 0,373 & 0,067 & 0,519 & 0,231 \\
\hline Zn & $-0,036$ & $-0,015$ & 0,596 & 0,092 & $-0,108$ & 0,123 & 0,221 & $-0,170$ & 0,400 & 0,048 \\
\hline $\mathrm{Pb}$ & 0,082 & $-0,169$ & 0,317 & $-0,065$ & $-0,227$ & $-0,029$ & 0,088 & $-0,317$ & 0,328 & 0,187 \\
\hline E2 & 0,470 & $-0,066$ & 0,112 & $-0,312$ & $-0,448$ & $-0,384$ & $-0,180$ & $-0,443$ & 0,245 & 0,067 \\
\hline As & 0,386 & $-0,148$ & 0,094 & $-0,391$ & $-0,558$ & $-0,474$ & $-0,351$ & $-0,491$ & 0,048 & $\mid-0,017$ \\
\hline E4 & 0,242 & 0,108 & 0,335 & 0,020 & $-0,132$ & $-0,054$ & 0,053 & $-0,210$ & 0,303 & 0,140 \\
\hline Limos & 0,266 & 0,138 & 0,055 & $-0,150$ & $-0,441$ & $-0,529$ & $-0,325$ & $-0,751$ & $-0,087$ & $-0,050$ \\
\hline V & 0,143 & 0,017 & 0,328 & $-0,122$ & $-0,295$ & $-0,274$ & $-0,301$ & $-0,592$ & $-0,061$ & 0,072 \\
\hline $\mathrm{ClC}$ & $-0,023$ & $-0,458$ & 0,000 & $-0,184$ & $-0,400$ & $-0,210$ & 0,001 & $-0,234$ & 0,129 & 0,112 \\
\hline $\mathrm{K}$ tot & 0,228 & $-0,398$ & 0,089 & $-0,333$ & $-0,565$ & $-0,367$ & $-0,277$ & $-0,416$ & 0,115 & 0,050 \\
\hline Esmectita & $-0,223$ & $-0,135$ & 0,179 & 0,146 & $-0,097$ & 0,196 & 0,166 & 0,134 & 0,106 & $-0,338$ \\
\hline Mn total & 0,277 & $-0,244$ & $-0,031$ & $-0,348$ & $-0,504$ & $-0,446$ & $-0,270$ & $-0,477$ & 0,096 & 0,080 \\
\hline Mn extr & 0,455 & $-0,213$ & $-0,273$ & $-0,610$ & $-0,651$ & $-0,771$ & \begin{tabular}{|l|}
$-0,691$ \\
\end{tabular} & $-0,600$ & $-0,406$ & $-0,210$ \\
\hline Filosilicatos & 0,330 & $-0,472$ & $-0,154$ & $-0,408$ & $-0,624$ & $-0,497$ & $-0,446$ & $-0,471$ & 0,141 & 0,109 \\
\hline Illita & 0,199 & $-0,354$ & 0,043 & $-0,163$ & $-0,385$ & $-0,148$ & $-0,078$ & $-0,194$ & 0,416 & 0,131 \\
\hline E3 & 0,288 & $-0,167$ & $-0,004$ & $-0,229$ & $-0,521$ & $-0,515$ & $-0,417$ & $-0,408$ & $-0,047$ & $-0,121$ \\
\hline E5 & 0,441 & \begin{tabular}{|l|}
$-0,302$ \\
\end{tabular} & $-0,129$ & $-0,544$ & $-0,616$ & $-0,677$ & $-0,641$ & $-0,534$ & $-0,292$ & $-0,142$ \\
\hline $\mathrm{Mg}$ tot & 0,475 & $-0,112$ & $-0,182$ & $-0,528$ & $-0,656$ & $-0,878$ & $-0,851$ & $-0,763$ & $-0,552$ & $-0,131$ \\
\hline Dolomita & 0,459 & 0,014 & $-0,239$ & $-0,448$ & $-0,419$ & $-0,689$ & $-0,706$ & $-0,452$ & $-0,610$ & $-0,135$ \\
\hline Mg extr & 0,324 & $-0,258$ & $-0,017$ & $-0,371$ & $-0,685$ & $-0,590$ & $-0,606$ & $-0,463$ & $-0,185$ & $-0,222$ \\
\hline K extr & 0,349 & $-0,179$ & $-0,023$ & $-0,350$ & $-0,596$ & $-0,437$ & $-0,461$ & $-0,400$ & $-0,145$ & $-0,164$ \\
\hline C.E & 0,407 & 0,131 & 0,010 & $-0,309$ & \begin{tabular}{|l|}
$-0,537$ \\
\end{tabular} & $-0,543$ & \begin{tabular}{|l|}
$-0,642$ \\
\end{tabular} & $-0,503$ & $-0,386$ & $-0,409$ \\
\hline Arcilla & 0,252 & $-0,058$ & 0,006 & $-0,498$ & $-0,439$ & $-0,550$ & $-0,572$ & $-0,774$ & $-0,346$ & $-0,146$ \\
\hline Sepiolita & $-0,167$ & 0,093 & 0,059 & $-0,008$ & $-0,154$ & $-0,268$ & $-0,387$ & $-0,380$ & $-0,440$ & $-0,254$ \\
\hline M.O & $-0,163$ & 0,254 & 0,218 & 0,165 & 0,216 & 0,040 & $-0,004$ & $-0,133$ & $-0,170$ & $-0,038$ \\
\hline Paligorkita & $-0,125$ & 0,356 & 0,172 & 0,189 & 0,059 & $-0,279$ & $-0,358$ & $-0,200$ & $-0,382$ & $-0,190$ \\
\hline $\mathrm{CO} 3$ & 0,403 & 0,021 & $-0,369$ & $-0,642$ & $-0,562$ & $-0,775$ & $-0,785$ & $-0,565$ & $-0,676$ & $-0,248$ \\
\hline Calcita & 0,098 & $-0,147$ & $-0,257$ & $-0,651$ & $-0,486$ & $-0,683$ & $-0,528$ & $-0,447$ & $-0,463$ & $\mid-0,148$ \\
\hline E1 & 0,543 & $-0,310$ & $-0,313$ & $-0,629$ & $-0,776$ & $-0,754$ & $-0,622$ & $-0,665$ & $-0,157$ & $-0,120$ \\
\hline$P$ & 0,282 & $-0,068$ & $-0,176$ & $-0,674$ & $-0,536$ & $-0,553$ & \begin{tabular}{|l|}
$-0,633$ \\
\end{tabular} & $-0,413$ & $-0,332$ & $-0,095$ \\
\hline Vermiculita & 0,476 & 0,040 & $-0,318$ & $-0,316$ & $-0,069$ & $-0,183$ & $-0,058$ & $-0,138$ & $-0,214$ & $-0,365$ \\
\hline Ca extr & 0,393 & \begin{tabular}{|l|}
$-0,071$ \\
\end{tabular} & $-0,118$ & $-0,568$ & \begin{tabular}{|l|}
$-0,504$ \\
\end{tabular} & $-0,709$ & $-0,575$ & $-0,527$ & $-0,424$ & $-0,114$ \\
\hline Caolinita & 0,135 & $-0,035$ & $-0,038$ & 0,134 & 0,119 & 0,167 & 0,135 & 0,201 & 0,056 & $-0,101$ \\
\hline Yeso & & 0,067 & $-0,272$ & $-0,447$ & $-0,361$ & $-0,515$ & $-0,420$ & $-0,384$ & $-0,173$ & $-0,223$ \\
\hline $\mathrm{Na}$ tot & $-0,054$ & & 0,517 & 0,360 & 0,515 & 0,176 & 0,204 & $-0,028$ & 0,081 & $-0,112$ \\
\hline $\mathrm{Cu}$ & $-0,157$ & 0,677 & & 0,313 & 0,266 & 0,352 & 0,341 & 0,052 & 0,425 & 0,026 \\
\hline $\mathrm{Na}$ extr & $-0,245$ & 0,604 & 0,330 & & 0,733 & 0,679 & 0,615 & 0,434 & 0,322 & 0,058 \\
\hline $\mathrm{pH}$ & $-0,293$ & 0,519 & 0,295 & 0,683 & & 0,733 & 0,653 & 0,535 & 0,247 & 0,215 \\
\hline Cuarzo & $-0,265$ & 0,299 & 0,264 & 0,426 & 0,780 & & 0,831 & 0,706 & 0,483 & 0,089 \\
\hline Feldespato & $-0,237$ & 0,298 & 0,341 & 0,448 & 0,672 & 0,741 & & 0,603 & 0,645 & 0,150 \\
\hline Arenas & $-0,191$ & 0,067 & $-0,062$ & 0,198 & 0,611 & 0,756 & 0,571 & & 0,354 & 0,136 \\
\hline Fe extr & $-0,104$ & 0,117 & 0,387 & 0,157 & 0,250 & 0,395 & 0,582 & 0,285 & & 0,401 \\
\hline Clorita & $-0,142$ & $-0,151$ & $-0,039$ & $-0,055$ & 0,032 & $-0,067$ & 0,016 & 0,082 & 0,324 & \\
\hline
\end{tabular}


A.V INFLUENCIA DE LAS PRÁCTICAS AGRÍCOLAS EN LA MOVILIZACIÓN Y DISPERSIÓN DE ARSÉNICO 



\begin{tabular}{|c|c|c|c|c|c|c|c|c|c|c|c|c|c|c|c|c|c|c|c|c|c|c|c|c|}
\hline & 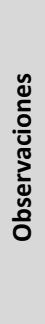 & & 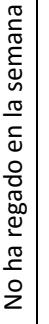 & 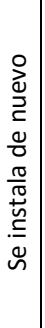 & & & & & 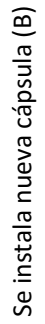 & & & & & 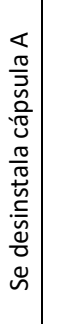 & 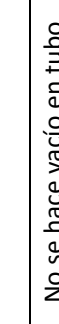 & 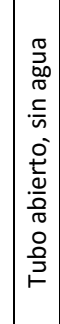 & & & & & & & & 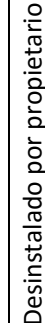 \\
\hline \multirow{5}{*}{ 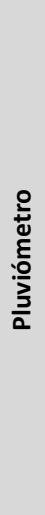 } & d & & $\begin{array}{l}0 \\
\stackrel{2}{ }\end{array}$ & 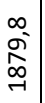 & 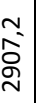 & $\begin{array}{l}0 \\
\text { Jे } \\
\text { సે }\end{array}$ & $\begin{array}{l}\stackrel{m}{*} \\
\stackrel{\tilde{N}}{N}\end{array}$ & $\begin{array}{l}\text { Oे } \\
\tilde{N} \\
0 \\
\text { N. }\end{array}$ & & 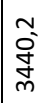 & 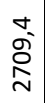 & 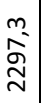 & 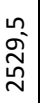 & $\begin{array}{l}0 \\
0 \\
0 \\
0 \\
\text { ond }\end{array}$ & 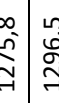 & $\underset{\sigma}{\tilde{\sigma}}$ & $\begin{array}{l}\vec{m} \\
\dot{m}\end{array}$ & $\begin{array}{c}\sigma_{1} \\
\infty\end{array}$ & $\stackrel{2}{\approx}$ & ? & $\stackrel{2}{\pi}$ & 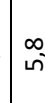 & 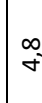 & \\
\hline & $\stackrel{\tilde{o}}{2}$ & & $\overrightarrow{+}$ & $\overrightarrow{\vec{b}}$ & ְ̃. & ֶ̃ & تే & 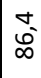 & & $\stackrel{m}{\stackrel{m}{\infty}}$ & $\overrightarrow{\tilde{N}}$ & $\underset{\substack{n \\
\infty}}{\mid-1}$ & $\begin{array}{l}\stackrel{n}{\sim} \\
\stackrel{\infty}{\infty}\end{array}$ & $\stackrel{m}{g}=$ & 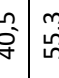 & m & $\overrightarrow{0}$ & $\stackrel{n}{\rightarrow}$ & $\underset{\sim}{\sim}$ & $?$ & O & $\stackrel{\circ}{\circ}$ & $\begin{array}{l}1 \\
\infty \\
\infty\end{array}$ & \\
\hline & $\bar{u}$ & & 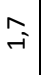 & $\begin{array}{l}\overrightarrow{0} \\
\text { s. }\end{array}$ & $\begin{array}{l}\mathscr{g}^{\prime} \\
\tilde{y}^{2}\end{array}$ & ì & $\begin{array}{l}0 \\
\infty \\
m \\
m\end{array}$ & જે & & 今ે & $\stackrel{\infty}{\tilde{N}_{n}^{-}}$ & $\begin{array}{l}\stackrel{g}{*} \\
\dot{g}\end{array}$ & $\begin{array}{l}0 \\
\dot{g} \\
g\end{array}$ & $\begin{array}{l}0 \\
\end{array}$ & 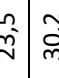 & $\stackrel{0}{0}$ & $\stackrel{n}{0}$ & $\stackrel{m}{\sim}$ & $\stackrel{\sim}{\sim}$ & 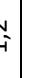 & O & $\stackrel{\circ}{\circ}$ & $\underset{-}{A}$ & \\
\hline & \& & 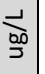 & $\hat{m}$ & $\begin{array}{c}\mathfrak{n} \\
\stackrel{\infty}{0}\end{array}$ & & 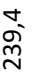 & 告 & 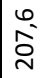 & & 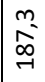 & \begin{tabular}{l}
$m$ \\
s. \\
\multirow{N}{*}{}
\end{tabular} & $\underset{\substack{m \\
\mathfrak{J}}}{\mid}$ & 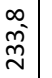 & $\underset{\substack{\tilde{N} \\
\sim}}{0}$ & $\begin{array}{l}- \\
n \\
n\end{array}$ & 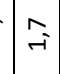 & $\mid \begin{array}{l}0 \\
\infty \\
\infty\end{array}$ & $\stackrel{\sim}{\Im}$ & $\vec{\sigma}$ & & : & $\overrightarrow{0}$ & O & \\
\hline & $>$ & $\stackrel{\xi}{\xi}$ & $\begin{array}{l}\mathfrak{N} \\
\stackrel{N}{N}\end{array}$ & î & & $\begin{array}{l}\text { İ } \\
\text { సे }\end{array}$ & वे & 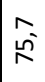 & & $\begin{array}{l}\text { बे } \\
\text { ले }\end{array}$ & \begin{tabular}{l}
$m$ \\
f \\
\multirow{1}{*}{}
\end{tabular} & $\begin{array}{l}0 \\
\text { in } \\
\text { no }\end{array}$ & 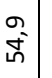 & $\begin{array}{l}0 \\
i \\
i\end{array}$ & 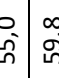 & 灾 & $\mid \begin{array}{l}0 \\
y^{\prime}\end{array}$ & $\sigma^{m}$ & \begin{tabular}{l}
$\stackrel{n}{ \pm}$ \\
\multirow{J}{*}{}
\end{tabular} & & $\stackrel{f}{s}$ & $\underset{\sim}{\infty}$ & $\overrightarrow{\text { Dे }}$ & \\
\hline \multirow{7}{*}{ 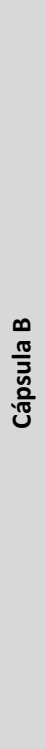 } & d & & & & & & & & & & $\begin{array}{l}0 \\
\text { নे } \\
\text { m }\end{array}$ & 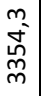 & 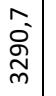 & $\begin{array}{c}\hat{2} \\
\tilde{\tilde{D}} \\
\tilde{m}\end{array}$ & 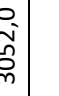 & & $\mid \begin{array}{l}0 \\
\infty \\
\infty \\
\sim \\
\sim\end{array}$ & \begin{tabular}{l}
$\infty$ \\
\multirow{J}{*}{} \\
$\underset{\sim}{*}$
\end{tabular} & 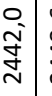 & & 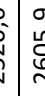 & 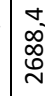 & $\mid \begin{array}{l}0 \\
\tilde{o} \\
o \\
\tilde{N}\end{array}$ & \\
\hline & ô & 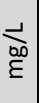 & & & & & & & & & $\begin{array}{l}n \\
\underset{\infty}{\infty}\end{array}$ & 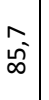 & $\begin{array}{l}\vec{\sigma} \\
\vec{\sigma}\end{array}$ & 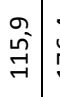 & 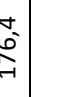 & & $\mid \begin{array}{c}m \\
\hat{0} \\
\tilde{m} \\
-1\end{array}$ & 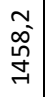 & $\begin{array}{l}\infty \\
m \\
\vec{y} \\
\vec{J} \\
\end{array}$ & & 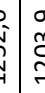 & 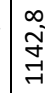 & $\begin{array}{l}\text { } \\
\hat{\tilde{m}} \\
\stackrel{-}{2}\end{array}$ & \\
\hline & $\bar{\Xi}$ & & & & & & & & & & જી & $\begin{array}{l}\infty \\
0^{-}\end{array}$ & $\hat{m}$ & ஸे & $\underset{\substack{n \\
N}}{n}$ & & $\begin{array}{l}\hat{\vec{J}} \\
\vec{N}\end{array}$ & $\begin{array}{l}\infty \\
\stackrel{\infty}{\sim} \\
\stackrel{n}{n}\end{array}$ & 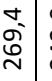 & & 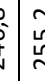 & $\mid \begin{array}{l}\tilde{N} \\
\tilde{N}\end{array}$ & $\begin{array}{l}\underset{\sim}{\sim} \\
\underset{N}{+}\end{array}$ & \\
\hline & ¿ & $\overleftrightarrow{\mathrm{d}}$ & & & & & & & & & $\hat{\tilde{n}}$ & $\begin{array}{l}0 \\
0 \\
0 \\
0\end{array}$ & 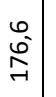 & $\begin{array}{l}0 \\
\mathbb{N} \\
\mathbb{N}\end{array}$ & $\begin{array}{l}\infty \\
\text { N } \\
m \\
m\end{array}$ & \begin{tabular}{|l}
$\infty$ \\
$\infty$ \\
$\stackrel{D}{0}^{\circ}$
\end{tabular} & 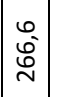 & 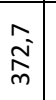 & $\begin{array}{c}m \\
\infty \\
\infty \\
m \\
m\end{array}$ & & $\hat{a}$ & $\mid \begin{array}{l}\infty \\
\text { N్ } \\
\text { N }\end{array}$ & 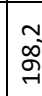 & \\
\hline & a & 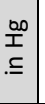 & & & & & & & $\begin{array}{l}n \\
\text { g }\end{array}$ & ì & ñ & $\stackrel{-}{i}$ & $\begin{array}{l}0 \\
\dot{N}\end{array}$ & $\begin{array}{l}0 \\
-i\end{array}$ & i & i & & $\begin{array}{c}0 \\
\stackrel{\infty}{a} \\
\rightarrow\end{array}$ & \begin{tabular}{l}
0 \\
\multirow{\sim}{*}{}
\end{tabular} & & $\vec{s}$ & iे & $\begin{array}{l}\stackrel{n}{2} \\
\text { N }\end{array}$ & \\
\hline & $>$ & $\stackrel{m}{\xi}$ & & & & & & & & 0 & 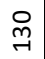 & 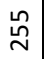 & 各 & \&) & ô & 0 & 怘 & $\begin{array}{l}\text { 吕 } \\
\infty\end{array}$ & ¿̊. & $p$ & ? & 多 & ঃ & \\
\hline & $\begin{array}{l}\stackrel{\circ}{\bar{J}} \\
\stackrel{5}{>}\end{array}$ & & & & & & & & & zo & in & $i$ & in & $\bar{n}$ & $\frac{2}{2}$ & $\mid \begin{array}{l}\frac{0}{0} \\
\frac{0}{2}\end{array}$ & $\bar{s}$ & $\bar{n}$ & $\bar{n}$ & & is & is & is & \\
\hline \multirow{4}{*}{ 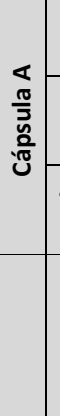 } & a & 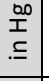 & 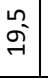 & 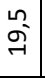 & & $\stackrel{\infty}{\sim}$ & & $\vec{\lambda}$ & $\vec{N}$ & $\vec{\lambda}$ & ñ & & & & & & & & & & & & & \\
\hline & & $\stackrel{m}{\xi}$ & 0 & 0 & 0 & 0 & 0 & 0 & 0 & 0 & 0 & 0 & & & & & & & & & & & & \\
\hline & $\begin{array}{l}\stackrel{\circ}{\mathscr{U}} \\
\stackrel{\Gamma}{>}\end{array}$ & & 2 & z & $\stackrel{0}{2}$ & $\bar{n}$ & is & z & 2 & $\frac{0}{2}$ & z & z & & & & & & & & & & & & \\
\hline & & 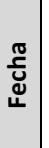 & 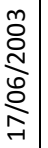 & 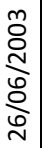 & & 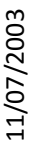 & 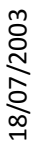 & 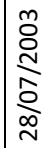 & 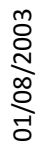 & 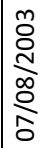 & 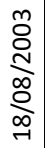 & 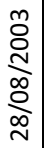 & 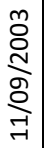 & 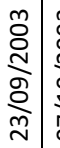 & 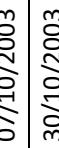 & 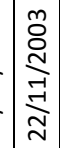 & 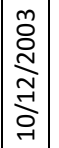 & 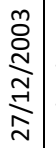 & 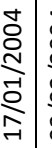 & & 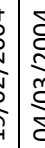 & 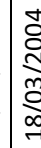 & 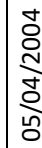 & 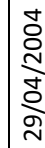 \\
\hline
\end{tabular}




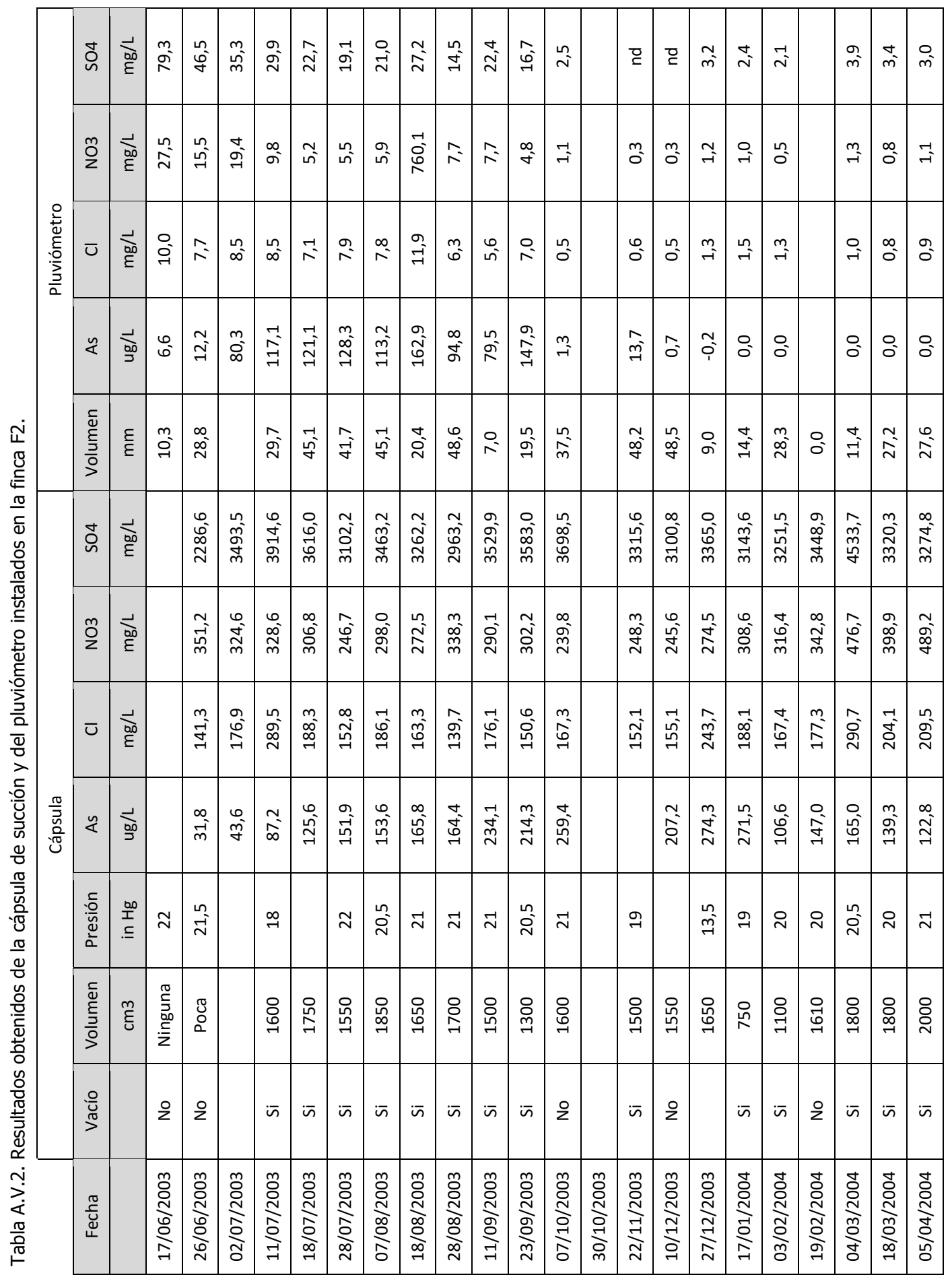




\begin{tabular}{|c|c|c|c|c|c|c|c|c|c|c|c|c|c|c|c|c|c|c|c|c|c|c|c|c|c|}
\hline & 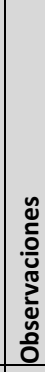 & & & & 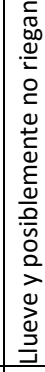 & & 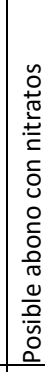 & & & & & & & & & 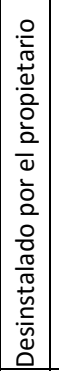 & 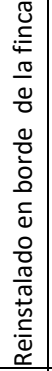 & & 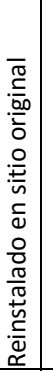 & & & & & & \\
\hline & ర్ & ठै & 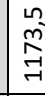 & 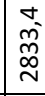 & $\begin{array}{l}\widehat{c} \\
\infty \\
\infty\end{array}$ & 竎 & 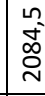 & 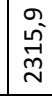 & $\begin{array}{l}0 \\
\text { g̀ } \\
\text { J }\end{array}$ & 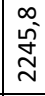 & $\begin{array}{l}\stackrel{0}{0} \\
\stackrel{0}{2} \\
\text {. }\end{array}$ & $\begin{array}{l}\stackrel{n}{\tilde{p}} \\
\tilde{m} \\
\sim\end{array}$ & $\begin{array}{l}\infty \\
\stackrel{\infty}{\sim} \\
\underset{N}{N}\end{array}$ & 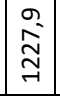 & $\begin{array}{l}\sigma \\
\hat{\rho} \\
\end{array}$ & $\begin{array}{l}\infty \\
\infty \\
心 \\
\text { i }\end{array}$ & & İ & & $\begin{array}{l}\infty \\
\vec{\sigma}\end{array}$ & & min & $\begin{array}{l}0 \\
\text { Oे } \\
\end{array}$ & $\stackrel{0}{\exists}$ & $\underset{d}{\stackrel{N}{d}}$ \\
\hline$\stackrel{\circ}{=}$ & ô & ठै & $\stackrel{1}{=}$ & $\stackrel{\circ}{\infty}$ & $\tilde{n}^{2}$ & $\stackrel{N}{\sim}$ & $\begin{array}{l}\tilde{N} \\
\tilde{N} \\
\infty\end{array}$ & 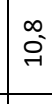 & 吾 & $\hat{m}$ & $\begin{array}{l}\infty \\
\exists \\
\exists\end{array}$ & $\stackrel{+}{\stackrel{v}{g}}$ & 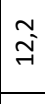 & $\overrightarrow{6}$ & $\stackrel{\sim}{二}$ & $\stackrel{\infty}{\infty}$ & & $\stackrel{\stackrel{L}{m}_{m}}{ }$ & & $\stackrel{9}{\mathbf{N}}$ & & $\stackrel{0}{i}$ & 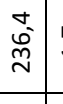 & 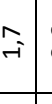 & $\begin{array}{l}0 \\
\infty^{\circ}\end{array}$ \\
\hline 苋 & $\bar{\Xi}$ & है & $\mid \begin{array}{c}m \\
\text { ò }\end{array}$ & 궁 & & 오 & $\begin{array}{l}0 \\
\tilde{m}\end{array}$ & $\begin{array}{l}\dot{+} \\
\dot{f}\end{array}$ & 号 & $\begin{array}{l}\tilde{y} \\
\tilde{g}\end{array}$ & $\stackrel{\hat{o}}{\tilde{m}^{-}}$ & F & $\hat{\vec{y}}$ & $\vec{d}$ & $\stackrel{m}{\rightarrow}$ & g. & & 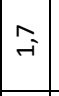 & & $\begin{array}{l}\text { 守 } \\
\underset{m}{\tilde{m}}\end{array}$ & & 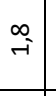 & O. & 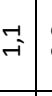 & $\stackrel{\infty}{\infty}$ \\
\hline & \& & 5 & $\vec{m}$ & $\stackrel{+}{A}$ & & $\stackrel{\vec{m}}{\stackrel{-}{m}}$ & $\stackrel{\vec{m}}{\vec{m}}$ & $\mid \begin{array}{l}\infty \\
\text { fं }\end{array}$ & & $\stackrel{\widehat{\infty}}{\sim^{-}}$ & 点 & $\stackrel{\vec{N}}{\stackrel{\sim}{N}}$ & \begin{tabular}{l}
\multirow{\alpha}{*}{} \\
$\tilde{m}$
\end{tabular} & 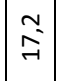 & $\begin{array}{l}0 \\
0\end{array}$ & $\tilde{N}$ & & $\underset{\rightarrow}{m}$ & & $\begin{array}{c} \\
\exists \\
\exists\end{array}$ & & $\begin{array}{l}\infty \\
0 \\
0\end{array}$ & $\stackrel{m}{\rightarrow}$ & $\begin{array}{l}0 \\
0\end{array}$ & $\stackrel{\infty}{\infty}$ \\
\hline & $\bar{\rho}$ & है & $\mid \begin{array}{l}\infty \\
\stackrel{\infty}{n}\end{array}$ & 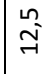 & & $\stackrel{m}{\tilde{m}}$ & ¿̀ & 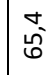 & 离 & $\mid \begin{array}{l}0 \\
0 \\
0 \\
0\end{array}$ & $\mid \begin{array}{c}0 \\
i \\
\infty\end{array}$ & ০े & $\begin{array}{l}0 \\
\infty \\
\infty\end{array}$ & $\overrightarrow{\hat{j}}$ & $\begin{array}{l}\sim \\
\tilde{F} \\
\tilde{m}\end{array}$ & 离 & & 0 & & $\mid \begin{array}{l}\infty \\
\vdots \\
i\end{array}$ & $:$ & $\left|\begin{array}{l}\tilde{\Xi} \\
\tilde{I}\end{array}\right|$ & 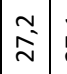 & $\vec{\sim}$ & in \\
\hline & ర్ & ठิ & $\mid$\begin{tabular}{l}
0 \\
\multirow{J}{*}{}
\end{tabular} & 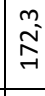 & $\begin{array}{l}\infty \\
\stackrel{\infty}{m} \\
\stackrel{m}{-1}\end{array}$ & 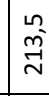 & 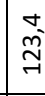 & $\hat{i}$ & 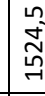 & $\begin{array}{l}0 \\
\text { ò } \\
\text { du }\end{array}$ & $\begin{array}{l}0 \\
\tilde{N} \\
\stackrel{N}{N}\end{array}$ & 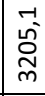 & 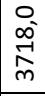 & $\mid \begin{array}{c}-1 \\
\infty \\
0 \\
\vec{\gamma}\end{array}$ & \begin{tabular}{|c}
$\mathcal{N}$ \\
$\tilde{z}$ \\
$\mathfrak{g}$ \\
\end{tabular} & $\begin{array}{l}a \\
\tilde{N} \\
\tilde{N} \\
\tilde{m}\end{array}$ & & & & 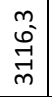 & & & $\mid \begin{array}{c}0 \\
0 \\
0 \\
0 \\
\sim \\
\sim\end{array}$ & $\begin{array}{l}\mathcal{N} \\
\text { న } \\
\text { N̦ }\end{array}$ & \\
\hline & $\overbrace{2}^{m}$ & ठิ & 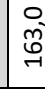 & 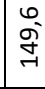 & 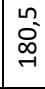 & $\begin{array}{l}0 \\
0 \\
0 \\
0\end{array}$ & $\begin{array}{l}\vec{A} \\
\stackrel{-}{m}\end{array}$ & 离 & 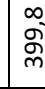 & 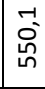 & 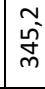 & 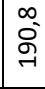 & 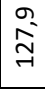 & $\begin{array}{l}\tilde{N} \\
\tilde{N}\end{array}$ & $\begin{array}{l}0 \\
\sigma\end{array}$ & & & & & $\vec{i}$ & & & $\mid$\begin{tabular}{|l}
$\vec{m}$ \\
$\bar{m}$
\end{tabular} & ڤ્) & \\
\hline & $\bar{U}$ & है & gे & 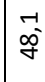 & $\frac{\pi}{6}$ & 今. & $\begin{array}{l}\hat{a} \\
\stackrel{े}{2}\end{array}$ & 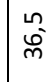 & 羕 & 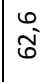 & 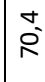 & $\frac{\tilde{a}}{\mathrm{o}}$ & $\stackrel{\infty}{\stackrel{\infty}{0}}$ & in & $\begin{array}{l}\infty \\
\tilde{\tilde{n}}\end{array}$ & io & & & & 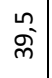 & & & $\left|\begin{array}{l}0 \\
\tilde{n} \\
n\end{array}\right|$ & (્) & \\
\hline $\begin{array}{l}\text { 势 } \\
\text { 总 }\end{array}$ & \& & ริ) & \begin{tabular}{|l}
$\infty$ \\
0 \\
0
\end{tabular} & 竎 & & 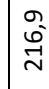 & $\begin{array}{l}6 \\
0 \\
0 \\
-1\end{array}$ & $\mid$\begin{tabular}{l}
\multirow{2}{\infty}{} \\
$\stackrel{\infty}{-1}$
\end{tabular} & $\mid \begin{array}{l}a \\
\infty \\
n \\
n\end{array}$ & 离 & $\underset{\substack{n \\
\mathcal{N}}}{ }$ & 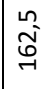 & $\underset{\sim}{\stackrel{N}{\sim}}$ & 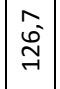 & $\mid \begin{array}{c}m \\
\vec{\exists}\end{array}$ & \begin{tabular}{l}
0 \\
\multirow{N}{N}{}
\end{tabular} & & & & $\stackrel{+}{\stackrel{N}{N}}$ & & & $\vec{g}$ & 管 & \\
\hline & 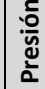 & 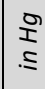 & $\stackrel{n}{\sim}$ & 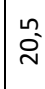 & & $\stackrel{\infty}{\sim}$ & & 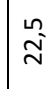 & $\stackrel{n}{\pi}$ & $\vec{N}$ & $\vec{N}$ & $\vec{N}$ & $\vec{N}$ & $\vec{N}$ & i & $\stackrel{\sim}{\sim}$ & $\stackrel{\infty}{\sim}$ & 凡 & $\stackrel{\sim}{\sim}$ & $\stackrel{\sim}{\sim}$ & 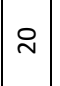 & 望 & i & مُ & \\
\hline & $\overline{>}$ & है & \begin{tabular}{|l}
$\widetilde{\Xi}$ \\
。
\end{tabular} & 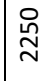 & & 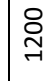 & 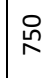 & 号 & 융 & ర్రి & 号 & 兽 & 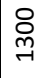 & 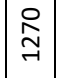 & & 员 & & 0 & 0 & 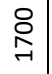 & 0 & 0 & 员 & : & 0 \\
\hline & $\begin{array}{l}\stackrel{\circ}{\square} \\
\stackrel{\pi}{>}\end{array}$ & & 울 & is & & $\bar{n}$ & is & in & is & is & is & is & $i \bar{n}$ & $\frac{0}{2}$ & in & in & & & $\bar{n}$ & $\bar{i}$ & $i$ & 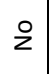 & is & in & 2 \\
\hline & 荵 & & 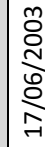 & 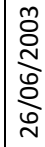 & 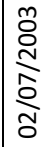 & 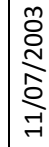 & 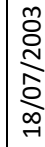 & 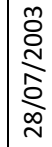 & 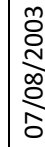 & 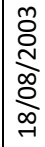 & $\mid \begin{array}{l}\infty \\
\stackrel{\infty}{\infty} \\
\stackrel{\infty}{\infty} \\
\stackrel{\infty}{N}\end{array}$ & 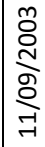 & 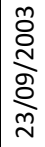 & 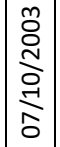 & 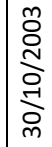 & 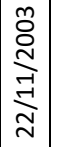 & 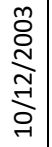 & 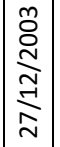 & 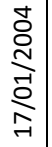 & 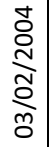 & 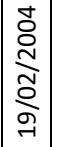 & 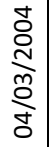 & 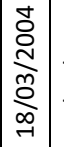 & 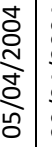 & 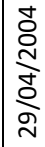 \\
\hline
\end{tabular}


Hidrogeoquímica de aguas subterráneas de un sector de la Cuenca del Duero con altos niveles de arsénico

Tabla A.V.4. Resultados analíticos de los suelos agrícolas.

\begin{tabular}{|c|c|c|c|c|c|c|}
\hline Muestra & Coordenada X & Coordenada Y & Cota & Estado & unidad geologica & As de los pozos \\
\hline & & & $m$ & & & $p p b$ \\
\hline 16 & 385662 & 4586079 & 874,6 & Sembrado & CP-TP & 3,7 \\
\hline $16^{*}$ & 385700 & 4586118 & 874,6 & Barbecho & CP-TP & 3,7 \\
\hline 37 & 377289 & 4584845 & 761,7 & Sembrado & CA-FVA-MP & 111,9 \\
\hline $37^{*}$ & 377361 & 4584825 & 761,7 & Barbecho & CA-FVA-MP & 111,9 \\
\hline 57 & 385006 & 4582723 & 771,9 & Sembrado & SA-FCs & 117,2 \\
\hline $57^{*}$ & 384968 & 4582684 & 771,9 & Barbecho & SA-FCs & 117,2 \\
\hline 61 & 382820 & 4583155 & 766,2 & Sembrado & SA-FVA & 273 \\
\hline $61^{*}$ & 382860 & 4583195 & 766,2 & Barbecho & SA-FVA & 273 \\
\hline 65 & 380550 & 4583260 & 761,3 & Sembrado & COL-FVA & 238,2 \\
\hline $65^{*}$ & 380588 & 4583299 & 761,3 & Barbecho & COL-FVA & 238,2 \\
\hline 68 & 377933 & 4584685 & 761,9 & Sembrado & CD-FVA & 112,9 \\
\hline $68^{*}$ & 377973 & 4584727 & 761,9 & Barbecho & CD-FVA & 112,9 \\
\hline 69 & 378451 & 4585790 & 774,1 & Sembrado & CD-Fci & 50,9 \\
\hline $69 *$ & 378421 & 4585758 & 774,1 & Barbecho & CD-Fci & 50,9 \\
\hline 70 & 378317 & 4586313 & 794,1 & Sembrado & CA-FCs & 19,1 \\
\hline $70 *$ & 378297 & 4586288 & 794,1 & Barbecho & CA-FCs & 19,1 \\
\hline $14 *$ & 384849 & 4585726 & 835,1 & Barbecho & CA-FCs & 2,6 \\
\hline 14 & 384864 & 4585808 & 835,1 & Sembrado & CA-FCs & 2,6 \\
\hline $20 *$ & 384070 & 4585203 & 817,5 & Barbecho & CA-FCs & 11,6 \\
\hline 20 & 384110 & 4585171 & 817,5 & Sembrado & CA-FCs & 11,6 \\
\hline $48^{*}$ & 379021 & 4583531 & 752,2 & Barbecho & ME-SA-FVA-MP & 117,2 \\
\hline 48 & 379004 & 4583531 & 752,2 & Sembrado & ME-SA-FVA-MP & 117,2 \\
\hline $66^{*}$ & 383008 & 4584640 & 800,8 & Barbecho & CA-FCs & 64,5 \\
\hline 66 & 383034 & 4584662 & 800,8 & Sembrado & CA-FCs & 64,5 \\
\hline
\end{tabular}

Tabla A.V.4. Continuación.

\begin{tabular}{|c|c|c|c|c|c|c|c|c|c|c|c|}
\hline Muestra & $\mathrm{pH}$ & $x$ & $\mathrm{M}, \mathrm{O}$ & Carbonatos & $\mathrm{P}$ & Fe tot & Mn tot & Ca extr & Mg extr & $\mathrm{Na}$ extr & K extr \\
\hline & & $\mu \mathrm{S} / \mathrm{cm}$ & $\%$ & $\%$ & $\mathrm{mg} / \mathrm{kg}$ & $g / k g$ & $\mathrm{mg} / \mathrm{kg}$ & $\mathrm{g} / \mathrm{kg}$ & $g / k g$ & $g / k g$ & $\mathrm{~g} / \mathrm{kg}$ \\
\hline 16 & 7.94 & 417.0 & 0.28 & 23.7 & 359.4 & 19.7 & 148.5 & 5.50 & 0.37 & 0.01 & 0.40 \\
\hline $16^{*}$ & 8.24 & 333.5 & 0.23 & 33.7 & 126.0 & 20.9 & 132.6 & 8.45 & 0.50 & 0.01 & 0.36 \\
\hline 37 & 8.99 & 167.7 & 0.11 & 3.7 & 47.3 & 23.5 & 148.7 & 7.16 & 0.21 & 0.11 & 0.16 \\
\hline $37^{*}$ & 7.41 & 178.8 & 0.11 & 0.2 & 23.2 & 19.1 & 129.9 & 0.81 & 0.15 & 0.00 & 0.20 \\
\hline 57 & 7.76 & 1489.5 & 0.13 & 10.2 & 33.8 & 18.1 & 109.1 & 11.62 & 0.53 & 0.02 & 0.10 \\
\hline $57 *$ & 8.80 & 206.1 & 0.02 & 1.2 & 3.1 & 8.4 & 33.2 & 0.93 & 0.28 & 0.01 & 0.02 \\
\hline 61 & 7.92 & 1926.0 & 0.23 & 36.3 & 28.7 & 38.8 & 232.3 & 9.62 & 0.82 & 0.03 & 0.18 \\
\hline $61^{*}$ & 8.22 & 916.5 & 0.26 & 46.1 & 60.5 & 37.8 & 201.5 & 8.93 & 0.48 & 0.53 & 0.47 \\
\hline 65 & 7.91 & 1895.5 & 0.20 & 45.3 & 55.4 & 41.1 & 193.6 & 14.33 & 1.00 & 0.06 & 0.41 \\
\hline $65^{*}$ & 8.45 & 425.5 & 0.07 & 8.6 & 24.6 & 13.0 & 56.4 & 6.54 & 0.16 & 0.09 & 0.10 \\
\hline 68 & 7.81 & 2510.0 & 0.24 & 16.4 & 52.7 & 30.9 & 170.7 & 44.97 & 0.78 & 0.02 & 0.23 \\
\hline $68^{*}$ & 7.86 & 1690.0 & 0.22 & 16.2 & 32.3 & 33.2 & 170.4 & 46.48 & 0.42 & 0.02 & 0.17 \\
\hline 69 & 8.21 & 457.0 & 0.18 & 11.1 & 32.6 & 49.0 & 278.5 & 7.29 & 0.51 & 0.02 & 0.38 \\
\hline 69* & 8.38 & 301.5 & 0.31 & 17.2 & 86.8 & 43.1 & 262.6 & 8.24 & 0.54 & 0.05 & 0.63 \\
\hline 70 & 8.50 & 262.5 & 0.22 & 37.1 & 36.5 & 39.3 & 214.9 & 6.47 & 0.42 & 0.01 & 0.37 \\
\hline $70 *$ & 8.62 & 266.5 & 0.24 & 28.2 & 28.4 & 33.2 & 174.4 & 5.71 & 0.39 & 0.03 & 0.39 \\
\hline $14 *$ & 8.67 & 195.0 & 0.19 & 49.2 & 21.9 & 23.2 & 109.4 & 5.62 & 0.34 & 0.01 & 0.26 \\
\hline 14 & 8.32 & 363.5 & 0.17 & 57.5 & 52.5 & 27.3 & 119.3 & 22.24 & 0.55 & 0.01 & 0.38 \\
\hline $20 *$ & 8.17 & 473.5 & 0.34 & 16.7 & 47.5 & 26.3 & 147.8 & 8.85 & 0.56 & 0.02 & 0.32 \\
\hline 20 & 8.00 & 1042.5 & 0.46 & 19.3 & 122.1 & 34.7 & 175.7 & 9.61 & 0.56 & 0.02 & 0.52 \\
\hline $48^{*}$ & 8.25 & 1389.0 & 0.05 & 0.7 & 35.1 & 13.0 & 103.3 & 0.57 & 0.16 & 0.01 & 0.04 \\
\hline 48 & 8.11 & 2540.0 & 0.25 & 8.9 & 42.3 & 16.8 & 67.4 & 8.30 & 0.65 & 0.09 & 0.26 \\
\hline $66^{*}$ & 8.39 & 383.5 & 0.24 & 55.2 & 66.2 & 40.8 & 228.5 & 9.87 & 0.86 & 0.02 & 0.94 \\
\hline 66 & 8.12 & 493.0 & 0.22 & 29.5 & 97.8 & 29.6 & 154.4 & 7.83 & 0.51 & 0.02 & 0.39 \\
\hline
\end{tabular}


Tabla A.V.4. Continuación.

\begin{tabular}{|c|c|c|c|c|c|c|c|c|c|}
\hline Muestra & Arenas & Limos & Arcillas & $\mathrm{As}$ & $\mathrm{Cu}$ & $\mathrm{Cr}$ & $\mathrm{Pb}$ & $\mathrm{V}$ & $\mathrm{Zn}$ \\
\hline & $\%$ & $\%$ & $\%$ & $m g / k g$ & $m g / k g$ & $m g / k g$ & $m g / k g$ & $\mathrm{mg} / \mathrm{kg}$ & $\mathrm{mg} / \mathrm{kg}$ \\
\hline 16 & 59,5 & 27,2 & 13,3 & 4,1 & 23,5 & 6,8 & 5,6 & 7,2 & 43,6 \\
\hline $16^{*}$ & 48,8 & 30,5 & 20,8 & 4,2 & 15,0 & 6,6 & 9,1 & 7,3 & 32,9 \\
\hline 37 & 75,9 & 10,9 & 13,1 & 3,4 & 4,4 & 5,0 & 3,9 & 6,7 & 21,2 \\
\hline $37^{*}$ & 84,8 & 4,1 & 11,1 & 0,8 & 5,6 & 3,5 & 4,5 & 4,3 & 13,0 \\
\hline 57 & 67,2 & 21,0 & 11,8 & 7,7 & 1,7 & 4,5 & 3,6 & 7,6 & 12,1 \\
\hline $57^{*}$ & 90,6 & 1,3 & 8,1 & 0,8 & $-1,0$ & 1,2 & 1,5 & 1,6 & 4,4 \\
\hline 61 & 42,6 & 48,7 & 8,7 & 12,6 & 7,8 & 9,8 & 7,1 & 15,0 & 30,6 \\
\hline $61^{*}$ & 16,6 & 43,7 & 39,7 & 9,8 & 7,3 & 9,7 & 6,7 & 14,3 & 38,9 \\
\hline 65 & 29,1 & 48,9 & 22,0 & 9,3 & 8,2 & 9,4 & 6,7 & 15,9 & 34,9 \\
\hline $65^{*}$ & 76,9 & 11,7 & 11,4 & 3,9 & 2,4 & 3,2 & 2,1 & 4,8 & 8,8 \\
\hline 68 & 43,1 & 45,6 & 11,4 & 15,7 & 3,9 & 6,1 & 5,1 & 14,7 & 22,9 \\
\hline $68^{*}$ & 34,5 & 60,1 & 5,4 & 13,9 & 6,1 & 7,1 & 5,0 & 14,8 & 36,8 \\
\hline 69 & 53,1 & 36,0 & 10,9 & 4,1 & 8,1 & 10,3 & 9,3 & 8,6 & 37,0 \\
\hline $69^{*}$ & 46,5 & 40,9 & 12,6 & 3,5 & 17,5 & 9,8 & 8,2 & 9,6 & 45,7 \\
\hline 70 & 32,0 & 51,8 & 16,2 & 4,3 & 8,2 & 9,3 & 6,8 & 9,9 & 34,6 \\
\hline $70^{*}$ & 49,1 & 45,9 & 5,0 & 3,6 & 9,2 & 8,7 & 6,6 & 9,0 & 28,5 \\
\hline $14^{*}$ & 46,2 & 38,9 & 14,9 & 5,1 & 2,8 & 6,2 & 4,8 & 11,4 & 17,0 \\
\hline 14 & 32,3 & 39,0 & 28,6 & 5,6 & 3,2 & 7,4 & 4,9 & 12,5 & 20,7 \\
\hline $20^{*}$ & 39,3 & 44,3 & 16,4 & 5,7 & 4,8 & 7,1 & 8,4 & 10,5 & 30,4 \\
\hline 20 & 29,9 & 50,5 & 19,6 & 6,8 & 9,7 & 8,7 & 7,1 & 13,2 & 41,7 \\
\hline $48^{*}$ & 77,5 & 10,7 & 11,8 & 7,6 & 9,4 & 4,0 & 4,8 & 12,9 & 22,5 \\
\hline 48 & 69,2 & 19,0 & 11,8 & 8,7 & 3,2 & 3,6 & 2,9 & 10,8 & 14,6 \\
\hline $66^{*}$ & 18,1 & 60,6 & 21,3 & 6,6 & 10,8 & 10,7 & 7,6 & 14,6 & 40,2 \\
\hline 66 & 46,3 & 33,3 & 20,5 & 4,5 & 11,4 & 7,9 & 10,6 & 9,4 & 40,0 \\
\hline
\end{tabular}

Tabla A.V.4. Continuación.

\begin{tabular}{|c|c|c|c|c|c|c|c|}
\hline Muestra & Cuarzo & Plagioclasa & Ortosa & Calcita & Dolomita & Yeso & Filosilicatos \\
\hline & $\%$ & $\%$ & $\%$ & $\%$ & $\%$ & $\%$ & $\%$ \\
\hline 16 & 25.4 & 5.8 & 11.2 & 10.4 & 12.7 & 0.0 & 34.6 \\
\hline $16^{*}$ & 29.4 & 7.0 & 6.8 & 10.5 & 22.3 & 0.0 & 24.0 \\
\hline 37 & 37.3 & 6.2 & 8.7 & 7.5 & 3.0 & 0.0 & 37.3 \\
\hline $37^{*}$ & 30.5 & 7.1 & 28.8 & 0.0 & 3.1 & 0.0 & 30.5 \\
\hline 57 & 26.1 & 3.3 & 16.8 & 8.5 & 9.8 & 3.0 & 32.6 \\
\hline $57^{*}$ & 43.4 & 11.9 & 22.4 & 1.5 & 5.6 & 0.0 & 15.2 \\
\hline 61 & 18.6 & 2.4 & 5.8 & 12.9 & 20.7 & 0.6 & 38.8 \\
\hline $61^{*}$ & 16.3 & 3.0 & 8.7 & 14.1 & 17.1 & 0.0 & 40.8 \\
\hline 65 & 12.9 & 2.8 & 5.6 & 8.7 & 16.8 & 2.3 & 50.9 \\
\hline $65^{*}$ & 34.2 & 4.9 & 21.6 & 6.5 & 8.3 & 0.9 & 23.6 \\
\hline 68 & 24.5 & 3.9 & 13.6 & 7.4 & 12.3 & 5.7 & 32.7 \\
\hline $68^{*}$ & 20.2 & 4.5 & 7.7 & 12.1 & 11.6 & 8.2 & 35.6 \\
\hline 69 & 29.4 & 6.9 & 10.3 & 6.5 & 11.8 & 0.0 & 35.3 \\
\hline $69^{*}$ & 30.2 & 6.0 & 10.8 & 9.2 & 9.9 & 0.0 & 34.0 \\
\hline 70 & 16.7 & 2.8 & 5.0 & 14.4 & 25.2 & 0.0 & 36.0 \\
\hline $70^{*}$ & 23.1 & 9.3 & 9.3 & 10.8 & 18.0 & 0.0 & 29.5 \\
\hline $14^{*}$ & 20.6 & 3.4 & 4.7 & 13.1 & 31.5 & 0.4 & 26.3 \\
\hline 14 & 14.9 & 4.3 & 0.0 & 14.5 & 29.0 & 0.0 & 37.2 \\
\hline $20^{*}$ & 21.9 & 5.2 & 10.4 & 10.9 & 20.3 & 0.0 & 31.3 \\
\hline 20 & 17.8 & 3.3 & 5.6 & 18.7 & 21.3 & 0.0 & 33.3 \\
\hline $48^{*}$ & 36.2 & 5.3 & 21.2 & 6.4 & 5.5 & 0.0 & 25.4 \\
\hline 48 & 28.4 & 6.7 & 16.7 & 3.8 & 2.5 & 4.5 & 37.5 \\
\hline $66^{*}$ & 10.6 & 2.2 & 4.4 & 16.0 & 27.7 & 0.0 & 39.0 \\
\hline 66 & 15.5 & 3.4 & 13.3 & 10.3 & 9.4 & 0.0 & 48.1 \\
\hline & & & & & & & \\
\hline
\end{tabular}


Tabla A.V.5. Matriz de correlación de los suelos sembrados.

\begin{tabular}{|c|c|c|c|c|c|c|c|c|c|c|c|}
\hline & $\mathrm{Mn}$ & $\mathrm{Fe}$ & $\mathrm{Cr}$ & $\mathrm{Zn}$ & $\mathrm{Pb}$ & K-ex & $M g-x$ & V & Filisilicatos & $\mathrm{CO} 3$ & Dolomita \\
\hline $\mathrm{Mn}$ & 0 & 0,95 & 0,91 & 0,51 & 0,79 & 0,26 & 0,17 & 0,36 & 0,16 & 0,33 & 0,4 \\
\hline $\mathrm{Fe}$ & 0,92 & 0 & 0,92 & 0,47 & 0,74 & 0,38 & 0,27 & 0,47 & 0,2 & 0,47 & 0,49 \\
\hline $\mathrm{Cr}$ & 0,87 & 0,91 & 0 & 0,57 & 0,85 & 0,46 & 0,2 & 0,4 & 0,3 & 0,57 & 0,55 \\
\hline $\mathrm{Zn}$ & 0,59 & 0,53 & 0,73 & 0 & 0,76 & 0,8 & $-0,2$ & 0,01 & 0,06 & 0,3 & 0,26 \\
\hline $\mathrm{Pb}$ & 0,69 & 0,7 & 0,79 & 0,78 & 0 & 0,51 & 0 & 0,21 & 0,25 & 0,42 & 0,3 \\
\hline K-ex & 0,25 & 0,4 & 0,56 & 0,76 & 0,54 & 0 & 0,07 & 0,24 & 0,17 & 0,46 & 0,36 \\
\hline Mg-ex & 0,16 & 0,36 & 0,3 & $-0,03$ & 0,09 & 0,03 & 0 & 0,91 & 0,21 & 0,27 & 0,22 \\
\hline V & 0,21 & 0,43 & 0,4 & 0,06 & 0,1 & 0,19 & 0,88 & 0 & 0,3 & 0,55 & 0,49 \\
\hline Filisilicatos & 0,08 & 0,25 & 0,3 & 0,27 & 0,43 & 0,24 & 0,42 & 0,31 & 0 & 0,36 & $-0,1$ \\
\hline $\mathrm{CO} 3$ & 0,14 & 0,32 & 0,53 & 0,25 & 0,26 & 0,4 & 0,39 & 0,53 & 0,46 & 0 & 0,8 \\
\hline Dolomita & 0,35 & 0,46 & 0,64 & 0,31 & 0,25 & 0,45 & 0,22 & 0,48 & $-0,03$ & 0,81 & 0 \\
\hline Calcita & 0,22 & 0,26 & 0,5 & 0,45 & 0,29 & 0,49 & $-0,07$ & 0,27 & $-0,11$ & 0,54 & 0,82 \\
\hline Limos & 0,59 & 0,73 & 0,78 & 0,5 & 0,49 & 0,5 & 0,57 & 0,75 & 0,15 & 0,62 & 0,79 \\
\hline $\mathrm{M}, \mathrm{O}$ & 0,07 & 0,12 & 0,26 & 0,55 & 0,22 & 0,64 & 0,15 & 0,34 & $-0,19$ & 0,02 & 0,29 \\
\hline P-ex & $-0,14$ & $-0,33$ & $-0,05$ & 0,54 & 0,05 & 0,39 & $-0,3$ & $-0,31$ & $-0,11$ & $-0,01$ & $-0,04$ \\
\hline $\mathrm{Cu}$ & 0,23 & 0,04 & 0,32 & 0,81 & 0,41 & 0,52 & $-0,21$ & $-0,22$ & 0,11 & 0,11 & 0,07 \\
\hline Na-ex & $-0,34$ & $-0,31$ & $-0,5$ & $-0,43$ & $-0,49$ & $-0,37$ & $-0,08$ & $-0,1$ & 0,2 & $-0,43$ & $-0,64$ \\
\hline Arcilla & $-0,2$ & 0,06 & 0,21 & 0,17 & 0,17 & 0,6 & 0,07 & 0,25 & 0,43 & 0,71 & 0,54 \\
\hline $\mathrm{pH}$ & 0,03 & 0,01 & $-0,07$ & $-0,08$ & $-0,08$ & $-0,03$ & $-0,66$ & $-0,44$ & 0,01 & $-0,1$ & $-0,1$ \\
\hline As & 0,01 & 0,06 & $-0,06$ & $-0,3$ & $-0,21$ & $-0,36$ & 0,78 & 0,74 & $-0,05$ & 0,04 & 0,04 \\
\hline $\mathrm{C}, \mathrm{E}$ & $-0,22$ & $-0,11$ & $-0,27$ & $-0,41$ & $-0,35$ & $-0,35$ & 0,77 & 0,61 & 0,03 & $-0,14$ & $-0,23$ \\
\hline Ca-ex & $-0,09$ & 0 & $-0,15$ & $-0,32$ & $-0,22$ & $-0,17$ & 0,44 & 0,52 & $-0,19$ & 0,12 & 0,14 \\
\hline Yeso & $-0,4$ & $-0,31$ & $-0,54$ & $-0,59$ & $-0,51$ & $-0,44$ & 0,52 & 0,34 & $-0,12$ & $-0,3$ & $-0,39$ \\
\hline Cuarzo & $-0,15$ & $-0,37$ & $-0,57$ & $-0,39$ & $-0,44$ & $-0,53$ & $-0,53$ & $-0,63$ & $-0,49$ & $-0,85$ & $-0,75$ \\
\hline Arenas & $-0,42$ & $-0,63$ & $-0,73$ & $-0,48$ & $-0,47$ & $-0,63$ & $-0,5$ & $-0,72$ & $-0,28$ & $-0,77$ & $-0,85$ \\
\hline Ortosa & $-0,38$ & $-0,49$ & $-0,62$ & $-0,32$ & $-0,21$ & $-0,45$ & $-0,07$ & $-0,4$ & $-0,16$ & $-0,74$ & $-0,83$ \\
\hline Plagioclasa & $-0,19$ & $-0,28$ & $-0,39$ & $-0,15$ & $-0,24$ & $-0,02$ & $-0,48$ & $-0,57$ & $-0,28$ & $-0,56$ & $-0,59$ \\
\hline
\end{tabular}


Tabla A.V.5. Continuación.

\begin{tabular}{|c|c|c|c|c|c|c|c|c|c|}
\hline & Calcita & Limos & $\mathbf{M}, \mathbf{O}$ & P-ex & $\mathrm{Cu}$ & Na-ex & Arcilla & $\mathrm{pH}$ & As \\
\hline Mn & 0,17 & 0,69 & 0,08 & $-0,26$ & 0,45 & $-0,07$ & $-0,23$ & 0,08 & 0,04 \\
\hline $\mathrm{Fe}$ & 0,2 & 0,76 & $-0,01$ & $-0,17$ & 0,41 & $-0,13$ & $-0,01$ & 0,08 & 0,09 \\
\hline $\mathrm{Cr}$ & 0,36 & 0,7 & 0,04 & $-0,17$ & 0,52 & $-0,23$ & 0,01 & 0,11 & $-0,01$ \\
\hline $\mathrm{Zn}$ & 0,36 & 0,39 & 0,49 & 0,56 & 0,96 & $-0,28$ & 0,23 & 0,06 & $-0,33$ \\
\hline $\mathrm{Pb}$ & 0,34 & 0,54 & 0,2 & 0,06 & 0,72 & $-0,31$ & 0,02 & 0,11 & $-0,1$ \\
\hline K-ex & 0,39 & 0,44 & 0,45 & 0,69 & 0,74 & $-0,24$ & 0,6 & 0,06 & $-0,15$ \\
\hline Mg-ex & $-0,04$ & 0,42 & 0,27 & $-0,11$ & $-0,31$ & 0,4 & $-0,1$ & $-0,62$ & 0,93 \\
\hline V & 0,24 & 0,7 & 0,35 & 0,02 & $-0,06$ & 0,2 & 0,11 & $-0,4$ & 0,83 \\
\hline Filisilicatos & $-0,01$ & 0,02 & $-0,14$ & $-0,02$ & 0,17 & 0,3 & 0,31 & 0,28 & 0,06 \\
\hline $\mathrm{CO} 3$ & 0,7 & 0,7 & 0,08 & 0,2 & 0,37 & $-0,52$ & 0,57 & 0,01 & 0,17 \\
\hline Dolomita & 0,83 & 0,82 & 0,19 & 0,09 & 0,27 & $-0,5$ & 0,36 & 0,03 & 0,12 \\
\hline Calcita & 0 & 0,61 & 0,22 & 0,3 & 0,45 & $-0,46$ & 0,53 & 0,13 & $-0,08$ \\
\hline Limos & 0,62 & 0 & 0,34 & 0,06 & 0,38 & $-0,29$ & 0,23 & $-0,1$ & 0,34 \\
\hline M.O & 0,55 & 0,48 & 0 & 0,43 & 0,43 & $-0,01$ & $-0,06$ & $-0,28$ & 0,28 \\
\hline P-ex & 0,16 & $-0,12$ & 0,41 & 0 & 0,57 & $-0,1$ & 0,65 & $-0,08$ & $-0,14$ \\
\hline $\mathrm{Cu}$ & 0,23 & 0,11 & 0,41 & 0,9 & 0 & $-0,33$ & 0,34 & 0,17 & $-0,41$ \\
\hline Na-ex & $-0,52$ & $-0,57$ & $-0,28$ & $-0,24$ & $-0,34$ & 0 & $-0,29$ & $-0,2$ & 0,34 \\
\hline Arcilla & 0,49 & 0,28 & 0,11 & 0,03 & $-0,01$ & $-0,2$ & 0 & 0,29 & $-0,21$ \\
\hline $\mathrm{pH}$ & 0 & $-0,35$ & $-0,36$ & $-0,2$ & $-0,16$ & 0,49 & 0,13 & 0 & $-0,72$ \\
\hline As & $-0,14$ & 0,38 & 0,13 & $-0,29$ & $-0,34$ & $-0,02$ & $-0,3$ & $-0,61$ & 0 \\
\hline $\mathrm{C}, \mathrm{E}$ & $-0,37$ & 0,14 & 0,14 & $-0,28$ & $-0,37$ & 0,22 & $-0,34$ & $-0,62$ & 0,88 \\
\hline Ca-ex & $-0,1$ & 0,29 & $-0,02$ & $-0,21$ & $-0,37$ & $-0,16$ & 0,08 & $-0,32$ & 0,71 \\
\hline Yeso & $-0,57$ & $-0,09$ & $-0,07$ & $-0,27$ & $-0,46$ & 0,24 & $-0,33$ & $-0,48$ & 0,75 \\
\hline Cuarzo & $-0,62$ & $-0,77$ & $-0,33$ & 0,02 & $-0,14$ & 0,56 & $-0,65$ & 0,38 & $-0,16$ \\
\hline Arenas & $-0,69$ & $-0,94$ & $-0,44$ & 0,09 & $-0,09$ & 0,55 & $-0,59$ & 0,24 & $-0,21$ \\
\hline Ortosa & $-0,71$ & $-0,57$ & $-0,13$ & 0,07 & $-0,06$ & 0,19 & $-0,6$ & $-0,33$ & 0,17 \\
\hline Plagioclasa & $-0,59$ & $-0,68$ & $-0,17$ & 0,21 & 0,08 & 0,43 & $-0,27$ & 0,39 & $-0,4$ \\
\hline
\end{tabular}


Tabla A.V.5. Continuación.

\begin{tabular}{|c|c|c|c|c|c|c|c|}
\hline & C.E & Ca-ex & Yeso & Cuarzo & Arenas & Ortosa & Plagioclasa \\
\hline $\mathrm{Mn}$ & $-0,06$ & $-0,1$ & $-0,24$ & $-0,19$ & $-0,55$ & $-0,45$ & $-0,35$ \\
\hline $\mathrm{Fe}$ & $-0,07$ & 0,05 & $-0,23$ & $-0,37$ & $-0,69$ & $-0,55$ & $-0,36$ \\
\hline $\mathrm{Cr}$ & $-0,13$ & $-0,07$ & $-0,39$ & $-0,41$ & $-0,66$ & $-0,59$ & $-0,37$ \\
\hline $\mathrm{Zn}$ & $-0,22$ & $-0,45$ & $-0,55$ & $-0,26$ & $-0,38$ & $-0,27$ & $-0,06$ \\
\hline $\mathrm{Pb}$ & $-0,11$ & $-0,22$ & $-0,48$ & $-0,36$ & $-0,48$ & $-0,32$ & $-0,28$ \\
\hline K-ex & $-0,09$ & $-0,14$ & $-0,43$ & $-0,52$ & $-0,57$ & $-0,4$ & $-0,01$ \\
\hline Mg-ex & 0,83 & 0,79 & 0,69 & $-0,38$ & $-0,49$ & $-0,02$ & $-0,43$ \\
\hline V & 0,61 & 0,69 & 0,44 & $-0,63$ & $-0,76$ & $-0,34$ & $-0,56$ \\
\hline Filisilicatos & 0,06 & $-0,05$ & $-0,08$ & $-0,37$ & $-0,16$ & $-0,25$ & $-0,17$ \\
\hline $\mathrm{CO} 3$ & $-0,14$ & 0,24 & $-0,25$ & $-0,91$ & $-0,81$ & $-0,69$ & $-0,57$ \\
\hline Dolomita & $-0,24$ & 0,22 & $-0,31$ & $-0,66$ & $-0,83$ & $-0,82$ & $-0,51$ \\
\hline Calcita & $-0,37$ & 0 & $-0,53$ & $-0,66$ & $-0,66$ & $-0,73$ & $-0,55$ \\
\hline Limos & 0,06 & 0,24 & $-0,1$ & $-0,69$ & $-0,94$ & $-0,66$ & $-0,65$ \\
\hline $\mathrm{M}, \mathrm{O}$ & 0,43 & $-0,11$ & 0,12 & $-0,12$ & $-0,25$ & 0,04 & $-0,07$ \\
\hline P-ex & $-0,1$ & $-0,04$ & $-0,23$ & $-0,38$ & $-0,22$ & $-0,08$ & 0,07 \\
\hline $\mathrm{Cu}$ & $-0,34$ & $-0,55$ & $-0,62$ & $-0,34$ & $-0,37$ & $-0,32$ & $-0,15$ \\
\hline Na-ex & 0,47 & 0,2 & 0,47 & 0,37 & 0,26 & 0,25 & 0,04 \\
\hline Arcilla & $-0,38$ & 0,05 & $-0,41$ & $-0,71$ & $-0,47$ & $-0,52$ & $-0,14$ \\
\hline $\mathrm{pH}$ & $-0,75$ & $-0,55$ & $-0,73$ & 0,1 & 0,12 & $-0,48$ & 0,43 \\
\hline As & 0,88 & 0,81 & 0,83 & $-0,32$ & $-0,36$ & 0,18 & $-0,5$ \\
\hline $\mathrm{C}, \mathrm{E}$ & 0 & 0,57 & 0,86 & $-0,02$ & $-0,06$ & 0,5 & $-0,22$ \\
\hline Ca-ex & 0,48 & 0 & 0,62 & $-0,39$ & $-0,37$ & 0,01 & $-0,33$ \\
\hline Yeso & 0,87 & 0,64 & 0 & 0,11 & 0,12 & 0,58 & $-0,19$ \\
\hline Cuarzo & $-0,04$ & $-0,11$ & 0,16 & 0 & 0,85 & 0,56 & 0,64 \\
\hline Arenas & 0,01 & $-0,27$ & 0,19 & 0,88 & 0 & 0,71 & 0,65 \\
\hline Ortosa & 0,4 & 0,03 & 0,59 & 0,52 & 0,69 & 0 & 0,31 \\
\hline Plagioclasa & $-0,19$ & $-0,19$ & 0 & 0,76 & 0,67 & 0,33 & 0 \\
\hline
\end{tabular}


Tabla A.V.6. Matriz de correlación de los suelos en barbecho.

\begin{tabular}{|c|c|c|c|c|c|c|c|c|c|c|c|}
\hline & $\mathrm{Mn}$ & $\mathrm{Fe}$ & $\mathrm{Cr}$ & $\mathrm{Zn}$ & $\mathrm{Pb}$ & K-ex & $M g-x$ & V & Filisilicatos & $\mathrm{CO} 3$ & Dolomita \\
\hline $\mathrm{Mn}$ & 0 & 0,98 & 0,97 & 0,92 & 0,72 & 0,9 & 0,76 & 0,53 & 0,85 & 0,58 & 0,4 \\
\hline $\mathrm{Fe}$ & 0,96 & 0 & 0,97 & 0,91 & 0,66 & 0,88 & 0,76 & 0,61 & 0,86 & 0,66 & 0,49 \\
\hline $\mathrm{Cr}$ & 0,93 & 0,96 & 0 & 0,94 & 0,73 & 0,9 & 0,81 & 0,66 & 0,83 & 0,69 & 0,52 \\
\hline $\mathrm{Zn}$ & 0,93 & 0,89 & 0,92 & 0 & 0,81 & 0,81 & 0,83 & 0,66 & 0,8 & 0,59 & 0,43 \\
\hline $\mathrm{Pb}$ & 0,77 & 0,69 & 0,79 & 0,84 & 0 & 0,75 & 0,87 & 0,38 & 0,49 & 0,55 & 0,57 \\
\hline K-ex & 0,84 & 0,84 & 0,87 & 0,75 & 0,7 & 0 & 0,76 & 0,36 & 0,69 & 0,77 & 0,59 \\
\hline Mg-ex & 0,72 & 0,76 & 0,82 & 0,77 & 0,72 & 0,88 & 0 & 0,5 & 0,59 & 0,69 & 0,68 \\
\hline V & 0,63 & 0,66 & 0,73 & 0,73 & 0,49 & 0,47 & 0,54 & 0 & 0,72 & 0,48 & 0,42 \\
\hline Filisilicatos & 0,86 & 0,87 & 0,84 & 0,79 & 0,57 & 0,7 & 0,6 & 0,76 & 0 & 0,43 & 0,27 \\
\hline $\mathrm{CO} 3$ & 0,5 & 0,61 & 0,73 & 0,52 & 0,51 & 0,71 & 0,71 & 0,58 & 0,52 & 0 & 0,91 \\
\hline Dolomita & 0,32 & 0,42 & 0,59 & 0,38 & 0,52 & 0,56 & 0,66 & 0,48 & 0,29 & 0,9 & 0 \\
\hline Calcita & 0,6 & 0,71 & 0,83 & 0,72 & 0,61 & 0,65 & 0,75 & 0,82 & 0,64 & 0,87 & 0,82 \\
\hline Limos & 0,75 & 0,85 & 0,88 & 0,81 & 0,64 & 0,69 & 0,8 & 0,78 & 0,74 & 0,71 & 0,67 \\
\hline M.O & 0,79 & 0,82 & 0,85 & 0,82 & 0,86 & 0,67 & 0,74 & 0,53 & 0,68 & 0,55 & 0,57 \\
\hline P-ex & 0,55 & 0,45 & 0,56 & 0,7 & 0,82 & 0,57 & 0,57 & 0,26 & 0,32 & 0,41 & 0,35 \\
\hline $\mathrm{Cu}$ & 0,73 & 0,58 & 0,63 & 0,77 & 0,78 & 0,6 & 0,48 & 0,32 & 0,4 & 0,25 & 0,14 \\
\hline Na-ex & 0,26 & 0,33 & 0,34 & 0,28 & 0,08 & 0,18 & 0,1 & 0,31 & 0,48 & 0,36 & 0,04 \\
\hline Arcilla & 0,34 & 0,34 & 0,45 & 0,4 & 0,4 & 0,44 & 0,41 & 0,38 & 0,49 & 0,6 & 0,38 \\
\hline $\mathrm{pH}$ & $-0,2$ & $-0,08$ & 0,02 & $-0,14$ & $-0,15$ & 0,06 & 0,15 & $-0,1$ & $-0,41$ & 0,29 & 0,35 \\
\hline As & 0,34 & 0,41 & 0,43 & 0,54 & 0,2 & 0,1 & 0,28 & 0,84 & 0,59 & 0,3 & 0,2 \\
\hline C.E & 0,09 & 0,08 & 0,07 & 0,3 & $-0,05$ & $-0,25$ & $-0,09$ & 0,62 & 0,31 & $-0,15$ & $-0,24$ \\
\hline Ca-ex & 0,28 & 0,38 & 0,28 & 0,43 & 0,1 & 0,03 & 0,25 & 0,49 & 0,41 & 0,1 & 0,07 \\
\hline Yeso & 0,06 & 0,15 & 0,03 & 0,19 & $-0,15$ & $-0,22$ & $-0,01$ & 0,35 & 0,23 & $-0,11$ & $-0,12$ \\
\hline Cuarzo & $-0,68$ & $-0,77$ & $-0,82$ & $-0,66$ & $-0,56$ & $-0,71$ & $-0,72$ & $-0,77$ & $-0,84$ & $-0,82$ & $-0,73$ \\
\hline Arenas & $-0,76$ & $-0,85$ & $-0,91$ & $-0,83$ & $-0,69$ & $-0,74$ & $-0,83$ & $-0,8$ & $-0,81$ & $-0,82$ & $-0,71$ \\
\hline Ortosa & $-0,58$ & $-0,69$ & $-0,8$ & $-0,71$ & $-0,66$ & $-0,62$ & $-0,78$ & $-0,68$ & $-0,49$ & $-0,85$ & $-0,86$ \\
\hline Plagioclasa & $-0,45$ & $-0,47$ & $-0,54$ & $-0,48$ & $-0,33$ & $-0,46$ & $-0,41$ & $-0,77$ & $-0,7$ & $-0,58$ & $-0,48$ \\
\hline
\end{tabular}


Tabla A.V.6. Continuación.

\begin{tabular}{|c|c|c|c|c|c|c|c|c|c|}
\hline & Calcita & Limos & M.O & P-ex & $\mathrm{Cu}$ & Na-ex & Arcilla & $\mathrm{pH}$ & As \\
\hline $\mathrm{Mn}$ & 0,6 & 0,78 & 0,85 & 0,69 & 0,7 & 0,57 & 0,34 & $-0,29$ & 0,29 \\
\hline $\mathrm{Fe}$ & 0,71 & 0,83 & 0,84 & 0,61 & 0,6 & 0,63 & 0,36 & $-0,19$ & 0,34 \\
\hline $\mathrm{Cr}$ & 0,73 & 0,85 & 0,82 & 0,71 & 0,7 & 0,6 & 0,41 & $-0,17$ & 0,42 \\
\hline $\mathrm{Zn}$ & 0,63 & 0,73 & 0,77 & 0,85 & 0,78 & 0,52 & 0,5 & $-0,34$ & 0,48 \\
\hline $\mathrm{Pb}$ & 0,49 & 0,59 & 0,83 & 0,9 & 0,73 & 0,29 & 0,58 & $-0,36$ & 0,33 \\
\hline K-ex & 0,63 & 0,67 & 0,83 & 0,69 & 0,66 & 0,55 & 0,56 & $-0,09$ & 0,14 \\
\hline Mg-ex & 0,69 & 0,73 & 0,8 & 0,76 & 0,54 & 0,38 & 0,59 & $-0,12$ & 0,35 \\
\hline V & 0,78 & 0,73 & 0,36 & 0,41 & 0,36 & 0,36 & 0,36 & $-0,27$ & 0,91 \\
\hline Filisilicatos & 0,66 & 0,74 & 0,69 & 0,48 & 0,41 & 0,47 & 0,38 & $-0,51$ & 0,54 \\
\hline $\mathrm{CO} 3$ & 0,87 & 0,65 & 0,57 & 0,45 & 0,36 & 0,49 & 0,62 & 0,26 & 0,34 \\
\hline Dolomita & 0,83 & 0,64 & 0,52 & 0,34 & 0,2 & 0,28 & 0,52 & 0,21 & 0,34 \\
\hline Calcita & 0 & 0,84 & 0,58 & 0,38 & 0,21 & 0,54 & 0,54 & $-0,01$ & 0,68 \\
\hline Limos & 0,9 & 0 & 0,71 & 0,46 & 0,38 & 0,58 & 0,21 & $-0,15$ & 0,57 \\
\hline M.O & 0,71 & 0,82 & 0 & 0,66 & 0,48 & 0,56 & 0,44 & $-0,3$ & 0,23 \\
\hline P-ex & 0,43 & 0,36 & 0,56 & 0 & 0,85 & 0,38 & 0,63 & $-0,37$ & 0,38 \\
\hline $\mathrm{Cu}$ & 0,33 & 0,37 & 0,51 & 0,84 & 0 & 0,21 & 0,34 & $-0,24$ & 0,21 \\
\hline Na-ex & 0,32 & 0,16 & 0,2 & 0,13 & $-0,02$ & 0 & 0,24 & 0,1 & 0,3 \\
\hline Arcilla & 0,47 & 0,24 & 0,34 & 0,47 & 0,19 & 0,81 & 0 & $-0,15$ & 0,4 \\
\hline $\mathrm{pH}$ & 0,24 & 0,04 & $-0,08$ & $-0,09$ & $-0,12$ & $-0,02$ & $-0,04$ & 0 & $-0,39$ \\
\hline As & 0,63 & 0,63 & 0,32 & 0,11 & 0,07 & 0,35 & 0,26 & $-0,22$ & 0 \\
\hline C.E & 0,21 & 0,24 & $-0,04$ & $-0,06$ & 0,02 & 0,2 & 0,01 & $-0,32$ & 0,87 \\
\hline Ca-ex & 0,4 & 0,61 & 0,32 & 0,05 & 0,03 & 0 & $-0,16$ & $-0,3$ & 0,78 \\
\hline Yeso & 0,18 & 0,39 & 0,06 & $-0,16$ & $-0,14$ & $-0,1$ & $-0,33$ & $-0,33$ & 0,71 \\
\hline Cuarzo & $-0,86$ & $-0,88$ & $-0,71$ & $-0,26$ & $-0,2$ & $-0,32$ & $-0,47$ & 0,13 & $-0,55$ \\
\hline Arenas & $-0,94$ & $-0,93$ & $-0,82$ & $-0,48$ & $-0,38$ & $-0,44$ & $-0,58$ & $-0,02$ & $-0,63$ \\
\hline Ortosa & $-0,94$ & $-0,89$ & $-0,75$ & $-0,5$ & $-0,38$ & $-0,15$ & $-0,34$ & $-0,31$ & $-0,5$ \\
\hline Plagioclasa & $-0,69$ & $-0,55$ & $-0,39$ & $-0,26$ & $-0,16$ & $-0,35$ & $-0,53$ & 0,22 & $-0,62$ \\
\hline
\end{tabular}


Tabla A.V.6. Continuación.

\begin{tabular}{|c|c|c|c|c|c|c|c|}
\hline & C.E & Ca-ex & Yeso & Cuarzo & Arenas & Ortosa & Plagioclasa \\
\hline $\mathrm{Mn}$ & 0,18 & 0,66 & $-0,27$ & $-0,69$ & $-0,71$ & $-0,5$ & $-0,34$ \\
\hline $\mathrm{Fe}$ & 0,18 & 0,69 & $-0,12$ & $-0,76$ & $-0,79$ & $-0,58$ & $-0,46$ \\
\hline $\mathrm{Cr}$ & 0,27 & 0,69 & $-0,22$ & $-0,76$ & $-0,79$ & $-0,64$ & $-0,45$ \\
\hline $\mathrm{Zn}$ & 0,41 & 0,73 & $-0,2$ & $-0,67$ & $-0,78$ & $-0,59$ & $-0,45$ \\
\hline $\mathrm{Pb}$ & 0,29 & 0,6 & $-0,39$ & $-0,51$ & $-0,6$ & $-0,55$ & $-0,2$ \\
\hline K-ex & $-0,05$ & 0,55 & $-0,38$ & $-0,68$ & $-0,66$ & $-0,58$ & $-0,34$ \\
\hline Mg-ex & 0,28 & 0,76 & $-0,28$ & $-0,66$ & $-0,75$ & $-0,66$ & $-0,38$ \\
\hline V & 0,66 & 0,6 & 0,23 & $-0,76$ & $-0,81$ & $-0,68$ & $-0,79$ \\
\hline Filisilicatos & 0,34 & 0,67 & $-0,09$ & $-0,8$ & $-0,81$ & $-0,43$ & $-0,59$ \\
\hline $\mathrm{CO} 3$ & $-0,01$ & 0,57 & $-0,03$ & $-0,78$ & $-0,75$ & $-0,89$ & $-0,57$ \\
\hline Dolomita & $-0,01$ & 0,54 & 0,08 & $-0,74$ & $-0,68$ & $-0,9$ & $-0,49$ \\
\hline Calcita & 0,34 & 0,76 & 0,18 & $-0,95$ & $-0,94$ & $-0,89$ & $-0,79$ \\
\hline Limos & 0,4 & 0,8 & 0,13 & $-0,86$ & $-0,83$ & $-0,72$ & $-0,55$ \\
\hline M.O & 0,17 & 0,63 & $-0,29$ & $-0,63$ & $-0,7$ & $-0,43$ & $-0,26$ \\
\hline P-ex & 0,44 & 0,58 & $-0,38$ & $-0,38$ & $-0,54$ & $-0,45$ & $-0,27$ \\
\hline $\mathrm{Cu}$ & 0,2 & 0,27 & $-0,44$ & $-0,25$ & $-0,3$ & $-0,38$ & $-0,06$ \\
\hline Na-ex & 0,38 & 0,58 & 0,21 & $-0,46$ & $-0,59$ & $-0,29$ & $-0,5$ \\
\hline Arcilla & 0,2 & 0,41 & $-0,3$ & $-0,48$ & $-0,6$ & $-0,5$ & $-0,6$ \\
\hline $\mathrm{pH}$ & $-0,41$ & $-0,33$ & 0,06 & 0,24 & 0,27 & $-0,06$ & 0,14 \\
\hline As & 0,83 & 0,57 & 0,29 & $-0,64$ & $-0,73$ & $-0,59$ & $-0,77$ \\
\hline C.E & 0 & 0,53 & 0,23 & $-0,27$ & $-0,48$ & $-0,2$ & $-0,5$ \\
\hline Ca-ex & 0,66 & 0 & 0,21 & $-0,78$ & $-0,86$ & $-0,64$ & $-0,6$ \\
\hline Yeso & 0,69 & 0,96 & 0 & $-0,15$ & $-0,16$ & $-0,17$ & $-0,4$ \\
\hline Cuarzo & $-0,13$ & $-0,4$ & $-0,19$ & 0 & 0,94 & 0,83 & 0,74 \\
\hline Arenas & $-0,21$ & $-0,45$ & $-0,2$ & 0,91 & 0 & 0,78 & 0,81 \\
\hline Ortosa & $-0,07$ & $-0,41$ & $-0,19$ & 0,76 & 0,88 & 0 & 0,63 \\
\hline Plagioclasa & $-0,35$ & $-0,3$ & $-0,18$ & 0,72 & 0,66 & 0,48 & 0 \\
\hline
\end{tabular}




